\title{
Experimental and Numerical Investigations for the Development of Safe Transportation of Hazardous Materials
}

\author{
By \\ MOHAMED ELSHAFEY \\ B.Sc., Higher Technological Institute, Cairo, Egypt \\ M.A.Sc., Carleton University \\ A thesis Submitted to \\ the Faculty of Graduate Studies and Research \\ in partial fulfilment \\ of the requirements of the degree of
}

\section{DOCTOR OF PHILOSOPHY}

In Civil Engineering

\author{
Department of Civil and Environmental Engineering \\ Carleton University \\ Ottawa, Ontario, Canada \\ (C) copyright \\ 2008, Mohamed Elshafey
}

The Doctor of Philosophy in Civil Engineering is a joint program with the University of Ottawa Administrated by the Ottawa-Carleton Institute for Civil Engineering 


$\begin{array}{ll}\begin{array}{l}\text { Library and } \\ \text { Archives Canada }\end{array} & \begin{array}{l}\text { Bibliothèque et } \\ \text { Archives Canada }\end{array} \\ \begin{array}{l}\text { Published Heritage } \\ \text { Branch }\end{array} & \begin{array}{l}\text { Direction du } \\ \text { Patrimoine de l'édition }\end{array} \\ \begin{array}{l}\text { 395 Wellington Street } \\ \text { Ottawa ON K1A 0N4 } \\ \text { Canada }\end{array} & \begin{array}{l}\text { 395, rue Wellington } \\ \text { Ottawa ON K1A 0N4 } \\ \text { Canada }\end{array}\end{array}$

Your file Votre référence ISBN: 978-0-494-47461-7 Our file Notre référence ISBN: 978-0-494-47461-7

NOTICE:

The author has granted a nonexclusive license allowing Library and Archives Canada to reproduce, publish, archive, preserve, conserve, communicate to the public by telecommunication or on the Internet, loan, distribute and sell theses worldwide, for commercial or noncommercial purposes, in microform, paper, electronic and/or any other formats.

The author retains copyright ownership and moral rights in this thesis. Neither the thesis nor substantial extracts from it may be printed or otherwise reproduced without the author's permission.
AVIS:

L'auteur a accordé une licence non exclusive permettant à la Bibliothèque et Archives Canada de reproduire, publier, archiver, sauvegarder, conserver, transmettre au public par télécommunication ou par l'Internet, prêter, distribuer et vendre des thèses partout dans le monde, à des fins commerciales ou autres, sur support microforme, papier, électronique et/ou autres formats.

L'auteur conserve la propriété du droit d'auteur et des droits moraux qui protège cette thèse. $\mathrm{Ni}$ la thèse ni des extraits substantiels de celle-ci ne doivent être imprimés ou autrement reproduits sans son autorisation.
In compliance with the Canadian Privacy Act some supporting forms may have been removed from this thesis.

While these forms may be included in the document page count, their removal does not represent any loss of content from the thesis.
Conformément à la loi canadienne sur la protection de la vie privée, quelques formulaires secondaires ont été enlevés de cette thèse.

Bien que ces formulaires aient inclus dans la pagination, il n'y aura aucun contenu manquant.

\section{Canada}


This Thesis is dedicated to the soul of my dear mother 


\begin{abstract}
Transportation of Dangerous Goods (DG) represents an important portion of the overall transport of freight in the world. Ground transport (excluding pipelines) moves approximately 21 to $31 \%$ of the total tonnage of DG in Canada. Accidents involving DG might occur at any time, at any location along transport routes or within storage areas. Such accidents not only affect people and the environment but also have a great impact on the economy. To minimize the effects of transportation accidents associated with DG, the use of suppressive shield technology has been recommended by several researchers.
\end{abstract}

This thesis presents the details of experimental and numerical investigations studying the performance of suppressive shield panels (SSPs) for civilian applications. The SSPs were built using commercially-available steel angles in various configurations and were tested to determine their blast mitigation capability against blast pressure from the detonation of three explosive masses of Pentolite, $0.25,0.50$ and $1.00 \mathrm{~kg}$. The SSP technology can be used for the storage, processing and transport of explosive materials, and can also be applied to protecting attractive targets and infrastructure that are deemed vulnerable to explosive attacks, including those attacks accompanied by the threat of fragment bombs.

The results obtained from the numerical investigation correlated well with those from the experimental tests on the SSPs, where the attenuation was found to range from 40 to $60 \%$. The accuracy in predicting the pressure attenuation demonstrates the capability of 
numerical modeling as an efficient tool in the study of SSPs applications in various scenarios and can be used to predict the performance of the SSPs when subjected to blast loads from larger explosive charges without the need to carry out expensive and complex field tests. 


\section{Acknowledgments}

The author would like to express his deep appreciation and thanks to his Professors Abd El Halim and Contestabile for their supervision and advice, continual guidance and support, endless assistance, invaluable time, and patience, which were the main keys to complete this thesis. Special thanks are due to Professors Isgor and Goldak for their advice and support.

Special thanks are due to Professor Katsabanis, Mr. Rielo of Queen's University, for providing generously their technical assistance throughout the course of the experimental testing. Sincere appreciation is extended to all my Professors, fellow colleagues and friends for their time, help and encouragement.

The financial support for the thesis was gratefully provided by Natural Sciences and Engineering Research Council (NSERC) and Mr. Wassim Hraiki, President, and Mr. Stipane Curic, Vice President of BCT Technologies Corporation, for the financial support throughout the course of this research.

Also, to all my family members, I would like to thank each and everyone for everything they did during my research years. I would like to mention my father whose love, help and support since my birth are very much appreciated. Finally, I would like to thank my lovely wife, Yasmin, and dear sons, Karim and Omar, for their everlasting patience, support, encouragement and sacrifices. 


\section{Table of Contents}

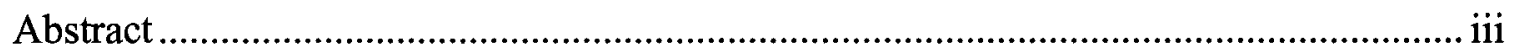

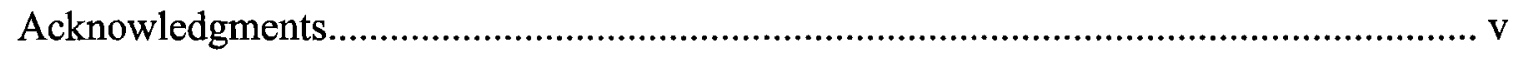

Table of Contents ............................................................................................... vi

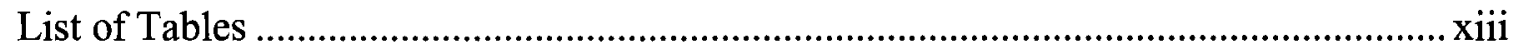

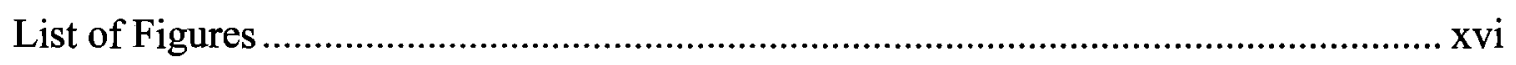

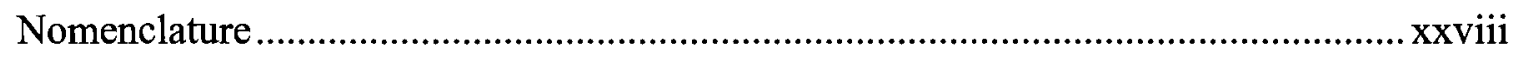

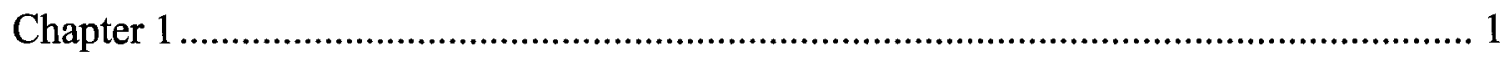

$1 \quad$ Introduction............................................................................................... 1

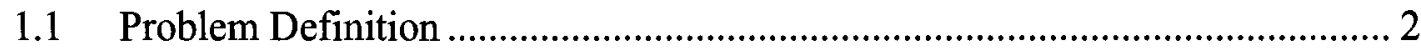

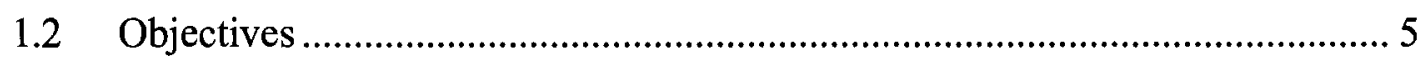

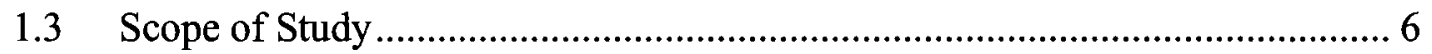

1.4 Rationale for the Research.................................................................. 7

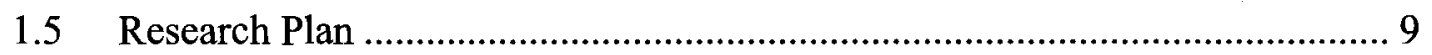

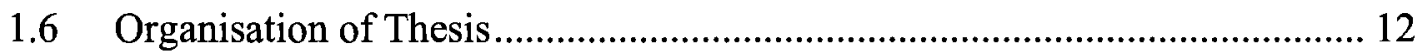

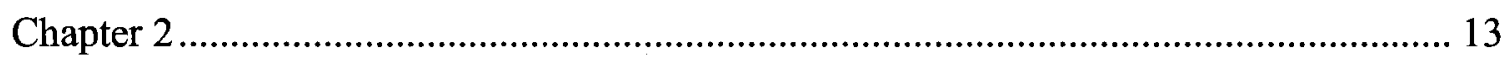

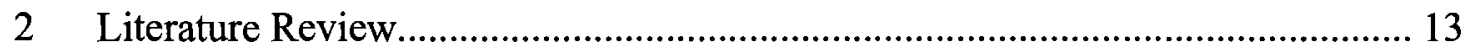

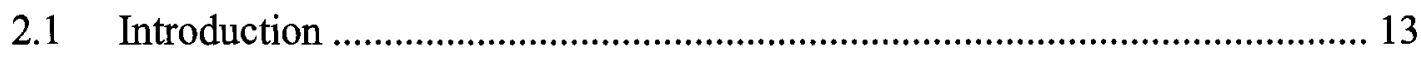

2.2 UN-TDG Regulations Review....................................................... 13

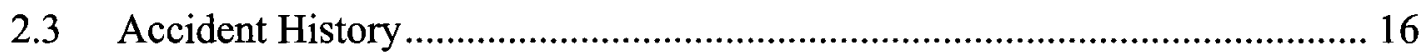

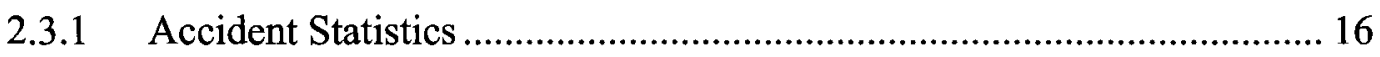




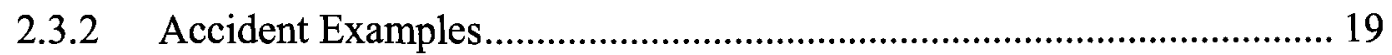

2.3.2.1 Ajman: Truck Explosion .............................................................. 19

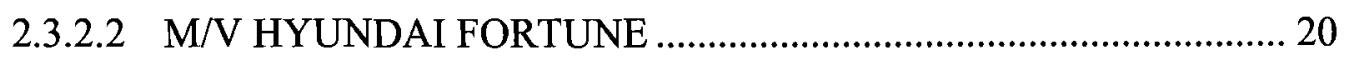

2.3.2.3 Romania: Truck Explosion............................................................ 21

2.3.2.4 Walden, Ontario: Truck Explosion ...................................................... 22

2.4 Existing Containers System..................................................................... 25

2.5 Explosion Phenomenon ....................................................................... 26

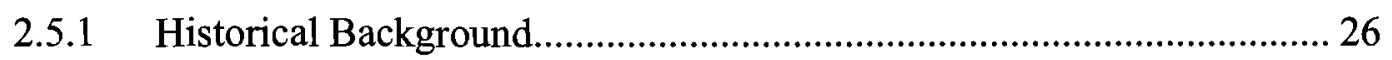

2.5.2 Explosions and Blast Phenomenon ...................................................... 28

2.5.2.1 Blast Wave (Damage) ……………………….................................. 28

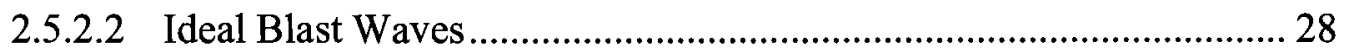

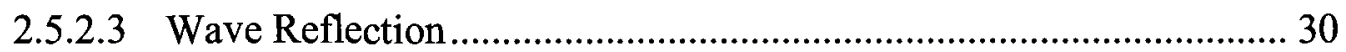

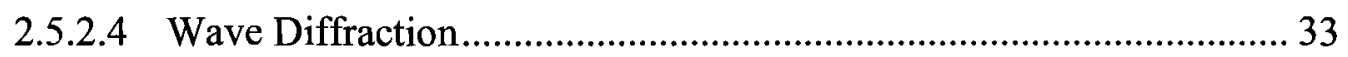

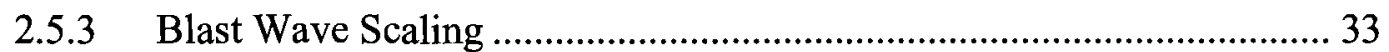

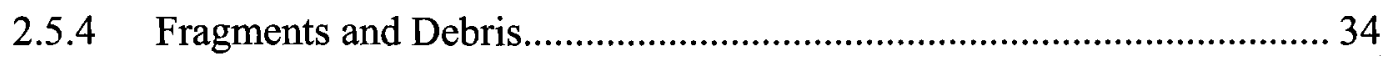

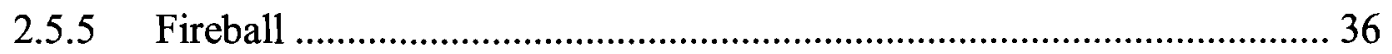

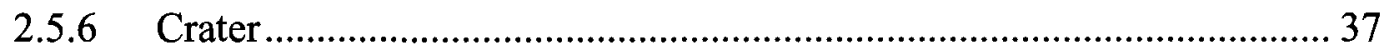

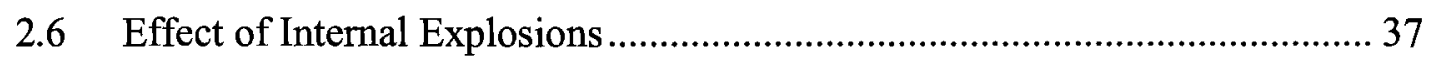

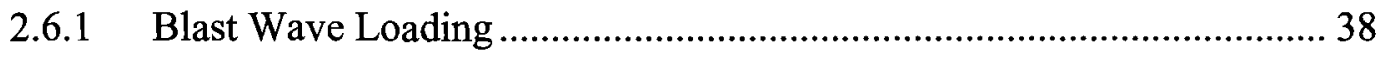

2.6.1.1 Estimation of Maximum Side-on Pressure........................................... 38

2.6.1.2 Estimation of Reflected Pressure …………..................................... 39

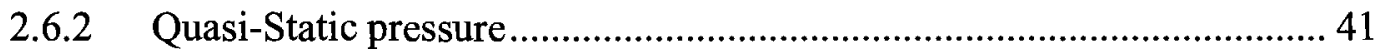




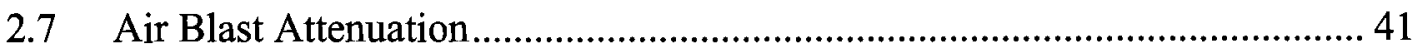

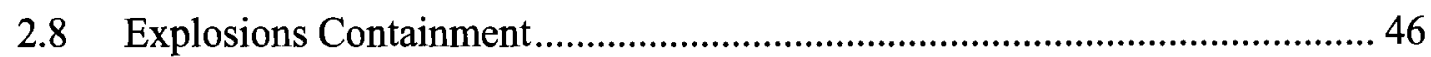

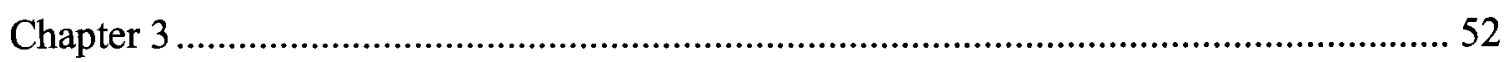

$3 \quad$ Numerical Approach and Model Development .................................................... 52

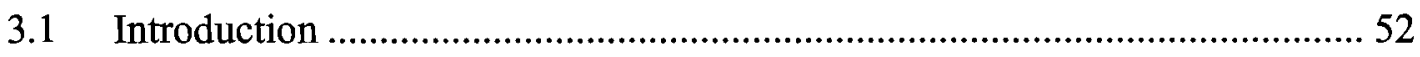

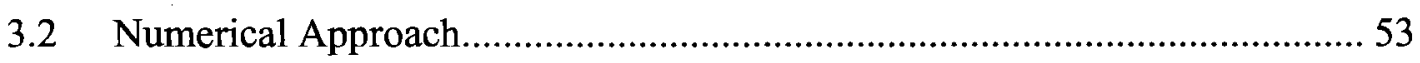

3.2.1 AUTODYN Elements Types .............................................................. 53

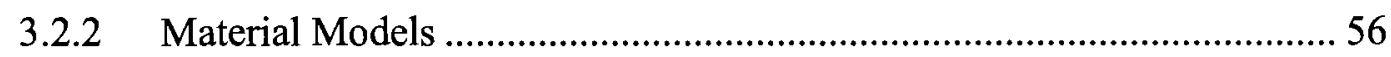

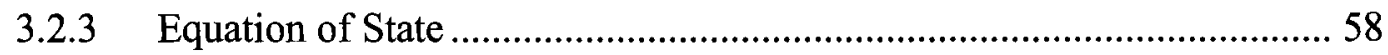

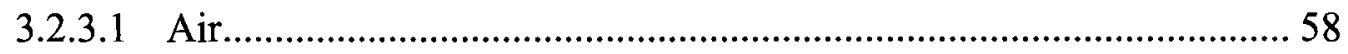

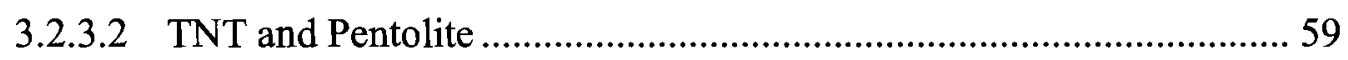

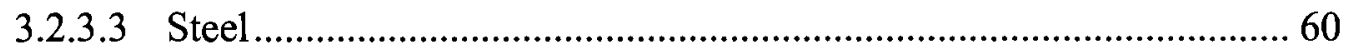

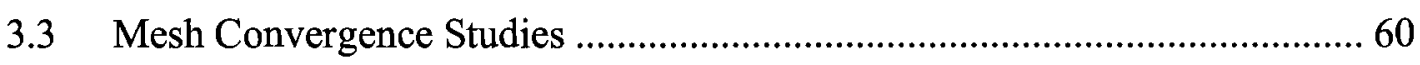

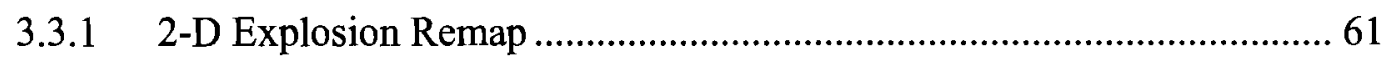

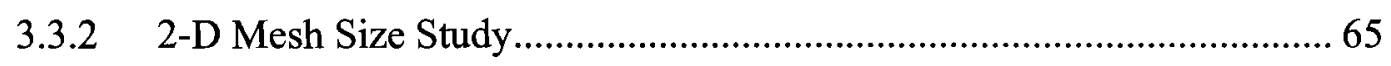

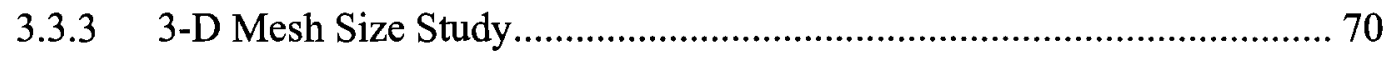

3.4 Blast Waves through Area Restriction ...................................................... 73

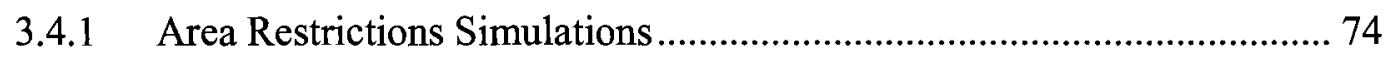

3.4.2 Area Restrictions: Results and Discussion............................................ 77

3.5 AUTODYN Verification using Category I Suppressive Shield Experimental

Data 84

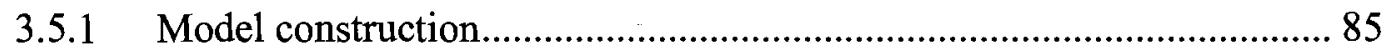

viii 


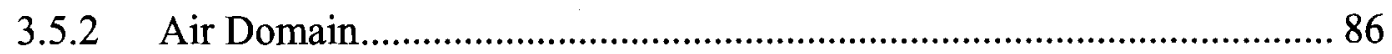

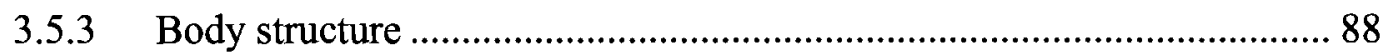

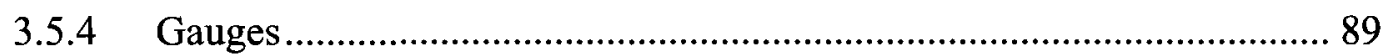

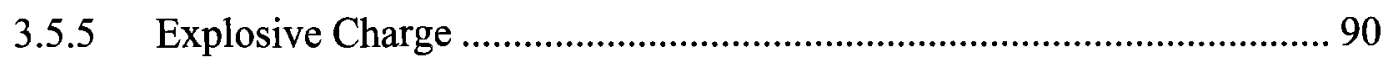

3.5.6 Category I Suppressive Shield: Results and Discussion .......................... 90

3.5.6.1 Peak Incident Pressure: (Outside of structure) .................................. 91

3.5.6.2 Reflected Pressure within Suppressive Shield Structure..................... 96

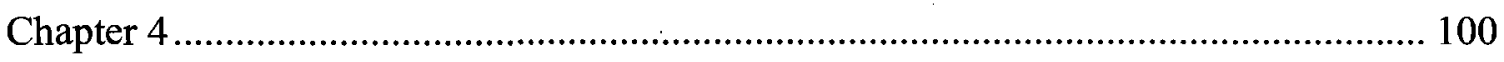

4 Preliminary Parametric Study ..................................................................... 100

4.1 Mass and Vent Area Calculations .............................................................. 101

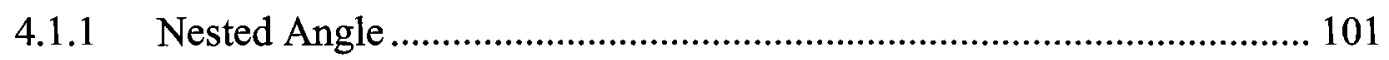

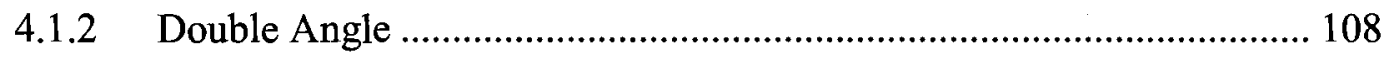

4.1.3 Blast Attenuation Effect: Model Construction...................................... 111

4.1.4 Pilot Study: Analysis and Discussion.................................................... 113

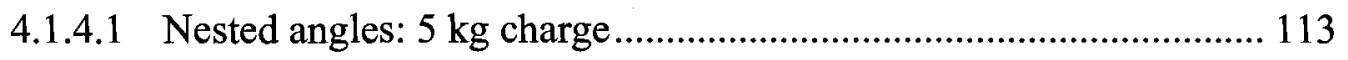

4.1.4.2 Nested Angles: 50 kg charge........................................................ 115

4.1.4.3 Double Angles: $5 \mathrm{~kg}$ charge …………………….......................... 125

4.1.4.4 Nested Angles vs Double Angles.................................................... 127

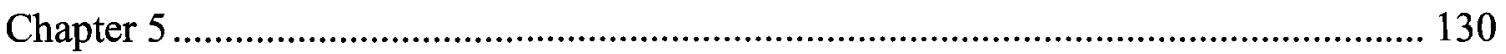

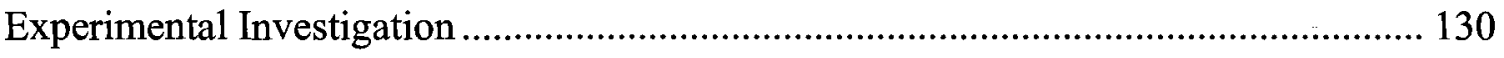

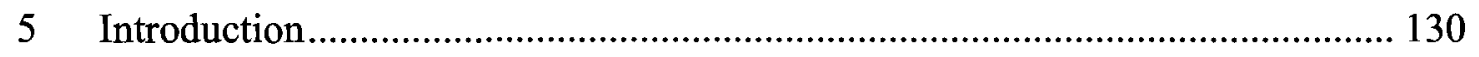

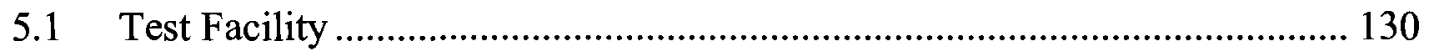




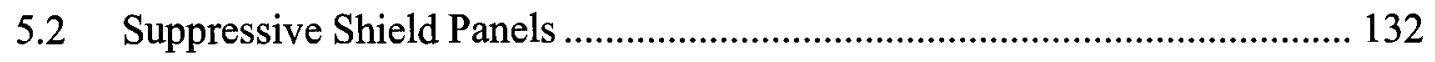

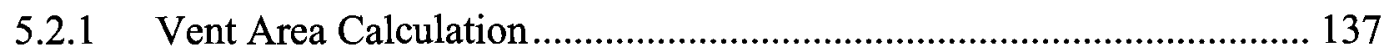

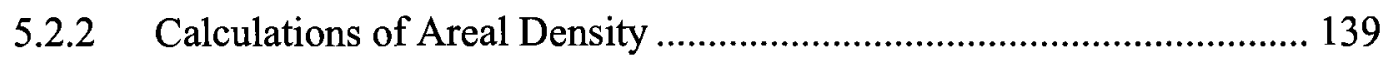

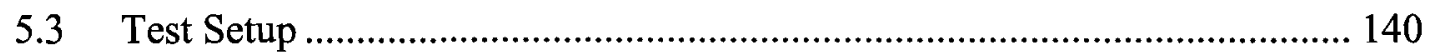

5.4 Material Properties ................................................................................ 141

5.4.1 Structural Steel ........................................................................... 142

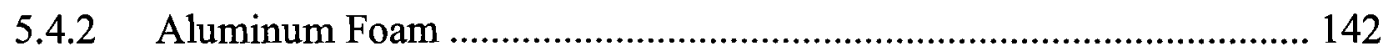

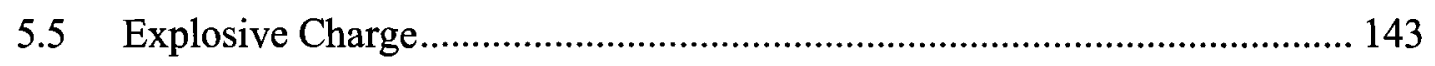

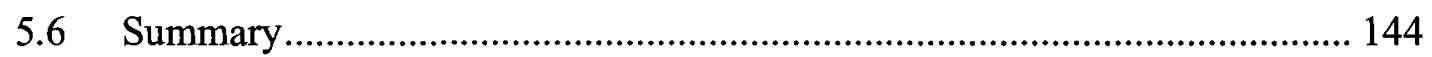

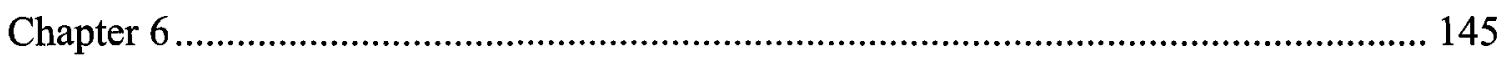

Experimental Results: Analysis and Discussion........................................................... 145

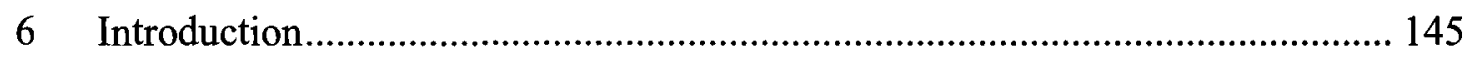

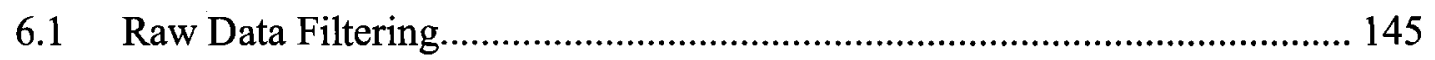

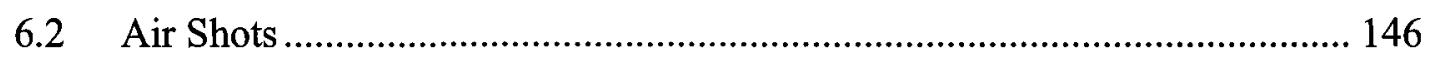

6.3 Suppressive Shield Panels ................................................................... 150

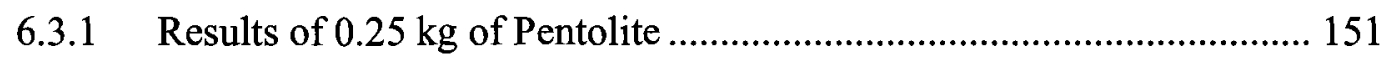

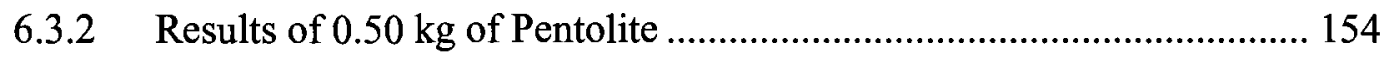

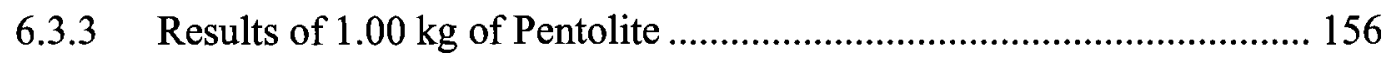

6.4 Suppressive Shield Panels-with Aluminum Foam ....................................... 158

6.4.1 Aluminum Foam tests without Backing ............................................... 159

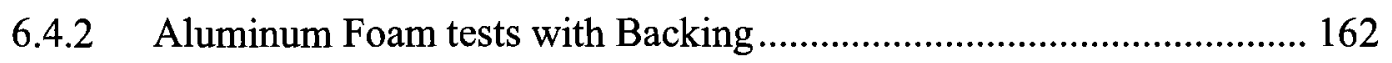

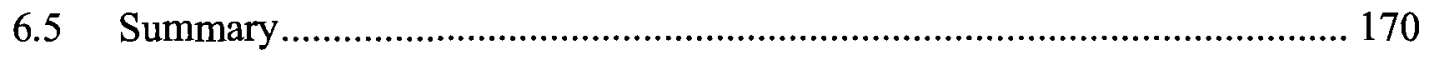




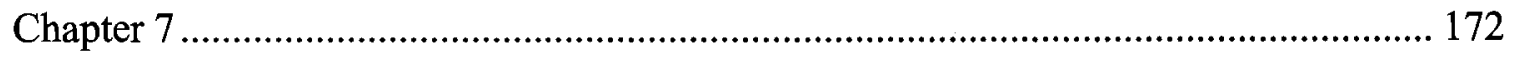

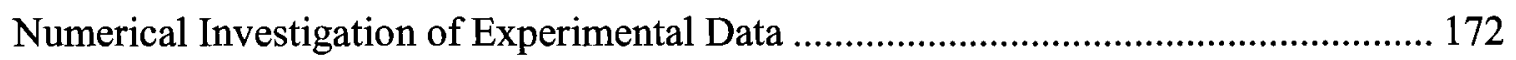

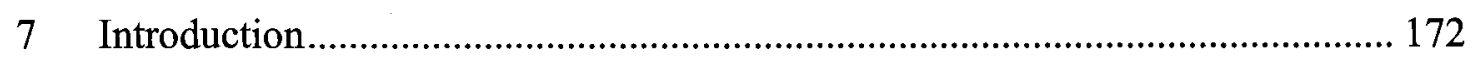

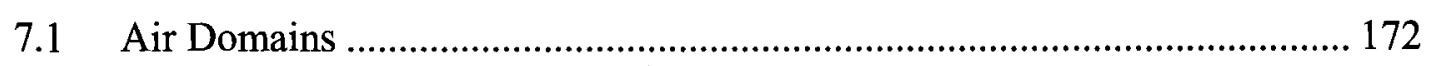

7.1.1 2-D Air Domain ............................................................................. 172

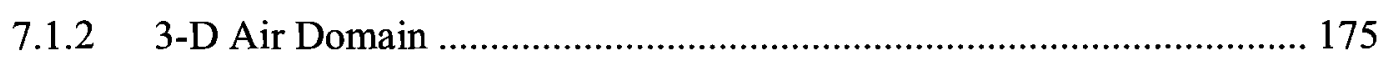

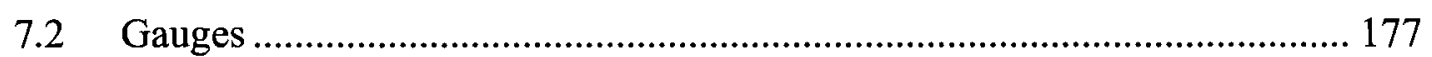

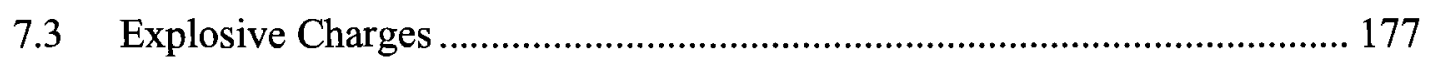

7.4 Suppressive Shield Panels Modelling........................................................ 180

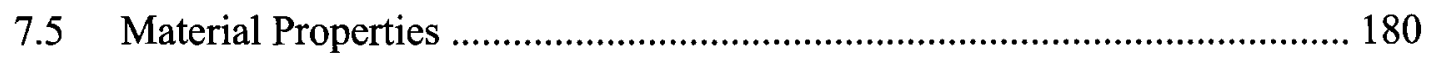

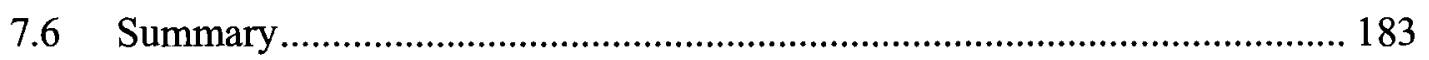

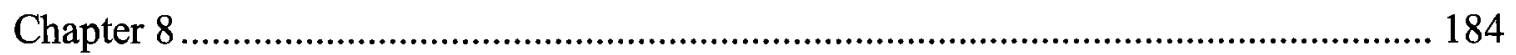

Numerical Investigation: Results and Verification....................................................... 184

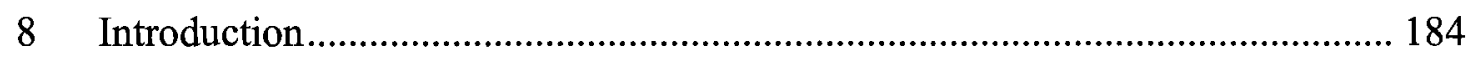

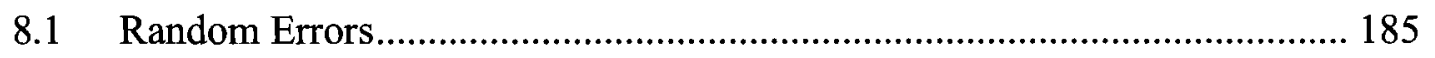

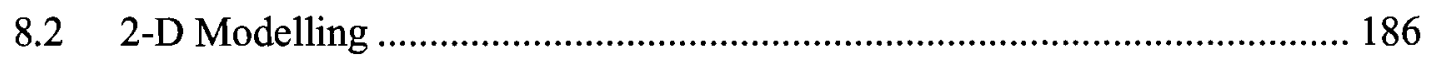

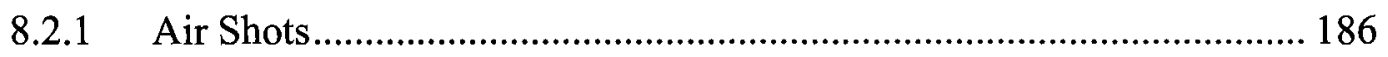

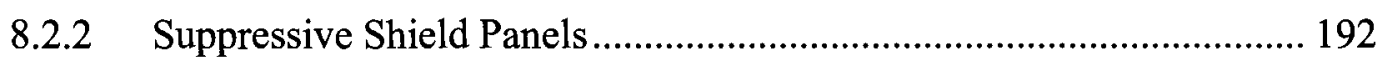

8.2.2.1 Results of the $0.25 \mathrm{~kg}$ of Pentolite ................................................. 192

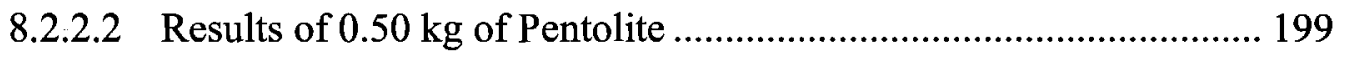

8.2.2.3 Results of $1.00 \mathrm{~kg}$ of Pentolite ………………............................. 206

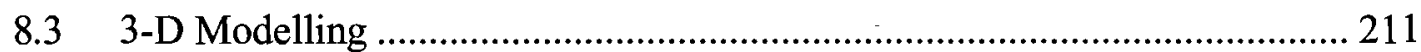


8.3.1 Numerical Analysis and Verification of the Suppressive Shield Panels211

8.3.1.1 Case of Basic SSP-A design......................................................... 212

8.3.1.2 Case of SSP-A with add-on Aluminum Foam .................................. 214

8.3.1.3 Case of SSP-A with backed Aluminum Foam .................................. 215

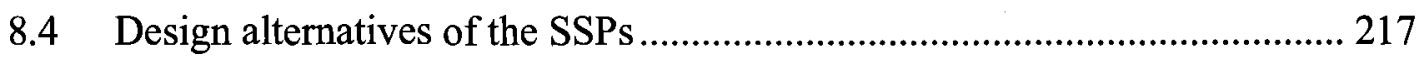

8.4.1 Case of SSPs subjected to higher charge masses .................................. 217

8.4.2 Case of the Cubicle subjected to $5 \mathrm{~kg}$ of Pentolite................................. 221

8.5 Basis for sizing and using SSPs.......................................................... 222

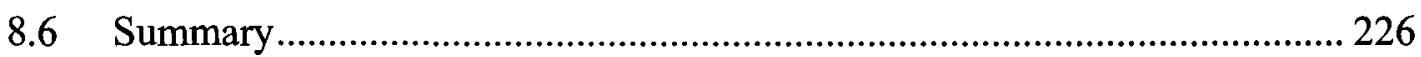

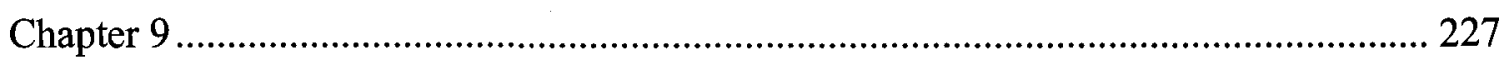

9 Conclusions, Recommendations and Future Research Work ............................. 227

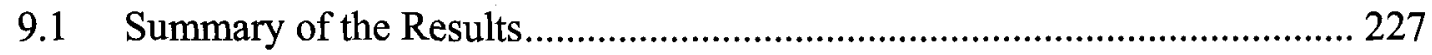

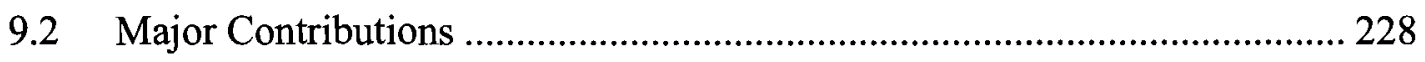

9.2.1 Blast Effects Assessment .................................................................... 228

9.2.2 Validity of Suppressive Shield Panels ................................................. 229

9.2.2.1 Experimental Investigation ............................................................ 229

9.2.2.2 Numerical Investigation ............................................................... 230

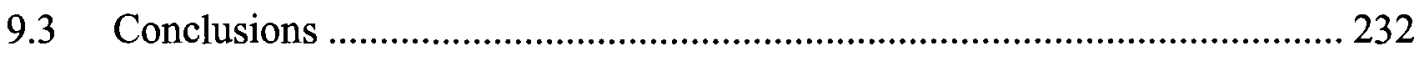

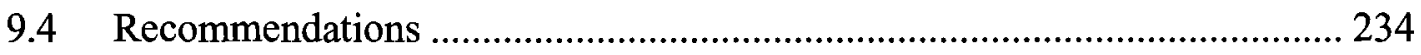

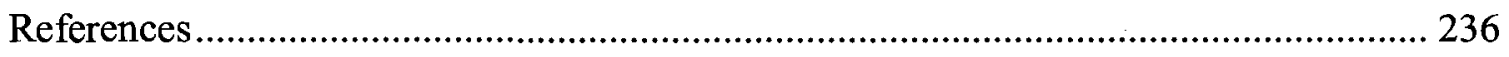




\section{List of Tables}

Table 1.1: 2000 freight transportation in Canada (M. Provencher, 2000) 3

Table 1.2: Dangerous goods accidents by mode of transport, 1998 - 2006 (TDG Excerpt, 2007) 3

Table 1.3: Total death and injuries resulted from dangerous goods accidents (TDG Excerpt, 2007) 5

Table 2.1: List of historical transportation accidents involving hazard materials (Production and Consumption Branch, APELL, Transportation disasters). 17

Table 2.2: Dimensions of standard 20 feet containers (German Marine Insurer) 25

Table 2.3: Dimensions of standard 40 feet containers (German Marine Insurer) ..... 26

Table 2.4: The Equivalence Factors for Chemical Explosives (Suppressive Shields Structural Handbook). 27

Table 2.5: Suppressive shield groups according to Edgewood Arsenal design (Suppressive Shield handbook). 48

Table 3.1: Charges radii 62

Table 3.2: Material data for air and TNT available in the library of AUTODYN 63

Table 3.3: Pressure values comparison between AUTODYN and ConWep for different 2-

D mesh sizes 67

Table 3.4: Theoretical and Numerical Transmitted pressure values. 74

Table 3.5: Parametric study parameters 76

Table 3.6: Experimental test peak pressure for $3.8 \mathrm{~kg}$ Pentolite in air 91

Table 3.7: Experimental test peak pressure for $3.8 \mathrm{~kg}$ Pentolite behind structure. 91 xiii 
Table 3.8: Experimental test reduction in peak incident pressure

Table 3.9: AUTODYN peak pressure for $3.8 \mathrm{~kg}$ Pentolite in air 93

Table 3.10: AUTODYN peak pressure for $3.8 \mathrm{~kg}$ Pentolite behind structure 93

Table 3.11: Experimental test reduction in peak incident pressure 94

Table 3.12: Air peak incident pressure comparison .95

Table 3.13: Reflected pressure values vs scaled distance. 96

Table 4.1: Used angle sections, Canadian Steel Handbook. 102

Table 4.2: Unit vent area calculations for Nested Angles 105

Table 4.3: Nested Angles Mass calculation 107

Table 4.4: Unit vent area calculations for Double Angles 109

Table 4.5: Double Angles Mass calculation 110

Table 4.6: Models developed for $50 \mathrm{Kg}$ charge 115

Table 5.1: Angle sections used in SSPs, Canadian Steel Handbook

Table 5.2: Thickness of used Aluminum Foam sheets 133

Table 5.3: Outline of the testing Program.

Table 5.4 Effective Multi-layer Vent Area Ratio Calculations for All SSPs

Table 5.5: Mass Calculation for SSPs.

Table 5.6: Mass calculation for retrofit ISO containers.

Table 6.1: Pressure values inside and outside blast chamber SSP-A (with \& without AF)

Table 6.2: Pressure values for the three explosive charges, Air \& SSPs. 169

Table 6.3: Pressure values for $0.5 \mathrm{~kg}$ of Pentolite, SSPs with AF 169 
Table 7.1: Material Data

Table 8.1: Percentage of differences between numerical predictions for $0.25 \mathrm{~kg}$ of Pentolite 199

Table 8.2: Percentage of differences between numerical predictions for $0.5 \mathrm{~kg}$ of

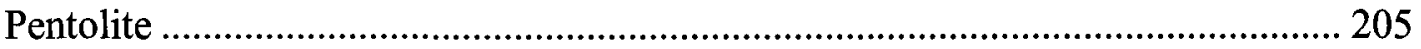

Table 8.3: Percentage of differences between numerical predictions for $1 \mathrm{~kg}$ of Pentolite 210

Table 8.4: Reduced safety distances when SSPs are used as secondary protection ....... 225 


\section{List of Figures}

Figure 1.1: Main Phases of Research Plan .................................................. 11

Figure 2.1: Crater resulted from explosion (Gulf News, April 11, 2007) .................... 20

Figure 2.2: Damage of the body of vessel (Weeth \& Associates ${ }_{\text {LLC }}$ )........................... 21

Figure 2.3: Crater resulted from explosion (One News, 2004)..................................... 22

Figure 2.4: Aerial photograph of the accident site (M. Provencher, 2005) .................... 23

Figure 2.5: The bogy of the truck after the explosion occurred (M. Provencher, 2005) .. 23

Figure 2.6: Highway asphalt shifts as a result of the huge explosion (M. Provencher, 2005) 24

Figure 2.7: Ideal Blast Wave, Free-field Phenomena (Baker, W.E., 1973)................... 29

Figure 2.8: Shock wave followed by refraction wave (Gas Explosion Handbook)......... 30

Figure 2.9: Normal Reflection of a Plane Shock from a Rigid Wall (Baker, W.E., 1973)31

Figure 2.10: Regular, Oblique Reflection (Baker, W.E., 1973) .................................. 31

Figure 2.11: Mach Reflections from a Rigid Wall (Baker, W.E., 1973) ........................ 32

Figure 2.12: Mach Reflections Geometry (Baker, W.E., 1973) .................................. 32

Figure 2.13: Wave diffraction over a wall (Baker, W.E., 1973)................................... 33

Figure 2.14: Blast wave reflection within suppressive structure (Suppressive Shields

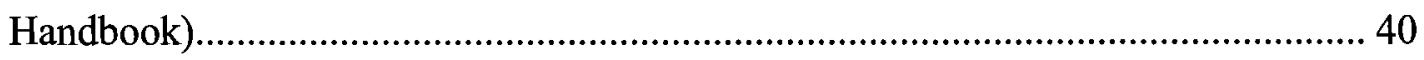

Figure 2.15: Idealized Internal Pressure-Time History (Suppressive Shields Handbook) 40

Figure 2.16: Pressure-Time History (Suppressive Shields Handbook) 41 
Figure 2.17: Subsonic shock wave passing through restriction (Technical Report: Air blast attenuation) 43

Figure 2.18: Standing shock wave at restriction area (Technical Report: Air blast attenuation) 45

Figure 2.19: Standing shock propagation behind restriction (Technical Report: Air blast attenuation) 45

Figure 2.20: Transmitted wave pressure values for supersonic wave (Technical Report: Air blast attenuation) 46

Figure 3.1: Euler formulation (Manual for AUTODYN software Agency of Century Dynamics Company (2003)) 53

Figure 3.2: Element parameters Location for Euler-FCT mesh (Manual for AUTODYN software Agency of Century Dynamics Company (2003)) 54

Figure 3.3: Lagrange formulation (Manual for AUTODYN software Agency of Century Dynamics Company (2003)) 55

Figure 3.4: Element parameters Location for Lagrange mesh (Manual for AUTODYN software Agency of Century Dynamics Company (2003)) 55

Figure 3.5: Representations of Shell Elements and Centering of Dependent Variables. (Manual for AUTODYN software Agency of Century Dynamics Company (2003)) (1)

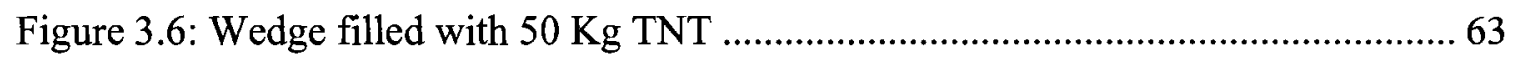

Figure 3.7: The Wedge part used to simulate air for remapping ......................................... 64

Figure 3.8: Velocity vectors of the shock wave............................................................... 64 
Figure 3.9: Remap Peak Incident Pressure Comparison between AUTODYN and ConWep 65

Figure 3.10: Boundary condition for air domain and location of gauges ........................66

Figure 3.11: 2-D Mesh size vs peak incident pressure at 1 meter .............................. 67

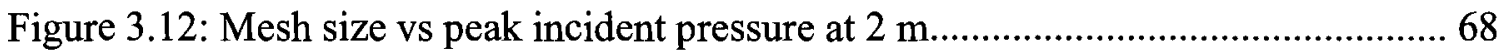

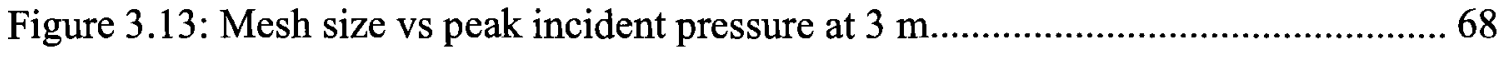

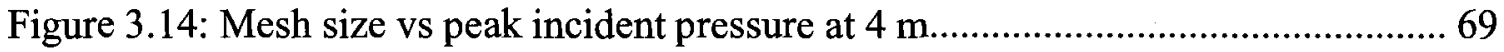

Figure 3.15 : Boundary condition for air domain and location of gauges ....................... 70

Figure 3.16: 3-D-5 kg Mesh size vs peak incident pressure at 1 meter ......................... 71

Figure 3.17: 3-D-50 kg Mesh size vs peak incident pressure at 1 meter ........................ 72

Figure 3.18: 3-D-50 kg Mesh size vs peak incident pressure at 2 meter ......................... 72

Figure 3.19: Transmitted wave pressure values for supersonic wave ........................... 74

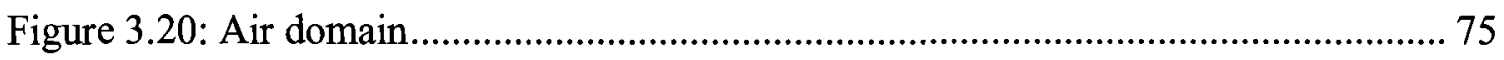

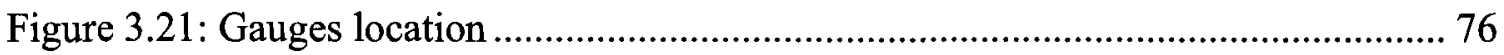

Figure 3.22: Velocity vectors of shock wave propagating through obstacles ............... 78

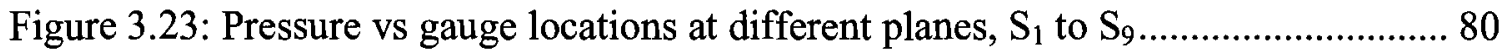

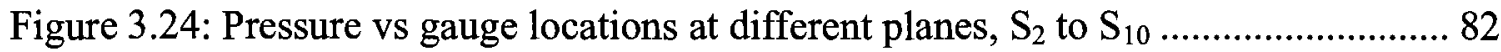

Figure 3.25: Pressure vs time at $1500 \mathrm{~mm}$ from obstacle ...................................... 83

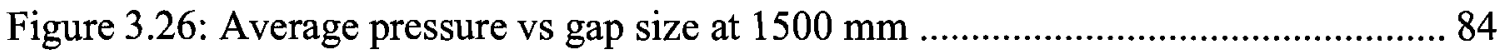

Figure 3.27: S 3x5.7 I-beam used in body of Category I Suppressive Shield ................. 85

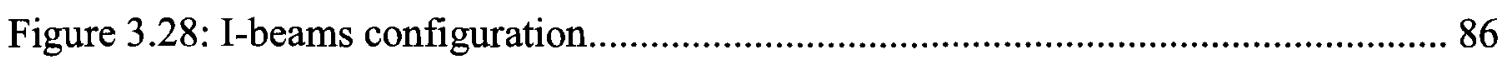

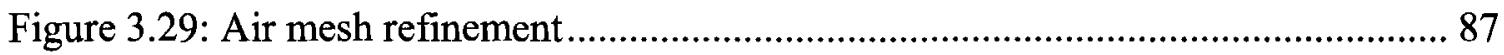

xviii 


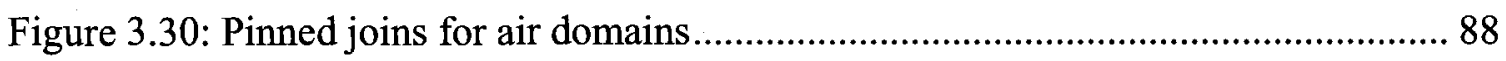

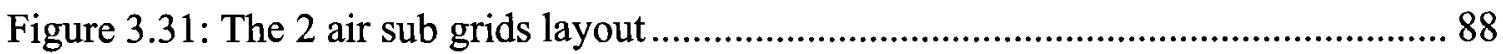

Figure 3.32: Gauges as located in AUOTDYN model ..................................................... 89

Figure 3.33: Location of gauges as in the experimental test (Schumacher et al) ............. 90

Figure 3.34: Experimental test peak pressure in air and behind structure ........................ 92

Figure 3.35: AUTODYN peak pressure in air and behind structure …........................... 93

Figure 3.36: Air peak incident pressure comparison ...................................................... 95

Figure 3.37: Pressure percentage reduction- Experimental test vs AUTODYN .............. 95

Figure 3.38: Reflected pressure vs Time (experimental test) at gauge \#7 ........................ 97

Figure 3.39: Reflected pressure vs Time (AUTODYN) at gauge \#4 ................................ 97

Figure 3.40: Reflected pressure vs Time (experimental test) at gauge \#8 ........................98

Figure 3.41: Reflected pressure vs Time (AUTODYN) at gauge \#5 .............................. 98

Figure 3.42: Reflected pressure vs Time (experimental test) at gauge \#10 ...................... 99

Figure 3.43: Reflected pressure vs Time (AUTODYN) at gauge \#9 .............................. 99

Figure 4.1: Nested angles configuration .................................................................. 100

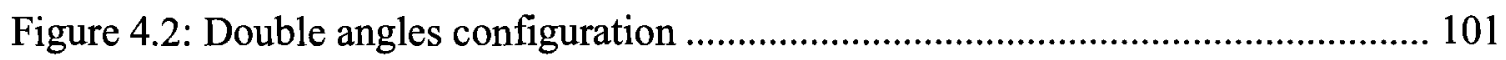

Figure 4.3: Vent Area Parameters................................................................................ 103

Figure 4.4: Unit Vent Area Ratio for $6.35 \mathrm{~mm}$ thickness .............................................. 106

Figure 4.5: Nested angles maximum allowable mass limit .......................................... 107

Figure 4.6: Double angle vent area parameters ............................................................... 108

Figure 4.7: Double angles maximum allowable mass limit........................................... 110

Figure 4.8: Typical model for nested angles............................................................... 112 
Figure 4.9: Typical model for double angles

Figure 4.10: Pressure values with respect to different angle size, Nested configuration 114

Figure 4.11: Attenuation percentage in pressure for $5 \mathrm{~kg}$, Nested configuration, different angle size.

Figure 4.12: L51 pressure values with different spacing 116

Figure 4.13: Jets formation through nested configuration.

Figure 4.14: Attenuation percentage in pressure for $50 \mathrm{~kg}$, L51 Nested, different spacing

Figure 4.15: $\mathrm{L} 76$ pressure values with different spacing 118

Figure 4.16: Attenuation percentage in pressure for $50 \mathrm{~kg}$, L76 Nested, different spacing

Figure 4.17: L102 pressure values with different spacing. 120

Figure 4.18: Attenuation percentage in pressure for $50 \mathrm{~kg}$, L102 Nested, different spacing 120

Figure 4.19: $12.7 \mathrm{~mm}$ spacing, different angle size

Figure 4.20: $25.4 \mathrm{~mm}$ spacing, different angle size 121

Figure 4.21: $38.1 \mathrm{~mm}$ spacing, different angle size 122

Figure 4.22: $50.8 \mathrm{~mm}$ spacing, different angle size 122

Figure 4.23: Attenuation percentage for average areal density $150 \mathrm{~kg} / \mathrm{m}^{2}$. 123

Figure 4.24: Attenuation percentage for average areal density $190 \mathrm{~kg} / \mathrm{m}^{2}$ 124

Figure 4.25: Attenuation percentage for average areal density $270 \mathrm{~kg} / \mathrm{m}^{2}\left(\mathrm{~A}_{\mathrm{v}}=11 \%\right) \ldots 124$ 
Figure 4.26: Pressure values with respect to different angle size, Double Angle configuration 125

Figure 4.27: Double Angle Jets 126

Figure 4.28: Attenuation percentage in pressure for $5 \mathrm{~kg}$, Double configuration, different angle size 126

Figure 4.29: Pressure values with respect to different angle configuration 127

Figure 4.30: Attenuation percentage in pressure with respect to different configuration, L51 128

Figure 4.31: Attenuation percentage in pressure with respect to different configuration, L102 128

Figure 5.1: Front view of the chamber

Figure 5.2: Chamber door-inside view

Figure 5.3: The inner surface of SSP-A and SSP-B 132

Figure 5.4: AF sheets without steel plate backing 134

Figure 5.5: Suppressive Shield Panel A............................................................ 136

Figure 5.6: Suppressive Shield Panel B .......................................................... 136

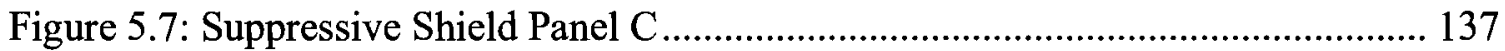

Figure 5.8: Suppressive Shield Panel D............................................................ 137

Figure 5.9 Double angle vent area parameters.................................................... 138

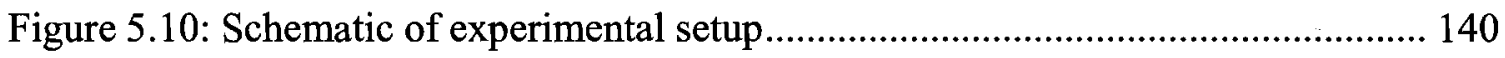

Figure 5.11: Schematic Diagram of PCB pencil gauge .......................................... 141

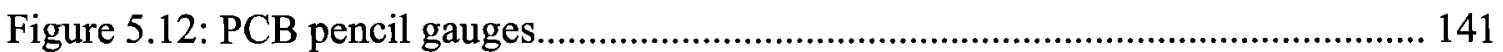


Figure 5.13: Typical stress-strain of steel (Gere, J. M. et al, 1990)

Figure 5.14: Typical stress-strain of AF under compressive loading (Rajan S. et al 2006)

Figure 6.1: Raw data before and after filtering......................................................... 146

Figure 6.2: Pressure versus charge mass- Air Shots ....................................................... 147

Figure 6.3: Blast pressure versus gauge location, Air-0.25 kg ................................... 148

Figure 6.4: Blast pressure versus gauge location, Air-0.5 kg ........................................ 148

Figure 6.5: Typical pressure-time profile ……………................................................ 149

Figure 6.6: Typical Pressure and Impulse Profiles .......................................................... 149

Figure 6.7: Impulse versus gauge location, Air-0.25 kg........................................... 150

Figure 6.8: Impulse versus gauge location, Air-0.5 kg................................................ 150

Figure 6.9: Blast pressure versus gauge location- $0.25 \mathrm{~kg}$ of Pentolite ............................ 151

Figure 6.10: SSPs pressure attenuation percentage- $0.25 \mathrm{~kg}$ of Pentolite ....................... 152

Figure 6.11: Average SSPs pressure attenuation percentage-0.25 kg of Pentolite......... 152

Figure 6.12: Impulse versus gauge location- $0.25 \mathrm{~kg}$ of Pentolite.................................... 153

Figure 6.13: Average SSPs impulse attenuation percentage $0.25 \mathrm{~kg}$ of Pentolite........... 153

Figure 6.14: Blast pressure versus gauge location- $0.5 \mathrm{~kg}$ of Pentolite ........................... 154

Figure 6.15: SSPs pressure attenuation percentage- $0.5 \mathrm{~kg}$ of Pentolite ......................... 154

Figure 6.16: Average SSPs pressure attenuation percentage-0.5 kg of Pentolite........... 155

Figure 6.17: Impulse versus gauge location- $0.5 \mathrm{~kg}$ of Pentolite...................................... 156

Figure 6.18: Average SSPs impulse attenuation percentage- $0.5 \mathrm{~kg}$ of Pentolite............ 156

Figure 6.19: Blast pressure versus gauge location-1 kg of Pentolite ................................ 157 
Figure 6.20: Impulse versus gauge location-1 $\mathrm{kg}$ of Pentolite

Figure 6.21: SSPs cross-section with loading direction. 158

Figure 6.22: Blast pressure versus gauge location-Unbaked AF-0.5 kg of Pentolite ..... 159

Figure 6.23: SSPs-pressure attenuation percentage-Unbaked AF-0.5 kg of Pentolite ... 160

Figure 6.24: Average SSPs pressure attenuation percentage-Unbaked AF-0.5 kg of

Pentolite 161

Figure 6.25: Impulse versus gauge location-Unbaked AF-0.5 kg of Pentolite. 162

Figure 6.26: Average SSPs impulse attenuation percentage-Unbaked AF-0.5 kg of Pentolite 162

Figure 6.27: Blast pressure versus gauge location-SSP-B-AF-0.5 kg of Pentolite 163

Figure 6.28: Blast pressure versus gauge location-SSPs \& AF with and without backing 164

Figure 6.29: SSPs Average pressure attenuation percentage-AF with \& without backing 165

Figure 6.30: Impulse versus gauge location-SSPs \& AF with and without backing ..... 166

Figure 6.31: SSPs Average impulse attenuation percentage-AF with \& without backing 166

Figure 6.32: AF in SSP-Ba 2 after testing. 167

Figure 6.33: Smallest AF sheet thickness after

Figure 6.34: Side-view of biggest thickness 167

Figure 6.35: AF sheet deformation after testing for $\mathrm{SSP}-\mathrm{Bc}_{2} \mathrm{SSP}-\mathrm{Cc}_{2}$ 168

Figure 7.1: Air mesh through SSPs. 174 
Figure 7.2: The small tunnel in front of the blast chamber door

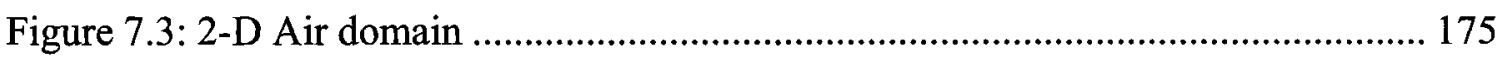

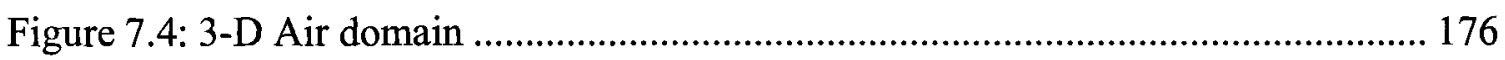

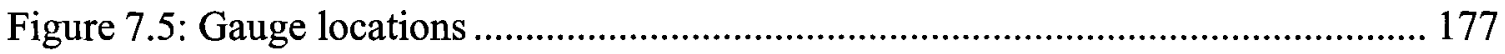

Figure 7.6: Explosive charge vectors after remapping in 2-D models ......................... 179

Figure 7.7: Explosive charge vectors after remapping in 3-D models ........................ 179

Figure 8.1: Numerical Pressure versus charge mass- Air Shots ............................... 187

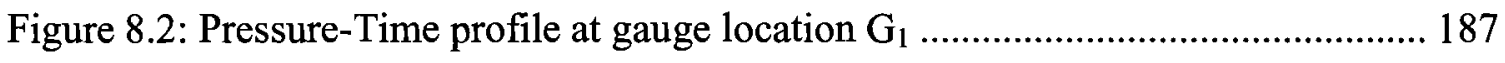

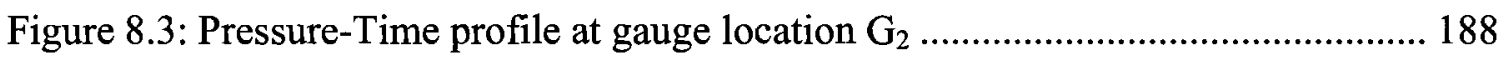

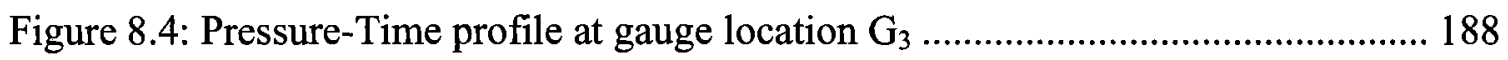

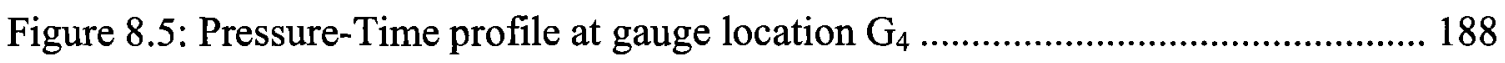

Figure 8.6: Numerical blast pressure versus gauge location, Air-0.25 kg ................... 189

Figure 8.7: Numerical blast pressure versus gauge location, Air-0.5 kg ..................... 190

Figure 8.8: Numerical and Experimental blast pressures versus gauge locations .......... 190

Figure 8.9: Numerical impulse versus gauge location, Air-0.25 kg ........................... 191

Figure 8.10: Numerical impulse versus gauge location, Air-0.5 kg .......................... 191

Figure 8.11: Shock wave propagation through air-0.5 kg ..................................... 192

Figure 8.12: Numerical \& Experimental pressure versus gauge location-SSP-A-0.25 kg of

Pentolite 193

Figure 8.13: Numerical \& Experimental pressure versus gauge location-SSP-B-0.25 kg of Pentolite 194 
Figure 8.14: Numerical \& Experimental pressure versus gauge location-SSP-C-0.25 kg of Pentolite 194

Figure 8.15: Numerical \& Experimental pressure versus gauge location-SSP-D-0.25 kg of Pentolite 194

Figure 8.16: Numerical pressure versus gauge location-All SSPs-0.25 kg of Pentolite. 195 Figure 8.17: SSPs Numerical pressure attenuation percentage- $0.25 \mathrm{~kg}$ of Pentolite...... 196 Figure 8.18: Average SSPs Numerical pressure attenuation percentage- $0.25 \mathrm{~kg}$ of Pentolite 197

Figure 8.19: Numerical impulse versus gauge location- $0.25 \mathrm{~kg}$ of Pentolite 198

Figure 8.20: Average SSPs numerical impulse attenuation percentage $0.25 \mathrm{~kg}$ of Pentolite 198

Figure 8.21: Numerical \& Experimental pressure versus gauge location-SSP-A-0.5 kg of Pentolite 201

Figure 8.22: Numerical \& Experimental pressure versus gauge location-SSP-B-0.5 kg of Pentolite 202

Figure 8.23: Numerical \& Experimental pressure versus gauge location-SSP-C-0.5 kg of Pentolite 202

Figure 8.24: Numerical \& Experimental pressure versus gauge location-SSP-D-0.5 kg of Pentolite 202

Figure 8.25: Numerical blast pressure versus gauge location- $0.5 \mathrm{~kg}$ of Pentolite.......... 203 Figure 8.26: Average SSPs numerical pressure attenuation percentage- $0.5 \mathrm{~kg}$ of Pentolite 203 
Figure 8.27: Numerical impulse versus gauge location- $0.5 \mathrm{~kg}$ of Pentolite 204

Figure 8.28: Average SSPs numerical impulse attenuation percentage $0.5 \mathrm{~kg}$ of Pentolite 205

Figure 8.29: Numerical \& Experimental pressure versus gauge location-SSP-A-1 kg of Pentolite 207

Figure 8.30: Numerical \& Experimental pressure versus gauge location-SSP-B-1 kg of Pentolite 207

Figure 8.31: Numerical \& Experimental pressure versus gauge location-SSP-C-1 kg of Pentolite 207

Figure 8.32: Numerical \& Experimental pressure versus gauge location-SSP-D-1 kg of Pentolite 208

Figure 8.33: Numerical blast pressure versus gauge location-1 kg of Pentolite. 208

Figure 8.34: Average SSPs numerical impulse attenuation percentage $1 \mathrm{~kg}$ of Pentolite 208

Figure 8.35: Numerical impulse versus gauge location-1 $\mathrm{kg}$ of Pentolite 209

Figure 8.36: Average SSPs numerical impulse attenuation percentage $1 \mathrm{~kg}$ of Pentolite 210

Figure 8.37: Yield stress contour for SSP-A subjected to $0.5 \mathrm{~kg}$ of Pentolite. 213

Figure 8.38: SSP-A after testing 213

Figure 8.39: Numerical modelling of un-backed AF sheets 214

Figure 8.40: Un-backed AF sheets after testing. 215

Figure 8.41: Experimental test versus numerical model- backed AF sheet. 216 


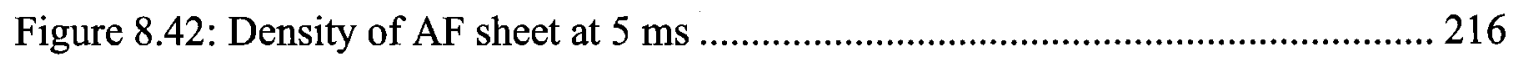

Figure 8.43: Yield stress contour for SSP-A subjected to $10 \mathrm{~kg}$ of Pentolite.................. 218

Figure 8.44: Angle shape effect on loading direction................................................ 219

Figure 8.45: Yield stress contour for SSP-A subjected to $25 \mathrm{~kg}$ of Pentolite................. 220

Figure 8.46: Yield stress contour for SSP-A subjected to $50 \mathrm{~kg}$ of Pentolite.................. 220

Figure 8.47: Yield stress contour for cubicle subjected to $5 \mathrm{~kg}$ of Pentolite ................... 221

Figure 8.48: Plastic deformation of cubicle at various time intervals ............................. 222

Figure 8.49: Vent Area Ratio versus Areal Density ....................................................... 224

Figure 8.50: Explosive mass versus transmitted pressure ……..................................... 224 


\section{Nomenclature}

\begin{tabular}{|c|c|}
\hline$a$ & Inclined spacing between angles \\
\hline$A_{1}$ & Area away from restriction \\
\hline$A_{r}$ & Area at restriction \\
\hline$A_{v}$ & Vent area \\
\hline$B$ & Mott scaling factor \\
\hline$D, H, L, n$ and $m$ & Material constants \\
\hline$D_{f}$ & Fireball diameter \\
\hline$d_{i}$ & Average inside diameter of casing \\
\hline$e$ & Internal energy \\
\hline$E^{\prime}$ & Gurney energy constant \\
\hline$F$ & Force \\
\hline$f_{y}$ & Yield stress \\
\hline$G_{i}$ & Gauges number \\
\hline$h$ & Projected width \\
\hline$I, J, K$ & Local coordinates within AUTODYN \\
\hline$I_{r}$ & Reflected impulse \\
\hline$I_{s}$ & Incident impulse \\
\hline$K$ & Bulk modulus $=E /[3(1-2 v)]$ \\
\hline$l$ & Length of exposed element \\
\hline$m$ & Mass \\
\hline$M$ & Mach number \\
\hline$M_{A}$ & Fragment distribution factor \\
\hline$n$ & Number of layers \\
\hline$N$ & Constant, depending on the number of openings per projected width \\
\hline$N_{T}$ & The total number of fragments \\
\hline$P_{o}$ & Ambient atmospheric pressure \\
\hline$P_{q s}$ & Quasi-static pressure \\
\hline$P_{r}$ & Reflected pressure \\
\hline
\end{tabular}

xxviii 


\begin{tabular}{|c|c|}
\hline$P_{\text {shift }}$ & Pressure shift \\
\hline$P_{\text {so }}$ & Positive peak side-on (incident) overpressure \\
\hline$q$ & Pseudo-viscous pressure \\
\hline$r$ & Radius of spherical charge \\
\hline$R$ & Standoff distance \\
\hline$S$ & Projected spacing \\
\hline$s$ & Stress deviator tensor \\
\hline$t_{a}$ & Time of arrival \\
\hline$t_{b}$ & Blown down time \\
\hline$t_{c}$ & Average casing thickness \\
\hline$T_{f}$ & Fireball duration time \\
\hline$T_{H}$ & Homologous temperature $=\left(\mathrm{T}-\mathrm{T}_{\text {room }}\right) /\left(\mathrm{T}_{\text {melt }}-\mathrm{T}_{\text {room }}\right)$ \\
\hline$U$ & Incident wave velocity \\
\hline$U_{r}$ & Reflected wave velocity \\
\hline$V$ & Volume \\
\hline$V_{o}$ & The initial velocity \\
\hline$V_{o}$ & Initial volume \\
\hline$W$ & Weight of explosive charge \\
\hline$W_{c}$ & Weight of casing \\
\hline$W_{f}$ & Largest fragment weight \\
\hline$x$ & Displacement \\
\hline$Z$ & Scaled distance \\
\hline$\alpha_{e}$ & Multi-layer vent area ratio \\
\hline$\alpha_{i}$ & Single layer vent area ratio \\
\hline$\alpha_{I}$ & Angle of incident \\
\hline$\alpha_{I \text { crit }}$ & Critical angle of incidence \\
\hline$\alpha_{R}$ & Reflection angle \\
\hline$\dot{e}$ & Energy conservation \\
\hline$\Delta t$ & Time step \\
\hline$\beta$ & Compression $\left[\left(\rho / \rho_{0}\right)-1\right]$ \\
\hline
\end{tabular}




$\begin{array}{ll}\gamma & \text { Ideal gas constant } \\ \varepsilon_{p} & \text { Effective plastic strain } \\ \varepsilon_{p}^{*} & \text { Normalized effective plastic strain rate } \\ \varepsilon & \\ \zeta & \text { Strain rates } \\ \zeta_{i} & \text { Scaled impulse } \\ \eta & \text { Strength of shock wave } \\ \mu & \rho / \rho_{o} \\ \rho & \text { Dynamic viscosity } \\ \rho_{o} & \text { Density } \\ \sigma & \text { Initial density } \\ \tau & \text { Stress tensor } \\ v & \text { Scaled time } \\ \dot{x}, \dot{y} & \text { Poisson's ratio } \\ & \text { Velocities }\end{array}$




\section{Chapter 1}

\section{Introduction}

The establishment and maintenance of the United Nations Regulations for the Transportation of Dangerous Goods (UN-TDG) and/or hazardous materials has been designed to protect people, property and the environment. It requires concentrated effort and cooperation by various national organizations from many parts of the world. Most people move everyday, alongside vehicles transporting hazardous materials, for example, the fuel trucks that populate the roads and city streets day and night. People do not feel the inherent hazard posed by these trucks because they are not necessarily aware of the hazards. In addition, there is a level of trust with the government that gives the population a sense of security in what is being transported and stored. Clearly, when accidents involving fuel trucks occur, transporting fuel could potentially be perceived as being very dangerous. This is just one example of one hazardous material that typically moves among the population every day; however the transport systems carry more than just fuel.

The Transportation of Dangerous Goods (TDG) Act, 1992, defines the term dangerous goods as " $a$ product, substance or organism included by its nature or by the regulations in any of the classes listed in the schedule" (Transport Canada-TDG Regulations - Part 2). There are thousands of tonnes of different chemicals that are transported along the transport system everyday. Many of these chemicals are toxic, flammable and/or explosive in nature. 
With current trends in security and in an era sensitive to terrorism, the security of transporting dangerous and hazardous materials, specifically explosives, becomes an important engineering and safety issue. Thus, there is an urgent need to investigate the risks associated with using different types of containers and their effectiveness in eliminating and/or minimizing explosion effects.

\subsection{Problem Definition}

The quantity and movement of hazardous materials depend on the conditions of the overall economy of the country and its trading partners. One should expect that the better the economy the higher the volume of hazardous materials transported among other goods being transported. In a developed country like Canada with its strong economy, it is expected that there are large amounts of hazardous materials traveling everyday on different components of the transportation infrastructure. The hazardous materials represent a portion of the overall freight transportation. Table 1.1 shows the freight for each mode of transport in Canada (M. Provencher, 2000). It is clear that the minimum amount of freight and the lowest percentage of dangerous goods are carried by air transport. On the other hand, as expected the maximum transported quantity of dangerous goods is divided equally between rail and road transportation modes. Although the marine transport is responsible for the maximum quantity of freight, 348.3 million tonnes for year 2000 , dangerous goods carried by ship did not exceed $4 \%$ of the total freight by ships. The data in Table 1.1 shows the importance of land transport modes relative to other modes. Since the largest portion of dangerous goods is transported by road and rail, 
the corresponding accidents for these two modes are higher than those for air and marine as presented in Table 1.2 (TDG Excerpt, 2007).

Table 1.1: 2000 freight transportation in Canada (M. Provencher, 2000)

\begin{tabular}{ccc}
\hline $\begin{array}{c}\text { Mode of } \\
\text { Transport }\end{array}$ & $\begin{array}{c}\text { Total Freight } \\
\text { (Million Tonnes) }\end{array}$ & $\begin{array}{c}\text { Percentage of } \\
\text { Dangerous Goods }\end{array}$ \\
\hline Air & 0.7 & $1 \%$ \\
Marine & 348.3 & $4 \%$ \\
Rail & 319.7 & $15 \%$ \\
Road & 278.4 & $7-16 \%$ \\
\hline
\end{tabular}

Table 1.2: Dangerous goods accidents by mode of transport, 1998 - 2006 (TDG Excerpt, 2007)

\begin{tabular}{|c|c|c|c|c|c|c|c|}
\hline \multirow[t]{2}{*}{ Year } & \multicolumn{5}{|c|}{ In-transit } & \multirow[t]{2}{*}{ Not In-transit } & \multirow[t]{2}{*}{ Total } \\
\hline & Road & Rail & Air & Marine & Subtotal & & \\
\hline 1998 & 178 & 11 & 4 & 0 & 193 & 239 & 432 \\
\hline 1999 & 185 & 17 & 3 & 0 & 205 & 274 & 479 \\
\hline 2000 & 234 & 18 & 4 & 3 & 259 & 215 & 474 \\
\hline 2001 & 182 & 11 & 6 & 3 & 202 & 234 & 436 \\
\hline 2002 & 170 & 16 & 8 & 1 & 195 & 244 & 439 \\
\hline 2003 & 102 & 5 & 5 & 1 & 113 & 245 & 358 \\
\hline 2004 & 106 & 9 & 6 & 0 & 121 & 248 & 369 \\
\hline 2005 & 129 & 8 & 5 & 0 & 142 & 244 & 386 \\
\hline 2006 & 125 & 10 & 5 & 0 & 140 & 230 & 370 \\
\hline
\end{tabular}

Table 1.2 represents accidents involving dangerous goods among different modes between 1998 and 2006. The accidents are divided into two groups according to their conditions within the transport system;

1. Transit: the accidents occurred during the transportation process, and

2. Not in-transit: the accidents occurred at the storage facilities or during handling.

In general, the accidents occurring for the "not in-transit" conditions are higher when compared to the ones occurring during "transit". Moreover, the total accidents for 2006 are substantially less compared to previous years. This apparent decrease is due to the latest (August 2002) modification in the accident reports of TDG Regulations (UN $13^{\text {th }}$ 
Edition). The new modifications limit the reporting of accidents depending on the amount of dangerous goods involved in the accident. It has been assumed that the amount of damage and number of fatalities would increase with the increase in the amount of dangerous goods involved in an accident. Subsequently, the total number of accidents will not be reflected by those which are reported. However, it should be noted that while the 2006-total reported accidents decreased, the number of accidents under "non-transit" conditions were kept unchanged.

Table 1.3 gives the total number of deaths and injuries rated as minor, moderate and major. The minor injuries mean that people involved in accidents received first aid treatment at the site of the accident, while moderate means that the people were transported to hospital emergency for treatment before been discharged. Finally, major injuries describe the condition where the people stayed in the hospital for more than 1 day to receive treatment. The data provided in the table shows reduction in the total number of injuries up to year 2004 and then the numbers start increasing. With current wave of terrorist organizations and their use of explosives as their weapon of preference, increase in explosives-related accidents and the total number of injuries/fatalities are expected to continue and hence the need to investigate safety enhancement for DG transportation is required. 
Table 1.3: Total death and injuries resulted from dangerous goods accidents (TDG Excerpt, 2007)

\begin{tabular}{cccccc}
\hline Year & Deaths & \multicolumn{5}{c}{ Injuries } \\
\hline $\mathbf{1 9 9 8}$ & 13 & Major & Moderate & Minor & Totals \\
$\mathbf{1 9 9 9}$ & 28 & 38 & 56 & 15 & 109 \\
$\mathbf{2 0 0 0}$ & 20 & 53 & 143 & 19 & 246 \\
$\mathbf{2 0 0 1}$ & 24 & 46 & 50 & 19 & 122 \\
$\mathbf{2 0 0 2}$ & 12 & 25 & 33 & 20 & 99 \\
$\mathbf{2 0 0 3}$ & 5 & 21 & 42 & 5 & 72 \\
$\mathbf{2 0 0 4}$ & 11 & 12 & 17 & 1 & 39 \\
$\mathbf{2 0 0 5}$ & 7 & 18 & 20 & 4 & 36 \\
$\mathbf{2 0 0 6}$ & 6 & 5 & 22 & 4 & 44 \\
& & & 30 & 5 & 40 \\
& In 1999, Seven deaths and 45 injuries were due to a multiple highway vehicle collision in Windsor, Ontario. \\
& However, no deaths or injuries were due to the dangerous goods themselves. \\
& In 1999, 98 passengers were injured in a train collision with three hopper railway vehicles in Thamesford, \\
\end{tabular}

While accidents involving hazardous materials affect people, in terms of fatalities and/or death and the environment, the greatest effect resulting from these accidents is its great impact on the national economies. An important example demonstrating the influence of fireworks accidents on the world economy is the M/V HYUNDAI FORTUNE accident (Weeth \& Associates LLC $_{2007)}$ on March, 2006, which was the latest container vessel to have an explosion on board. The loss in cargo due to this fire was estimated to exceed $\$ 100$ million. After this accident global suspension on the movement of all fireworks shipments was enforced by Hyundai Marine (Weeth \& Associates $\left._{L L C}, 2007\right)$. This decision clearly affects negatively the fireworks industry and subsequently the trade and economic activities among countries.

\subsection{Objectives}

The primary objective of this thesis is directed at understanding the main variables that influence the safety and security of transport and storage of hazardous materials to design 
and develop better and safer systems for minimizing the risks associated with such materials. More specifically, this objective can be achieved through better design of suppressive shield-type systems (termed herein as 3-S) for mitigating blast effects. The suppressive shield system, 3-S, is an American military system originally designed for storing explosives and munitions (Suppressive Shields Handbook). The 3-S design has not spread into civilian use. The main goal behind using containers based on the 3-S principles for civilian purposes is to reduce hazards associated with the transport of explosives, thereby minimizing fatalities, and damage to both property and the environment. More specifically, the main objectives of this thesis are:

To assess the present state of transport and storage containers,

To examine the consequences resulting from accidental explosions with existing containers,

$>$ To enhance the safety and security measures for transportation of dangerous goods by mitigating the explosion effects, such as blast loading through the utilization of advanced 3-S technology.

To quantify the degree of improvement due to the adoption of the advanced 3-s containers,

To establish basis for the sizing and using of SSPs containers, for the amount of explosives that can be stored or transported and the associated safety distances.

\subsection{Scope of Study}

This thesis is limited to performing analytical and experimental investigations on suppressive shield panels (SSPs) containers for amounts of explosives up to $50 \mathrm{~kg}$. In 
addition and due to experimental limitations, large explosive masses to and beyond $50 \mathrm{~kg}$ will be simulated using numerical methods only. Accordingly, the work described in this thesis utilized AUTODYN, a finite element analysis (FEA) program to simulate scenarios supported with information from the literature and experimental test data. This study provides the civilian users, transport companies and the government new possibilities and more reliable guidelines for transportation and storage of DG. All explosives studied in this research are assumed to be free from fragments because the study will be limited to bare explosive charges that have paper or plastic casings. Thus, the most critical parameters to be investigated will be the blast pressures and impulses resulting from the explosions.

\subsection{Rationale for the Research}

Transportation and security experts are facing many challenges when it comes to securing transportation infrastructure assets, especially those with continuous and direct contact to dangerous goods. As was mentioned earlier, the main modes that are used for transportation of dangerous goods are rail and road. Dangerous goods are most often transported and stored temporarily and for long terms, in typical transport (International Organization for Standardization) ISO containers. The ISO containers do not have any capability to contain the blast consequences if an internal explosion occurred. Thus, the UN-TDG regulations require specific safety distance between ISO containers carrying energetic materials such as explosives and those containing non-dangerous goods. Similarly, storage regulations by all countries require that storage facilities for explosives be located according to Quantity-Distance (Q-D) requirements from other activities 
including dwellings and transportation routes. These safety distances are very important to minimize fatalities and prevent excessive damage when an explosion occurs. Clearly, any improved system resulting in containing the explosion effects and in shortening these distances will increase safety for people and economize space, respectively,

This thesis focuses on explosive amounts of up to $50 \mathrm{~kg}$ TNT equivalent. This amount has special status under the Canadian storage regulations. First, it is an amount that satisfies activities of various segments of society, including stores of explosives for avalanche control and oil perforating industry, bomb disposal agencies, sporting ammunition re-loaders, and some fireworks operators. Secondly, the Canadian regulations allow for reduced separation distances for storage of $50 \mathrm{~kg}$ or less if fragments resulting from an explosion can be contained or their throw distances limited. The requirements are different with larger amounts. The regulations state that if the amount of explosives exceeds $50 \mathrm{~kg}$, the separation distance must be sufficient to mitigate the hazards posed by blast overpressure and fragments. Note that the maximum allowable amount of fireworks or explosives allowed for road transport in Canada is 20 tonnes, an amount which blast effects, in the event of an explosion, are practically impossible to mitigate.

Therefore, one of the most promising outcomes of this thesis is the application of the proposed technology to develop new designs which are suitable to store and transport small amounts of explosives. Larger amounts can be divided into smaller quantities to maintain the same level of safety. 


\subsection{Research Plan}

The main objective of this thesis is to improve the safety and security of transporting and storing explosive materials. As was discussed earlier a military-developed suppressive shield system (3-S) is utilized and modified to meet the main objective stated above. Therefore, it is expected that developing this technology further would help reduce the risks and threats associated with transport of explosives and other danger goods and thereby minimize fatalities, protect property and reduce environmental damage. The research plan adopted consists of several phases and tasks and involves numerical and experimental investigations as shown in Figure 1.1.

The first phase involves two tasks. The first deals with identifying the problem and defining the main parameters that govern it. The second task consists of carrying out an in-depth literature review.

Phase two includes four tasks. The first task describes the details of the numerical approach using AUTODYN program and carrying out a sensitivity analysis as well as mesh convergence study to identify the optimum element size to be used. The second task involves the verification of the AUTODYN program using results from published experimental data. The third task includes preliminary parametric study to assess and select different parameters for further analysis and involves evaluating available numerical programs. The forth task includes the design of civilian SSPs. The results of this task are used to develop details of the experimental investigation and at the same time carry out a detailed numerical investigation to study the attenuation effect of the identified parameters and structural response of the proposed SSPs prototype. 
The third phase deals with the experimental verification of the numerical phase by performing field tests using actual explosives. The results and observations obtained from the experimental investigation will then be used for verifying the numerical findings.

The fourth phase includes fine tuning of the analysis and adjusting the values and contribution of the identified parameters. Also, a comparison of experimental test results is made with the numerical results to examine its degree of accuracy.

The fifth phase involves the development of preliminary design guidelines for enhancing the safety and security of storage and transportation of dangerous goods and hazardous materials.

The sixth and final phase consists of reporting the main findings of the research, and its important conclusions and recommendations. 


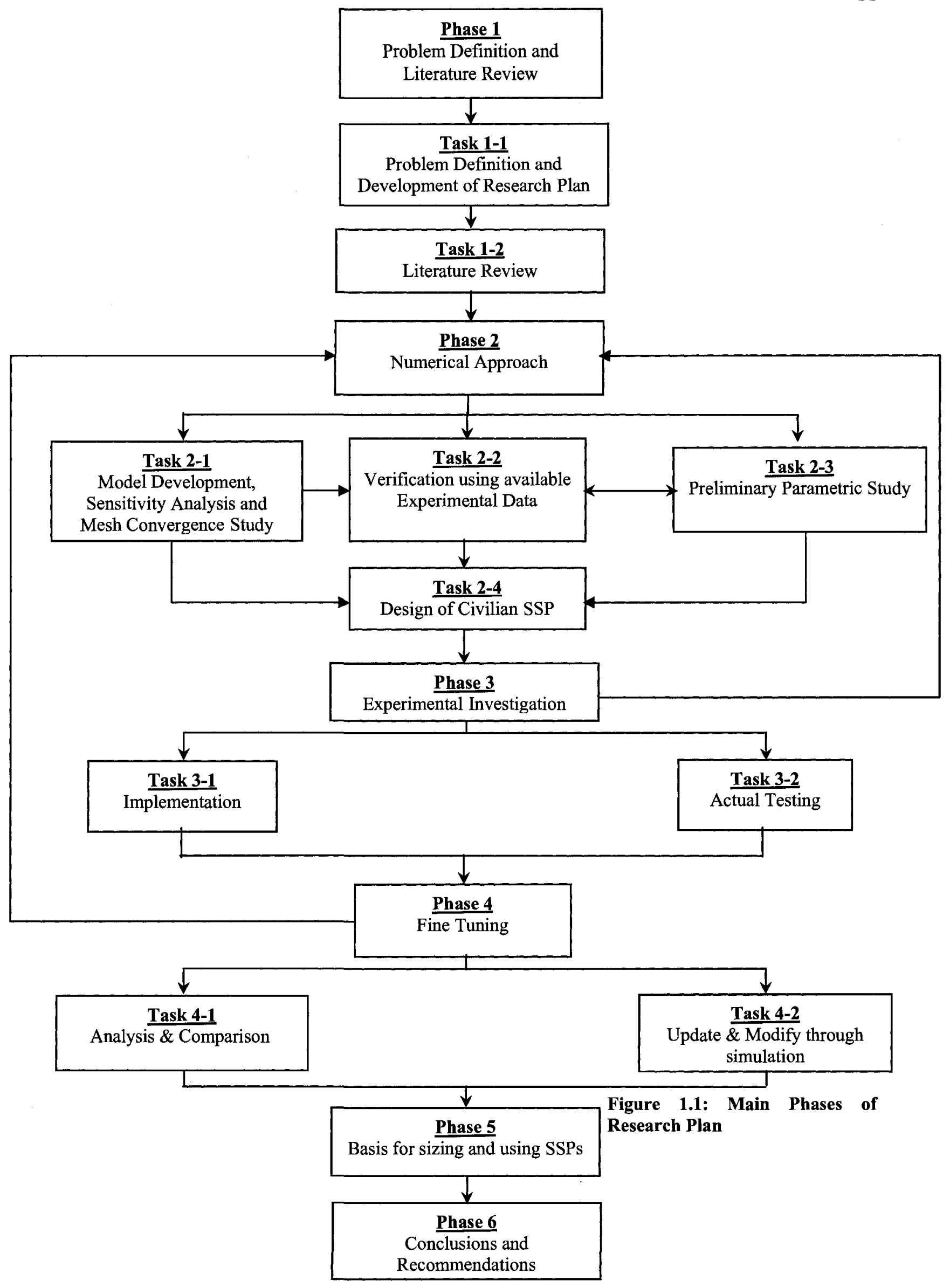




\subsection{Organisation of Thesis}

The thesis is structured into nine chapters. The first chapter presents an introductory overview on the storage and transport of hazardous materials and defines the objectives and the rationale behind this research and describes the research plan. The second chapter includes in-depth discussion of the problem by presenting accident statistics, examples of accidents accompanied by analysis of why and how these accidents occurred and finally gives an explanation of the explosion parameters and its consequence and the evolution of the suppressive shield concept. The third chapter provides details of the numerical approach and presents the verification of numerical simulation using theoretical data as well as experimental data from literature. The forth chapter describes the preliminary study of SSPs. The fifth chapter explains the experimental investigation procedures including the test setup and panels design. The sixth chapter addresses the results, analysis and discussion of the experimental data. The seventh chapter gives details of the numerical models with respect to model construction, material properties,...etc. for 2-D and 3-D simulations. The eighth chapter presents the verification of the experimental results through numerical simulations. Finally, the ninth chapter covers the summary, conclusions and recommendations for the work completed. 


\section{Chapter 2}

\section{Literature Review}

\subsection{Introduction}

Since transportation is essential for manufacturing development and in turn for economic growth, a remarkable increase in the transportation of hazardous materials has occurred in the past few years. This increase in transportation volume amplified the probability of accidents on different transportation systems such as road, rail, air and marine systems. The main reasons for the accidents were either due to the sensitivity of the transported material, damage to transport containers, or by accidents with other vehicles. The results of such accidents often resulted in great impact on the environment as well as the transport system. As a result there is a need to study the effect of using different container systems on transportation and storage of dangerous goods. The analysis of new 3-S container systems to contain blast loads requires an in-depth understanding of the explosion phenomenon and its consequences. This chapter will focus on a brief review of the UN-TDG regulations, accidents history and consequences, explosion phenomena parameters and finally on the different types of existing suppressive shield designs.

\section{$2.2 U N-T D G$ Regulations Review}

The UN regulations for transportation of dangerous goods were published as model regulation for the first time after the tenth revised edition. The tenth edition was modified again for three more times and was published as the eleventh, twelfth and the most recent 
one, the thirteenth edition in summer of 2003 (UN Model Regulations). Generally speaking, the UN model regulations cover all essential transportation aspects in order to supply the transportation organizations and companies working in moving of dangerous goods with a homogeneous code or regulation worldwide. These regulations include a broad principle for classifying the dangerous goods for transport. The classification of dangerous goods consists of the following classes (UN Model Regulations). The classification of most concern in this research is Class 1 - Explosives. Class 1 Explosives are sub-classified into six categories according to their ramifications. Note that the classification is applied for packages or boxes including explosives/fireworks not the materials themselves. This means that if the package is damaged, the classification principle is no longer applicable.

- Class 1 - Explosives

Class 1.1, mass explosion hazard;
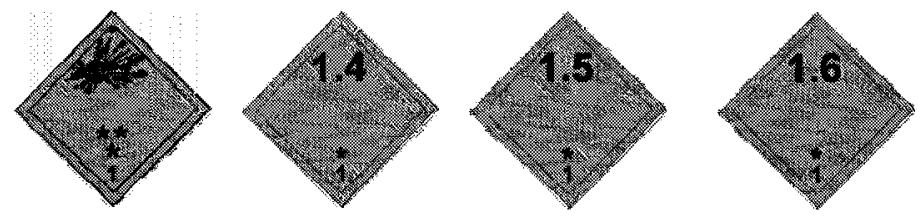

Class 1.2, projection hazard but not a mass explosion hazard;

Class 1.3, fire hazard and either a minor blast hazard or a minor projection hazard or both but not a mass explosion hazard;

Class 1.4, no significant hazard beyond the package in the event of ignition or initiation during transport;

Class 1.5 , very insensitive substances with a mass explosion hazard; and

Class 1.6, extremely insensitive articles with no mass explosion hazard

- Class 2 - Gases

Class 2.1 flammable gas
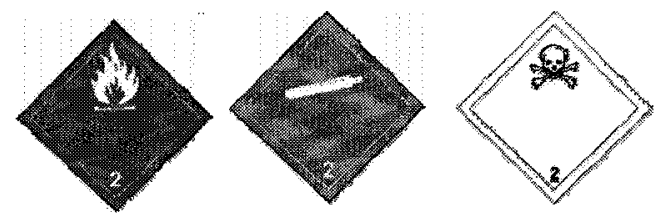
Class 2.2 non-flammable gas

Class 2.3 toxic gas

- Class 3 - Flammable Liquids

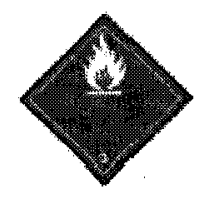

- Class 4-Flammable Substances

Class 4.1 flammable solid

Class 4.2 spontaneously combustible

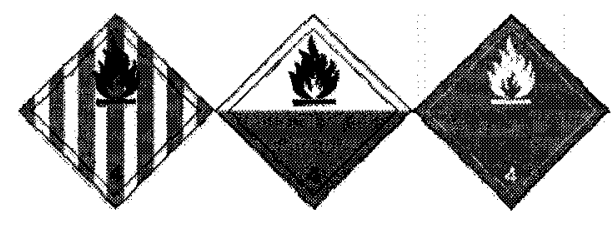

Class 4.3 dangerous when wet

- Class 5 - Oxidizers and Organic Peroxides

Class 5.1 oxidizing agent

Class 5.2 organic peroxide

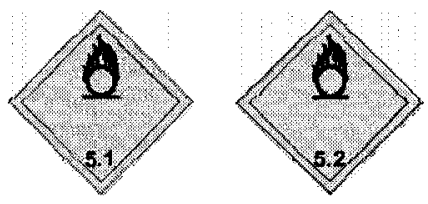

- Class 6- Toxic and Infectious Substances

Class 6.1 toxic

Class 6.2 infectious

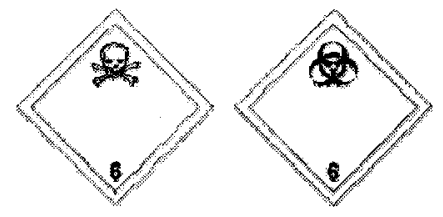

- Class 7 - Radioactive

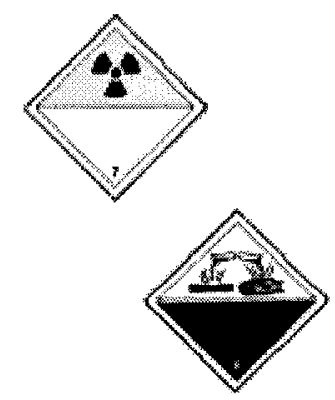

- Class 9-Miscellaneous

Class 9.1 Miscellaneous dangerous goods

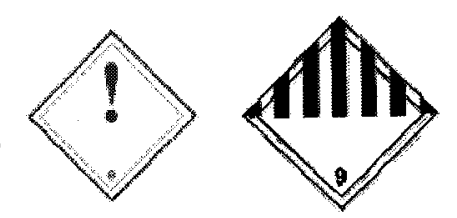


Class 9.2 Environmentally hazardous materials

Class 9.3 Dangerous wastes

\subsection{Accident History}

Accidents are a major issue and of great concern to everyone. No one can predict or know exactly when or where an accident could happen, especially when it comes to transportation or storage of dangerous goods. Thus before talking about accident statistics and accident history over the past 30 years, it is necessary to define the term, "accident". The term accident can be defined as "An event that results in a fatality, work injury, property damage or material loss arising out of, linked with or occurring in the course of employment" (Treasury Board of Canada Secretariat). The following sections present accident statistics as well as few accident examples related to transport and storage of dangerous goods to express the reasons and consequences of such accidents. Moreover, a short analysis of the reasons behind those accidents are presented form the researcher's point of view.

\subsubsection{Accident Statistics}

This section mainly focuses on illustrating worldwide accident statistics involving dangerous goods. Table 2.1 lists accidents associated with different transport modes as well as the type of explosives and the consequences, either total number of fatalities, death or injuries, or property damage and rehabilitation costs. 
Table 2.1: List of historical transportation accidents involving hazard materials (Production and Consumption Branch, APELL, Transportation disasters)

\begin{tabular}{|c|c|c|c|c|}
\hline Date & Location & Origin of accident & $\begin{array}{l}\text { Material } \\
\text { Involved }\end{array}$ & Consequences \\
\hline $\begin{array}{l}\text { Apr. 30, } \\
1974\end{array}$ & $\begin{array}{l}\text { JAPAN, } \\
\text { YOKKAICHI }\end{array}$ & $\begin{array}{l}\text { Leakage of chlorine } \\
\text { during a } \\
\text { transhipment }\end{array}$ & Chlorine & 521 injured \\
\hline $\begin{array}{l}\text { Feb. 23, } \\
1976\end{array}$ & $\begin{array}{l}\text { USA, DEER } \\
\text { PARK }\end{array}$ & $\begin{array}{l}\text { Accident during } \\
\text { road transportation } \\
\text { of ammonia }\end{array}$ & Ammonia & 5 died, 200 injured \\
\hline $\begin{array}{l}\text { Feb., } \\
1978\end{array}$ & $\begin{array}{l}\text { USA, } \\
\text { YOUNGSTOW } \\
\mathrm{N}\end{array}$ & $\begin{array}{l}\text { Leakage of chlorine } \\
\text { during rail } \\
\text { transportation }\end{array}$ & Chlorine & 8 died, 138 injured \\
\hline $\begin{array}{l}\text { Oct. } 1, \\
1979\end{array}$ & $\begin{array}{l}\text { GREECE, } \\
\text { SUDA BAY }\end{array}$ & $\begin{array}{l}\text { Explosion during } \\
\text { transportation of } \\
\text { propane }\end{array}$ & Propane & 7 died, 140 injured \\
\hline $\begin{array}{l}\text { Nov.10, } \\
1979\end{array}$ & $\begin{array}{l}\text { CANADA, } \\
\text { MISSISSAUGA } \\
\text { ONT }\end{array}$ & $\begin{array}{l}\text { Derailment of a train } \\
\text { carrying dangerous } \\
\text { goods } 3 \text { cars } \\
\text { carrying propane } \\
\text { exploded, a chlorine } \\
\text { tank was punctured, } \\
\text { release of chlorine } \\
\text { in the air }\end{array}$ & $\begin{array}{l}\text { Chlorine, } \\
\text { Propane, } \\
\text { LPG }\end{array}$ & $\begin{array}{l}250000 \text { evacuated } \\
\text { from the } \\
\text { surrounding urban } \\
\text { area }\end{array}$ \\
\hline $\begin{array}{l}\text { Aug. 4, } \\
1981\end{array}$ & $\begin{array}{l}\text { MEXICO, } \\
\text { MONTANAS }\end{array}$ & $\begin{array}{l}\text { Accident during } \\
\text { road transportation } \\
\text { of chlorine }\end{array}$ & Chlorine & $\begin{array}{l}28 \text { died, } 1000 \\
\text { injured, } 5000 \\
\text { evacuated }\end{array}$ \\
\hline $\begin{array}{l}\text { May, } \\
1983\end{array}$ & $\begin{array}{l}\text { EGYPT, NILE } \\
\text { RIVER }\end{array}$ & $\begin{array}{l}\text { Explosion during } \\
\text { transportation of } \\
\text { LPG }\end{array}$ & LPG & $\begin{array}{l}317 \text { died, } 44 \\
\text { injured }\end{array}$ \\
\hline $\begin{array}{l}\text { Dec. 17, } \\
1984\end{array}$ & $\begin{array}{l}\text { MEXICO, } \\
\text { MATAMOROS }\end{array}$ & $\begin{array}{l}\text { Accident during } \\
\text { transportation of } \\
\text { ammonia }\end{array}$ & Ammonia & $\begin{array}{l}182 \text { injured, } 3000 \\
\text { evacuated }\end{array}$ \\
\hline $\begin{array}{l}\text { July } 7 \\
1987\end{array}$ & USSR, ANNAU & $\begin{array}{l}\text { Accident during } \\
\text { transportation of } \\
\text { chlorine }\end{array}$ & Chlorine & 200 injured \\
\hline $\begin{array}{l}\text { July, } \\
1988\end{array}$ & $\begin{array}{l}\text { USSR, } \\
\text { CHAKHNOUNI } \\
\text { A }\end{array}$ & $\begin{array}{l}\text { Leakage of } \\
\text { pesticides during } \\
\text { rail transportation }\end{array}$ & Pesticides & 20000 evacuated \\
\hline $\begin{array}{l}\text { Jan. 17, } \\
1990\end{array}$ & $\begin{array}{l}\text { GERMANY, } \\
\text { AHLSFELD }\end{array}$ & $\begin{array}{l}\text { Release of chlorine } \\
\text { from a truck }\end{array}$ & Chlorine & $\begin{array}{l}\text { More than } 182 \\
\text { injured }\end{array}$ \\
\hline $\begin{array}{l}\text { Sept. 25, } \\
1990\end{array}$ & $\begin{array}{l}\text { THAILAND, } \\
\text { BANGKOK }\end{array}$ & $\begin{array}{l}\text { Crash of a tanker } \\
\text { carrying liquefied } \\
\text { petroleum gas }\end{array}$ & $\begin{array}{l}\text { Petroleum } \\
\text { gas }\end{array}$ & $\begin{array}{l}63 \text { died, more than } \\
90 \text { injured }\end{array}$ \\
\hline $\begin{array}{l}\text { Sept. 29, } \\
1990\end{array}$ & $\begin{array}{l}\text { THAILAND, } \\
\text { BANGKOK }\end{array}$ & $\begin{array}{l}\text { Accident during } \\
\text { transportation of } \\
\text { LPG }\end{array}$ & LPG & $\begin{array}{l}\text { More than } 51 \text { died, } \\
\text { more than } 54 \\
\text { injured }\end{array}$ \\
\hline
\end{tabular}




\begin{tabular}{|c|c|c|c|c|}
\hline $\begin{array}{l}\text { Feb. 13, } \\
1991\end{array}$ & $\begin{array}{l}\text { USA, } \\
\text { CALIFORNIA }\end{array}$ & $\begin{array}{l}\text { Overturn of a } \\
\text { tractor-semi trailer } \\
\text { (cargo tank) with the } \\
\text { release of } \\
\text { automotive gasoline } \\
\text { and fire }\end{array}$ & carmichael & $\begin{array}{l}\text { injured, } \\
\text { residents from a 2- } \\
\text { mile-square area } \\
\text { evacuated, four } \\
\text { homes destroyed }\end{array}$ \\
\hline $\begin{array}{l}\text { Oct., } \\
1991\end{array}$ & $\begin{array}{l}\text { INDIA, NEW } \\
\text { BOMBAY }\end{array}$ & $\begin{array}{l}\text { Accident during } \\
\text { transportation of } \\
\text { ammonia gas }\end{array}$ & $\begin{array}{l}\text { Ammonia } \\
\text { gas }\end{array}$ & 1 died, 150 injured \\
\hline $\begin{array}{l}\text { Apr., } \\
1994\end{array}$ & $\begin{array}{l}\text { INDIA, THANE } \\
\text { DISTRICT }\end{array}$ & $\begin{array}{l}\text { Transportation } \\
\text { accident }\end{array}$ & $\begin{array}{l}\text { Chlorine } \\
\text { gas }\end{array}$ & 4 died, 298 injured \\
\hline $\begin{array}{l}\text { June 9, } \\
1994\end{array}$ & $\begin{array}{l}\text { USA } \\
\text { ALLENTOWN, } \\
\text { PENNSYLVAN } \\
\text { IA }\end{array}$ & $\begin{array}{l}\text { Natural gas } \\
\text { distribution pipeline } \\
\text { explosion and fire }\end{array}$ & $\begin{array}{l}\text { Natural } \\
\text { gas }\end{array}$ & $\begin{array}{l}1 \text { died, } 66 \text { injured, } \\
\text { more than } \$ 5 \\
\text { million of property } \\
\text { damage }\end{array}$ \\
\hline $\begin{array}{l}\text { July } 27 \text {, } \\
1994\end{array}$ & $\begin{array}{l}\text { USA, NEW } \\
\text { YORK }\end{array}$ & $\begin{array}{l}\text { Propane truck } \\
\text { collision and fire } \\
\text { tank fractured, } \\
\text { releasing the } \\
\text { propane. }\end{array}$ & Propane & $\begin{array}{l}1 \text { died, } 23 \text { injured, } \\
400 \text { feet radius } \\
\text { area engulfed by } \\
\text { fire }\end{array}$ \\
\hline $\begin{array}{l}\text { Nov. 11, } \\
1994\end{array}$ & $\begin{array}{l}\text { NIGERIA, } \\
\text { ONITSCHA }\end{array}$ & $\begin{array}{l}\text { Leakage of fuel oil } \\
\text { during } \\
\text { transportation } \\
\text { causing fire of the } \\
\text { vehicle }\end{array}$ & Fuel oil & 60 died \\
\hline $\begin{array}{l}\text { Dec. 14, } \\
1994\end{array}$ & $\begin{array}{l}\text { MONZAMBIQ } \\
\text { UE, } \\
\text { PALMEIRA }\end{array}$ & $\begin{array}{l}\text { Transportation } \\
\text { accident }\end{array}$ & Gas & 36 died \\
\hline $\begin{array}{l}\text { Dec., } \\
1995\end{array}$ & $\begin{array}{l}\text { INDIA, } \\
\text { MADRAS }\end{array}$ & $\begin{array}{l}\text { Transportation } \\
\text { accident }\end{array}$ & Fuel & $\begin{array}{l}\text { Around } 100 \text { died, } \\
23 \text { injured }\end{array}$ \\
\hline $\begin{array}{l}\text { Apr. 11, } \\
1996\end{array}$ & $\begin{array}{l}\text { USA, } \\
\text { ALBERTON } \\
\text { MT }\end{array}$ & $\begin{array}{l}\text { Derailment of a train } \\
\text { carrying dangerous } \\
\text { goods } 5 \text { tank cars } \\
\text { leaked releasing } \\
122000 \text { pounds of } \\
\text { chlorine gas }\end{array}$ & $\begin{array}{l}\text { Sodium } \\
\text { chlorate, } \\
\text { Potassium } \\
\text { Crystals, } \\
\text { Chlorine }\end{array}$ & $\begin{array}{l}1000 \text { evacuated, } \\
300 \text { light injured, } \\
1200 \text { yards of } \\
\text { contaminated soil } \\
\text { had to be removed }\end{array}$ \\
\hline $\begin{array}{l}\text { Jan. 2, } \\
1997\end{array}$ & $\begin{array}{l}\text { JAPAN, SEA } \\
\text { OF JAPAN }\end{array}$ & $\begin{array}{l}\text { Break in two of a } \\
\text { Russian oil tanker in } \\
\text { the Sea of Japan, } \\
\text { spilling } 1.2 \text { million } \\
\text { gallons of fuel oil }\end{array}$ & Fuel oil & $\begin{array}{l}\text { several clean-up } \\
\text { workers died, } 500 \\
\text { mile of coastal } \\
\text { land contaminated } \\
\text { (including marine } \\
\text { life/fisheries) and } \\
\text { beaches polluted }\end{array}$ \\
\hline $\begin{array}{l}\text { Jan. 21, } \\
1997\end{array}$ & $\begin{array}{l}\text { INDIA, } \\
\text { BHOPAL }\end{array}$ & $\begin{array}{l}\text { Ammonia leakage } \\
\text { during } \\
\text { transportation }\end{array}$ & Ammonia & 400 injured \\
\hline
\end{tabular}




\begin{tabular}{|c|c|c|c|c|}
\hline $\begin{array}{l}\text { Jan., } \\
1997\end{array}$ & $\begin{array}{l}\text { PAKISTAN, } \\
\text { LAHORE }\end{array}$ & $\begin{array}{l}\text { Transportation } \\
\text { accident }\end{array}$ & Chlorine & $\begin{array}{l}32 \text { died, } 900 \\
\text { injured, } 1000 \\
\text { evacuated }\end{array}$ \\
\hline $\begin{array}{l}\text { Oct. 25, } \\
1997\end{array}$ & $\begin{array}{l}\text { SOUTH } \\
\text { AFRICA, } \\
\text { STANGER }\end{array}$ & Road accident & Petroleum & 34 died, 2 injured \\
\hline $\begin{array}{l}\text { Feb. 14, } \\
1998\end{array}$ & $\begin{array}{l}\text { CAMEROON } \\
\text { YAUNDI }\end{array}$ & $\begin{array}{l}\text { Transportation } \\
\text { accident }\end{array}$ & $\begin{array}{l}\text { Petroleum } \\
\text { products }\end{array}$ & $\begin{array}{l}220 \text { died, } 130 \\
\text { injured }\end{array}$ \\
\hline $\begin{array}{l}\text { Aug. 9, } \\
1998\end{array}$ & $\begin{array}{l}\text { USA, BILOXI, } \\
\text { MISSISSIPPI }\end{array}$ & $\begin{array}{l}\text { Overflow of } \\
\text { Gasoline and Fire at } \\
\text { a Service Station- } \\
\text { Convenience Store }\end{array}$ & Gasoline & $\begin{array}{l}5 \text { died, } 1 \text { injured, } \\
\text { damages for } \\
\$ 55,000\end{array}$ \\
\hline $\begin{array}{l}\text { Oct. } 20 \\
1998\end{array}$ & $\begin{array}{l}\text { NIGERIA, } \\
\text { IDJERHE, } \\
\text { NIGER DELTA }\end{array}$ & $\begin{array}{l}\text { Fire explosion in a } \\
\text { leaking pipeline } \\
\text { carrying fuel }\end{array}$ & fuel & $\begin{array}{l}\text { Over } 500 \text { died, } \\
\text { many farms and } \\
\text { houses destroyed }\end{array}$ \\
\hline $\begin{array}{l}\text { Aug. 2, } \\
1999\end{array}$ & $\begin{array}{l}\text { INDIA, NEU- } \\
\text { JALPAIGURI }\end{array}$ & $\begin{array}{l}\text { Two trains crashed } \\
\text { head-on }\end{array}$ & none & $\begin{array}{l}\text { More than } 200 \\
\text { died }\end{array}$ \\
\hline $\begin{array}{l}\text { May 29, } \\
1999\end{array}$ & $\begin{array}{l}\text { AUSTRIA, } \\
\text { TAUERTUNNE } \\
\text { L-BRAND }\end{array}$ & $\begin{array}{l}\text { Crash of a lorry } \\
\text { carrying lacquer into } \\
\text { a queue of cars in } \\
\text { the tunnel }\end{array}$ & Lacquer & $\begin{array}{l}12 \text { died, } 50 \\
\text { injured, closure of } \\
\text { the tunnel for } 3 \\
\text { months, } \$ 17 \mathrm{M} \\
\text { spent for the } \\
\text { operation of } \\
\text { reconstruction/ren } \\
\text { ovation }\end{array}$ \\
\hline
\end{tabular}

\subsubsection{Accident Examples}

\subsubsection{Ajman: Truck Explosion}

On April 11, 2007, a truck carrying $300 \mathrm{~kg}$ of fireworks exploded killing two and injuring two. The reported cause of the accident was the hot weather since it is not the first accident for the same type of shipments under such conditions. Figure 2.1 shows the size of the crater resulting from the explosion. Moreover, it can be seen that the truck was completely destroyed. It is worth mentioning that by applying the new proposed technology, it might have helped in containing the explosion effects and, with possibly no fatalities or deaths. 


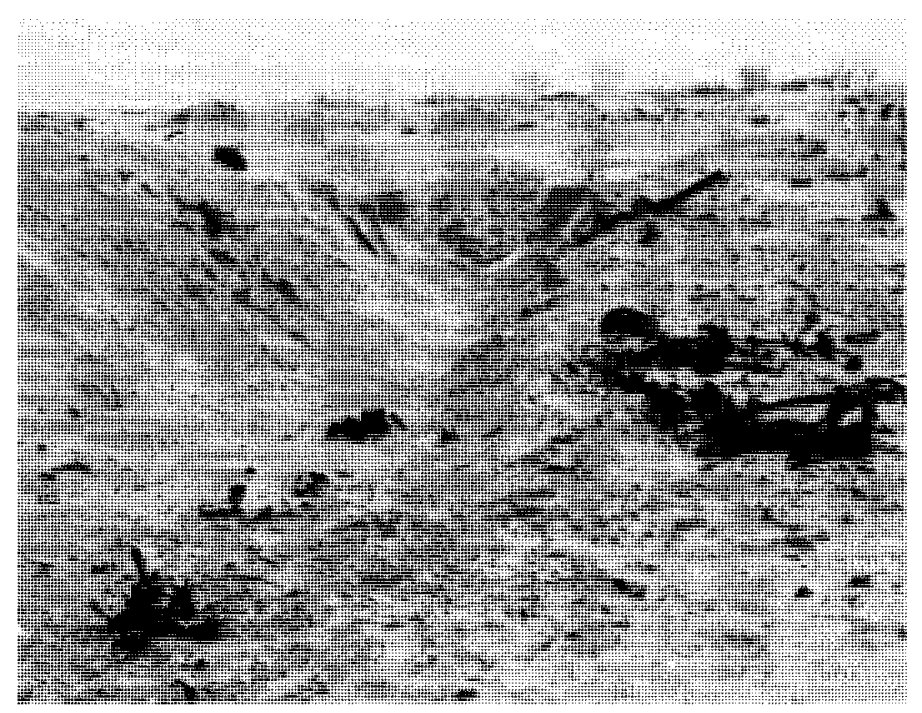

Figure 2.1: Crater resulted from explosion (Gulf News, April 11, 2007)

\subsubsection{M/V HYUNDAI FORTUNE}

The M/V HYUNDAI FORTUNE was the latest container vessel to have an explosion on board on March, 2006 in the Gulf of Aden. It was reported that seven fireworks containers were on board of this vessel. The IMDG regulations state that all containers carrying fireworks must be on deck. However, it is clear from the photos taken just after the explosion that either the regulations were not met and the containers were stacked below the deck or another material exploded underneath the deck. Figure 2.2 shows the damage resulting from the explosion. If the first suggestion is applicable, then more enforcement of regulations are needed to assure safe transport. On the other hand if the second suggestion is applicable, this means that there might be a fire beneath the deck most probably in engine room and this fire transferred heat and high temperature to the cargo on top which in turn caught fire and exploded. This shows one of the drawbacks of the current transport container system where accurate identification of cargo is not easily available for proper container placement and isolation on a cargo ship. The loss in cargo 
due to this fire was expected to exceed $\$ 100$ million plus the value of the vessel itself which is around $\$ 40$ to $\$ 50$ million. Fortunately there were neither fatalities nor deaths however the impact on economy is noteworthy. After this accident a global suspension on the movement of all fireworks shipments was enforced by Hyundai Marine (Weeth \&

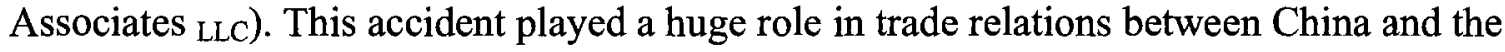
rest of the world. To this day, fall of 2008, no Class 1.1 fireworks are being shipped from China and only one port allows shipment of Class 1.3 fireworks. Only, the safest of fireworks, Class 1.4, are being shipped from several ports. This affects negatively the fireworks industry and thus affects the economy of many countries through influencing festivals and other celebrations that stimulate the economy.

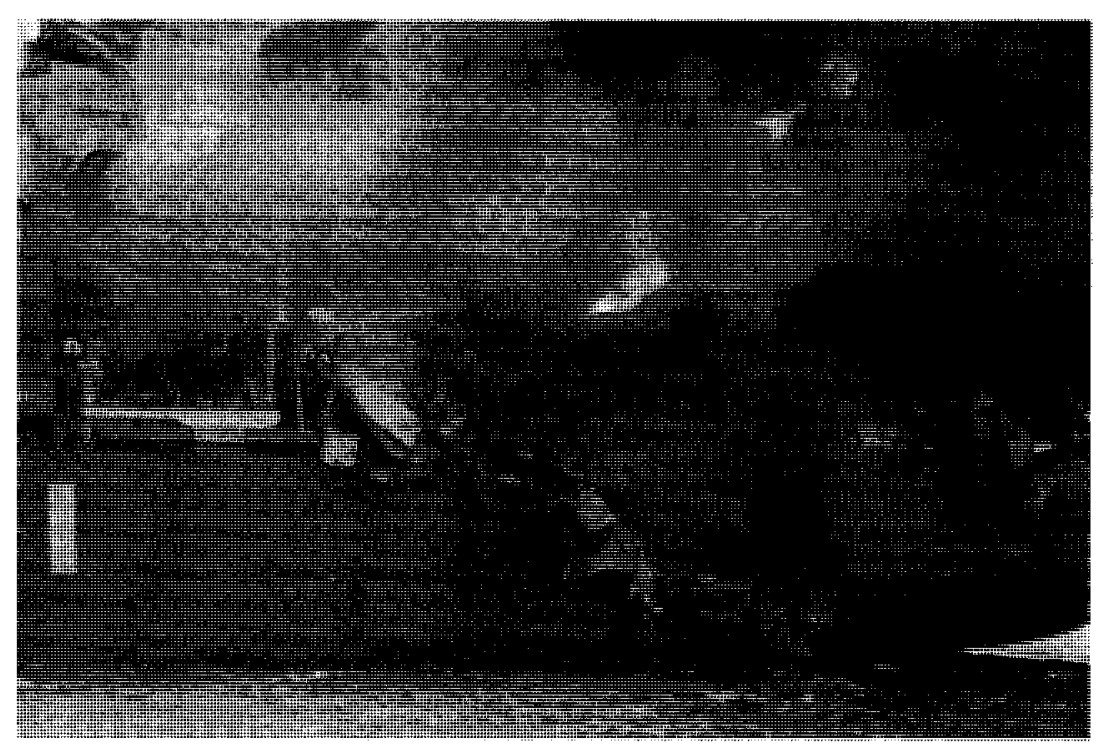

Figure 2.2: Damage of the body of vessel (Weeth \& Associates LLC)

\subsubsection{Romania: Truck Explosion}

On May 24, 2004, a truck carrying ammonium nitrate (AN) overturned on the side of the road, caught fire and then exploded. The explosion killed 15 people including rescue 
workers, journalists, as well as firefighters and injured many others. When the accident occurred the driver left the truck and went to ask for help. People driving along the road called the police. When rescue and media crews arrived at the scene, they started working on extinguishing the fire. All of a sudden an explosion occurred. It was strong enough to cause a 14-meter diameter crater as shown in Figure 2.3. People congregated around the accident out of curiosity or to assist to fight the fire. Unfortunately, due to lack of placards indicating the dangerous goods on the vehicle and the inability of the driver to recognize the hazard, injuries and fatalities resulted. In addition, the road was closed for minimum of two weeks for rehabilitation. This accident is a good example of regulations failure. Compare this to the Walden accident presented in next section (One News, 2004).

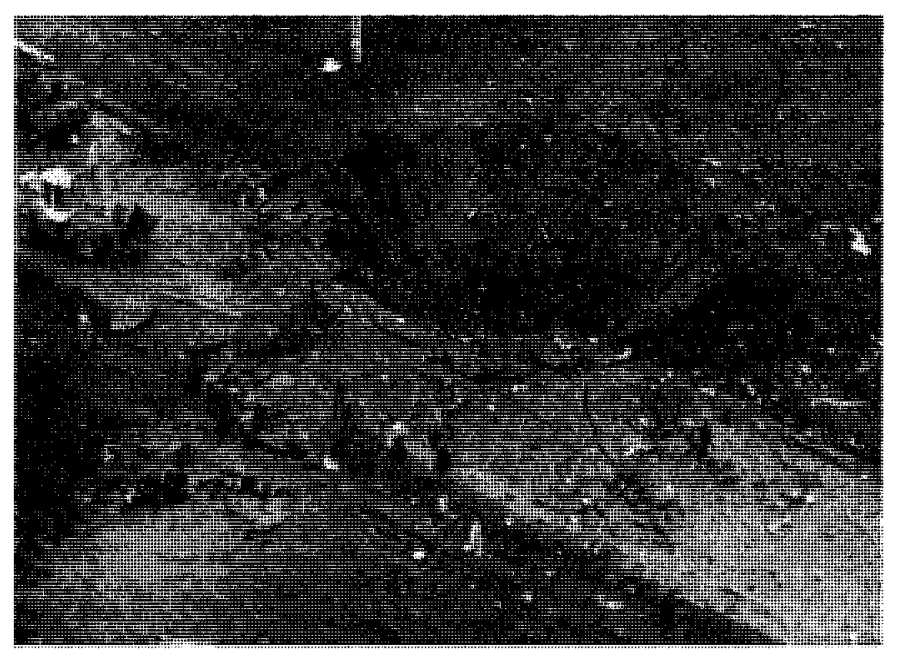

Figure 2.3: Crater resulted from explosion (One News, 2004)

\subsubsection{Walden, Ontario: Truck Explosion}

On August 5, 1998, a truck carrying $18,000 \mathrm{~kg}$ of blasting explosives heading to the Hemlo gold mine area, went off the road near Walden, Ontario. Figures $2.4 \& 2.5$ show the damage resulted from the explosion. 


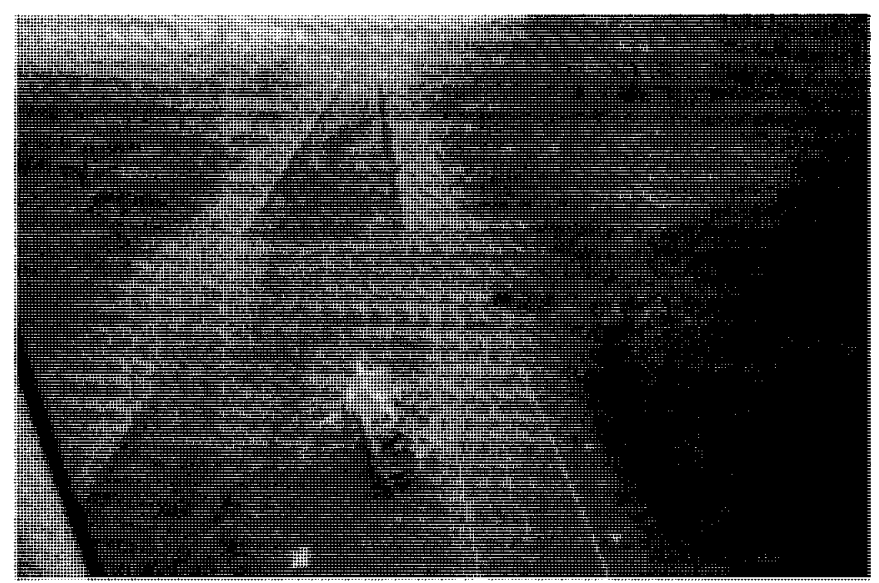

Figure 2.4: Aerial photograph of the accident site (M. Provencher, 2005)

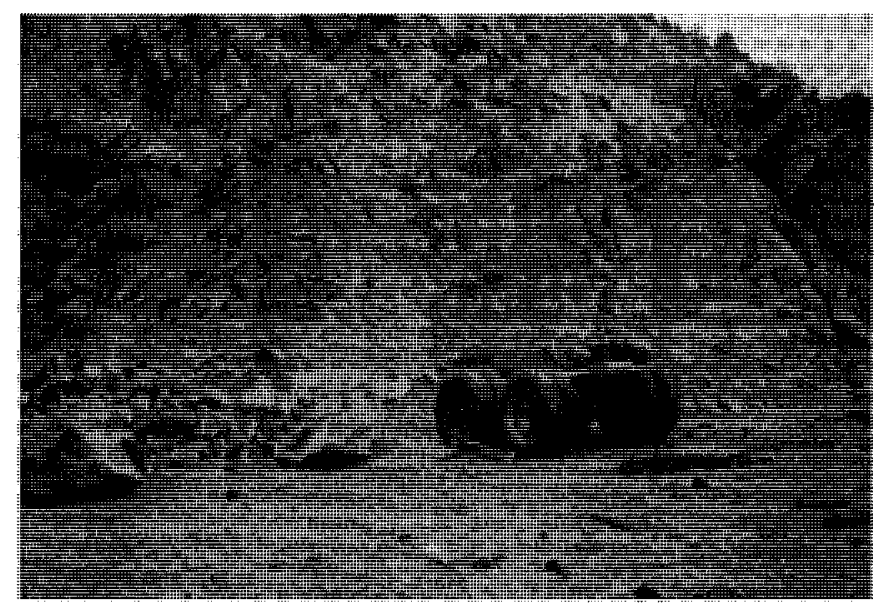

Figure 2.5: The bogy of the truck after the explosion occurred (M. Provencher, 2005)

According to the investigators, the truck went off the highway at a speed of approximately $90 \mathrm{~km} / \mathrm{h}$ and hit the rock face along the side of the highway. The vehicle caught fire and after approximately 40 minutes, the explosives detonated. The explosion formed a crater and shifted the asphalt of the highway from its original alignment (Figure 2.6).

The Canadian authorities immediately cut the transportation amount to $50 \%$ after the accident. Although smaller amounts would present less hazard in case of an accident, it must be understood that more trucks will be on the road, thereby increasing the likelihood 
of an accident. Once studies began to show how unlikely a repeat of this occurrence was, the original transport loads were reinstated.

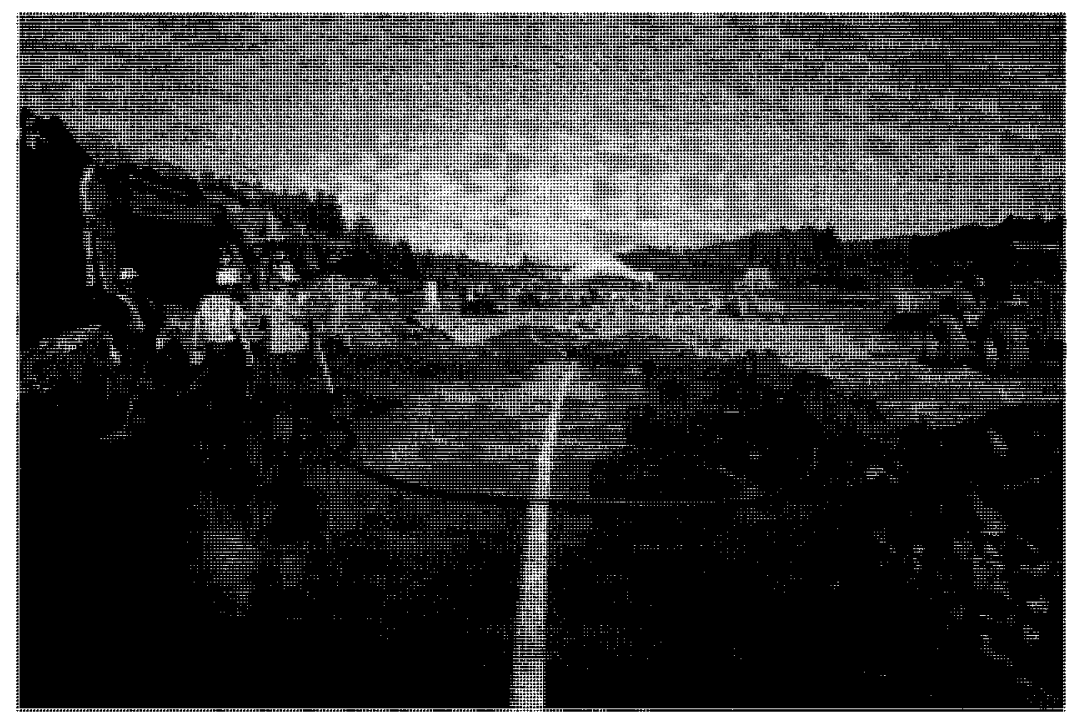

Figure 2.6: Highway asphalt shifts as a result of the huge explosion (M. Provencher, 2005)

The Walden accident is an excellent example of the success of the regulations. Immediately after the accident occurred two trucks stopped on the westbound lanes. One of the drivers saw the placards on the truck involved in the accident. Subsequently after pulling the driver out of the truck, one of the drivers called 911 to inform them that the truck involved in the accident was carrying explosives. Moreover, he drove back west on the eastbound lanes to stop the traffic till the emergency personnel arrive. At the same time an off-duty Ontario Provincial Police (OPP) officer was near the accident scene. $\mathrm{He}$ used a citizen band radio and asked the truckers to block the lanes preventing motorists from getting close to the accident. This immediate response from the OPP officers helped in preventing loss of life. 
The above examples demonstrate the effects and consequences of accidental explosions. All hazardous materials involved in these examples were transported within standard transport containers in accordance with ISO code. More details about the different types of ISO containers are presented in the following section.

\subsection{Existing Containers System}

The existing containers are used not only in transportation but also in short term storage within harbours, airports and/or at supplier and consumer facilities. Typical containers have outside dimensions of either $20(5,895 \mathrm{~mm})$ or 40 feet $(12,029 \mathrm{~mm})$ long and 8.5 feet $(2,929 \mathrm{~mm})$ high. Generally speaking, the main frame of the containers is made of steel while the material used for walls may differ from one container to another. The common materials used for containers walls are corrugated steel sheets, aluminum sheets and/or plywood with fiber-glass coating. Every material has advantages and disadvantages ranging from material costs through maximum weight and finally simplicity and costs of repairs. Tables 2.2 and 2.3 list the internal dimensions as well as the maximum weight limits for 20 and 40 feet containers.

Table 2.2: Dimensions of standard 20 feet containers (German Marine Insurer)

\begin{tabular}{|c|c|c|c|c|c|c|c|c|}
\hline \multicolumn{9}{|c|}{$\begin{array}{l}\text { Standard container of steel: } 20^{\prime} \text { long and } 8^{\prime} 6^{\prime \prime} \text { high with corrugated walls and } \\
\text { wooden floor }\end{array}$} \\
\hline \multicolumn{3}{|c|}{ Internal dimensions } & \multicolumn{2}{|c|}{ Door openings } & \multicolumn{2}{|c|}{ Weights } & \multirow[b]{2}{*}{$\begin{array}{l}\text { Max. } \\
\text { payload } \\
\text { (kg) }\end{array}$} & \multirow{2}{*}{$\begin{array}{c}\text { Volume } \\
\left(\mathrm{m}^{3}\right)\end{array}$} \\
\hline $\begin{array}{l}\text { Length } \\
(\mathrm{mm})\end{array}$ & $\begin{array}{l}\text { Width } \\
(\mathrm{mm})\end{array}$ & $\begin{array}{l}\text { Height } \\
(\mathrm{mm})\end{array}$ & $\begin{array}{l}\text { Width } \\
(\mathrm{mm})\end{array}$ & $\begin{array}{l}\text { Height } \\
(\mathrm{mm})\end{array}$ & $\begin{array}{l}\text { Max. gross } \\
\text { mass } \\
(\mathrm{kg})\end{array}$ & $\begin{array}{c}\text { Tare mass } \\
(\mathrm{kg})\end{array}$ & & \\
\hline 5895 & 2350 & 2392 & 2340 & 2292 & 30480 & 2250 & 28230 & 33.2 \\
\hline 5895 & 2350 & 2385 & 2338 & 2292 & 24000 & 2250 & 21750 & 33.2 \\
\hline
\end{tabular}


Table 2.3: Dimensions of standard 40 feet containers (German Marine Insurer)

\begin{tabular}{|c|c|c|c|c|c|c|c|c|}
\hline \multicolumn{9}{|c|}{$\begin{array}{l}\text { Standard container of steel: } 40^{\prime} \text { long and } 8^{\prime} 6^{\prime \prime} \text { high with corrugated walls and } \\
\text { wooden floor }\end{array}$} \\
\hline \multicolumn{3}{|c|}{ Internal dimensions } & \multicolumn{2}{|c|}{ Door openings } & \multicolumn{3}{|c|}{ Weights } & \multirow{2}{*}{$\begin{array}{l}\text { Volume } \\
\left(\mathrm{m}^{3}\right)\end{array}$} \\
\hline $\begin{array}{l}\text { Length } \\
(\mathrm{mm})\end{array}$ & $\begin{array}{l}\text { Width } \\
(\mathrm{mm})\end{array}$ & $\begin{array}{l}\text { Height } \\
(\mathrm{mm})\end{array}$ & $\begin{array}{l}\text { Width } \\
(\mathrm{mm})\end{array}$ & $\begin{array}{l}\text { Height } \\
(\mathrm{mm})\end{array}$ & $\begin{array}{l}\text { Max. gross } \\
\text { mass } \\
(\mathrm{kg})\end{array}$ & $\begin{array}{c}\text { Tare mass } \\
(\mathrm{kg})\end{array}$ & $\begin{array}{l}\text { Max. } \\
\text { payload } \\
(\mathrm{kg})\end{array}$ & \\
\hline 12029 & 2350 & 2392 & 2340 & 2292 & 30480 & 3780 & 26700 & 67.7 \\
\hline
\end{tabular}

These containers are commonly used for dry cargo including explosives and fireworks. The limit for such materials to be carried within such containers is within the 20 tonnes.

\subsection{Explosion Phenomenon}

\subsubsection{Historical Background}

The beginning of the explosives business started with gunpowder manufacturing. The gunpowder was produced by mixing potassium nitrate (saltpetre), carbon (charcoal) and sulphur (The nature of explosions). Due to the lack of sufficient saltpetre, percentage of gunpowder changed from the old days. Consequently, the gunpowder of the thirteenth century was known as black powder, as a result of the high percentage of carbon content. The main problem associated with the black powder was its ease of ignition that resulted in many accidents and the production of copious amounts of smoke. Thus, a French scientist improved the black powder properties by mixing it with gelatin to produce smokeless propellant.

Nitric acids played a big role in the evolution of most explosives starting with Guncotton, to dynamite till the most modern explosives available today. When talking about explosives and its evolution, it's worth mentioning the role of Alfred Bernhard Nobel 
whose fortune was the asset to begin the Nobel Foundation from which it is known with its prizes that became the most honourable prizes. During the same era of the nineteenth century, trinitrotoluene, which is commonly known as TNT, was discovered. TNT gained its great importance because of its relative economy and safety during the manufacturing process. These properties resulted in TNT being the most used explosive in the First World War and becoming the reference explosive for all conventional or nuclear explosives. The TNT equivalence can be determined by various methods. Table 2.4 lists the TNT equivalence for various explosives, determined from their heat of explosion:

Table 2.4: The Equivalence Factors for Chemical Explosives (Suppressive Shields Structural Handbook)

\begin{tabular}{lc}
\hline Explosive & TNT Equivalent $\left(\mathbf{e}_{\mathrm{t}}\right)$ \\
\hline Amatol 60/40 (60\% ammonium nitrate, 40\% TNT) & 0.586 \\
Baronal (50\% barium nitrate, 35\% TNT,15\% aluminum) & 1.051 \\
Comp B (60\% RDX, 40\%TNT) & 1.148 \\
C4 (91\% RDX, 9\% Plasticizer) & 1.078 \\
Explosive D (Ammonium Picrate) & 0.740 \\
H-6 (45\% RDX, 30\% TNT, 20\% A1, 5\% D-2 wax) & 0.854 \\
HBX-1 (40\% RDX, 38\% TNT, 17\% Al, 5\% D-2 wax) & 0.851 \\
HMX & 1.256 \\
Lead Azide & 0.340 \\
Lead Styphnate & 0.423 \\
Mercury Fulminate & 0.395 \\
Nitroglycerine (Liquid) & 1.481 \\
Nitroguanidine & 0.668 \\
Octol, 70/30 (70\% HMX, 30\% TNT) & 0.994 \\
PETN & 1.282 \\
Pentolite, 50/50 (50\% PETN, 50\% TNT) & 1.129 \\
Picric Acid & 0.926 \\
RDX (Cyclonite) & 1.185 \\
Silver Azide & 0.419 \\
Tetryl & 1.00 \\
\hline
\end{tabular}


TNT

Torpex (42\% RDX, 40\% TNT, 18\% Al)

Tritonal (80\% TNT, 20\% Al)

Generally speaking, the term explosion is defined as "An event leading to rapid increase in pressure" (Gas Explosion Handbook). Ground surface explosion typically generate a fireball, ground shock, crater and associated ejecta (fragments), and blast wave. The following sections will focus on understanding these parameters.

\subsubsection{Explosions and Blast Phenomenon}

\subsubsection{Blast Wave (Damage)}

Blast wave is defined as "The air wave set in motion by an explosion" (Gas Explosion Handbook). Blast waves consist of a variation of waves including:

- Shock waves

- Sonic compression wave

- Reflection or Refraction waves

Combinations of the above-mentioned blast wave types result from the distance between the detonation source and the target as well as the magnitude of the energy released from the explosion. A discussion of blast wave phenomenon follows.

\subsubsection{Ideal Blast Waves}

Figure 2.7 illustrates an ideal blast wave or free-field phenomenon in which the explosion occurs under homogeneous atmosphere and from a spherically symmetrical source. It is 
shown that the pressure rises suddenly to the peak value when the shock front arrives at the point of interest at a certain arrival time after the explosion occurs. Afterwards the pressure starts to decrease gradually until it reaches the ambient value. The pressure keeps falling below the ambient pressure to a specific value in the negative phase and then it starts to rise again to the ambient pressure. It may oscillate again about the ambient value but then settles to the ambient value. The values of the peak and the negative pressures mainly depend on the amount and the type of explosive (Baker, W.E., 1973). In real life incidents, it is not common to observe ideal blast wave scenario but most probably a non-ideal blast wave is more likely to result. The non-ideal blast wave results from sources such as cased charges that produce fragments upon which the air is disturbed, altering the decay of the blast pressure profile. Such effects also occur from interference of the shock wave as it traverses irregular ground and protruding features.

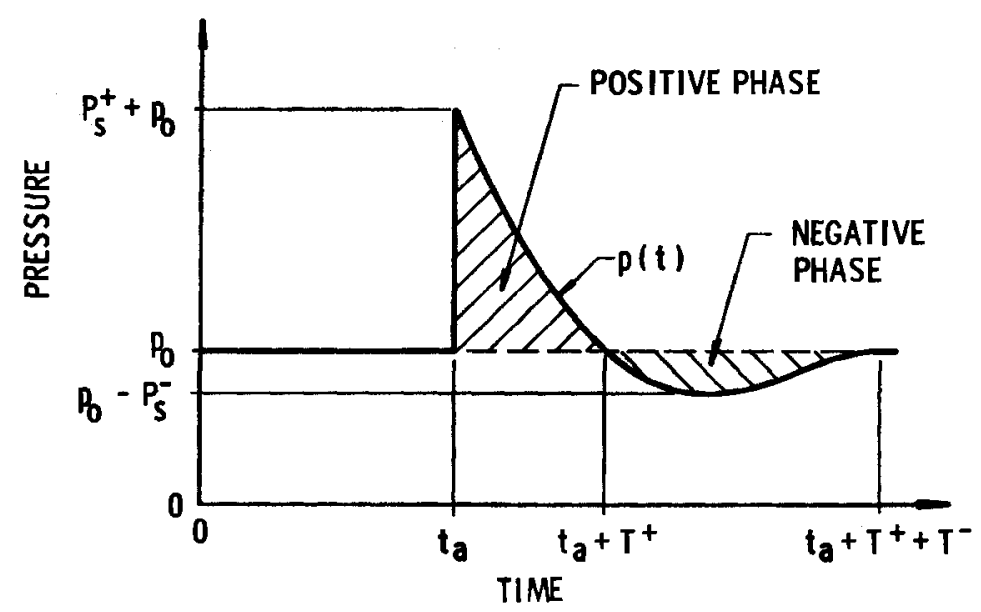

Figure 2.7: Ideal Blast Wave, Free-field Phenomena (Baker, W.E., 1973)

Figure 2.8 illustrates the first combination between the shock wave and reflected waves. The loading scenario of the walls of SSPs is expected to be typically shock waves 
followed by reflected waves. Therefore, the following section will focus on understanding the concept of reflected waves.

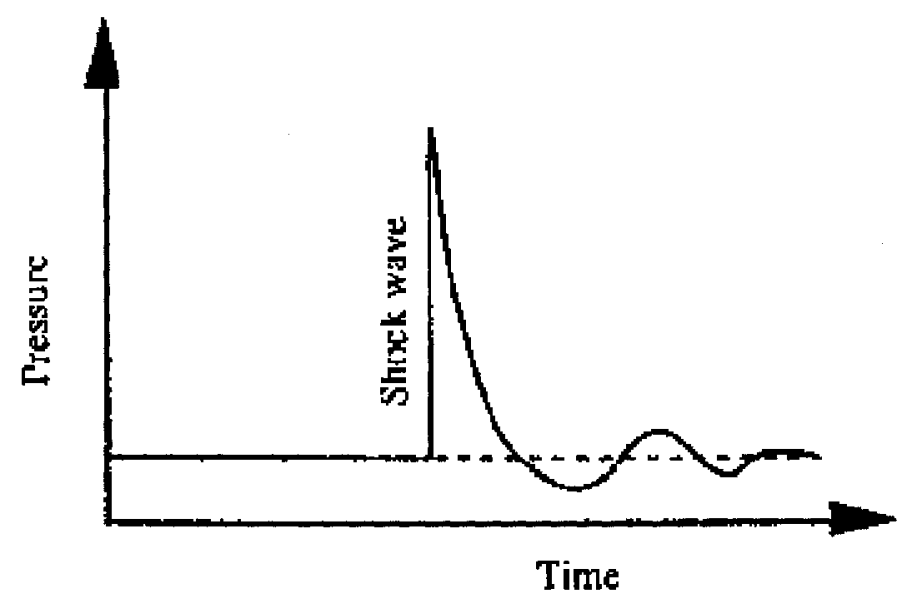

Figure 2.8: Shock wave followed by refraction wave (Gas Explosion Handbook)

\subsubsection{Wave Reflection}

The simplest shock reflection scenario is the normal reflection of a plane shock wave from an infinite planar rigid surface. Figure 2.9 shows an incident wave with velocity " $U$ " through air and reflecting from a plane rigid surface with velocity " $U_{r}$ " through the compressed region associated with the incident wave. The reflected pressure at the face of the rigid surface is referred to as " $P_{r}$ ". The value of the " $P_{r}$ " is twice the value of the incident pressure for weak shocks and approximately up to eight times the incident pressure for strong shocks (Baker, W.E., 1973). 


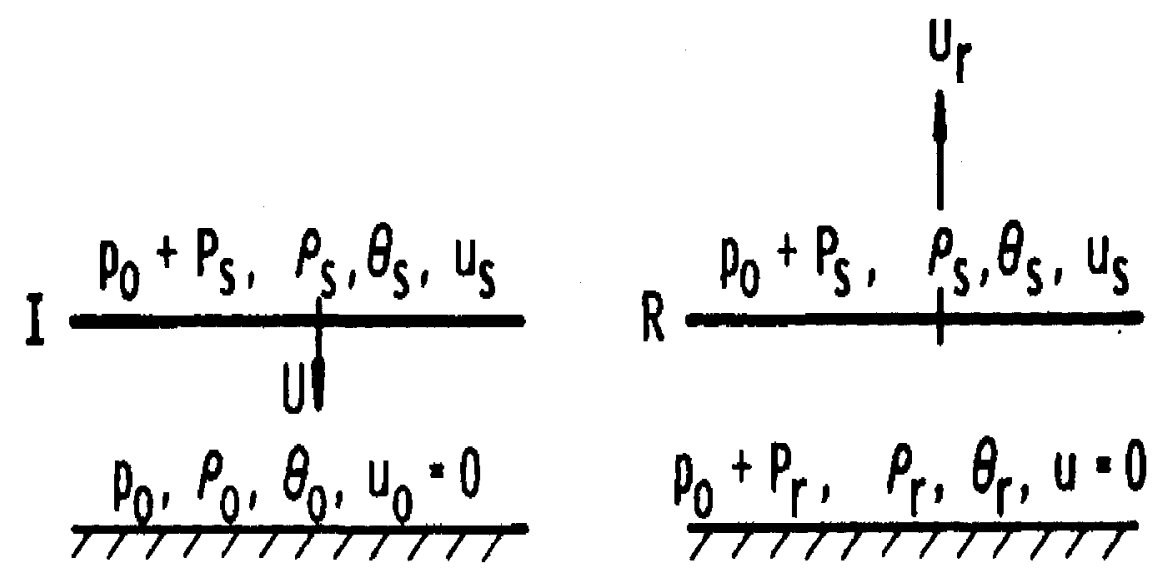

Figure 2.9: Normal Reflection of a Plane Shock from a Rigid Wall (Baker, W.E., 1973)

Another wave reflection scenario is the oblique shock wave reflection in which the wave moves through still air with velocity " $U$ " and impinges at an angle of incident " $\alpha_{I}$ " with a rigid surface. When the angle of incidence is less than the critical angle " $\alpha_{I}$ crit", the wave reflection is shown in Figure 2.10. The direction of the wave in this case is reversed and turned from its initial direction with the reflection angle, " $\alpha_{R}$ ", being different from the incident angle " $\alpha$ ".

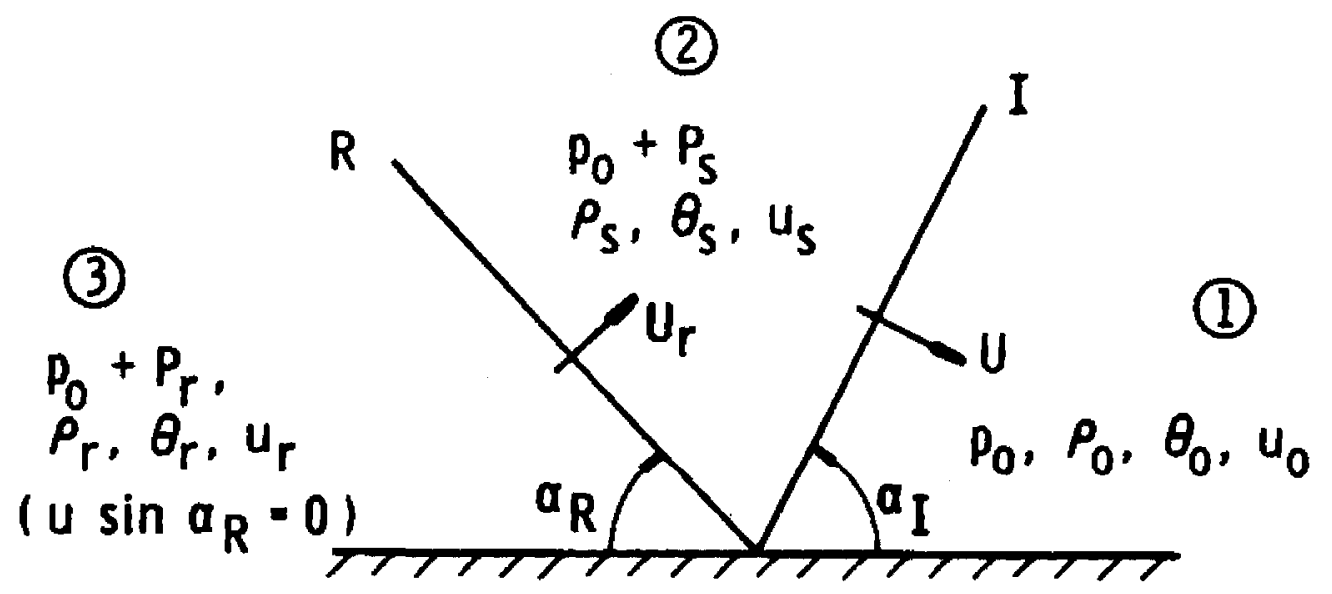

Figure 2.10: Regular, Oblique Reflection (Baker, W.E., 1973) 
Ernst Mach proved that the incident and reflected waves can combine together to produce a third shock wave called a Mach stem (Baker, W.E., 1973). The Mach stem occurs when the angle of incidence is greater than the critical angle which causes the incident and reflected waves to intersect above the ground forming the Mach stem (Figure 2.11). The three wave fronts intersect at point " $T$ ", the "Triple Point". Moreover, Figure 2.12 shows the curved nature of the incident, the reflected, and the Mach stem in more details.

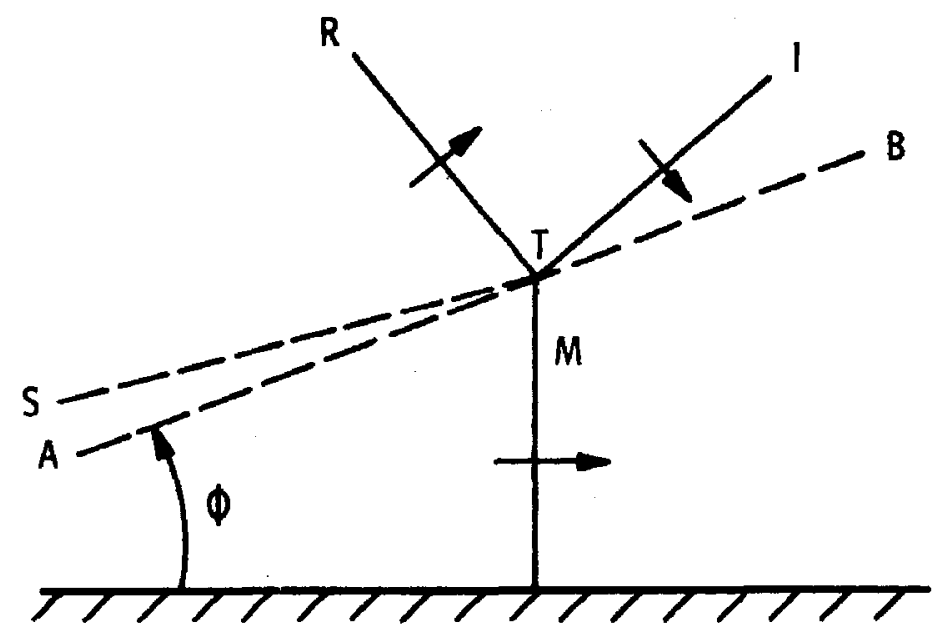

Figure 2.11: Mach Reflections from a Rigid Wall (Baker, W.E., 1973)

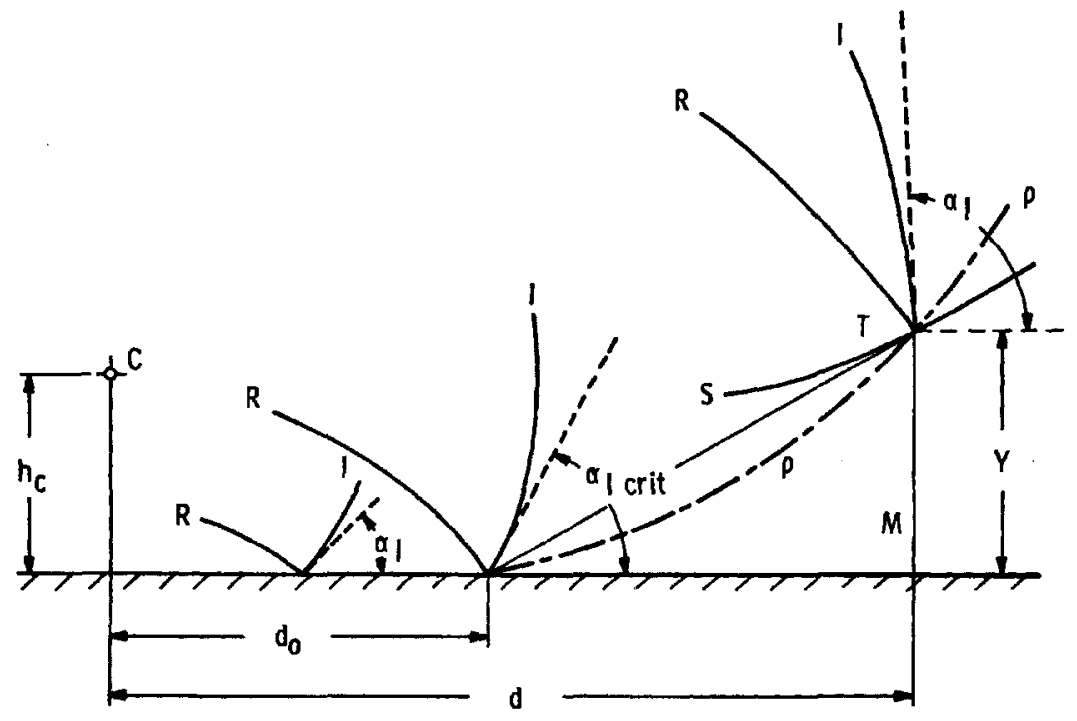

Figure 2.12: Mach Reflections Geometry (Baker, W.E., 1973) 


\subsubsection{Wave Diffraction}

Wave diffraction occurs when shock waves interact with obstacles (Baker, W.E., 1973).

That is, blast waves moves over or around solid objects. This is shown in Figure 2.13.

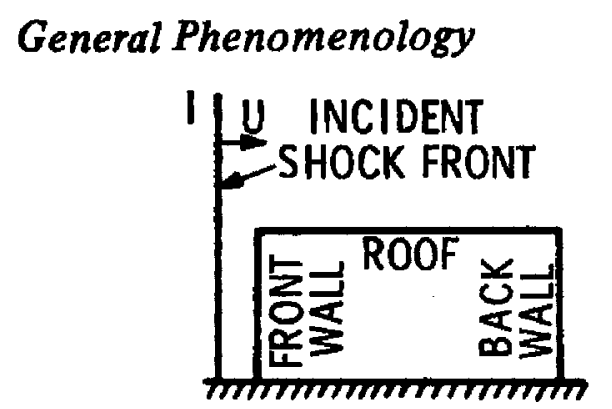

(a)

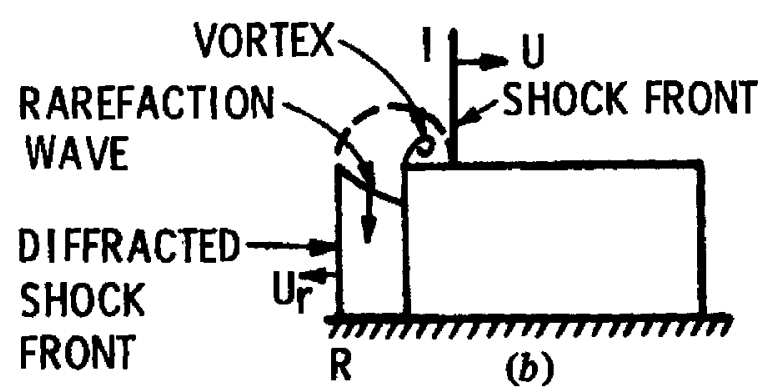

(b)

Figure 2.13: Wave diffraction over a wall (Baker, W.E., 1973)

\subsubsection{Blast Wave Scaling}

Full scale experimental tests with explosives can be very expensive. Thus, much research was carried out to find blast scaling laws that help predict blast wave parameters from small scale tests. Various scaling laws are used but the most common and widely used is the Hopkinson's scaling law. Hopkinson presented his law in 1915 and he proved that the detonation of any two explosives of different size but with the same geometric properties and composition in the same environment will result in exactly the same blast wave characteristics. The Hopkinson's law is also called "Cube Root". This scaling law can be applied to the distance between the charge and any point of interest, the arrival time and the impulse. However, the Hopkinson's law is not applicable for side-on pressure and velocity. Hopkinson's scaled parameters are as follows (Baker, W.E., 1973): 


$$
Z=\frac{R}{W^{1 / 3}}
$$

Where $R$ is the distance between the center of the explosive and the point of interest while $\mathrm{W}$ is the mass of the explosive charge. The units of $Z$, the scaled distance, can be expressed in either metric or imperial units.

$$
\tau=\frac{t}{W^{1 / 3}}
$$

Where $\tau$ is the scaled time of arrival time, $t$ is the arrival time and $W$ is the weight of the explosive charge.

$$
\zeta=\frac{I}{W^{1 / 3}}
$$

Where $\zeta$ is scaled impulse, $I$ is the impulse and $W$ is the weight of the explosive charge.

\subsubsection{Fragments and Debris}

Damage for any intentional or accidental explosion is not only caused by blast loading but also by fragments and/or debris that is thrown. Generally speaking the fragments are classified into two types, primary fragments and secondary fragments. Primary fragments mainly result from charge casing failure. The number and the weight of these fragments depend on the type of explosive and the material and thickness of the casing. Thus to be able to design a storage facility for ammunition or cased explosives, one must predict the 
primary fragments characteristics. The most common theoretical relationship that has been verified with a reasonable number of tests is presented in the TM5-1300 manual. The following equations represent the prediction of primary fragments from other publications from Swisdak, 2000:

$$
\begin{aligned}
& W_{f}=\left[M_{A} \ln \left(\frac{8 W_{c}}{M_{A}^{2}}\right)\right]^{2} \\
& M_{A}=B t_{c}^{5 / 6} d_{i}^{1 / 3}\left(1+t_{c} / d_{i}\right)
\end{aligned}
$$

Where,

$W_{f}$. largest fragment weight, oz.

$W_{c}$ : weight of casing, lbs

$M_{A}$ : fragment distribution factor

$B$ : Mott scaling factor, $\mathrm{oz}^{1 / 2} \mathrm{in}^{-7 / 6}$

$t_{c}$ : average casing thickness, in.

$d_{i:}$ average inside diameter of casing, in.

$$
N_{T}=8 W_{c} / M_{A}^{2}
$$

Where,

$N_{T}$ : The total number of fragments

$$
V_{o}=\left(2 E^{\prime}\right)^{1 / 2}\left[\frac{W / W_{c}}{1+0.5\left(W / W_{c}\right)}\right]^{1 / 2}
$$

Where,

$V_{o}:$ the initial velocity

$\left(2 E^{\prime}\right)^{1 / 2}$ : Gurney energy constant, $\mathrm{ft} / \mathrm{sec}$

$W: 1.2 \times$ actual charge weight, lbs 
The secondary fragments result from the interaction between primary fragments and other objects or by the blast wave dislodging objects proximate to the seat of the explosion. The initial velocity of secondary fragments is the only parameter that can be estimated with a semi empirical equation given in the TM 5-1300 for spherical charges. Finally, the fragments either primary or secondary are important parameter when designing storage or transport containers for munitions or other cased explosives, which is not the focus of this research. All explosives that are of interest in this research are considered to be bare explosives.

\subsubsection{Fireball}

The danger resulting from fireball during an explosion can be as critical as blast and fragments if combustible substances are nearby. Thus it is very important when designing any containment to take into consideration the suppression of fireball. Additionally, knowing the size and diameter of fireballs will help in assessing the associated hazards. The diameter and duration of fireballs can be predicted form the following equation:

$$
D_{f}=9.56 W^{0.325}
$$

$$
t_{f}=0.196 W^{0.349}
$$

Where,

$D_{f}:$ fireball diameter, $\mathrm{ft}$

$T_{f}$ : fireball duration time, $\mathrm{s}$

$W$ : charge weight, $\mathrm{lb}$ 


\subsubsection{Crater}

Craters are formed as a result of an explosion. The main factors affecting the crater formation are the type and quantity of explosives, the type of soil and finally, either the distance between the charge and the ground if the charge is off-set above ground or the distance of the charge below the ground surface if the charge is buried. In general, the larger the quantity of explosive, the deeper and larger volume of crater produced. Moreover, the type of soil affects the crater size depending on the response of the soil if it is soft such as sand or hard such as rock. Soft soil absorbs the blast wave in a better way compared to hard soil, thus the amount of soil to be affected is less in soft soil. Finally, the distance between the charge and the ground helps in having deep or shallow crater. The craters are become deeper as the distance between the charge and the ground tends to be zero or less than zero, which means that the charge is buried under the ground. When the charge detonated below the ground surface more soil will be removed as a result of the explosion.

\subsection{Effect of Internal Explosions}

The detonation of an explosive charge within a structure will result in complex reflections which make analysis difficult beyond tracking the first and second reflections. If the structure is sufficiently strong so that the products of detonation are contained, then the structure can also be loaded by the gas pressure, often referred to as the quasi-static loading. The main factor affecting the loading in this scenario is the venting area where, the trapped explosion gases can escape through the openings. The following sections discuss the two loading phases in more details. 


\subsubsection{Blast Wave Loading}

The side-on and reflected pressure can be estimated through the following equations or through charts available in some references, e.g. Baker, 1973.

\subsubsection{Estimation of Maximum Side-on Pressure}

The equation for the maximum side-on pressure in bars, $\mathrm{P}_{\mathrm{so}}$, was first introduced by Newmark and Hansen in 1961 for high explosive charges detonated at ground surface.

$$
P_{s o}=6784 \frac{W}{R^{3}}+93\left(\frac{W}{R^{3}}\right)^{1 / 2}
$$

Where,
$R$ : The distance between the point of interest and the explosive charge, $\mathrm{m}$ $W$ : Total detonation energy in equivalent TNT weight, $t$

Later in 1987, Mills developed another equation for the maximum side-on pressure $P_{s o}$, in $\mathrm{kPa}$, where $Z$ is the scaled distance as explained earlier in equation 2.11 (Mills 1987).

$$
P_{s o}=\frac{1772}{Z^{3}}-\frac{114}{Z^{2}}-\frac{108}{Z}
$$

In more recent work carried out by Crawford and Karagozian in 1995, another equation was developed for the maximum side-on pressure $P_{s o}$, in psi, where $\mathrm{x}$ is the distance between the point of interest and the explosive charge, in meters and $P_{o}$ is the ambient atmospheric pressure, in psi. 


$$
\frac{P_{s o}}{P_{o}}=\frac{40.4 x^{2}+810}{\left[\left(1+434 x^{2}\right)\left(9.77 x^{2}\right)\left(1-0.55 x^{2}\right)\right]^{1 / 2}}
$$

\subsubsection{Estimation of Reflected Pressure}

As mentioned earlier the detonation of an explosive charge within a structure will result in an incident shock wave that will reflect upon striking an object in its path. Thus, a reflected pressure wave is obtained as shown in Figure 2.14 (Baker, 1973). The reflected pressure, $P_{r}$, will be at least twice the incident pressure for weak shocks and up to eight times higher than the incident pressure for strong shocks. The incident and reflected pulses $\left(P_{s o}\right.$ and $\left.P_{r}\right)$ are approximated as triangular shapes with a pressure-time history according to the following equations as shown in Figure 2.15 (Baker, 1973).

$$
\begin{aligned}
& P_{s o}(t)=P_{s o}\left(1-\frac{t}{T_{s o}}\right) \\
& P_{r}(t)=P_{r}\left(1-\frac{t}{T_{r}}\right)
\end{aligned}
$$

Where the $T_{s o}$ and $T_{r}$ can be estimated from the following relations

$$
\begin{gathered}
T_{s o}=\frac{2 i_{s o}}{P_{s o}} \\
T_{r}=\frac{2 i_{r}}{P_{r}}
\end{gathered}
$$


When calculating the final blast loading on structural surface, the effect of the rereflected pressure can be ignored because of its nature in which it decayed with time. In 1983, Baker et al determined that all re-reflected pulses would increase the total load by $75 \%$. Therefore, the above mentioned time durations have to be factored by 1.75 to accommodate this increase in load resulting from the re-reflected pulses.

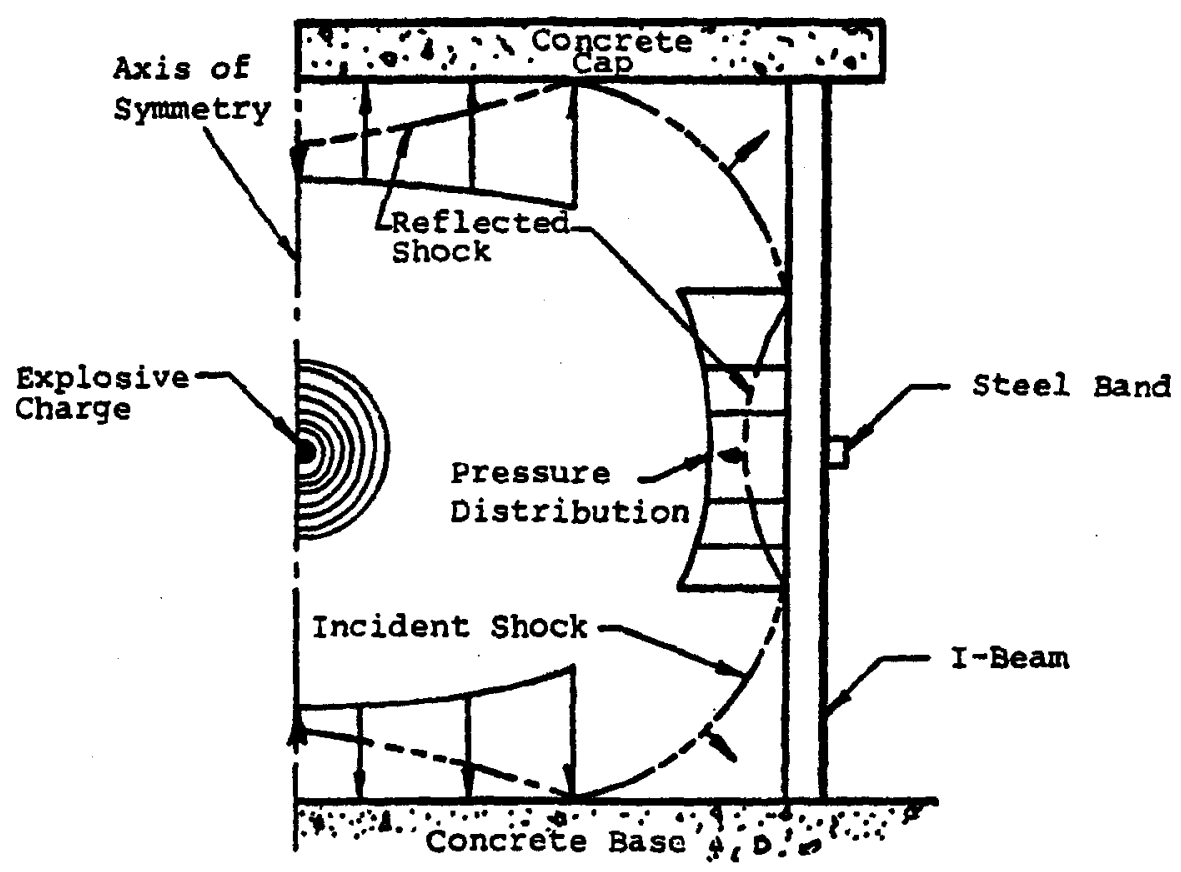

Figure 2.14: Blast wave reflection within suppressive structure (Suppressive Shields Handbook)

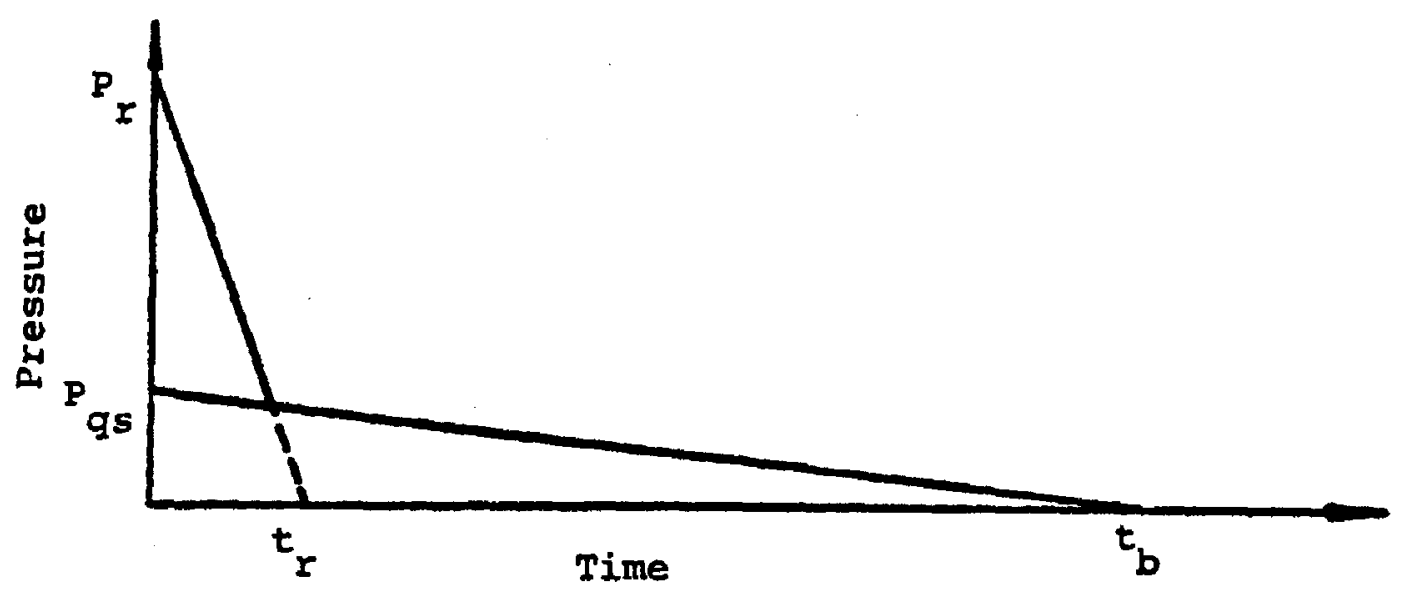

Figure 2.15: Idealized Internal Pressure-Time History (Suppressive Shields Handbook) 


\subsubsection{Quasi-Static pressure}

The peak quasi-static pressure depends on the type and amount of explosive that detonated the volume of the enclosure and the enclosure's ability to withstand the load. The absence of vents will result in an increase in the quasi-static pressure. Thus, the vent area plays a major role in controlling the quasi-static pressure. The final pressure in an enclosure depends on two important factors which are the maximum quasi-static pressure, $P_{q s}$, and the blown down time, $t_{b}$. The value of $P_{q s}$, and $t_{b}$ can be determined from previous established charts. Figure 2.16 illustrates a typical pressure-time history of maximum pressure as well as the quasi-static pressure with time within a vented structure.

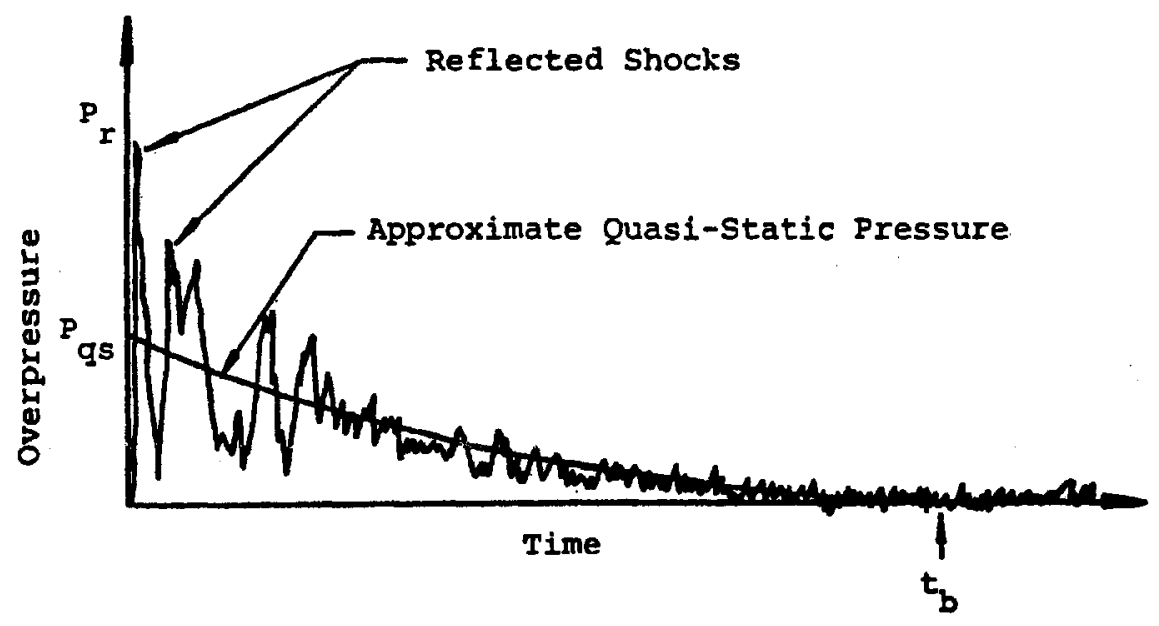

Figure 2.16: Pressure-Time History (Suppressive Shields Handbook)

\subsection{Air Blast Attenuation}

Suppressive shields (SS) are vented structures consisting of layers of steel elements such as perforated plates, or angles, channels, Z-sections and W-sections assembled to vent blast pressure. Such structures are relatively light compared to solid structures used to 
contain the detonation of large amounts of explosives. The main advantage of SS is to attenuate blast parameters (pressure, impulse, fireball, and fragments).

Some of the SS structures designed and built by the US Army to mitigate explosion hazards are described as follows.

a. Warhead Shield, a cylinder container designed to hold up to $75 \mathrm{lbs}$ TNT equivalent material and it weighs $90,000 \mathrm{lbs}$,

b. Qatar Shield, designed to contain explosives found in luggage and packages at airports and it weighs $9,600 \mathrm{lbs}$,

c. Bomb Squad Shield, designed mainly to contain pipe bombs and small packages of explosives and it weighs 2,500 lbs (D. Beal, 1996).

These are a few examples of SS structures built to contain explosives at various applications.

The SS structures are based on the concept of wave propagation through orifices or restricted areas either from larger to smaller area or vice versa. The research in this thesis involves blast wave propagation from large to small areas. There are two cases to be considered. The first is the case where the incident shock passing through the restriction does not reach supersonic speed. Figure 2.17 shows the shock wave propagating through an area restriction with subsonic shock speed (Technical Report: Air Blast Attenuation). In this case, the shock wave is divided into three components, the transmitted wave, the reflected wave and the interface (shock front), that is, the boundary between transmitted and reflected waves. The strength of each component depends on the pressures in front and behind each shock as presented in the following equations. 


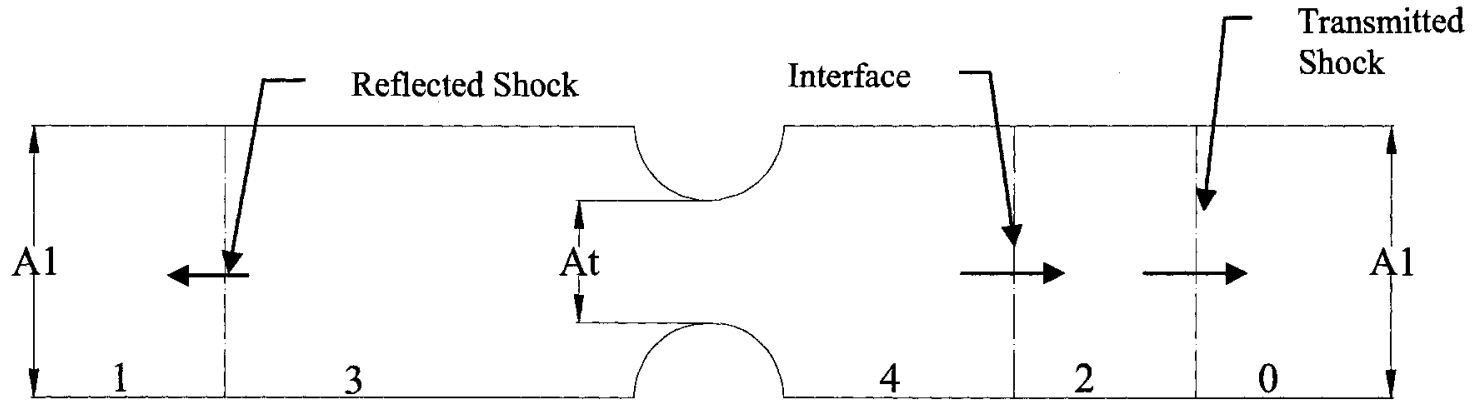

Figure 2.17: Subsonic shock wave passing through restriction (Technical Report: Air blast attenuation)

$$
\xi_{1}=\frac{P_{1}}{P_{0}} \geq 1
$$

Where,

$\zeta_{1}$ : the strength of incident shock

$P_{I}$ : the gas pressure behind incident shock

$P_{0}$ : the ambient gas pressure

$$
\xi_{2}=\frac{P_{2}}{P_{0}} \geq 1
$$

Where,

$\zeta_{2}:$ the strength of transmitted shock

$P_{2}$ : the gas pressure behind transmitted shock

$P_{0}$ : the ambient gas pressure

$$
\xi_{3}=\frac{P_{3}}{P_{1}} \geq 1
$$

where,

$\zeta_{3}:$ the strength of reflected shock

$P_{3}$ : the gas pressure behind reflected shock

$P_{1}$ : the gas pressure behind incident shock 
The pressures and particle velocities in front and behind the interface are equal according to physical laws governing the conditions at the interface. Thus, pressure, $\mathrm{P}_{2}$, and particle velocity, $\mathrm{u}_{2}$, in front of the interface are equal to the pressure, $\mathrm{P}_{4}$, and particle velocity, $\mathrm{u}_{4}$, behind interface and. Moreover, since the area behind the interface and the reflected wave are equal, the pressures are equal. That is, $\mathbf{P}_{3}=\mathbf{P}_{4}$. With this information, it is concluded that as long as the wave velocity is subsonic, the restriction area does not have any effect on the incident shock wave. That is, the strength of incident shock is equal to the sum of the transmitted shock and the reflected shock.

In the second case, the incident shock is great enough to exceed the speed of sound and go supersonic at the restriction as shown in Figures 2.18 and 2.19. The Mach number, shock wave speed divided by sound speed, at the restriction area is 1 . In this case the pressure and particle velocity behind the reflected wave depends on the cross-sectional area ratio. Thus, the strength of such a wave is calculated through equations relating the area ratio, a, and the Mach number in this region as given by Equations 2.20 and 2.21 (Technical Report: Air Blast Attenuation).

$$
\begin{aligned}
& a=\frac{A_{r}}{A_{1}}=M_{3}\left[\frac{(\mu-1)+M_{3}^{2}}{\mu}\right]^{-\mu / 2} \\
& M_{3}=(\mu-1) \sqrt{\frac{1+\mu \xi_{3}}{(\mu+1)\left(\mu+\xi_{3}\right)\left(\mu+\xi_{1}\right) \xi_{3} \xi_{1}}}\left[\left(\xi_{1}-1\right)-\left(\xi_{3}-1\right) \sqrt{\frac{\xi_{1}\left(\mu+\xi_{1}\right)}{1+\mu \xi_{3}}}\right]
\end{aligned}
$$

Where,

$$
A_{r:} \text { area at restriction }
$$


$A_{1:}$ area away from restriction

$M_{3:}$ Mach number at region 3

$\mu$ : dynamic viscosity

$\zeta_{1}:$ the strength of incident shock

$\zeta_{3}:$ the strength of reflected shock

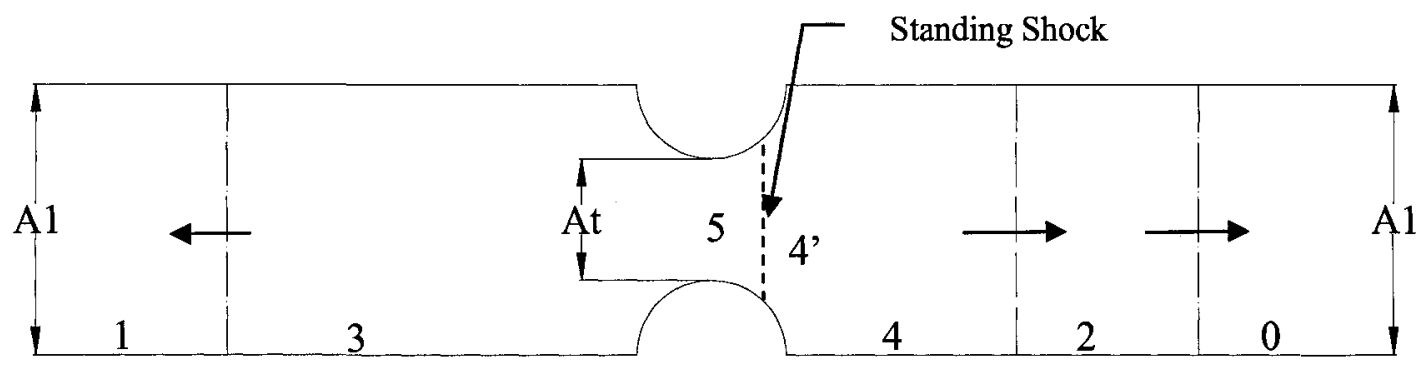

Figure 2.18: Standing shock wave at restriction area (Technical Report: Air blast attenuation)

The strength of the transmitted wave is calculated through an iterative computational method using equations 2.17 to 2.21 , as shown in Figure 2.20, Region (b). Region (a) gives the pressure values of the transmitted wave on the condition that the pressure ratio across the full flow region is equal to the transmitted wave as given by Equation 2.22.

$$
\frac{P_{1}}{P_{0}} \cdot \frac{P_{3}}{P_{1}} \cdot \frac{P_{5}}{P_{3}} \cdot \frac{P_{4}}{P_{5}} \cdot \frac{P_{2}}{P_{4}}=\frac{P_{2}}{P_{0}}=\xi_{2}
$$

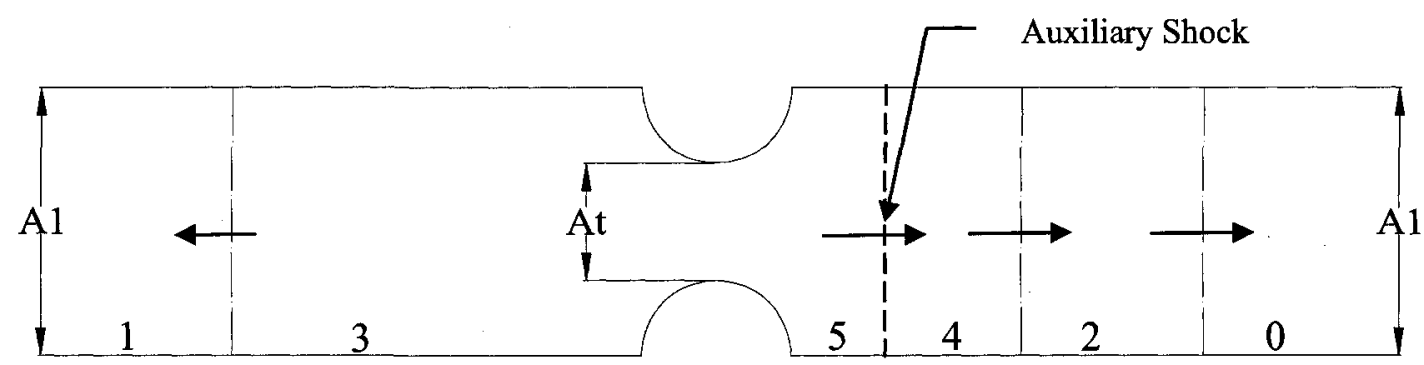

Figure 2.19: Standing shock propagation behind restriction (Technical Report: Air blast attenuation) 


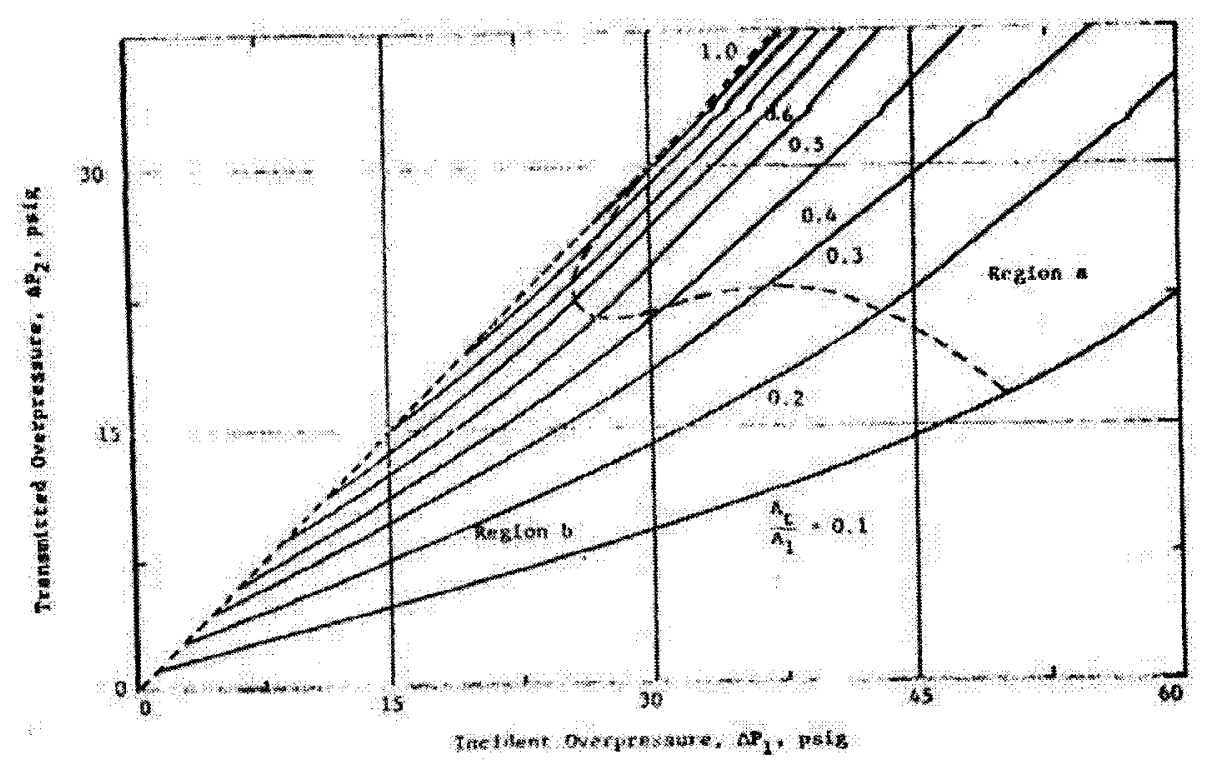

Figure 2.20: Transmitted wave pressure values for supersonic wave (Technical Report: Air blast attenuation)

\subsection{Explosions Containment}

The main goal of explosion containment is to attenuate the blast, and mitigate the effects of fragments and fireball from escaping the container so as to prevent possible fatalities and death among people as well as to minimize property damage. The applications for containment containers are in the area of transport and storage of explosives. Explosion containment can be divided into three main branches:

- Explosive Safety,

- Explosive Security, and

- Explosive Segregation.

Explosives safety, which is the main concern of this research, focuses on containment of accidental explosions at storage facilities especially where limited area of land is available or during transportation of explosives from manufacturers to retailers and users. Explosive security focuses on securing explosive materials from external attacks. This 
case can be seen in combat areas where ammunition is temporarily stored. Finally, explosive segregation means separating explosives in transport or storage by distances that prevent sympathetic initiation that could result in a mass explosion and catastrophic events.

There are different types of suppressive containers or barricades used to contain explosions. Starting as early as the 1960 's, the first investigation that led to the concept of suppressive shields to contain white phosphorous projectiles was carried out by Edgewood Arsenal. Before that, there were different types of containment structures, such as closed cubicles that were used for small amounts of explosives and vented blast mats used in construction blasting. Edgewood Arsenal was the first to study small, uniformly vented cubicles to attenuate fragments and blast pressures resulting from detonation of 4.2-inch white phosphorous mortar projectile. Subsequent to the success of these tests, they worked together with NASA National Space Technology laboratories to design and test a portable suppressive shield to contain $5 \mathrm{lbs}$ of C-4 explosive. The shield was cylindrical in shape, $5 \mathrm{ft}$ diameter and $5 \mathrm{ft}$ high. Moreover, the shield was uniformly vented to allow shock and gas to escape and at the same time contain the fragments. The success of this test was so promising that they worked on improving the technology, designing several prototypes and published the early handbook on suppressive shields. Eight groups of suppressive shields were developed by Edgewood Arsenal. Prior to their design, a hazard analysis was performed to determine hazard categories. Four hazard categories were established, negligible (Category I), marginal (Category II), critical (Category III), and catastrophic (Category IV). The eight suppressive shield groups are 
summarized in the following table and they provide level of protection for hazard Category "I":

Table 2.5: Suppressive shield groups according to Edgewood Arsenal design (Suppressive Shield handbook)

\begin{tabular}{|c|c|c|c|c|}
\hline $\begin{array}{l}\text { Shield } \\
\text { Group }\end{array}$ & \multicolumn{2}{|c|}{$\begin{array}{c}\text { Hazard parameter } \\
\text { Blast } \\
\text { Fragmentation }\end{array}$} & Applications & Level of Protection \\
\hline 1 & High & Severe & $\begin{array}{l}\text { Porcupine Melter ( } 2000 \\
\text { lbs) plus } 2 \text { pour units } \\
250 \text { lbs each }\end{array}$ & $\begin{array}{c}\text { Reduce blast pressure } \\
\text { at intraline distance by } \\
50 \%\end{array}$ \\
\hline 2 & High & Severe & $\begin{array}{l}\text { HE bulk }(750 \mathrm{lbs}) \\
\text { Minute Melter }\end{array}$ & $\begin{array}{c}\text { Reduce blast pressure } \\
\text { at intraline distance by } \\
50 \%\end{array}$ \\
\hline 3 & High & Moderate & $\begin{array}{l}\text { HE bulk ( } 37 \mathrm{lbs}) \\
\text { Detenators, fuzes }\end{array}$ & $\begin{array}{l}\text { Category I hazard at } \\
6.2 \text { feet from shield }\end{array}$ \\
\hline 4 & Medium & Severe & $\begin{array}{l}\text { HE bulk ( } 9 \mathrm{lbs}) \\
\text { Processing rounds }\end{array}$ & $\begin{array}{l}\text { Category I hazard at } \\
19 \text { feet from shield }\end{array}$ \\
\hline 5 & Low & Light & $\begin{array}{l}30 \mathrm{lbs} \text { Illuminant igniter } \\
\text { slurry mixing } \mathrm{HE} \\
\text { processing }(1.84 \mathrm{lbs})\end{array}$ & $\begin{array}{l}\text { Category I hazard at } \\
3.7 \text { feet from shield }\end{array}$ \\
\hline 6 & $\begin{array}{l}\text { Very } \\
\text { High }\end{array}$ & Light & $\begin{array}{l}\text { Laboratory, handling, } \\
\text { and transportation }\end{array}$ & $\begin{array}{l}\text { Category I hazard at } \\
1.0 \text { feet from shield }\end{array}$ \\
\hline 7 & Medium & Moderate & $\begin{array}{l}\text { Flame/fireball } \\
\text { attenuation }\end{array}$ & $\begin{array}{l}\text { Category I hazard at } \\
5.0 \text { feet from shield }\end{array}$ \\
\hline $81 \mathrm{~mm}$ & High & Moderate & $\begin{array}{l}81 \mathrm{~mm} \text { mortar drill-and- } \\
\text { face and/or cast- } \\
\text { finishing operation }\end{array}$ & $\begin{array}{l}\text { Category I hazard at } \\
3.0 \text { feet from shield }\end{array}$ \\
\hline
\end{tabular}

King, P.V. (King et al, 1981) received the approval from United States Patent on the blast suppression shield invention. Several tests were carried out with small amounts of explosives, propellants and pyrotechnics. One of the tests was a comparison between storing white phosphorus mortar shells in a regular magazine and in a blast suppression shield. It was found that when the mortar shells were detonated in the magazine, the fragments were scattered to a distance of $500 \mathrm{ft}$. On the other hand, the suppressive shield not only contained all the fragments but also reduced the size of the fireball. Another test was performed on a portable suppressive shield container with $5 \mathrm{lbs}$ of high explosive. 
The results from this test showed complete attenuation of fragments and blast pressure. These container systems had vent areas ranging from $25 \%$ to $60 \%$ of the overall area. It is clear that vents allow for blast and fireball attenuation, and fragment retention, while economizing the mass of the structure.

Generally speaking, the vent area ratio depends on the number of layers comprising the wall structure. For a single layer wall, the vent area ratio " $\alpha_{i}$ " is equal to the vent area divided by the total area of the wall. However for the multi-layer walls, the vent area ratio can be estimated using the following equation:

$$
\frac{1}{\alpha_{e}}=\sum_{i=1}^{n} \frac{1}{\alpha_{i}}
$$

Where,

$\alpha_{e}:$ Multi-layer vent area ratio

$\alpha_{i}$ : Single layer vent area ratio

$n$ : number of layers

The suppressive shield structures typically include multi-layer configurations. Thus each layer will be calculated separately then added together. The calculation of each layer depends on the cross section of each element in the layer. Different element configurations will result in different vent area calculations. For example, angles in a nested configuration will have different calculation procedures than, say, the same angles used in a side-by-side configuration. Generally, the vent area calculation for each layer depends on the number of openings, length of exposed element, and length and width of the wall. 
In 1994, VanWees introduced another concept for explosion containment. This concept was based on reducing the loads on container walls by installing an inner layer made of steel or concrete blocks that would transfers loads to the container walls through air springs. The assumption was that the air springs would be equally compressed by the initial as well as the quasi-static loads and thus transfers a softer load to the container walls. Although this concept sounds efficient and minimizes the load on the container walls, in fact it was impractical due to its complexity and high cost of construction.

Kim W. King et al in 2002 designed a containment chamber for $10 \mathrm{~kg}$ of TNT. The chamber was $8 \mathrm{ft}$ in diameter and $11 \mathrm{ft}$ in height, with a gross weight of $16,000 \mathrm{lbs}$. The walls of the chamber consisted of three layers, an inner and outer steel layer sandwiching a layer of sand. Scaled and full size tests were carried out to verify the ability of the chamber to mitigate blast waves and fragments. The chamber was tested and withstood the detonation of $12.5 \mathrm{~kg}$ of TNT. The positive results led to an approval from the Department of Defense Explosive Safety Board for use this chamber as a storage magazine for quantities of explosive up to $10 \mathrm{~kg}$.

Generally speaking, pumice, a naturally occurring material made of foamed volcanic glass, consists of $60-70 \%$ closed air voids and $30-40 \%$ silica, and as such, has great ability to absorb shocks. Early research occurred in 1968. Later in 1995, the Ordnance Evaluation Branch of the Naval Air Warfare Center Weapons Division (NAWCWD) performed tests to evaluate the ability of pumice to prevent sympathetic detonation among small quantities of mixed munitions. Containers using pumice were built to house approximately $1.25 \mathrm{lbs}$ of explosive with a total load of $254 \mathrm{lbs}$. The results of these tests 
were promising and more research was recommended. All applications and tests with pumice technology till now are oriented to military purposes only. The latest reported research was by Dixon, P. et al in 2000 , who reported data on the use of pumice as a blast attenuating material for small amounts of explosives.

Another method that is widely used to safely store explosives is by means of sand fill barricades. The sand filled barricades are used as barriers between storage containers. L.K. Davis described the experimental results of using sand filled barricades to prevent the spread of detonation among storage containers. Two wall designs were tested; the first included a sloped, side wall while the second design included a thin vertical wall. The results showed that the sloped barricades were much better in deflecting the blast wave compared to the thin wall barricades. Although this concept is good in separating storage containers, it cannot be used for storage in ports and/or airports. Thus, there is a need to investigate how to safely store hazardous materials in transit until they reach their final destinations. 


\section{Chapter 3}

\section{Numerical Approach and Model Development}

\subsection{Introduction}

The use of numerical modeling in engineering applications has been growing fast in last few decades. There are now many finite element programs in the market that can be used to analyze different engineering problems with high degree of complexity. Some of these programs are capable of simulating field conditions quite accurately; therefore they are widely used prior to more expensive field tests to maximize the benefits of both approaches. In this thesis, a software package known as ANSYS AUTODYN referred herein as AUTODYN (ANSYS Inc.) was used to investigate the behaviour of several designs of blast suppression steel container systems subjected to detonations from different charge masses.

The behaviour of the suppressive steel containers was studied in two steps. The first dealt with the influence of the proposed designs on the attenuation of the shock wave through the development 2-D models. The second step analyzed the structural responses to the shock loads that will determine the selection of the optimum design to be used. The ability of AUTODYN to analyze problems similar to the one studied in this research was carried out by comparing the results of incident pressure in air with the ConWep (TM5855, Conventional Weapons Effects) program as well as with experimental test data from literature. The following sections give a brief overview of the finite element technique as 
applied to the problem at hand and the steps of constructing numerical models to solve these problems.

\subsection{Numerical Approach}

\subsubsection{AUTODYN Elements Types}

Euler-FCT formulation: The Euler-FCT (Flux Corrected Transport) formulation is generally designed to solve gas dynamic problems including large deformations and/or fluid flow such as air blast simulation. The Eulerian numerical mesh is fixed in space where the material flows through it as shown in Figure 3.1. The Euler formulation consists of different schemes chosen according to the problem definition to obtain accurate results. "The first-order scheme is used for fluid-structure, gas-structure interaction problems. The multi-material Godunov second-order scheme is used for purely fluid and gas dynamic calculations or highly distorted structural materials" (Theory Manual for AUTODYN 2003). The parameters of each element are defined at either the corner or the center of the cells as illustrated in Figure 3.2.

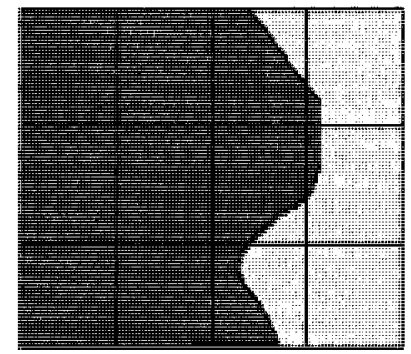

$t=t_{1}$

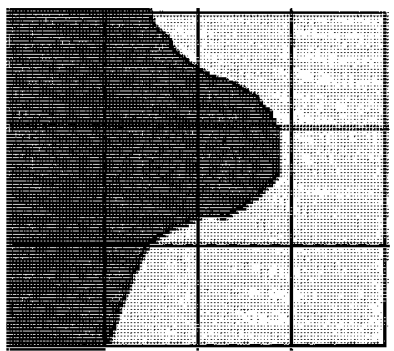

$t=t_{2}$

Figure 3.1: Euler formulation (Manual for AUTODYN software Agency of Century Dynamics Company (2003)) 


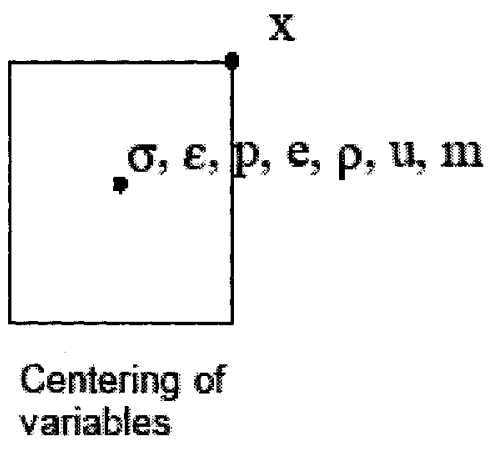

Figure 3.2: Element parameters Location for Euler-FCT mesh (Manual for AUTODYN software Agency of Century Dynamics Company (2003))

Where,
$x$ : Displacement,
$u$ : Velocity,
$m:$ Mass,
$\sigma$. Stress,
$\varepsilon$ Strain,
$p$ : Pressure,
$e:$ Internal energy, and
$\rho$ : Density
$F:$ Force

The Euler-FCT formulation will be used to simulate the air sub-grid. A benefit of using the Euler-FCT to represent the air is that in this element type there is no grid distortion, which means that there is no change in size and shape of the gird during the analysis. Hence, the time step $(\Delta t)$ controlled by this element type will be constant through out the analysis. Thus, the simulation will not be affected by convergence problems that originate from the selection of the time step. 
Lagrange formulation: The Lagrange formulation algorithms are based on the finite volume method used by Wilkins (Theory Manual for AUTODYN 2003) in the timedependent Lagrangian finite-difference code, HEMP. The Lagrangian numerical mesh moves and deforms with the material as shown in Figure 3.3. The movement of the mesh means that no material is transported between elements. The parameters of each element are defined at either the corner or the center of the cells as shown in Figure 3.4. Although this formulation can be used to model solid behaviour, it does not work efficiently for large deformation problems. The main challenge with this formulation is that small time steps $(\Delta t)$ need to be selected when large distortions are expected. The small time steps may lead to computational inefficiencies.

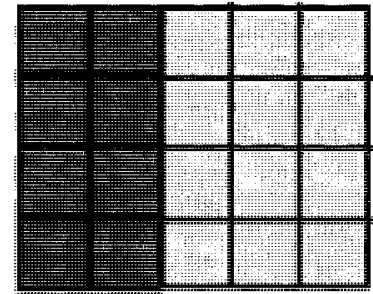

$t=0.0$

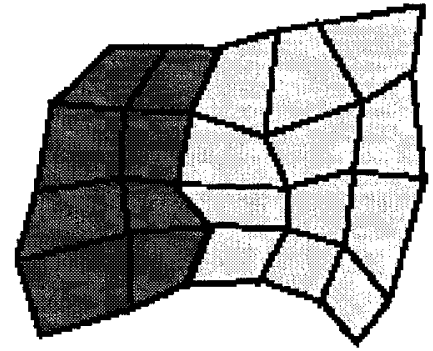

$\mathrm{t}=\mathrm{t}_{1}$

Figure 3.3: Lagrange formulation (Manual for AUTODYN software Agency of Century Dynamics Company (2003))

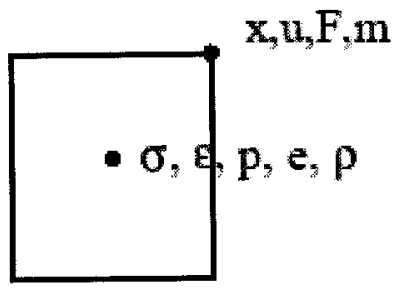

Centering of variables

Figure 3.4: Element parameters Location for Lagrange mesh (Manual for AUTODYN software Agency of Century Dynamics Company (2003)) 
Shell element formulation: This formulation is used to model thin structural elements for which the use of the standard Lagrange formulation would impose a very small time step during computation. The shell formulation makes the assumption that the structure being modeled is "thin" such that a biaxial state of stress may be considered. No wave propagation occurs across the shell but only along its length. Thus, the time step $(\Delta t)$ is constrained only by the mesh dimension along the length. The shell sub-grid consists of linear segments joined together by nodes and is defined with local coordinates at which $\mathrm{I}=1$ with $\mathrm{J}$ representing string of nodes along the shell in 2-D and $\mathrm{K}$ defining the surface of nodes in 3-D. The parameters of each element are defined at the mid surface of those linear segments as shown in Figure 3.5. Shell elements will be used to model the steel angles used in the walls of the containers in 3-D models.

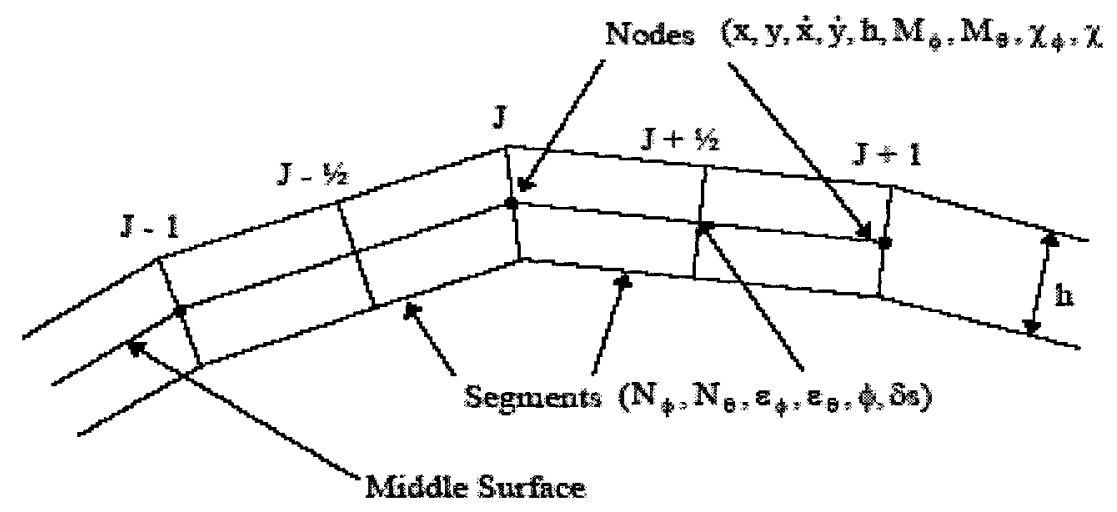

Figure 3.5: Representations of Shell Elements and Centering of Dependent Variables. (Manual for AUTODYN software Agency of Century Dynamics Company (2003))

\subsubsection{Material Models}

In this research, various types of materials were used to simulate the field conditions. These materials are, air, TNT or Pentolite and steel. AUTODYN has built-in material models to simulate these materials as follows: 
Hydro (Ideal gas) for Air simulation

The strength models for Air material were taken as Hydro (no Strength)

JWL Model for TNT simulation

The strength models for TNT explosive were taken as Hydro (no Strength)

Johnson-Cook model for steel simulation

The Johnson-Cook model was used in this research due to its ability to simulate materials behaviour subjected to large strains, high strain rates and high temperatures. These factors are obtained from intense impulsive loading resulting from high velocity impact and/or explosive detonation, which is the case in this research. Thus, this model was best for representing the problem. The yield stress, $f_{y}$, is the controlling parameter and it is defined in Equation 3.1 (Theory Manual for AUTODYN software Agency of Century Dynamics Company (2003)).

$$
f_{y}=\left[D+H \varepsilon_{p}^{n}\left[1+L \log \varepsilon_{p}^{*}\left[1-T_{H}^{m}\right]\right.\right.
$$

Where,

$$
\begin{aligned}
& \mathcal{E}_{p}: \text { effective plastic strain } \\
& \mathcal{E}_{p}^{*}: \text { normalized effective plastic strain rate } \\
& T_{H}: \text { homologous temperature }=\left(T-T_{\text {room }}\right) /\left(T_{\text {melt }}-T_{\text {room }}\right) \\
& D, H, L, n \text { and } m \text { : material constants }
\end{aligned}
$$

Finally, it is worth mentioning that for steel material failure and erosion models were used to control the failure behaviour of such material. The failure model for steel is a plastic strain value of 0.2 that is pre-defined in material models. The steel material fails by reaching such value. However the erosion model is a geometric strain value of 0.2 at which cells are eroded when reached this value. In other words, any cell reaches erosion 
value of 0.2 ; it is excluded from the calculation. This helps in preventing small time steps causing termination of the program.

\subsubsection{Equation of State}

The equation of state is a thermodynamic equation to describe the material status and properties using relations between various variables to best define each material. The general form of the equation of state (EOS) for pressure is function of the local density (or specific volume) and the local specific internal energy of material as shown in Equation 3.2 (Theory Manual for AUTODYN software Agency of Century Dynamics Company (2003))

$$
p=f(\rho, e)
$$

Where,

$$
\begin{aligned}
& \rho: \text { density } \\
& e: \text { specific internal energy }
\end{aligned}
$$

Generally, finite element programs used for static analysis, material behaviour is expressed linearly without defining explicitly the EOS. However for dynamic loading, such as explosion structure interaction, the non-linear material behaviour must be taken into consideration where high pressures and high strain rates are expected.

\subsubsection{Air}

Equation 3.3 represents the Ideal gas EOS that was used to model the Air. (Theory Manual for AUTODYN software Agency of Century Dynamics Company (2003)). 


$$
P=(\gamma-1) \rho e+P_{\text {shift }}
$$

Where,

$P:$ pressure

$\gamma$ : ideal gas constant

$\rho:$ density

$P_{\text {shift }}$ pressure shift (small initial pressures to give zero starting pressure in a model)

$e$ : specific internal energy

\subsubsection{TNT and Pentolite}

The explosive material, either in terms of TNT or Pentolite, was characterized by the “Jones-Wilkins-Lee" (JWL) EOS. The JWL was used to model the rapid expansion of high explosive detonation before converting to ideal gas EOS. Equation 3.4 relates the pressure of the expanding gas to different parameters depending on the type of explosive. The following parameters were obtained from dynamic experiments for different explosives and they are available in the AUTODYN Library. (Theory Manual for AUTODYN software Agency of Century Dynamics Company (2003)).

$$
P=A\left(1-\frac{\varpi \eta}{R_{1}}\right) e^{-\frac{R_{1}}{\eta}}+B\left(1-\frac{\varpi \eta}{R_{2}}\right) e^{-\frac{R_{2}}{\eta}}+\varpi \rho e
$$

Where,

$$
\begin{aligned}
& \eta: \rho / \rho_{0} \\
& \rho: \text { density } \\
& \rho_{o}: \text { reference (initial) density } \\
& e: \text { specific internal energy }
\end{aligned}
$$


$A, B, R_{1}, R_{2}, \varpi$ : empirically derived constants

\subsubsection{Steel}

The steel was controlled by the Hooke's law knowing that the steel is an elastic material, the stress is function of the modulus of elasticity and the strain, and expressed here by linear EOS. The linear EOS expresses the pressure level as a function of the bulk modulus, $K$, and the compression, $\mu$. Equation 3.5 indicates the relationship between the pressure level and the bulk modulus and compression. (Theory Manual for AUTODYN software Agency of Century Dynamics Company (2003)).

$$
P=K \beta=K\left(\frac{\rho}{\rho_{0}}-1\right)
$$

Where,

$$
\begin{aligned}
& \rho: \text { density } \\
& \beta: \text { compression }\left[\left(\rho / \rho_{\mathrm{o}}\right)-1\right] \\
& K: \text { bulk modulus }=\mathrm{E} /[3(1-2 v)] \\
& v: \text { Poisson's ratio }
\end{aligned}
$$

\subsection{Mesh Convergence Studies}

The mesh convergence studies are carried out for 2-D and 3-D simulations to obtain the optimum mesh size that provides a reasonable balance between the computation time and accuracy. The mesh size is important to accurately predict pressure. The results were then compared to those predicted by ConWep, a program that makes use of a large amount of true field data. 
Seven different 2-D mesh sizes were studied and compared to determine the best mesh size to be used. Moreover, the explosion itself was remapped before developing the 2-D models. The main advantages of remapping are the possibility of having a very fine mesh size to increase the accuracy of measurements without increasing the run time and help in decreasing the run time in the 2-D and 3-D final models. Three remapping scenarios were studied. The following section presents the remapping process and the different mesh sizes used.

\subsubsection{2-D Explosion Remap}

Remapping allows for detonating the amount of explosives that is of interest in 1-D and then transform it into 2-D or 3-D models. The remap is prepared by knowing the shortest distance between the center of the explosion and the nearest point of interest. In this study the point of interest is one meter from the center of explosion. This distance is used when building the 2-D mesh to set out the length of the portion representing the air. The part used to simulate a 2-D explosion is called the "Wedge". This can be meshed in the local coordinate system "I" and "J". The meshing is done through the " $\Gamma$ " direction while keeping it constant in the " $J$ " direction and equal to one cell, two " $J$ " lines. Similarly, the remapping is done using three different mesh sizes, one, one-half and one-quarter millimetres. The equivalent number of cells for each size is 1000,2000 and 4000 cells, respectively.

After creating the wedge, it was filled completely with air. Subsequently, the radius of the spherical charge, determined using Equation 3.6, was calculated for three different 
masses, 5,50 and $500 \mathrm{~kg}$. Table 3.1 shows the radii of the aforementioned charges. The calculated radii are used to fill the wedge for different charges using the geometric fill option within AUTODYN. Table 3.2 shows the material data for air and TNT available in the AUTODYN library. Figures 3.6 and 3.7 represent the material location for air and TNT and the velocity vectors after detonation within the wedge. After filling the air with the explosive charge, a detonation point was defined at $\mathrm{X}=0$ and $\mathrm{Y}=0$. Then, the program was initiated and ran to the point at which the shock front was almost at the end of the wedge. At this point the program was terminated, a remap file was created and the wrapup time was recorded. The recorded wrap-up time is used in the 2-D and 3-D models as the initial time for the models. The EOS in the material model for the TNT is automatically updated from JWL to Ideal Gas when the compression is close to -1. Figure 3.8 shows the velocity vectors of the shock wave through the wedge; approximately where the program was terminated.

$$
r=\sqrt[3]{\frac{3 \times W \times 1000}{1.63 \times 4 \times \pi}}
$$

Where,

$$
\begin{aligned}
& r: \text { radius of spherical charge, } \mathrm{cm} \\
& W: \text { mass of charge, } \mathrm{kg}
\end{aligned}
$$

Table 3.1: Charges radii

\begin{tabular}{cc}
\hline $\begin{array}{c}\text { Charge mass } \\
(\mathrm{kg})\end{array}$ & $\begin{array}{c}\text { Radius } \\
(\mathrm{cm})\end{array}$ \\
\hline 5 & 9.02 \\
50 & 19.42 \\
500 & 41.84 \\
\hline
\end{tabular}




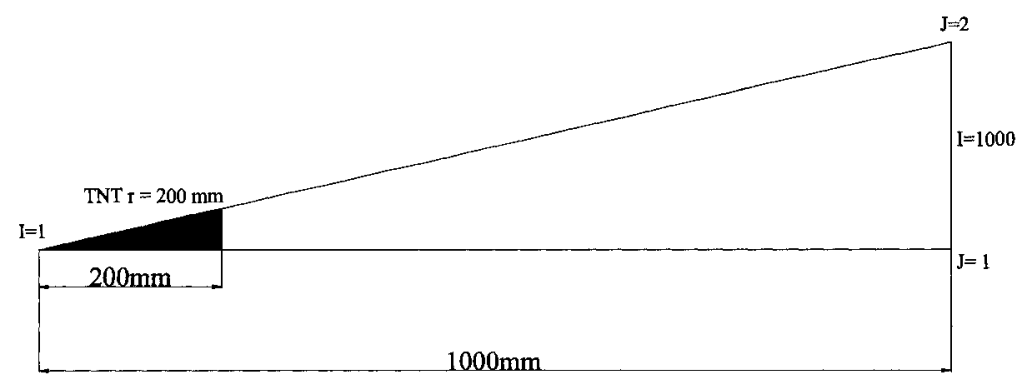

Figure 3.6: Wedge filled with $50 \mathrm{Kg}$ TNT

Table 3.2: Material data for air and TNT available in the library of AUTODYN

\begin{tabular}{llll}
\hline Material & Air & TNT & TNT (Ideal) \\
\hline Equation of State & Ideal Gas & JWL & Ideal Gas \\
& $\gamma=1.4$ & Standard & $\gamma=1.35$ \\
& $\rho=1.225 \times 10^{-3} \mathrm{~g} / \mathrm{cm}^{3}$ & Library data & $\rho=1.0 \times 10^{-3} \mathrm{~g} / \mathrm{cm}^{3}$ \\
& Ref. Energy $=0.0 \mu \mathrm{J}$ & & Ref. Energy $=0.0 \mu \mathrm{J}$ \\
& Press. shift $=0.0 \mathrm{kPa}$ & & Press. shift $=0.0 \mathrm{kPa}$ \\
Initial Conditions & $\rho=1.225 \times 10^{-3} \mathrm{~g} / \mathrm{cm}^{3}$ & Default & From detonation \\
& Ref. Energy $=2.068 \times 10^{5} \mu \mathrm{J} / \mathrm{mg}$ & & Model $/$ remap data \\
\hline
\end{tabular}



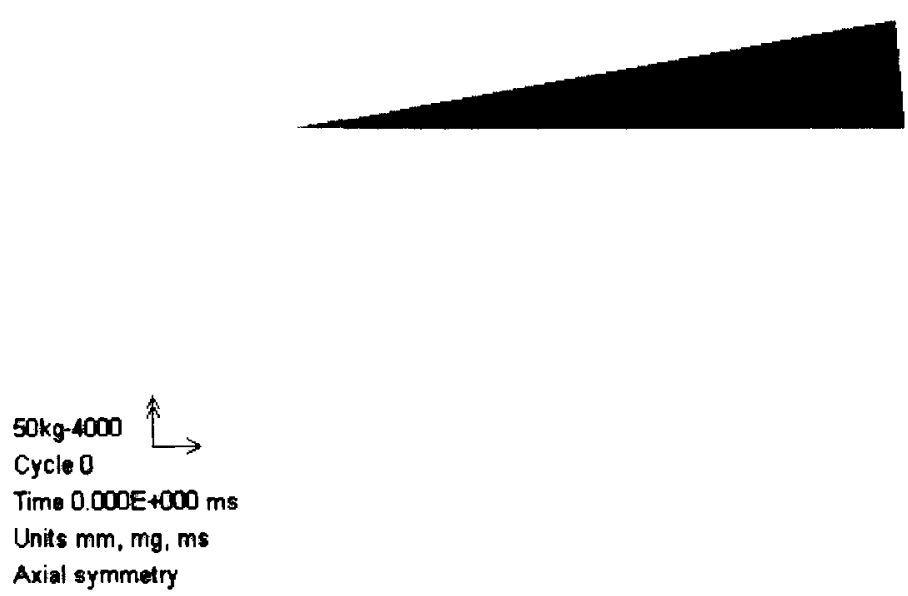

Figure 3.7: The Wedge part used to simulate air for remapping
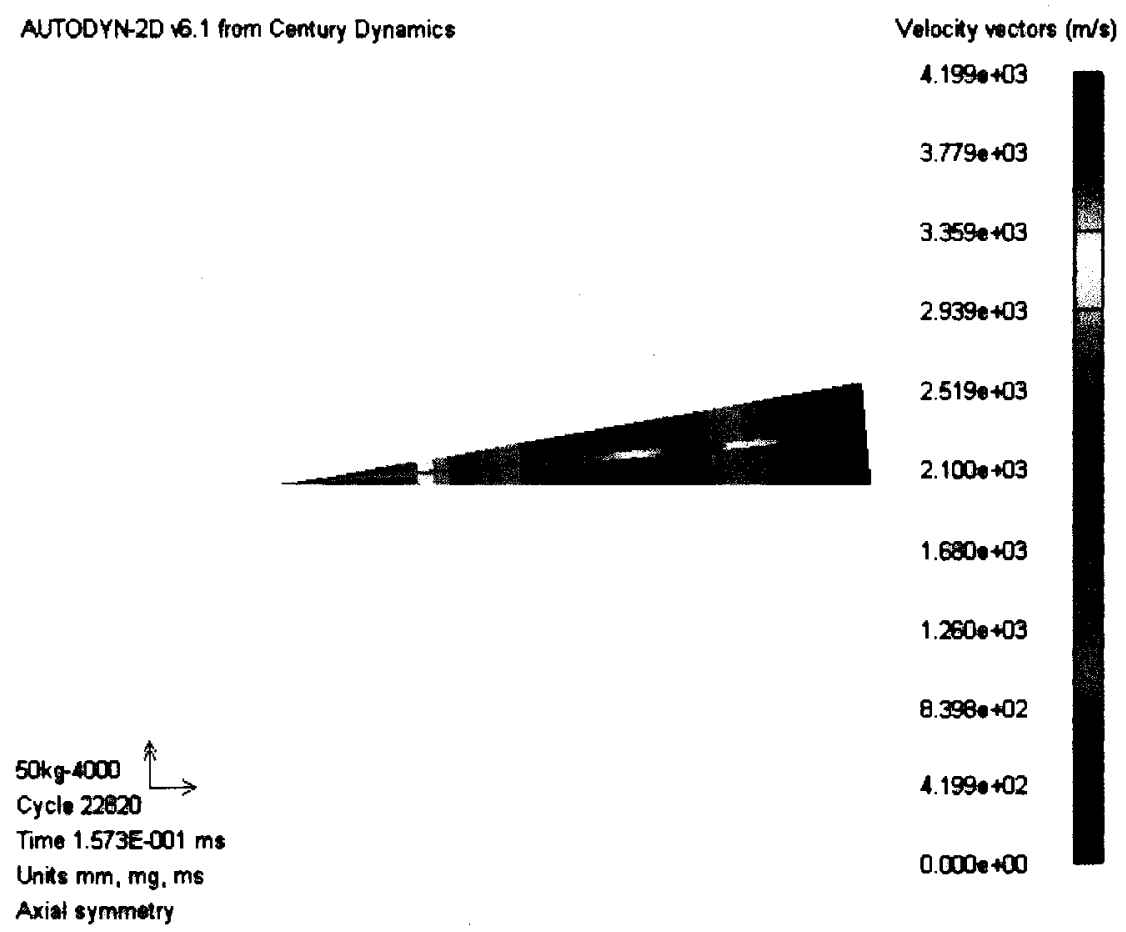

Figure 3.8: Velocity vectors of the shock wave 
Figure 3.9 shows the comparison of peak incident pressure determined with AUTODYN using different number of cells in the remap process and the ConWep calculated pressure values. It is obvious that as the number of cells increases the pressure values computed by AUTODYN agree better with the ConWep values. The maximum number of cells used was 4000 or $0.25 \mathrm{~mm}$ divisions resulting in a pressure value of $9,807 \mathrm{kPa}$ compared to $10,360 \mathrm{kPa}$ obtained from ConWep. It is important to note that the program does not allow divisions less than $0.25 \mathrm{~mm}$. Better pressure values can be obtained in the final 2-D and 3-D models by using a finer mesh size in those models accompanied with the 4000 cells remap.

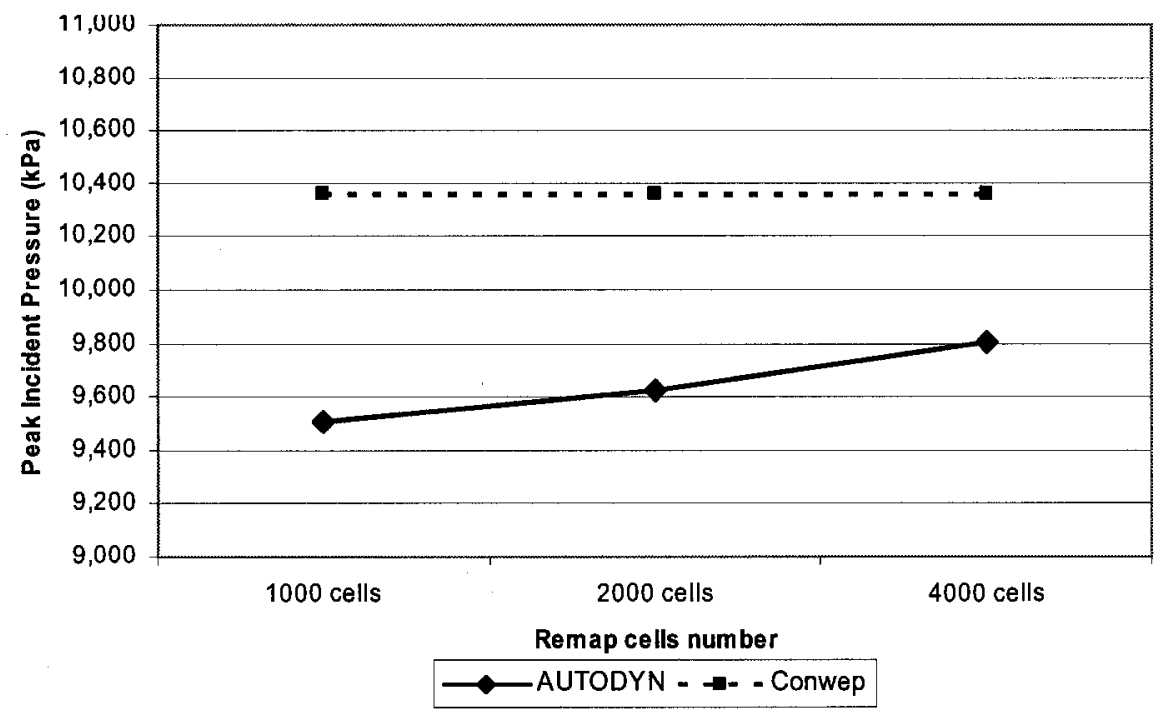

Figure 3.9: Remap Peak Incident Pressure Comparison between AUTODYN and ConWep

\subsubsection{2-D Mesh Size Study}

Seven mesh sizes are used in the mesh size study, 4, 6, 8, 10, 20, 30 and $40 \mathrm{~mm}$. A $50 \mathrm{~kg}$ TNT charge was used for the seven models. The 2-D models had dimensions of $1 \mathrm{~m}$ in the $\mathrm{X}$-direction and $4 \mathrm{~m}$ in the $\mathrm{Y}$-direction and it was defined by Euler-FCT using axial symmetry. After creating the air part, the remap file from the previous process was used 
to represent the explosive charge. Moreover, the wrap-up time from the remap process was entered as the initial time for the models. Next, the boundary condition was defined as "flow-out", to the sides and the top of the air domain as shown in Figure 3.10, which allows the shock wave to exit the air domain and not reflect back. Subsequently, the gauges were inserted at 1,2,3 and 4 meters (Figure 3.10) from the center of the explosion to track the pressure history of the shock wave. These gauges are fixed with the grid and they are not affected with the movement of the shock wave. The pressure values obtained from these gauges were compared with pressure values at the same distances obtained form ConWep.

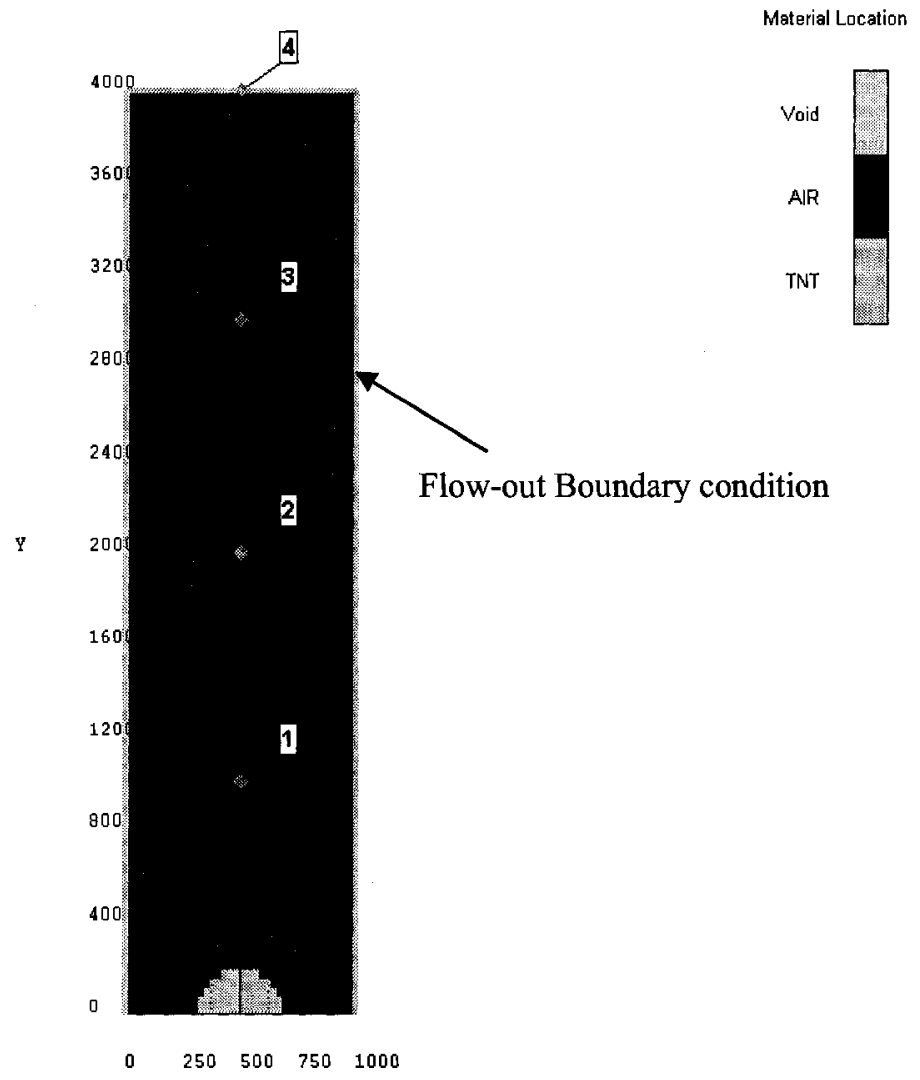

Figure 3.10: Boundary condition for air domain and location of gauges

The results presented in Table 3.3 and Figures 3.11 through 3.14 indicate that as the mesh becomes finer, the pressure values approach those predicted by ConWep. Figure 3.11 
shows the computed pressure values from AUTODYN and CONWEP at $1 \mathrm{~m}$ from point of detonation. Note that since the pressure values obtained from ConWep do not depend on mesh size, they remain constant at $10,300 \mathrm{kPa}$. On the other hand, values calculated using AUTODYN depend on the mesh size and it appears that mesh size less than $8 \mathrm{~mm}$ would provide best agreement with the ConWep values.

Table 3.3: Pressure values comparison between AUTODYN and ConWep for different 2-D mesh sizes

\begin{tabular}{|c|c|c|c|c|c|c|c|c|}
\hline & Mesh Size & $\overline{4 m m}$ & $6 \mathrm{~mm}$ & $8 \mathrm{~mm}$ & $10 \mathrm{~mm}$ & $20 \mathrm{~mm}$ & 30mm & $40 \mathrm{~mm}$ \\
\hline $1 \mathrm{~m}$ & $\begin{array}{l}\text { AutoDyn (kPa) } \\
\text { ConWep (kPa) }\end{array}$ & 9,871 & 10,455 & 10,474 & $\begin{array}{l}9,844 \\
10,360\end{array}$ & 9,699 & 9,576 & 9,669 \\
\hline $2 \mathrm{~m}$ & $\begin{array}{l}\text { AutoDyn (kPa) } \\
\text { ConWep (kPa) }\end{array}$ & 3,071 & 3,026 & 3,070 & $\begin{array}{c}3,156 \\
3,332\end{array}$ & 3,530 & 3,372 & 2,614 \\
\hline $3 \mathrm{~m}$ & $\begin{array}{l}\text { AutoDyn (kPa) } \\
\text { ConWep (kPa) }\end{array}$ & 1,883 & 1,908 & 1,901 & $\begin{array}{l}1,883 \\
1,465\end{array}$ & 1,723 & 1,664 & 1,455 \\
\hline $4 m$ & $\begin{array}{l}\text { AutoDyn }(\mathrm{kPa}) \\
\text { ConWep }(\mathrm{kPa}) \\
\end{array}$ & 1,093 & 1,085 & 1,083 & $\begin{array}{r}1,080 \\
778 \\
\end{array}$ & 1,005 & 891 & 787 \\
\hline
\end{tabular}

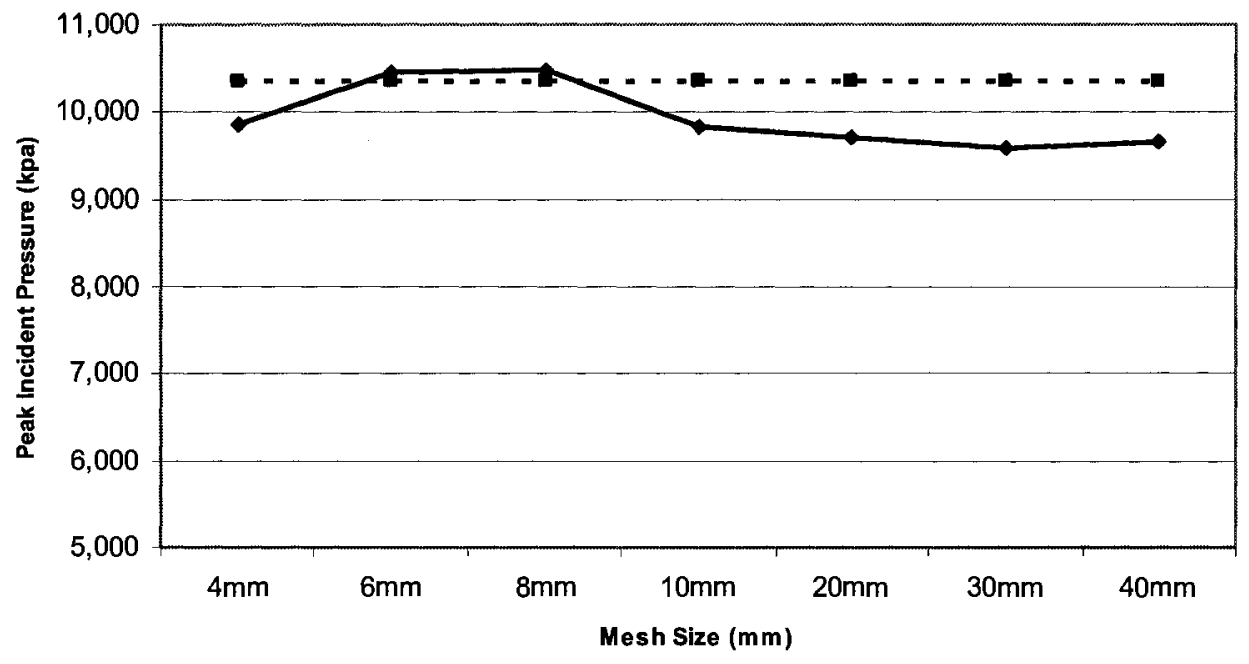

$\rightarrow-$ AutoDyn Peak Incident Pressure $\quad$ - $\rightarrow-$ - ConWep

Figure 3.11: 2-D Mesh size vs peak incident pressure at 1 meter

Figure 3.12 illustrates the pressure values from AUTODYN and ConWep at $2 \mathrm{~m}$ from point of detonation. Again, the pressure values from ConWep remain constant, in this 
case, at $3,332 \mathrm{kPa}$. It appears from the AUTODYN results shown in Figure 3.12 that mesh size less than $30 \mathrm{~mm}$ would provide best agreement with the ConWep values.

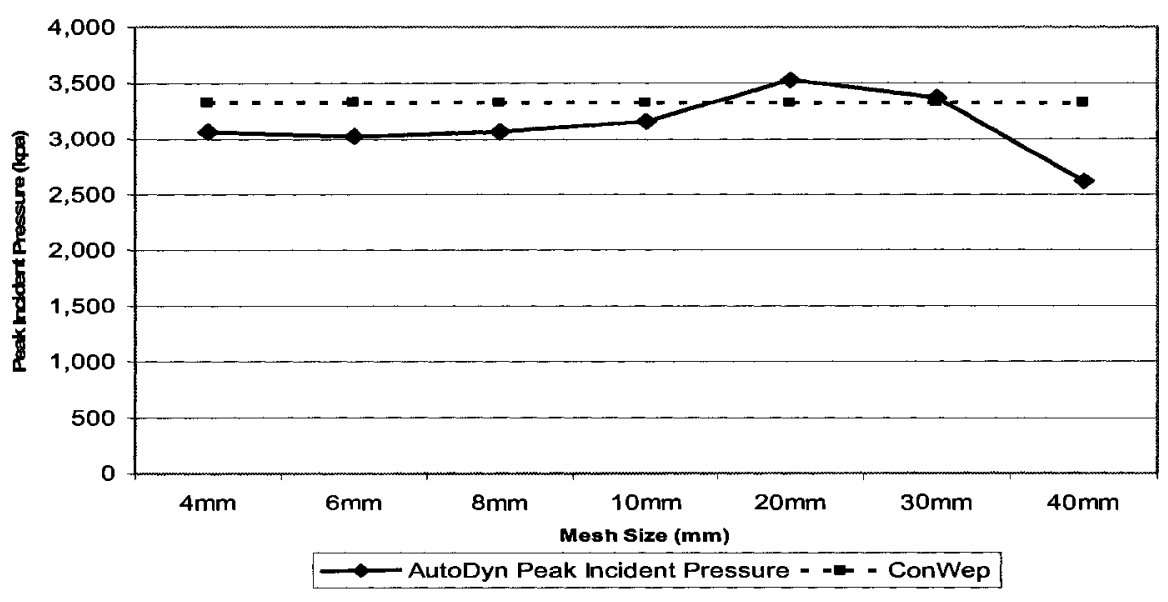

Figure 3.12: Mesh size vs peak incident pressure at 2 m

Figure 3.13 shows the computed pressure values from AUTODYN and ConWep at $3 \mathrm{~m}$ from point of detonation. The ConWep pressure values remain constant at $1,465 \mathrm{kPa}$. On the other hand, pressure values calculated using AUTODYN shows that mesh size less than $30 \mathrm{~mm}$ would provide best agreement with ConWep values.

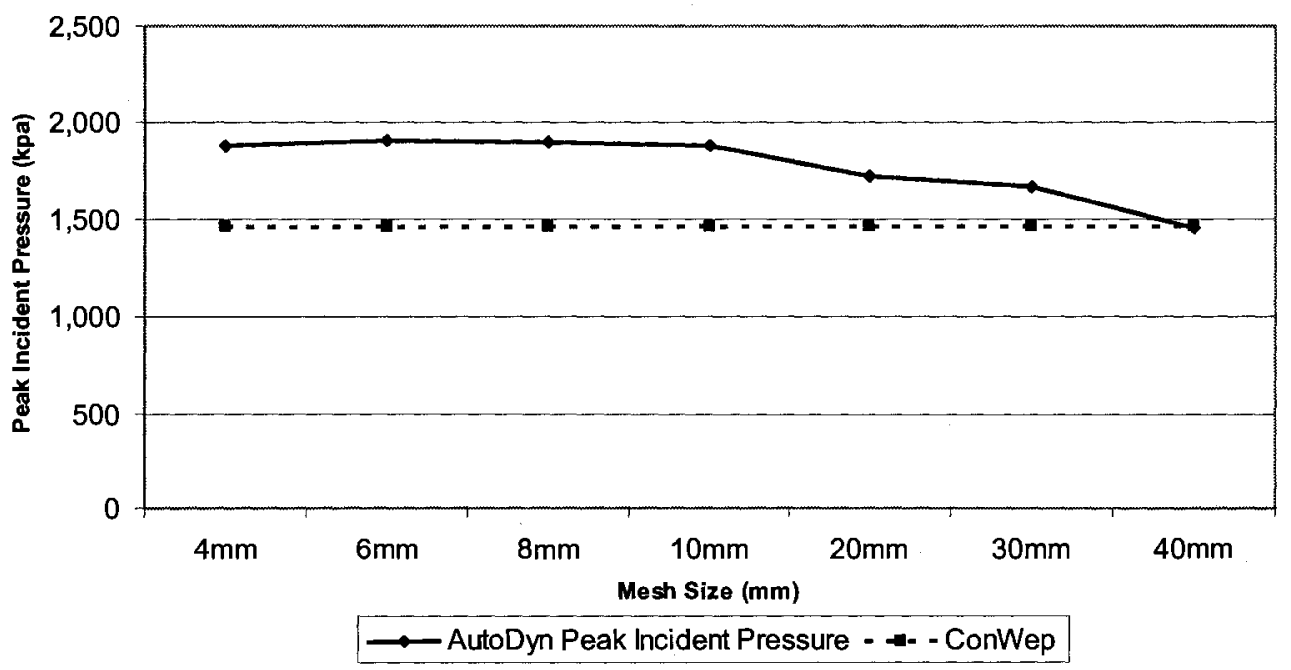

Figure 3.13: Mesh size vs peak incident pressure at $3 \mathrm{~m}$ 
Figure 3.14 shows the computed pressure values from AUTODYN and ConWep at $4 \mathrm{~m}$ from point of detonation. The ConWep pressure values are constant at $778 \mathrm{kPa}$ and the AUTODYN values show that mesh size less than $40 \mathrm{~mm}$ provide the best agreement with the ConWep values.

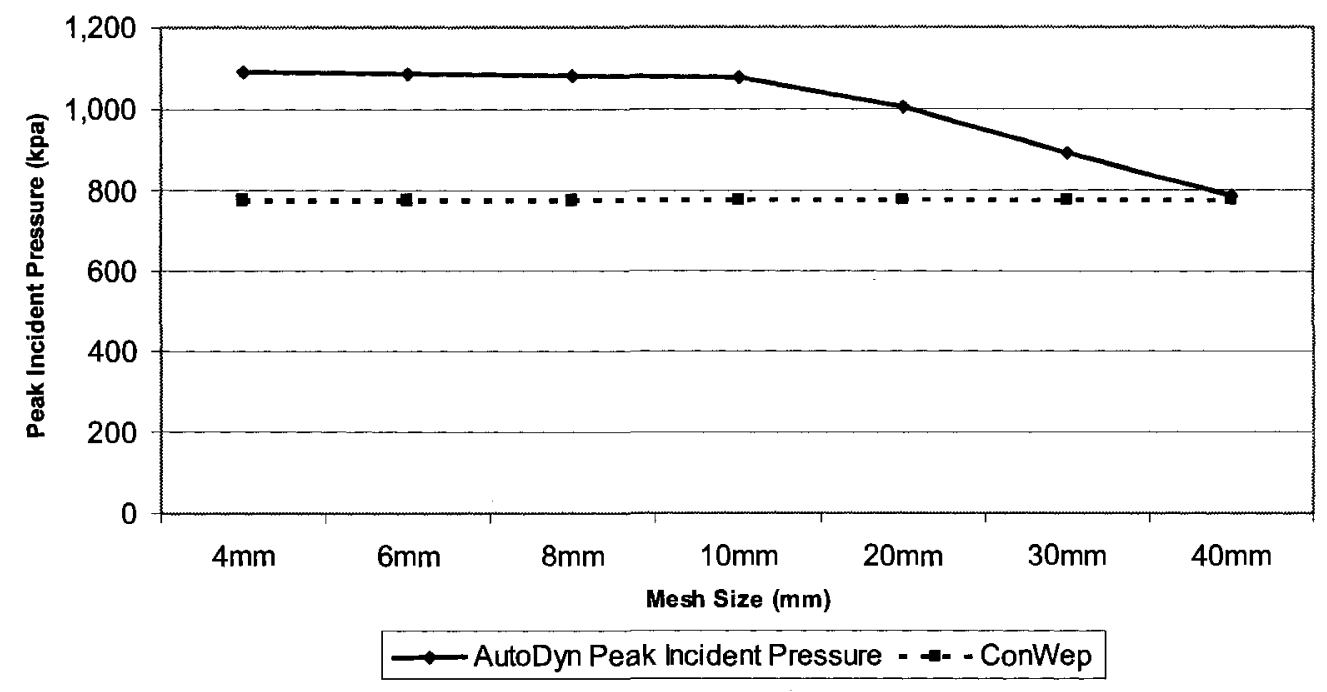

Figure 3.14: Mesh size vs peak incident pressure at $4 \mathrm{~m}$

The results that are shown above demonstrate that a mesh size less than $10 \mathrm{~mm}$ will provide the most consistent and comparable pressures at a $2 \mathrm{~m}$ distance from the centre of the explosion. According to the AUTODYN manual, the minimum number of cells to be used to track pressure through vents should be between three to five cells per centimetre. To comply with this condition the mesh size was forced to be $2 \mathrm{~mm}$. This also satisfies the conclusion stated above regarding the $10 \mathrm{~mm}$ mesh size. The $2 \mathrm{~mm}$ mesh will provide six cells for the minimum spacing of $12.7 \mathrm{~mm}$, between the suppressive shield angles as will be presented later in the pilot study. As for the case of $1 \mathrm{~m}$, the model appears to provide inaccurate values at close range. This will be discussed later. 


\subsubsection{3-D Mesh Size Study}

Five mesh sizes, 20, 30, 40, 50 and $100 \mathrm{~mm}$, and two explosive charges, 5 and $50 \mathrm{~kg}$, were used for the 3-D mesh size study. The 3-D models had dimensions of $1.5 \mathrm{~m}$ in the $\mathrm{X}$-direction, $1.5 \mathrm{~m}$ in the $\mathrm{Y}$-direction and $2.5 \mathrm{~m}$ in the Z-direction along with Euler-FCT sub-grid. After creating the air domain, it was filled by the remap file using exactly the same procedures as in the 2-D models. Next, the "flow-out" boundary condition was applied to the sides and the top of the air domain as shown in Figure 3.15. Subsequently, the gauges were inserted at 1,2 and 2.5 meters from the center of the explosion as presented the same figure. The pressure values obtained from these gauges were compared with those at the same distances obtained form ConWep.

3

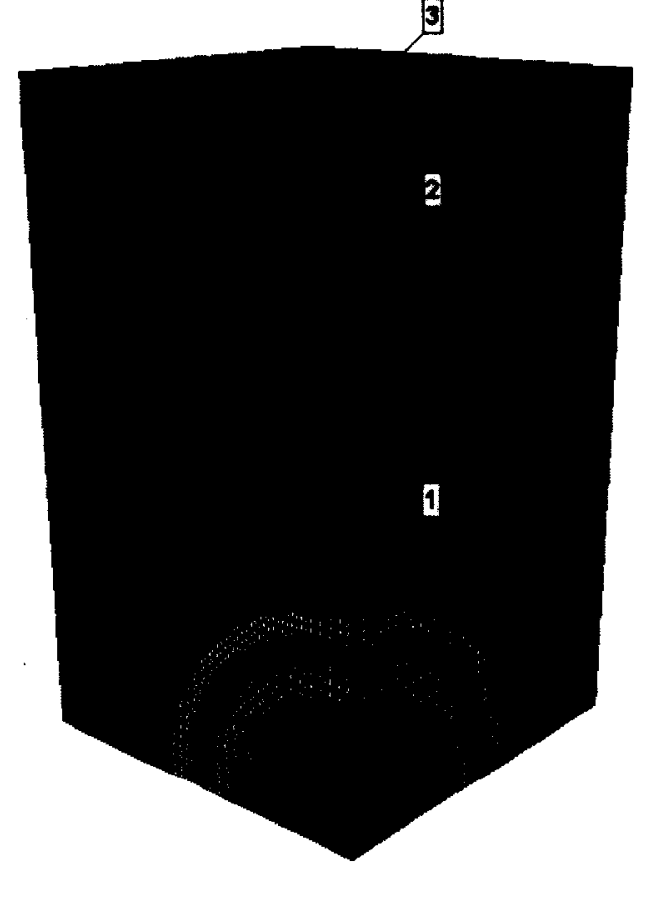

Figure 3.15: Boundary condition for air domain and location of gauges 
Figure 3.16 presents the comparison of the calculated pressures using AUTODYN and ConWep for a $5 \mathrm{~kg}$ charge at $1 \mathrm{~m}$ from the center of the explosion. It is clear that the pressure values obtained from AUTODYN approach the values obtained from CONWEP calculations as the mesh becomes finer. Figure 3.17 shows the pressure values for both AUTODYN and ConWep for a $50 \mathrm{~kg}$ charge $1 \mathrm{~m}$ away from the center of the explosion. The results of the $50 \mathrm{~kg}$ confirmed the conclusion obtained in the case of $5 \mathrm{~kg}$. As can be seen in the figure the pressure values for both methods approached identical values for the $40 \mathrm{~mm}$ mesh and remain the same for meshes finer than $40 \mathrm{~mm}$. When the pressure is computed at a $2 \mathrm{~m}$ distance, results confirmed the observations discussed for the $1 \mathrm{~m}$ distance as shown in Figure 3.18.

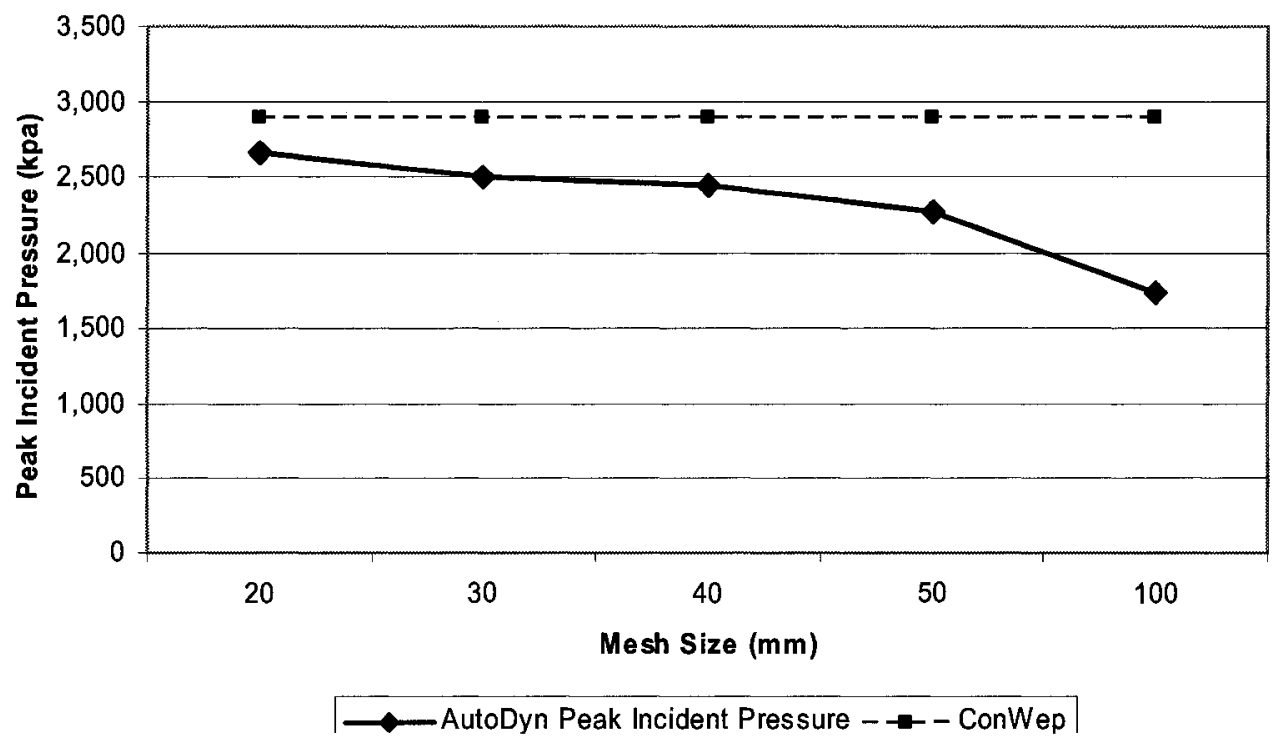

Figure 3.16: 3-D-5 kg Mesh size vs peak incident pressure at 1 meter 


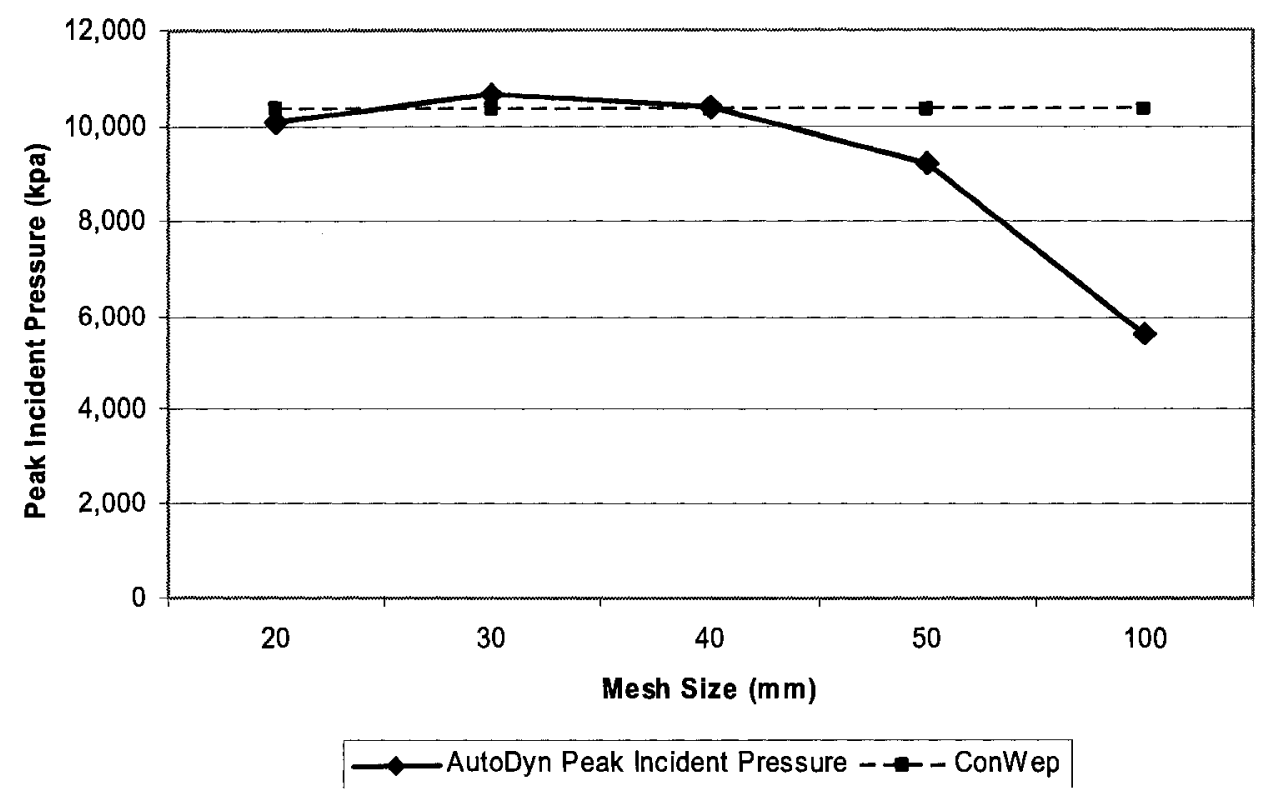

Figure 3.17: 3-D-50 kg Mesh size vs peak incident pressure at 1 meter

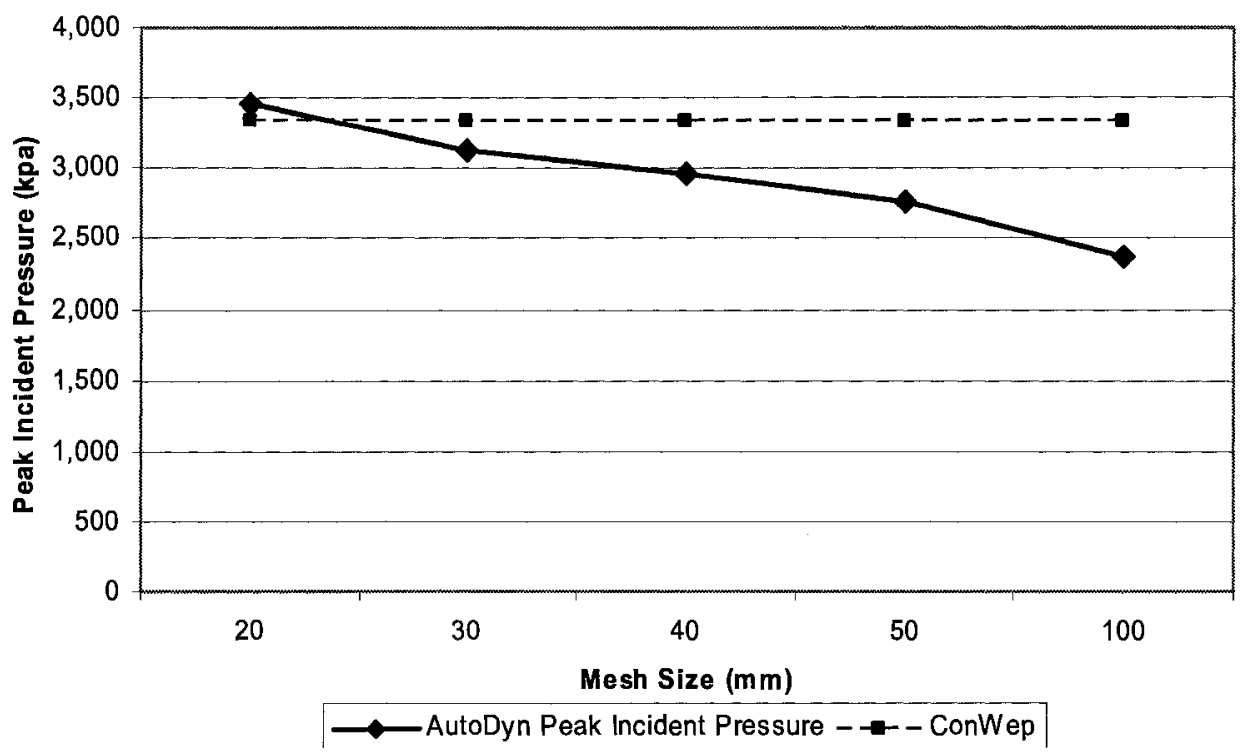

Figure 3.18: 3-D-50 kg Mesh size vs peak incident pressure at 2 meter

Thus, a mesh size of $40 \mathrm{~mm}$ is utilized for the 3-D models when pressure values are calculated away from the structure. When the calculations are performed closer to the structure a finer mesh of $2 \mathrm{~mm}$ is used throughout the analysis. 


\subsection{Blast Waves through Area Restriction}

In order to minimize the effect of the propagating waves the SSPs were designed based on a principle termed "area restriction". This principle is based on specific arrangement of angles which permits certain gaps between the angles to restrain and subsequently attenuate the strength of the wave, hence the term "area restriction". To better understand how the principle of area restriction works, various designs were selected to investigate the path of shock waves before impacting the SSPs and after propagating through them. The first step was to build SSPs with area ratios of 0.1 and 0.2 and analyze them using AUTODYN. The main objective of this step was to verify the results against the plotted values of Figure 2.21. Once the verification was confirmed, the main parameters governing the efficiency of the SSPs were investigated. In the selected scenarios spacing and length of gaps between elements were considered.

The dimensions of the air domain in the area restriction models were $28.175 \mathrm{~mm}$ by 1500 $\mathrm{mm}$ with flow-out boundary conditions on the sides, filled with an explosive charge of $0.25 \mathrm{~kg}$ of Pentolite, a commercial booster. The area restriction was defined at $1 \mathrm{~m}$ from the explosive charge with 3.175 and $6.35 \mathrm{~mm}$ width and corresponding area ratios of 0.1 and 0.2. Pressure values were measured at the entrance and exit of the area restriction as well as every $10 \mathrm{~mm}$ thereafter. These gauges recorded the pressure over the defined range. Table 3.4 shows the pressure values of the incident wave and transmitted wave obtained numerically by AUTODYN. Also, Table 3.4 shows the equivalent transmitted wave from the chart shown in Figure 3.19 using numerical incident values. It is clear from this table that the values obtained from the numerical model correlate well with the 
theoretical values obtained from the chart. This provides confidence in the capabilities of AUTODYN to model and verify the experimental work of this research.

Table 3.4: Theoretical and Numerical Transmitted pressure values

\begin{tabular}{c|ccccc}
\hline & \multicolumn{3}{|c}{ Theoretical } & \multicolumn{2}{c}{ Numerical } \\
$\begin{array}{c}\text { Explosive } \\
\text { Charge }\end{array}$ & $\begin{array}{c}\text { Area } \\
\text { Ratio }\end{array}$ & $\begin{array}{c}\text { Incident } \\
\text { value } \\
\mathrm{kPa}(\mathrm{psi})\end{array}$ & $\begin{array}{c}\text { Transmitted } \\
\text { value } \\
\mathrm{kPa}(\mathrm{psi})\end{array}$ & $\begin{array}{c}\text { Incident } \\
\text { value } \\
\mathrm{kPa}(\mathrm{psi})\end{array}$ & $\begin{array}{c}\text { Transmitted } \\
\text { value } \\
\mathrm{kPa}(\mathrm{psi})\end{array}$ \\
\hline $\begin{array}{c}0.25 \mathrm{~kg} \text { of } \\
\text { Pentolite }\end{array}$ & 0.1 & $390(56.6)$ & $138(20)$ & $390(56.6)$ & $128(18.56)$ \\
\hline $\begin{array}{c}0.25 \mathrm{~kg} \text { of } \\
\text { Pentolite }\end{array}$ & 0.2 & $390(56.6)$ & $227(33)$ & $390(56.6)$ & $196(28.28)$ \\
\hline
\end{tabular}

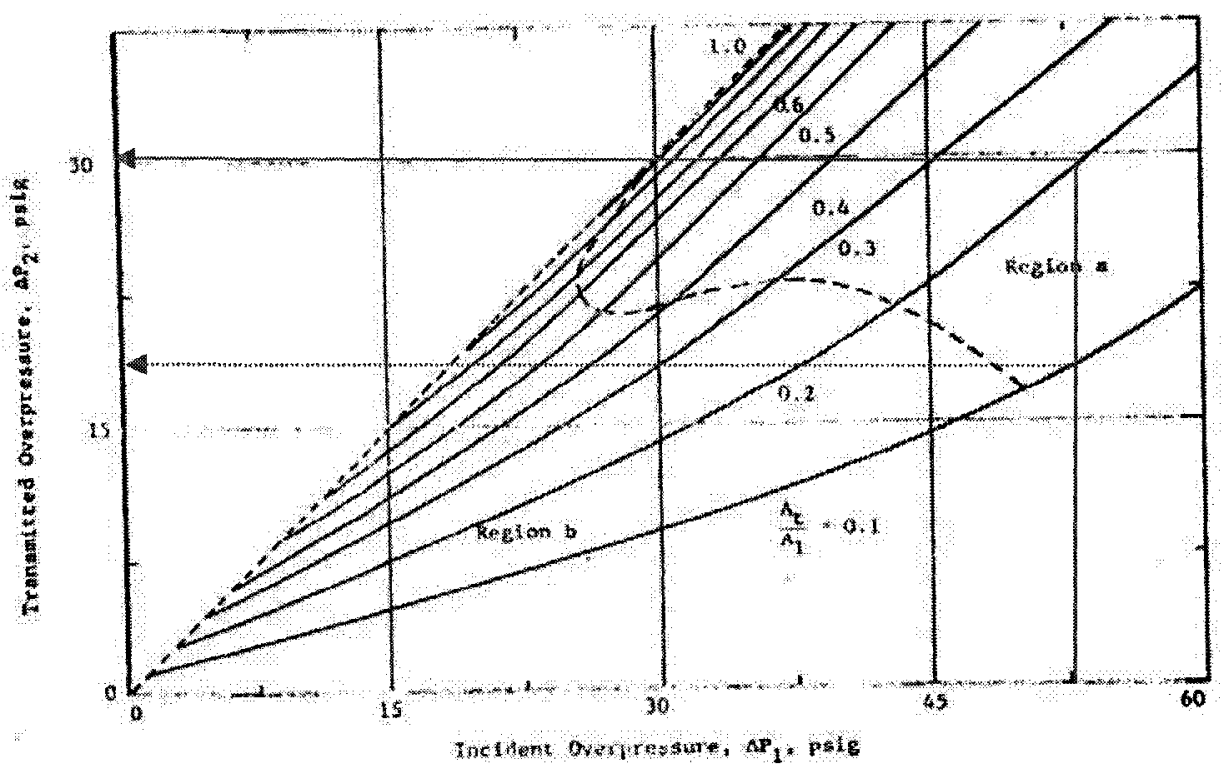

Figure 3.19: Transmitted wave pressure values for supersonic wave

\subsubsection{Area Restrictions Simulations}

The study presented in this section discusses the wave propagation through simplified vented barrier or obstacle that is comprised of solid blocks separated by air gaps. The dimensions of such blocks were $25.4 \mathrm{~mm}$ by $25.4 \mathrm{~mm}$. Ten design scenarios were 
considered and analyzed using AUTODYN to track shock wave through and beyond simple obstacles. Various gap lengths and width were used to study their effect on the shock front and when it will reform again or when it regains its original form. The air domain is modeled using the Euler-FCT (Flux Corrected Transport) formulation that is designed to solve gas dynamic problems and/or fluid flow such as the air blast. Its dimension is $250 \mathrm{~mm}$ by $2000 \mathrm{~mm}$ with flow-out boundary conditions on the sides to allow the release of air and explosive material. These dimensions were chosen to track the reformation of the shock wave beyond the obstacles. The mesh size was chosen to satisfy the minimum requirements, as given in the AUTODYN user manual, of tracking pressure through vents and structures, 2 to 5 cells per centimetre. Therefore, the mesh size was set to $4 \mathrm{~mm}$ square elements as shown in Figure 3.20. The total number of nodes for the air domain was 23,625 . Next, gauges were defined at various planes to track blast pressure behind obstacles as shown in Figure 3.21. The gauges were distributed to cover a grid of $25.4 \mathrm{~mm}$ in the $\mathrm{x}$-direction and $50 \mathrm{~mm}$ in the y-direction. Finally, all models were tested using $0.50 \mathrm{~kg}$ of Pentolite. Table 3.5 summarizes the ten design alternatives representing this parametric study. The vent area ratio, equal to the gap width times number of openings and divided by cross sectional area, was set to $250 \mathrm{~mm}^{2}$.

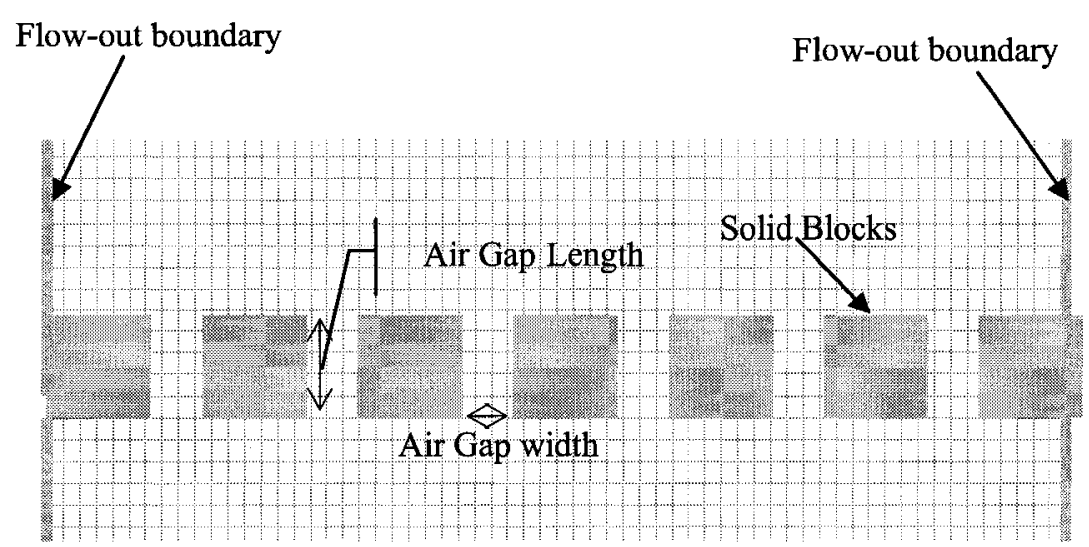

Figure 3.20: Air domain 


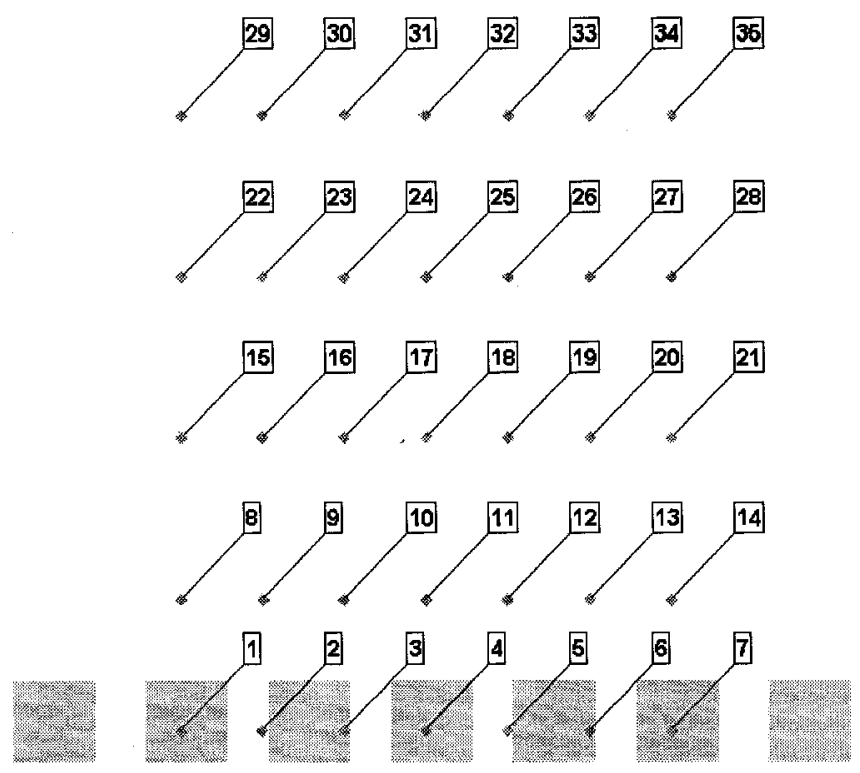

Figure 3.21: Gauges location

Table 3.5: Parametric study parameters

\begin{tabular}{|c|c|c|c|c|}
\hline Scenarios $_{1}$ & $\begin{array}{l}\text { Cross } \\
\text { Section }\end{array}$ & $\begin{array}{c}\text { Gap } \\
\text { length } \\
(\mathrm{mm})\end{array}$ & $\begin{array}{c}\text { Gap } \\
\text { width }_{4} \\
(\mathrm{~mm})\end{array}$ & $\begin{array}{c}\text { Vent Area } \\
\text { Ratios }\end{array}$ \\
\hline $\mathrm{S}_{1}$ & Rectangle & 25.4 & 3.175 & \multirow{2}{*}{0.10} \\
\hline $\mathrm{S}_{2}$ & Rectangle & 50.8 & 3.175 & \\
\hline $\mathrm{S}_{3}$ & Rectangle & 25.4 & 6.35 & \multirow{2}{*}{0.20} \\
\hline $\mathrm{S}_{4}$ & Rectangle & 50.8 & 6.35 & \\
\hline $\mathrm{S}_{5}$ & Rectangle & 25.4 & 12.7 & \multirow{2}{*}{0.31} \\
\hline $\mathrm{S}_{6}$ & Rectangle & 50.8 & 12.7 & \\
\hline $\mathrm{S}_{7}$ & Square & 25.4 & 25.4 & \multirow{2}{*}{0.41} \\
\hline $\mathrm{S}_{8}$ & Rectangle & 50.8 & 25.4 & \\
\hline $\mathrm{S}_{9}$ & Rectangle & 25.4 & 50.8 & \multirow{2}{*}{0.61} \\
\hline$S_{10}$ & Square & 50.8 & 50.8 & \\
\hline
\end{tabular}

1. Scenarios represent the model number for each run

2. Cross-section indicates the shape of the gap

3. Gap length represents the depth of the gap

4. Gap width is the distance at which shock wave travels through

5. Vent area ratio, gap width times number of openings divided by cross sectional area, 250 $\mathrm{mm}^{2}$. (i.e. Scenario 7\&8: $25.4+25.4=50.8,250 / 50.8=4.92 \sim 5$ blocks with 4 spacing, $4 * 25.4=101.6,101.6 / 250=0.406$ ) 


\subsubsection{Area Restrictions: Results and Discussion}

This section discusses the effect of obstacles on shock wave propagation under different shock pressures. Figure 3.22 shows the velocity vectors of the shock wave propagating through the obstacles at a sequence of time intervals for scenario $S_{7}$. Pressure values are measured at different planes in order to track when the transmitted wave is reformed again. It can be seen that after $0.6 \mathrm{~ms}$ the shock wave strikes the obstacles, and hence it starts diverging. Wave vectors are divided into two components. One component passes through the available gaps, while the second is reflected from the solid portions of the obstacles. It is observed that the first component gains more speed, forming jets, as the gap area between the obstacles becomes smaller. Figure 3.22 shows the complexity of various shock interactions through and after obstacles. 


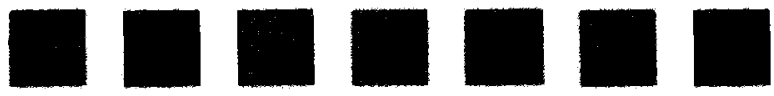

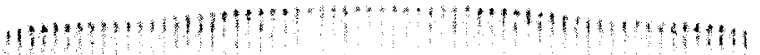

$$
\mathrm{T}=0.55 \mathrm{~ms}
$$
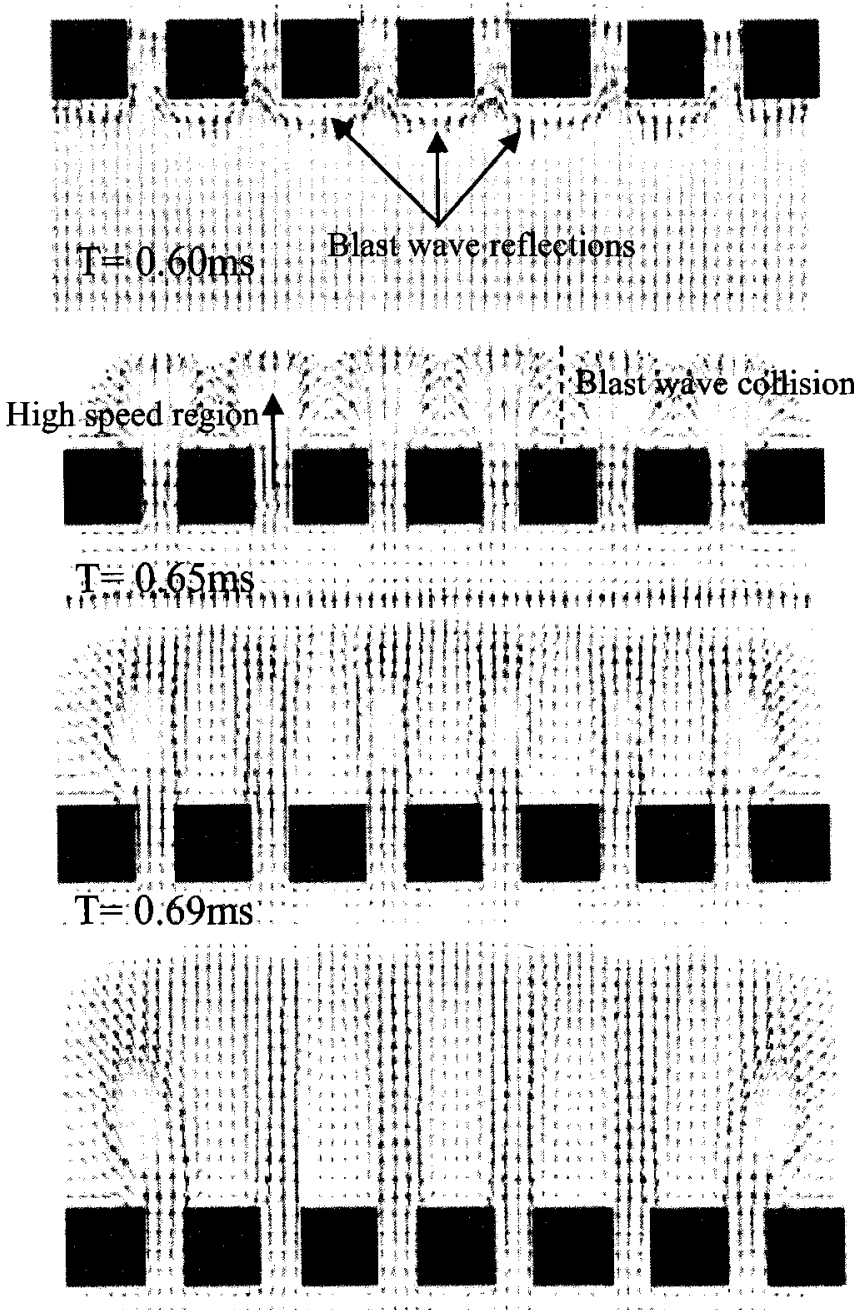

$$
\text { W=0.75ms }
$$

Figure 3.22: Velocity vectors of shock wave propagating through obstacles 
Figures 3.23(a) to (c) show the pressure values at different gauge locations at specific times for the same gap length, $25.4 \mathrm{~mm}$, but different gap width, $3.175,6.35,12.7,25.4$, and $50.8 \mathrm{~mm}$, respectively for scenarios $S_{1}$ to $S_{9}$. These pressure values are measured behind the obstacles at different locations, 1100,1300 and $1500 \mathrm{~mm}$ from the center of the explosion (Figure 3.21). It is noted that as the gap width increases (larger vent area) the pressure values behind the structure increase. When the gap becomes smaller (lower vent area) more of the incident wave is reflected and less is transmitted. Generally speaking the results showed similar behavior of the pressure calculated at the specified locations. However, some differences were observed in the pressure values calculated for scenario $\mathrm{S}_{9}$ at $1100 \mathrm{~mm}$ gauge location. This particular configuration of gap length, 25.4 $\mathrm{mm}$ and gap width, $50.8 \mathrm{~mm}$, results in blast wave wrapping around each of the obstacles and colliding at their back face to generate higher pressure regions as recorded by the gauges at those locations (Figure 3.22).

Note that the pressure values for scenario $S_{1}$ at $1500 \mathrm{~mm}$ are constant at $50 \mathrm{kPa}$ due to the fact that the shock front has reformed by this distance. Other scenarios required larger distances beyond the structure for the wave to reform. 


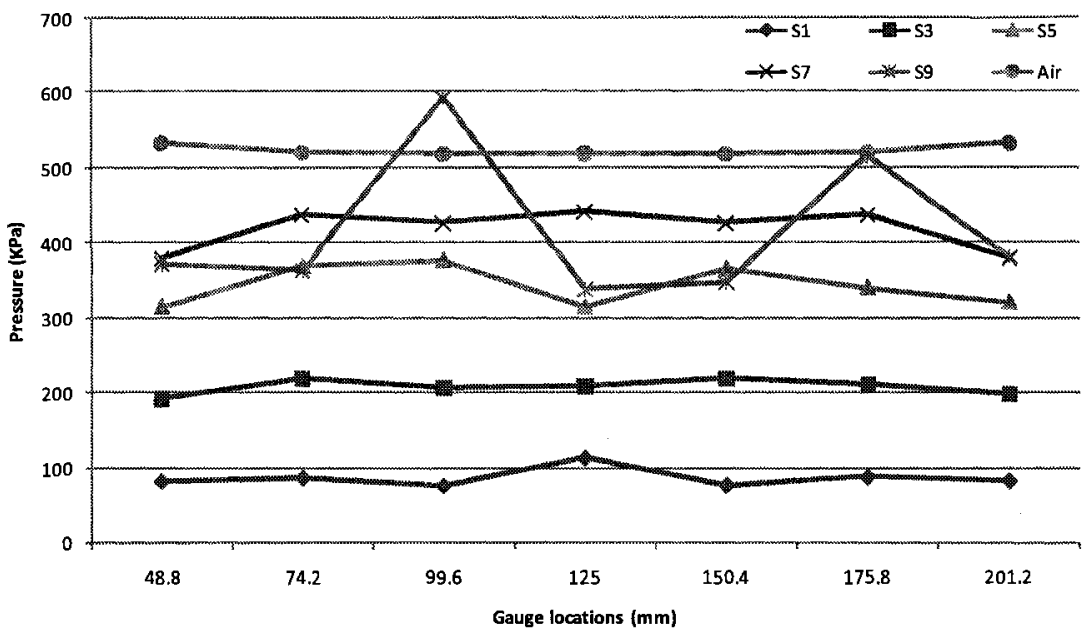

(a) Location $=1100 \mathrm{~mm}$

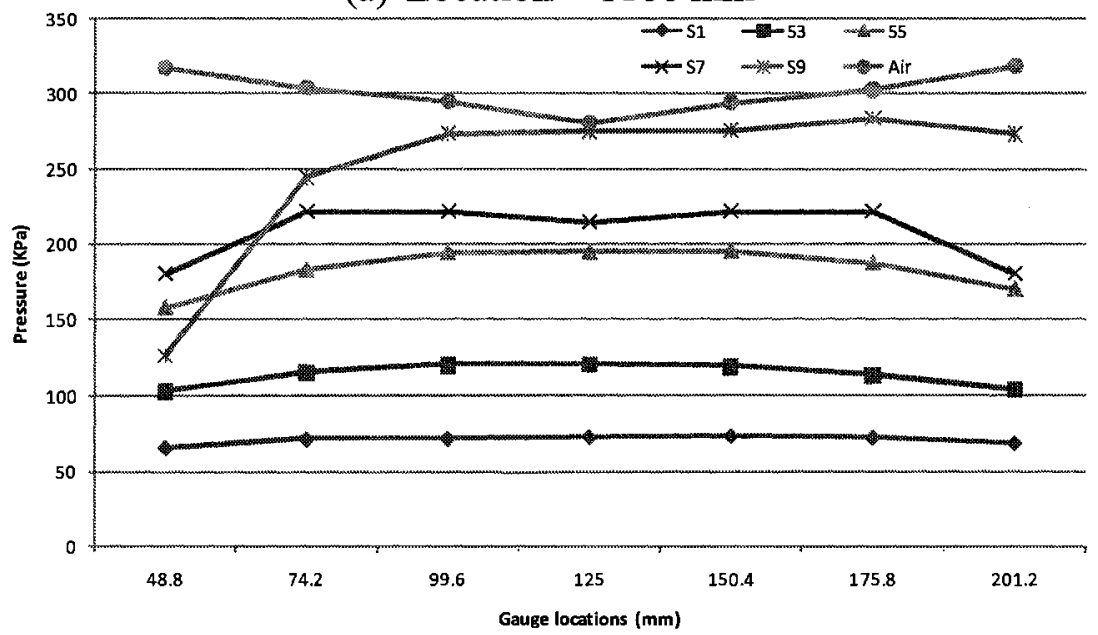

(b) Location $=1300 \mathrm{~mm}$

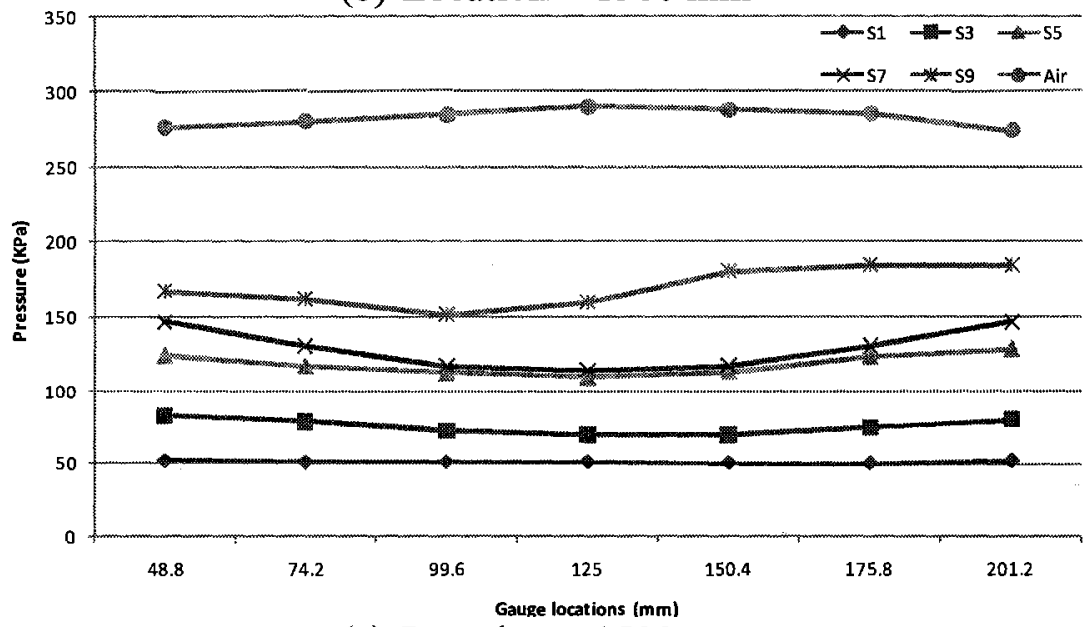

(c) Location $=1500 \mathrm{~mm}$

Figure 3.23: Pressure vs gauge locations at different planes, $S_{1}$ to $S_{9}$ 
Figures 3.24(a) to (c) show the pressure values at different gauge locations at specific time for the same gap length, $50.8 \mathrm{~mm}$, but different gap width, $3.175,6.35,12.7,25.4$, and $50.8 \mathrm{~mm}$, respectively, for scenarios $S_{2}$ to $S_{10}$. The same gauge locations used in the odd-numbered scenarios were used with these even-numbered scenarios Again at the $1100 \mathrm{~mm}$ location it is noted that the gap width and length where such that blast wave collisions occurred at the rear face of the obstacles of scenarios $S_{8}$ and $S_{10}$ to generate high pressure regions.

Gauges further away from structure recorded smoother profiles as the shock front reformed. Generally speaking at far field, example at a distance of $1500 \mathrm{~mm}$, where the shock fronts emanating from the gaps have coalesced into a uniform shock front, the smaller gap widths resulted in greater blast pressure attenuations (Figures 3.23 (c) and 3.24 (c)). Two gap lengths, one double the other, were used in these scenarios but both resulted in approximate same attenuation.

Note that the same observation regarding shock wave reforming for scenario $S_{1}$ at 1500 $\mathrm{mm}$ was obtained for scenario $\mathrm{S}_{2}$ again with constant value of $50 \mathrm{kPa}$. 


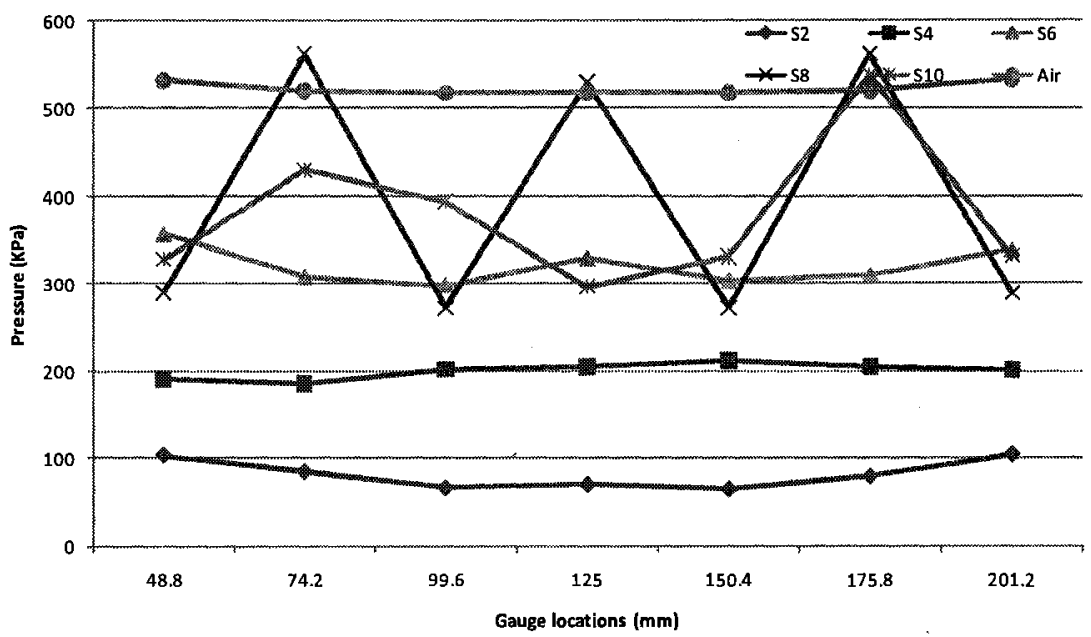

(a) Location $=1100 \mathrm{~mm}$

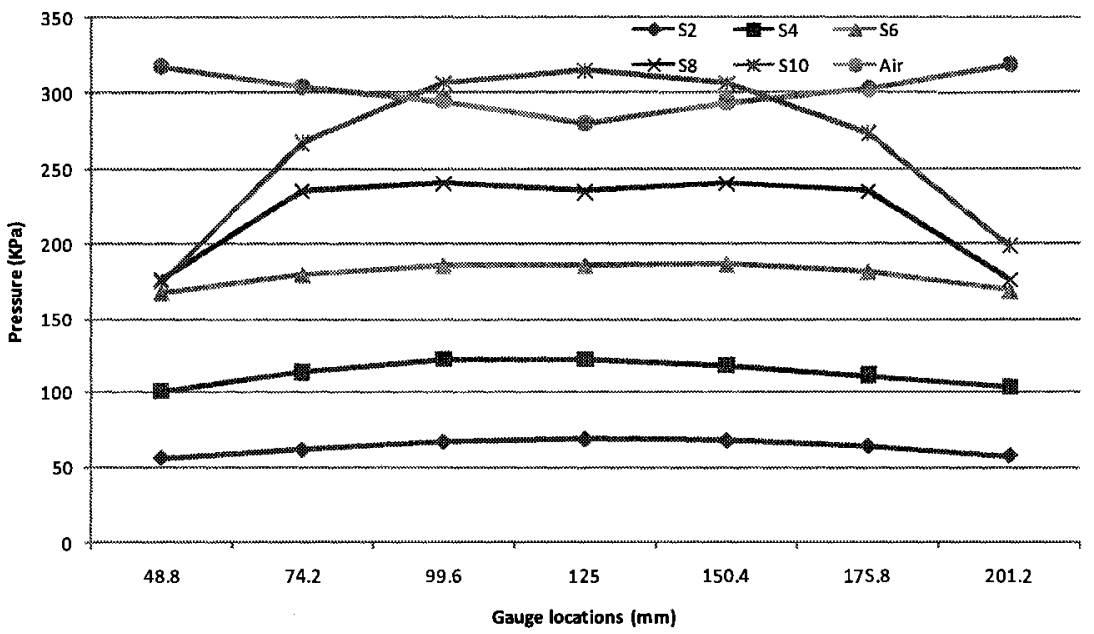

(b) Location $=1300 \mathrm{~mm}$

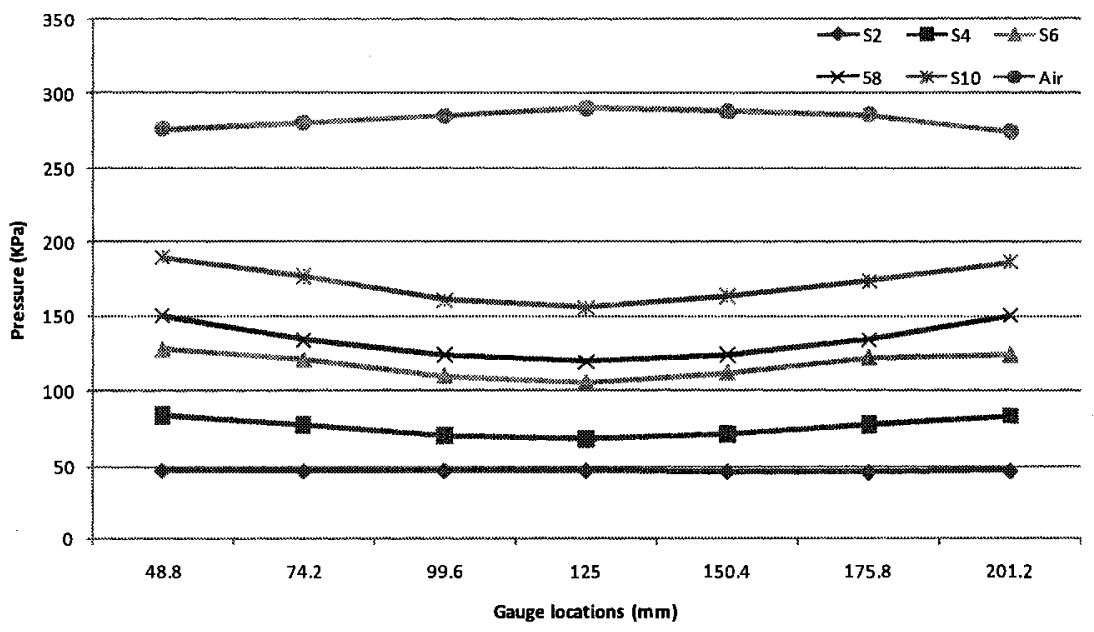

(c) Location $=1500 \mathrm{~mm}$

Figure 3.24: Pressure vs gauge locations at different planes, $S_{2}$ to $S_{10}$ 
Figure 3.25 shows average pressure values versus time for scenarios, $S_{1}$ to $S_{9}$ and air, with same gap length, $25.4 \mathrm{~mm}$, but different width, $3.175,6.35,12.7,25.4$, and 50.8 $\mathrm{mm}$, at only one location, $1500 \mathrm{~mm}$. It is seen that as the gap size decreases, more time is needed for the wave to travel to a specific location.

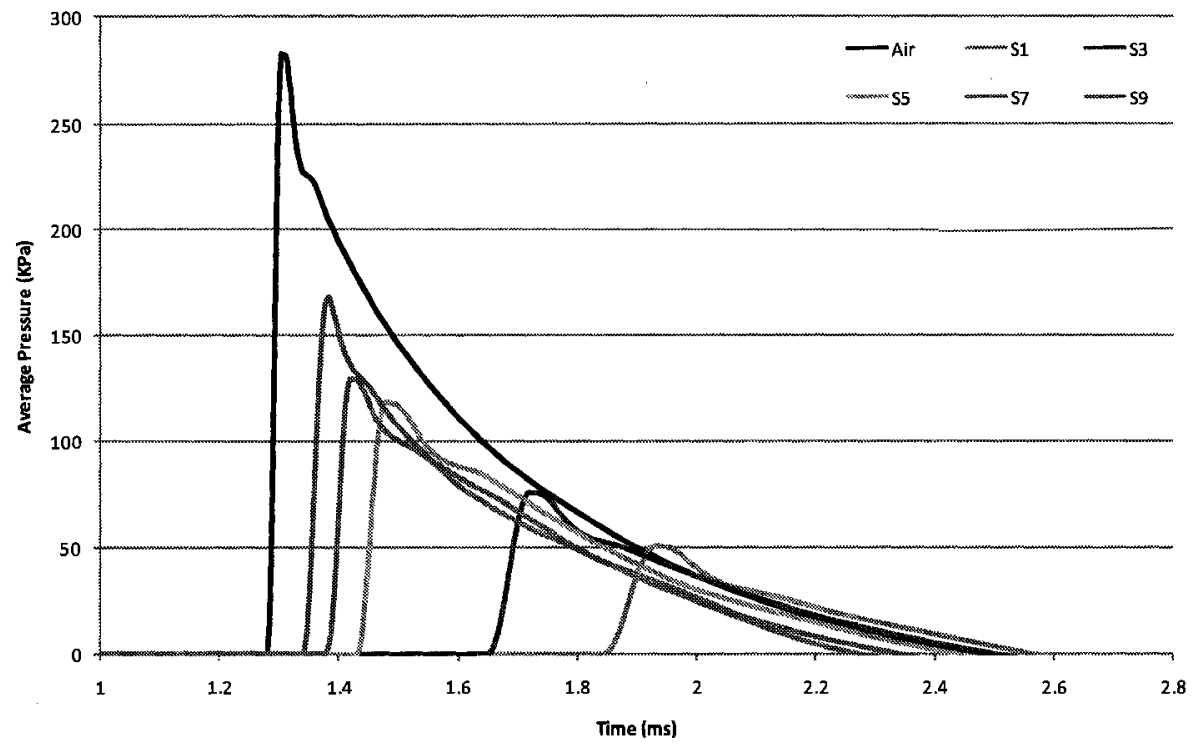

Figure 3.25: Pressure vs time at $1500 \mathrm{~mm}$ from obstacle

Figure 3.26 summarizes the average pressure values as function of gap size at $1500 \mathrm{~mm}$ location for the different scenarios. It can be seen that gaps up to $15 \mathrm{~mm}$ give the greatest attenuation. With gaps greater than $15 \mathrm{~mm}$, the change in attenuation is not significant. This graph agrees with the results obtained earlier at which gap size or vent area ratio is direct proportional with pressure release. Thus, this graph gives guidance to the design of SSPs with respect to gap size, vent area ratio. 


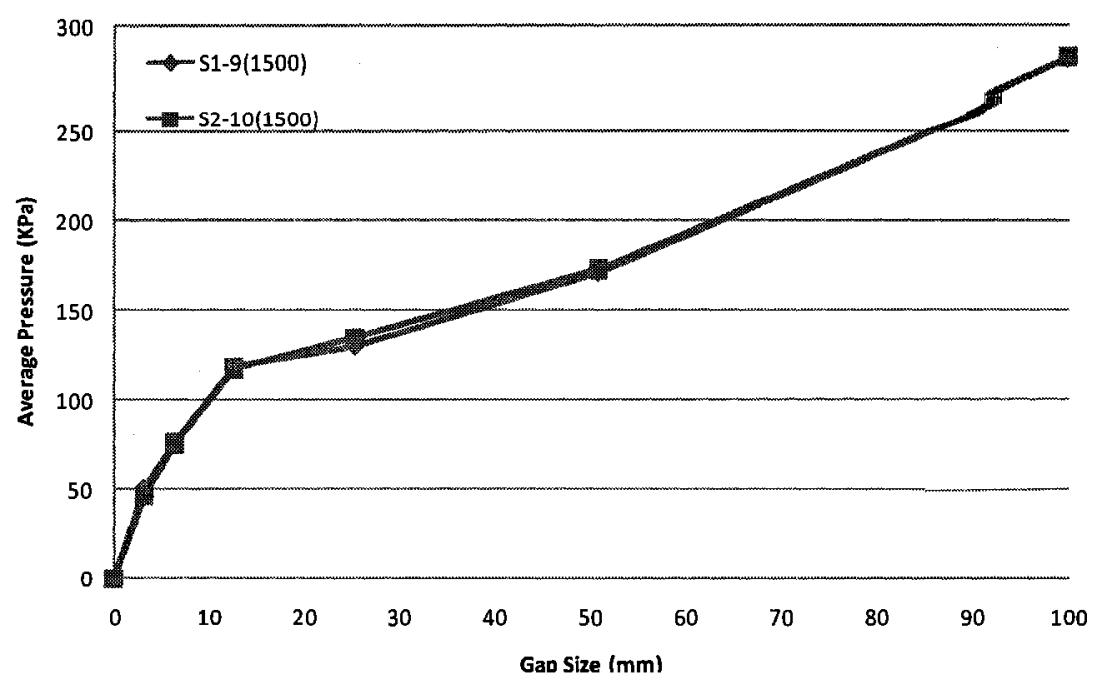

Figure 3.26: Average pressure vs gap size at $1500 \mathrm{~mm}$

Finally, it can be concluded from this study that the vent area ratio, gap length and geometry have significant effect on the shock wave propagation. As the geometry gets more complex, the wave interaction complexity amplified through and beyond the obstacles resulting in higher blast pressure attenuation.

\subsection{AUTODYN Verification using Category I Suppressive Shield Experimental Data}

A previous work carried out by R. N. Schumacher and C. N. Kingery (R. N. Schumacher et.al.) for the USA Ballistic Research Laboratory (BRL) will be modelled in AUTODYN to build confidence in the program by comparing its predicted pressure values to those from the experimental tests. The experimental work was conducted on a quarter scale Category I Suppressive Shield (SS), circular in shape and consisting of interlocked Ibeams with reinforced concrete floor and roof. Gauges were used to track pressure inside and outside the SS. The main objective from this experimental work was to test the suppressive shield ability to attenuate pressure. The following sections will present the 
model construction and a comparison between the experimental work and AUTODYN predictions.

\subsubsection{Model construction}

The quarter scale Category I SS was 10 feet $(3 \mathrm{~m})$ in height and 13 feet 4 inches $(4 \mathrm{~m})$ in diameter. The total number of S 3x5.7 I-beams used to build the container was 296 . Figure 3.27 shows the dimension of the I-beam used to build the suppressive container model. The I-beams nested in two layers as shown in Figure 3.28. The internal radius of the inner layer was 5 feet $7-1 / 2$ inch $(1.715 \mathrm{~m})$ and the internal radius of the outer layer was 5 feet $8-1 / 8(1.731 \mathrm{~m})$. These I-beams were welded to steel ring beams that was screwed to the $457 \mathrm{~mm}$ thick and $4 \mathrm{~m}$ diameter concrete slabs. Moreover, there were three steel ring beams installed around the container $0.762,1.524$, and $2.286 \mathrm{~m}$ from the floor. Five gauges were located at ground level to track peak incident pressure, at 3.66, $5.48,7.92,10.88$, and $14.63 \mathrm{~m}$ from the container wall. Three internal gauges captured the pressure within the container.

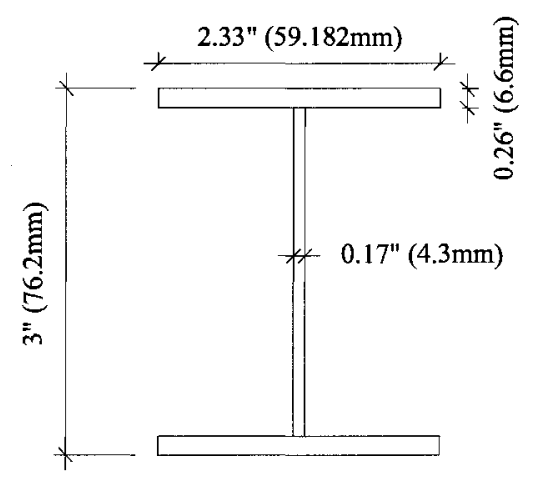

Figure 3.27: S 3x5.7 I-beam used in body of Category I Suppressive Shield 


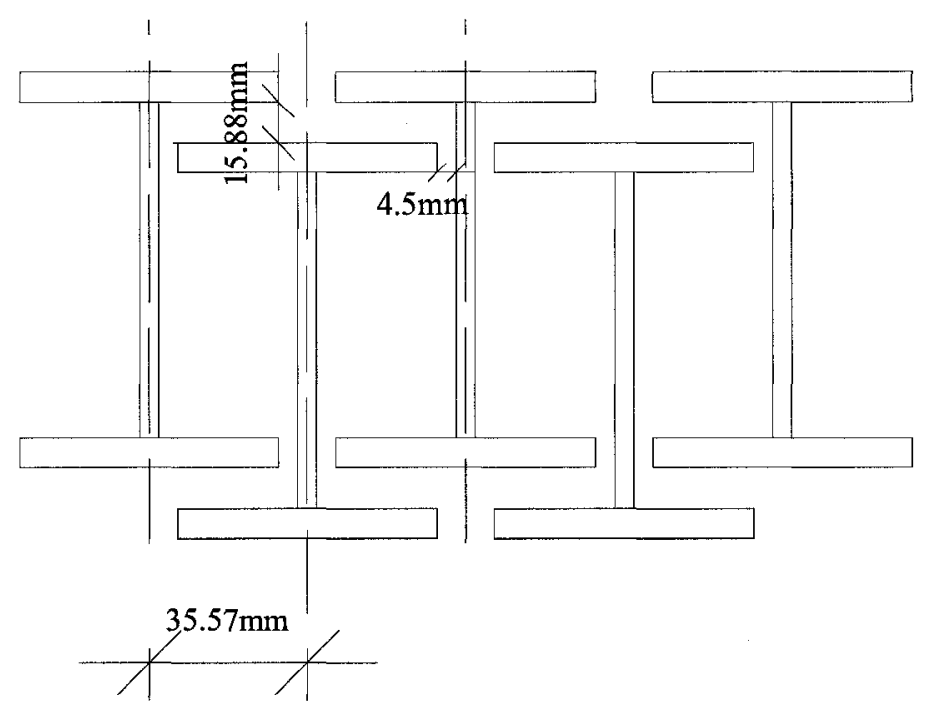

Figure 3.28: I-beams configuration

\subsubsection{Air Domain}

Since it would be too time consuming to model the air domain for all outside gauges, only the closest three gauges were modelled and hence the air sub grid size was chosen to be 8 meters from the center of explosion. As concluded in section 3.3.3, a $40 \mathrm{~mm}$ mesh size was used for the free air explosion. Having an air-structure interaction, the mesh size around the container body has to be refined to satisfy the minimum requirements for tracking pressure through vents. Therefore, the air domain was divided into two parts. The first part was of dimension $2 \mathrm{~m}$ long, $2 \mathrm{~m}$ wide and $2 \mathrm{~m}$ high. The number of $40 \mathrm{~mm}$ mesh size resulted in 50 cells meshed within the local coordinates I, J and K. Since the first part includes the structure, more cell refinement is needed around the structure. The cells were refined ahead, through and beyond the structure as shown in Figure 3.29.

Since the second air domain part was designed to track pressure in air with no structure interaction, there is no need to refine the grid. The front cells of second part must be the same cells size at the end of first part to be able to join both parts together. By joining 
both parts together, the flow will transfer between them as if they are one. The two parts were joined together with pinned joints. The pinned joins are joins that allow movement with no rotation, this type of join was used to assure the 2 air domains are moving together and hence continuity is guaranteed. Figure 3.30 and 3.31 show the joints between the two parts and the layout of the two parts.

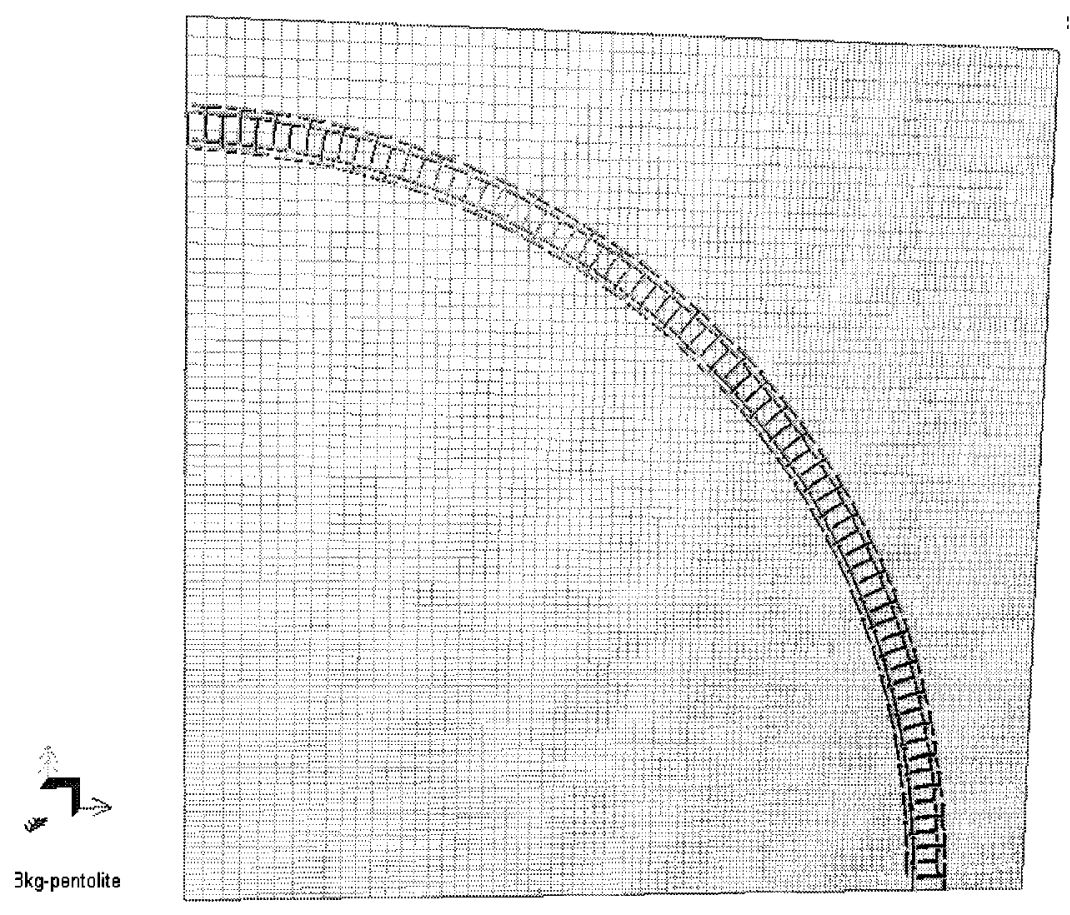

Figure 3.29: Air mesh refinement 


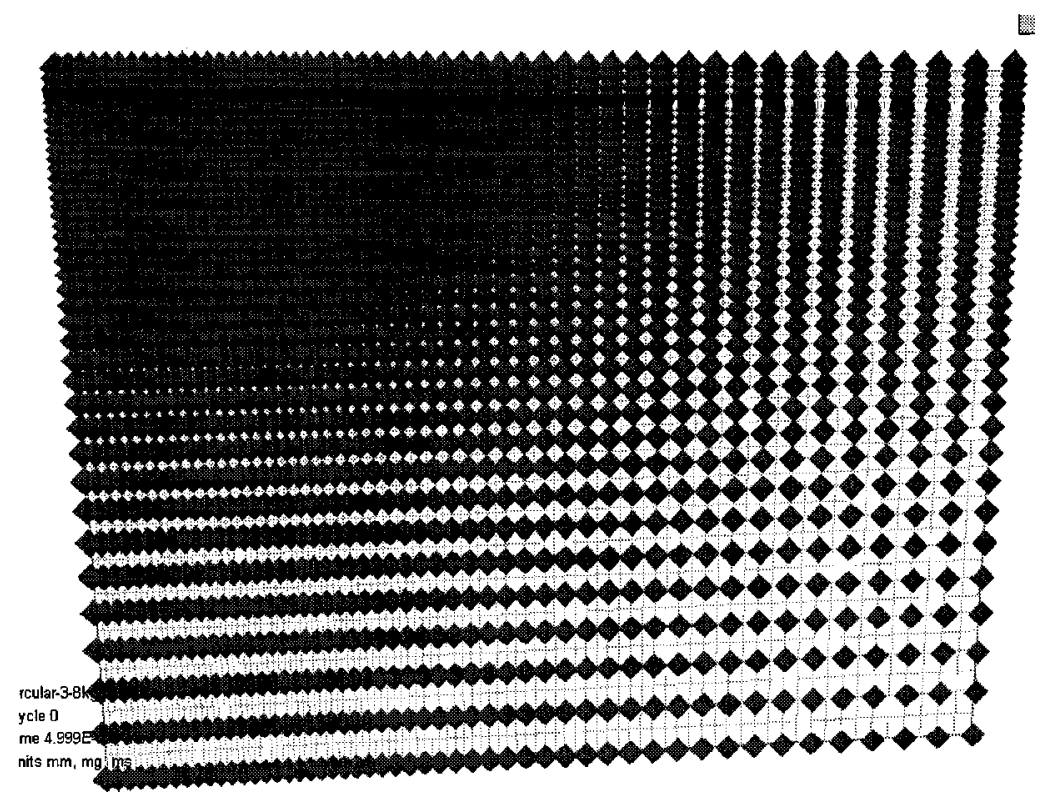

Figure 3.30: Pinned joins for air domains

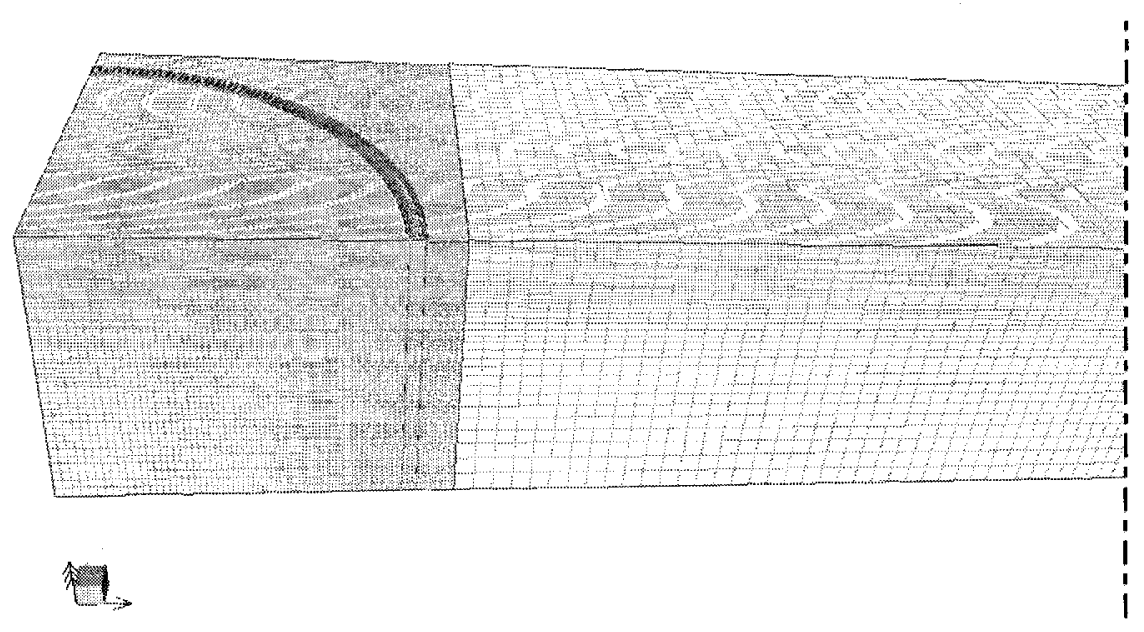

Figure 3.31: The 2 air sub grids layout

\subsubsection{Body structure}

To reduce the run time, the model was built using quarter-symmetry. Thus, seventy four I-beams divided into 2 layers ( 37 per layer) were used to build up the model within AUTODYN. I-beams were built using shell elements as three plates that were joined together. The coordinates and deflection angle of each I-beam for each layer were calculated in order to place them in the right position. Then, fixed boundary condition was applied to the top cells of the I-beams to simulate the fix condition of the I-beams to 
the concrete slab. Moreover, the three ring beams were modelled using square beam elements $127 \mathrm{~mm}$ wide and $6.35 \mathrm{~mm}$ thick. Subsequently, the I-beams were joined to the ring beams to represent the weld between ring beams and I-beams in the experimental test. After building the I-beams, rigid layers were used to represent the reinforced concrete floor and roof. Since the concrete slab was excessively thick, $0.5 \mathrm{~m}$, a rigid layer is acceptable to represent the slabs thereby reducing the run time and still getting same response. The next step was to insert the gauges at the same locations as in the experimental test.

\subsubsection{Gauges}

Only the first three outside gauges, aligned along the ground were used to track the pressure outside the container. Thus, a reflected surface was used as boundary condition as shown in Figure 3.32. On the other hand, all internal gauges (See gauges \# 7, 8 and 10 in Figure 3.33) were used. Gauge \# 4 in the numerical model is equivalent to gauge \# 7 in the experimental test, $203.2 \mathrm{~mm}$ from floor. Gauge \# 5 in the numerical model is equivalent to gauge \# 8 in the experimental test, $1372 \mathrm{~mm}$ from the floor on the interior wall surface. Finally, gauge \# 9 in the numerical model is equivalent to gauge \# 10 in the experimental test, $73 \mathrm{~mm}$ from the center near the roof.

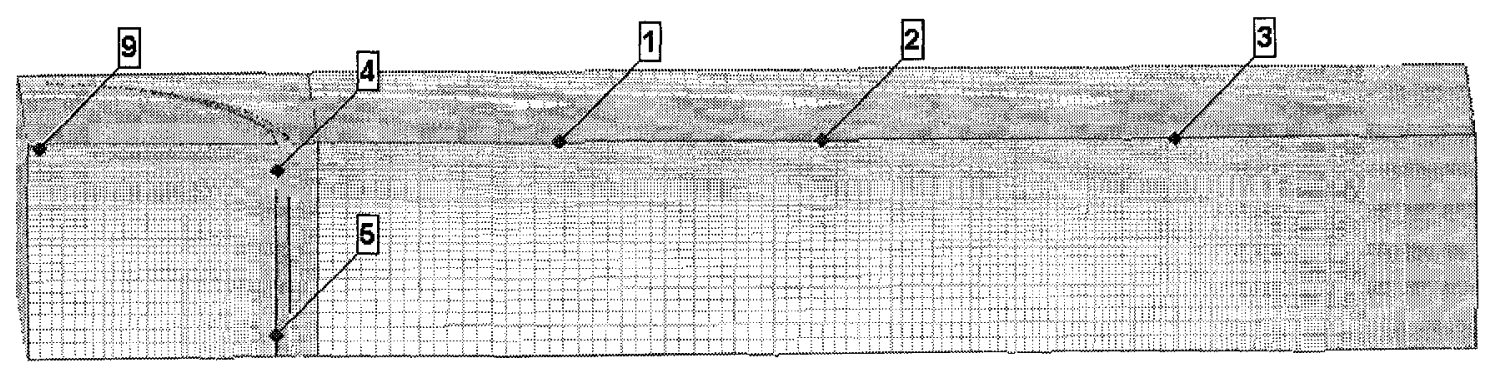

Figure 3.32: Gauges as located in AUOTDYN model 


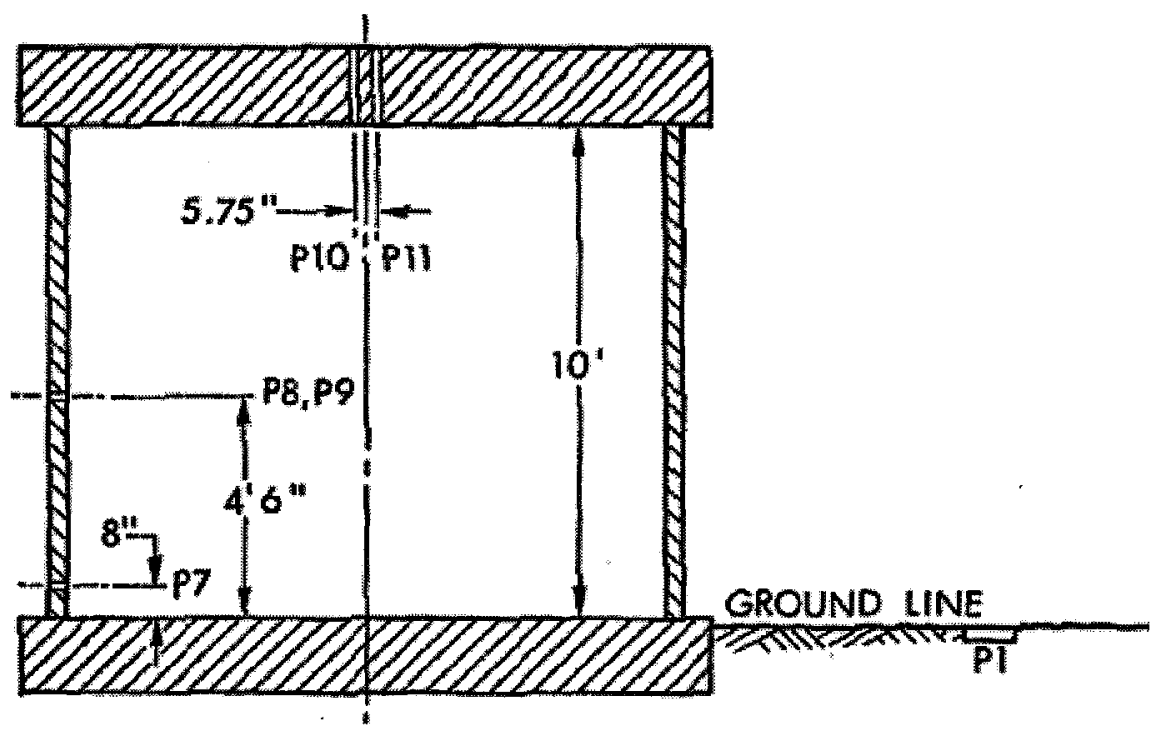

Figure 3.33: Location of gauges as in the experimental test (Schumacher et al)

\subsubsection{Explosive Charge}

The experimental test was carried out by detonating a spherical charge of $8.3 \mathrm{lb}(3.8 \mathrm{~kg})$ of Pentolite in the geometric center of the structure. Equation 3.7 was used to calculate the radius of the sphere.

$$
r=\sqrt[3]{\frac{3 \times W \times 1000}{1.7 \times 4 \times \pi}}=8.1 \mathrm{~cm} \cong 81.1 \mathrm{~mm}
$$

Where,

$r$ : radius of spherical charge, $\mathrm{cm}$

$W$ : mass of charge, $\mathrm{kg}$

\subsubsection{Category I Suppressive Shield: Results and Discussion}

The following sections present the results obtained from the experimental tests and AUTODYN as well as comparison between computer simulation and experimental test. 


\subsubsection{Peak Incident Pressure: (Outside of structure)}

\section{Experimental Test}

One of the most important parameters to be measured and compared to the experimental test is the pressure outside the structure. Tables 3.6 and 3.7 show pressures for free air and after installing the structure respectively.

Table 3.6: Experimental test peak pressure for $3.8 \mathrm{~kg}$ Pentolite in air

\begin{tabular}{ccccc}
\hline \multicolumn{5}{c}{ Exp. Test air-8.3lb Pentolite } \\
m & ft & ${\text { ft } / 1 b^{1 / 3}}^{1 / 3}$ & psi & kPa \\
\hline $\mathbf{3 . 6 6}$ & 12 & 5.93 & 49.54 & $\mathbf{3 4 1 . 5 4}$ \\
$\mathbf{5 . 4 9}$ & 18 & 8.89 & 29.75 & $\mathbf{2 0 5 . 1 1}$ \\
$\mathbf{7 . 9 3}$ & 26 & 12.84 & 21.73 & $\mathbf{1 4 9 . 8 2}$ \\
$\mathbf{1 0 . 8 8}$ & 35.7 & 17.63 & 18.35 & $\mathbf{1 2 6 . 5 0}$ \\
$\mathbf{1 4 . 6 3}$ & 48 & 23.71 & 16.68 & $\mathbf{1 1 4 . 9 8}$ \\
$\mathbf{1 8 . 5 9}$ & 61 & 30.13 & 15.90 & $\mathbf{1 0 9 . 6 5}$ \\
\hline
\end{tabular}

Table 3.7: Experimental test peak pressure for $3.8 \mathrm{~kg}$ Pentolite behind structure

\begin{tabular}{ccccc}
\hline \multicolumn{5}{c}{ Exp. Test 191-8.3lb Pentolite } \\
m & $\mathrm{ft}$ & $\mathrm{ft} / \mathrm{lb}^{1 / 3}$ & $\mathrm{psi}$ & $\mathbf{k P a}$ \\
\hline $\mathbf{3 . 6 6}$ & 12 & 5.93 & 23.97 & $\mathbf{1 6 5 . 2 4}$ \\
$\mathbf{5 . 4 9}$ & 18 & 8.89 & 19.90 & $\mathbf{1 3 7 . 2 0}$ \\
$\mathbf{7 . 9 2}$ & 26 & 12.84 & 17.78 & $\mathbf{1 2 2 . 5 8}$ \\
$\mathbf{1 0 . 8 8}$ & 35.7 & 17.63 & 16.66 & $\mathbf{1 1 4 . 8 6}$ \\
$\mathbf{1 4 . 6 3}$ & 48 & 23.71 & 15.99 & $\mathbf{1 1 0 . 2 1}$ \\
$\mathbf{1 8 . 5 9}$ & 61 & 30.12 & 15.61 & $\mathbf{1 0 7 . 6 5}$ \\
\hline
\end{tabular}




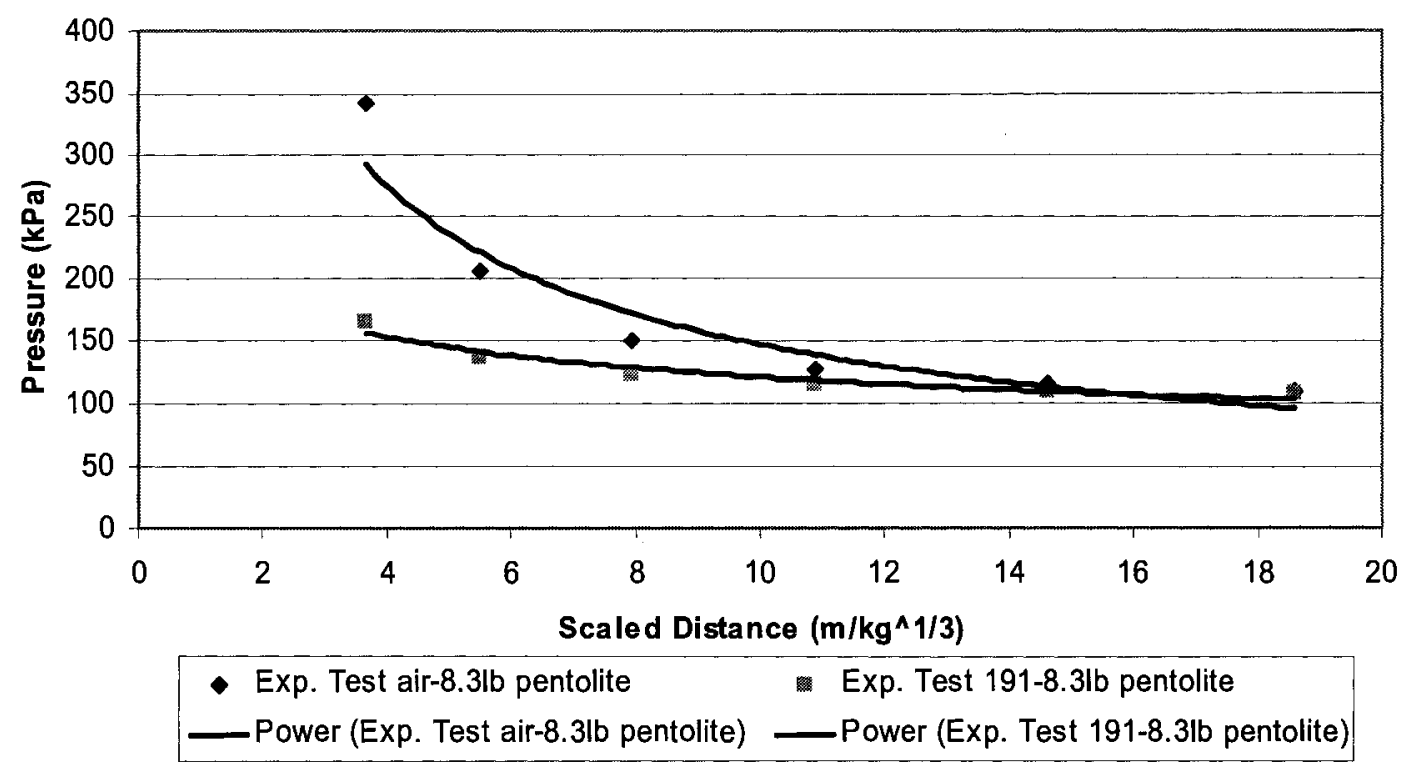

Figure 3.34: Experimental test peak pressure in air and behind structure

It is clear from Figure 3.34 that the pressure decays with the scaled distance when a power trend line was used. Table 3.8 shows the pressure reduction percentage that will be compared later to values obtained from the AUTODYN simulation. It can be seen from this table that the maximum reduction in pressure is $52 \%$ at $2.34\left(\mathrm{~m} / \mathrm{kg}^{1 / 3}\right)$ and the lowest value was $2 \%$ at $11.9\left(\mathrm{~m} / \mathrm{kg}^{1 / 3}\right)$.

Table 3.8: Experimental test reduction in peak incident pressure

\begin{tabular}{cc}
\hline $\begin{array}{c}\text { Scaled Distance } \\
\mathrm{m} / \mathrm{kg}^{1 / 3}\end{array}$ & $\begin{array}{c}\text { Pressure reduction percentage } \\
\%\end{array}$ \\
\hline 2.34 & 52 \\
3.52 & 33 \\
5.08 & 18 \\
6.97 & 9 \\
9.38 & 4 \\
11.91 & 2 \\
\hline
\end{tabular}

\section{AUTODYN}

After building the model in AUTODYN, it was executed for about 5 days to get the simulation results. Tables 3.9 and 3.10 show the peak pressure in air and outside the 
structure, respectively, as predicted by the model for the first three external gauges in the experimental test.

Table 3.9: AUTODYN peak pressure for $3.8 \mathrm{~kg}$ Pentolite in air

\begin{tabular}{ccc}
\hline \multicolumn{3}{c}{ AUTODYN air-3.8 kg Pentolite } \\
$\mathrm{m}$ & $\mathrm{m} / \mathrm{kg}^{1 / 3}$ & $\mathrm{kPa}$ \\
\hline 3.66 & 2.34 & 243.04 \\
5.48 & 3.52 & 189.07 \\
7.92 & 5.08 & 150.56 \\
\hline
\end{tabular}

Table 3.10: AUTODYN peak pressure for $3.8 \mathrm{~kg}$ Pentolite behind structure

\begin{tabular}{|c|c|c|}
\hline \multicolumn{3}{|c|}{ AUTODYN-Structure-3.8 Kg Pentolite } \\
\hline $\mathrm{m}$ & $\mathrm{m} / \mathrm{kg}^{1 / 3}$ & $\mathrm{kPa}$ \\
\hline 3.66 & 2.34 & 119.33 \\
\hline 5.48 & 3.52 & 116.43 \\
\hline 7.92 & 5.08 & 113.85 \\
\hline
\end{tabular}

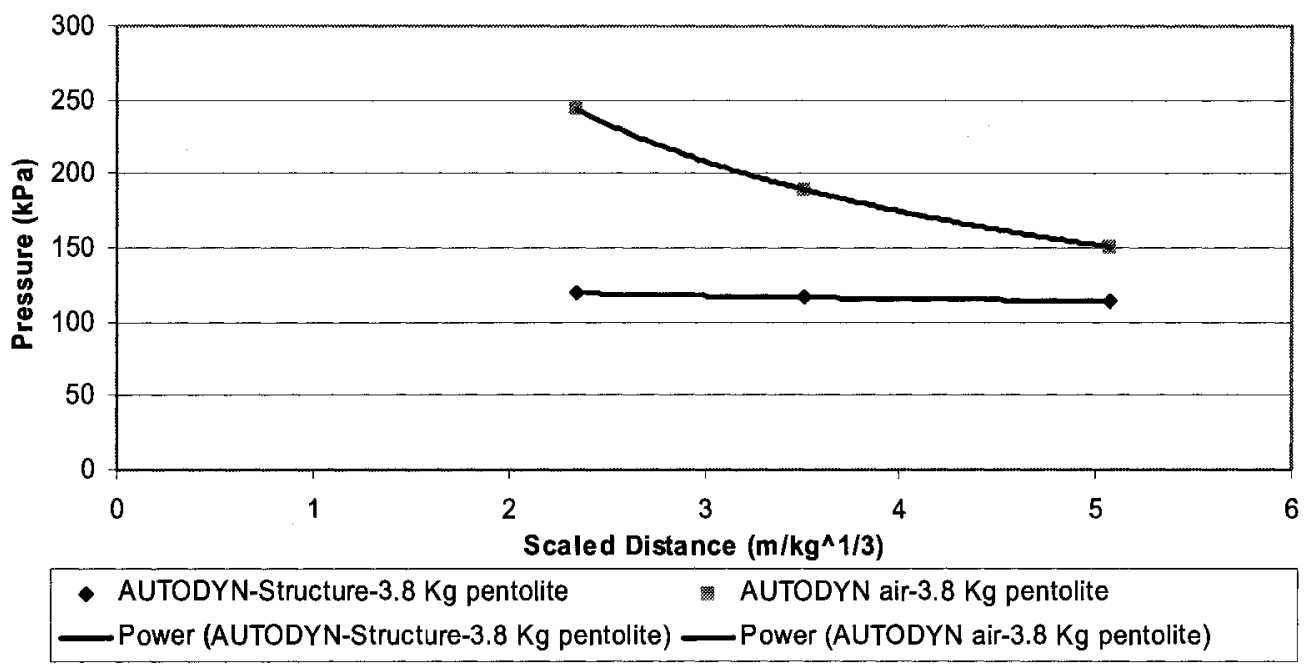

Figure 3.35: AUTODYN peak pressure in air and behind structure

It is clear from Figure 3.35 that the pressure decay behaves the same as in the experimental test when a power trend line was used. The pressure values resulting from the air and structure tend toward merging if more points were studied, which is similar to the experimental tests. Hence by knowing the pressure values in air and behind the 
structure, the reduction percentage in pressure can be calculated. Table 3.11 shows the pressure reduction percentage. It can be seen from this table that the maximum reduction in pressure was $51 \%$ at $2.34\left(\mathrm{~m} / \mathrm{kg}^{1 / 3}\right)$.

Table 3.11: Experimental test reduction in peak incident pressure

\begin{tabular}{cc}
\hline $\begin{array}{c}\text { Scaled Distance } \\
\left(\mathrm{m} / \mathrm{kg}^{1 / 3}\right)\end{array}$ & $\begin{array}{c}\text { Pressure Reduction } \\
(\%)\end{array}$ \\
\hline 2.34 & 51 \\
3.52 & 38 \\
5.08 & 24 \\
\hline
\end{tabular}

Experimental test results vs AUTODYN predictions

Note that all the values measured in the experimental tests were gauge pressures (atmospheric pressure is equal to zero). However, AUTODYN default value for atmospheric pressure is $101.3 \mathrm{kPa}$. Thus, for comparison, all values must have a common datum which is the absolute zero. Therefore, the constant value of atmospheric pressure (101.3 kPa) will need to be added to all experimental test values. These values along with those obtained from ConWep, and the AUTODYN results are presented in Table 3.12 and Figure 3.36. It can be seen from the figure that the ConWep and AUTODYN values are close to each others. At the same time the experimental test values are far from those of ConWep and AUTODYN at the closer gauges and tend to reach the ConWep values at the further gauges. Figure 3.37 shows that the maximum reduction in pressure is $51 \%$ at $2.34\left(\mathrm{~m} / \mathrm{kg}^{1 / 3}\right)$ compared to $52 \%$ from the experimental test and the minimum value is $24 \%$ compared to $18 \%$ from the experimental test at $11.9 \mathrm{~m} / \mathrm{kg}^{1 / 3}$. 
Table 3.12: Air peak incident pressure comparison

\begin{tabular}{cccc}
\hline $\begin{array}{c}\text { Scaled Distance } \\
\left(\mathrm{m} / \mathrm{kg}^{1 / 3}\right)\end{array}$ & \multicolumn{3}{c}{$\begin{array}{c}\text { Peak Incident Pressure } \\
(\mathrm{kPa})\end{array}$} \\
\hline & ConWep & AUTODYN & Exp. Test \\
2.34 & 252 & 243 & 342 \\
3.52 & 179 & 189 & 205 \\
5.08 & 131 & 151 & 150 \\
\hline
\end{tabular}

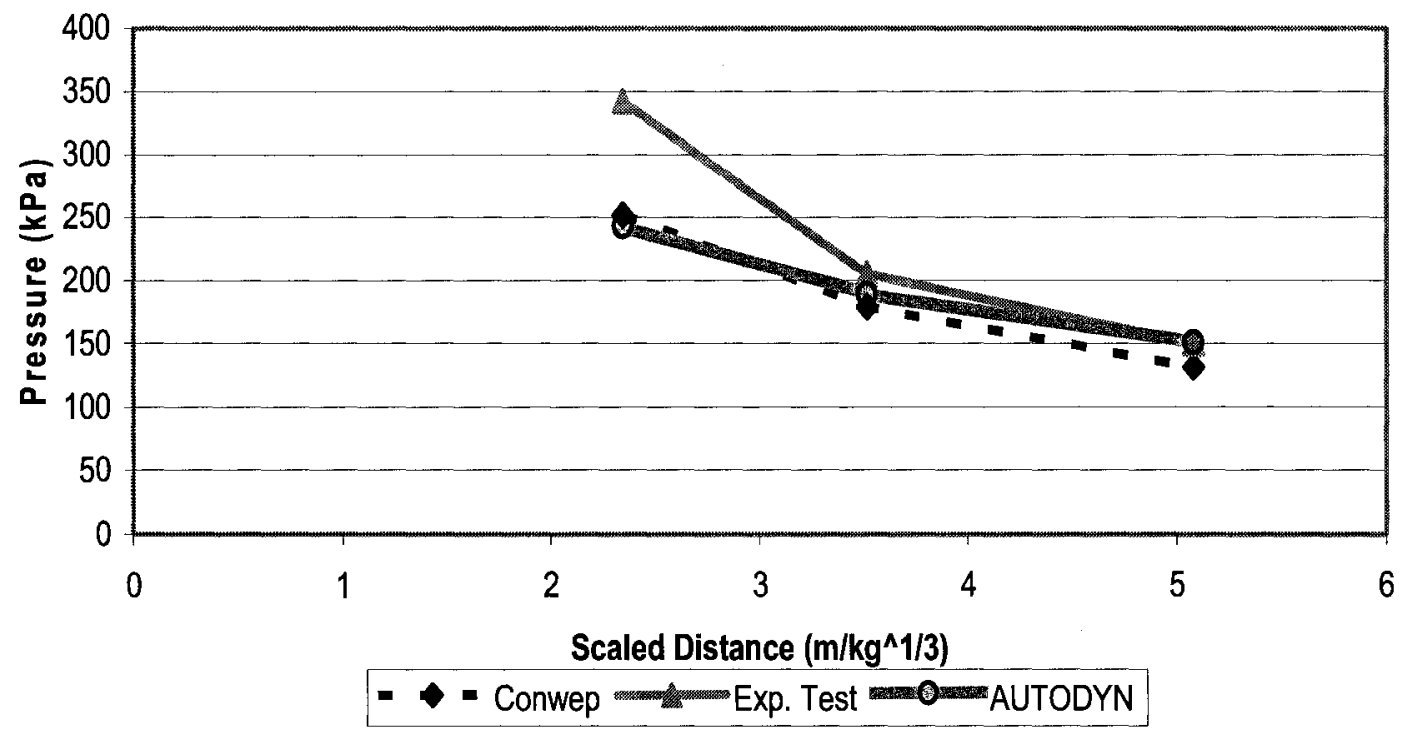

Figure 3.36: Air peak incident pressure comparison

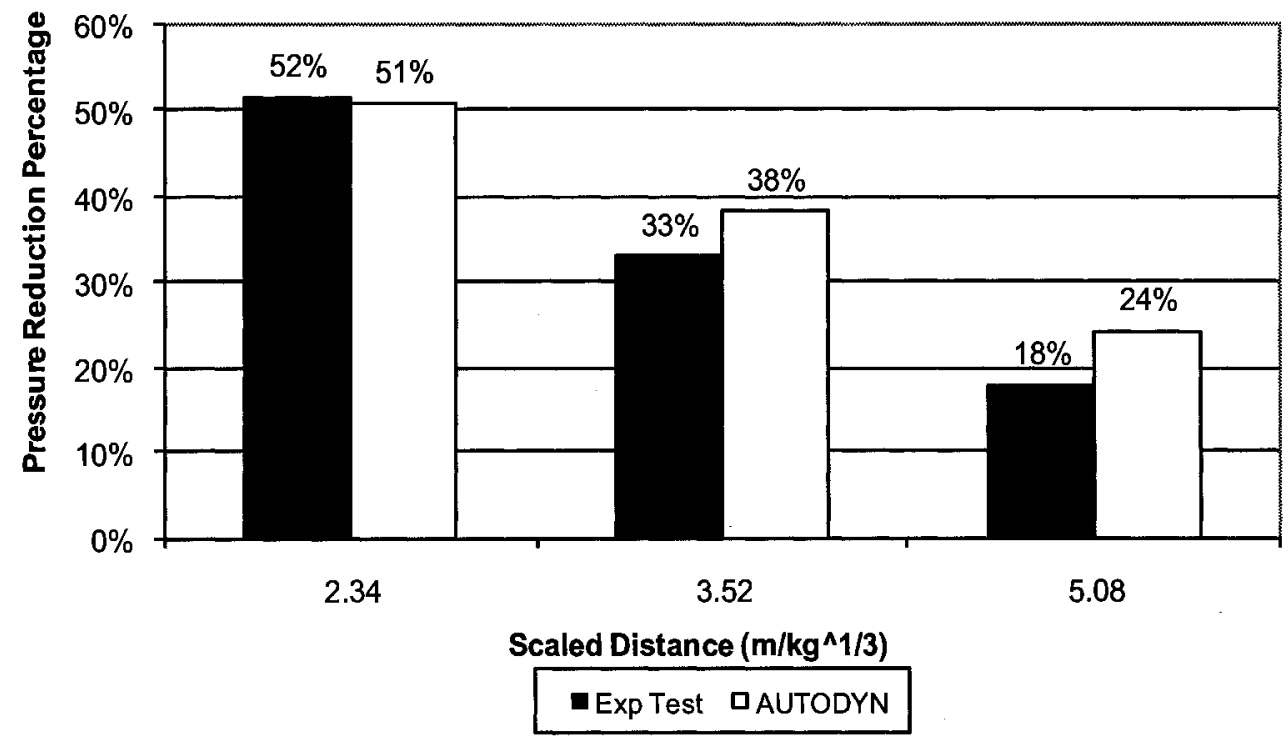

Figure 3.37: Pressure percentage reduction- Experimental test vs AUTODYN 


\subsubsection{Reflected Pressure within Suppressive Shield Structure}

Figures 3.38 and 3.39 in this section the pressures recorded by the three gauges in the SS structure are compared to those predicted by AUTODYN simulation. From Figures 3.38 and 3.39 one can see that the trend of the reflected pressure versus time is exactly the same but not the values. This can be explained by the error due to electronic noise in the gauges used in the experimental test. As shown in Figure 3.38, there is a spike over the actual value of pressure. By taking a closer look on that spike, it is clear that it is an error since there is no time recorded for this value. The pressure value used in the experimental test was the maximum value of the spike which gave false results compared to what obtained from AUTODYN. On the other hand when the experimental test values corrected from this spike, the values tend to be close to what obtained from AUTODYN. Table 3.13 presents the reflected pressure values at the three gauges before and after modification in the experimental test and values obtained from AUTODYN. Comparing Figures 3.38 through 3.43 , it proves the ability of AUTODYN to correctly predict the same trend of experimental work.

Table 3.13: Reflected pressure values vs scaled distance

\begin{tabular}{cccc}
\hline $\begin{array}{c}\text { Scaled Distance } \\
\left(\mathrm{m} / \mathrm{kg}^{1 / 3}\right)\end{array}$ & \multicolumn{3}{c}{$\begin{array}{c}\text { Reflected Pressure Values } \\
(\mathrm{kPa})\end{array}$} \\
\hline & $\begin{array}{c}\text { Experimental } \\
\text { test }\end{array}$ & $\begin{array}{c}\text { Modified experimental } \\
\text { test }\end{array}$ & AUTODYN \\
1.39-First Peak & 2797 & 1825 & 1790 \\
$1.39-$ Second Peak & 3542 & 2515 & 2427 \\
1.10 & 5052 & 4238 & 3077 \\
0.98 -First Peak & 12,064 & 6307 & 2984 \\
0.98 -Second Peak & 5686 & 3204 & 8184 \\
\hline
\end{tabular}




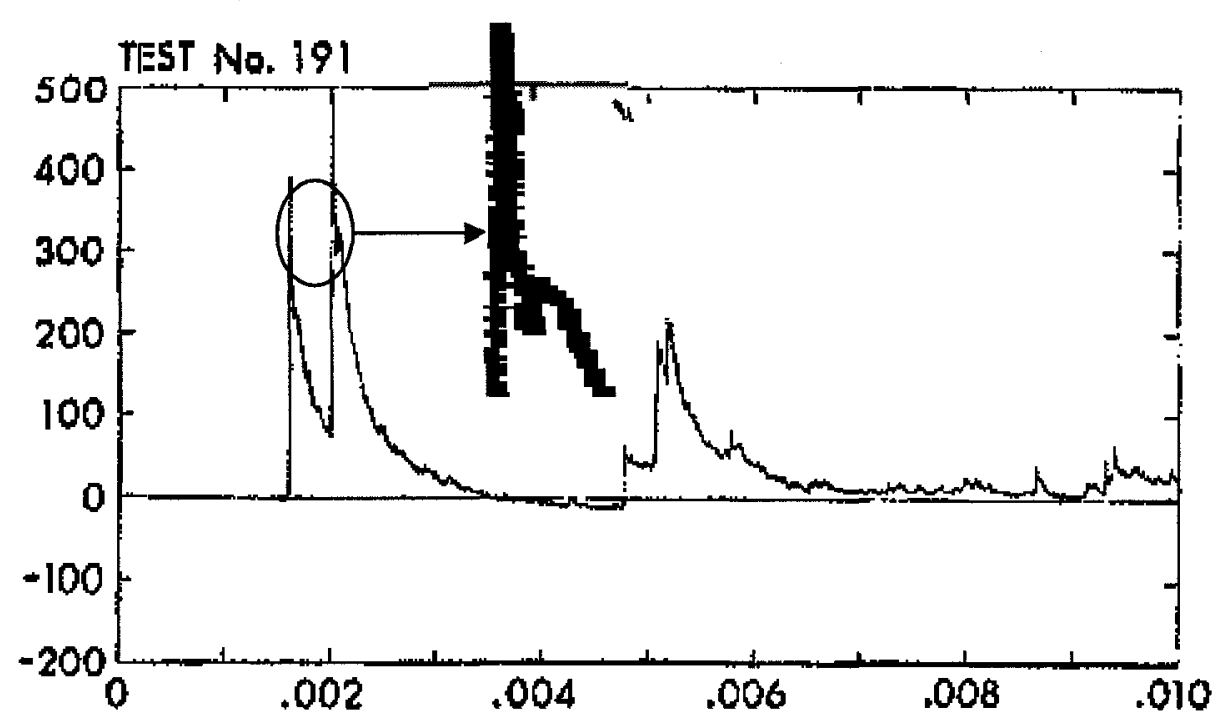

Figure 3.38: Reflected pressure vs Time (experimental test) at gauge \#7

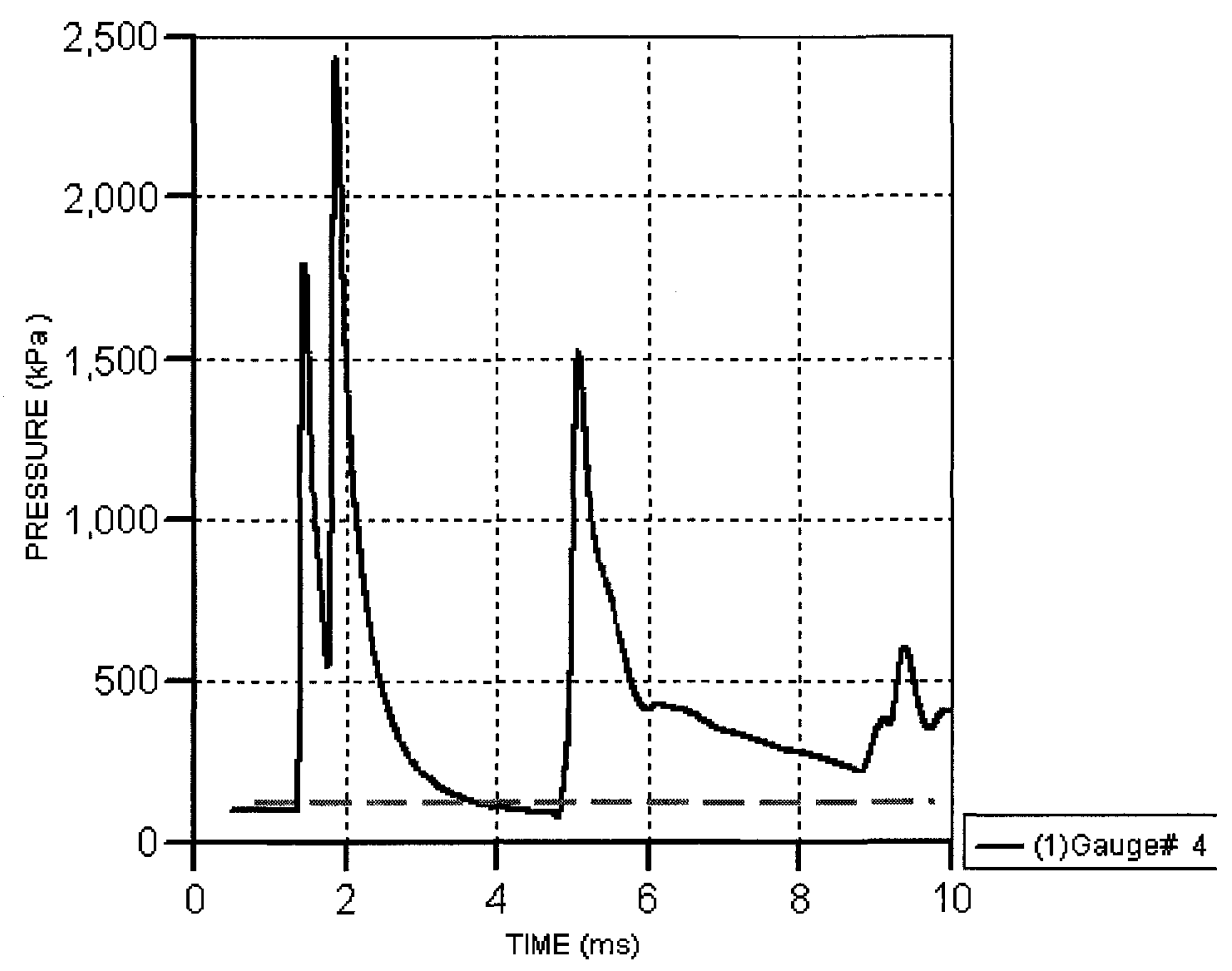

Figure 3.39: Reflected pressure vs Time (AUTODYN) at gauge \#4 


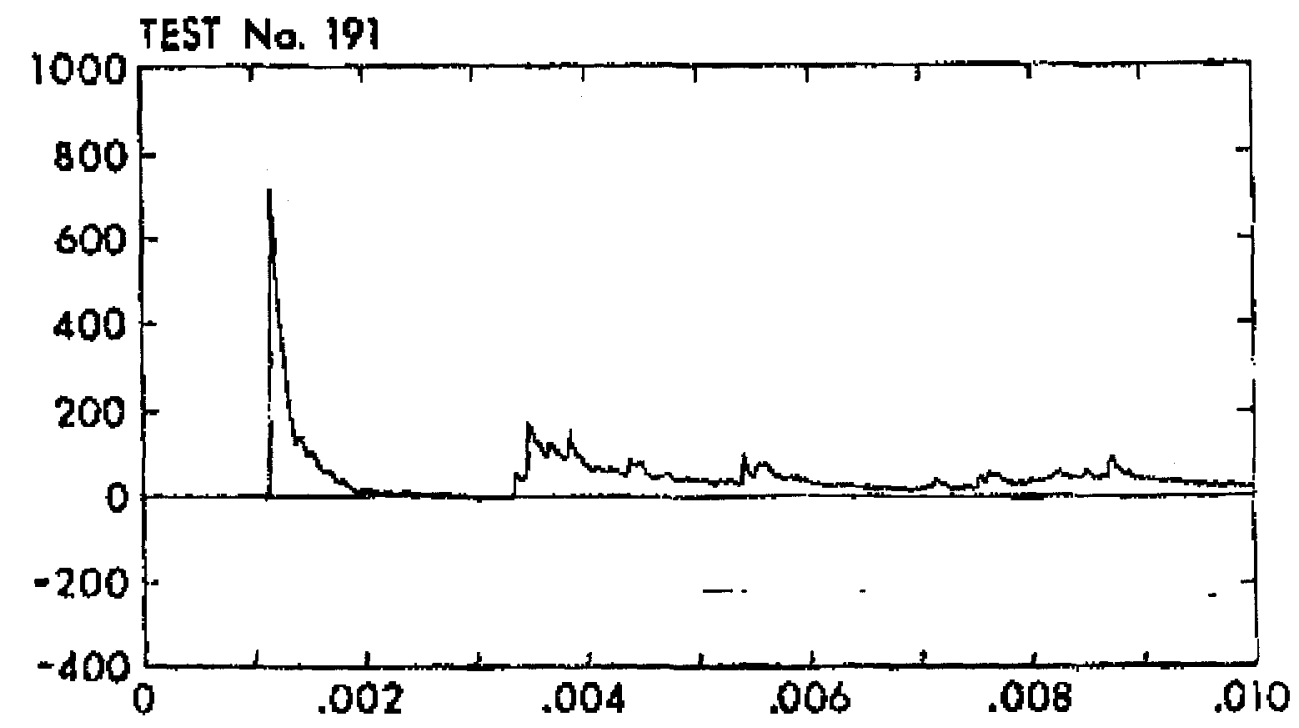

Figure 3.40: Reflected pressure vs Time (experimental test) at gauge \#8

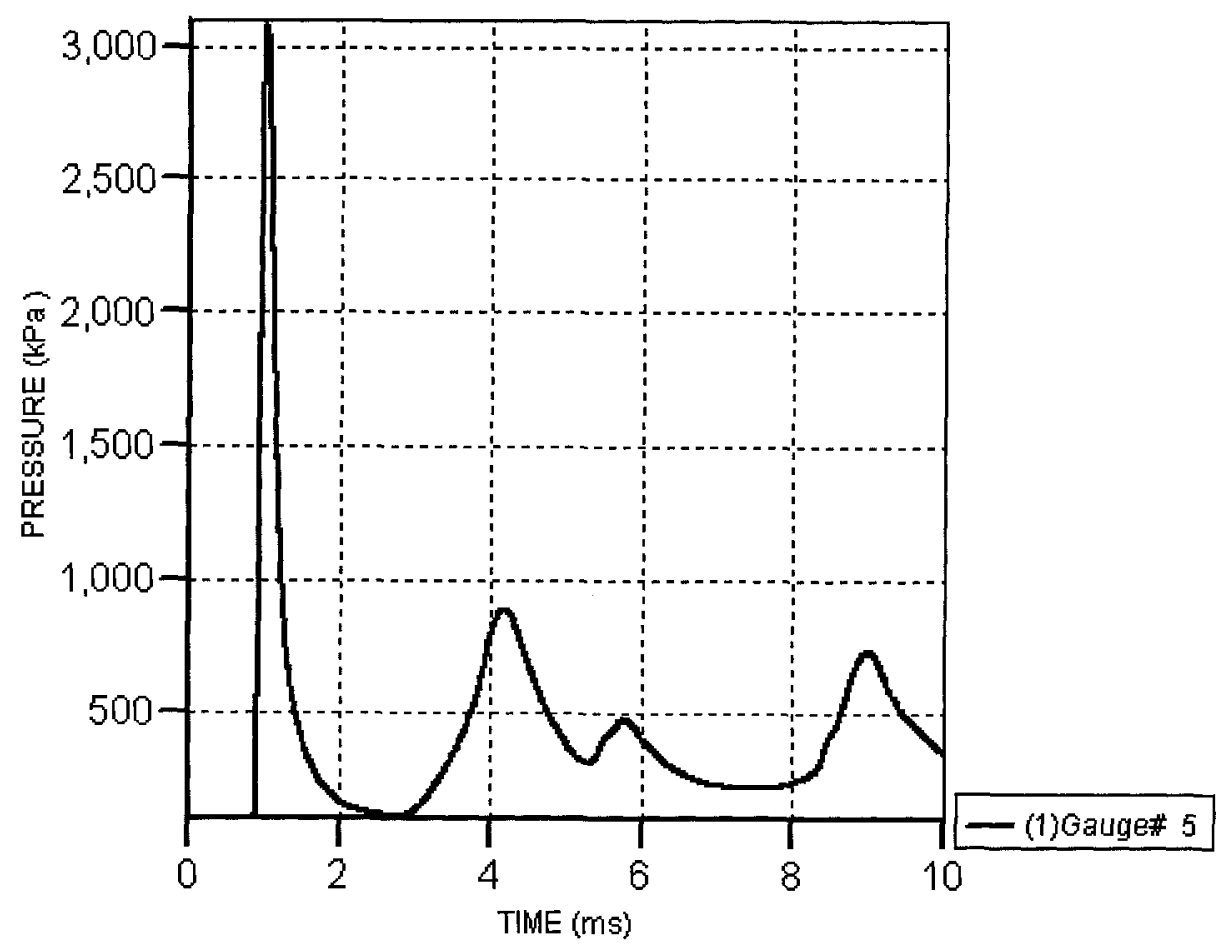

Figure 3.41: Reflected pressure vs Time (AUTODYN) at gauge \#5 


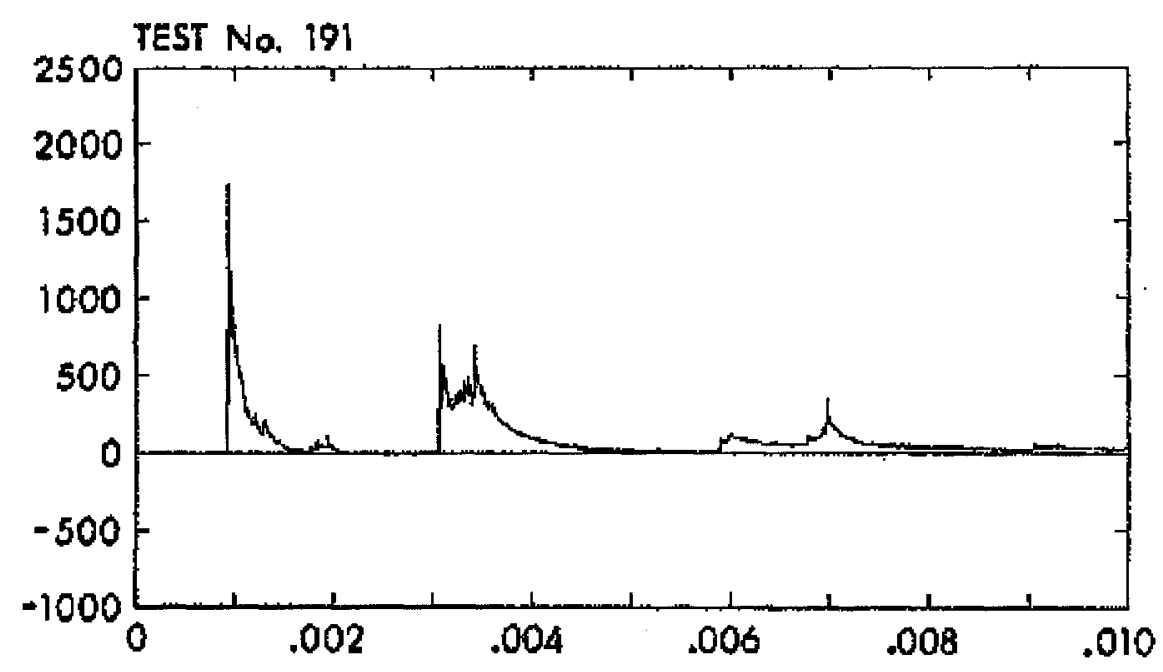

Figure 3.42: Reflected pressure vs Time (experimental test) at gauge \#10

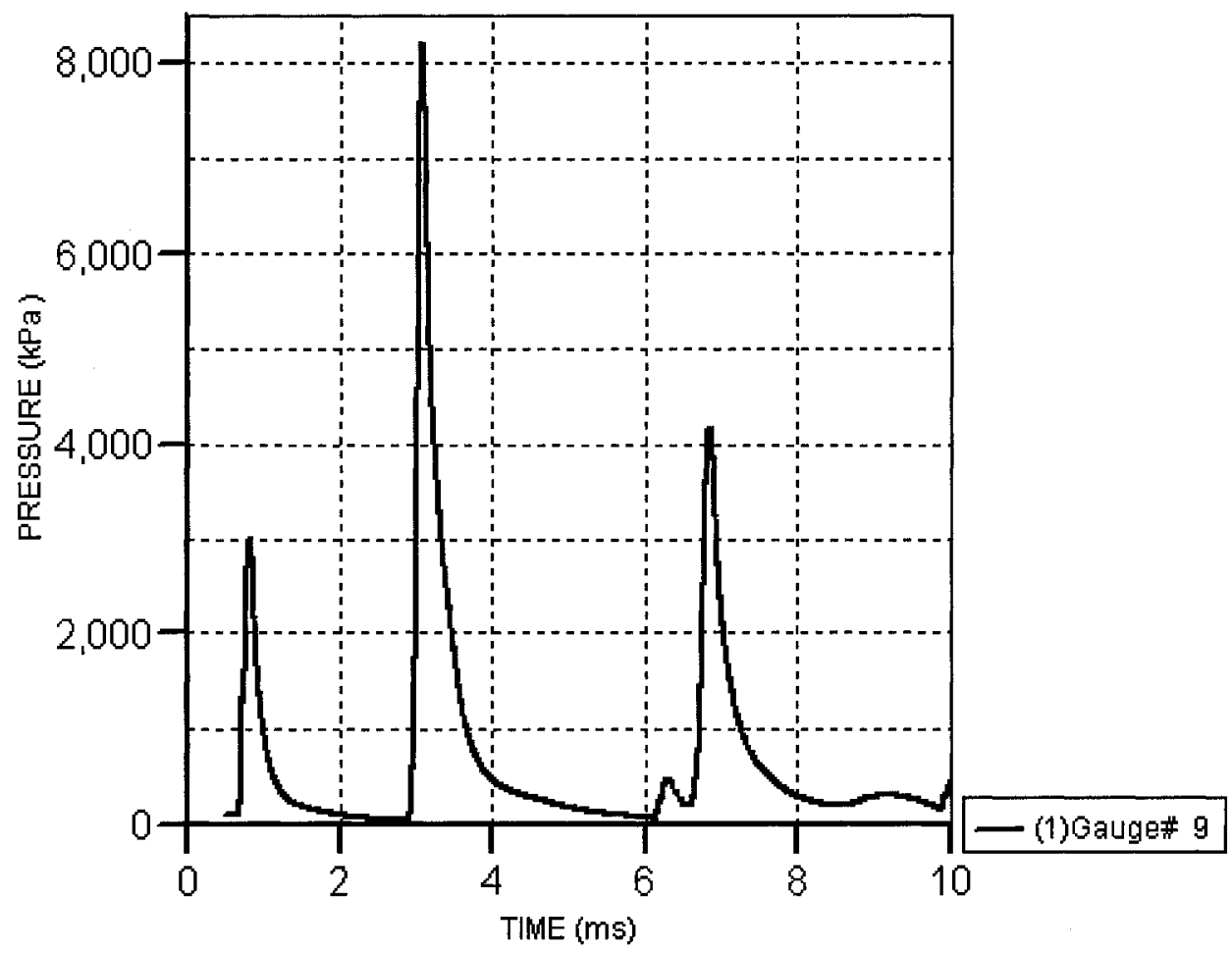

Figure 3.43: Reflected pressure vs Time (AUTODYN) at gauge \#9 


\section{Chapter 4}

\section{Preliminary Parametric Study}

The main objective of the preliminary study was to perform parametric analyses to determine the attenuation effect of SSPs with different angle sizes and configurations. Two explosive charges sizes, 5 and $50 \mathrm{~kg}$, were used. The first configuration consisted of nesting angles at forty five degrees facing the explosive charges as shown in Figure 4.1. The second configuration consisted of two sets of angles interlocking together as shown in Figure 4.2. Both SSPs were set at 1-m from the center of explosive charges. The air domain was $1 \mathrm{~m}$ in the $\mathrm{X}$-direction by $1.5 \mathrm{~m}$ in the $\mathrm{Y}$-direction. Two sets of gauges were installed to track the pressure shock front outside the SS panel. The vent areas and the mass resulting from using different angle sizes and configurations were calculated to prepare the designs and later to decide the optimum configuration and weight of the panels. The following sections explain how the various scenarios were built and analyzed.

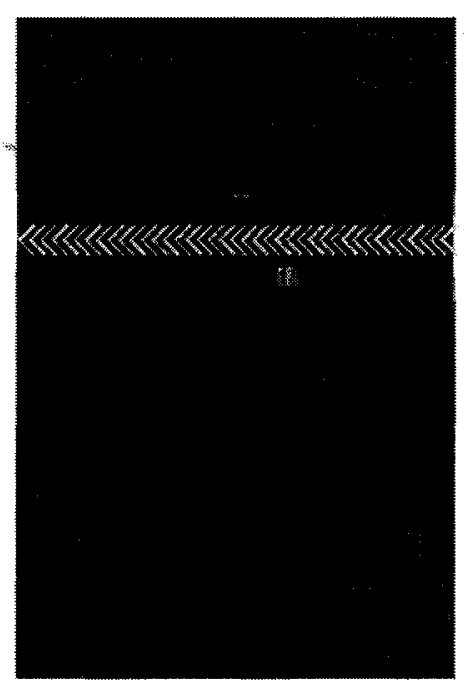

Figure 4.1: Nested angles configuration 


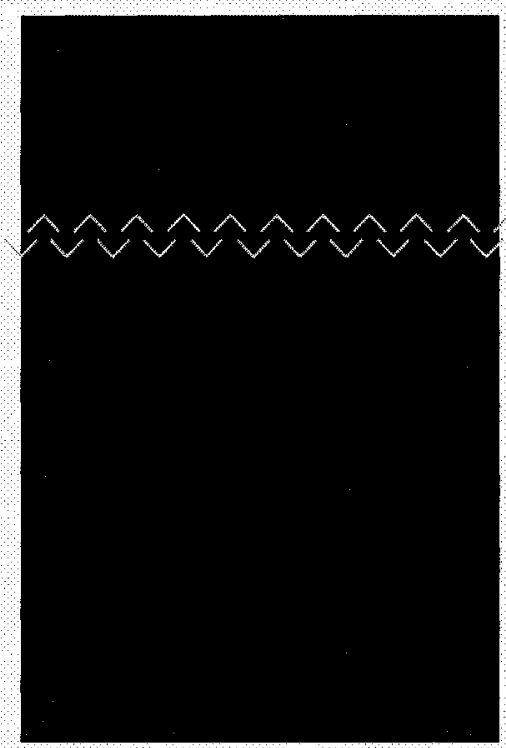

Figure 4.2: Double angles configuration

\subsection{Mass and Vent Area Calculations}

This step is very important especially when it comes to using the proposed SSPs for transport applications. The challenge is to apply the SSP technology so that it is incorporated in existing transport systems in terms of the allowable weights for trucks, cranes, as well as satisfying the safety measures and regulations. Thus, this step defines the different angles to be used in the manufacturing of the SSPs and the associated mass and vent areas for both nested and double angle, SSP configurations.

\subsubsection{Nested Angle}

The study concentrates on three L-section angles, L51, L76 and L102. The properties of these sections were obtained from the Canadian Steel Handbook and are reproduced in Table 4.1. For the purpose of comparison, this study was performed utilizing one thickness for all three considered angles; $6.35 \mathrm{~mm}$. However, to estimate the mass and the 
vent area for typical 6-m ISO containers, various angle thicknesses were used. The inside container dimensions used in this study were $5800 \mathrm{~mm}$ for the length and $2000 \mathrm{~mm}$ for the width and height. These were used to determine the length of the angles and their number per side to compute the mass of the container.

Table 4.1: Used angle sections, Canadian Steel Handbook

\begin{tabular}{|c|c|c|c|c|}
\hline Section & $\begin{array}{l}\text { Depth } \\
(\mathrm{mm})\end{array}$ & $\begin{array}{l}\text { Width } \\
\text { (mm) }\end{array}$ & $\begin{array}{c}\text { Thickness } \\
(\mathrm{mm})\end{array}$ & $\begin{array}{l}\text { Mass per Unit } \\
\text { Length } \\
(\mathrm{kg} / \mathrm{m})\end{array}$ \\
\hline \multirow[t]{4}{*}{ L51x51 } & 50.8 & 50.8 & 3.18 & 2.46 \\
\hline & & & 4.76 & 3.62 \\
\hline & & & 6.35 & 4.75 \\
\hline & & & 7.94 & 5.84 \\
\hline \multirow[t]{4}{*}{ L76x76 } & 76.2 & 76.2 & 4.76 & 5.52 \\
\hline & & & 6.35 & 7.28 \\
\hline & & & 7.94 & 9.00 \\
\hline & & & 9.53 & 10.7 \\
\hline \multirow[t]{4}{*}{ L102x102 } & 102 & 102 & 6.35 & 9.85 \\
\hline & & & 7.94 & 12.2 \\
\hline & & & 9.53 & 14.5 \\
\hline & & & 11.1 & 16.8 \\
\hline
\end{tabular}

The mass of the containers differed depending on the vent areas. The projected width for the nested angles, used to determine the vent area, was found geometrically by taking into consideration their $45^{\circ}$ orientation (Figure 4.3). Since the nesting of the angles was to provide complete obscuration (no direct line of sight openings), the angles required a minimum gap size. For example Figure 4.3 shows a three nested angles combination. 


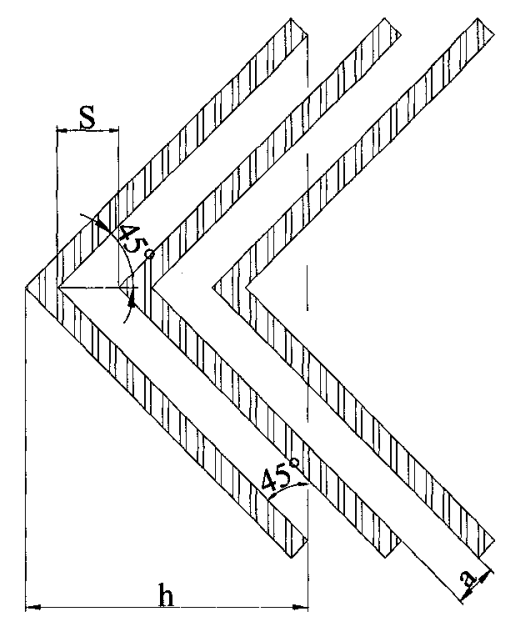

Figure 4.3: Vent Area Parameters

Given the projected width, h, of each angle, the projected spacing, $P_{s}$, was selected to be in the range of $1 / 2$ " to 1 " for the smallest angle and up to $2-1 / 2$ " for the largest angle. Subsequently, the vent area, $A_{v}$, was determined according to Equation 4.1 (Suppressive Shield Handbook).

$$
A_{v}=n l a / N
$$

Where,

$$
\begin{aligned}
& n: \text { number of openings } \\
& l: \text { length of exposed element, } \mathrm{mm} \\
& a: \text { inclined spacing between angles, } \mathrm{mm} \\
& N \text { : constant, depending on the number of openings per projected width }
\end{aligned}
$$

The number of openings, $n=[(\mathrm{L} / \mathrm{S})-1]$, were $\mathrm{L}$ is the length of container side and $\mathrm{S}$ is the spacing between the angles. The length of the exposed element, $l$, was taken as the total 
span of the angle, $2 \mathrm{~m}$. The inclined spacing between the angles, $a$, was calculated with Equation 4.2.

$a=(S-t) \sin 45^{\circ}=0.707(S-t)$

Where,
$S$ : Projected spacing
$t$ : angles thickness

Finally, $N$, which is a constant that depends on the number of openings per projected width, was set equal to 2 for one opening and equal to 4 for two or more openings. Herein, $N$, was taken as 4 since there were a minimum of two openings per projected width for all angles. The vent area ratio, which is the ratio between vent area and wall area, was calculated to finalize the vent area calculations. The vent area ratio is a good indicator to represent the opening percentage of the walls of the container. Table 4.2 summarizes the vent area calculations for the three used angles. It is clear from the results in this table that by fixing the projected spacing for all angles to $25.4 \mathrm{~mm}$, the vent area ratio was constant for the different angles which had the same thickness, $6.35 \mathrm{~mm}$.

Figure 4.4 shows the unit vent area ratio for the three angles used. Since the spacing between angles depends on the projected width of each angle, it is clear from the figure that the smallest angle only include two gaps, the mid size angle includes four gaps and finally the largest angle includes a maximum of five gaps. The vent area ratios for the spacings listed in Table 4.2 range from $5 \%$ to $15 \%$. 
Table 4.2: Unit vent area calculations for Nested Angles

\begin{tabular}{|c|c|c|c|c|c|c|c|c|}
\hline Section & $\begin{array}{c}\mathbf{h} \\
(\mathrm{mm})\end{array}$ & $\begin{array}{c}\mathbf{h} \\
\text { (in) }\end{array}$ & $\begin{array}{c}\mathbf{t} \\
(\mathrm{mm})\end{array}$ & $\begin{array}{c}\text { Ps } \\
(\mathrm{mm})\end{array}$ & $\begin{array}{c}\mathbf{a} \\
(\mathrm{mm})\end{array}$ & $\begin{array}{c}\mathbf{A v} \\
\left(\mathrm{mm}^{2}\right)\end{array}$ & $\begin{array}{c}\mathbf{A w} \\
\left(\mathrm{mm}^{2}\right)\end{array}$ & $\begin{array}{c}\alpha \\
0 \%\end{array}$ \\
\hline \multirow[t]{8}{*}{ L51 } & 12.7 & $1 / 2$ & 3.18 & 4.50 & 5.80 & $1,324,468$ & $11,600,000$ & 11 \\
\hline & & & 4.76 & 6.73 & 4.22 & 963,681 & $11,600,000$ & 8 \\
\hline & & & 6.35 & 8.98 & 2.63 & 600,610 & $11,600,000$ & 5 \\
\hline & & & 7.94 & 11.23 & 1.04 & 237,539 & $11,600,000$ & 2 \\
\hline & 25.4 & 1 & 3.18 & 4.50 & 14.78 & $1,687,539$ & $11,600,000$ & 15 \\
\hline & & & 4.76 & 6.73 & 13.20 & $1,507,145$ & $11,600,000$ & 13 \\
\hline & & & 6.35 & 8.98 & 11.61 & $1,325,610$ & $11,600,000$ & 11 \\
\hline & & & 7.94 & 11.23 & 10.02 & $1,144,074$ & $11,600,000$ & 10 \\
\hline \multirow[t]{16}{*}{$\mathrm{L} 76$} & 12.7 & $1 / 2$ & 4.76 & 6.73 & 4.22 & 963,681 & $11,600,000$ & 8 \\
\hline & & & 6.35 & 8.98 & 2.63 & 600,610 & $11,600,000$ & 5 \\
\hline & & & 7.94 & 11.23 & 1.04 & 237,539 & $11,600,000$ & 2 \\
\hline & & & 9.53 & 13.48 & -0.55 & $-125,532$ & $11,600,000$ & $-1^{*}$ \\
\hline & 25.4 & 1 & 4.76 & 6.73 & 13.20 & $1,507,145$ & $11,600,000$ & 13 \\
\hline & & & 635 & 8.98 & 11.61 & $1,325,610$ & $11,600,000$ & 11 \\
\hline & & & 7.94 & 11.23 & 10.02 & $1,144,074$ & $11,600,000$ & 10 \\
\hline & & & 9.53 & 13.48 & 8.43 & 962,539 & $11,600,000$ & 8 \\
\hline & 38.1 & $1 \frac{1}{2}$ & 4.76 & 6.73 & 22.18 & $1,688,300$ & $11,600,000$ & 15 \\
\hline & & & 6.35 & 8.98 & 20.6 & $1,567,276$ & $11,600,000$ & 14 \\
\hline & & & 7.94 & 11.23 & 19.0 & $1,446,253$ & $11,600,000$ & 12 \\
\hline & & & 9.53 & 13.48 & 17.4 & $1,32,5229$ & $11,600,000$ & 11 \\
\hline & 50.8 & 2 & 4.76 & 6.73 & 31.16 & $1,778,877$ & $11,600,000$ & 15 \\
\hline & & & 6.35 & 8.98 & 29.57 & $1,688,110$ & $11,600,000$ & 15 \\
\hline & & & 7.94 & 11.23 & 27.98 & $1,597,342$ & $11,600,000$ & 14 \\
\hline & & & 9.53 & 13.48 & 26.39 & $1,506,574$ & $11,600,000$ & 13 \\
\hline \multirow[t]{20}{*}{ L102 } & 12.7 & $1 / 2$ & 4.76 & 6.73 & 4.22 & 963,681 & $11,600,000$ & 8 \\
\hline & & & 6.35 & 8.98 & 2.63 & 600,610 & $11,600,000$ & 5 \\
\hline & & & 7.94 & 11.23 & 1.04 & 237,539 & $11,600,000$ & 2 \\
\hline & & & 9.53 & 13.48 & -0.55 & $-125,532$ & $11,600,000$ & $-1^{*}$ \\
\hline & 25.4 & 1 & 4.76 & 6.73 & 13.20 & $1,507,145$ & $11,600,000$ & 13 \\
\hline & & & 635 & 8.98 & 11.61 & $1,325,610$ & $11,600,000$ & 11 \\
\hline & & & 7.94 & 11.23 & 10.02 & $1,144,074$ & $11,600,000$ & 10 \\
\hline & & & 9.53 & 13.48 & 8.43 & 962,539 & $11,600,000$ & 8 \\
\hline & 38.1 & $11 / 2$ & 4.76 & 6.73 & 22.18 & $1,688,300$ & $11,600,000$ & 15 \\
\hline & & & 6.35 & 8.98 & 20.59 & $1,567,276$ & $11,600,000$ & 14 \\
\hline & & & 7.94 & 11.23 & 19.00 & $1,446,253$ & $11,600,000$ & 12 \\
\hline & & & 9.53 & 13.48 & 17.41 & 1.325 .229 & 11.600 .000 & 11 \\
\hline & 50.8 & 2 & 4.76 & 6.73 & 31.16 & $1,778,877$ & $11,600,000$ & 15 \\
\hline & & & 6.35 & 8.98 & 29.57 & $1,688,110$ & $11,600,000$ & 15 \\
\hline & & & 7.94 & 11.23 & 27.98 & $1,597,342$ & $11,600,000$ & 14 \\
\hline & & & 9.53 & 13.48 & 26.39 & $1,506,574$ & $11,600,000$ & 13 \\
\hline & 63.5 & $2 \frac{1}{2}$ & 4.76 & 6.73 & 40.14 & $1,833,224$ & $11,600,000$ & 16 \\
\hline & & & 6.35 & 8.98 & 38.55 & $1,760,610$ & $11,600,000$ & 15 \\
\hline & & & 7.94 & 11.23 & 36.96 & $1,687,995$ & $11,600,000$ & 15 \\
\hline & & & 9.53 & 13.48 & 35.37 & $1,615,381$ & $11,600,000$ & 14 \\
\hline
\end{tabular}

* Indicated gap not possible with this angle thickness 


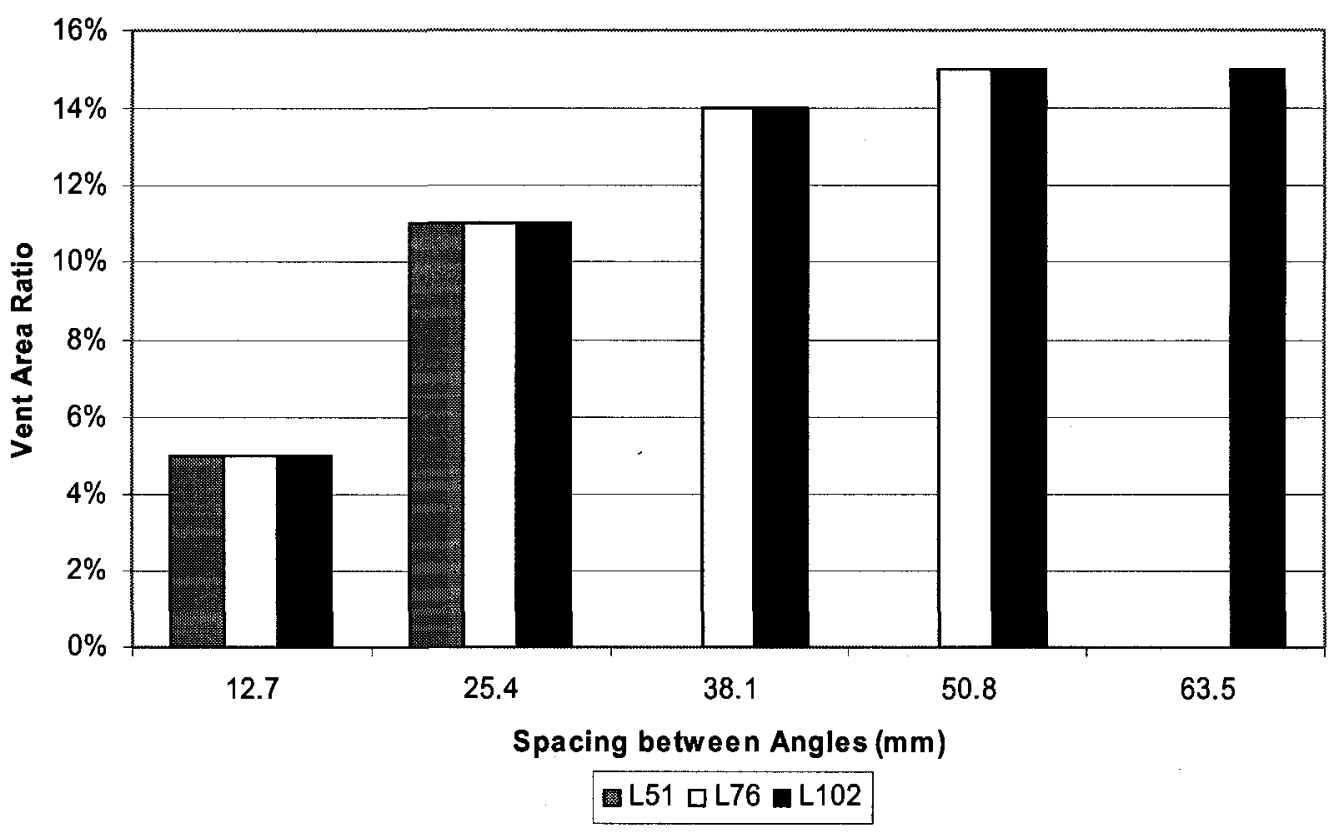

Figure 4.4: Unit Vent Area Ratio for $6.35 \mathrm{~mm}$ thickness

After determining the vent area, the mass of the 3-S was calculated through the use of the area of the container and areal density of the 3-S. Maintaining the ratio of the mass of goods transported to the mass of the container, is the challenge of this study. The maximum allowable mass of the 3-S container was chosen according to the amount of explosives permitted for transport, 20 tonnes. Since the retrofitted container will weigh substantially more, the amount of allowable explosives to be transported will need to be reduced. It was assumed that the $3-\mathrm{S}$ container would weigh at most $600 \%$ of the original container weight of 2 tonnes. Consequently, the maximum amount of explosives to be transported will range between 5 to 10 tonnes.

Table 4.3 lists the mass calculations for the nested angle configurations. It is clear that the mass ratio has a minimum value of $250 \%$ for $\mathrm{L} 76 / 50.8$ and a maximum value of $1780 \%$ for L102/12.7. Seven configurations satisfy the $600 \%$ limit set above. Figure 4.5 shows 
the different sections and their equivalent mass ratio depending on the spacing, and the maximum allowable mass limit.

Table 4.3: Nested Angles Mass calculation

\begin{tabular}{lcccccccc}
\hline Section & Thickness & Spacing & $\begin{array}{c}\text { Angles } \\
\text { per } \\
\text { Container } \\
\text { Side }\end{array}$ & $\begin{array}{c}\text { Angles per } \\
\text { Container } \\
\text { End }\end{array}$ & $\begin{array}{c}\text { Areal } \\
\text { Density }\end{array}$ & $\begin{array}{c}\text { Mass of } \\
\text { Contain } \\
\text { er }\end{array}$ & $\begin{array}{c}\text { Mass } \\
\text { Ratio }\end{array}$ & $\begin{array}{c}\text { Mass } \\
\text { Increase }\end{array}$ \\
& $(\mathrm{mm})$ & $(\mathrm{mm})$ & & & $\left(\mathrm{kg} / \mathrm{m}^{2}\right)$ & $(\mathrm{kg})$ & $(\%)$ & \\
\hline L51 & 6.35 & 12.7 & 458 & 158 & 375 & 20,403 & 807 & 9.0 \\
& & 25.4 & 229 & 80 & 188 & 10,230 & 355 & 4.5 \\
\hline L76 & 6.35 & 12.7 & 458 & 158 & 574 & 31,271 & 1290 & 14.0 \\
& & 25.4 & 229 & 80 & 288 & 15,679 & 597 & 7.0 \\
& & 38.1 & 153 & 53 & 192 & 10,482 & 366 & 5.0 \\
& & 50.8 & 115 & 40 & 145 & 7,883 & 250 & 3.5 \\
\hline L102 & 6.35 & 12.7 & 458 & 158 & 781 & 42,310 & 1780 & 19.0 \\
& & 25.4 & 229 & 80 & 389 & 21,214 & 843 & 9.5 \\
& & 38.1 & 153 & 53 & 260 & 14,182 & 530 & 6.5 \\
& & 50.8 & 115 & 40 & 196 & 10,666 & 374 & 5.0 \\
& & 63.5 & 92 & 32 & 157 & 8,557 & 280 & 4.0 \\
\hline
\end{tabular}

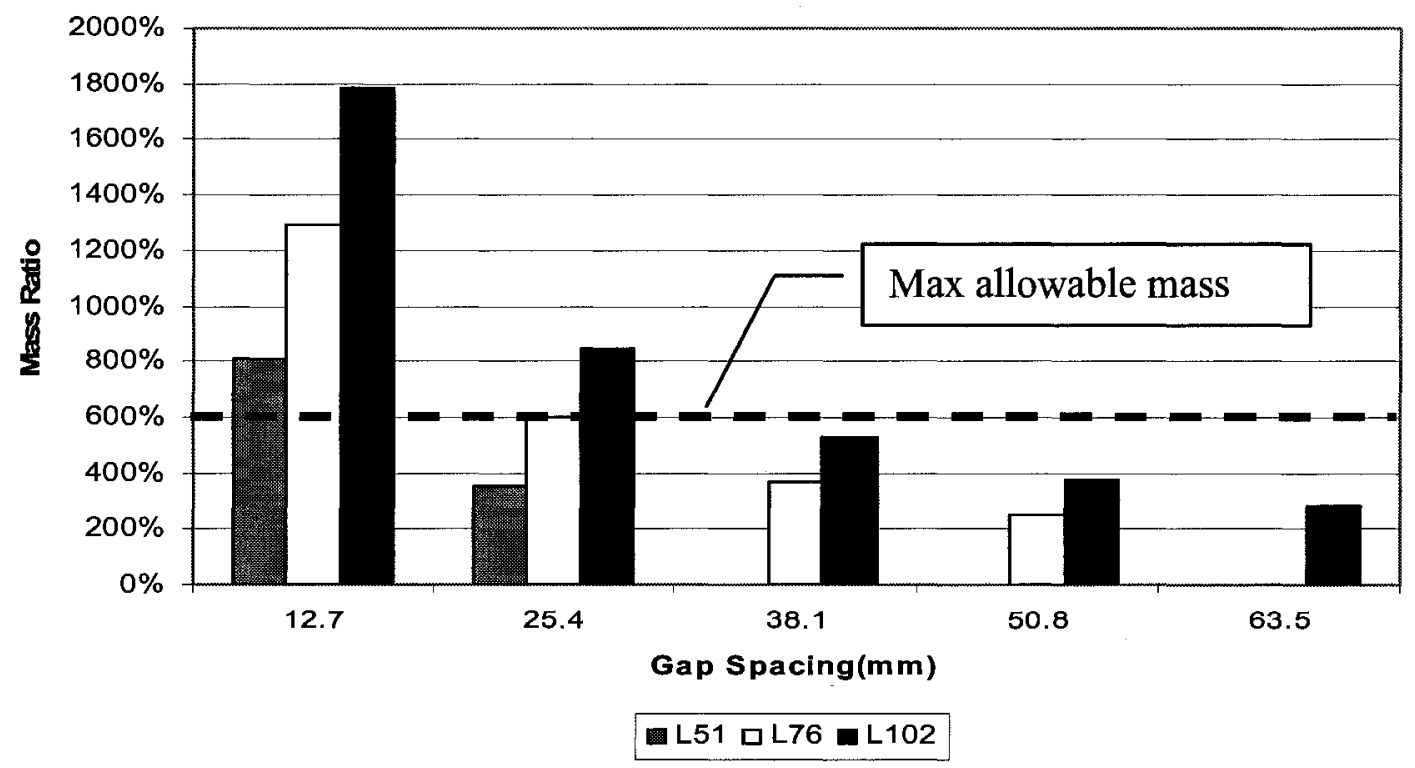

Figure 4.5: Nested angles maximum allowable mass limit 


\subsubsection{Double Angle}

The same procedures was for the double angle configurations, except that the unit vent area, $A_{v}$, (Equation 4.3) is a function of the number of openings, length of exposed elements and the spacing between angles. Figure 4.6 shows the unit vent area parameters as well as the dimensions that were used to build the double angle configuration.

$$
A_{v}=n l a
$$

Where,
$n$ : number of openings
$l:$ length of exposed element
$a$ : spacing between angles

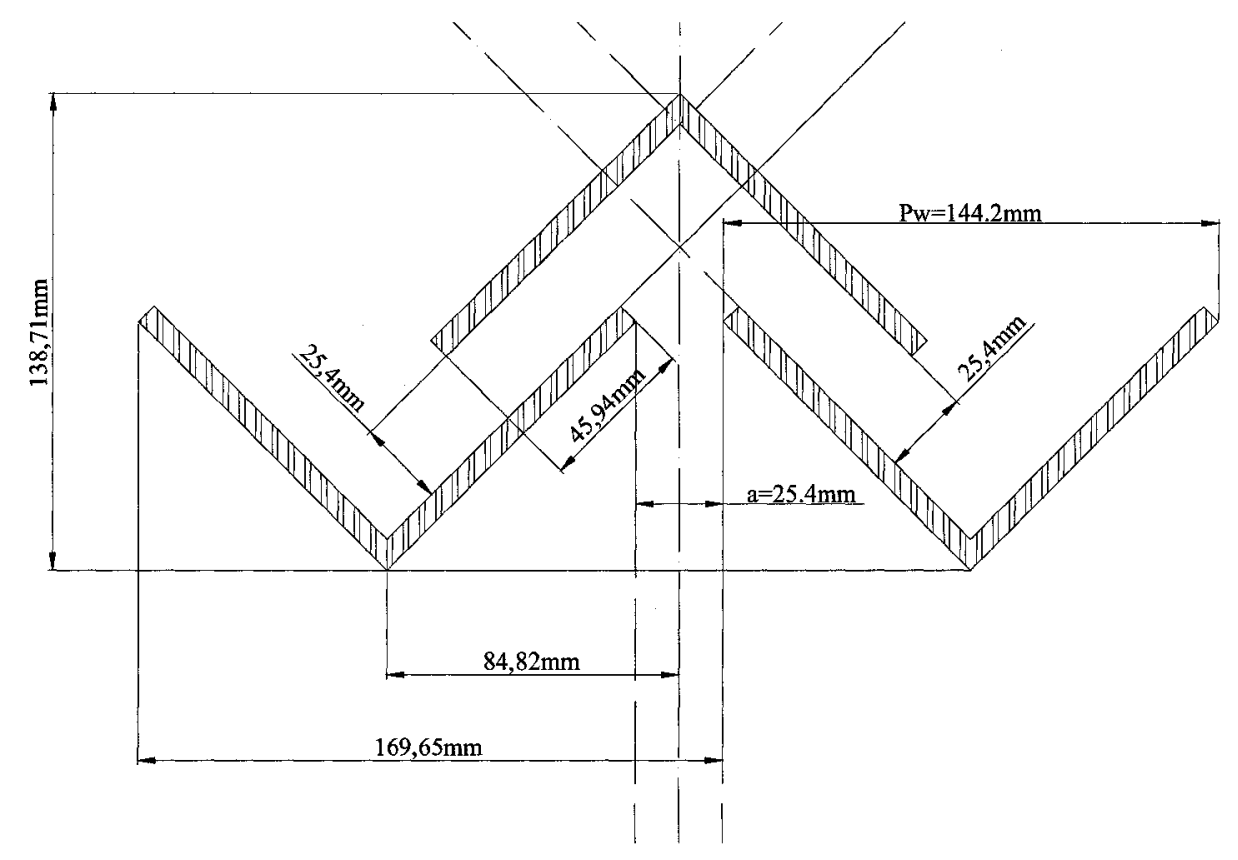

Figure 4.6: Double angle vent area parameters

The number of openings, $n$, was calculated by dividing the length of container side by the selected spacing. The spacing was equal to the projected angle width, $P_{w}$, plus the gap 
spacing, $a$, set to $25.4 \mathrm{~mm}$. The length of the exposed element, $l$, was taken as the total span of the angle and was equal to $2 \mathrm{~m}$. The unit effective vent area ratio, $\alpha_{e}$, (Equation 4.4) is the summation of the unit vent areas from each row of angles.

$$
\frac{1}{\alpha_{e}}=\frac{1}{\alpha_{1}}+\frac{1}{\alpha_{2}}
$$

Where,

$$
\alpha_{1 \& 2}=\frac{A_{v}}{A_{w}}
$$

Table 4.4 summarizes the unit vent area calculations for the three angles and the $25.4 \mathrm{~mm}$ gap. Note that the effective vent area ranges from $7 \%$ for L102 to $13 \%$ for L51.

Table 4.4: Unit vent area calculations for Double Angles

\begin{tabular}{ccccccccc}
\hline Section & $\begin{array}{c}\mathbf{P w} \\
(\mathrm{mm})\end{array}$ & $\begin{array}{c}\mathbf{t} \\
(\mathrm{mm})\end{array}$ & $\begin{array}{c}\mathbf{a} \\
(\mathrm{mm})\end{array}$ & $\begin{array}{c}\mathbf{A v} \\
\left(\mathrm{mm}^{2}\right)\end{array}$ & $\begin{array}{c}\mathbf{A w} \\
\left(\mathrm{mm}^{2}\right)\end{array}$ & $\boldsymbol{\alpha}$ & $\mathbf{1} / \boldsymbol{\alpha}_{\mathbf{e}}$ & $\begin{array}{c}\boldsymbol{\alpha}_{\mathbf{e}} \\
(\%)\end{array}$ \\
\hline $\mathbf{L 5 1}$ & 72 & 3.18 & 25.4 & $3.03 \mathrm{E}+06$ & $1.16 \mathrm{E}+07$ & 0.261 & 7.669 & 13 \\
& & 4.76 & & $3.03 \mathrm{E}+06$ & $1.16 \mathrm{E}+07$ & 0.261 & 7.669 & 13 \\
& & 6.35 & & $3.03 \mathrm{E}+06$ & $1.16 \mathrm{E}+07$ & 0.261 & 7.669 & 13 \\
& & 7.94 & & $3.03 \mathrm{E}+06$ & $1.16 \mathrm{E}+07$ & 0.261 & 7.669 & 13 \\
\hline $\mathbf{L 7 6}$ & 107.8 & 4.76 & 25.4 & $2.21 \mathrm{E}+06$ & $1.16 \mathrm{E}+07$ & 0.191 & 10.488 & 10 \\
& & 6.35 & & $2.21 \mathrm{E}+06$ & $1.16 \mathrm{E}+07$ & 0.191 & 10.488 & 10 \\
& & 7.94 & & $2.21 \mathrm{E}+06$ & $1.16 \mathrm{E}+07$ & 0.191 & 10.488 & 10 \\
& & 9.53 & & $2.21 \mathrm{E}+06$ & $1.16 \mathrm{E}+07$ & 0.191 & 10.488 & 10 \\
\hline \multirow{2}{*}{ L102 } & 144.2 & 6.35 & 25.4 & $1.73 \mathrm{E}+06$ & $1.16 \mathrm{E}+07$ & 0.149 & 13.386 & 7 \\
& & 7.94 & & $1.73 \mathrm{E}+06$ & $1.16 \mathrm{E}+07$ & 0.149 & 13.386 & 7 \\
& & 9.53 & & $1.73 \mathrm{E}+06$ & $1.16 \mathrm{E}+07$ & 0.149 & 13.386 & 7 \\
& & 11.1 & & $1.73 \mathrm{E}+06$ & $1.16 \mathrm{E}+07$ & 0.149 & 13.386 & 7 \\
\hline
\end{tabular}

The following calculations indicate the effect of varying the angle thicknesses as initially listed in Table 4.4. Table 4.5 shows the mass calculation and Figure 4.7 shows the effect of angle thickness on the mass ratio values for the three different angle sections. It is clear that the mass ratios for all sections are within the maximum allowable mass limit, which 
was set earlier to $600 \%$. Thus, all sections qualified for further blast attenuation investigation.

Table 4.5: Double Angles Mass calculation

\begin{tabular}{cccccccc}
\hline Section & $\mathbf{t}$ & $\mathbf{a}$ & $\begin{array}{c}\text { Angles } \\
\text { per } \\
\text { Container } \\
\text { Side }\end{array}$ & $\begin{array}{c}\text { Angles } \\
\text { per } \\
\text { Container } \\
\text { End }\end{array}$ & $\begin{array}{c}\text { Areal } \\
\text { Density }\end{array}$ & $\begin{array}{c}\text { Mass of } \\
\text { Container }\end{array}$ & $\begin{array}{c}\text { Mass } \\
\text { Ratio }\end{array}$ \\
& & $(\mathrm{kg})$ & $(\mathrm{kg})$ & $(\%)$ \\
\hline $\mathbf{L 5 1}$ & 3.18 & 25.4 & 120 & 42 & 50.937 & $2.8 \mathrm{E}+03$ & $23 \%$ \\
& 4.76 & & 120 & 42 & 74.957 & $4.1 \mathrm{E}+03$ & $82 \%$ \\
& 6.35 & & 120 & 42 & 98.355 & $5.4 \mathrm{E}+03$ & $138 \%$ \\
& 7.94 & & 120 & 42 & 120.925 & $6.6 \mathrm{E}+03$ & $193 \%$ \\
$\mathbf{L 7 6}$ & 4.76 & 25.4 & 88 & 31 & 83.835 & $4.6 \mathrm{E}+03$ & $103 \%$ \\
& 6.35 & & 88 & 31 & 110.564 & $6.0 \mathrm{E}+03$ & $168 \%$ \\
& 7.94 & & 88 & 31 & 136.687 & $7.5 \mathrm{E}+03$ & $232 \%$ \\
$\mathbf{L} 102$ & 9.53 & & 88 & 31 & 162.505 & $8.9 \mathrm{E}+03$ & $294 \%$ \\
& 6.35 & 25.4 & 69 & 25 & 117.581 & $6.4 \mathrm{E}+03$ & $185 \%$ \\
& 7.94 & & 69 & 25 & 145.633 & $8.0 \mathrm{E}+03$ & $254 \%$ \\
& 9.53 & & 69 & 25 & 173.088 & $9.5 \mathrm{E}+03$ & $320 \%$ \\
& 11.1 & & 69 & 25 & 200.544 & $1.1 \mathrm{E}+04$ & $387 \%$ \\
\hline
\end{tabular}

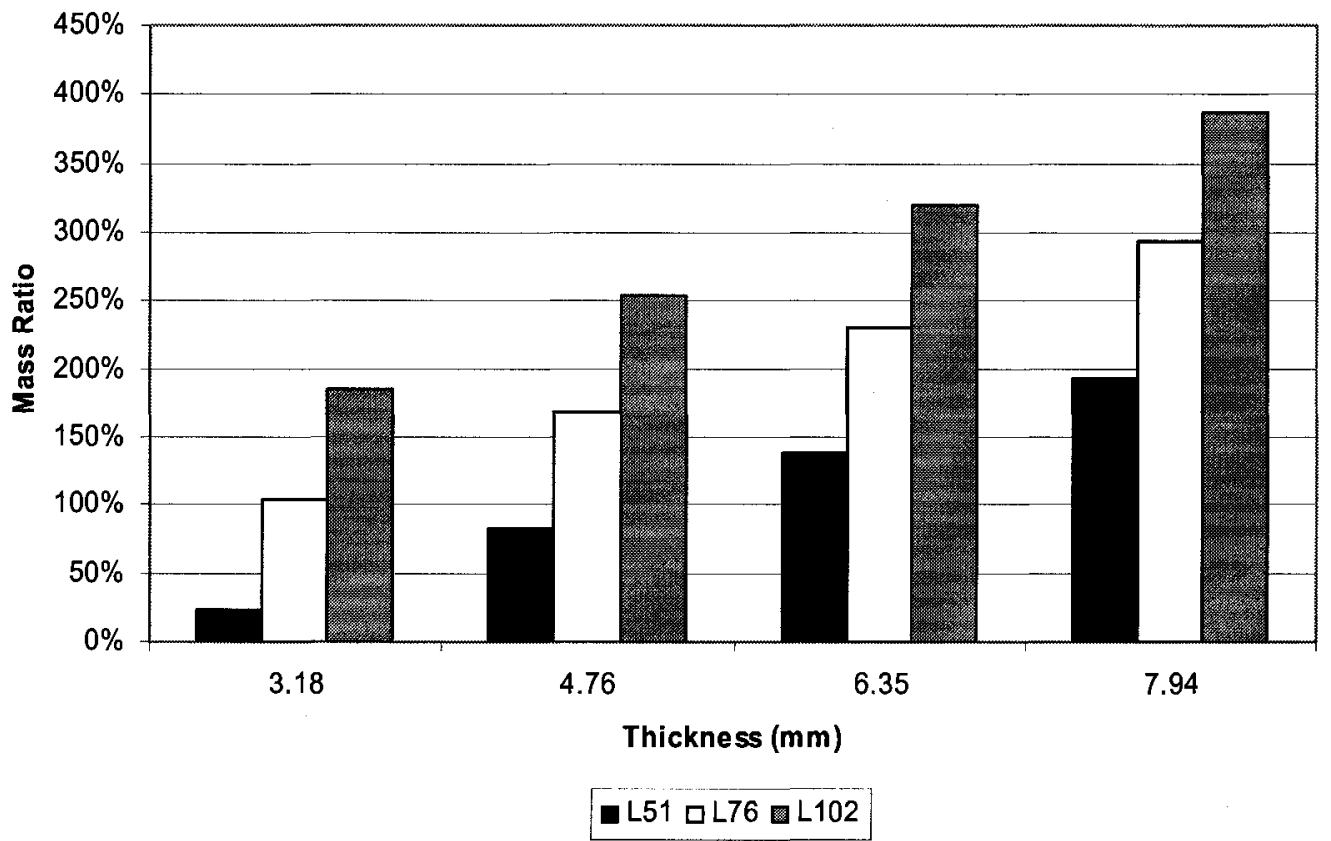

Figure 4.7: Double angles maximum allowable mass limit 


\subsubsection{Blast Attenuation Effect: Model Construction}

After completing the mass and vent area calculations, a 2-D non-structural response study was carried out to check the attenuation effect of different angle sizes in two different configurations, nested and double angle. The following sections describe the model configurations and their attenuation capacity, the results of which will be analysed and compared to determine the optimum configuration in the construction of a container.

For a fair comparison between different models, the size of the air region and the amount of explosive were kept constant in all the models. The thickness of air was maintained at $1 \mathrm{~m}$ in the $\mathrm{x}$-direction and $1.5 \mathrm{~m}$ in the $\mathrm{y}$-direction. Two explosive masses were remapped and used in these models as previously explained. The mesh size for the air sub-grid was set at $2 \mathrm{~mm}$ to have a sufficient number of cells between the angles. Subsequently, the air domain was filled with the remapped explosive charge. The insertion point of the remapped charge was chosen so as to have perpendicular explosion expansion to minimize the effect of oblique reflections. The coordinates of the insertion point was 500 in. the $\mathrm{X}$-direction and $0 \mathrm{in}$. the $\mathrm{Y}$-direction. A flow-out boundary condition was created along the sides of the air domain to allow release of shock thereby simulating blast wave interaction with an infinitely large SSP. After applying the boundary condition for air, the angles were installed one meter from the explosive charge with fixed boundary condition to prevent their movement or their deformation. This allowed purely the study of the attenuation effect. The structural response of angles will be considered later. Subsequently, two arrays of gauges were placed before and after the SSP to track pressure. One gauge was placed before the SSP at $80 \mathrm{~cm}$ from the charge while five gauges were placed beyond the SSP, $10 \mathrm{~cm}$ apart starting at $1.1 \mathrm{~m}$ and ended at $1.5 \mathrm{~m}$ 
from the explosive charge. The reason for two arrays of gauges was to track the shock front to determine when and where the shock front would return back to its normal shape after traversing the SSP. Figures 4.8 and 4.9 show typical models of the nested and double angles configurations.

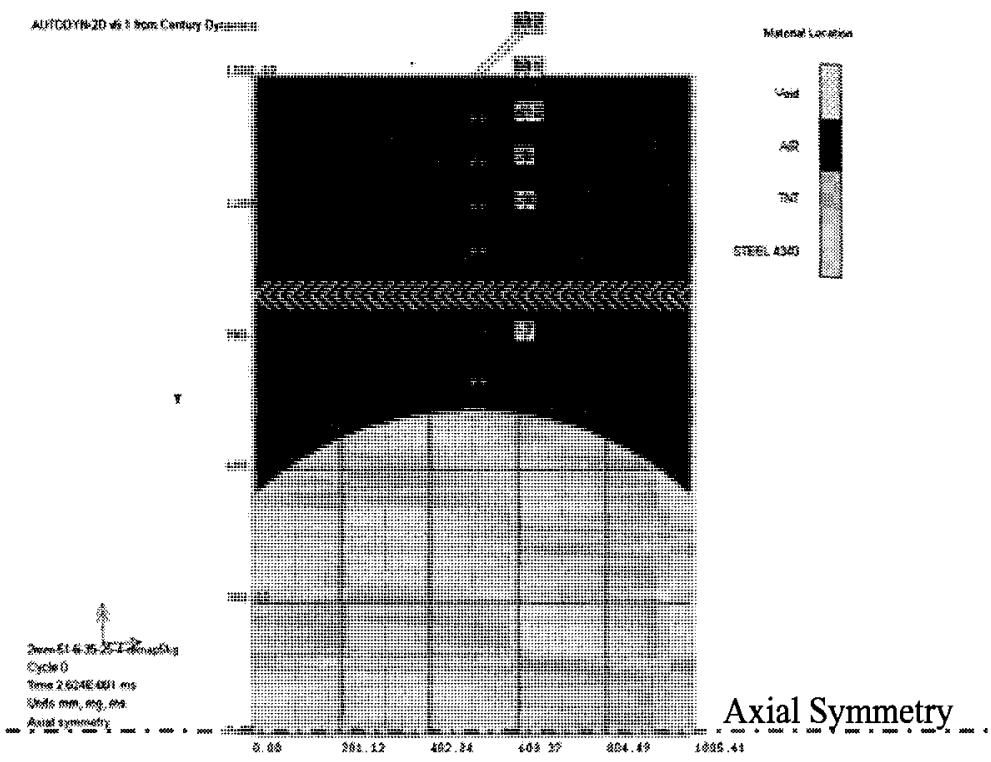

Figure 4.8: Typical model for nested angles

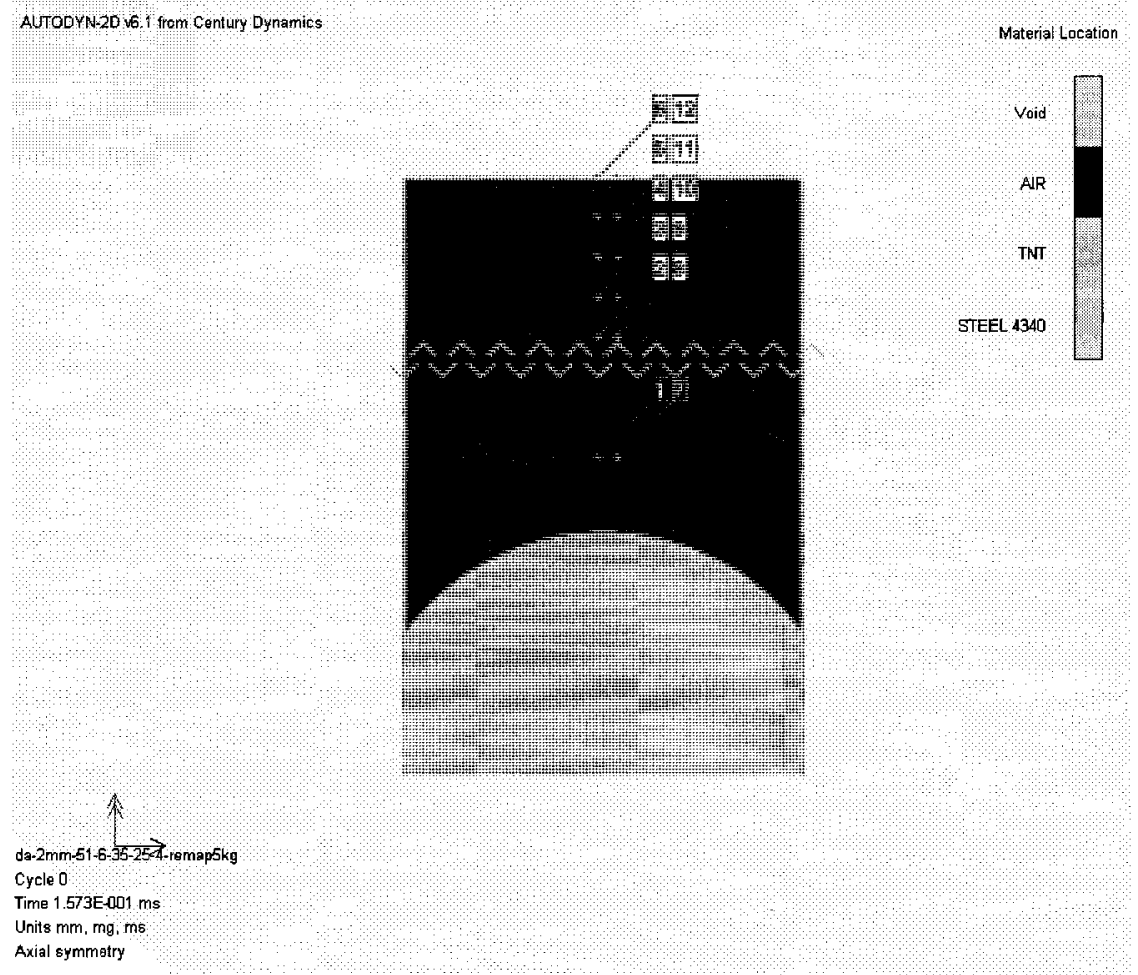

Figure 4.9: Typical model for double angles 


\subsubsection{Pilot Study: Analysis and Discussion}

\subsubsection{Nested angles: $5 \mathrm{~kg}$ charge}

Two models were used to test the attenuation effect for small charges by tracking the blast pressure. These two models were built using the smallest, L51, and largest angle size, L102, with same thickness, and $1 \mathrm{in}$. spacing. The results from this preliminary test will aid in developing models with larger explosive charges.

Figure 4.10 shows the pressure values of for three trials using $5 \mathrm{~kg}$ of TNT. In the first test, the TNT was initiated in air with no structure interaction to check the free air normal attenuation. In the second test, the L51 SSP was used to obstruct the wave while in the third test, the L102 SSP was used. It is clear from the Figure 4.10 that there is difference between the attenuated pressure values among the three models. The pressure value at the first gauge at 0.8 meter was set to one value, which is the value of pressure resulting form the detonation of $5 \mathrm{~kg}$ just in air with no structure interaction. Despite the fact that there are some reflections expected in the models including the suppressive shield structure, this value was used as a reference point. The reflected pressure value is not of concern at this step. The pressure values obtained from the air trial was as high as $4000 \mathrm{kPa}$ at $0.8 \mathrm{~m}$ and as low as $1300 \mathrm{kPa}$ at $1.5 \mathrm{~m}$ due to normal attenuation by air. On the other hand when the SSP was put at one meter from the explosion, it was found that the pressure dropped to as low as $860 \mathrm{kPa}$ for the L51 SSP and $930 \mathrm{kPa}$ for the L102 SSP. 


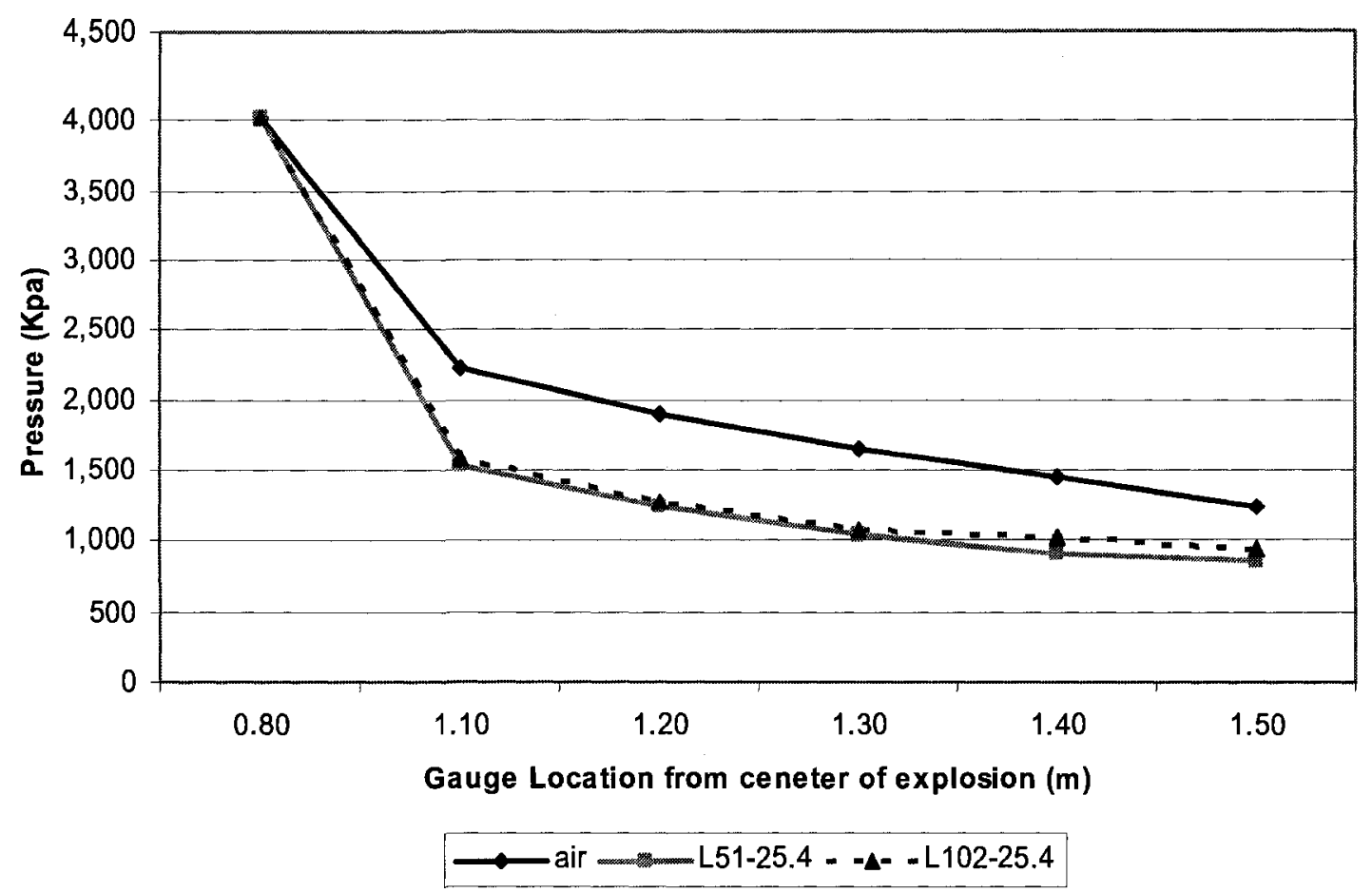

Figure 4.10: Pressure values with respect to different angle size, Nested configuration

Although it was expected that the L102 trial would give more attenuation, the place of gauges played a big role in the difference in pressure values. Since the gauge location were constant and the change was only in the angle size, the distance between the shock front behind the angles and the gauges location was a little different between the two trials. The gauges location was closer to the L102 SSP that to the L51 model due to the difference in angle opening between the two sizes. However, these gauge locations did not cause significant errors.

Figure 4.11 shows a comparison in pressure attenuation percentages between the L51 and L102 compared normal attenuation through air. It is clear that the average attenuation is approximately $30 \%$ compared to the model where there was no SSP. This provides confidence to continue the investigation with larger explosive charges. 


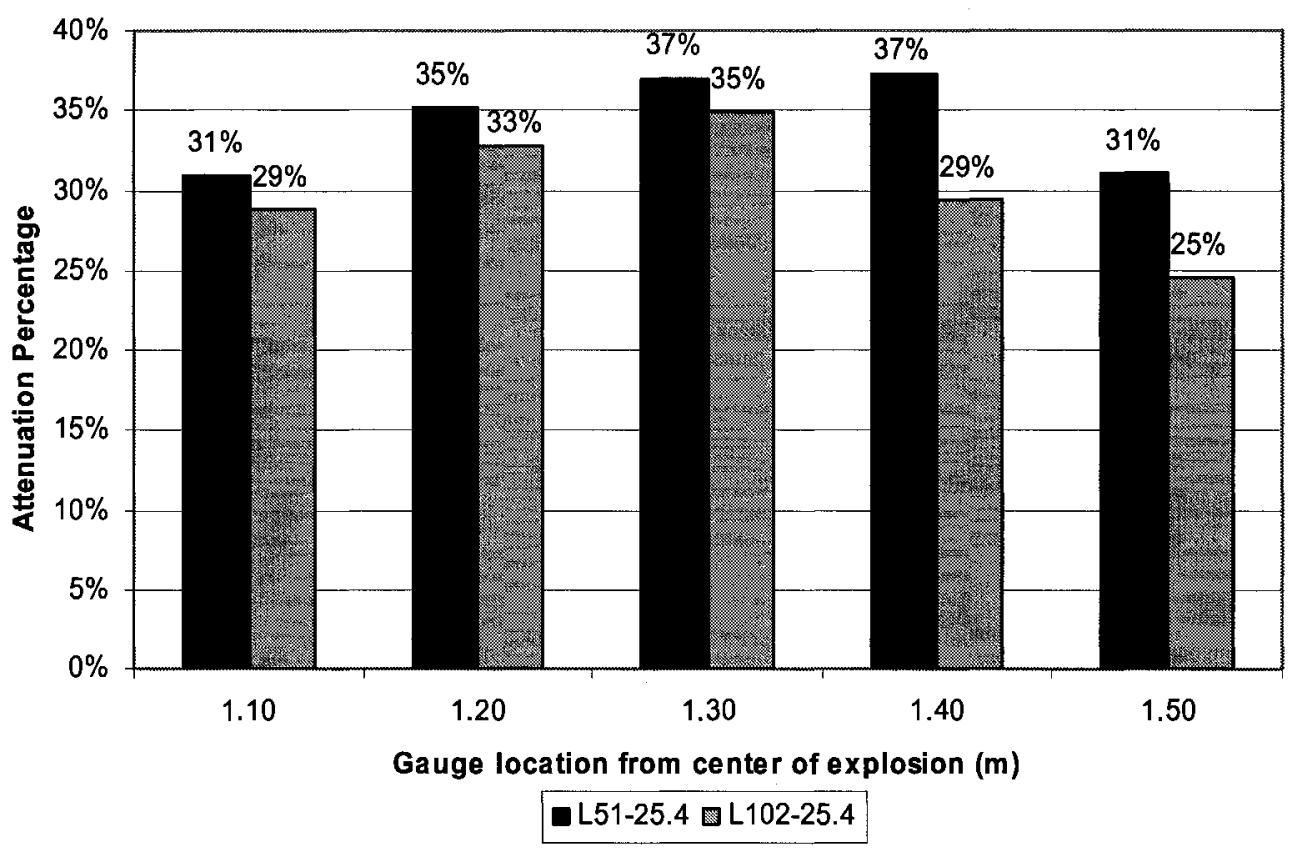

Figure 4.11: Attenuation percentage in pressure for $5 \mathrm{~kg}$, Nested configuration, different angle size

\subsubsection{Nested Angles: 50 kg charge}

Subsequent to the promising results obtained for the $5 \mathrm{~kg}$ tests, further modelling was done with a $50 \mathrm{~kg}$ charge. A total of eleven models were generated using the three angle sizes as well as the maximum number of spacing for each angle size (Table 4.6). A comparison between these configurations will be presented in this section that will help in obtaining the optimum angle size for maximum attenuation.

Table 4.6: Models developed for $50 \mathrm{Kg}$ charge

\begin{tabular}{llll}
\hline Angle Size & L51 & L76 & L102 \\
\hline Spacing $(\mathrm{mm})$ & 12.7 & 12.7 & 12.7 \\
& 25.4 & 25.4 & 25.4 \\
& & 38.1 & 38.1 \\
& & 50.8 & 50.8 \\
& & & 63.5 \\
\hline
\end{tabular}

The L51 models were among the first to be tested. Figure 4.12 shows the pressure values of the three models, which were carried out with the L51. The first model simulated the 
detonation of $50 \mathrm{~kg}$ of TNT in air with no SSP, while the other two models were run with the SSP at $1 \mathrm{~m}$ from the center of explosion. The only difference between the two models is the spacing between angles as shown in Table 4.6. The pressure values obtained from the air trial was as high as $12,400 \mathrm{kPa}$ at $0.8 \mathrm{~m}$ and as low as $5400 \mathrm{kPa}$ at $1.5 \mathrm{~m}$. On the other hand when the SSP was placed at $1 \mathrm{~m}$ from the explosion, it was found that the pressure value was as low as $4600 \mathrm{kPa}$ for the L51/25.4 trial and $3000 \mathrm{kPa}$ for the L51/12.7 trial at $1.5 \mathrm{~m}$. Again, the highest attenuation occurred with the SSP with the smaller gap. Full attenuation results when there are no gaps in the SSP.

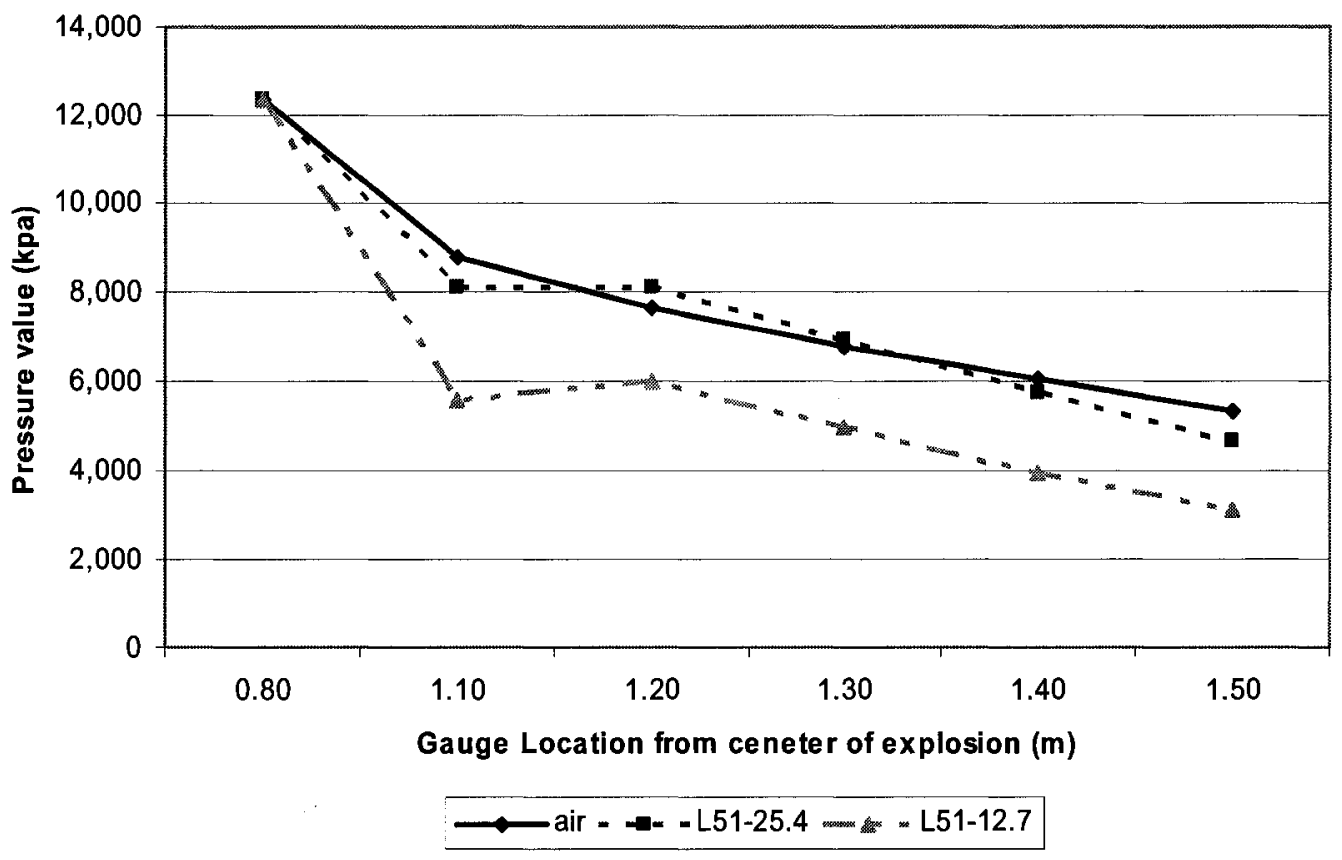

Figure 4.12: L51 pressure values with different spacing

The increase in pressure value at the $1.2 \mathrm{~m}$ gauge was due to the jets resulting from the breaking of the shock front at the SSP as illustrated in Figure 4.13. The shock front started to reform again after that and it could be seen in the reduction observed in the pressure values at and after the gauges at the $1.3 \mathrm{~m}$. 


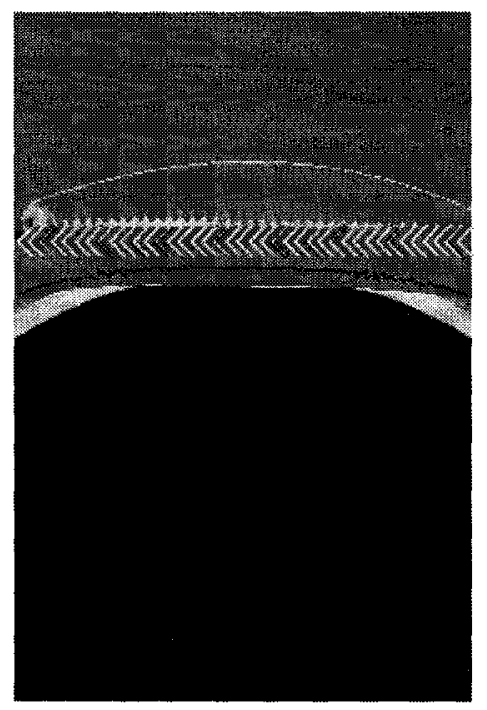

Figure 4.13: Jets formation through nested configuration

It is obvious from Figure 4.14 that the pressure attenuation of the $12.7 \mathrm{~mm}$ spacing is much higher than that of $25.4 \mathrm{~mm}$ spacing. The negative values shown for the $25.4 \mathrm{~mm}$ spacing were due to the jets resulting from breaking of the shock front on the SSP. The optimum model to satisfy the maximum allowable mass limit was that for the L51/25.4. Thus, the L51/25.4 model will be compared later on with the optimum models from the other angles sizes to determine the optimum design for the nested configuration.

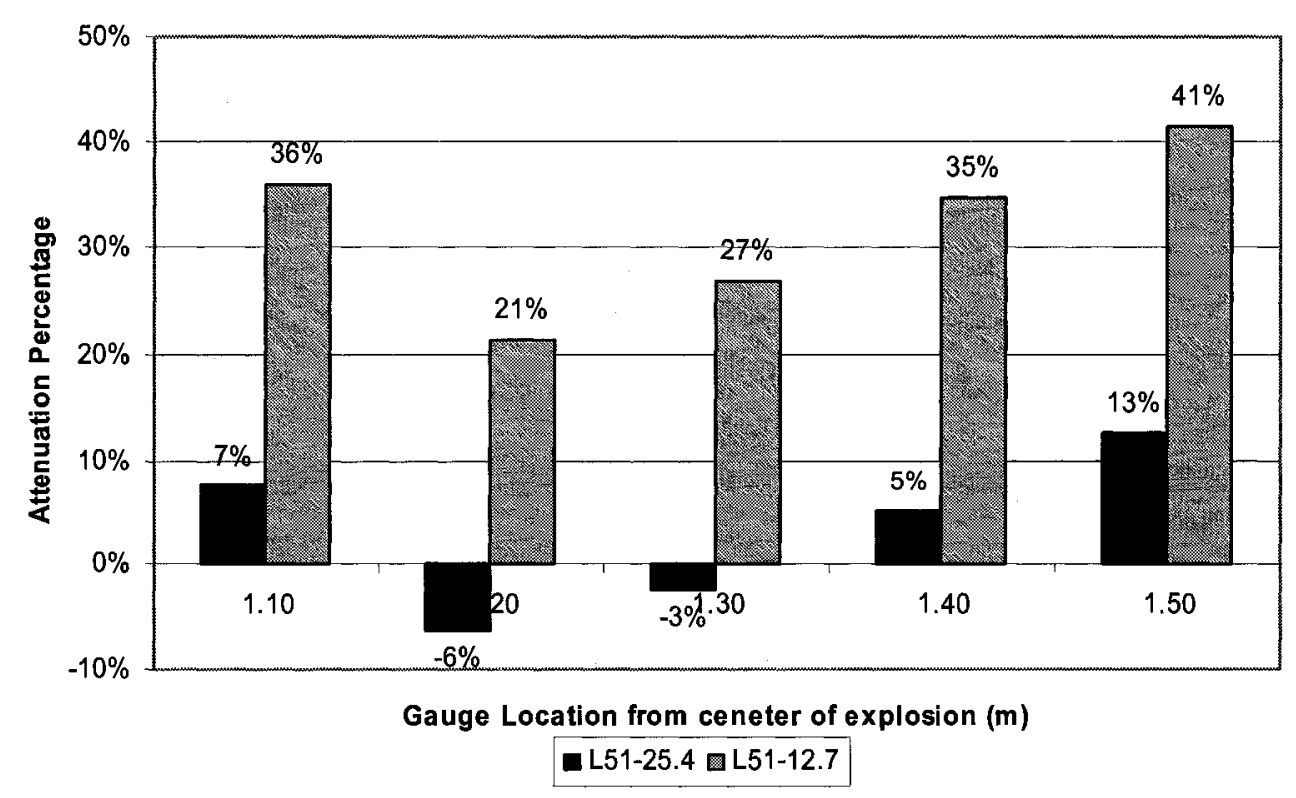

Figure 4.14: Attenuation percentage in pressure for $50 \mathrm{~kg}$, L51 Nested, different spacing 
Four models were developed to test the pressure attenuation using L76 section with different spacing. Figure 4.15 illustrates the pressure values for the different spacing. Once again, with the pressure at the $0.8-\mathrm{m}$ gauge set to a constant value, the sudden increase in pressure at the $1.2-\mathrm{m}$ gauges due to jetting was again witnessed. However beyond the gauges at $1.2 \mathrm{~m}$, it is obvious that there was attenuation with all models. As expected the best attenuation was achieved with the $12.7 \mathrm{~mm}$ spacing followed by the $50.8 \mathrm{~mm}$, and then the 38.1 and the $25.4 \mathrm{~mm}$, as illustrated in Figure 4.16. Since the aerial density of the $12.7-\mathrm{mm}$ SSP was higher than the maximum allowable limit, it was not considered. On the other hand, models with 38.1 and $50.8 \mathrm{~mm}$ will be considered since they satisfied the mass limit and produced satisfactory pressure attenuation.

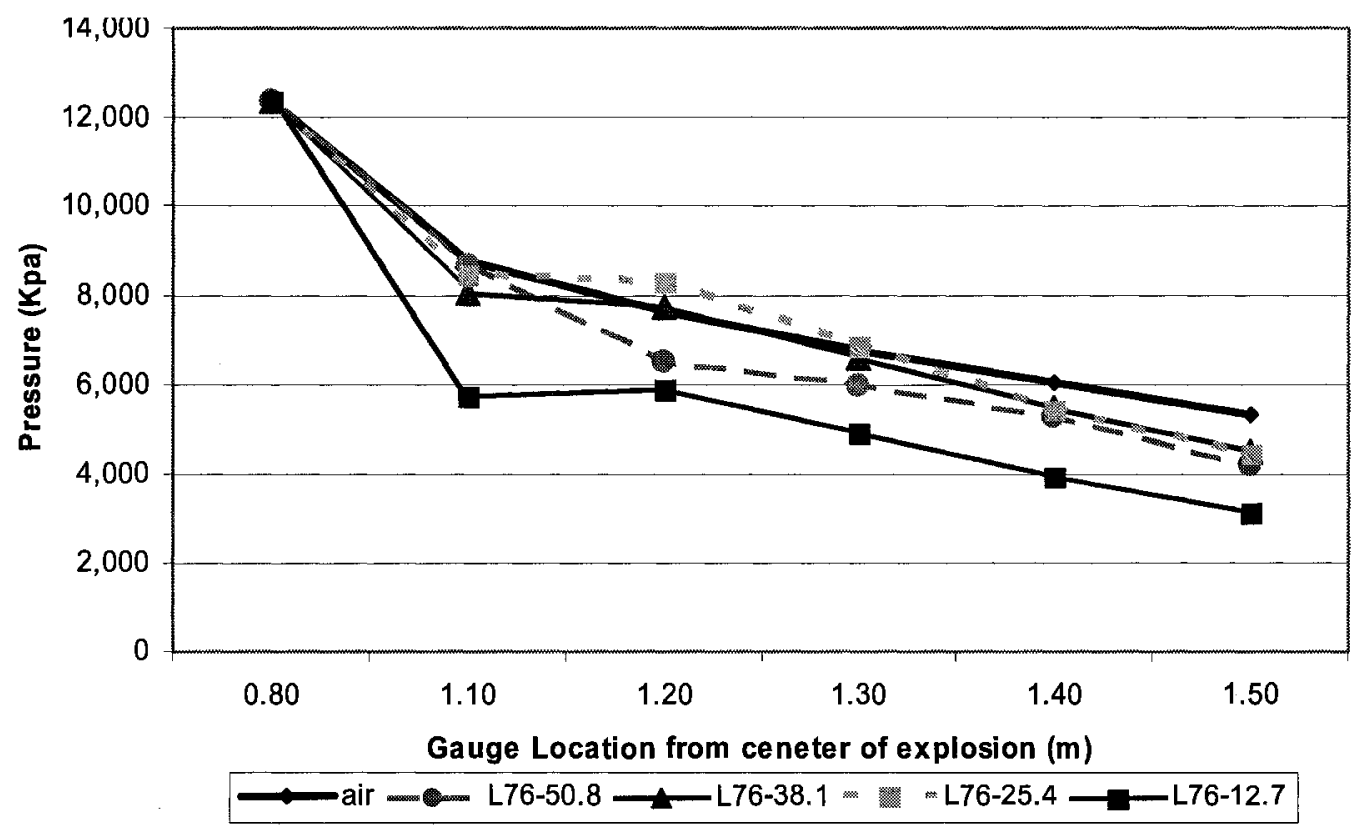

Figure 4.15: L76 pressure values with different spacing 


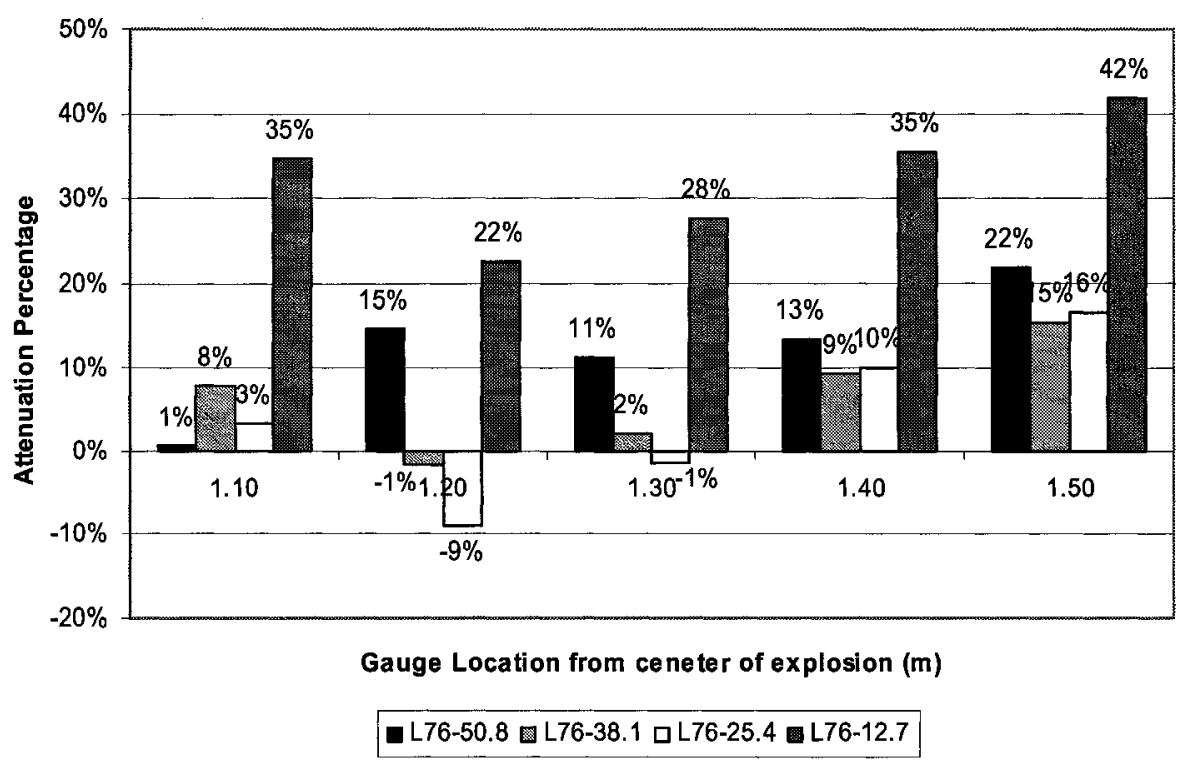

Figure 4.16: Attenuation percentage in pressure for $50 \mathrm{~kg}$, L76 Nested, different spacing

The five models built with the L102 angles showed similar behaviour as the others, showing attenuation after the sudden increase at the 1.2 meters gauge (Figure 4.17). The maximum attenuation was achieved with the $12.7 \mathrm{~mm}$ gap, however it has to be excluded because it exceeds the allowable mass limit. The models that were within the mass limit were the $63.5,50.8,38.1 \mathrm{~mm}$ models. Thus, a quick comparison of their attenuation to find the optimum model indicated that there was not much difference among them but there was a big difference in their mass. The mass was found to range between 8.5 tonnes for the 63.5 millimetres to 14 tonnes for the $38.1 \mathrm{~mm}$ when incorporated in transport container. 


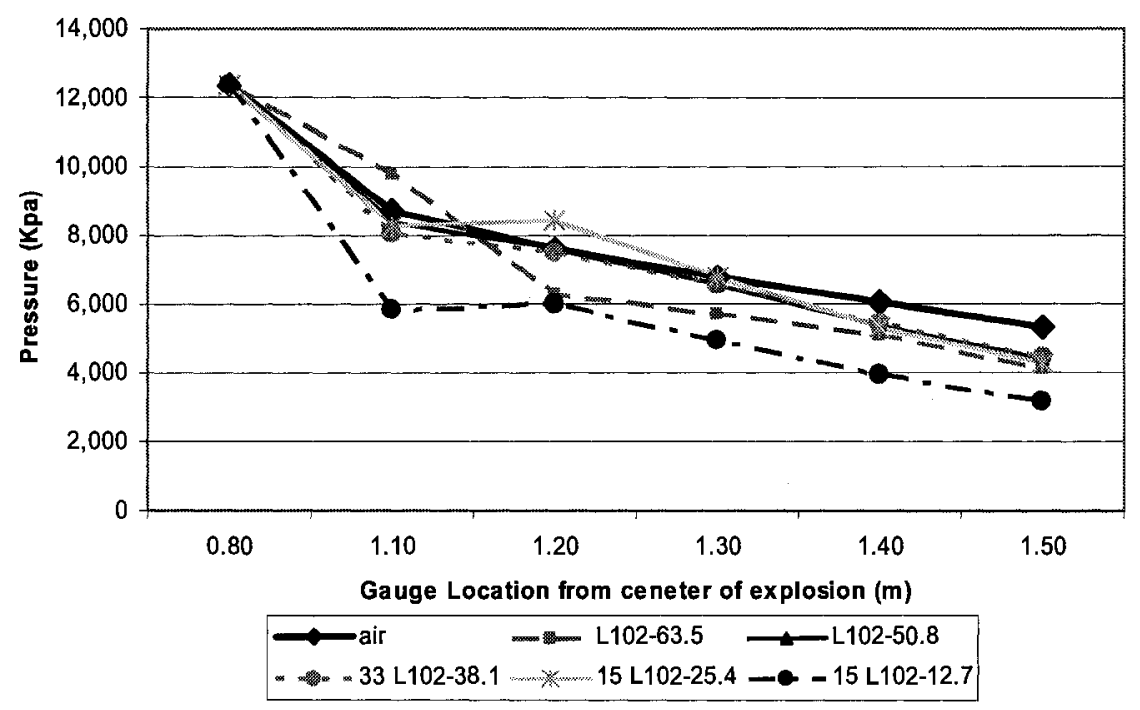

Figure 4.17: L102 pressure values with different spacing

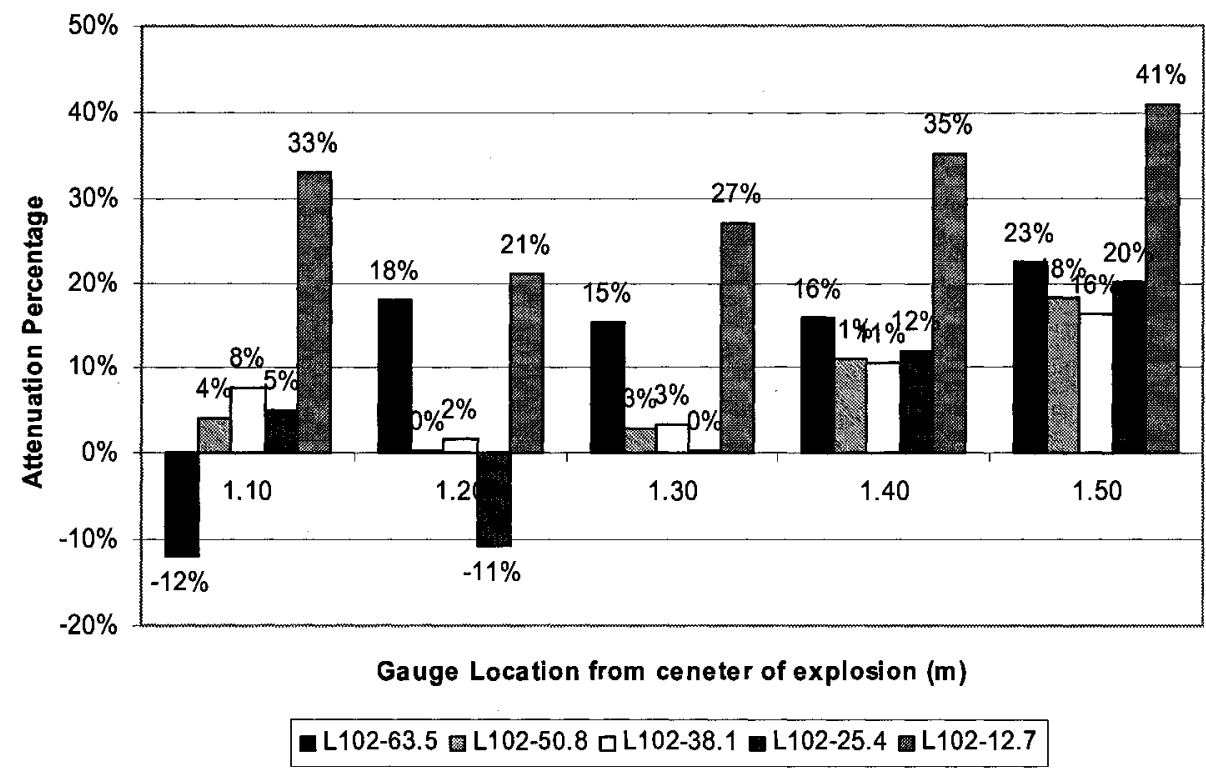

Figure 4.18: Attenuation percentage in pressure for $50 \mathrm{~kg}, \mathrm{L102}$ Nested, different spacing

After analyzing the blast attenuation with gap size, it was decided to determine the effect of path length on the attenuation. Figures 4.19 through 4.22 showed that the path length (angle length) has small or negligible effect on the attenuation therefore; it was decided to focus on SSP with the lowest aerial density. 


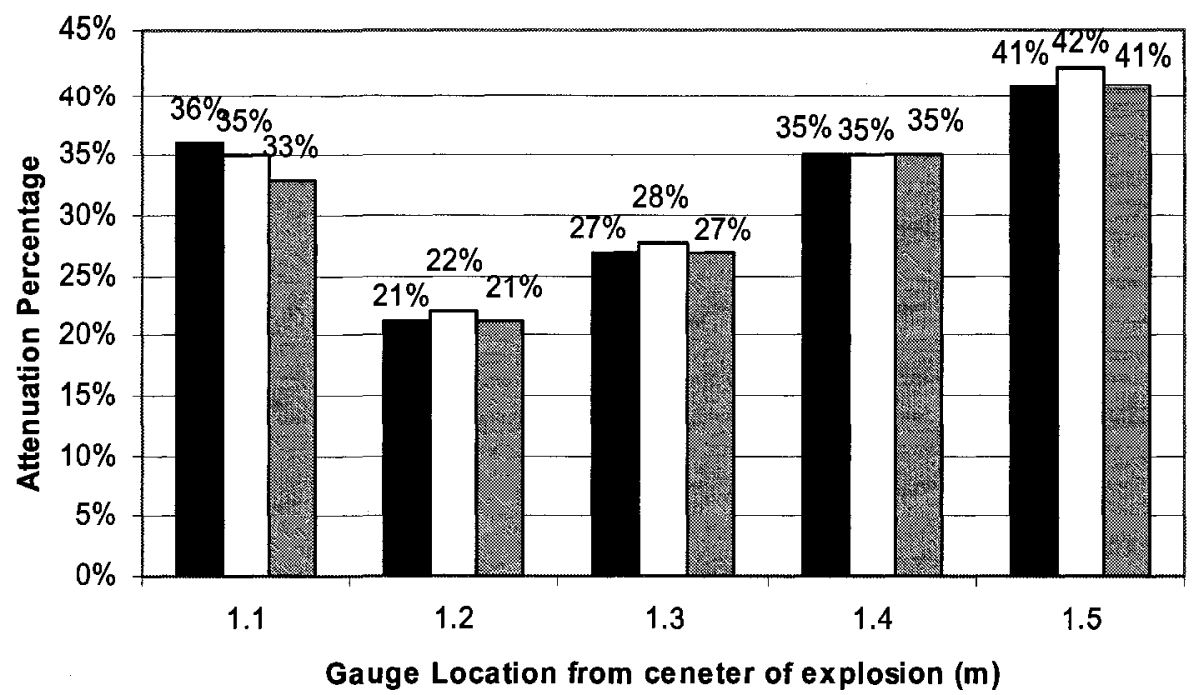

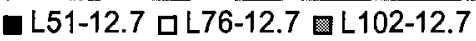

Figure 4.19: $12.7 \mathrm{~mm}$ spacing, different angle size

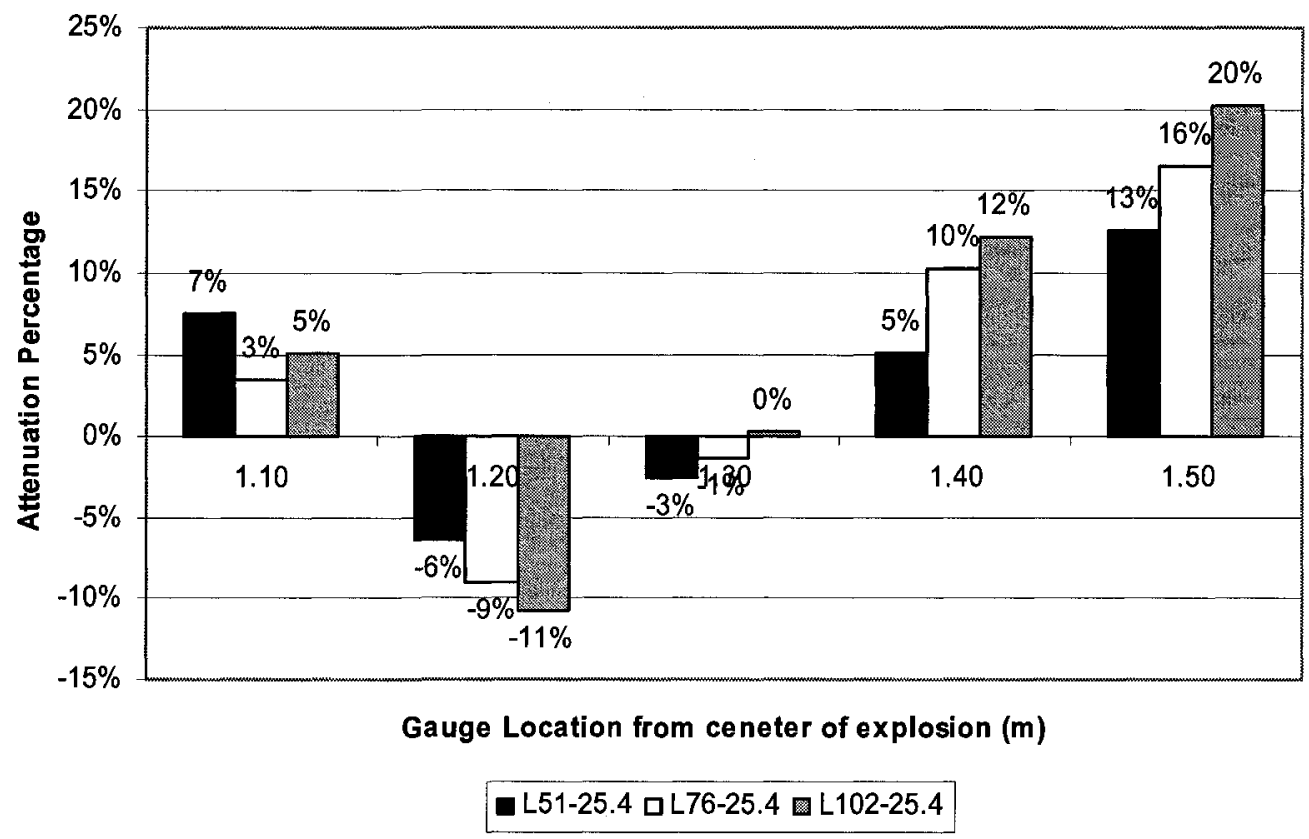

Figure 4.20: $25.4 \mathrm{~mm}$ spacing, different angle size 


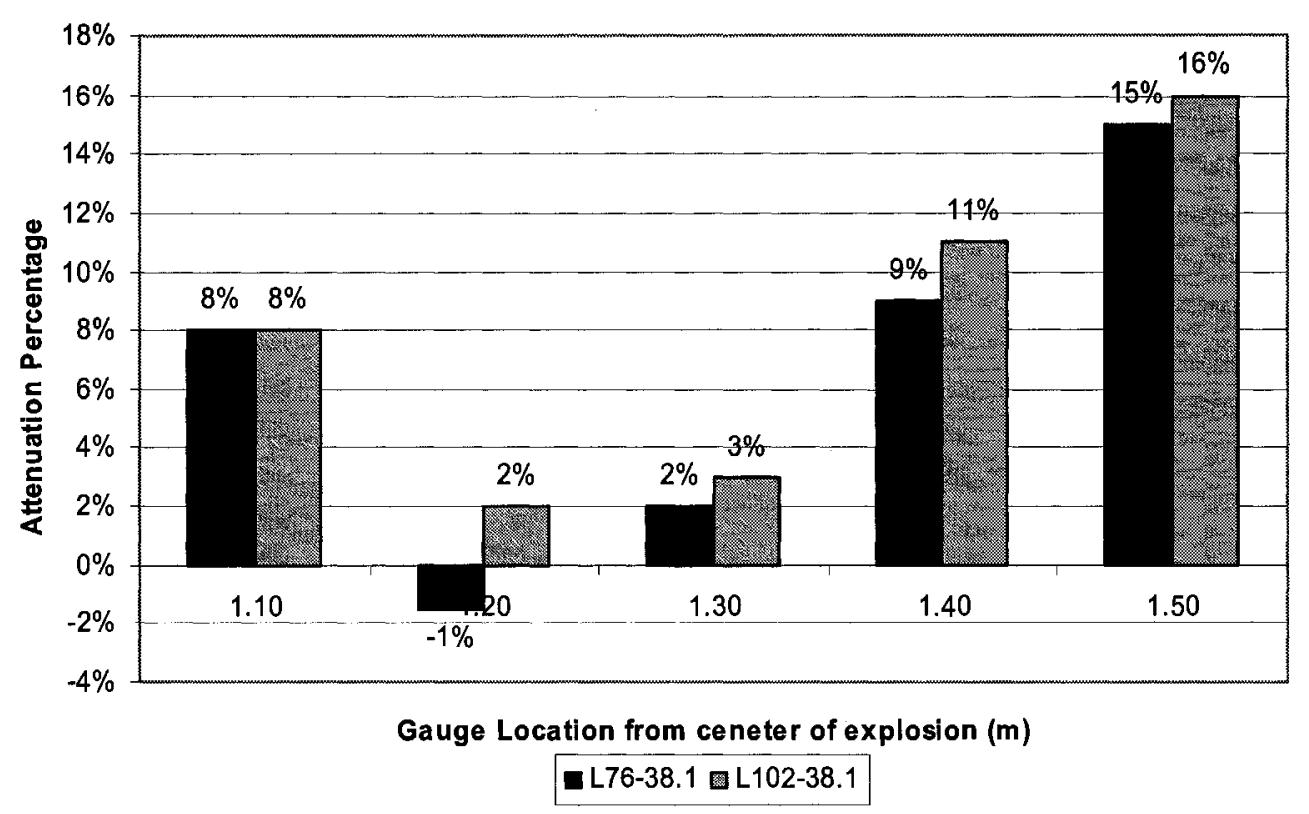

Figure 4.21: $38.1 \mathrm{~mm}$ spacing, different angle size

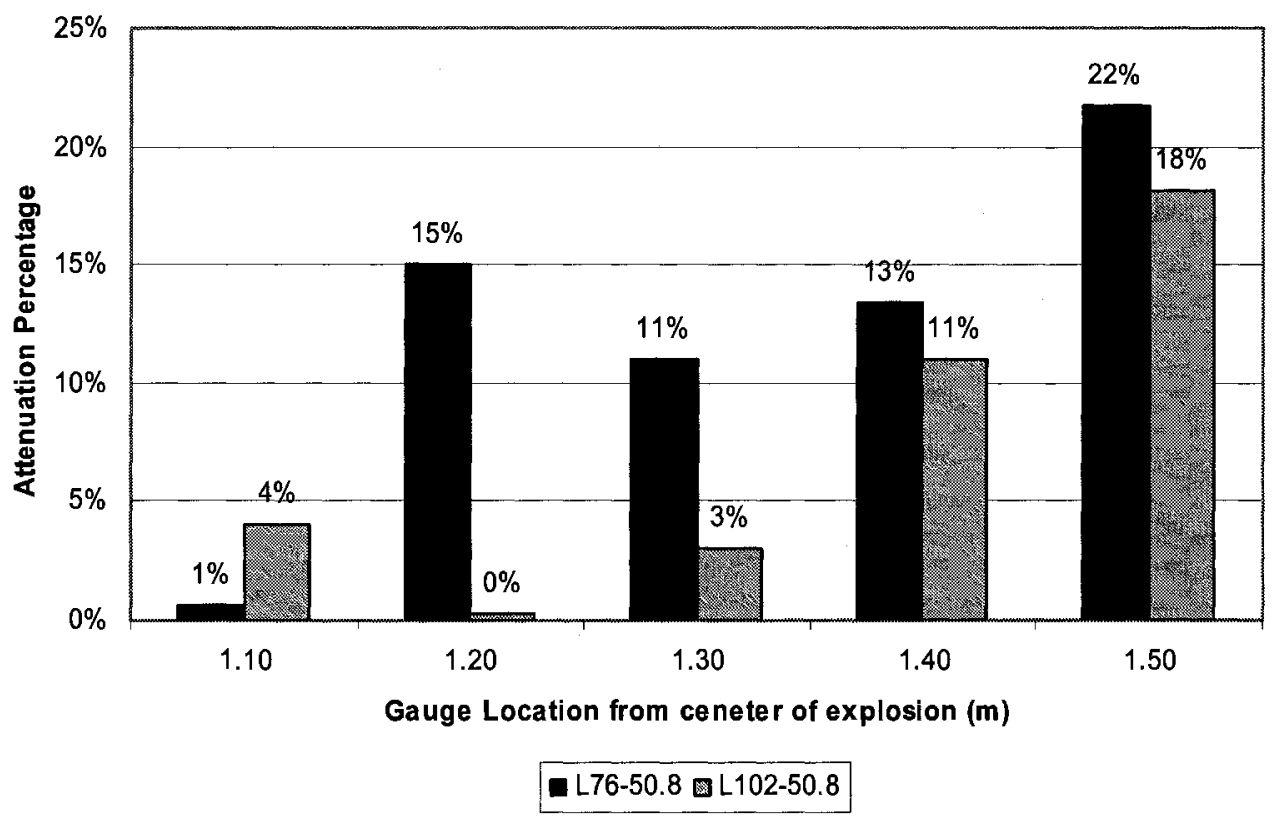

Figure 4.22: $50.8 \mathrm{~mm}$ spacing, different angle size

To compare the different models with aerial density, three averaged areal densities were computed. The $150 \mathrm{~kg} / \mathrm{m}^{2}$ areal density included two models, the $\mathrm{L} 76 / 50.8$ and the $\mathrm{L} 102 / 63.5$. The $190 \mathrm{~kg} / \mathrm{m}^{2}$ areal density included three models, the $\mathrm{L} 51 / 25.4$, the 
L76/38.1, and the $\mathrm{L} 102 / 50.8$. Finally the $270 \mathrm{~kg} / \mathrm{m}^{2}$ included the $\mathrm{L} 76 / 25.4$ and the L102/38.1. Figure 4.23 shows a comparison of the two models comprising $150 \mathrm{~kg} / \mathrm{m}^{2}$ averaged areal density. It is clear from this figure that both models gave approximately the same pressure attenuation, however the L76/50.8 model is preferable since it has the lower aerial density (Table 4.3). Therefore, it is recommended to use the L76/50.8 model.

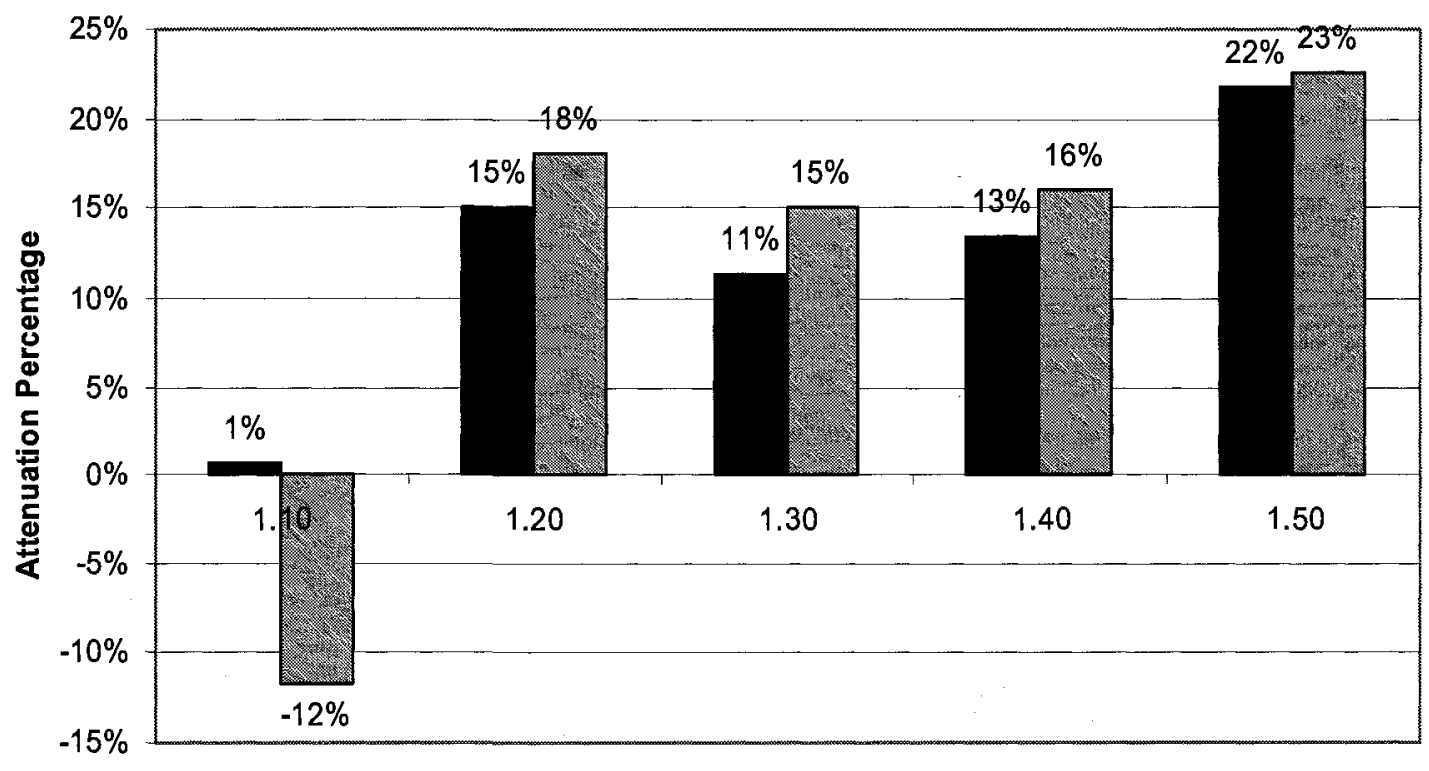

Gauge Location from ceneter of explosion (m)

L76-50.8 $\mathrm{L}$ L102-63.5

Figure 4.23: Attenuation percentage for average areal density $150 \mathrm{~kg} / \mathrm{m}^{2}$

Figure 4.24 shows a comparison of different models with average areal density of 190 $\mathrm{kg} / \mathrm{m}^{2}$. Again, there is almost no difference in pressure attenuation especially at the 1.4 and 1.5 meters gauges where the effect of jets is minimal; hence any model can be used for this average areal density. Finally, Figure 4.25 shows a comparison of models with average areal density of $270 \mathrm{~kg} / \mathrm{m}^{2}$. Again there is no change in attenuation percentage and thus any model can be used. 


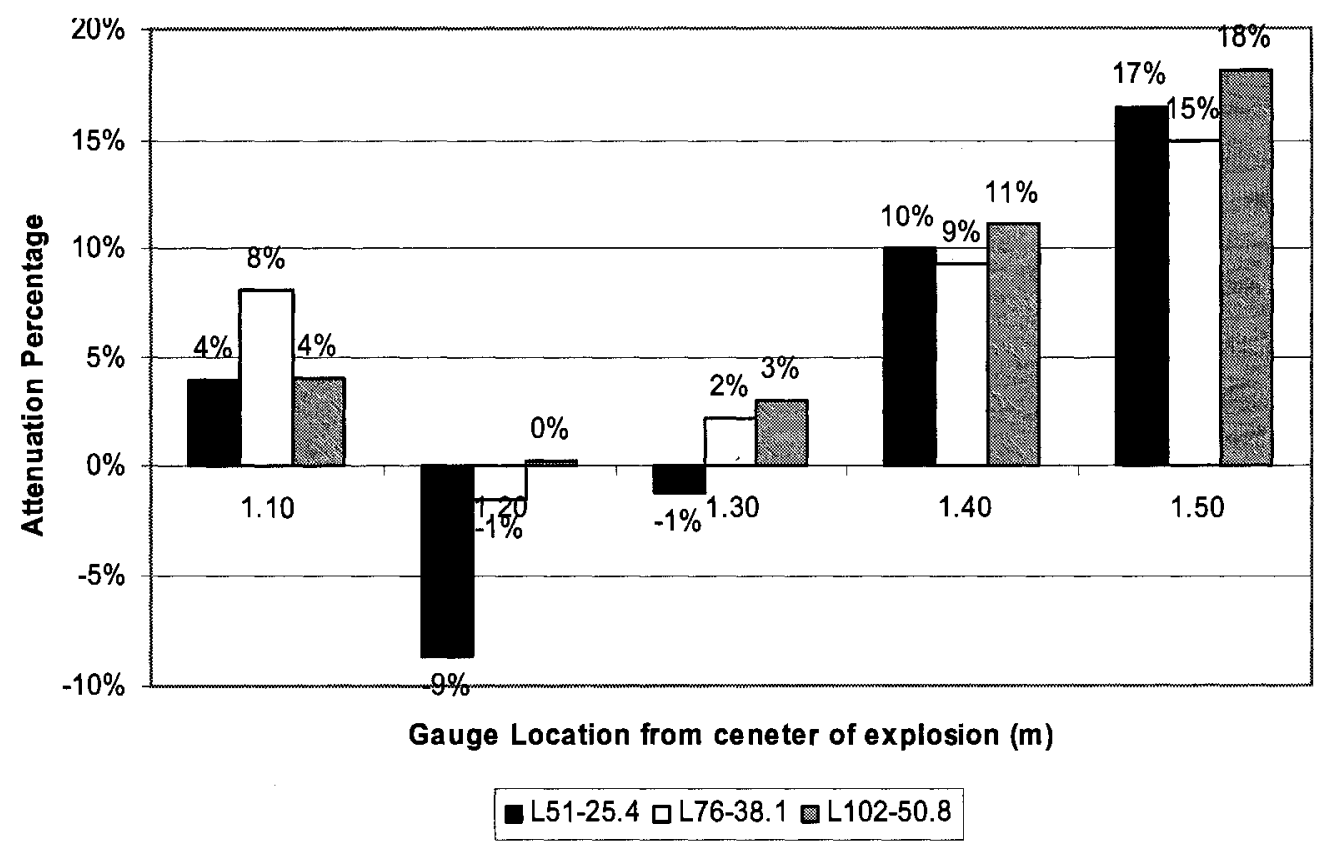

Figure 4.24: Attenuation percentage for average areal density $190 \mathrm{~kg} / \mathrm{m}^{2}$

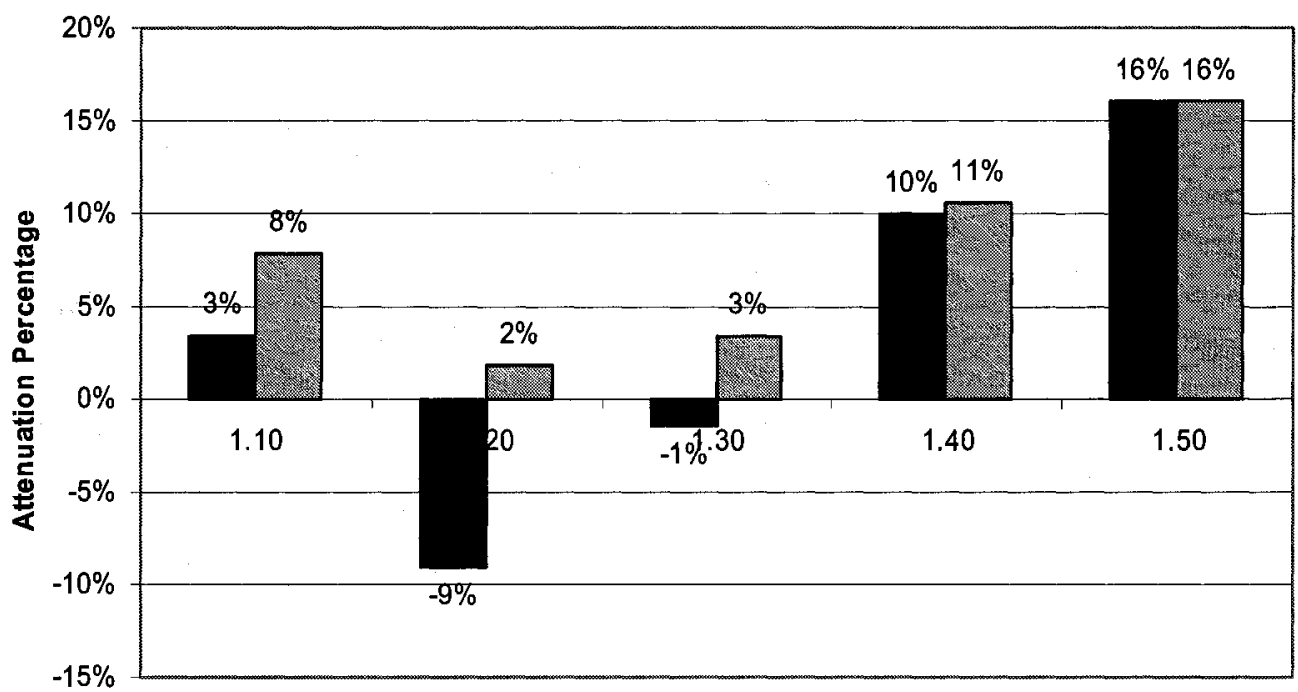

Gauge Location from ceneter of explosion (m)

L76-25.4 눙 L102-38.1

Figure 4.25: Attenuation percentage for average areal density $270 \mathrm{~kg} / \mathrm{m}^{2}\left(A_{\mathrm{v}}=11 \%\right)$

The above comparison based on areal density showed that the models with smallest areal density gave the highest pressure attenuation, $23 \%$ for $\mathrm{L} 102 / 63.5$ and $22 \%$ for $\mathrm{L} 76 / 50.8$ at $1.5 \mathrm{~m}$ gauge compared to $18 \%$ for $\mathrm{L} 102 / 50.8$ and $16 \% \mathrm{~L} 102 / 38.1$ with areal density of 
$190 \mathrm{~kg} / \mathrm{m}^{2}$ and $270 \mathrm{~kg} / \mathrm{m}^{2}$ respectively. Therefore, the best nested configuration model was the $\mathrm{L} 76 / 50.8$ for the $50 \mathrm{~kg}$ explosive charge.

\subsubsection{Double Angles: $5 \mathrm{~kg}$ charge}

Two models were used to test the effect of small charges on the attenuation when the angle size was changed. They were built using the smallest, L51, and largest angle size, L102, with same thickness and $2.54 \mathrm{~cm}$ spacing. Figure 4.26 shows the pressure values resulting from the detonation of a $5 \mathrm{~kg}$ TNT charge. The pressure values obtained from the air trial were the same as for the nested configuration. On the other hand when the SSP was put at 1-m from the explosion, it was found that the pressure value was as low as $783 \mathrm{kPa}$ for the L51 trial and $611 \mathrm{kPa}$ for the L102 trial. Note that the two lines of gauges were installed one in front of the opening and the other in front of the angles. It is clear from the figure that the pressure values are going down then up again and this is because of the jets resulting from the double angle configuration as shown in Figure 4.27.

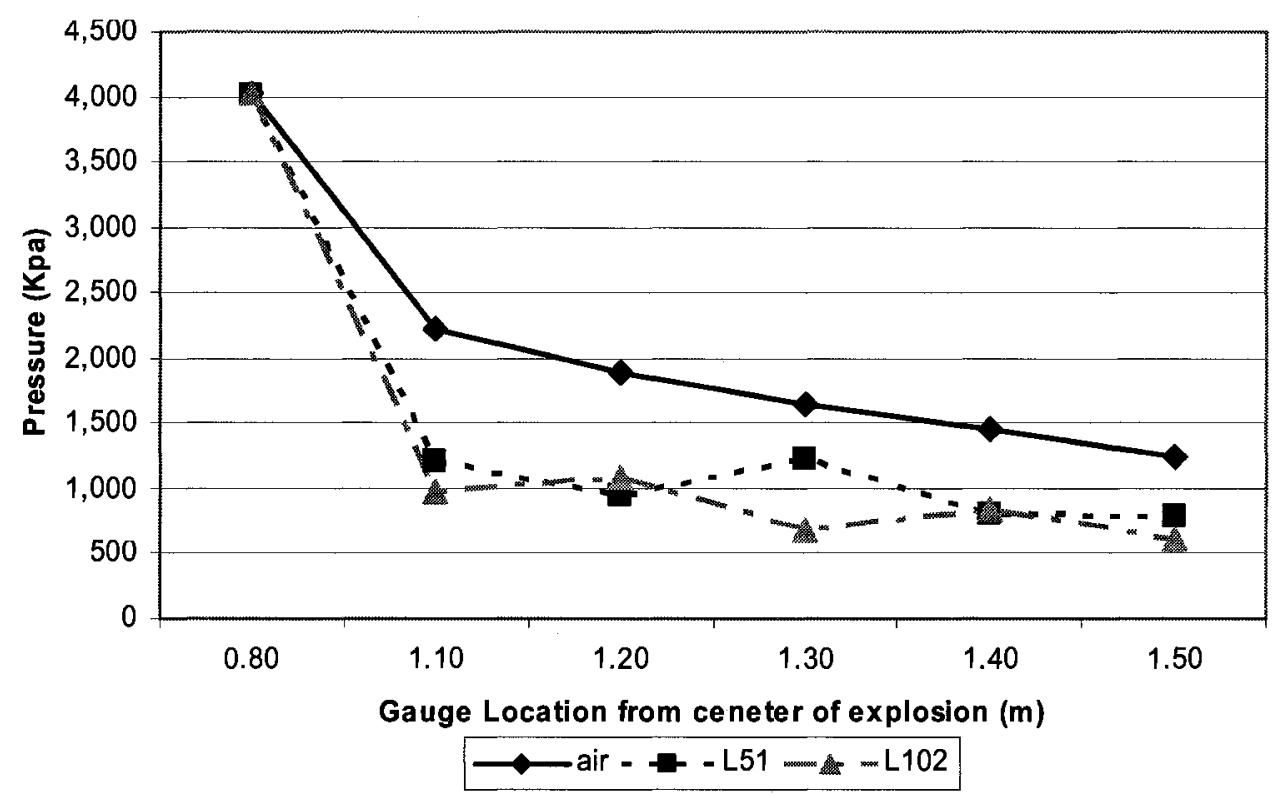

Figure 4.26: Pressure values with respect to different angle size, Double Angle configuration 


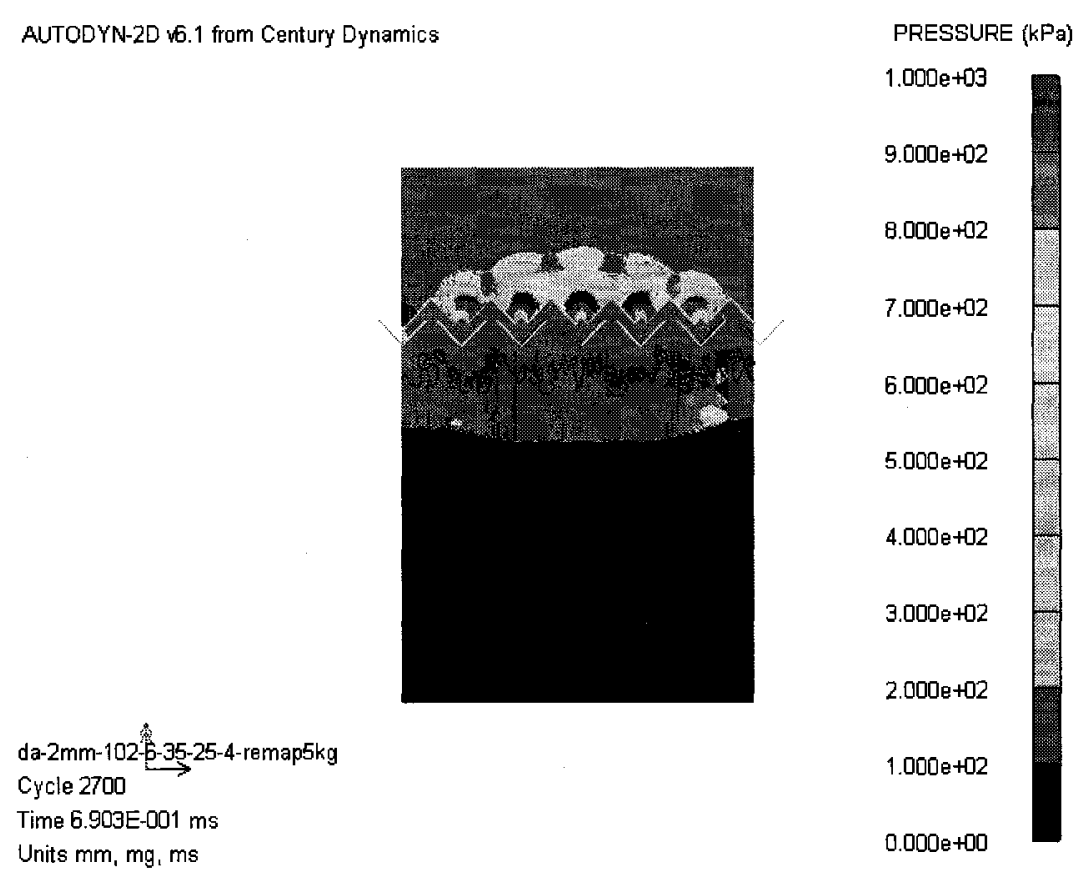

Figure 4.27: Double Angle Jets

Figure 4.28 represents a comparison in pressure attenuation between the L51 and L102 indicating that the average attenuation is approximately $40 \%$ for L51 model and $50 \%$ for L102. The average attenuation in pressure with this configuration is higher than with the nested configuration as will be shown later.

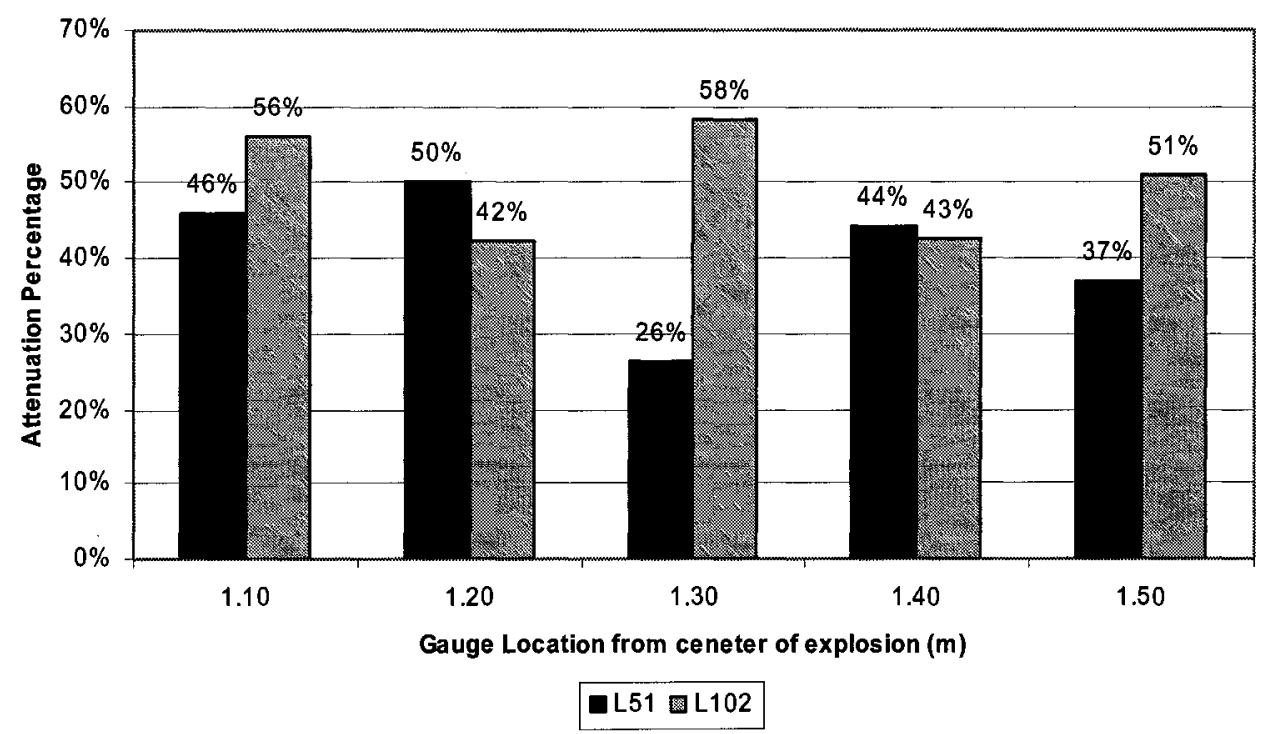

Figure 4.28: Attenuation percentage in pressure for $5 \mathrm{~kg}$, Double configuration, different angle size 


\subsubsection{Nested Angles vs Double Angles}

The pilot study was completed by comparing the results for the nested and the double angle configurations for a $5 \mathrm{~kg}$ TNT charge (Figure 4.29). The pressure value obtained from the air trial for both configurations was $1300 \mathrm{kPa}$ at 1.5 meters. The pressure values with the SSPs at $1 \mathrm{~m}$ from the center of explosive was $860 \mathrm{kPa}$ for L51-Nested and 930 $\mathrm{kPa}$ for L102-Nested however, the pressure values for the Double angle configuration was $783 \mathrm{kPa}$ for L51-Double and $611 \mathrm{kPa}$ for L102-Double. It is clear that the Double angle configuration achieved more attenuation than Nested configuration as indicated in Figures 4.30 and 4.31 .

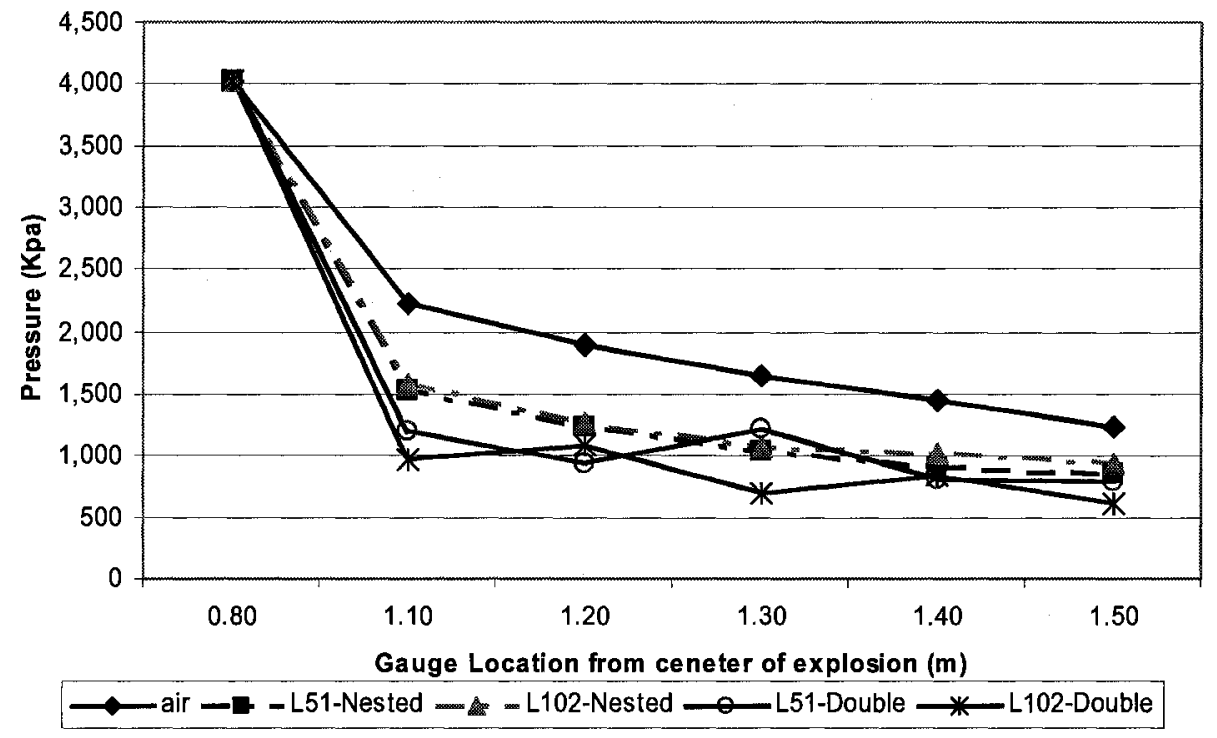

Figure 4.29: Pressure values with respect to different angle configuration

Figure 4.30 shows that the attenuation for L51-Nested was 31\% compared to L51-Double which was $37 \%$. Not only double angle configuration gave higher attenuation but it also has the lower aerial density. Figure 4.31 shows that the L102-Double configuration 
achieved much better pressure attenuation ( $51 \%$ at $1.5 \mathrm{~m}$ from the explosion) compared to the L102-Nested and at the same time better than the L51-Double attenuation.

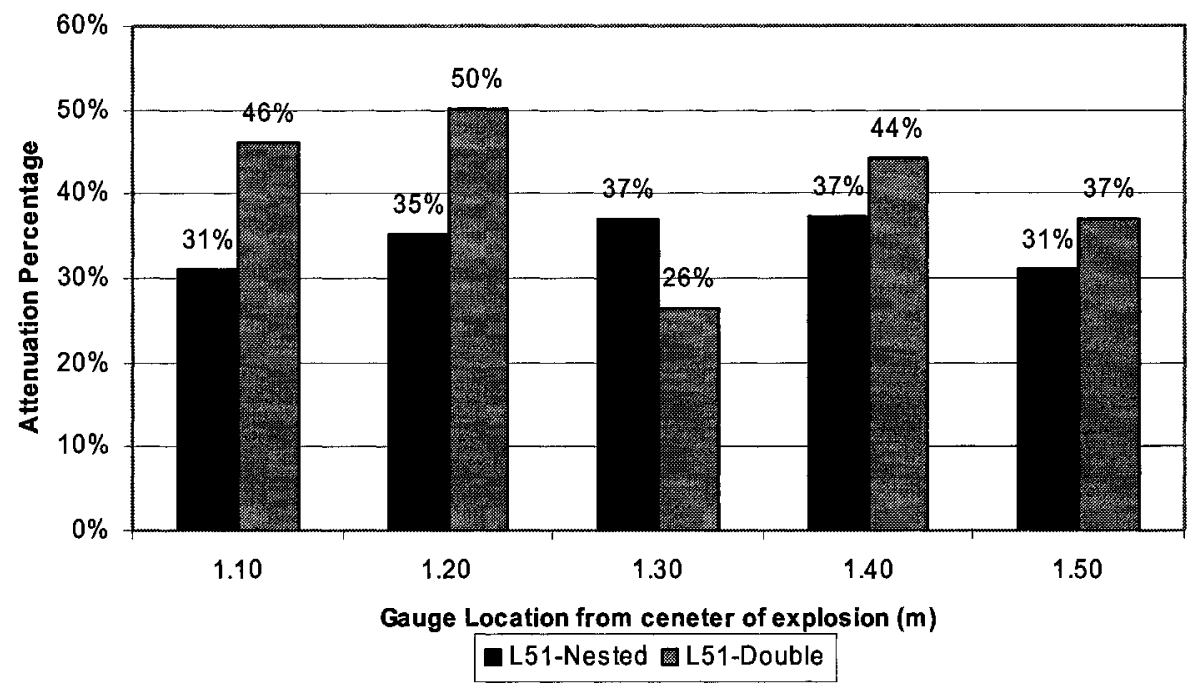

Figure 4.30: Attenuation percentage in pressure with respect to different configuration, L51

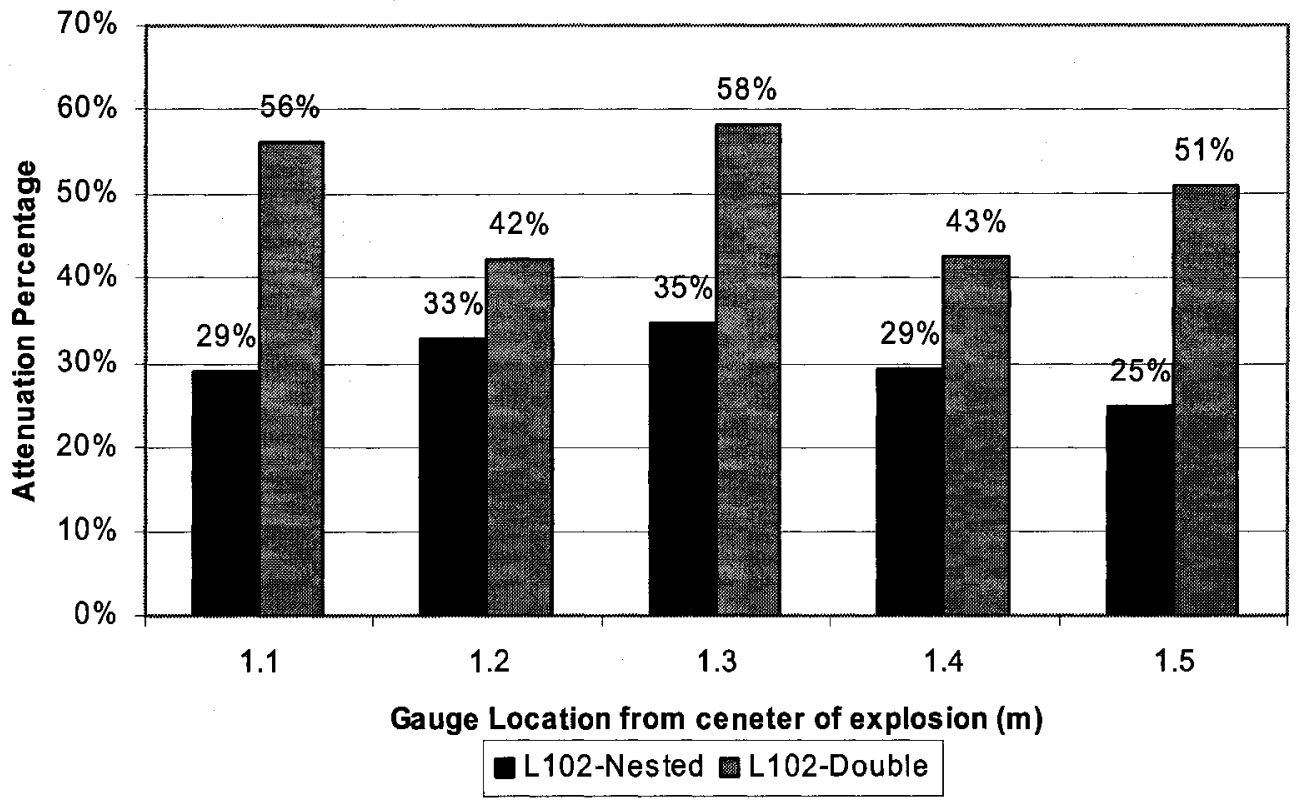

Figure 4.31: Attenuation percentage in pressure with respect to different configuration, L102

The results obtained from this pilot study showed the capabilities of SSPs to reduce blast parameters especially with the double angle configuration; therefore an experimental 
study was setup to investigate the attenuation capacity of different, double angle configurations in more detail. The results of this exercise are presented in next chapter. 


\section{Chapter 5}

\section{Experimental Investigation}

\section{Introduction}

The results obtained in the preliminary study in chapter 4 showed potential for the proposed designs of suppressive shield panels (SSPs) with double angle configuration. These results led to setting up a comprehensive experimental investigation to study the attenuation capacity of different double angles configurations SSPs in more details. This chapter presents the details of the experimental investigation, describes its procedures including test facility, samples characteristics, material properties, test set-up and explosive charges used. The testing program was carried out in two separate stages. The first involved subjecting the SSPs to blast loads from $0.25,0.50$ and $1.00 \mathrm{~kg}$ of explosive. The second stage utilized an additional add-on layer of newly developed Aluminum Foam termed (AF). The tests were carried out utilizing $0.50 \mathrm{~kg}$ of explosive and three different AF thicknesses.

\subsection{Test Facility}

Experimental tests were performed with Queen's University blast chamber $(2380 \mathrm{~mm}$ in diameter, $3040 \mathrm{~mm}$ deep and $1770 \mathrm{~mm}$ high) as shown in Figure 5.1. Since it was so expensive to build full SS containers for testing, SSPs with the same dimensions as the blast chamber door were built. The blast chamber door was removed and in its stead was placed the SSPs for testing. The door dimensions were $600 \mathrm{~mm}$ wide and $1400 \mathrm{~mm}$ high. 
Figure 5.2 shows a view from inside the chamber door. Testing was performed with up to $1 \mathrm{~kg}$ of TNT to remain within the limit of the blast chamber.

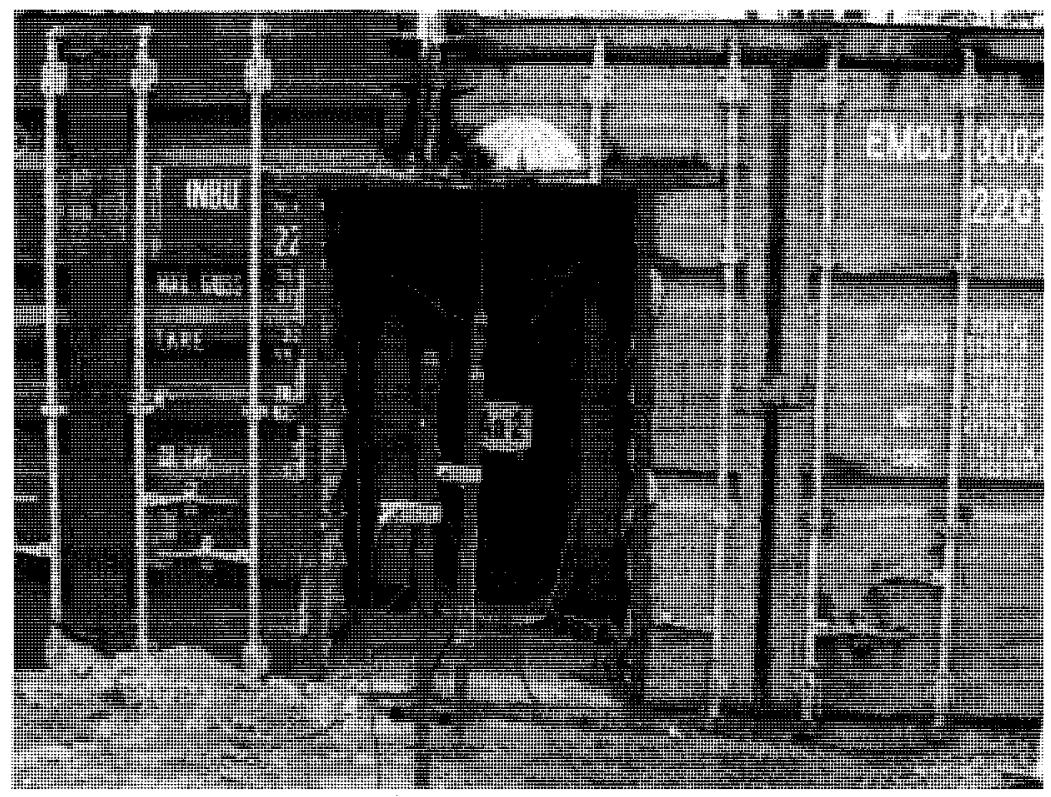

Figure 5.1: Front view of the chamber

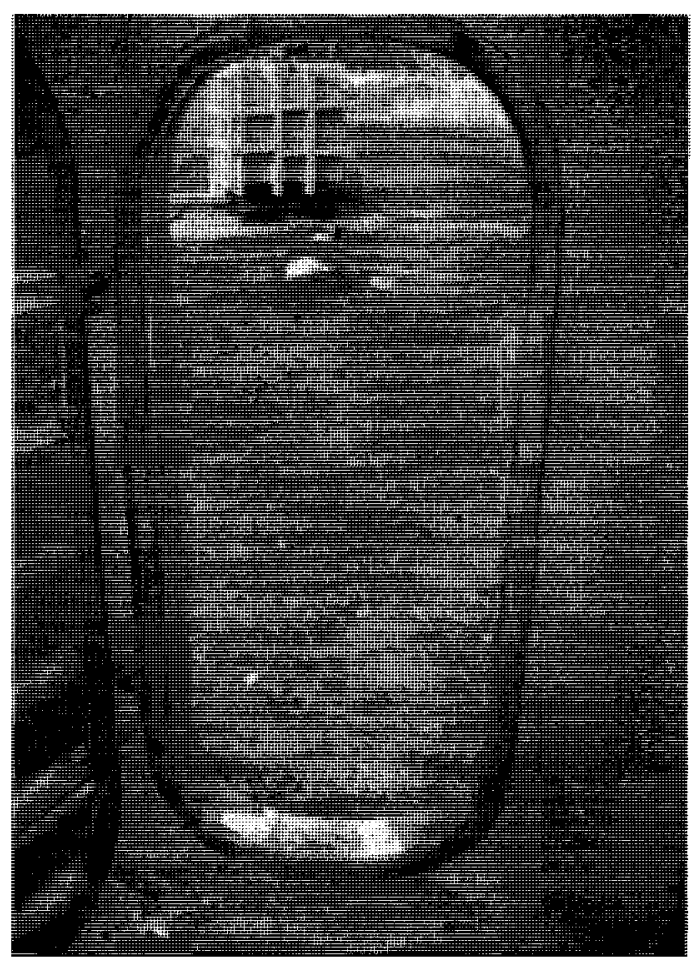

Figure 5.2: Chamber door-inside view 


\subsection{Suppressive Shield Panels}

Four SSPs were built for testing (Figure 5.3). All panels were built with a combination of commercially-available mild steel angle sections. The Aluminum Foam AF was placed on the SSP side facing the explosive as shown in Figure 5.4. The angle sections used in the analysis performed in the preliminary study of Chapter 4 were used to build the SSPs tested in this study and are shown in Table 5.1. The combinations of angels and their spacing shown in Figures 5.5 through 5.8 provided SSPs with different parameters to be evaluated such as the vent area and the areal density while ensuring economic effectiveness. The design of these combinations helped in reducing the number of test panels. As indicated earlier, this investigation included the use of advanced material, AF, sheets supplied in three thicknesses (density, 5\%) by Cymat Corp., Toronto. Properties of the AF are listed in Table 5.2.
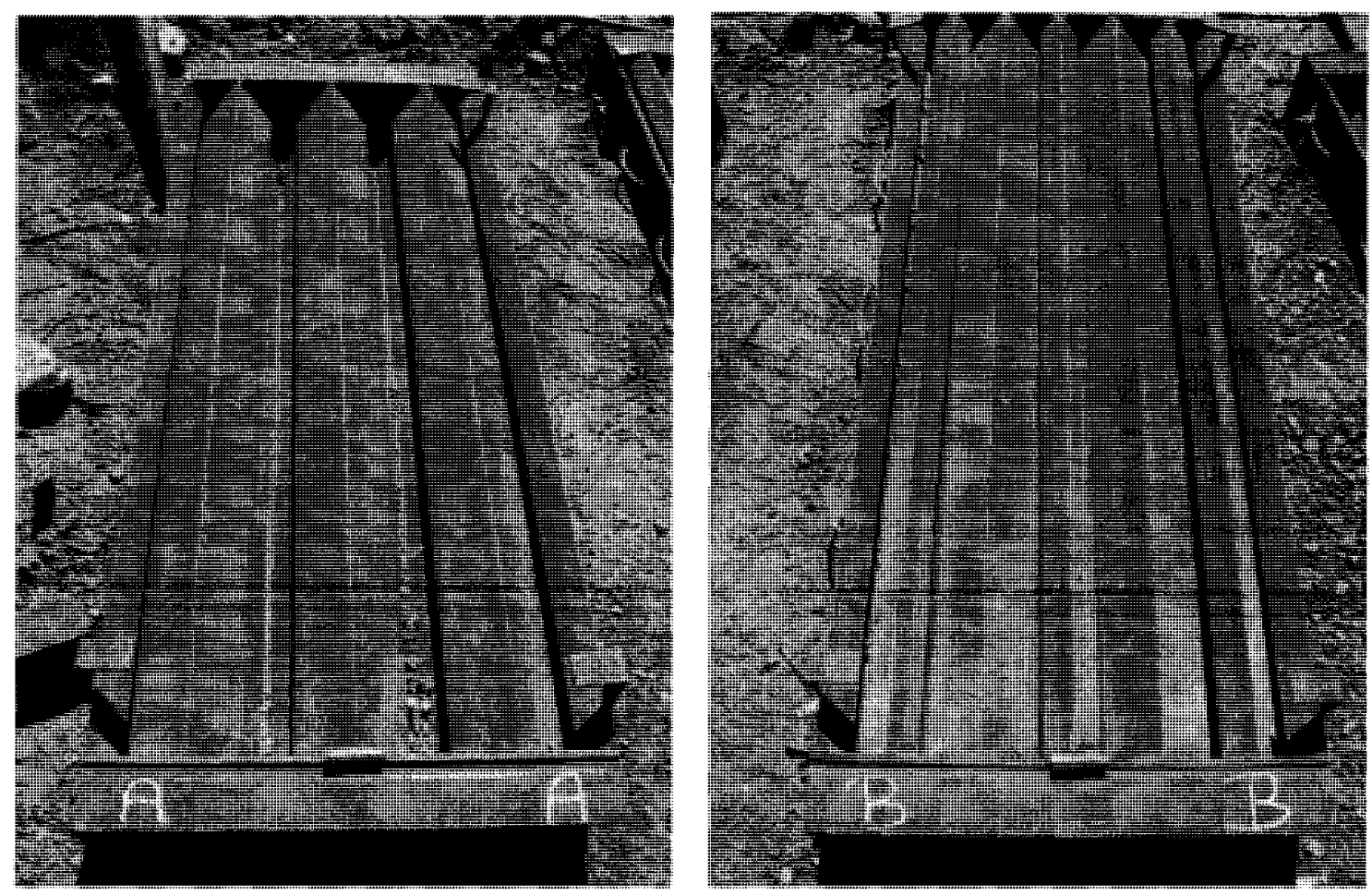

Figure 5.3: The inner surface of SSP-A and SSP-B 
Table 5.1: Angle sections used in SSPs, Canadian Steel Handbook

\begin{tabular}{|c|c|c|c|c|}
\hline Section & $\begin{array}{l}\text { Depth } \\
(\mathrm{mm})\end{array}$ & $\begin{array}{l}\text { Width } \\
(\mathrm{mm}) \\
\end{array}$ & $\begin{array}{l}\text { Thickness } \\
(\mathrm{mm})\end{array}$ & $\begin{array}{l}\text { Mass per } \\
\text { Unit Length } \\
(\mathrm{kg} / \mathrm{m})\end{array}$ \\
\hline L51x51 & 50.8 & 50.8 & 6.35 & 4.75 \\
\hline L76x76 & 76.2 & 76.2 & 6.35 & 7.28 \\
\hline L102×102 & 102 & 102 & 6.35 & 9.85 \\
\hline
\end{tabular}

Table 5.2: Thickness of used Aluminum Foam sheets

\begin{tabular}{cc}
\hline AF Labels & $\begin{array}{c}\text { Thickness } \\
(\mathrm{mm})\end{array}$ \\
\hline a & 13 \\
b & 29 \\
c & 43 \\
\hline
\end{tabular}

Each SSP was tested several times with different explosive charges, and with and without AF sheets. A total of twenty one tests were completed, two were reference tests using 0.25 and $0.50 \mathrm{~kg}$ of Pentolite to establish the blast pressures outside the blast chamber. These tests were performed without any SSPs. Due to restriction on noise levels at the test site, 1-kg Pentolite charges could not be used in this configuration. These tests were performed to acquire the normal attenuation of shock through air and the results were used to estimate the attenuation by the respective SSPs. The other nineteen tests were performed with the SSPs with and without AF sheets.

Twelve tests were performed on SSPs, one test per charge per SSP. The remaining seven tests were performed on SSPs with AF sheets added. Of these tests, three were performed on SSP-A in conjunction with three AF thicknesses, 13, 29, and $43 \mathrm{~mm}$, and are referred to as SSP-A $\mathrm{A}_{2 \mathrm{a}}, \mathrm{SSP}-\mathrm{A}_{2 \mathrm{~b}}, \mathrm{SSP}-\mathrm{A}_{2 \mathrm{c}}$, respectively (Figure 5.4). Three other tests were done with the SSP-B, two with a $2 \mathrm{~mm}$ steel plate backing the thinnest and thickest thicknesses 
AF sheets, 13 and $29 \mathrm{~mm}$, referred to as tests SSP-B ${ }_{2 a}, S S P-B_{2 c}$, respectively. The third test, $\mathrm{SSP}-\mathrm{B}_{\mathrm{S}}$, was performed with the steel plate alone, to check its capacity to carry the blast load. Finally, one test was performed on SSP-C with steel plate backing in conjunction with the thickest AF sheet, and is referred to as test $\mathrm{SSP}-\mathrm{C}_{2 \mathrm{c}}$.
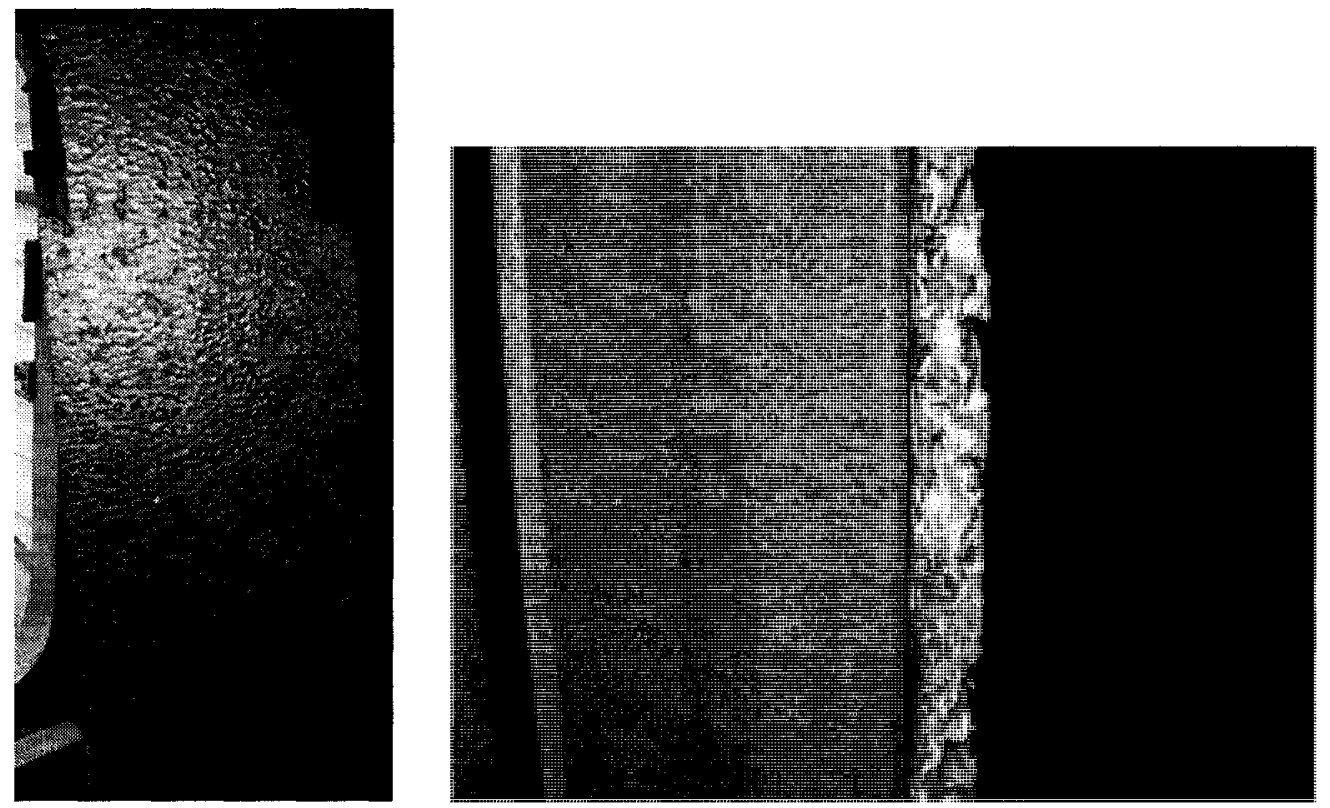

Figure 5.4: AF sheets without steel plate backing

Table 5.3 gives the details of the testing program and different design groups adopted in this thesis. The grouping is based on SSPs design, AF thickness and explosive charges.

Table 5.3: Outline of the testing Program

\begin{tabular}{lll}
\hline Test & & Description \\
\hline & $\mathrm{A}_{1}$ & Panel A-Charge 0.25kg Pentolite \\
& $\mathrm{A}_{2}$ & Panel A- Charge 0.5kg Pentolite \\
$\mathrm{A}$ & $\mathrm{A}_{3}$ & Panel A-Charge 1kg Pentolite \\
& $\mathrm{A}_{\mathrm{a} 2}$ & Panel A- Alum Thickness a $=13 \mathrm{~mm}$-Charge 0.5kg Pentolite \\
& $\mathrm{A}_{\mathrm{b} 2}$ & Panel A- Alum Thickness b=29mm-Charge 0.5kg Pentolite \\
& $\mathrm{A}_{\mathrm{c} 2}$ & Panel A- Alum Thickness c=43mm-Charge 0.5kg Pentolite \\
\hline \multirow{3}{*}{$\mathrm{B}$} & $\mathrm{B}_{1}$ & Panel B- Charge 0.25kg Pentolite \\
& $\mathrm{B}_{2}$ & Panel B- Charge 0.5kg Pentolite \\
& $\mathrm{B}_{3}$ & Panel B- Charge 1kg Pentolite
\end{tabular}




\begin{tabular}{|c|c|c|}
\hline & \multirow{2}{*}{$\begin{array}{l}\mathrm{B}_{\mathrm{a} 2} \\
\mathrm{~B}_{\mathrm{c} 2}\end{array}$} & Panel B- Alum Thickness $\mathrm{a}=13 \mathrm{~mm}$ plus steel plate-Charge $0.5 \mathrm{~kg}$ \\
\hline & & $\begin{array}{l}\text { Pentolite } \\
\text { Panel B- Alum Thickness } \mathrm{c}=43 \mathrm{~mm} \text { plus steel plate-Charge } 0.5 \mathrm{~kg} \\
\text { Pentolite }\end{array}$ \\
\hline \multirow{4}{*}{$\mathrm{C}$} & $\mathrm{C}_{1}$ & Panel C- Charge $0.25 \mathrm{~kg}$ Pentolite \\
\hline & $\mathrm{C}_{2}$ & Panel C- Charge $0.5 \mathrm{~kg}$ Pentolite \\
\hline & $\mathrm{C}_{3}$ & Panel C- Charge 1kg Pentolite \\
\hline & $\mathrm{C}_{\mathrm{c} 2}$ & $\begin{array}{l}\text { Panel C- Alum Thickness } c=43 \mathrm{~mm} \text { plus steel plate-Charge } 0.5 \mathrm{~kg} \\
\text { Pentolite }\end{array}$ \\
\hline \multirow{3}{*}{$\mathrm{D}$} & $\overline{D_{1}}$ & Panel D- Charge 0.25kg Pentolite \\
\hline & $\mathrm{D}_{2}$ & Panel D-Charge $0.5 \mathrm{~kg}$ Pentolite \\
\hline & $\mathrm{D}_{3}$ & Panel D- Charge $1 \mathrm{~kg}$ Pentolite \\
\hline Air 1 & Air -0.25 & No SSPs- Air shot -Charge $0.25 \mathrm{~kg}$ Pentolite \\
\hline Air 2 & Air -0.5 & No SSPs- Air shot -Charge $0.5 \mathrm{~kg}$ Pentolite \\
\hline
\end{tabular}

The SSPs were grouped as follows:

- Group (A): This group is the first SSP design that was studied earlier in the pilot study. This panel was built with only L102 angle in both rows as shown in Figure 5.5. Six tests $\left(A_{1}, A_{2}, A_{3}, A_{a 2}, A_{b 2}\right.$ and $\left.A_{c 2}\right)$ were performed on this group. The letter "A" with subscript numbers only represents different charge size for SSPs without AF, nevertheless the subscript of numbers and letters represents SSPs with different AF thicknesses.

- Group (B): This is the second suppressive shield panels design. This panel was built with combination of L51 and L102 angle sections as shown in Figure 5.6. It consists of 6 tests $\left(\mathrm{B}_{1}, \mathrm{~B}_{2}, \mathrm{~B}_{3}, \mathrm{~B}_{\mathrm{a} 2}\right.$ and $\left.\mathrm{B}_{\mathrm{c} 2}\right)$.

- Group (C): This is the third suppressive shield panels design. This panel was built with combination of L51, L76 and L102 angle sections as shown in Figure 5.7. The L51 section was used as backing for the L102 section in the first row, while L76 used in the other row. It consists of 4 tests $\left(C_{1}, C_{2}, C_{3}\right.$, and $\left.C_{c 2}\right)$. 
- Group (D): This is the last suppressive shield panels design. This panel was built with combination of L51, L76 and L102 angle sections as shown in Figure 5.8. L51 angle is used this time to reduce gap between L102 and L76 in both rows. It consists of 3 tests $\left(D_{1}, D_{2}\right.$ and $\left.D_{3}\right)$.

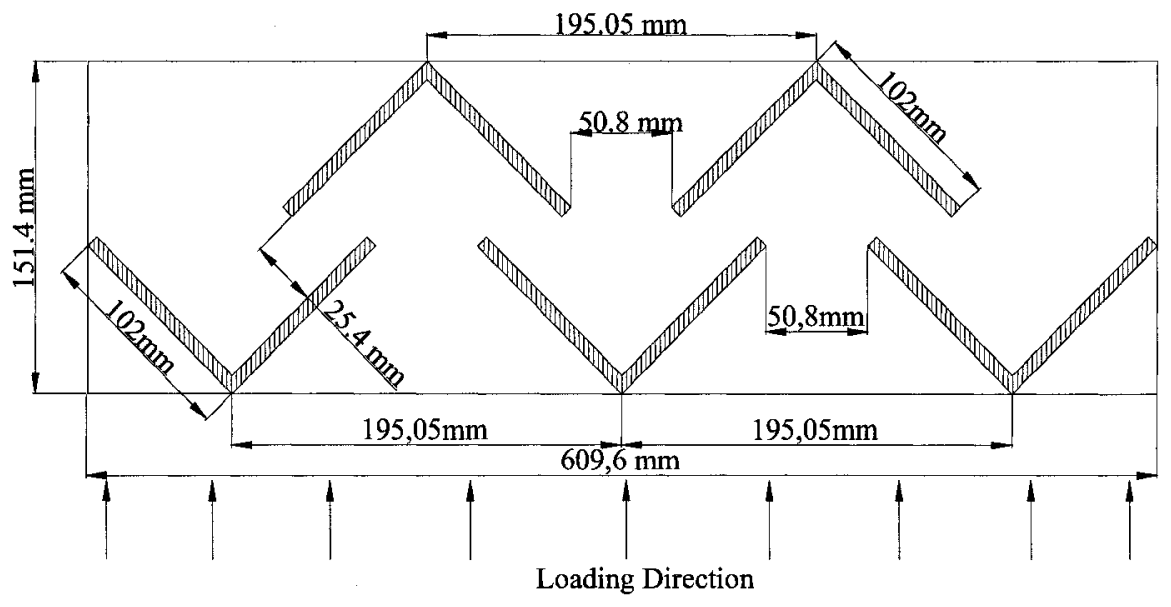

Figure 5.5: Suppressive Shield Panel A

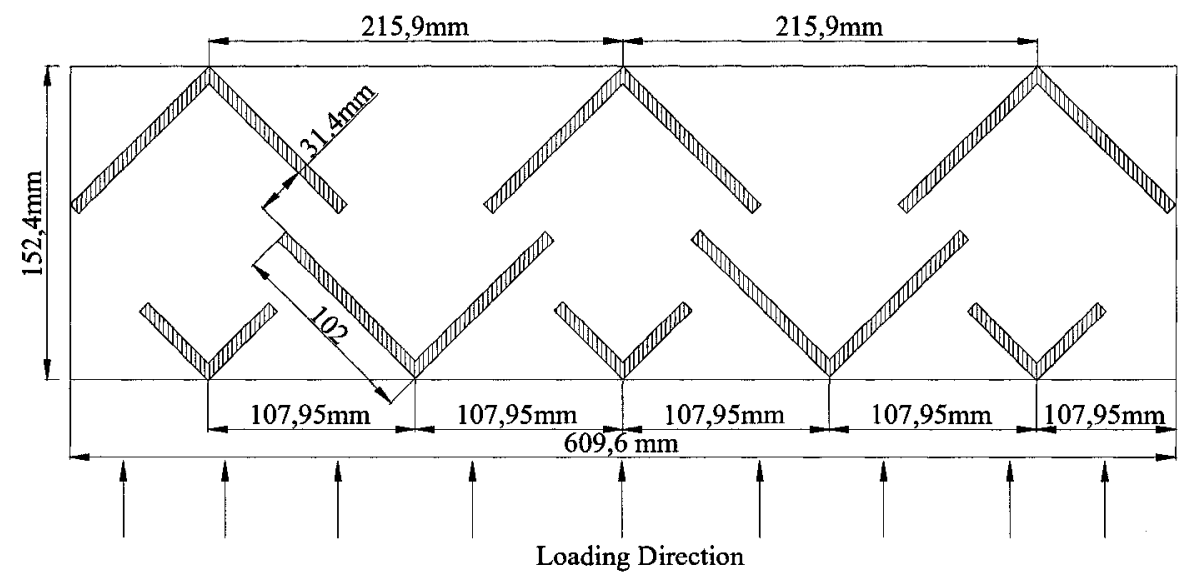

Figure 5.6: Suppressive Shield Panel B 


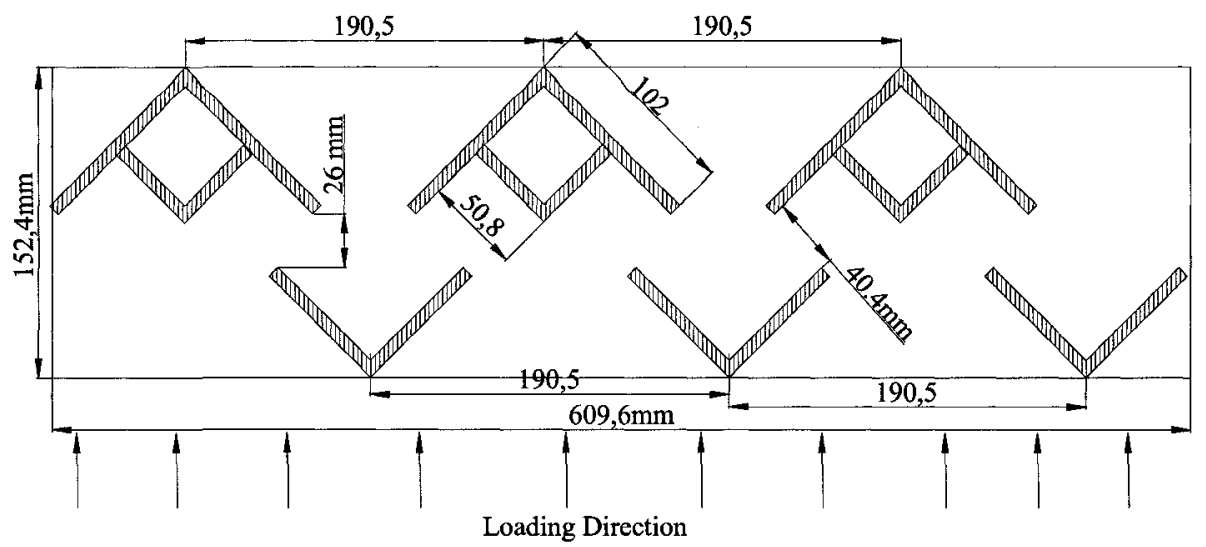

Figure 5.7: Suppressive Shield Panel C

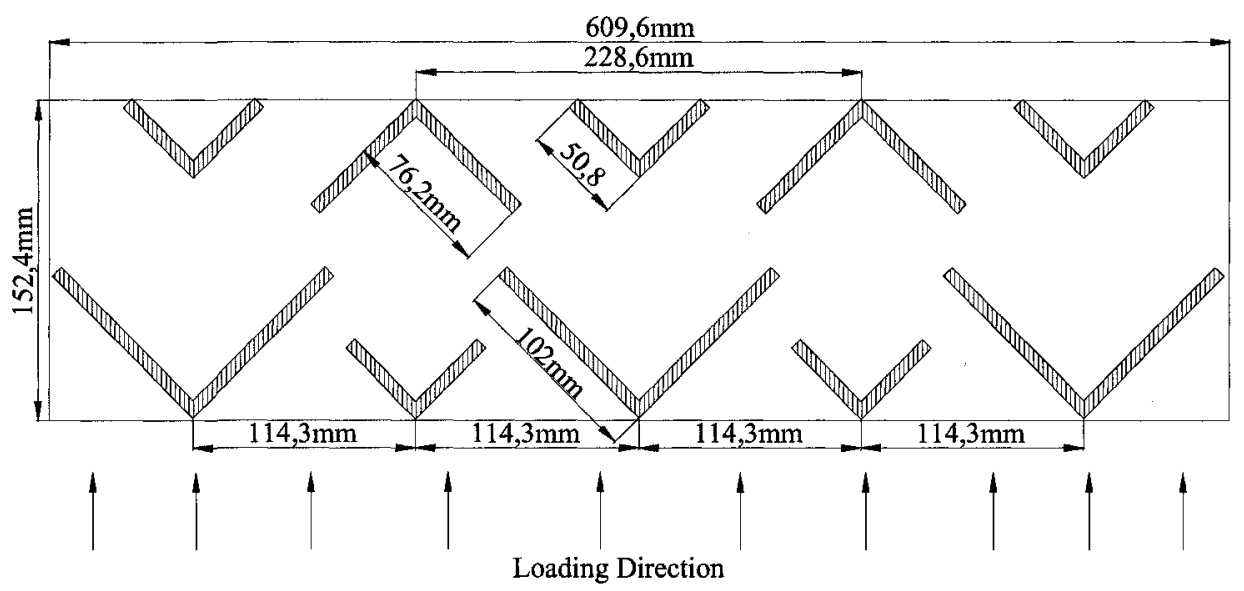

Figure 5.8: Suppressive Shield Panel D

\subsubsection{Vent Area Calculation}

The unit vent area, $A_{v}$, in Equation 5.1 (Suppressive Shields Handbook, Equation) is a function of the number of openings, $n$, the length of the exposed elements, $l$, and the gap between the angles, $a$. Figure 5.9 shows the unit vent area (when viewed from the bottom) parameters defined by Equation 5.1.

$$
A_{v}=n l a
$$

The number of openings, $n$, was calculated by dividing the width of the SSPs by the angle spacing, where the spacing is equal to the projected width of the angles, $P_{w}$, plus, $a$, the 
gap between the angles. The length of the exposed angle, $l$, was taken as the length of the angle which in the SSPs was $1370 \mathrm{~mm}$ so that the panel area, $A_{p}$, is simply the width of the panel, $610 \mathrm{~mm}$ times the length, or $840 \mathrm{~mm}^{2}$. As indicated by Equation 5.2 (Suppressive Shields Handbook, Equation), the effective multi-layer vent area ratio, $\alpha_{e}$, is the sum of the unit vent area ratios for each angle layer, where the unit vent area ratio, $\alpha_{i}$, is the ratio between the vent area, $A_{v}$, and the panel area, $A_{p}$, as given by Equation 5.3 (Suppressive Shields Handbook, Equation).

$$
\begin{aligned}
& \frac{1}{\alpha_{e}}=\sum_{i=1}^{n} \frac{1}{\alpha_{i}} \\
& \alpha_{i}=\frac{A_{v i}}{A_{p i}}
\end{aligned}
$$

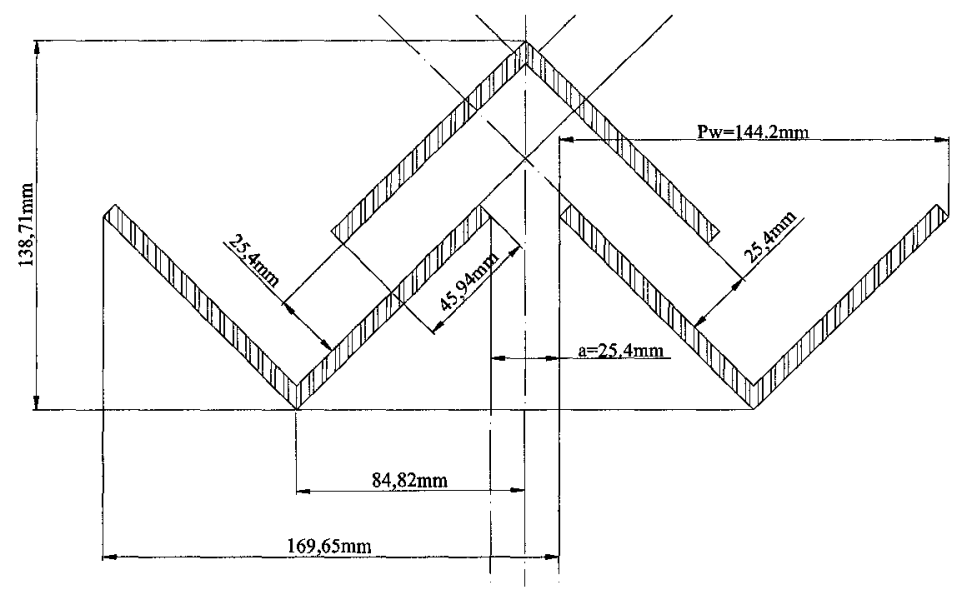

Figure 5.9 Double angle vent area parameters.

Table 5.4 summarizes the effective multi-layer vent area ratio for the SSPs. The effective vent area ratio is $0.13,0.02,0.08$ and 0.02 for panels $\mathrm{A}, \mathrm{B}, \mathrm{C}$ and $\mathrm{D}$, respectively. 
Table 5.4 Effective Multi-layer Vent Area Ratio Calculations for All SSPs

\begin{tabular}{|c|c|c|c|c|c|c|c|}
\hline SSP & $\begin{array}{l}\text { Angle } \\
\text { Sections/row }\end{array}$ & $\begin{array}{l}\mathbf{P}_{\mathbf{w}} \\
(\mathrm{mm})\end{array}$ & $\begin{array}{l}\mathbf{a} \\
(\mathrm{mm})\end{array}$ & $\begin{array}{l}\mathbf{A}_{\mathbf{v}} \\
\left(\mathrm{mm}^{2}\right)\end{array}$ & $\boldsymbol{\alpha}_{\mathbf{i}}$ & $1 / \alpha_{e}$ & $\boldsymbol{\alpha}_{\mathbf{e}}$ \\
\hline $\bar{A}$ & L102x102 & 144 & 50.8 & $2.18 \mathrm{E}+05$ & 0.26 & 7.68 & 0.13 \\
\hline \multirow[t]{2}{*}{ B } & L102x102 & 144 & 71.7 & $2.77 \mathrm{E}+05$ & 0.33 & \multirow{2}{*}{49.21} & \multirow[b]{2}{*}{0.02} \\
\hline & L102x102 & 144 & 10.0 & $3.87 \mathrm{E}+04$ & 0.05 & & \\
\hline \multirow[t]{2}{*}{$\mathrm{C}$} & L76x76 & 108 & 46.0 & $1.01 E+05$ & 0.12 & \multirow{2}{*}{12.93} & \multirow{2}{*}{0.08} \\
\hline & $\mathrm{L} 102 \times 102$ & 144 & 82.0 & $1.80 \mathrm{E}+05$ & 0.22 & & \\
\hline \multirow[t]{2}{*}{ D } & L76x76 & 108 & 50.0 & $9.14 \mathrm{E}+04$ & 0.11 & \multirow{2}{*}{44.31} & \multirow{2}{*}{0.02} \\
\hline & L102x102 & 144 & 13.0 & $2.38 \mathrm{E}+04$ & 0.03 & & \\
\hline
\end{tabular}

\subsubsection{Calculations of Areal Density}

Table 5.5 lists the areal density for the SSPs. Panel A is the lightest followed by panel B, panel C, and finally panel D, being the heaviest. In case of using the SSPs as retrofit for ISO containers, the total mass and mass ratio increase were computed referenced to the mass of existing containers as presented in Table 5.6. The lowest increase in mass ratio was achieved when SSP-A was used, while the maximum mass ratio increase was attained when SSP-D was utilized.

Table 5.5: Mass Calculation for SSPs

\begin{tabular}{llc}
\hline SSP & Angles Section & $\begin{array}{c}\text { Areal Density } \\
\left(\mathrm{kg} / \mathrm{m}^{2}\right)\end{array}$ \\
\hline $\mathrm{A}$ & $\mathrm{L} 102$ & 102 \\
$\mathrm{~B}$ & $\mathrm{~L} 51+\mathrm{L} 102$ & 115 \\
$\mathrm{C}$ & $\mathrm{L} 51+\mathrm{L} 76+\mathrm{L} 102$ & 119 \\
$\mathrm{D}$ & $\mathrm{L} 51+\mathrm{L} 76+\mathrm{L} 102$ & 120 \\
\hline
\end{tabular}

Table 5.6: Mass calculation for retrofit ISO containers

\begin{tabular}{llcc}
\hline SSPs & Angle Section & $\begin{array}{c}\text { Mass of Container } \\
(\mathrm{kg})\end{array}$ & $\begin{array}{c}\text { Mass Ratio } \\
(\%)\end{array}$ \\
\hline Panel A & L102 & $5.6 \mathrm{E}+03$ & 150 \\
Panel B & L51+L102 & $6.3 \mathrm{E}+03$ & 182 \\
Panel C & L51+L76+L102 & $6.5 \mathrm{E}+03$ & 189 \\
Panel D & L51+L76+L102 & $6.6 \mathrm{E}+03$ & 193 \\
\hline
\end{tabular}




\subsection{Test Setup}

Three explosive charge masses were used in the experimental tests, $0.25 \mathrm{~kg}, 0.50 \mathrm{~kg}$ and $1.00 \mathrm{~kg}$ of Pentolite, a PETN/TNT commercial explosive booster. All charges were placed $1 \mathrm{~m}$ from the SSPs inside the blast chamber as indicated in Figure 5.10.

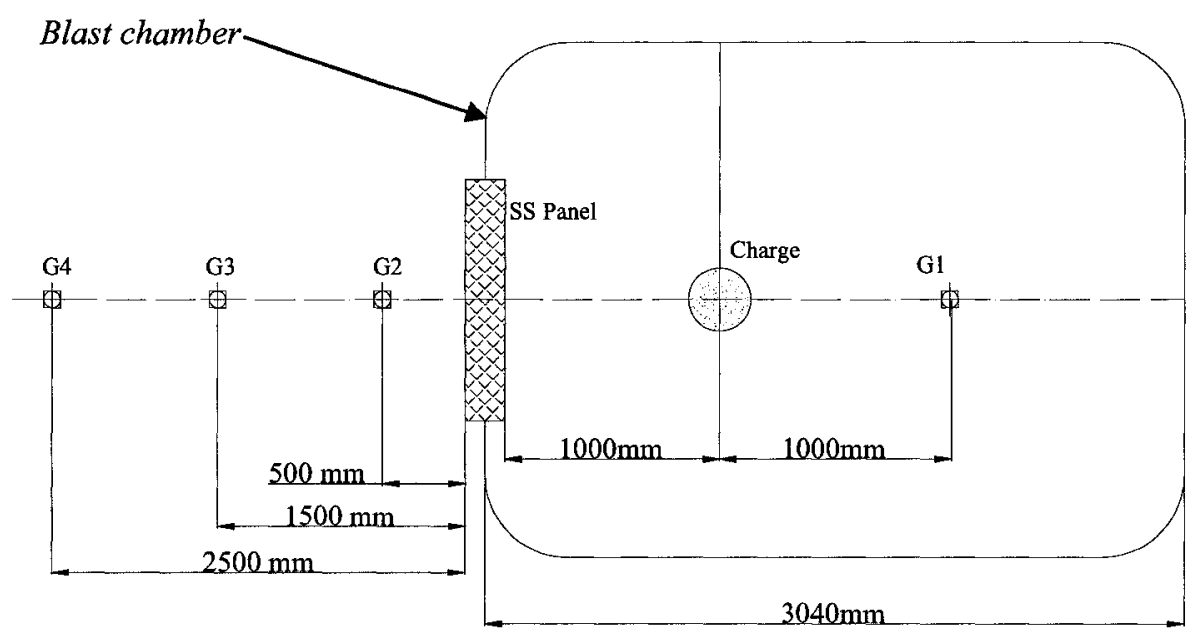

Figure 5.10: Schematic of experimental setup

Four gauges were used to track the blast pressure, one inside the chamber and three outside. $\mathrm{G}_{1}$, is the inside gauge, positioned as indicated, $1 \mathrm{~m}$ from the charge and $2 \mathrm{~m}$ from the back wall of the chamber. Due to the difficulty of positioning a pressure transducer on the inside surface of the SSPs when mounted on the chamber, the pressure profiles measured at $G_{1}$ were used as being those impinging on the inside surface of the SSPs. The other three gauges $\left(\mathrm{G}_{2}, \mathrm{G}_{3}\right.$ and $\left.\mathrm{G}_{4}\right)$ were positioned outside the chamber at distances of $0.5 \mathrm{~m}, 1.5 \mathrm{~m}$ and $2.5 \mathrm{~m}$ from the SSPs. Figure 5.11 shows a schematic of the piezoelectric, pencil gauges (PCB Piezotronics catalogue) which had an accuracy of 1 $\mathrm{mV} / \mathrm{psi}$. As seen in figure, the sensing element is free to rotate 360 degrees around the axis of the holder. Through out the course of testing, the sensing element was set facing 
upwards to minimize reflections from ground. The external gauges setup during testing is shown in Figure 5.12.

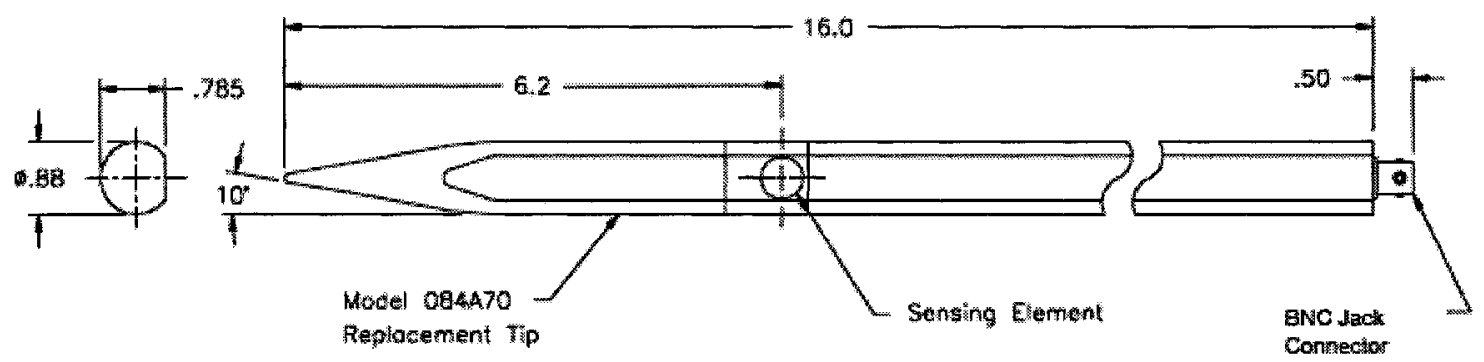

Figure 5.11: Schematic Diagram of $\mathrm{PCB}$ pencil gauge

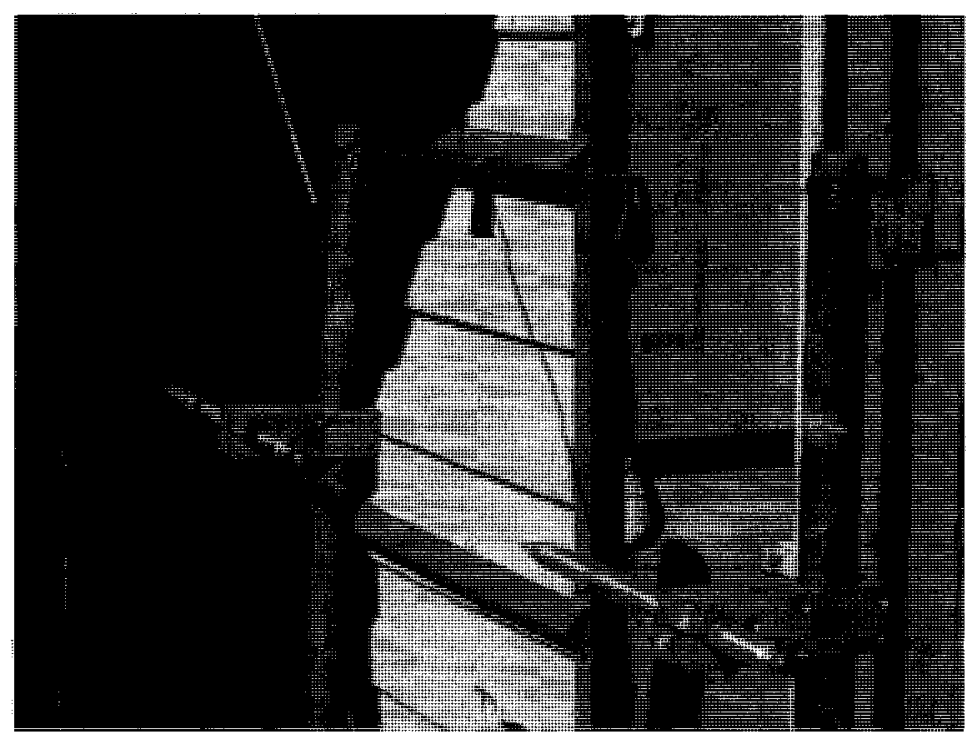

Figure 5.12: PCB pencil gauges

\subsection{Material Properties}

This section presents the mechanical and physical properties of materials used in building the SSPs. All material properties were provided by the manufacturer and/or the supplier. 


\subsubsection{Structural Steel}

All SSPs were built from commercially-available mild-steel angles. The steel has a density of $7.86 \mathrm{~g} / \mathrm{cm}^{3}$, a tensile strength of $500 \mathrm{MPa}$ and a Young's modulus of $210 \mathrm{GPa}$. Figure 5.13 shows the typical stress-strain curve for mild steel (soft steel) material used to build the SSPs. It can be seen from this figure that the maximum strain for such material at fracture is 0.25 . Note that strain value of 0.2 is used in the numerical modeling to define the failure and erosion models.

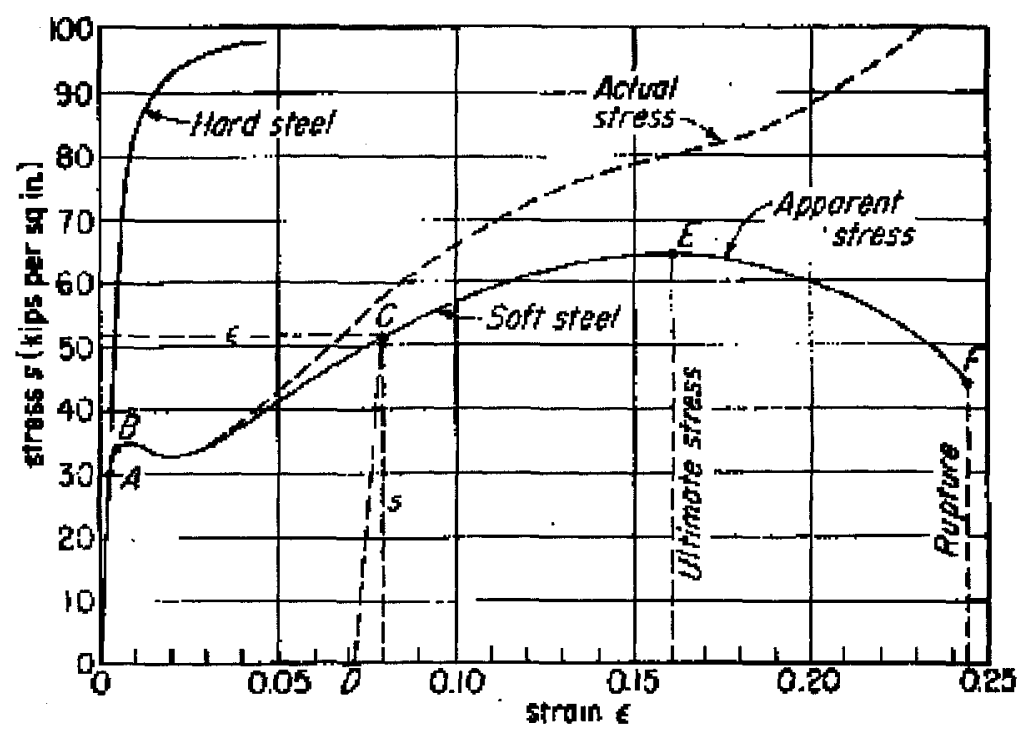

Figure 5.13: Typical stress-strain of steel (Gere, J. M. et al, 1990)

\subsubsection{Aluminum Foam}

The AF was manufactured and supplied by Cymat, Toronto. The AF is anisotropic, and lightweight, with great energy absorbing ability and is produced by the gas injection process (Cymat Technical Manual). Figure 5.14 presents the typical stress-strain behaviour of AF that includes three phases, linear elastic, plastic and densification. In the first phase deformations are recoverable while deformations are permanent at phase two. 
Finally, densification occurs in phase three where the material is crushed. The amount of energy absorbed by the $\mathrm{AF}$ is equal to the area under the curve up to the densification strain. Several studies were done under different loading to measure the capabilities of the AF in absorbing energy. Hanssen et al 2002, performed full scale testing to investigate the behaviour of AF under dynamic loading. It was observed that by attaching AF panels to a pendulum device the impulse and energy transferred to the pendulum increased substantially.

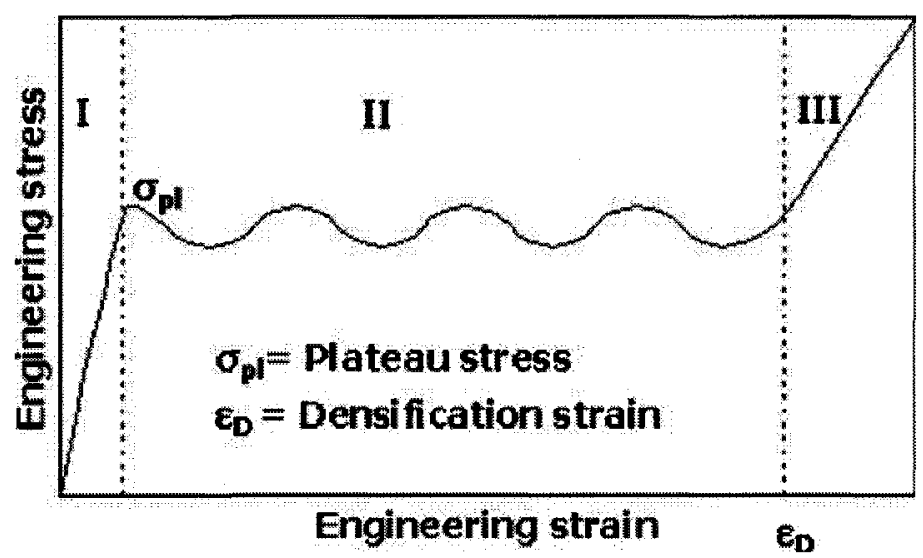

Figure 5.14: Typical stress-strain of $A F$ under compressive loading (Rajan $S$. et al 2006)

\subsection{Explosive Charge}

The SSPs were tested using three explosive charge masses, $0.25 \mathrm{~kg}, 0.50 \mathrm{~kg}$, and $1.00 \mathrm{~kg}$ of Pentolite. Pentolite is a mixture of 50\% PETN, Pentaerythritol Tetranitrate, and 50\% TNT, Trinitrotoluene. PETN/TNT is a commercial explosive booster with a reference density of $1.7 \mathrm{~g} / \mathrm{cm}^{3}$ and TNT equivalency of 1.129 (Suppressive shield handbook). All tests were performed by detonating the Pentolite charges inside the blast chamber at $1 \mathrm{~m}$ from the inside face of the SSPs and $2 \mathrm{~m}$ from the back surface of the chamber. The 
explosive charges were hung $0.9 \mathrm{~m}$ from ground in order to have it at the mid span of the SSPs.

\subsection{Summary}

This chapter summarized the experimental investigation procedures, described the test facility and setup, material properties, and sample configurations. Also, the effective vent area ratio as well as the mass ratio was computed for each SSPs. These values will be used along with the percentage attenuation of each SSP to evaluate them for use in transportation applications. A total of twenty one tests were accomplished, the results of which are presented in next chapter. The results include blast parameters, pressure and impulse, tracked by gauges as well as the attenuation capacity determined for each SSP. 


\section{Chapter 6}

\section{Experimental Results: Analysis and Discussion}

\section{Introduction}

The SSPs described in Chapter 5, were subjected to detonations of $0.25,0.5$ and $1.00 \mathrm{~kg}$ of Pentolite as explained earlier. A total of twenty one tests were performed to investigate the mitigation capability of the different SSP designs. Two test configurations were used. The first series used all three charge masses to test only the SSPs. The second test series utilized AF sheets in conjunction with the SSPs and were tested only with the $0.50 \mathrm{~kg}$ charge. The blast pressures were tracked inside and outside the blast chamber.

This chapter deals with the analysis and discussion of the collected data, specifically, pressure and impulse which are the principle blast parameters that can affect people and structures. The results of the analysis will help in identifying the optimum SSP design to retrofit ISO containers. Thus, confidence based on experimental and analytical evidence will be gained to improve the safety and security of the storage and transport of dangerous goods.

\subsection{Raw Data Filtering}

Due to the nature of experiments with explosives, where gauges, cables and recording equipment may be disturbed by the blast, signal noise is often seen in the recorded data. The digital oscilloscopes and data loggers in use today store thousands of data points per 
cycle. The signal records can be filtered live as with a high- or low-pass filter, or a Butterworth filter. Post recording filtering can also be performed with an array of socalled smoothing functions. For example, the program DPlot, includes several options that were used in this thesis including one that filtered random spikes as well as smoothing and integrating the data record. Figure 6.1 shows an example of the raw data before and after smoothing. This data treatment was applied to all the pressure profiles as it facilitated the systematic determination of the impulses through the integration of the pressure curves.

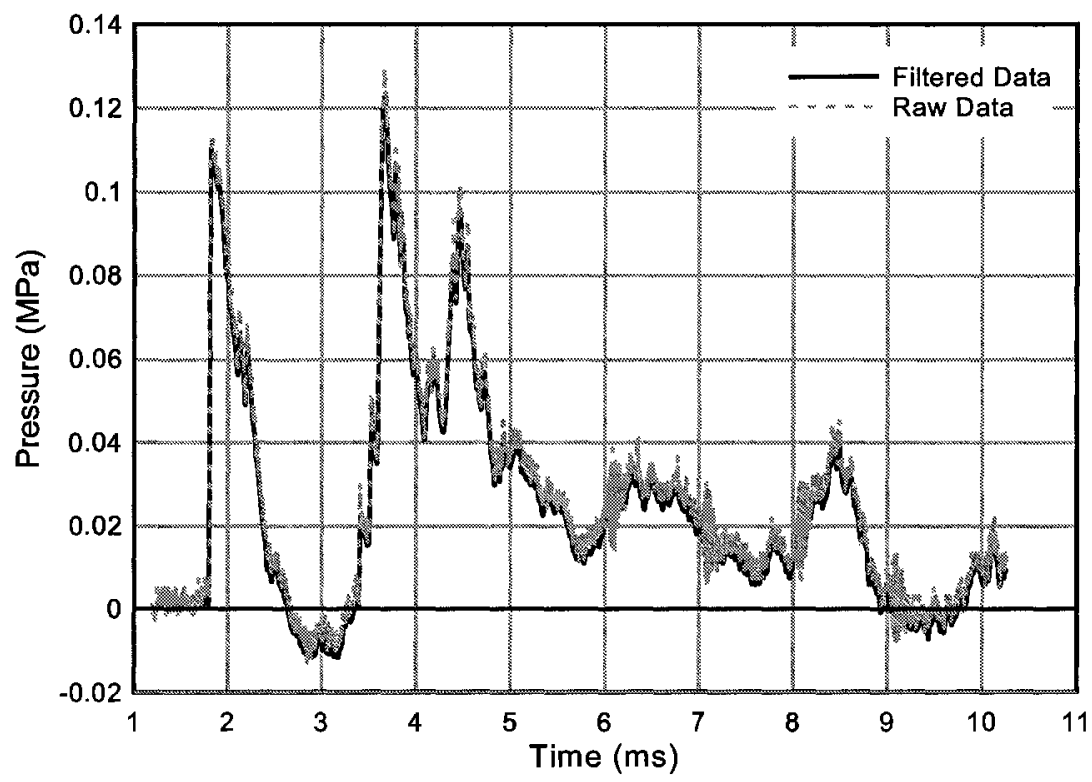

Figure 6.1: Raw data before and after filtering

\subsection{Air Shots}

Two shots were performed using 0.25 and $0.50 \mathrm{~kg}$ of Pentolite without the utilization of SSPs. These are referred to as "air shots". Due to restrictions on sound levels at the test site, 1-kg Pentolite charges could not be used in this configuration because they would exceed the allowable noise limit. These tests were performed to acquire the normal attenuation of shock through air, the results of which were used to estimate the attenuation by the respective SSPs. Figure 6.2 shows the incident pressure, as a function 
of charge mass, at the various gauge locations for the air shots and the pressures predicted by ConWep. As expected, the pressure increases with the increase in charge mass. Experimental results and ConWep predictions correlate well and show similar pressure profiles. The data was extrapolated (dashed lines) to include 1-kg charge.

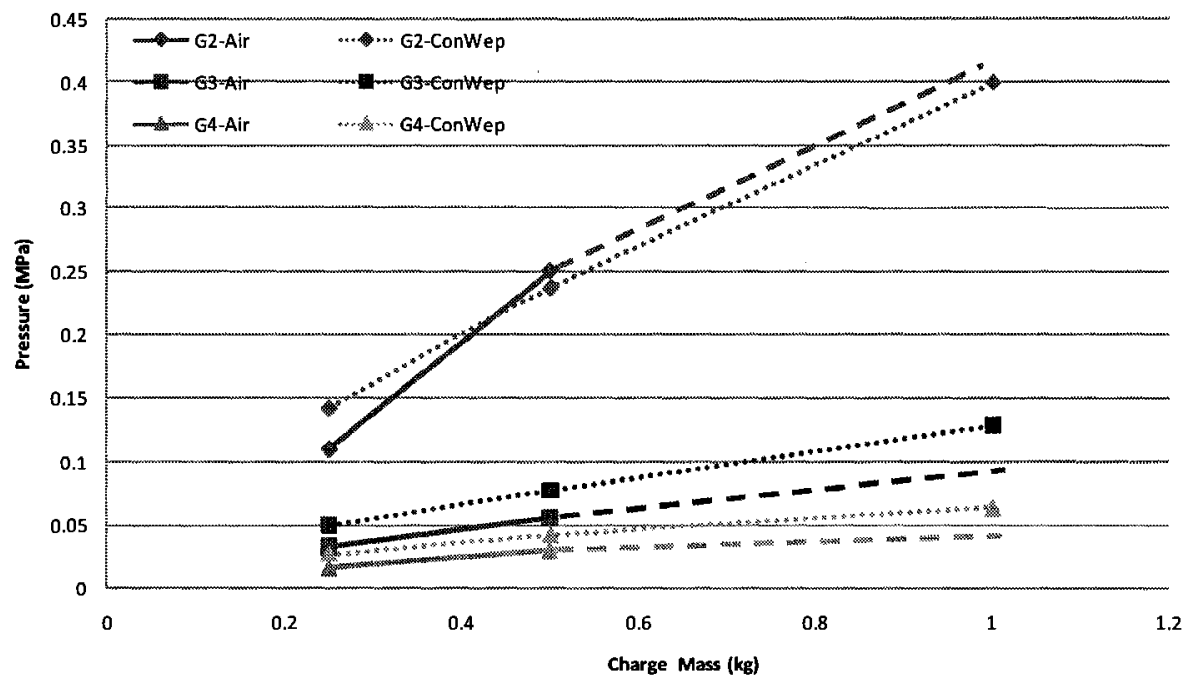

Figure 6.2: Pressure versus charge mass- Air Shots

Figures 6.3 and 6.4 present the blast pressures at the various gauge locations. Points at the "-1 m" distance are measurements taken by the gauge inside the blast chamber, while all the other data points are from the three gauges outside the blast chamber. As shown in Figure 6.3, the ConWep calculated values of the pressure are in agreement with those measured. The higher values obtained from ConWep were due to the fact that ConWep does not consider reflecting surfaces in its predictions. However, the experimental pressure values were closer to those predicted by ConWep as the mass of explosive charge increases, Figures 6.3 and 6.4 . 


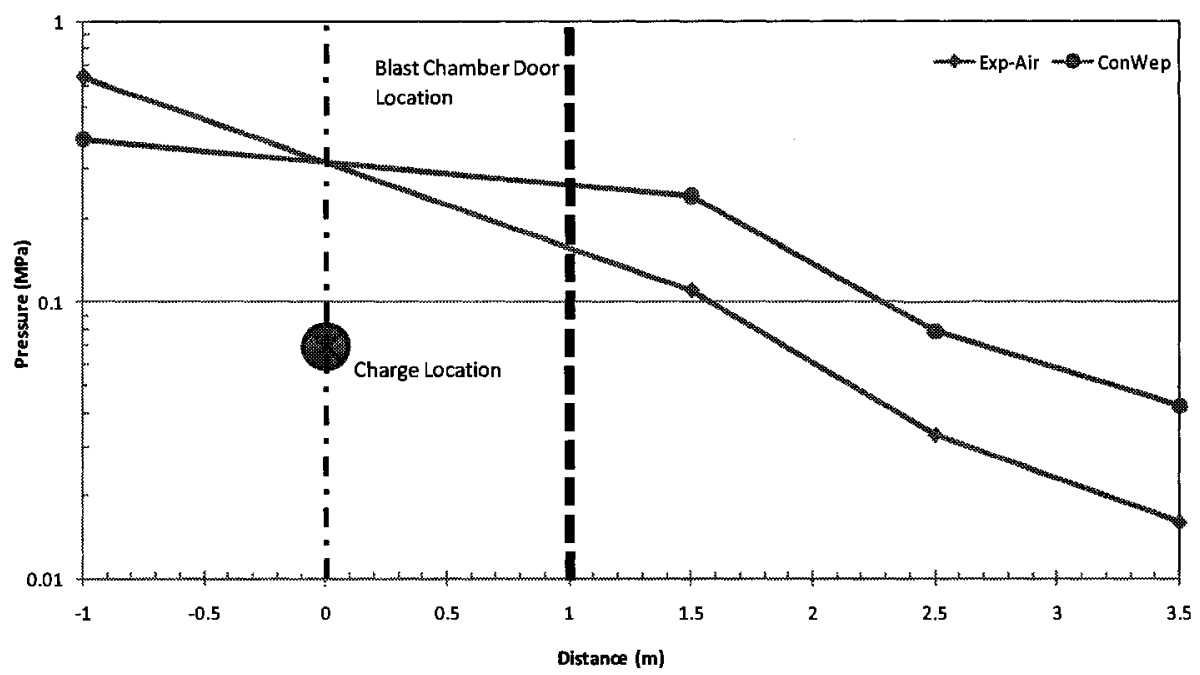

Figure 6.3: Blast pressure versus gauge location, Air- $0.25 \mathrm{~kg}$

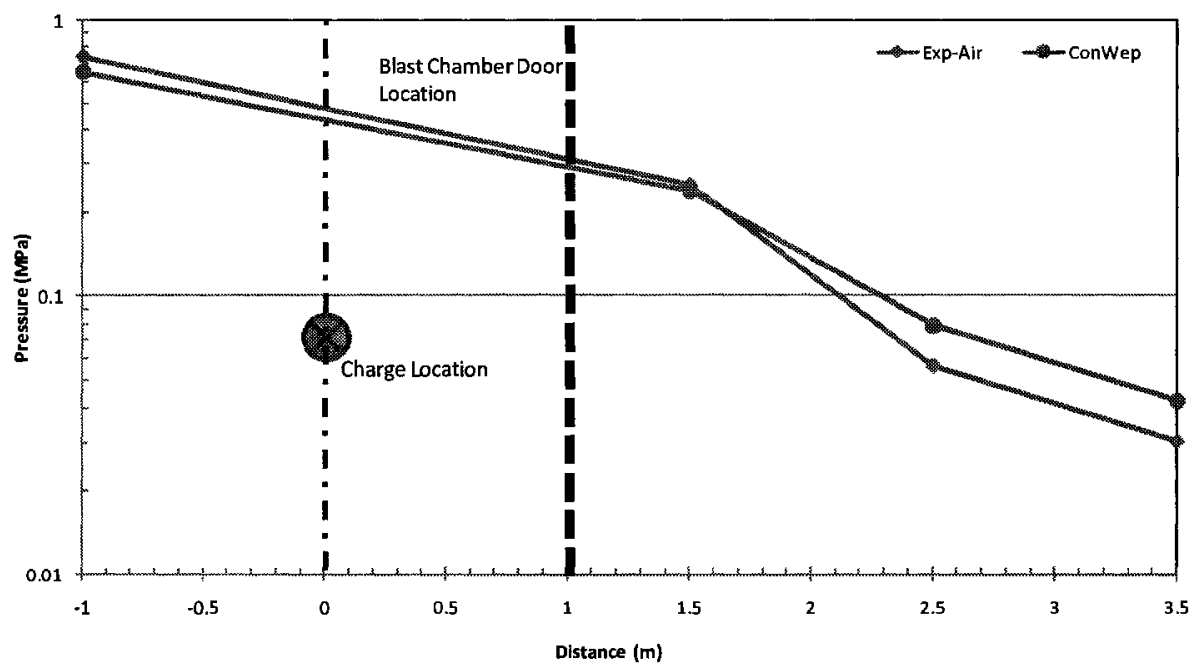

Figure 6.4: Blast pressure versus gauge location, Air- $0.5 \mathrm{~kg}$

The positive pressure impulse was computed through integration using DPlot over the positive pressure phase duration as shown in Figure 6.5. Figure 6.6 shows the pressure and impulse profiles as function of time. 


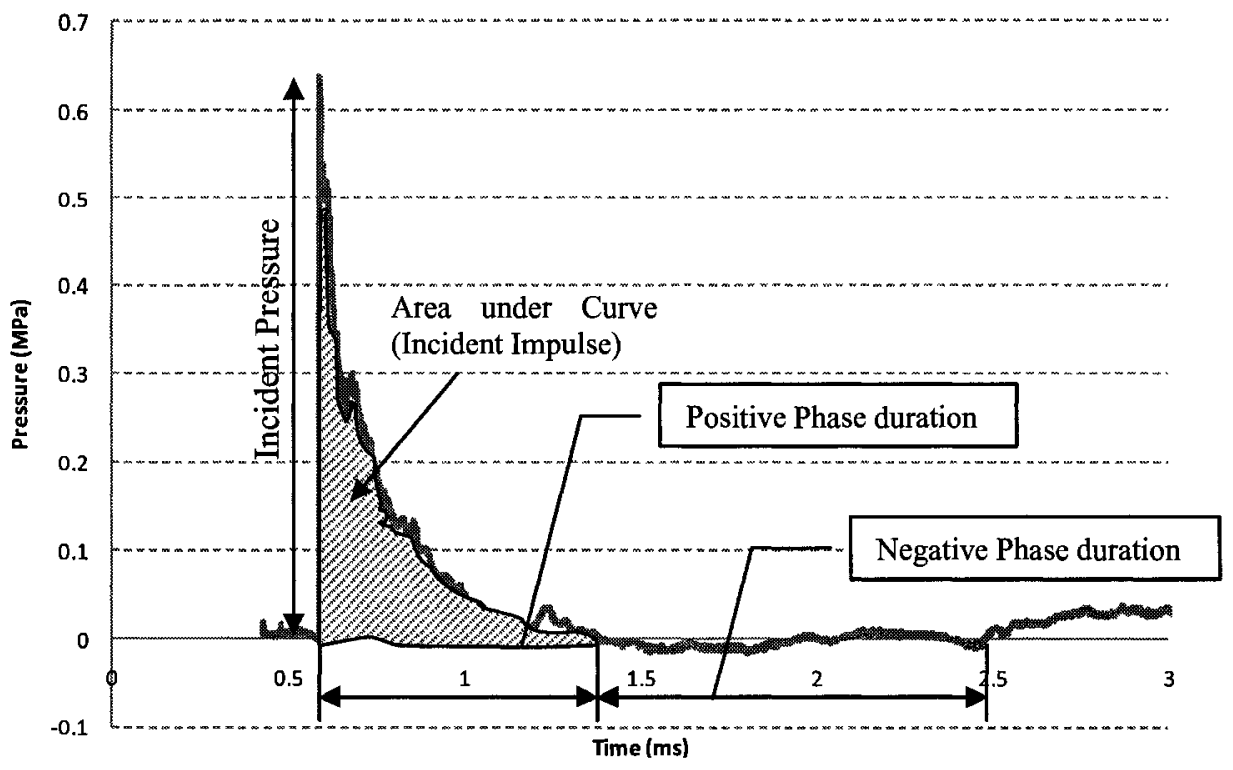

Figure 6.5: Typical pressure-time profile

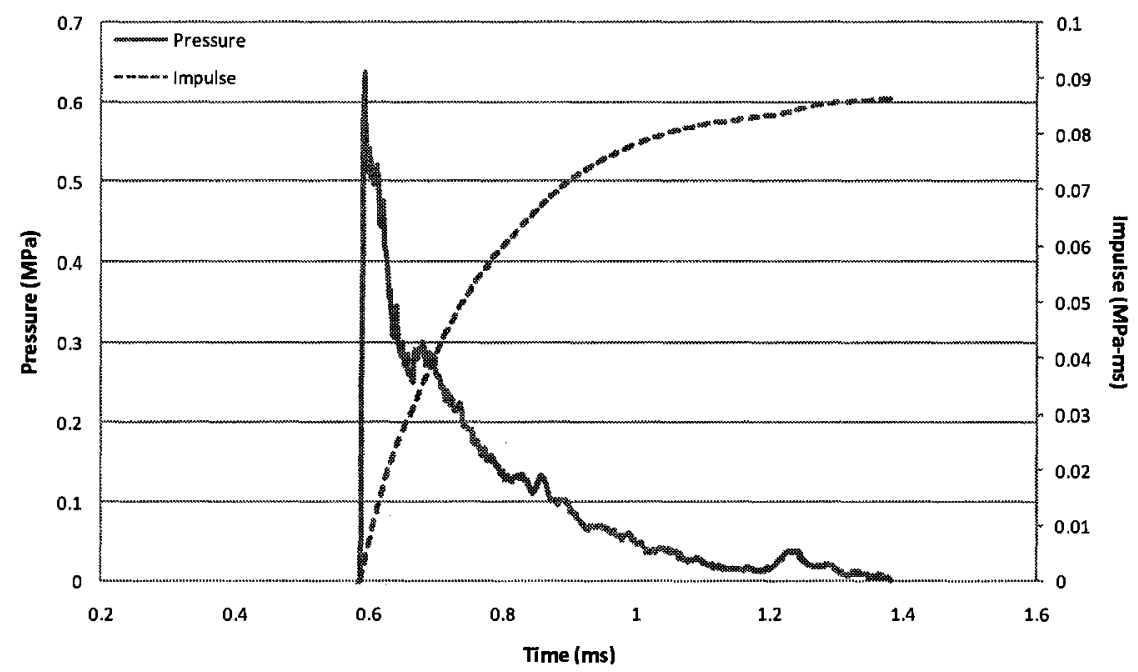

Figure 6.6: Typical Pressure and Impulse Profiles

Figures 6.7 and 6.8 represent the incident positive impulses at the various gauge locations for 0.25 and $0.50 \mathrm{~kg}$ charges, respectively. It can be seen that the experimental results correlate well with those predicted from ConWep. Although for the outside gauges $G_{3}$ and $\mathrm{G}_{4}$, , they tend to be off, but this can be explained by the fact that prediction of pressure through ConWep only accounted for normal air attenuation without taking into consideration the effect of the blast chamber walls. 


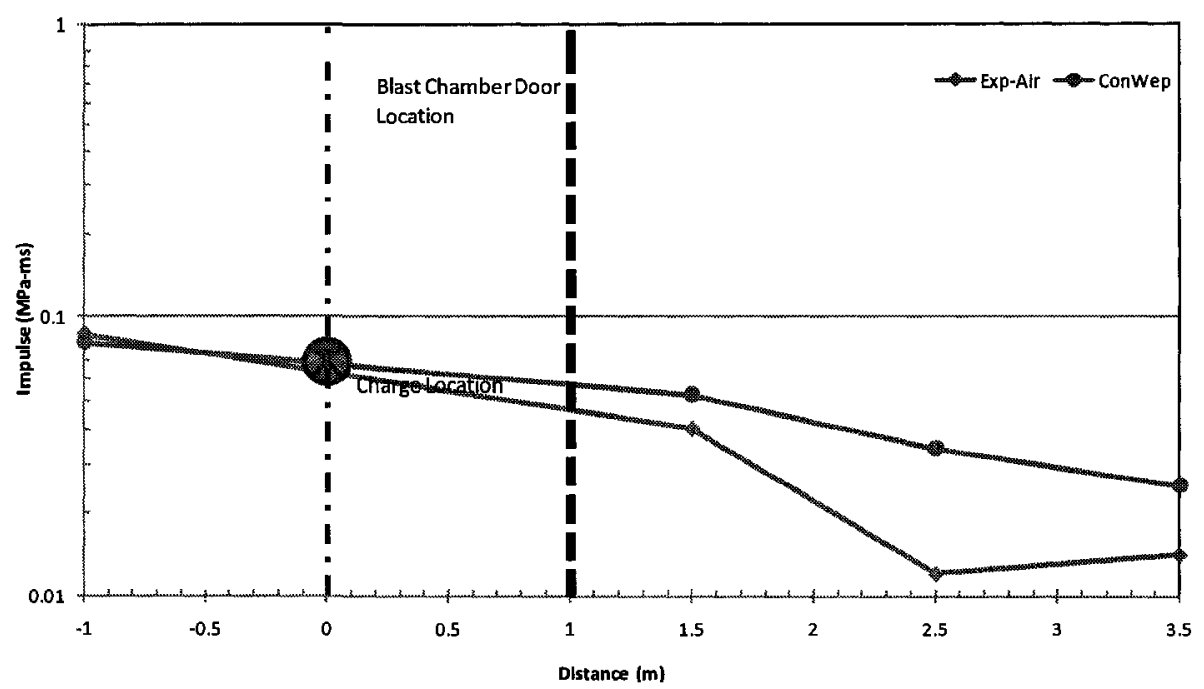

Figure 6.7: Impulse versus gauge location, Air- $0.25 \mathrm{~kg}$

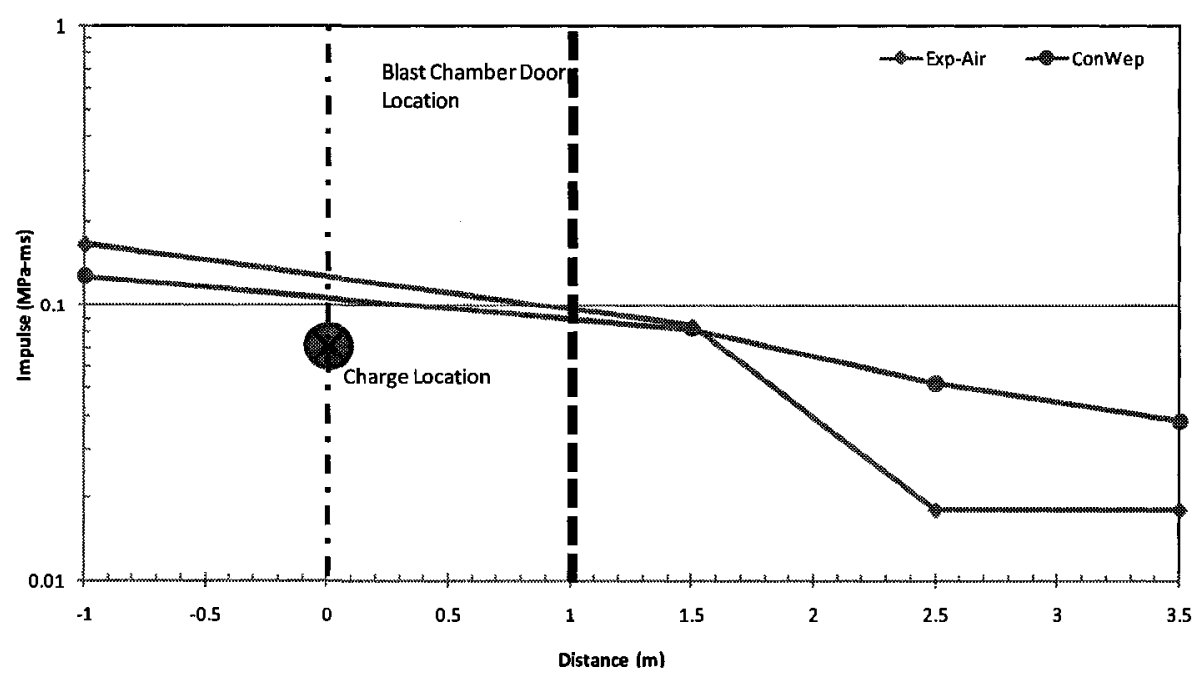

Figure 6.8: Impulse versus gauge location, Air-0.5 kg

\subsection{Suppressive Shield Panels}

The following sub-sections present the results obtained from the twelve tests performed on the various SSPs, one test per charge per panel. The presented results include pressure and impulse as well as the attenuation of these blast parameters referenced to the air shots discussed in the previous section. 


\subsubsection{Results of $0.25 \mathrm{~kg}$ of Pentolite}

Figure 6.9 shows the blast pressures at the various gauge locations for the air and SSPs from the detonation of $0.25 \mathrm{~kg}$ of Pentolite. It is clear that pressure values decrease with distance from the seat of detonation, however, a substantial reduction was obtained across the SSPs, corresponding to their respective effective multi vent area ratio. Pressures at $\mathrm{G}_{2}, \mathrm{G}_{3}$ and $\mathrm{G}_{4}$ were highest for SSP-A, the test sample with large vent area ratio. Lower pressure values were measured with the SSPs with the lower vent area ratios. The resulting percent pressure attenuation referenced to the air tests is shown in Figure 6.10.

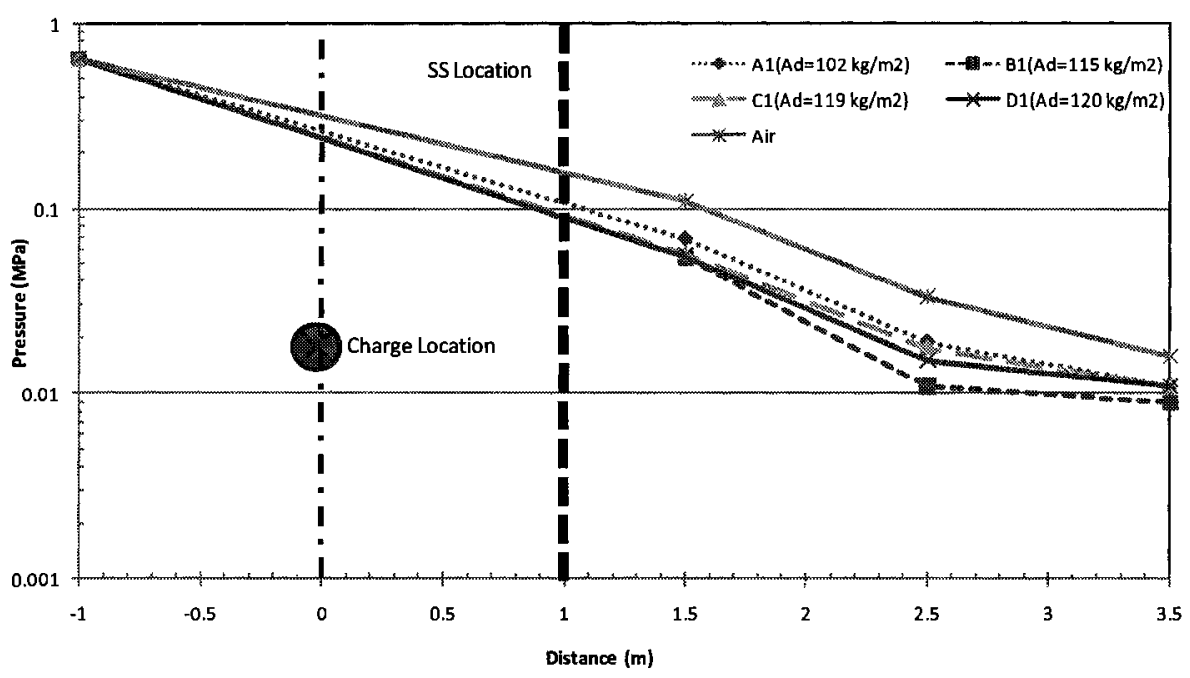

Figure 6.9: Blast pressure versus gauge location- $0.25 \mathrm{~kg}$ of Pentolite

At gauge location, $\mathrm{G}_{2}$, it is clear that SSP-B and SSP-D have similar attenuation percentage of $51 \%$ and $50 \%$, respectively, next was SSP-C with $48 \%$ and finally SSP-A with $37 \%$. These values correlate well with the vent area ratio of $0.02,0.02,0.08$, and 0.13 for SSP-B, SSP-D, SSP-C and SSP-A, respectively. The panels with the lower vent area ratios relieve blast pressures to a lesser extent than the panels with the higher vent areas; as a result, they will be subjected to higher blast loads but will produce the greater 
blast pressure attenuation. Average attenuation percentage would be of more value in SSPs comparison, thus average values were computed and is presented in Figure 6.11.

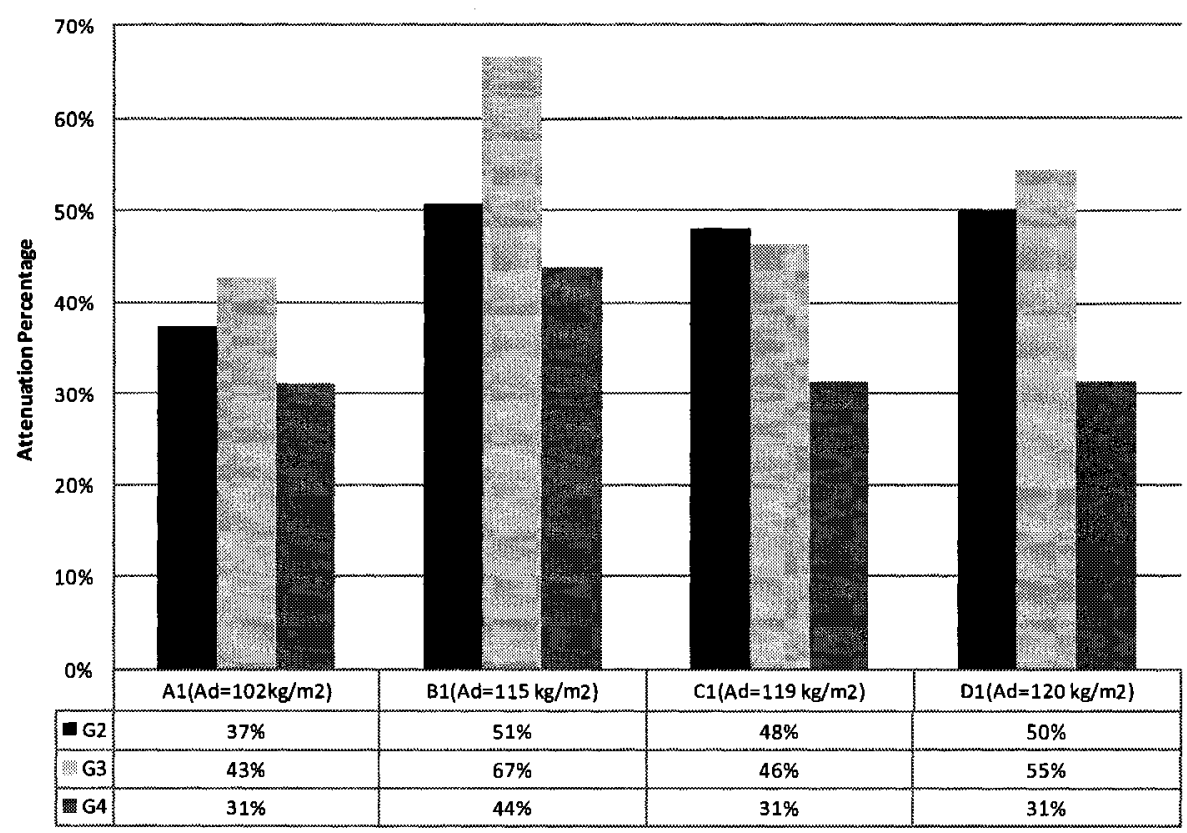

Figure 6.10: SSPs pressure attenuation percentage- $0.25 \mathrm{~kg}$ of Pentolite

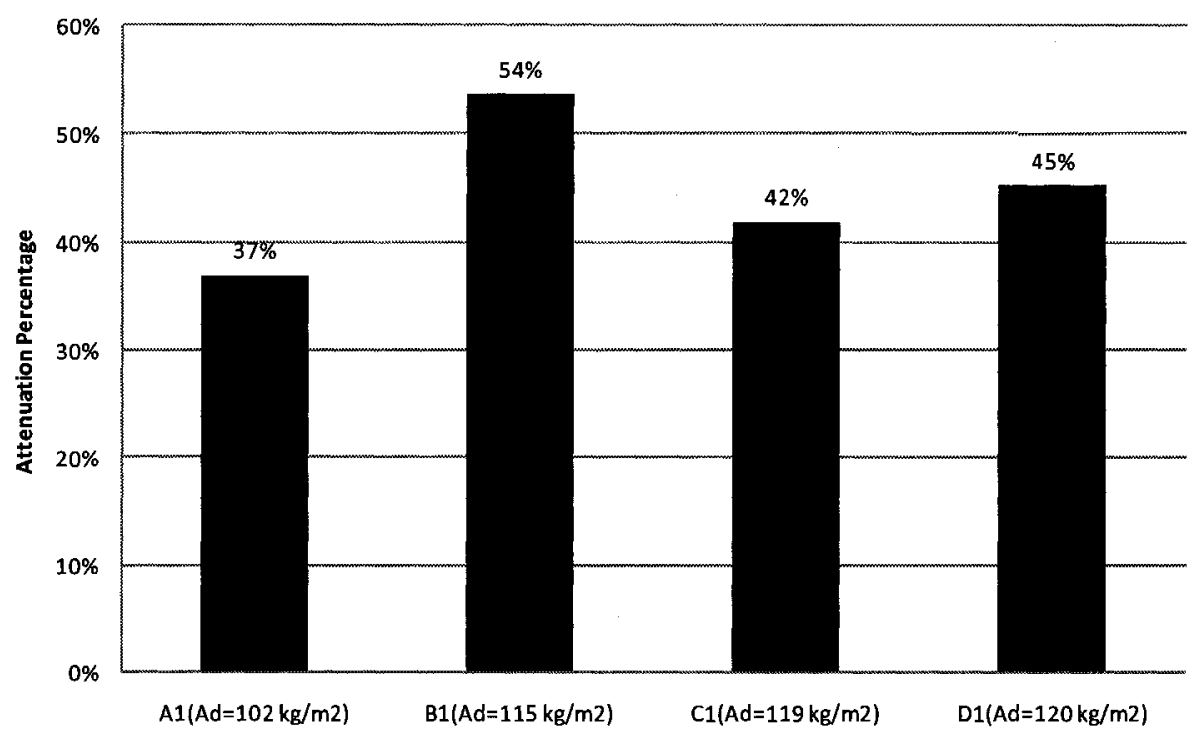

Figure 6.11: Average SSPs pressure attenuation percentage-0.25 kg of Pentolite

It can be seen in Figure 6.11 that SSP-B has the highest average attenuation with 54\%, followed by SSP-D with 45\%, next SSP-C and SSP-A with $42 \%$ and $37 \%$, respectively. 
Figure 6.12 represents the impulse at the various gauge locations. It is observed that SSPs significantly reduce impulse compared to the air shots from detonating $0.25 \mathrm{~kg}$ of Pentolite. The average percentage of impulse attenuation for the SSPs is shown in Figure 6.13. It is clear that the best performance was with SSP-B with an impulse attenuation of 75\%. The impulse attenuation correlates well with the pressure attenuation results, with the order of best to worst performance being SSP-B, SSP-D, SSP-C, and SSP-A.

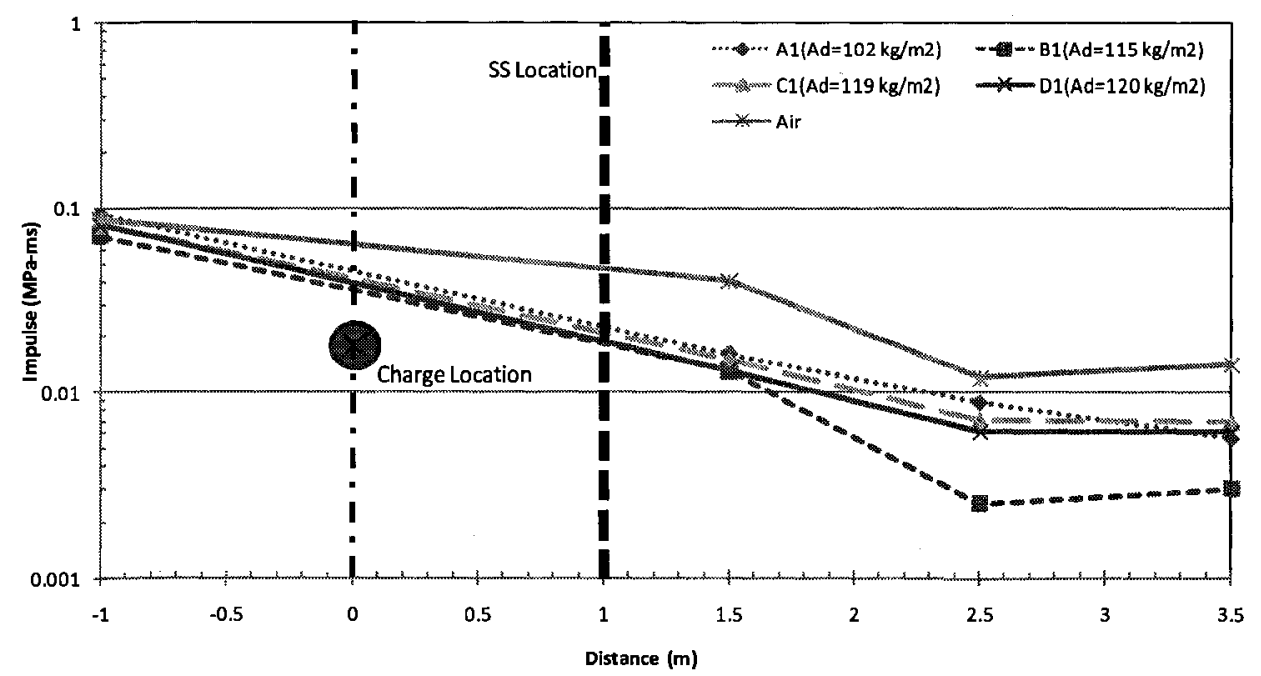

Figure 6.12: Impulse versus gauge location- $0.25 \mathrm{~kg}$ of Pentolite

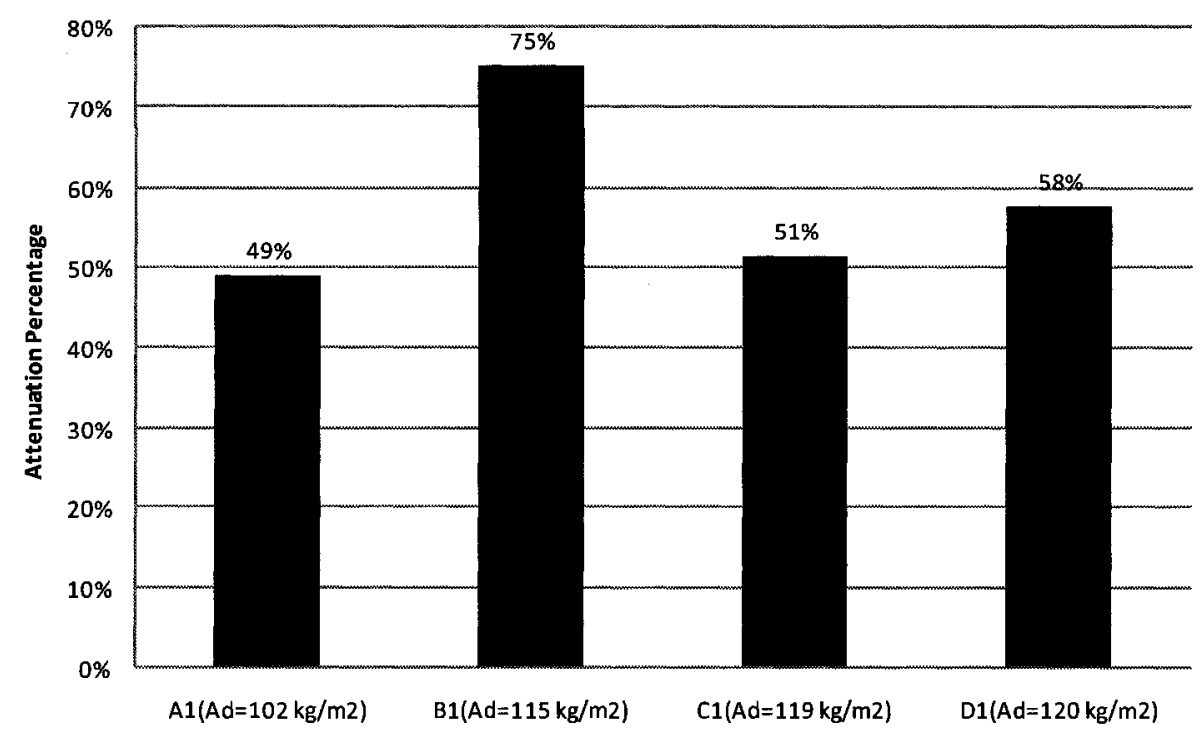

Figure 6.13: Average SSPs impulse attenuation percentage0.25 kg of Pentolite 


\subsubsection{Results of $0.50 \mathrm{~kg}$ of Pentolite}

Figure 6.14 shows the blast pressures at the various gauge locations for the air and SSPs and pressures predicted by ConWep for the detonation of the $0.50 \mathrm{~kg}$ of Pentolite. The significant reduction in pressure values is obvious with the SSPs. It is clear that SSP-B and SSP-D performed better with this larger explosive charge.

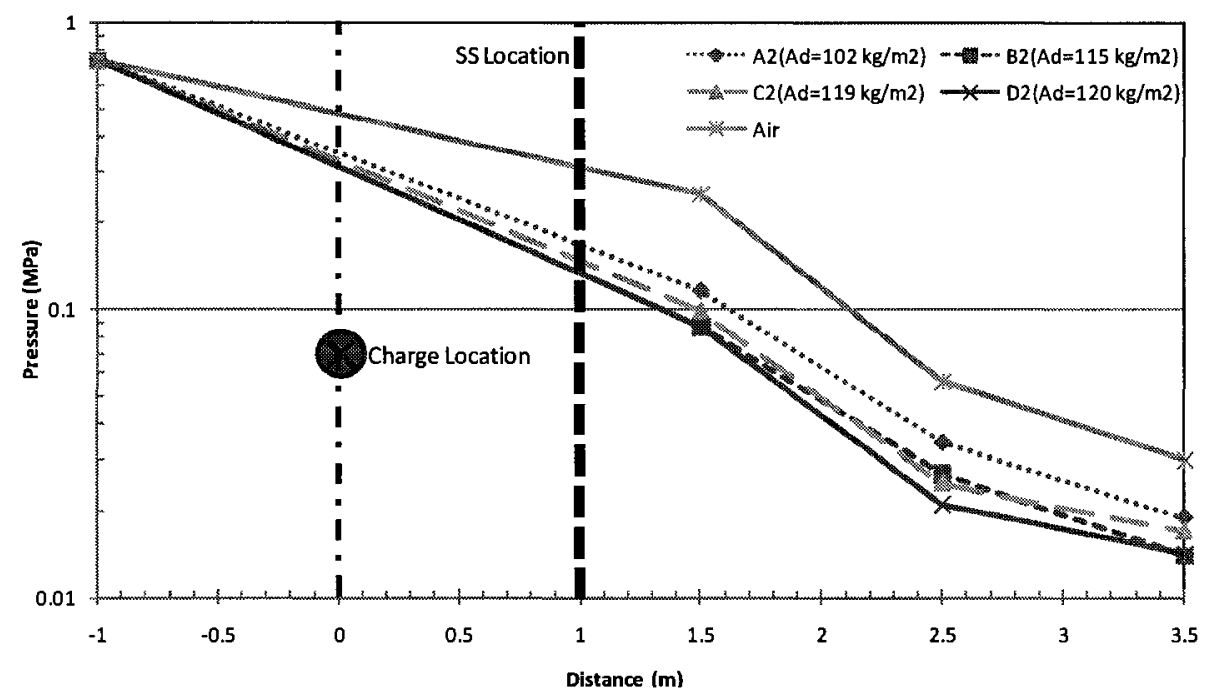

Figure 6.14: Blast pressure versus gauge location- $0.5 \mathrm{~kg}$ of Pentolite

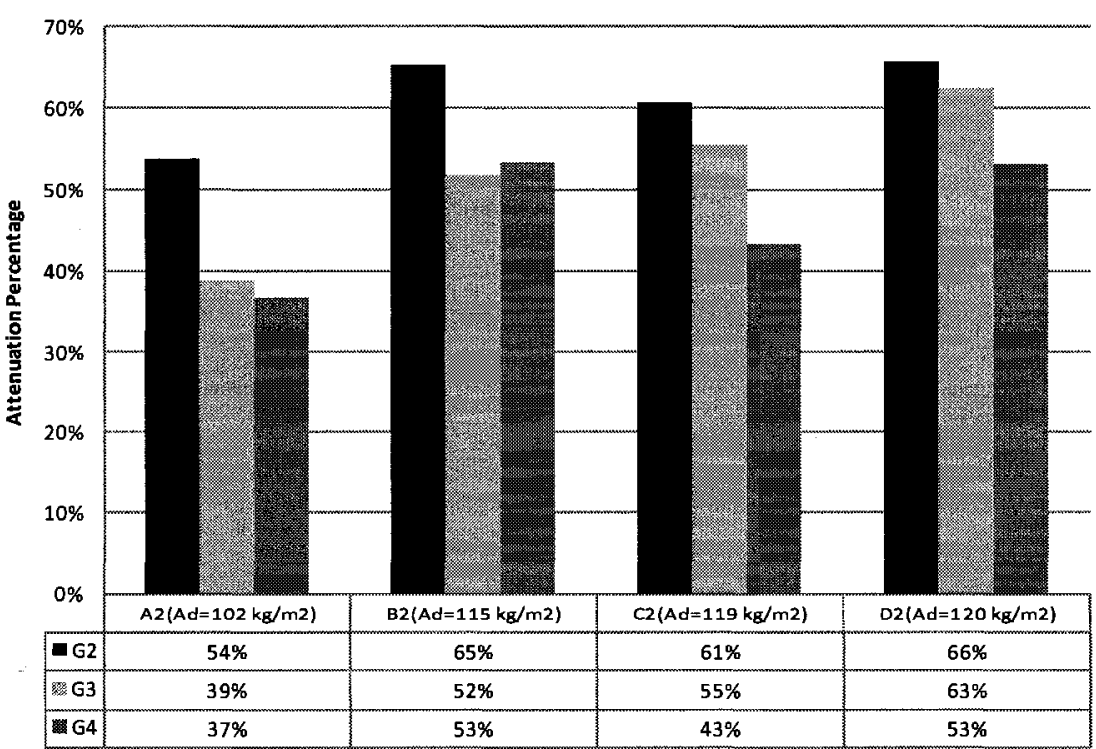

Figure 6.15: SSPs pressure attenuation percentage- $0.5 \mathrm{~kg}$ of Pentolite 
Figure 6.15 shows the percentage attenuation for all the SSPs. At $\mathrm{G}_{2}$, SSP-B and SSP-D have similar attenuation percentage of $65 \%$ and $66 \%$, respectively, next was SSP-C with $61 \%$ and finally SSP-A with $54 \%$. The attenuation trend is similar for the other two gauge locations. The average attenuation (Figure 6.16) for SSP-B and SSP-D is 57\% and $60 \%$, respectively, followed by SSP-C with $53 \%$, and SSP-A with $43 \%$.

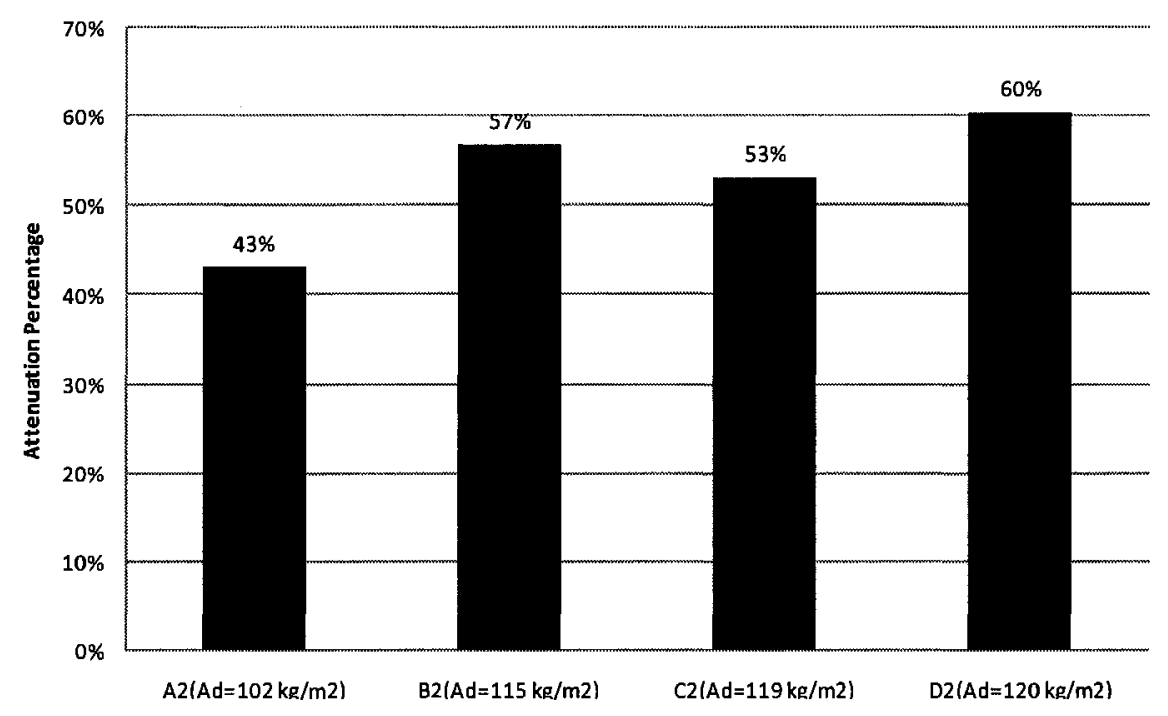

Figure 6.16: Average SSPs pressure attenuation percentage- $0.5 \mathrm{~kg}$ of Pentolite

Figure 6.17 shows the pressure impulse for the various gauge locations. It is clear that with the $0.50 \mathrm{~kg}$ explosive mass, the SSPs have more consistent pressure profiles compare to the $0.25 \mathrm{~kg}$ results. As concluded above, SSP-B and SSP-D are the best performing panel over the other SSPs. In order to evaluate SSPs performance with respect to impulse attenuation, average attenuations were calculated and are shown in Figure 6.18. Samples SSP-B and SSP-D, with attenuations of 54\% and 58\%, respectively, were the best performers for attenuating impulse as they were at attenuating pressure. 


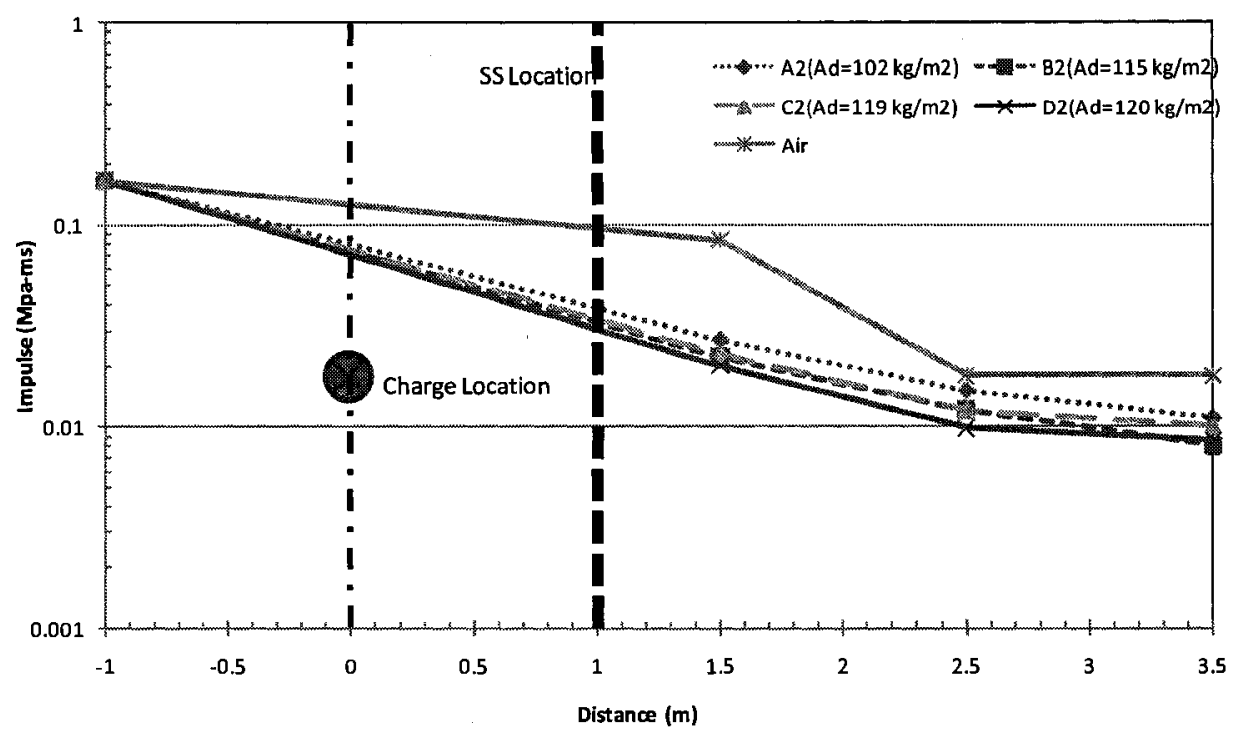

Figure 6.17: Impulse versus gauge location- $0.5 \mathrm{~kg}$ of Pentolite

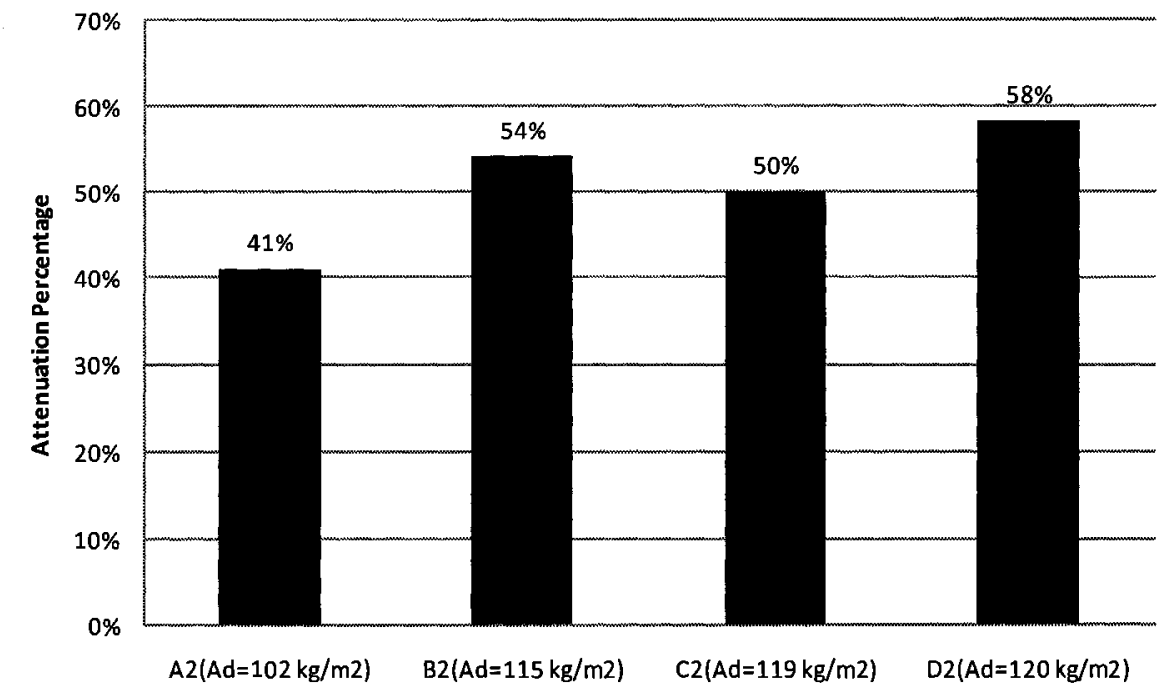

Figure 6.18: Average SSPs impulse attenuation percentage-0.5 kg of Pentolite

\subsubsection{Results of $1.00 \mathrm{~kg}$ of Pentolite}

Figure 6.19 and 6.20 show the pressure and impulse at the various gauge locations, for the SSPs for the tests with $1.00 \mathrm{~kg}$ Pentolite charges. Since no air shot was performed with $1.00 \mathrm{~kg}$ of Pentolite, pressure and impulse attenuation percentages could not be 
determined, however, significant reductions in pressure and impulse values are clear with the SSP-B and SSP-D performing better than the SSP-A and SSP-C.

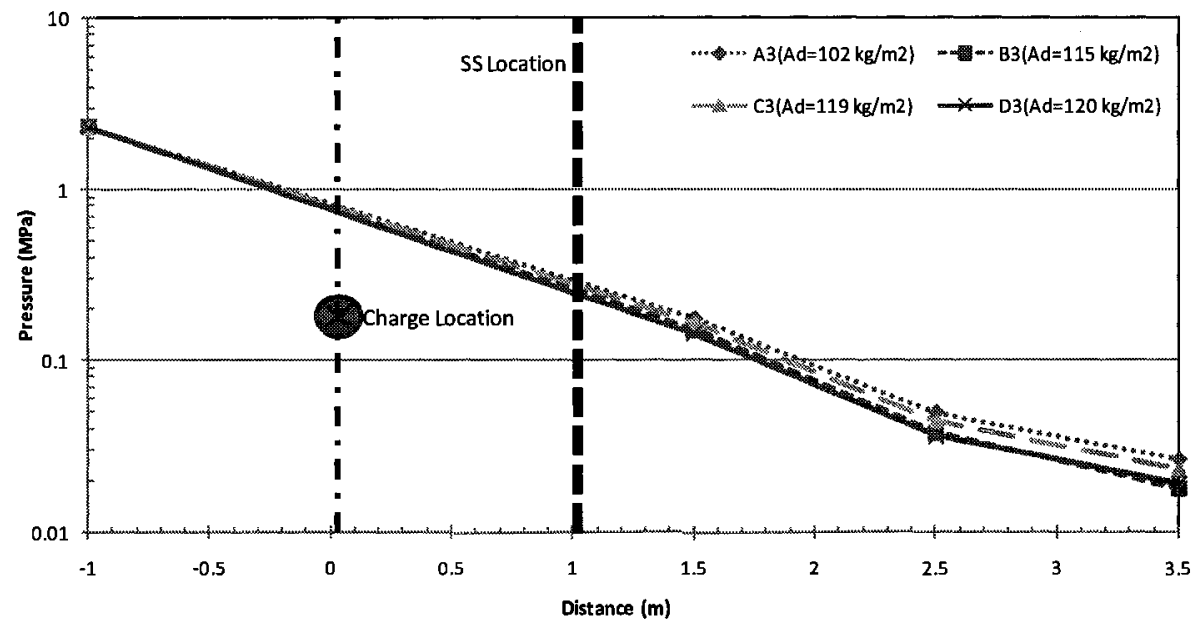

Figure 6.19: Blast pressure versus gauge location-1 kg of Pentolite

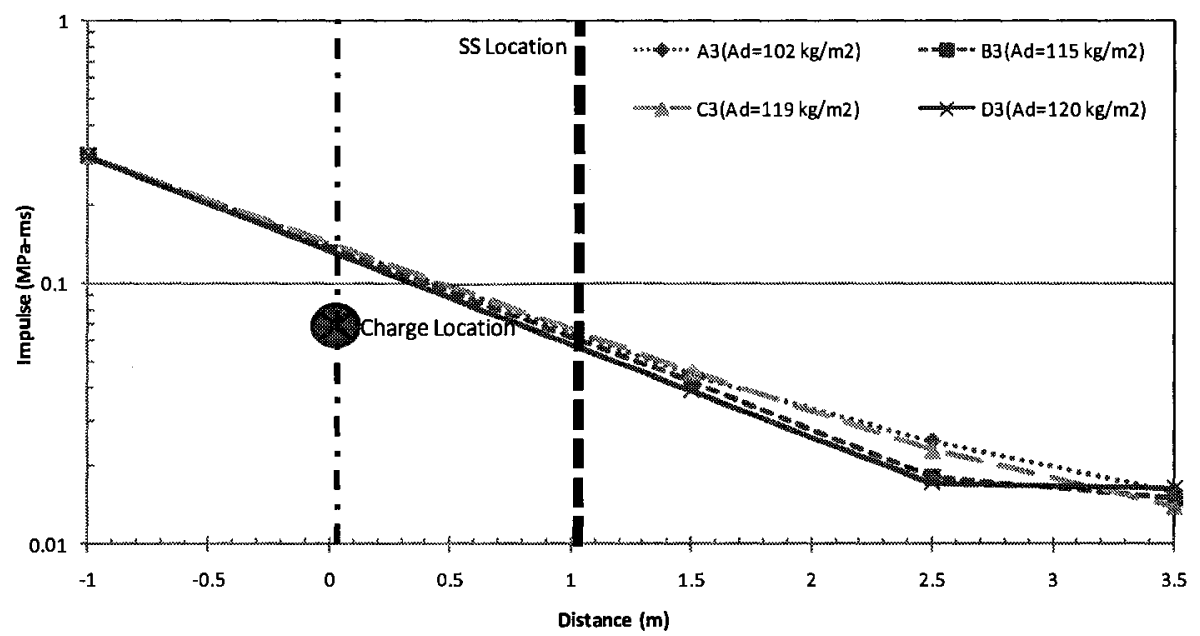

Figure 6.20: Impulse versus gauge location-1 kg of Pentolite

Figure 6.21 shows the SSPs cross-sections and the direction of loading. Details of the SSPs were given in Chapter 5. Note that the inner layer of the SSPs is the layer facing the explosive charge. It can be seen that both layers of SSP-A were manufactured with L102. SSP-B was also built with L102 in both layers with bigger spacing between the angles and another row of angle section, L51, was added to the inner layer to reduce the spacing 
and help in obstructing the blast. Next, SSP-C was manufactured with L76 section forming the inner layer and L102 section forming the outer layer. The smaller angle section, L51, was welded to the outer layer, as shown. Finally, the inner layer of SSP-D was built with L102 and L51, while the outer layer was built with L76 and L51.
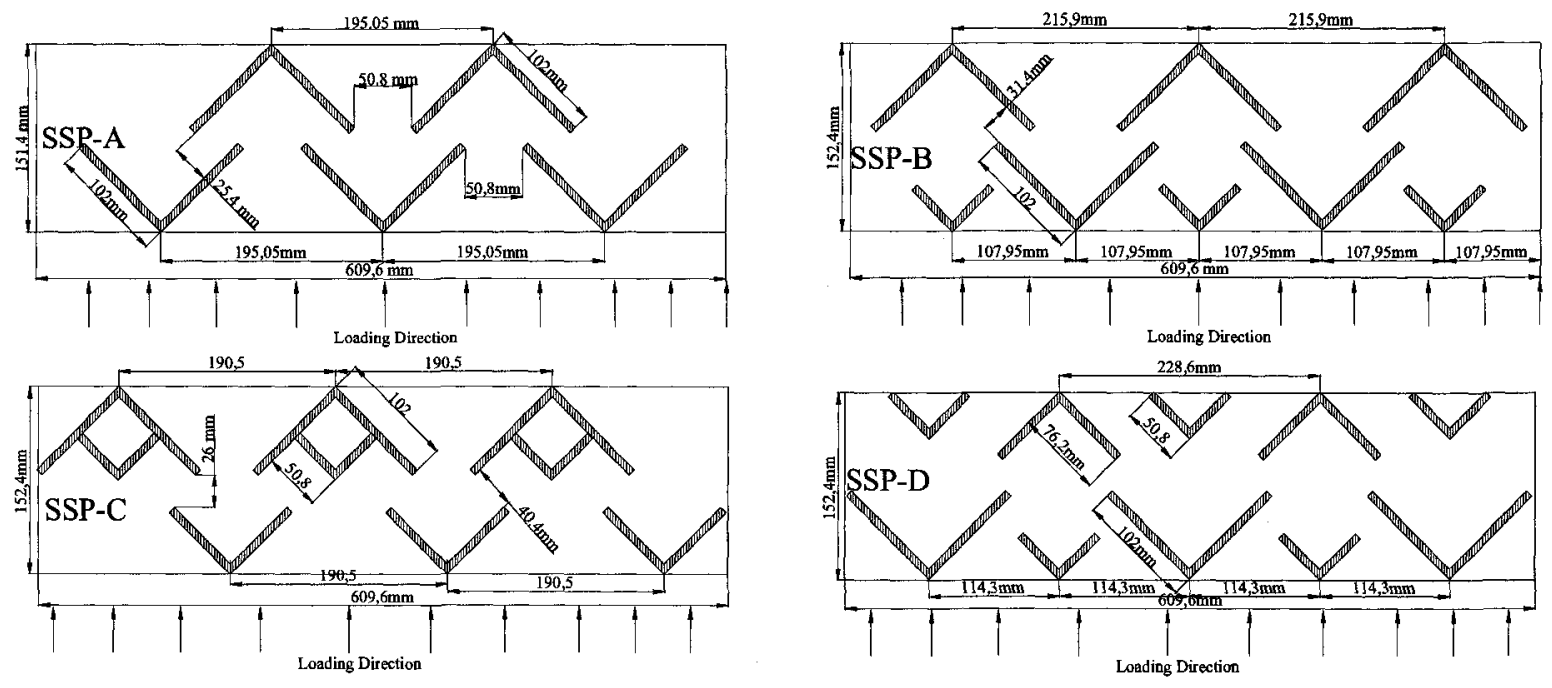

Figure 6.21: SSPs cross-section with loading direction

It is obvious that SSPs with more than one angle section per row performed better. It can be seen that SSP-A and SSP-C, one angle section per row, have fewer reflecting surfaces and thus less blast attenuation capability. It is clear that SSP-B and SSP-D performed better. This enhanced performance is credited to the reduction in vent area ratio and the obstruction of blast wave by the higher number of reflecting surfaces.

\subsection{Suppressive Shield Panels-with Aluminum Foam}

The following sub-sections present the results obtained from the six tests performed on the various SSPs with AF panels. One charge mass, $0.50 \mathrm{~kg}$ of Pentolite was used for all 
six tests. The presented results include blast pressure and impulse as well as their attenuation.

\subsubsection{Aluminum Foam tests without Backing}

Figure 6.22 shows the blast pressures at the various gauge locations for the air and SSPs with bare AF sheets resulted from $0.50 \mathrm{~kg}$ of Pentolite. As already stated, there is a significant pressure reduction with SSPs, however when the AF sheets were added, even more reduction was achieved.

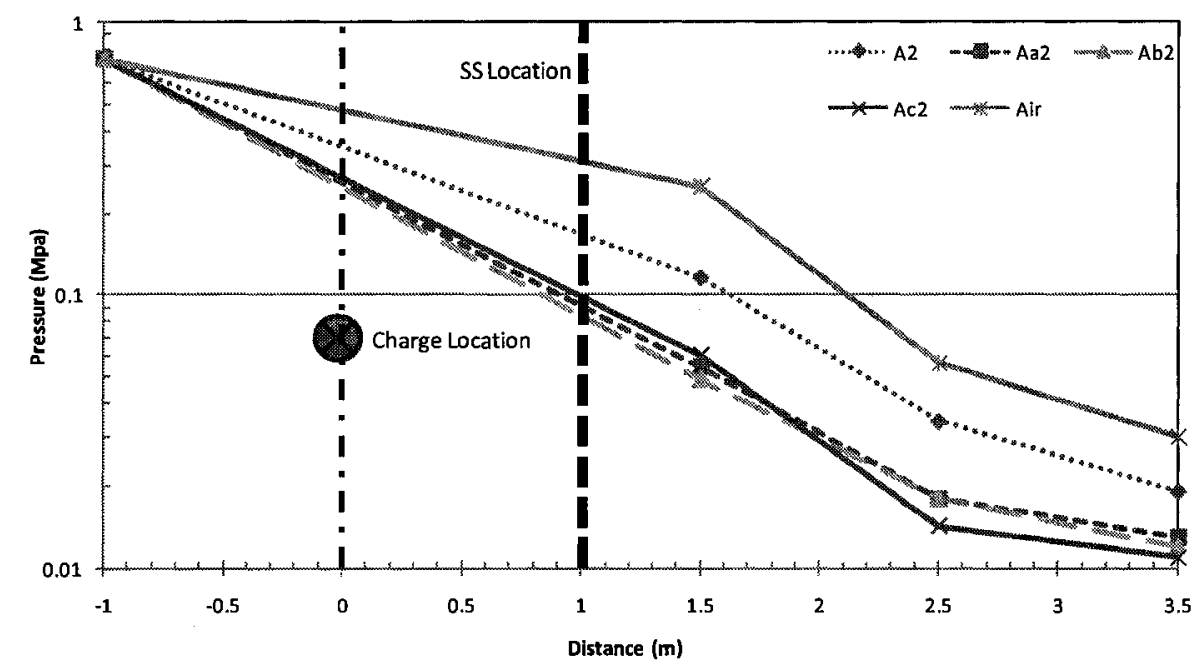

Figure 6.22: Blast pressure versus gauge location-Unbaked AF-0.5 kg of Pentolite

Figure 6.23 shows the performance of SSPs with bare AF sheets with a minimum and maximum attenuation of $57 \%$ and $80 \%$, respectively. For example at gauge location $\mathrm{G}_{4}$, the furthest gauge from the explosive charge, it is clear that the thickness of $\mathrm{AF}$ affect the pressure attenuation values at which the highest attenuation percentage was achieved by the thickest, $63 \%$, followed by the mid thickness, $60 \%$, and finally the least thick with $57 \%$. 


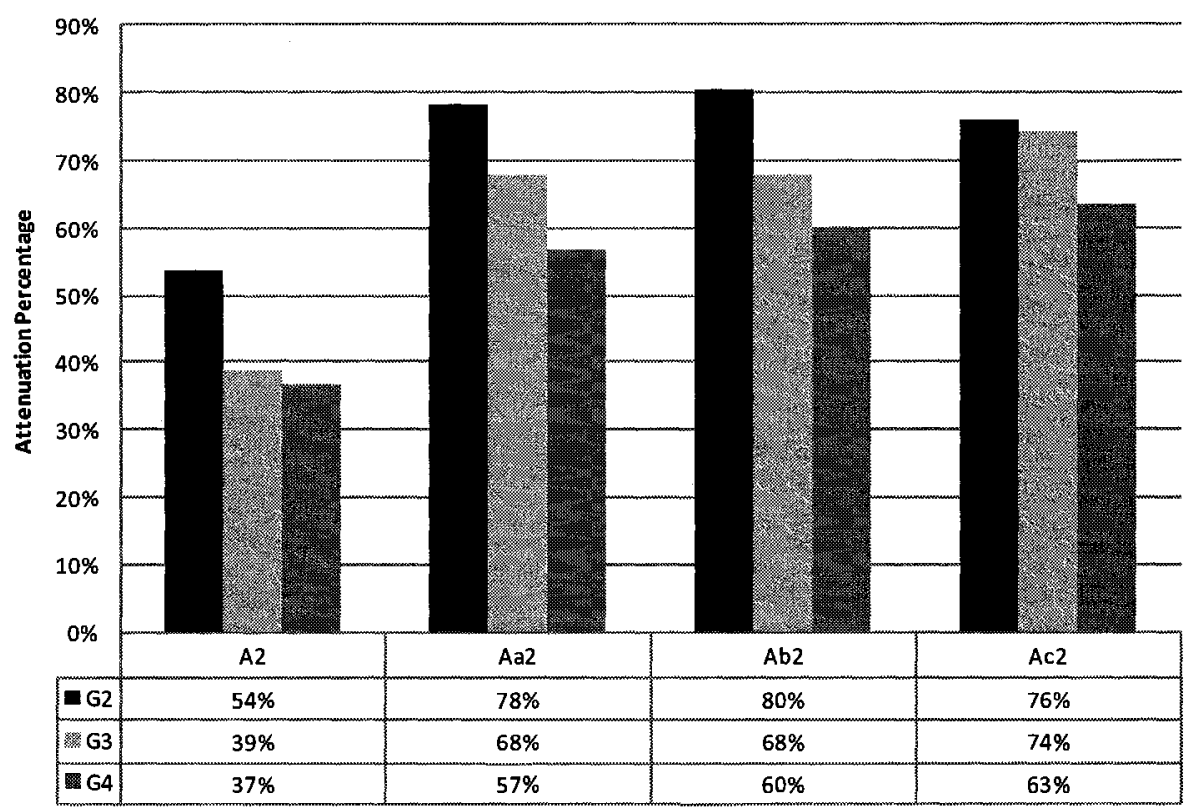

Figure 6.23: SSPs-pressure attenuation percentage-Unbaked AF- $0.5 \mathrm{~kg}$ of Pentolite

The overall performance of SSPs with AF over SSP without AF can be evaluated from Figure 6.24 and Table 6.1. It can be seen that, the various thicknesses of AF sheets resulted in an attenuation of $25 \%$ to $28 \%$ when compared to the same panel without $\mathrm{AF}$ sheets. After testing, it was observed that all thicknesses of AF suffered various degrees of distortion and disintegration. The thinnest AF sheet was totally shredded into small bits and nothing stayed attached to the panel. However for the other two thicknesses, various parts were recovered between the angles of the SSP. 


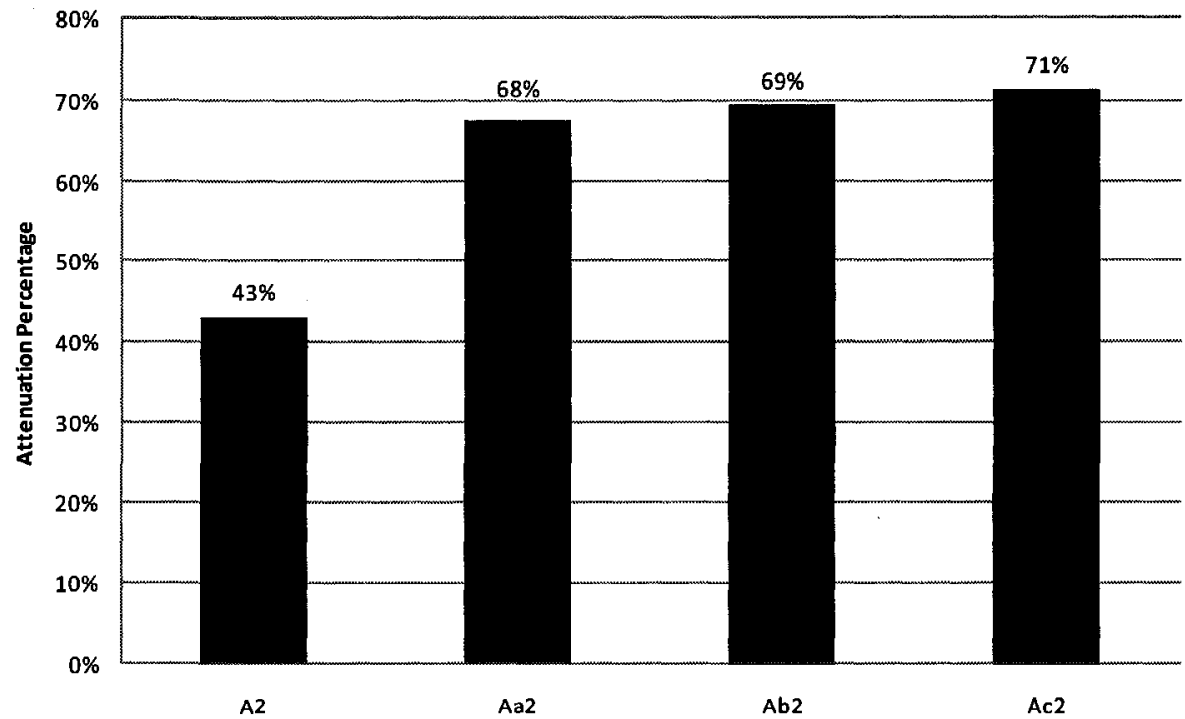

Figure 6.24: Average SSPs pressure attenuation percentage-Unbaked AF-0.5 kg of Pentolite

Table 6.1: Pressure values inside and outside blast chamber SSP-A (with \& without AF)

\begin{tabular}{cccccc}
\hline Gauges & Air & $\boldsymbol{A}_{2}$ & $\boldsymbol{A}_{\boldsymbol{a} 2}$ & $\boldsymbol{A}_{\boldsymbol{b} 2}$ & $\boldsymbol{A}_{\boldsymbol{c} 2}$ \\
\hline $\mathrm{G}_{1}$ & 0.733 & 0.733 & 0.733 & 0.733 & 0.733 \\
$\mathrm{G}_{2}$ & 0.25 & 0.1156 & 0.054 & 0.049 & 0.0598 \\
$\mathrm{G}_{3}$ & 0.056 & 0.0343 & 0.018 & 0.018 & 0.0143 \\
$\mathrm{G}_{4}$ & 0.03 & 0.019 & 0.013 & 0.012 & 0.011 \\
\hline
\end{tabular}

Figure 6.25 shows the incident impulse at the various gauge locations. It is clear that SSPs with AF lining absorbed more energy than those without. It is observed that, more impulse reduction occurred with the increase in AF thickness. Average attenuations were calculated and are shown in Figure 6.26. It is clear that SSP with AF reduced impulse to a minimum and a maximum of $68 \%$ and $72 \%$, respectively, approximately $30 \%$ more than the SSPs without AF. 


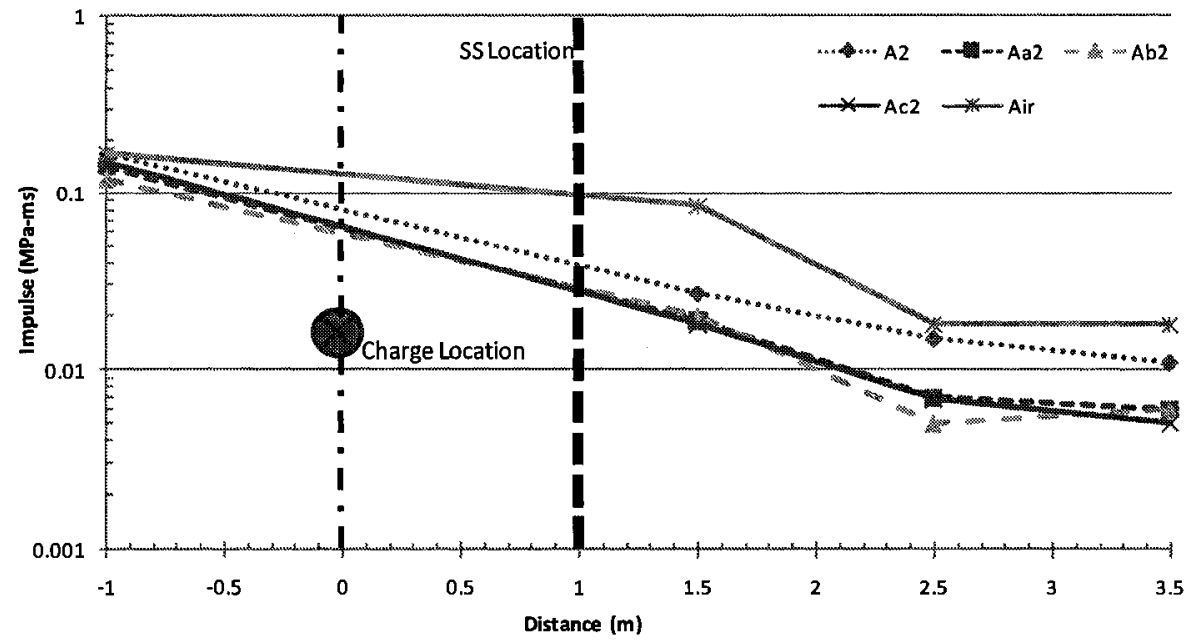

Figure 6.25: Impulse versus gauge location-Unbaked AF-0.5 $\mathrm{kg}$ of Pentolite

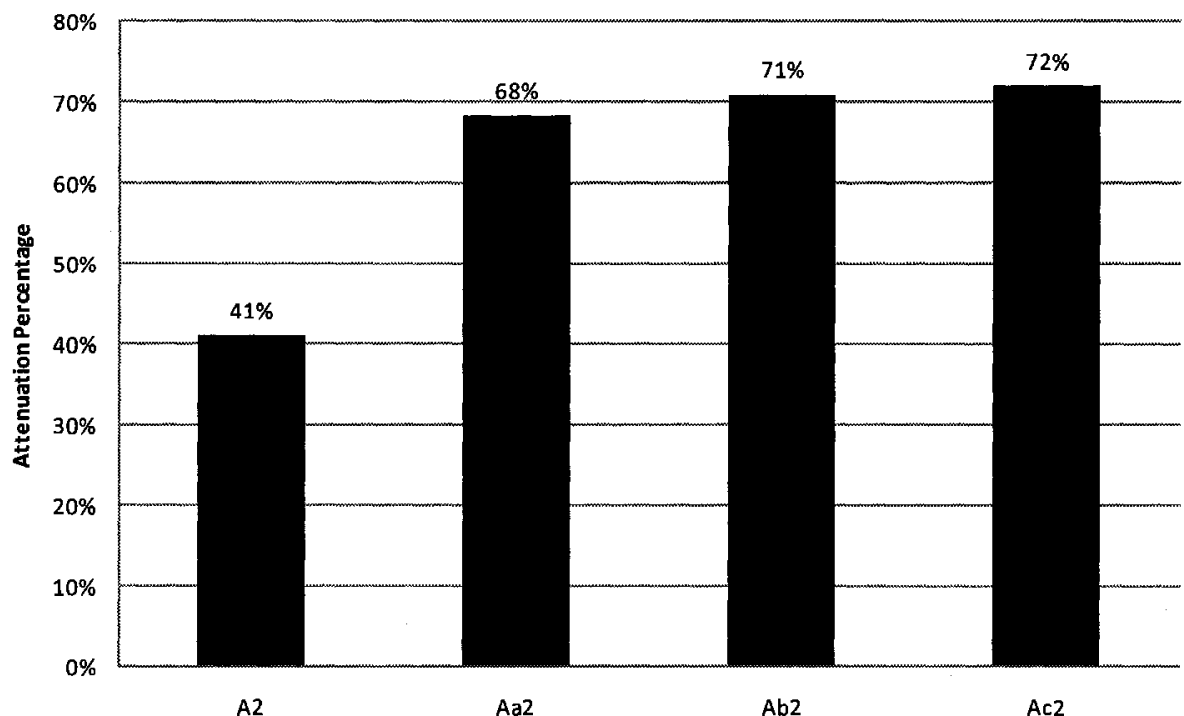

Figure 6.26: Average SSPs impulse attenuation percentage-Unbaked AF-0.5 kg of Pentolite

\subsubsection{Aluminum Foam tests with Backing}

These tests were performed using steel plate as backing to the AF sheets. Actually, the use of such plate drastically reduces the vent area ratio of the SSPs, but the reason behind using it was to investigate the attenuation capacity of the AF sheets with a steel backing plate. 
Figure 6.27 presents the pressure versus gauge locations for SSP-B, SSP- $\mathrm{B}_{22}$ and SSP$B_{\mathrm{c} 2}$. It is expected that, if the plate did not break up during the test, pressure attenuation would occur since the detonation effect would be contained within the blast chamber. The plate survived the test and so was used in a second test as backing to an AF sheet.

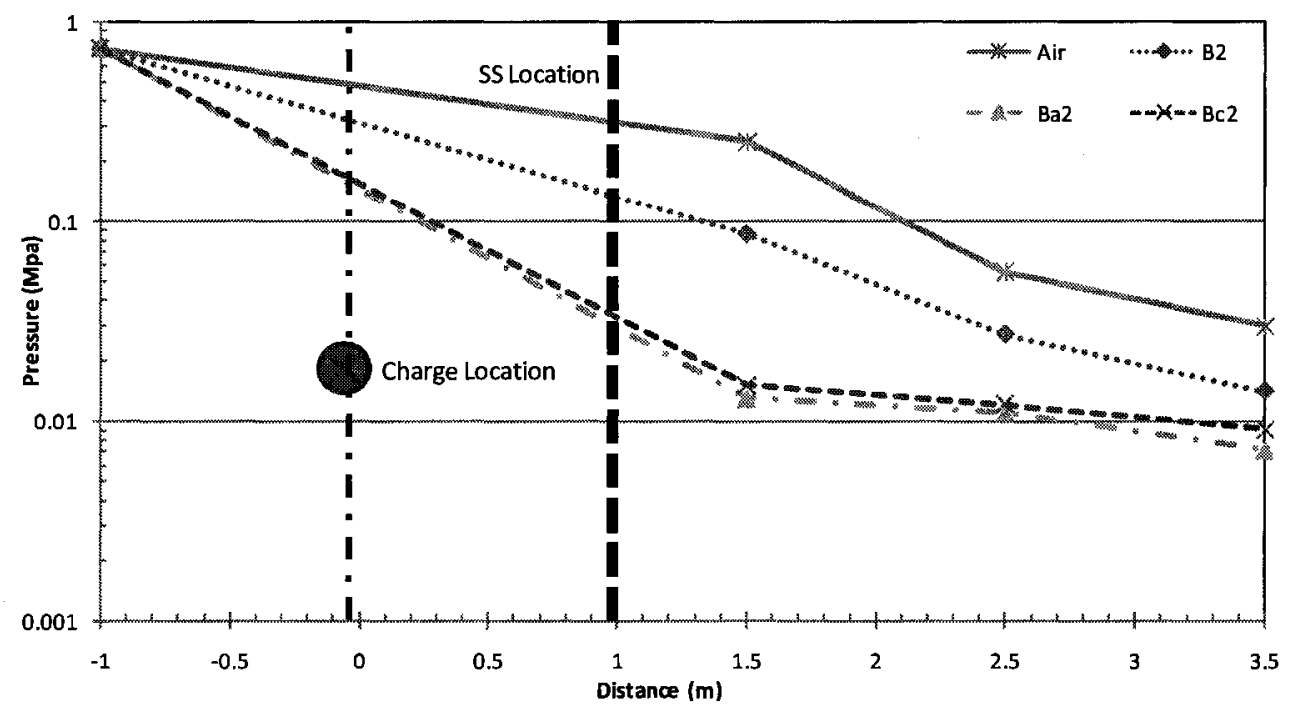

Figure 6.27: Blast pressure versus gauge location-SSP-B-AF-0.5 kg of Pentolite

It is clear from Figure 6.28 that the SSPs in conjunction with AF sheets attenuated the pressure values substantially more than SSPs without AF sheets. The main reason for having a steel plate as backing to $\mathrm{AF}$ sheets is to distribute the acting pressure on the total area of the sheet, thus, allowing the sheet to react more evenly to the blast. This is clearer when the average attenuation percentage of pressure was calculated as shown in Figure 6.29 . 


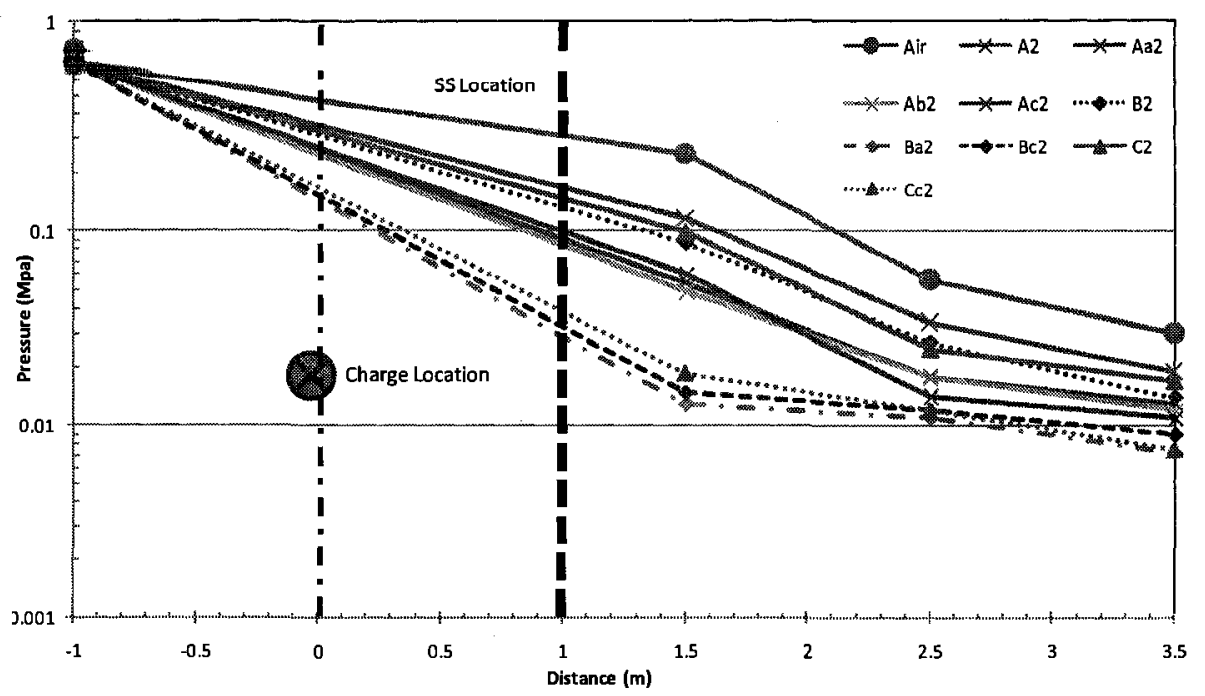

Figure 6.28: Blast pressure versus gauge location-SSPs \& AF with and without backing

It is clear from Figure 6.29 that by backing the AF sheets, the pressure was attenuated to more than $40 \%$ compared to SSPs with no AF sheets and more than $30 \%$ compared to panels with AF but with no backing. Note that the attenuation with the steels backing plate results from both, the reduced vent area ratio and the support to the AF panel that allows its deformation without disintegration. Despite the fact that the backing of $\mathrm{AF}$ sheets reduces pressure values to higher extent over other panels, it is recommended to use perforated steel plate instead of a solid one, to allow venting of the blast pressure while still providing support to distribute the blast pressure acting on larger area. 


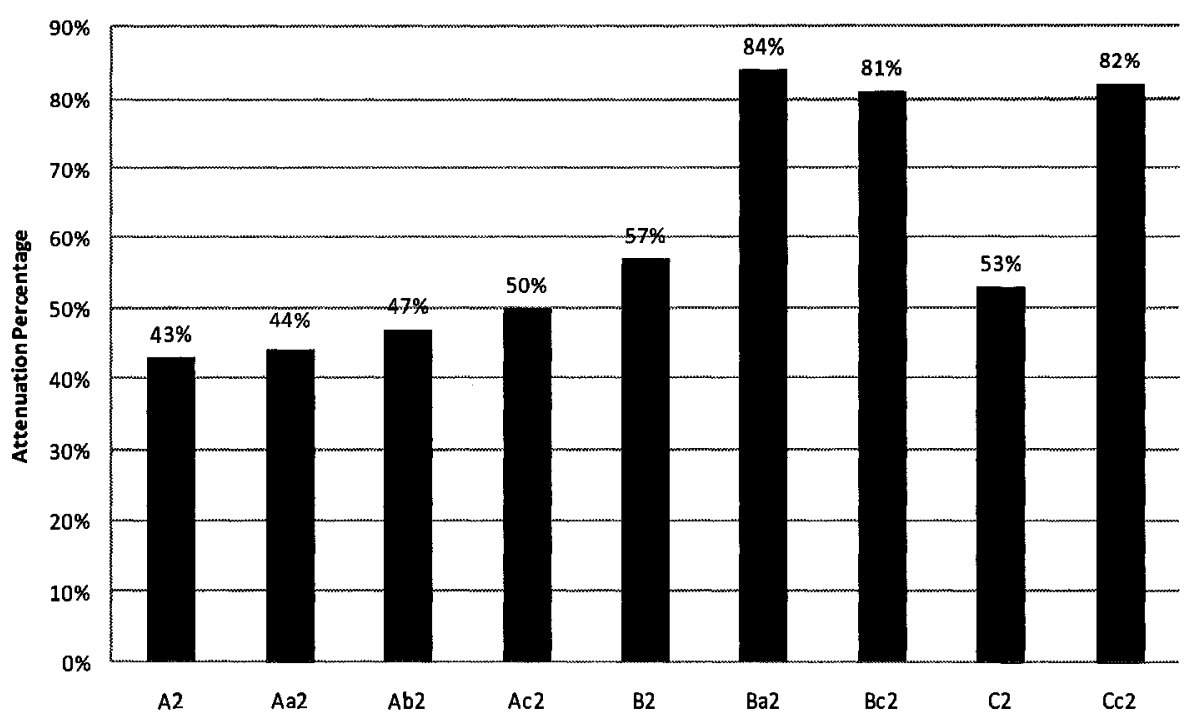

Figure 6.29: SSPs Average pressure attenuation percentage-AF with \& without backing

Figure 6.30 shows the blast impulse at the various gauge locations. It is clear that the SSPs with AF sheets attenuated impulse similarly to pressure, more than without the AF backing. It is observed that, higher impulse attenuation occurs with the increase in AF sheet thickness as seen for samples SSP- $\mathrm{B}_{\mathrm{a} 2}$ and $\mathrm{SSP}-\mathrm{B}_{\mathrm{c} 2}$. However, the spacing and size of angles played a role over the same AF thickness as presented with samples SSP-B $\mathrm{B}_{\mathrm{c} 2}$ and SSP-C $\mathrm{C}_{\mathrm{c} 2}$. In these two tests the thickness of AF was constant while the SSP design was changed. It was observed that SSP-B $\mathrm{B}_{\mathrm{c} 2}$ resulted in better performance over SSP-C $\mathrm{C}_{\mathrm{c} 2}$, which was the case when both panels were compared without AF sheets. In order to evaluate the SSPs performance with respect to impulse attenuation, the average attenuations were calculated and are shown in Figure 6.31. It is clear that the SSPs coupled with the AF sheets reduced impulse to an average value of $90 \%$ referenced to air and close to $20 \%$ compared to the SSP without AF. Although the AF thickness, $43 \mathrm{~mm}$, was used with SSP-C, the reduction in impulse did not exceed the values obtained with the thinnest AF, $13 \mathrm{~mm}$, when used with SSP-B. One can conclude here that the vent area and size of angles played a major role even when AF sheets were added. 


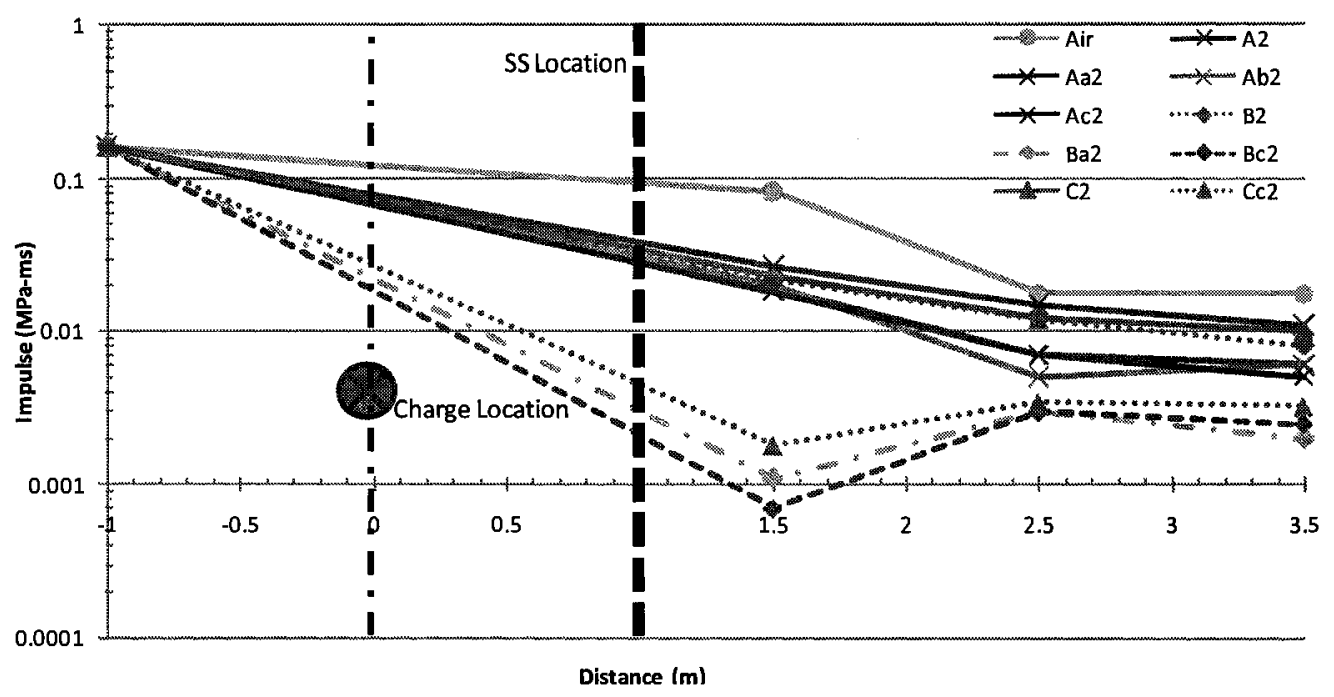

Figure 6.30: Impulse versus gauge location-SSPs \& AF with and without backing

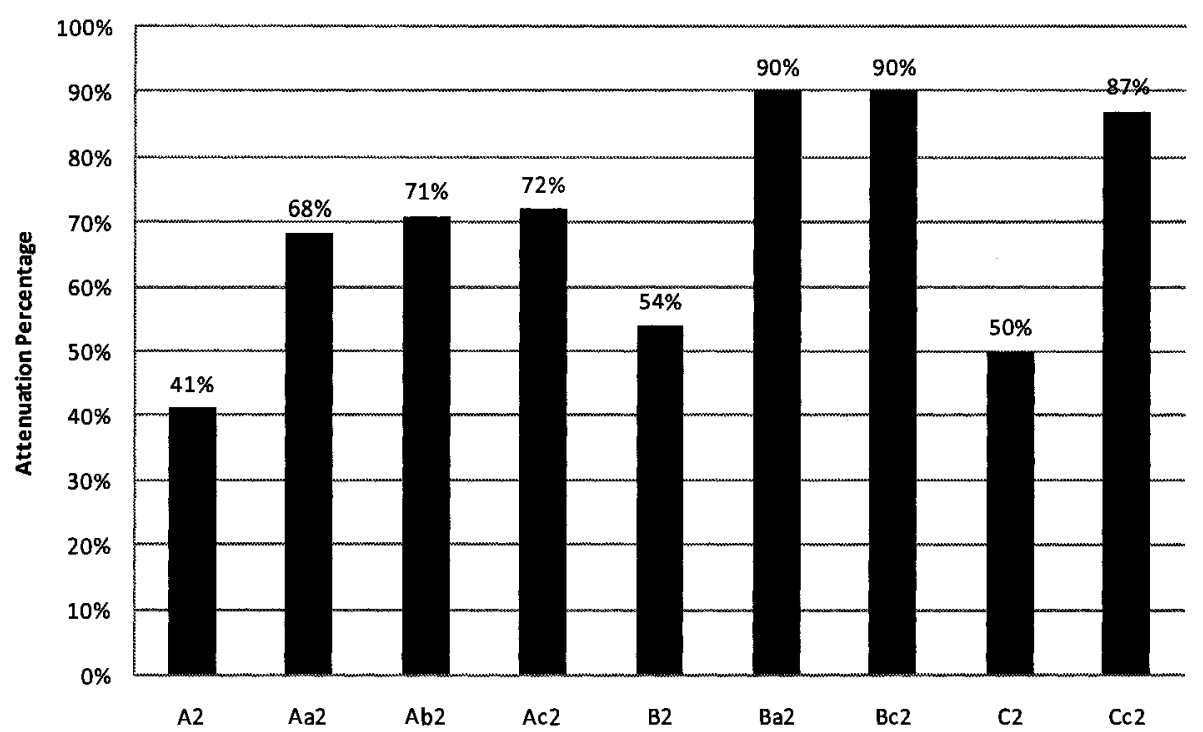

Figure 6.31: SSPs Average impulse attenuation percentage-AF with \& without backing

Figures 6.32 through 6.35 show the failure and damage suffered by the AF sheets in the tests. The sheet was squashed against the panels and deforms taking the shape of the angles. It is obvious that all sheets sustained the blast better than the ones without backing. However, the thinnest was observed to have some damage that did not occur in the case of the thicker samples. Figure 6.34 shows the side-view of the $43 \mathrm{~mm}$ thick AF 
sheet from the SSP-Bc $c_{2}$ test at which it was observed that the mid span of the sheet was compressed to more than one third of its original thickness without any apparent damage.
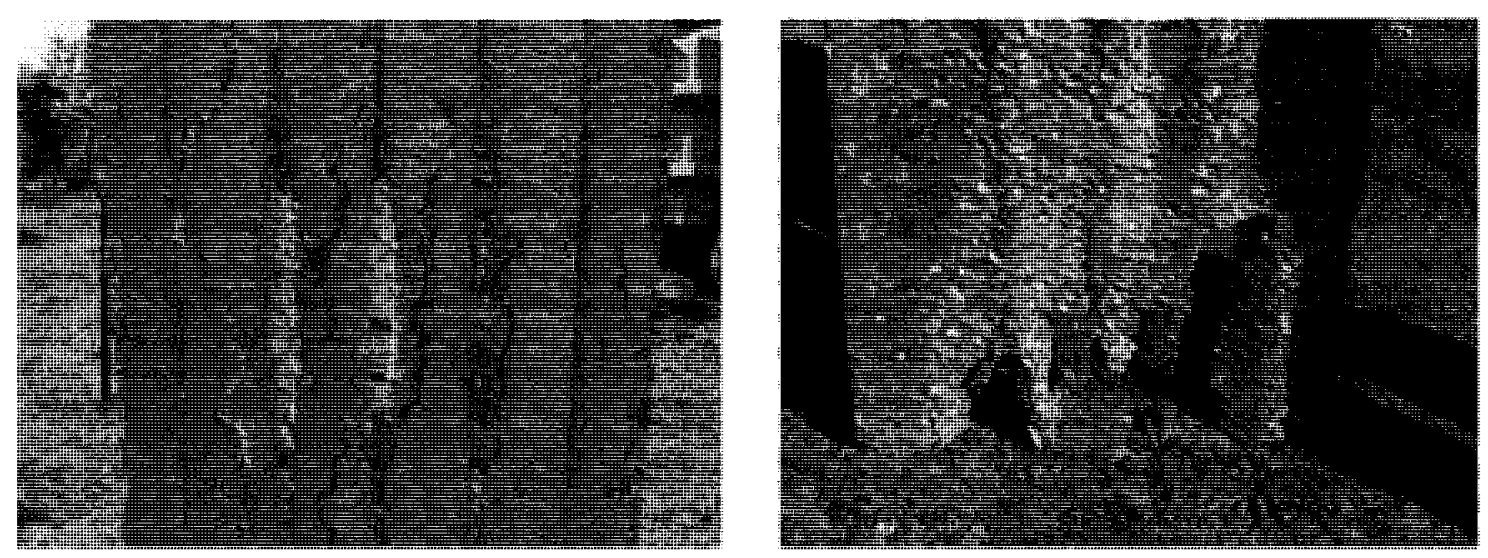

Figure 6.32: AF in SSP-Ba $\mathrm{S}_{2}$ after testing

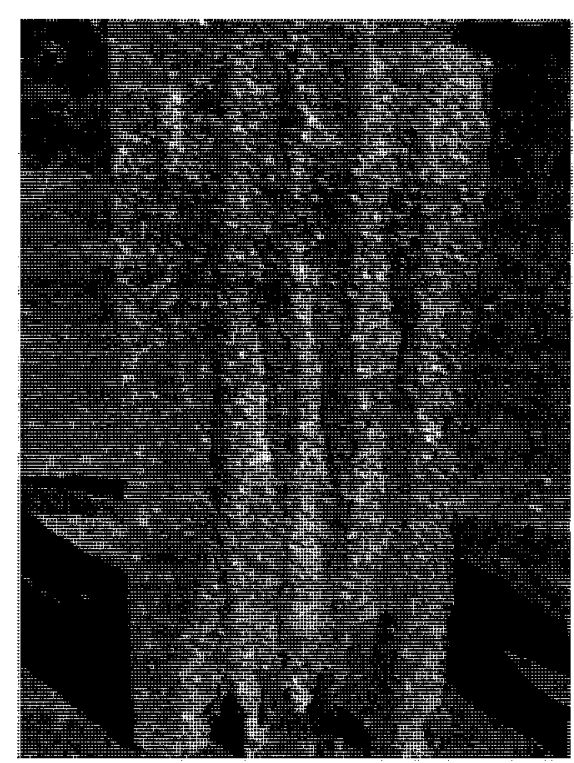

Figure 6.33: Smallest AF sheet thickness after testing with backing, SSP-Ba

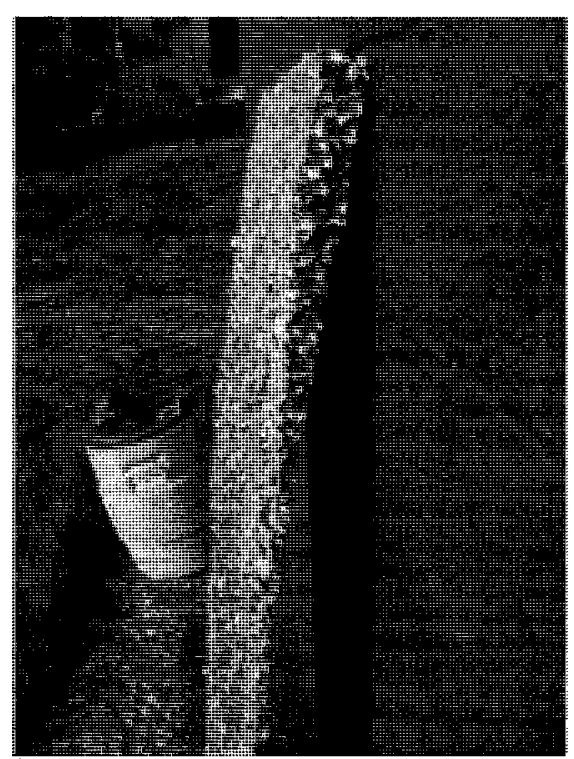

Figure 6.34: Side-view of biggest thickness of AF sheet after testing, SSP-Bc

Figure 6.35 shows the various deformations for the thickest $\mathrm{AF}$ sheet, $43 \mathrm{~mm}$, when tested with SSP-B and SSP-C. It can be seen that the AF sheets were squashed against the panels and took their shapes. The AF sheet used with SSP-C suffered more cracks 
compared to the one used with SSP-B. This damage is due to the wider spacing between angles in the SSP-C, $190 \mathrm{~mm}$, compared to $107 \mathrm{~mm}$ in the SSP-B sample.
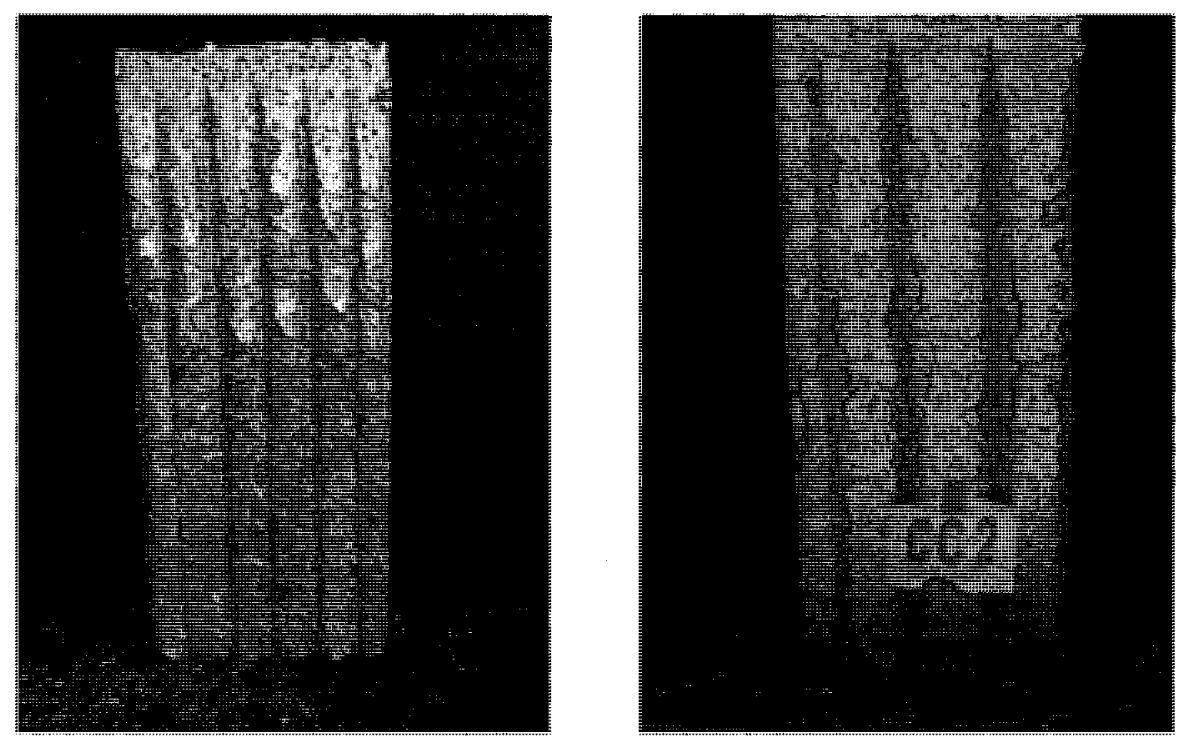

Figure 6.35: AF sheet deformation after testing for $\mathrm{SSP}-\mathrm{Bc}_{2} \mathrm{SSP}-\mathrm{Cc}_{2}$

As reference, consider that the maximum effective pressure values as defined in TM5$1300,0.105 \mathrm{MPa}$ for $50 \%$ eardrum rupture, $0.56 \mathrm{MPa}$ for 50\% lung damage and 1.724 MPa for $100 \%$ lethality (TM5-1300). The results with the SSPs demonstrate that they attenuated pressures to safe levels, lower than the pressure threshold values that cause injury to humans and possibly fatalities. The SSPs have the capability to mitigate blast pressure to safe values even at distances of $0.5 \mathrm{~m}$ from the SSPs (1.5 $\mathrm{m}$ from the charge) as shown in Tables 6.2 and 6.3.

Finally, it is concluded that SSPs have the potential to reduce shock pressure and impulse with and without AF sheets, without any obvious damage to panels subjected to blast load from $1.00 \mathrm{~kg}$ of Pentolite at $1 \mathrm{~m}$ standoff. On the other hand, AF sheets succeeded in attenuating blast pressure and impulse to a higher extent than the bare SSPs. 
Table 6.2: Pressure values for the three explosive charges, Air \& SSPs

\begin{tabular}{|c|c|c|c|c|}
\hline \multirow{2}{*}{ SSPs } & \multirow{2}{*}{ Gauge \# } & \multicolumn{3}{|c|}{ Pressure values $(\mathrm{MPa})$} \\
\hline & & $0.25 \mathrm{~kg}$ & $0.50 \mathrm{~kg}$ & $1.00 \mathrm{~kg}$ \\
\hline \multirow{4}{*}{ Air } & $\mathrm{G}_{1}$ & 0.638 & 0.733 & $\mathrm{~N} / \mathrm{A}$ \\
\hline & $\mathrm{G}_{2}$ & 0.110 & 0.250 & N/A \\
\hline & $\mathrm{G}_{3}$ & 0.033 & 0.056 & N/A \\
\hline & $\mathrm{G}_{4}$ & 0.016 & 0.030 & $\mathrm{~N} / \mathrm{A}$ \\
\hline \multirow{4}{*}{$\mathbf{A}$} & $\mathrm{G}_{1}$ & 0.638 & 0.733 & 2.313 \\
\hline & $\mathrm{G}_{2}$ & 0.069 & 0.116 & 0.173 \\
\hline & $\mathrm{G}_{3}$ & 0.019 & 0.034 & 0.049 \\
\hline & $\mathrm{G}_{4}$ & 0.011 & 0.019 & 0.026 \\
\hline \multirow{4}{*}{$\mathbf{B}$} & $\mathrm{G}_{1}$ & 0.638 & 0.733 & 2.313 \\
\hline & $\mathrm{G}_{2}$ & 0.054 & 0.087 & 0.150 \\
\hline & $\mathrm{G}_{3}$ & 0.011 & 0.027 & 0.038 \\
\hline & $\mathrm{G}_{4}$ & 0.009 & 0.014 & 0.018 \\
\hline \multirow{4}{*}{$\mathbf{C}$} & $\mathrm{G}_{1}$ & 0.638 & 0.733 & 2.313 \\
\hline & $\mathrm{G}_{2}$ & 0.057 & 0.098 & 0.162 \\
\hline & $\mathrm{G}_{3}$ & 0.018 & 0.025 & 0.044 \\
\hline & $\mathrm{G}_{4}$ & 0.011 & 0.017 & 0.023 \\
\hline \multirow{4}{*}{$\mathbf{D}$} & $\mathrm{G}_{1}$ & 0.638 & 0.733 & 2.313 \\
\hline & $\mathrm{G}_{2}$ & 0.054 & 0.086 & 0.150 \\
\hline & $\mathrm{G}_{3}$ & 0.011 & 0.021 & 0.038 \\
\hline & $\mathrm{G}_{4}$ & 0.009 & 0.014 & 0.018 \\
\hline
\end{tabular}

Table 6.3: Pressure values for $0.5 \mathrm{~kg}$ of Pentolite, SSPs with AF

\begin{tabular}{ccc}
\hline \multirow{2}{*}{ SSPs } & Gauge \# & Pressure values (MPa) \\
\cline { 3 - 3 } & & $\mathbf{0 . 5 0} \mathbf{~ k g}$ \\
\hline \multirow{3}{*}{$\mathbf{A}_{\mathbf{a}}$} & $\mathrm{G}_{1}$ & 0.733 \\
& $\mathrm{G}_{2}$ & 0.054 \\
& $\mathrm{G}_{3}$ & 0.018 \\
& $\mathrm{G}_{4}$ & 0.013 \\
\hline \multirow{4}{*}{$\mathbf{A}_{\mathbf{b}}$} & $\mathrm{G}_{1}$ & 0.733 \\
& $\mathrm{G}_{2}$ & 0.049 \\
& $\mathrm{G}_{3}$ & 0.018 \\
& $\mathrm{G}_{4}$ & 0.012 \\
\hline & $\mathrm{G}_{1}$ & 0.733 \\
$\mathbf{A}_{\mathbf{c}}$ & $\mathrm{G}_{2}$ & 0.060 \\
& $\mathrm{G}_{3}$ & 0.014 \\
& $\mathrm{G}_{4}$ & 0.011 \\
\hline $\mathbf{B}_{\mathbf{a}}$ & $\mathrm{G}_{1}$ & 0.733
\end{tabular}




\begin{tabular}{ccc} 
& $\mathrm{G}_{2}$ & 0.013 \\
& $\mathrm{G}_{3}$ & 0.011 \\
& $\mathrm{G}_{4}$ & 0.007 \\
\hline \multirow{3}{*}{$\mathbf{B}_{\mathbf{c}}$} & $\mathrm{G}_{1}$ & 0.733 \\
& $\mathrm{G}_{2}$ & 0.015 \\
& $\mathrm{G}_{3}$ & 0.012 \\
& $\mathrm{G}_{4}$ & 0.009 \\
\hline & $\mathrm{G}_{1}$ & 0.733 \\
$\mathbf{C}_{\mathbf{c}}$ & $\mathrm{G}_{2}$ & 0.019 \\
& $\mathrm{G}_{3}$ & 0.012 \\
& $\mathrm{G}_{4}$ & 0.008 \\
\hline
\end{tabular}

\subsection{Summary}

The results of the twenty tests to investigate the mitigation ability of SSPs were presented and discussed in this Chapter. Potential of such structures to attenuate blast parameters, pressure and impulse, to a safer extent was observed throughout the results. It was observed that SSPs attained average pressure attenuation of $40 \%$ to $60 \%$ and average attenuation in impulse of $40 \%$ to $70 \%$. Furthermore the SSPs with AF sheets including the add-on steel plate, averaged attenuation of pressure of $40 \%$ to $85 \%$ and average attenuation in impulse of $68 \%$ to $90 \%$. These large values demonstrate the ability of AF sheets to absorb huge amount of energy.

The capability of such systems to attenuate pressure and impulse to safer limits points to uses such as their incorporation into transport containers where transport of explosives by conventional means could be restricted. In addition, transportation engineers can use the technology to enhance safety and security of dangerous goods shipments on conventional routes. Furthermore, they can be a great asset in protecting civilians as well as 
transportation infrastructure where such panels can be integrated into storage buildings for explosives or onto facades of critical buildings to improving their ability to survive intentional or accidental explosions. 


\section{Chapter 7}

\section{Numerical Investigation of Experimental Data}

\section{Introduction}

The experimental investigation presented in Chapter 5 and 6 was carried out to evaluate the blast attenuation capability of SSPs. The main objective of this chapter is to present the various design scenarios that were considered in the experimental investigation and to verify its main findings. The following sections describe the details related to the air and SSPs, boundary conditions, explosive charges remapping and locations of gauges considered in the numerical study and discuss its results.

\subsection{Air Domains}

This section deals with the definition of the simulated air domains, 2-D and 3-D, and the factors included in the numerical simulation of the experimental investigation. The simulations of Suppressive Shield Panels were divided into two main components. Firstly, the attenuation effect of the shock wave was simulated using 2-D models. Secondly, the structure response to the shock loads was studied using 3-D models.

\subsubsection{2-D Air Domain}

The air domain is modeled using the Euler-FCT (Flux Corrected Transport) formulation which is designed to solve gas dynamic problems and/or fluid flow such as shock wave 
propagation. It is divided into two parts, the blast chamber and the air outside the chamber. The explosive chamber was presented as air with reflecting sides, while the air domain outside the explosive chamber had a "flow-out" boundary condition to allow the transmission of the shock waves. This air domain had dimensions of $6000 \mathrm{~mm}$ in length and of $1190 \mathrm{~mm}$ in width, dimensions selected to encompass the gauge locations outside the chamber. The mesh size was chosen according to the mesh size convergence study presented in Chapter 3, Section 3.3.2, that recommended having a minimum cell size of $10 \mathrm{~mm}$ with no structure interaction. But when air-structure interaction was considered the mesh size around the SSPs had to be refined to satisfy the minimum requirements, (AUTODYN User Manual), for tracking pressure through vents and structures such that it was 3 to 5 cells per centimetre. Therefore, the mesh size was set to $3 \mathrm{~mm}$ square elements as shown in Figure 7.1. The total number of nodes for the air domain was 796,398.

It is important to note that the blast chamber had a small tunnel in front of its door with $1000 \mathrm{~mm}$ depth and $1500 \mathrm{~mm}$ width as shown in Figure 7.2. In order to represent such tunnel in the modeling "unused region" was used to cut into the air domain with the exact dimensions of tunnel. Generally, "unused region" is defined as void cells with no material within them and by default, it has reflecting boundary conditions. Figure 7.3 shows the air domain with unused region representing the tunnel, denoted as Section 2 while the air domain representing the blast chamber is denoted as Section 1 (Note reflecting boundary condition in both these sections). Section 3 , the air domain outside the chamber, has "flow-out" boundary conditions as indicated earlier. 


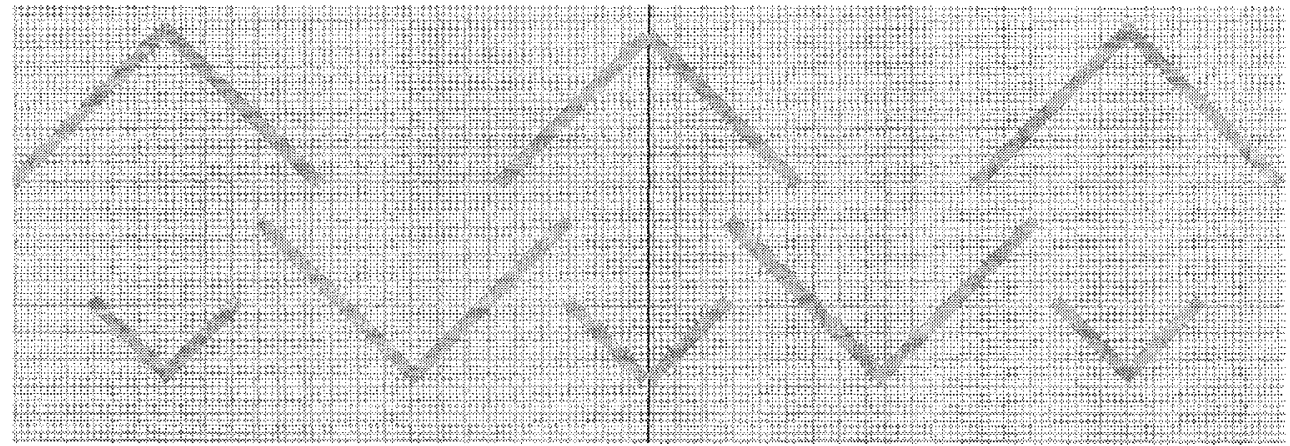

Figure 7.1: Air mesh through SSPs

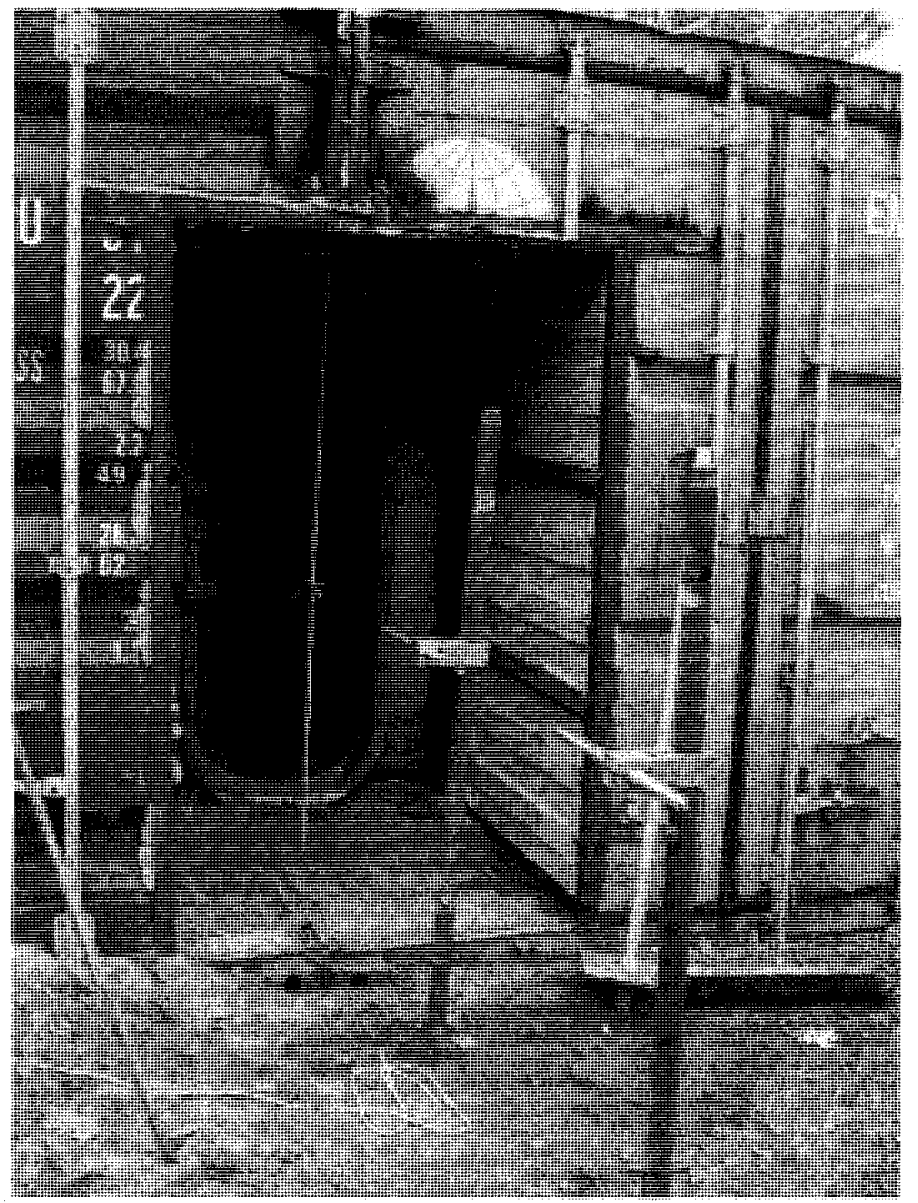

Figure 7.2: The small tunnel in front of the blast chamber door 


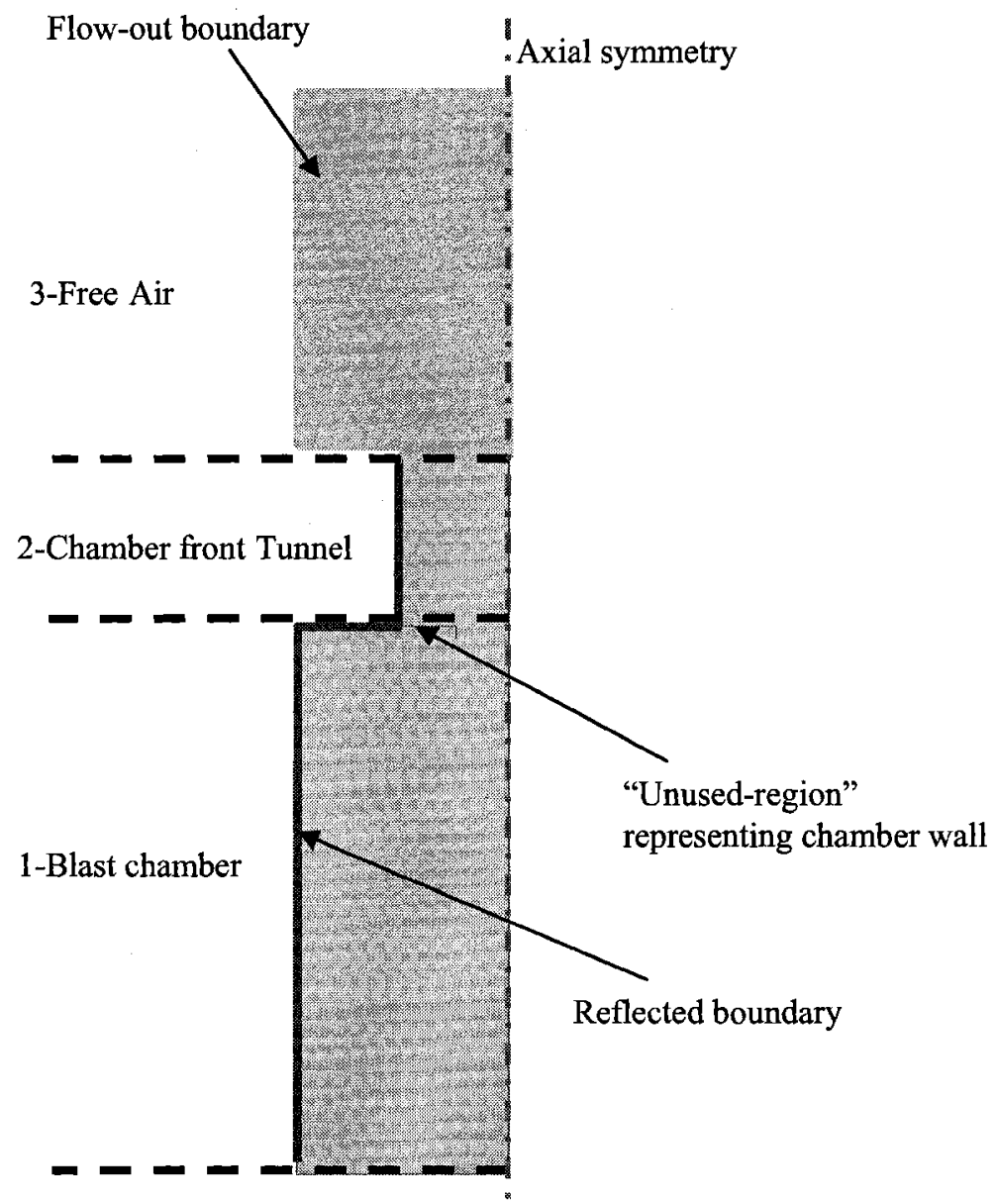

Figure 7.3: 2-D Air domain

\subsubsection{3-D Air Domain}

Similar to the 2-D condition discussed above, the 3-D air domain was modeled using the Euler-FCT (Flux Corrected Transport) formulation. It consisted of two parts, the blast chamber and the air outside the chamber. The blast chamber was presented as air with reflecting sides, while the air domain outside the blast chamber had a "flow-out" boundary condition to allow the transmission of the shock waves. The air domain had dimensions of $5000 \mathrm{~mm}$ in length, $2380 \mathrm{~mm}$ in width and $885 \mathrm{~mm}$ in height, similar to those of the blast chamber, tunnel in front of chamber door plus part of the air outside the 
chamber. The mesh size was chosen according to the mesh size convergence study presented in Chapter 3, Section 3.3.3, which recommended a minimum cell size of 40 $\mathrm{mm}$ if the pressure outside structure was not to be measured. Since the interest in the 3-D simulations is to investigate the structural responses only, the mesh size was set to $40 \mathrm{~mm}$ square elements as shown in Figure 7.4. The total number of nodes for the air domain was 139,380 .

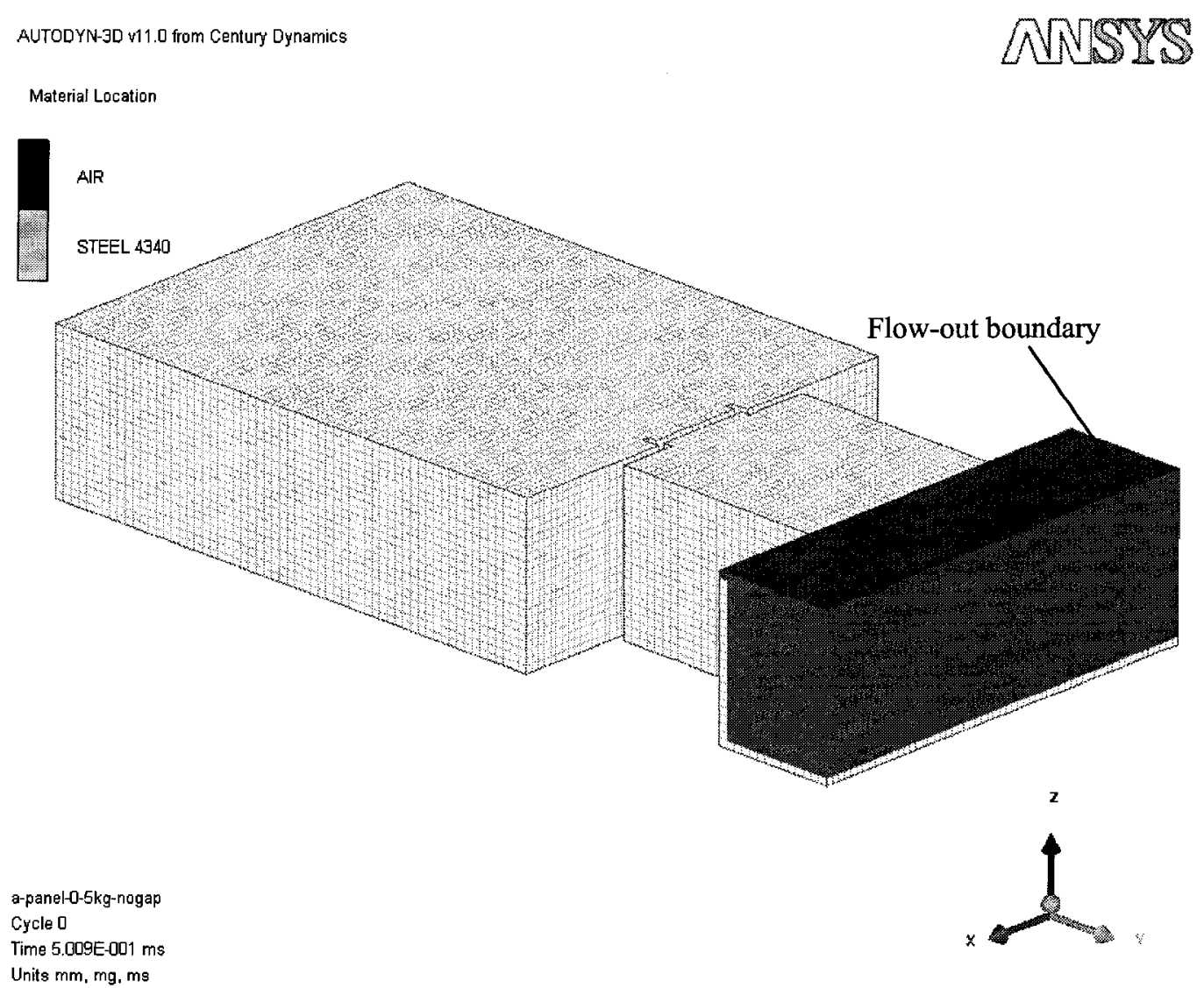

Figure 7.4: 3-D Air domain 


\subsection{Gauges}

As mentioned earlier there were three gauge locations outside the chamber to track pressure. They were located at $0.5 \mathrm{~m}, 1.5 \mathrm{~m}$ and $2.5 \mathrm{~m}$ from the outer face of the SSPs, along the line of symmetry (Figure 7.5). Another gauge was placed inside the chamber, positioned at $1.0 \mathrm{~m}$ from the charge and $1.0 \mathrm{~m}$ from inner face of the SSPs and $2.0 \mathrm{~m}$ from the back of the chamber. $G_{1}$ denote the inner gauge, while $G_{2}, G_{3}$ and $G_{4}$ represent the outer gauges for the $2 \mathrm{D}$ models.
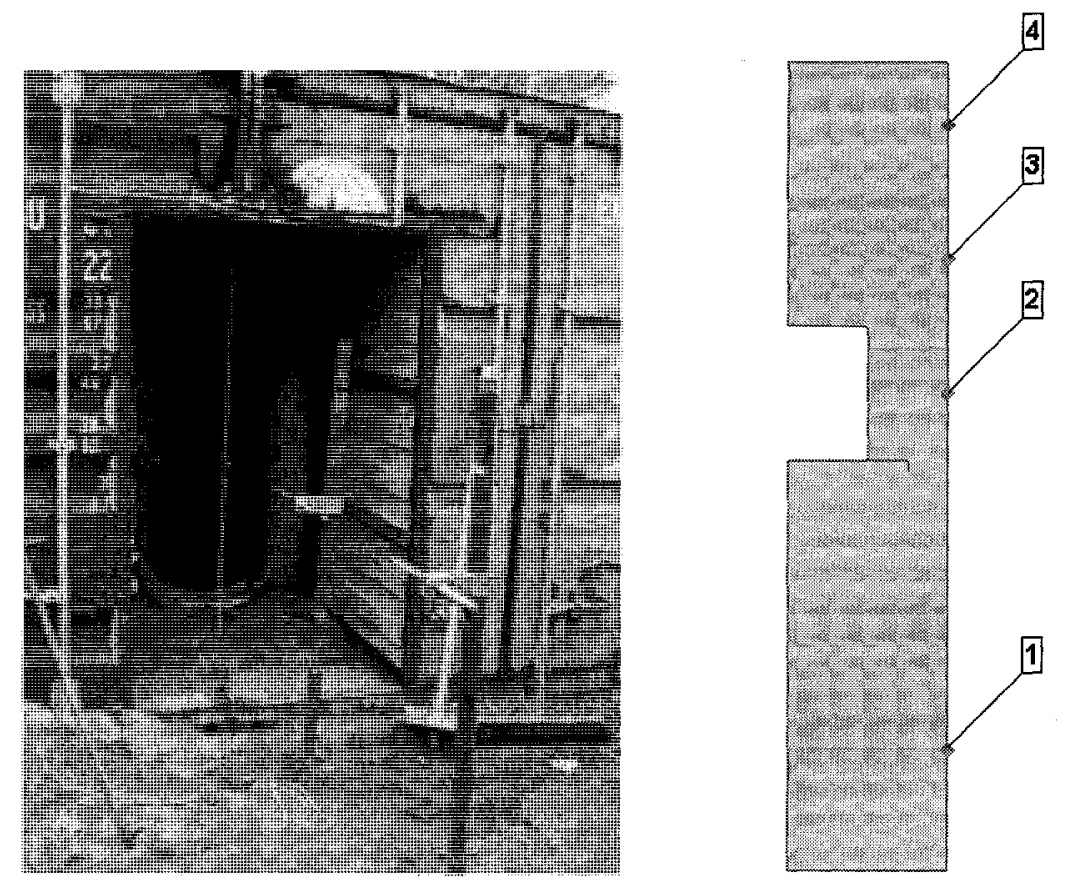

Figure 7.5: Gauge locations

\subsection{Explosive Charges}

The three explosive charges, $0.25 \mathrm{~kg}, 0.50 \mathrm{~kg}$, and $1.00 \mathrm{~kg}$ of Pentolite used in the experimental study were remapped in separate files before they were introduced to the final models. Generally speaking, remapping allows for detonating any amount of explosive to the point of interest in 1-D and then transforming it into 2-D or 3-D models. 
In this research, the point of interest is one meter from the center of the explosion. The part used to simulate a 1-D explosion is called the "Wedge", at which meshing is done through the " $P$ " direction while keeping it constant, at 1 cell, in the " $P$ " direction. After creating the wedge, it was completely filled with air. Subsequently, the radius of the spherical charge was calculated for the three different masses using Equation 3.6 presented in Chapter 3, Section 3.3.1. The wedge was filled with explosives through the "geometric fill" option within AUTODYN; ellipse shape. After filling the air with the explosive charge, a detonation point was defined at $\mathrm{X}=0$ and $\mathrm{Y}=0$. Then, the program was initiated to the point at which the shock front was almost at the end of the wedge. At this point the program was terminated, a remap file was created and the wrap-up time was recorded. The recorded wrap-up time was be used as the initial time for the final models, 2-D or 3-D. The insertion point of the remapped charges was chosen to represent the actual position of charges in experimental tests. For the 2-D models, the coordinates of insertion point was 0 in $\mathrm{X}$-axis and 1877 in $\mathrm{Y}$-axis. On the other hand for the 3-D models, the coordinates were, 1190 in $\mathrm{X}$-axis, 1877 in $\mathrm{Y}$-axis and 0 in the $\mathrm{Z}$-axis, the symmetry axis. Figure 7.6 shows an example of the explosive charge vectors for the $1.00 \mathrm{~kg}$ of Pentolite after remapping for the SSP-B model in the 2-D simulation. Figure 7.7 shows the explosive charge vectors for the $0.50 \mathrm{~kg}$ of Pentolite after remapping in the 3-D simulation of SSP-A. 


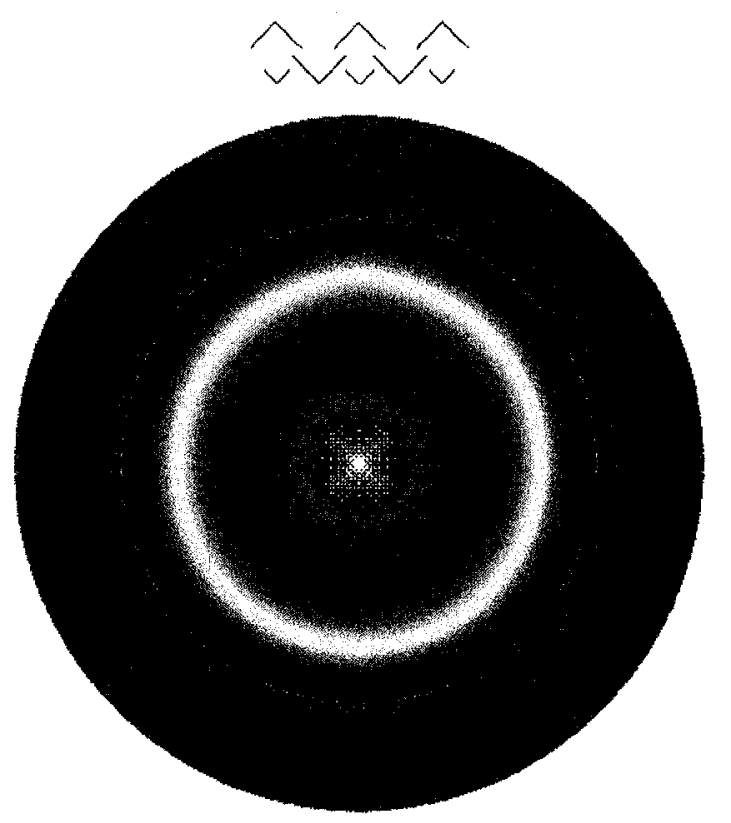

Figure 7.6: Explosive charge vectors after remapping in 2-D models
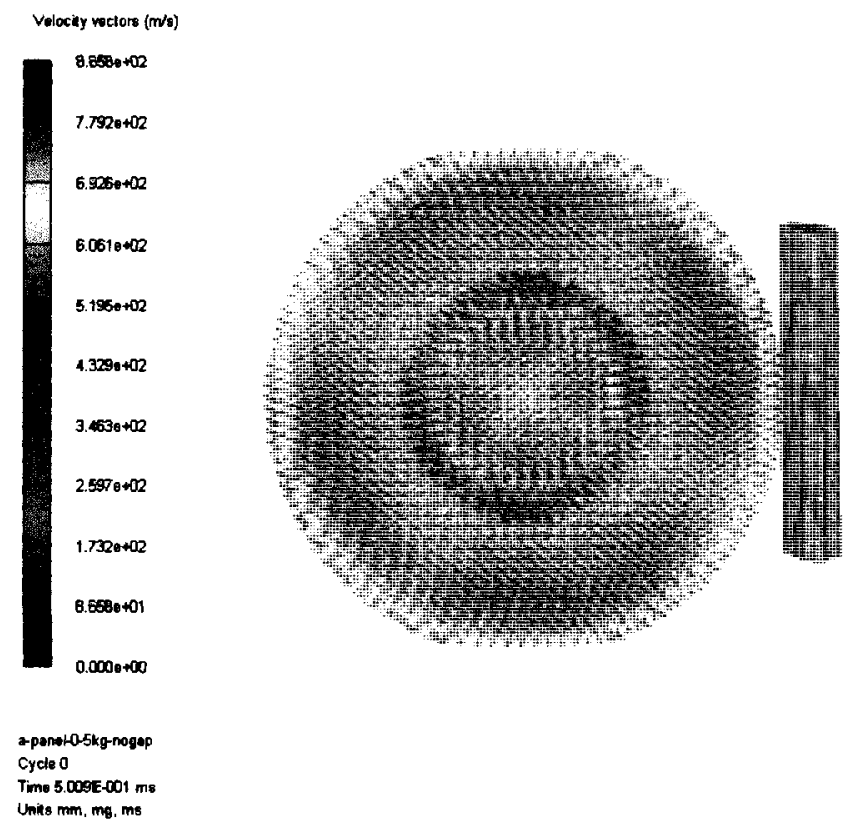

Cycle 0

Units $\mathrm{mm}, \mathrm{mg}, \mathrm{ms}$

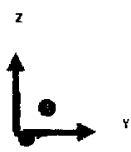

Figure 7.7: Explosive charge vectors after remapping in 3-D models 


\subsection{Suppressive Shield Panels Modelling}

After modeling the air domain, the design scenarios of the SSPs were modeled at 1-m from the explosive charges. For the 2-D simulations, the angles representing SSPs were modeled using Lagrange elements with fixed boundary conditions to prevent any movement or deformation of the angles, since interest was only in the blast attenuation effect. The structural response of various panels was studied in the 3-D models using shell elements to model the angles and Lagrange elements to model the AF sheets. Shell elements were used to represent angle sections because the ratio between length and thickness is more than five. On the other hand, the AF sheets could not be modeled as shell elements because of the strength model, which is a crushable foam model, defining the material properties. The author found that, the only element type that works with such type of strength model in AUTODYN was the Lagrange elements. Since the ratio between length and thickness is still greater than five, the AF sheet is modeled as three Lagrange parts joined together. The dimensions of each part were $500 \mathrm{~mm}$ in width, 200 $\mathrm{mm}$ in length and $43 \mathrm{~mm}$ in thickness. Pinned joined was used to assure continuity between the three parts. Moreover, an erosion model was used for both shell and Lagrange elements to prevent the termination of the program when large deformations occurred.

\subsection{Material Properties}

Table 7.1 shows the material properties of the different elements (i.e. air, steel and AF) used in the numerical investigation. The air and Pentolite material models were selected directly from AUTODYN. However the steel material, 4340 steel, was chosen from the 
library with some modifications to yield stress, bulk modulus and shear modulus to better replicate properties of the mild steel used in the manufacture of the SSPs. As for AF material, a new material was defined with the material properties obtained from the producer, bulk and shear modulus, maximum tensile stress and the relation between volumetric strain and compaction stress. The latter property, relation between volumetric strain and compaction stress, is considered very important because it represents the densification behaviour of the material. Finally, failure and erosion models were defined to prevent errors due to expected large deformations for the steel and the AF. 
Table 7.1: Material Data

\begin{tabular}{|c|c|c|c|c|}
\hline \multicolumn{5}{|c|}{ Air } \\
\hline Equation of State & \multicolumn{3}{|c|}{ Ideal Gas } & \\
\hline Reference density $\left(\mathrm{g} / \mathrm{cm}^{3}\right)$ & \multicolumn{3}{|c|}{$1.225 \mathrm{E}-03$} & \\
\hline Reference Energy $(\mu \mathrm{J} / \mathrm{mg})$ & \multicolumn{3}{|c|}{$2.068 \mathrm{E}+05$} & \\
\hline Pressure Shift $(\mathrm{kPa})$ & \multicolumn{3}{|l|}{0.0} & \\
\hline \multicolumn{5}{|c|}{ Steel 4340-Modified } \\
\hline Equation of State & Linear & \multicolumn{2}{|c|}{ Hardening constant $(\mathrm{kPa})$} & $5.10 \mathrm{E}+05$ \\
\hline Reference density $\left(\mathrm{g} / \mathrm{cm}^{3}\right)$ & 7.83 & \multicolumn{2}{|c|}{ Hardening exponent } & 0.26 \\
\hline Bulk modulus $(\mathrm{kPa})$ & $2.00 \mathrm{E}+08$ & \multicolumn{2}{|c|}{ Strain rate constant } & 0.002 \\
\hline Reference temperature $(\mathrm{K})$ & 300 & \multirow{2}{*}{\multicolumn{2}{|c|}{$\begin{array}{l}\text { Thermal softening exponent } \\
\text { Melting temperature }(\mathrm{K})\end{array}$}} & 1.03 \\
\hline $\begin{array}{l}\text { Specific heat capacity } \\
(\mathrm{J} / \mathrm{kgK})\end{array}$ & 477 & & & 1793 \\
\hline Shear modulus $(\mathrm{kPa})$ & $8.18 \mathrm{E}+07$ & \multicolumn{2}{|c|}{ Failure model } & $\begin{array}{l}\text { Plastic } \\
\text { strain }(0.2)\end{array}$ \\
\hline Yield Stress $(\mathrm{kPa})$ & $4.00 \mathrm{E}+05$ & \multicolumn{2}{|c|}{ Erosion model } & $\begin{array}{l}\text { Geometric } \\
\text { strain }(0.2)\end{array}$ \\
\hline \multicolumn{5}{|c|}{ Aluminum Foam } \\
\hline Equation of State & Linear & \multicolumn{2}{|c|}{ Failure model } & None \\
\hline Reference density $\left(\mathrm{g} / \mathrm{cm}^{3}\right)$ & 0.108 & \multicolumn{2}{|c|}{ Erosion model } & $\begin{array}{l}\text { Geometric } \\
\text { strain }(2.00)\end{array}$ \\
\hline Bulk modulus ( $\mathrm{kPa})$ & \multicolumn{3}{|c|}{$3.167 \mathrm{E}+04$} & \\
\hline Reference temperature $(\mathrm{K})$ & \multicolumn{3}{|l|}{293} & \\
\hline Shear modulus (kPa) & \multicolumn{3}{|c|}{$3.436 \mathrm{E}+04$} & \\
\hline Max Tensile Stress $(\mathrm{kPa})$ & \multicolumn{3}{|c|}{$1.312 \mathrm{E}+02$} & \\
\hline Compaction curve & \multicolumn{3}{|l|}{10 Points } & \\
\hline $\ln$ (Volumetric Strain) \#1 & \multicolumn{2}{|c|}{$1.000 \mathrm{E}-06$ (none ) } & Compaction Stress \#1 & $0.000 \mathrm{E}+00(\mathrm{kPa}$ \\
\hline $\ln ($ Volumetric Strain $) \# 2$ & \multirow{2}{*}{\multicolumn{2}{|c|}{$\begin{array}{l}4.143 \mathrm{E}-03 \text { (none) } \\
2.983 \mathrm{E}-01 \text { (none) }\end{array}$}} & Compaction Stress \#2 & $1.312 \mathrm{E}+02(\mathrm{kPa}$ \\
\hline $\ln ($ Volumetric Strain) \#3 & & & Compaction Stress \#3 & $1.511 \mathrm{E}+02(\mathrm{kPa}$ \\
\hline $\ln ($ Volumetric Strain $) \# 4$ & \multicolumn{2}{|c|}{$4.972 \mathrm{E}-01$ (none) } & Compaction Stress \#4 & $2.583 \mathrm{E}+02(\mathrm{kPa}$ \\
\hline $\ln$ (Volumetric Strain) \#5 & \multicolumn{2}{|c|}{$6.274 \mathrm{E}-01$ (none) } & Compaction Stress \#5 & $4.551 \mathrm{E}+02(\mathrm{kPa})$ \\
\hline $\ln ($ Volumetric Strain $) \# 6$ & \multicolumn{2}{|c|}{ 7.127E-01 (none) } & Compaction Stress \#6 & $7.889 \mathrm{E}+02(\mathrm{kPa})$ \\
\hline $\ln$ (Volumetric Strain) \#7 & \multicolumn{2}{|c|}{$7.599 \mathrm{E}-01$ (none) } & Compaction Stress \#7 & $1.314 \mathrm{E}+03(\mathrm{kPa})$ \\
\hline $\ln ($ Volumetric Strain $) \# 8$ & \multicolumn{2}{|c|}{$0.000 \mathrm{E}+00$ (none $)$} & Compaction Stress \#8 & $0.000 \mathrm{E}+00(\mathrm{kPa})$ \\
\hline $\ln ($ Volumetric Strain) \#9 & \multicolumn{2}{|c|}{$0.000 \mathrm{E}+00$ (none ) } & Compaction Stress \#9 & $0.000 \mathrm{E}+00(\mathrm{kPa})$ \\
\hline $\ln ($ Volumetric Strain) \#10 & \multicolumn{2}{|c|}{$0.000 \mathrm{E}+00$ (none) } & Compaction Stress $\# 10$ & $0.000 \mathrm{E}+00(\mathrm{kPa})$ \\
\hline
\end{tabular}




\subsection{Summary}

This chapter summarizes the numerical investigation procedures to simulate the experimental tests. The procedures included model construction, material properties, different formulations used to represent SSPs. SSP simulations were divided into two main components. First, the attenuation effect of the shock wave was carried out by developing 2-D models. Second, the structure response to the shock loads was carried out by developing 3-D models. The results of these simulations are presented in the following chapter.. 


\section{Chapter 8}

\section{Numerical Investigation: Results and Verification}

\section{Introduction}

Details of the numerical approach presented in the previous chapter was used to simulate the explosion, the transmission of the shock through air, its diffraction through the SSPs design scenarios and the resulting attenuated blast wave beyond the SSPs using the finite element program, AUTODYN. The behaviour of the SSPs was divided into two main parts: shock wave attenuation (using 2-D simulations) and structural response (using 3-D simulations).

The numerical simulation presented in this thesis helped understanding the main variables that govern the explosive phenomenon and evaluating the efficiency of the SSPs. In addition the numerical simulation provided the means for the verification of the results and major findings of the experimental work. In complex experimental studies, such as the one performed using explosives on the SSPs, numerical investigations are particularly important since, once they are verified, they open a new window of opportunity to study various SSPs and explosion scenarios with less dependence on very expensive and difficult field tests. This chapter presents the findings of the numerical investigation including blast pressure values, pressure attenuation percentages as well as comparison between experimental and numerical results. The comparisons showed small percentage of error between experimental and numerical results which increases the confidence in the conclusions of this research work. 


\subsection{Random Errors}

Generally speaking, there are often certain random errors that might occur during experimental investigations. Clearly, one would expect these errors to also occur when the experimental investigation involves explosive charges, and subsequently, will have some effects on the measured data. The acceptable error of field testing is generally in the range of 20 percent. The sources of errors to consider throughout the course of the presented experimental investigation are briefly discussed below.

1. The actual shape of the explosive being a non-spherical charge produces some error due to its loss of symmetry;

2. The reflecting surfaces within the test facility, such as tunnel in front of the blast chamber door which affect the accuracy of measuring the propagated wave without the effect of resulting turbulences;

3. The effect of the thickness of the welding of SSPs angles on the vent area ratio and gap between angles;

4. The sensitivity of the gauges and their relative position to the actual center of the wave;

5. The ambient temperature during the testing especially the testing program was completed over a long period of time including the cold days of Canadian winter and warmer days of the spring; and

6. The effect of filtering due to the management of data collected. 


\subsection{2-D Modelling}

The simulation of the 2-D scenarios included twelve scenarios to evaluate the blast attenuation capability of SSPs and to verify the main findings of the experimental tests.

\subsubsection{Air Shots}

Figure 8.1 shows the incident pressure in $\mathrm{MPa}$ as a function of the charge mass $(\mathrm{kg})$ at the various gauge locations for the numerical models, experimental air shots and pressures predicted by ConWep. As expected the pressure values increase with the increase in the mass of the charge. It is clear that the numerical predictions correlate well with the experimental results and also with the ConWep predictions. As was mentioned before, the $1.00 \mathrm{~kg}$ charge mass could not be performed in the field due to permissible noise limits. Therefore, a line connecting the other results of the two smaller charges was extended to obtain the pressure value that would be expected from the detonation of 1.00 $\mathrm{kg}$ charge in the field as shown with the broken line in the figure. Figures 8.2 to 8.5 show results of the pressure profiles of the numerical versus the experimental for the $0.25 \mathrm{~kg}$ of Pentolite. The pressure profiles for the numerical models correlate well with those measured from the experimental tests with respect to time of arrival of the incident and reflected pressures. 


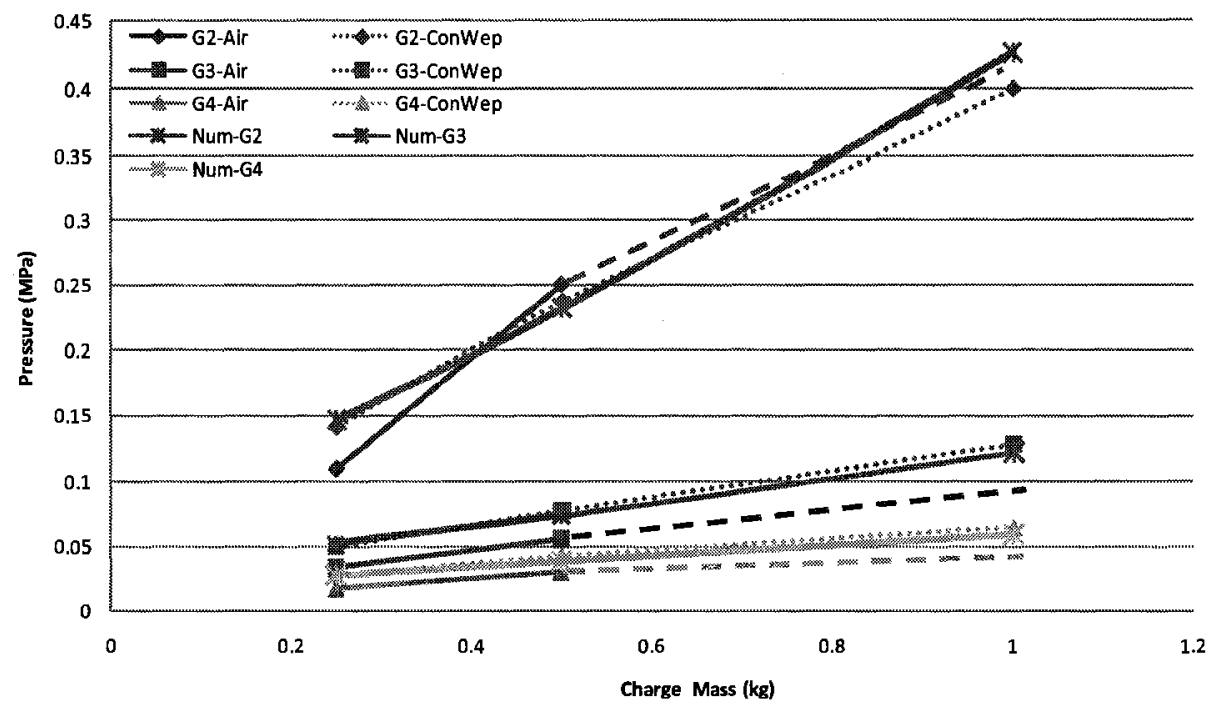

Figure 8.1: Numerical Pressure versus charge mass- Air Shots

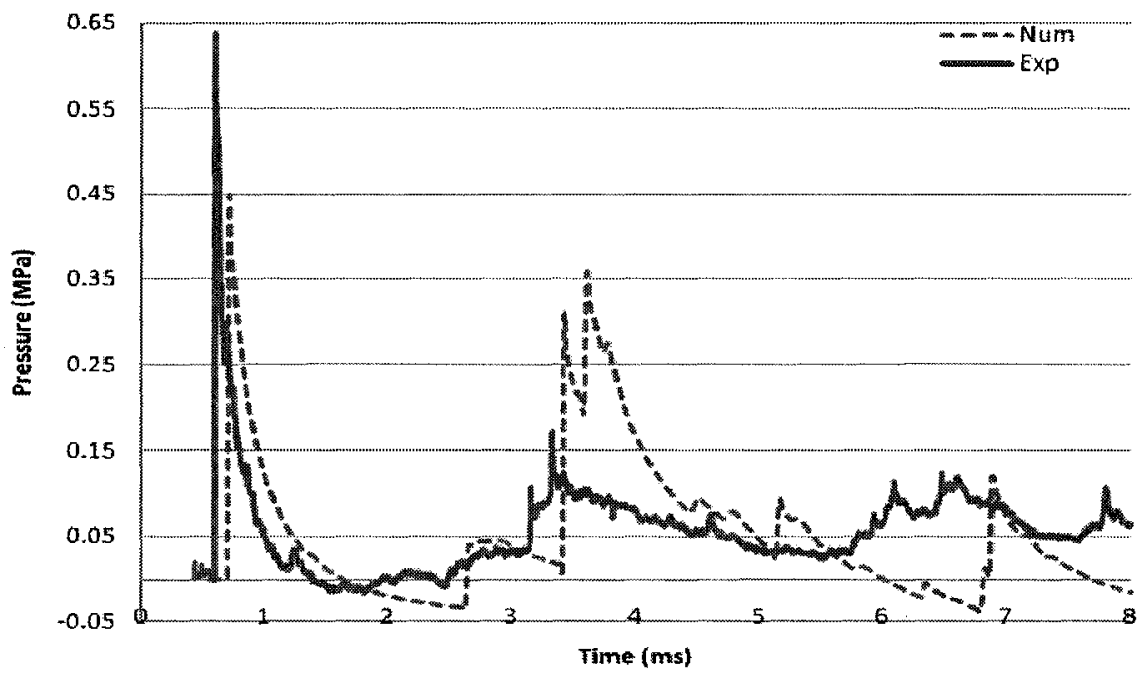

Figure 8.2: Pressure-Time profile at gauge location $\mathbf{G}_{1}$ 


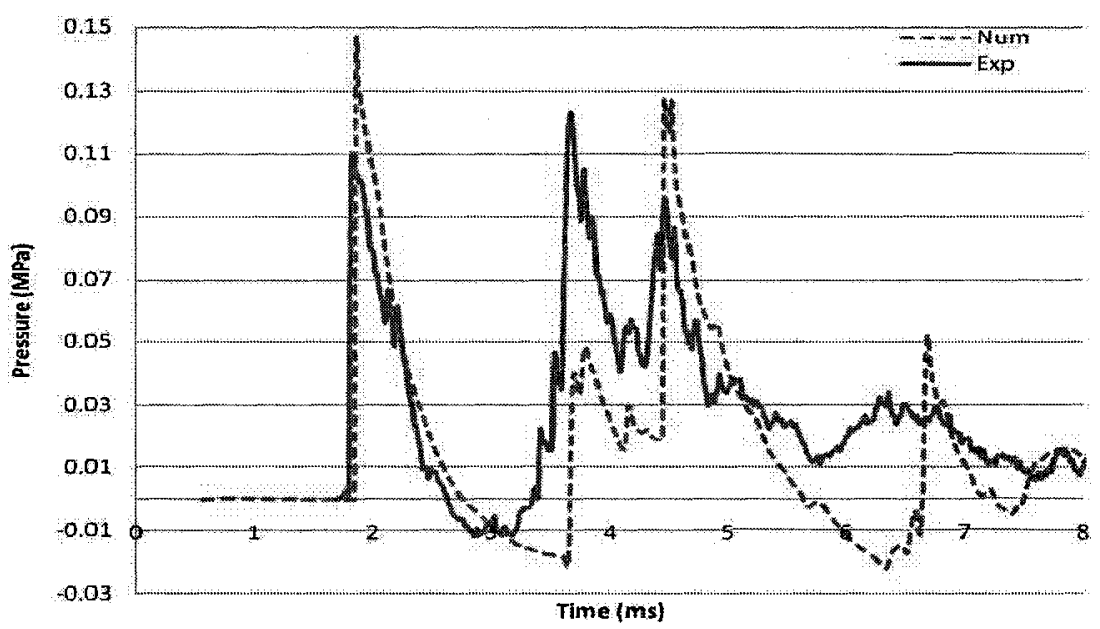

Figure 8.3: Pressure-Time profile at gauge location $\mathbf{G}_{\mathbf{2}}$

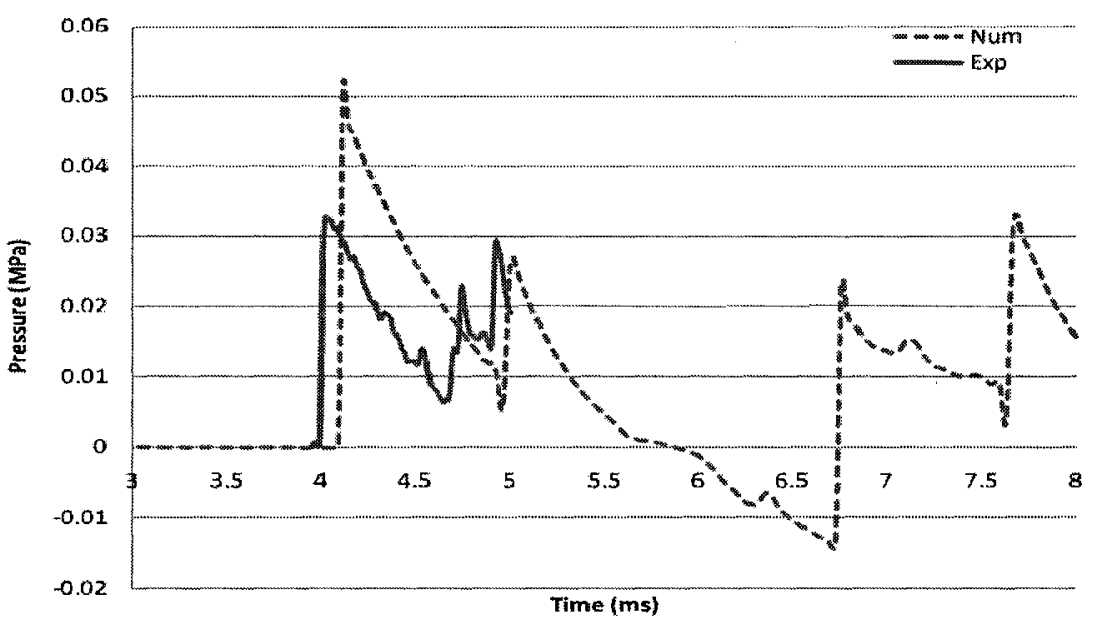

Figure 8.4: Pressure-Time profile at gauge location $\mathbf{G}_{3}$

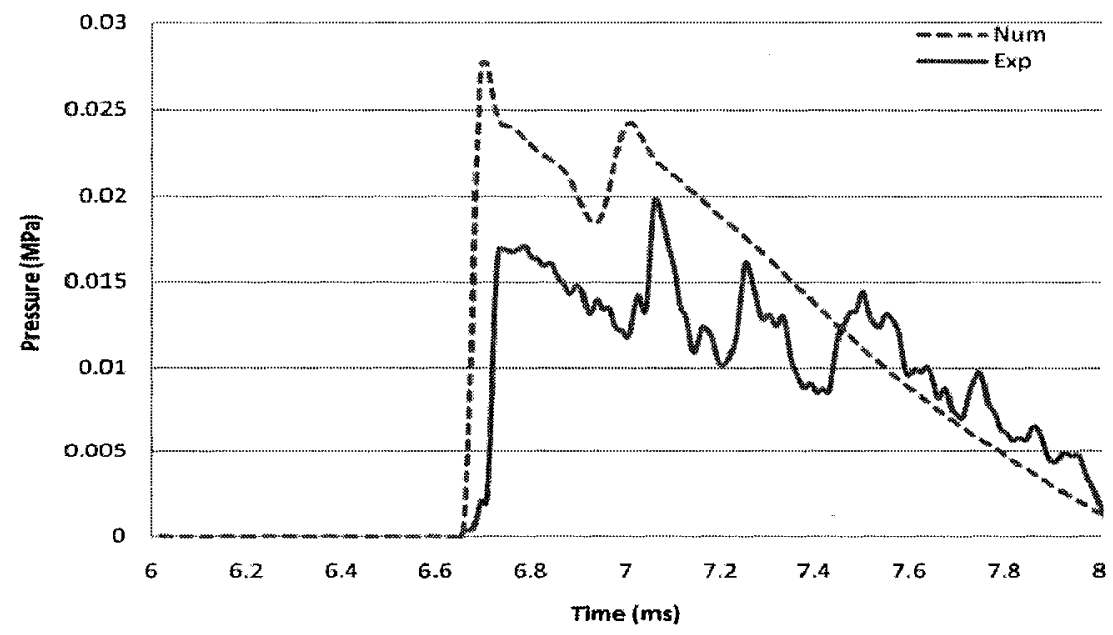

Figure 8.5: Pressure-Time profile at gauge location $\mathbf{G}_{4}$ 
Figures 8.6 and 8.7 present the blast pressures for the air shots at the various gauge locations for the experimental tests and numerical simulation. Measurements at the "-1 m" distance were measurements taken from the gauge inside the blast chamber, while all the other data points were obtained from the three gauges outside the blast chamber. Again, the numerical pressure values correlate well with those measured in the field as the mass of explosive charge increases. Thus, the pressure values resulting from the 1.00 $\mathrm{kg}$ charge of Pentolite can be predicted with confidence using the numerical model. Furthermore, Figure 8.8 illustrates the blast pressure values for all charges at which these values are used for latter computation of pressure and impulse attenuation percentages.

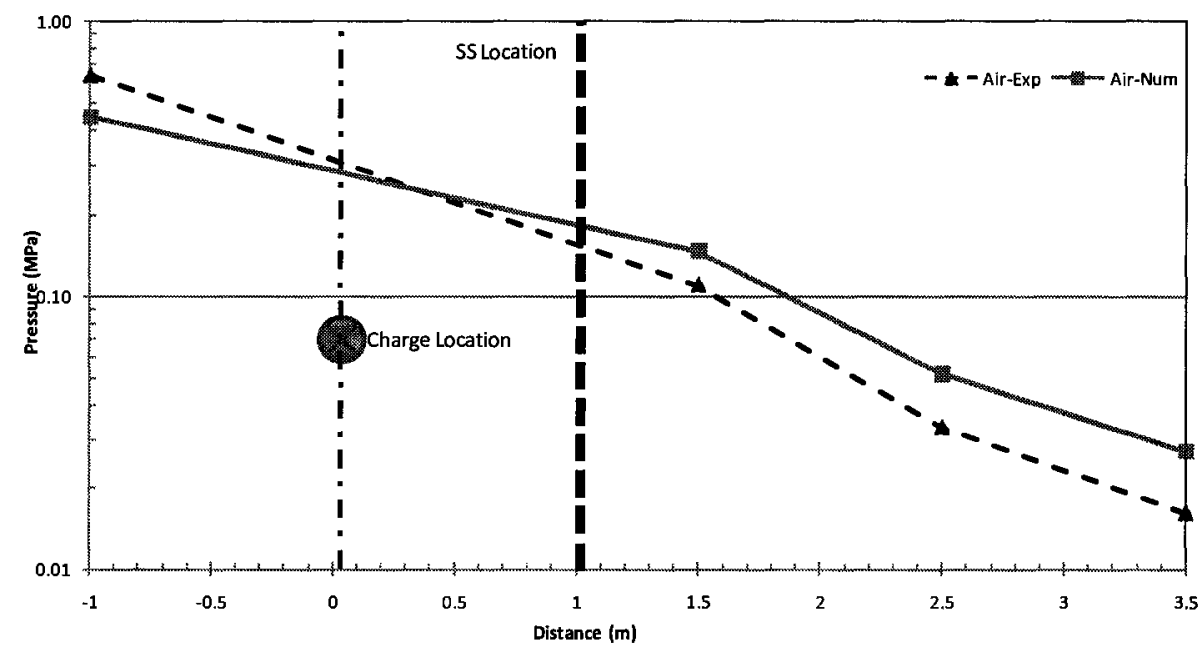

Figure 8.6: Numerical blast pressure versus gauge location, Air- $0.25 \mathrm{~kg}$ 


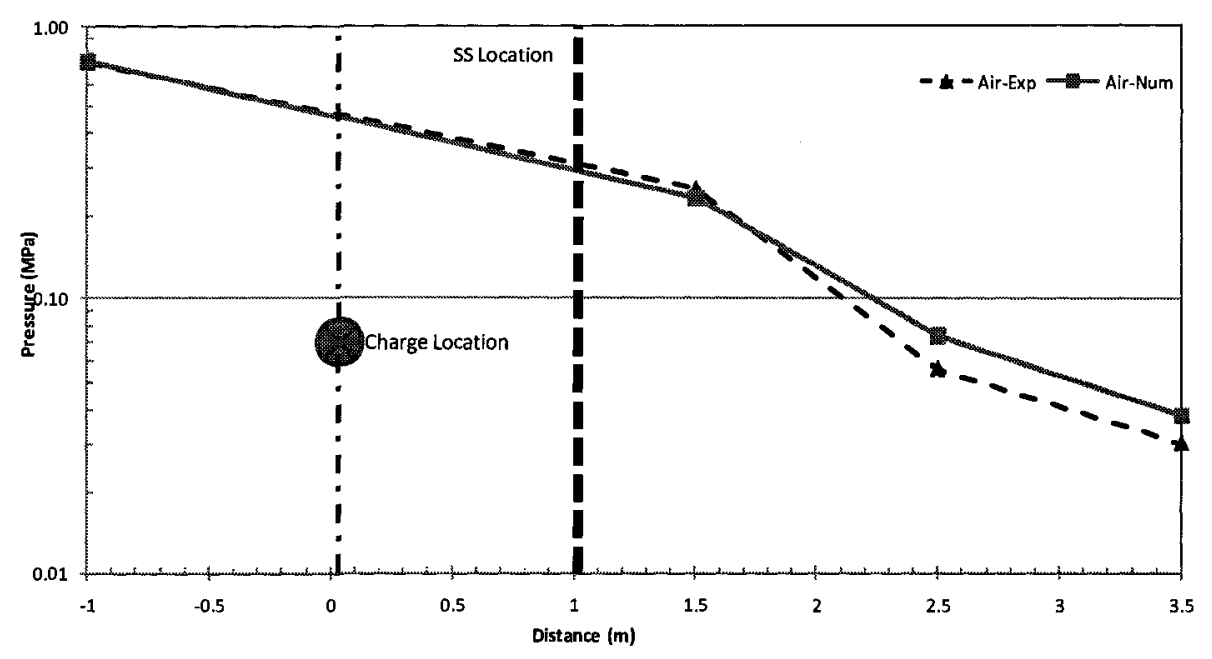

Figure 8.7: Numerical blast pressure versus gauge location, Air-0.5 kg

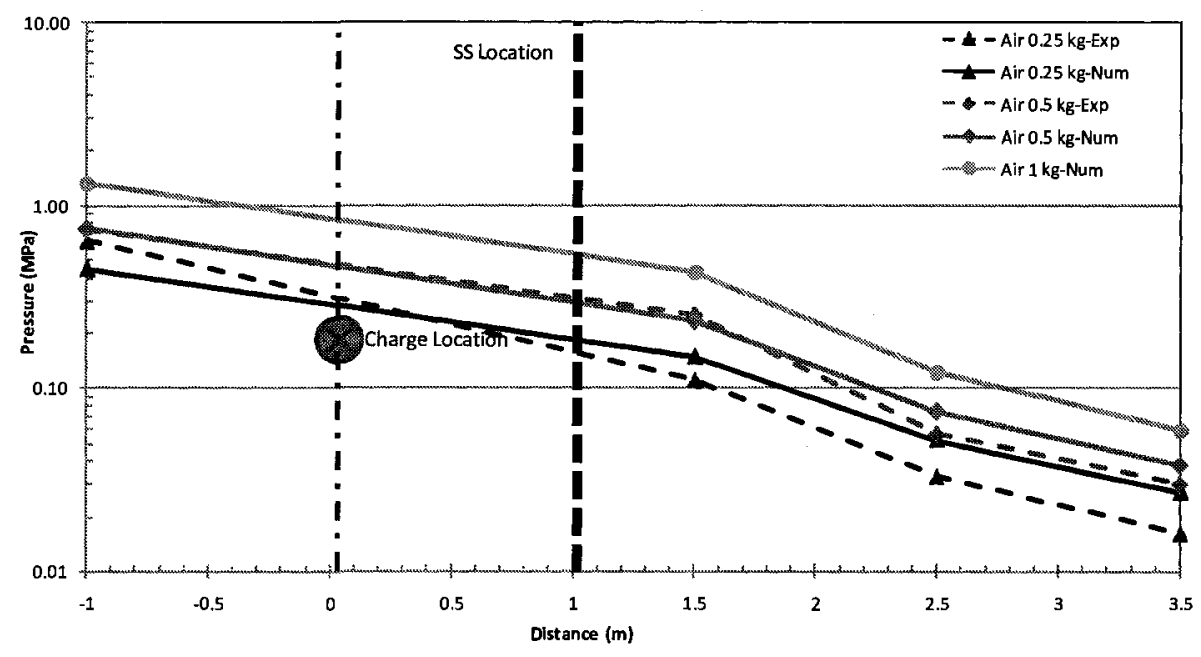

Figure 8.8: Numerical and Experimental blast pressures versus gauge locations

Figures 8.9 and 8.10 show the incident positive impulses at the various gauge locations for the two explosive charges. It can be seen that the experimental results correlate well with those obtained from experimental tests. The results in Figure 8.9 show that the numerical model was able to predict very closely the experimentally obtained impulse profile taking into consideration the effect of the 6 factors identified in section 8.1 above. However, the sudden drop in the pulse value shown at the location of $G_{3}$ is due to the effect of having this gauge at the exit of the tunnel where the shock front was not 
reformed behind the chamber door. Similar results are shown in Figure 8.10 which suggested a closer agreement than the results shown in the case of the smaller charge. It is important to note that in both conditions the numerical simulation over estimated the values especially outside the closure of the blast chamber. Again the results in Figure 8.10 showed a similar drop as the one reported in Figure 8.9 which could be explained by the influence of the turbulence zone due to the various reflections from the tunnel walls. This analysis is confirmed numerically and the results are given in Figure 8.11.

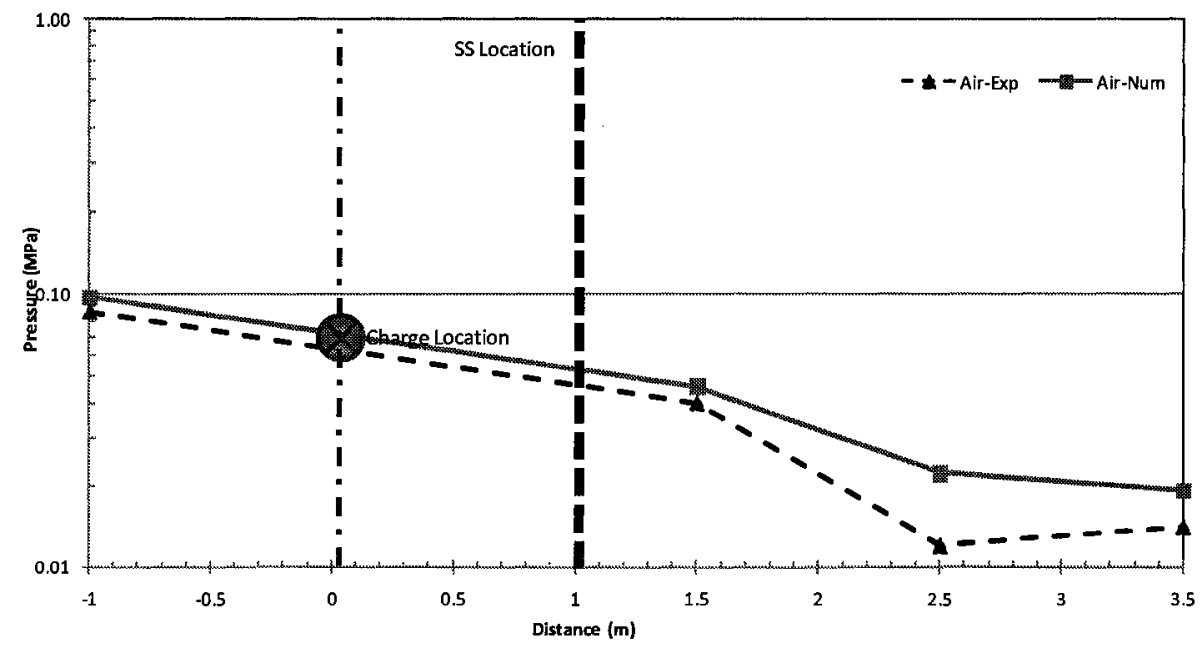

Figure 8.9: Numerical impulse versus gauge location, Air- $0.25 \mathrm{~kg}$

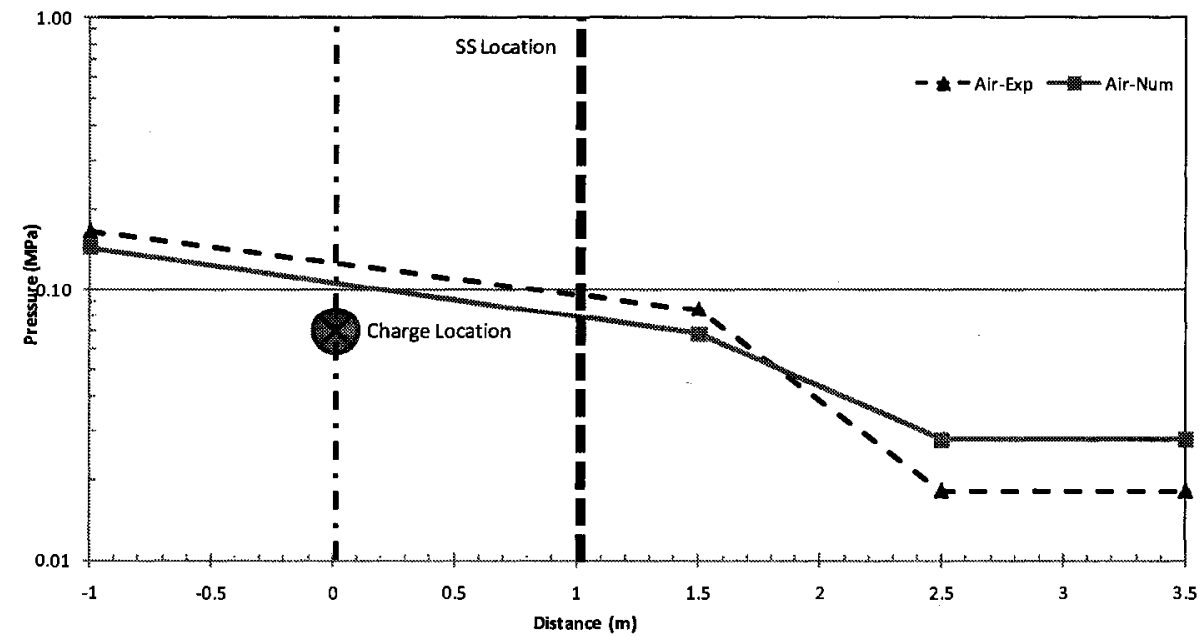

Figure 8.10: Numerical impulse versus gauge location, Air-0.5 kg 


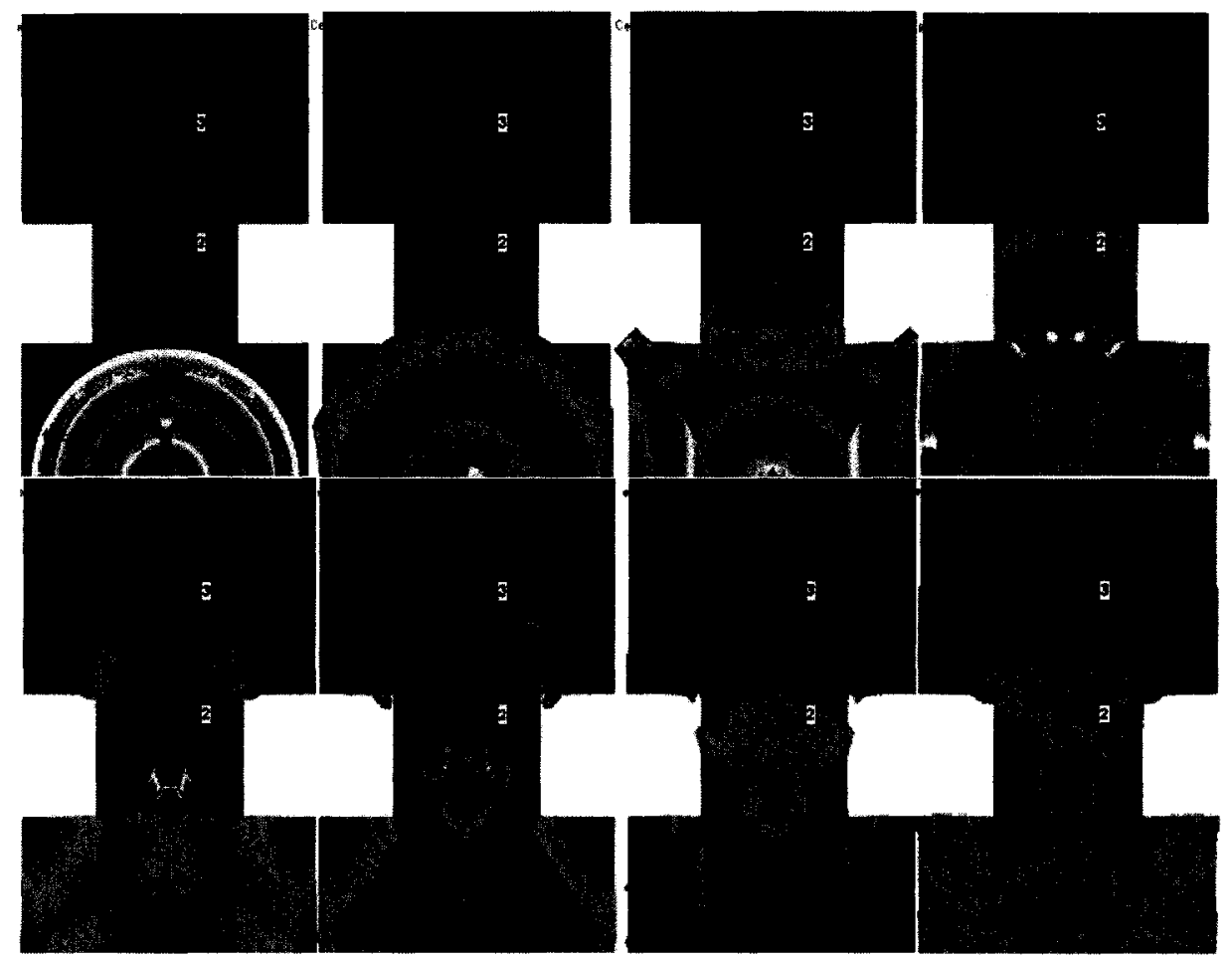

Figure 8.11: Shock wave propagation through air- $0.5 \mathrm{~kg}$

\subsubsection{Suppressive Shield Panels}

The following section presents the results of the experimental investigation and their comparisons with the computations obtained from the numerical analysis performed on the SSPs without the use of the AF sheets.

\subsubsection{Results of the $0.25 \mathrm{~kg}$ of Pentolite}

Figures 8.12 to 8.15 show the results of the numerical and the experimental blast pressures at the various gauge locations for the $0.25 \mathrm{~kg}$ of Pentolite for the air and the SSP-A, SSP-B, SSP-C and SSP-D, respectively. The results shown in the figures provide 
sufficient evidence supported by the experimental data that numerical simulation is capable to predict with reasonable accuracy the pressure values. Furthermore, similar results were obtained when pressure profiles were compared to those obtained from equivalent tests performed in the field. It is important to note that in all the four figures the numerical analysis over estimated the pressure values outside the blast chamber which clearly useful as a factor of safety.

Figure 8.16 shows the numerical results for the air and SSPs design scenarios. It is obvious that pressure values decrease as the blast wave moves out which is expected. However, a substantial reduction in pressure was observed due to the use of SSPs. Similar to the results of the experimental investigation, the SSP-A design with the large unit vent area ratio showed higher pressure when compared with results of the panels with smaller vent area ratios. The percentages of pressure attenuation referenced to the case of the air obtained from the results of the numerical simulations are presented in Figures 8.17 and 8.18 .

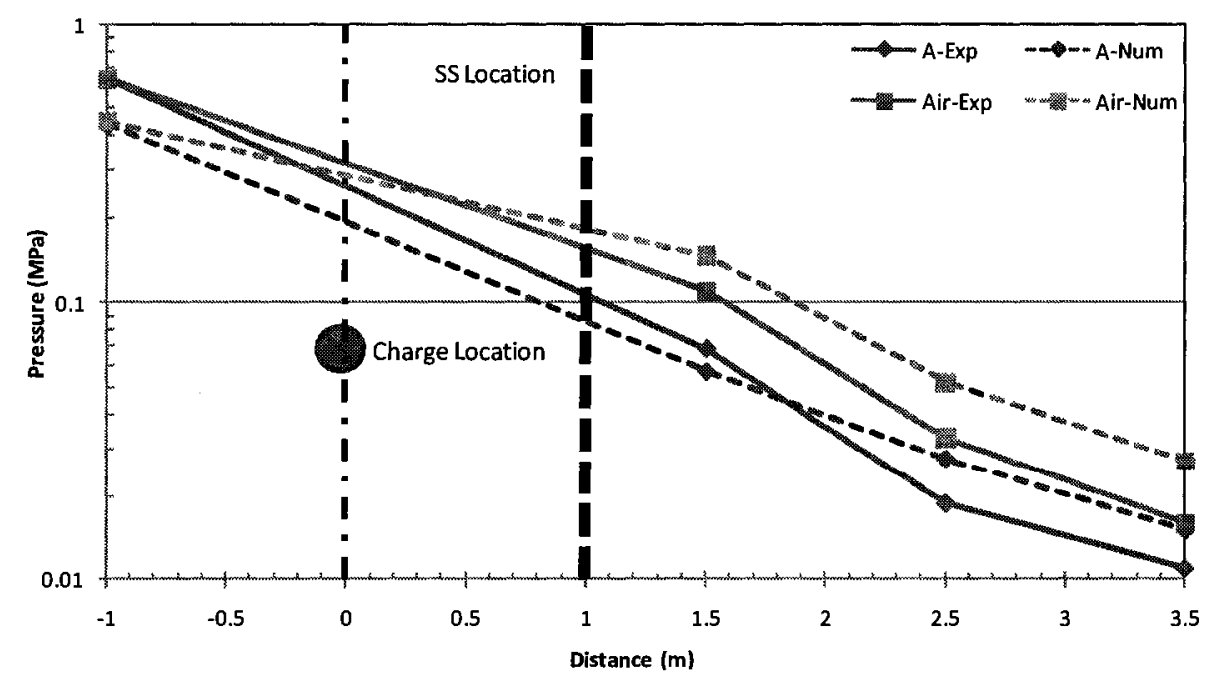

Figure 8.12: Numerical \& Experimental pressure versus gauge location-SSP-A-0.25 kg of Pentolite 


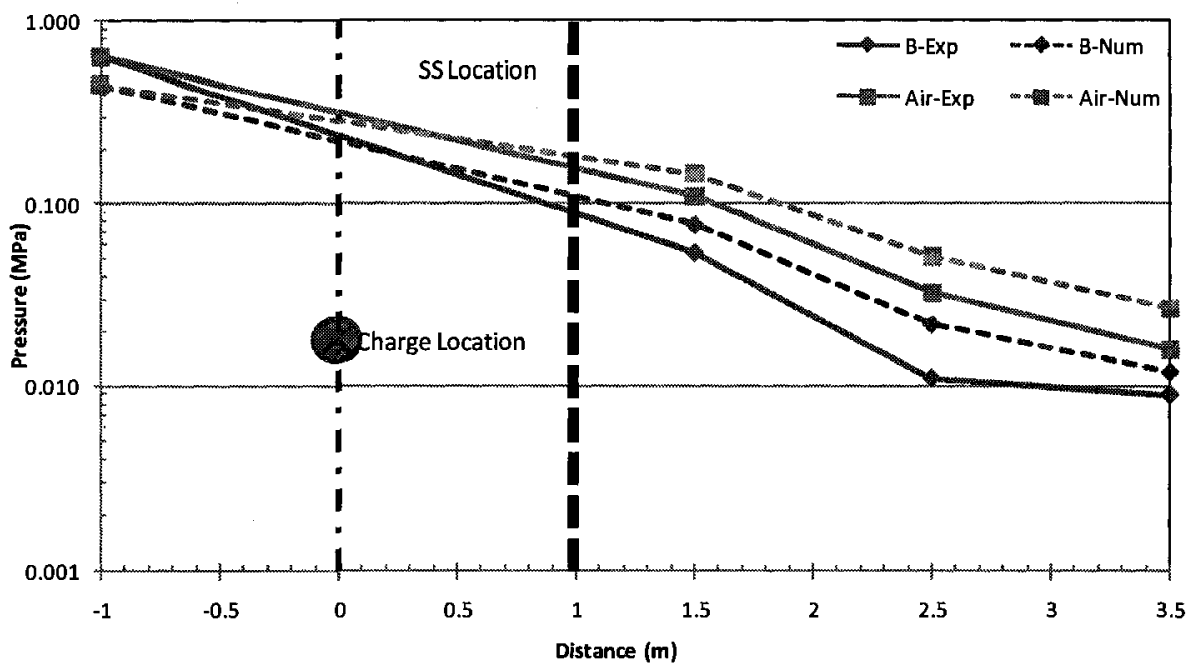

Figure 8.13: Numerical \& Experimental pressure versus gauge location-SSP-B-0.25 kg of Pentolite

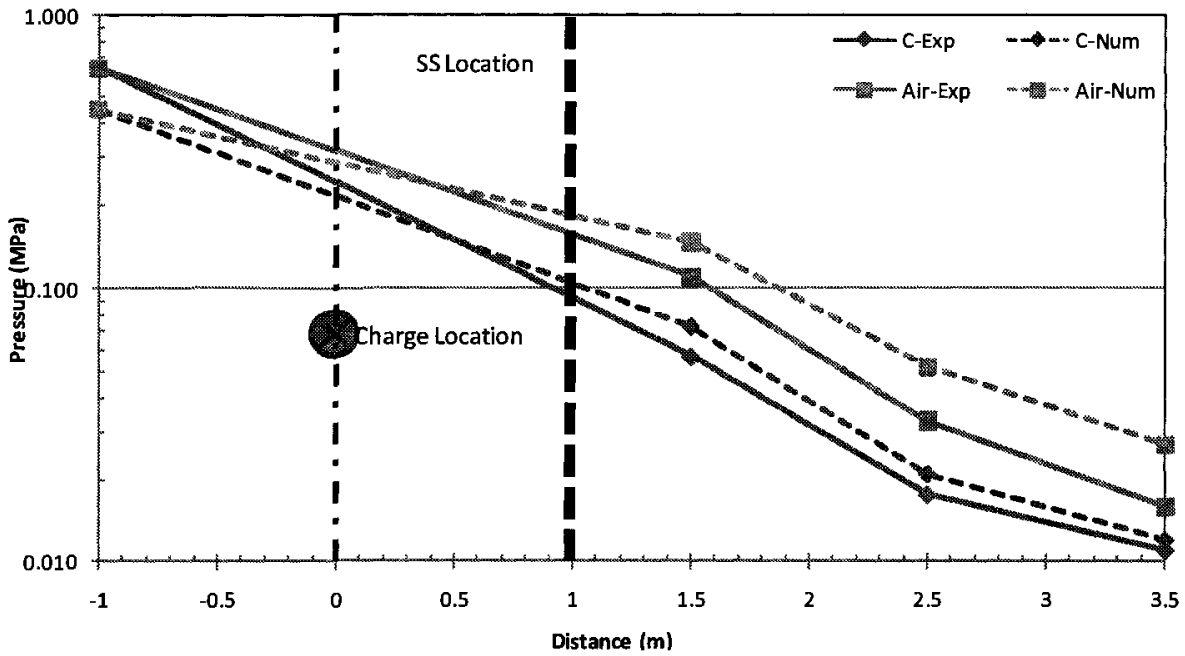

Figure 8.14: Numerical \& Experimental pressure versus gauge location-SSP-C-0.25 kg of Pentolite

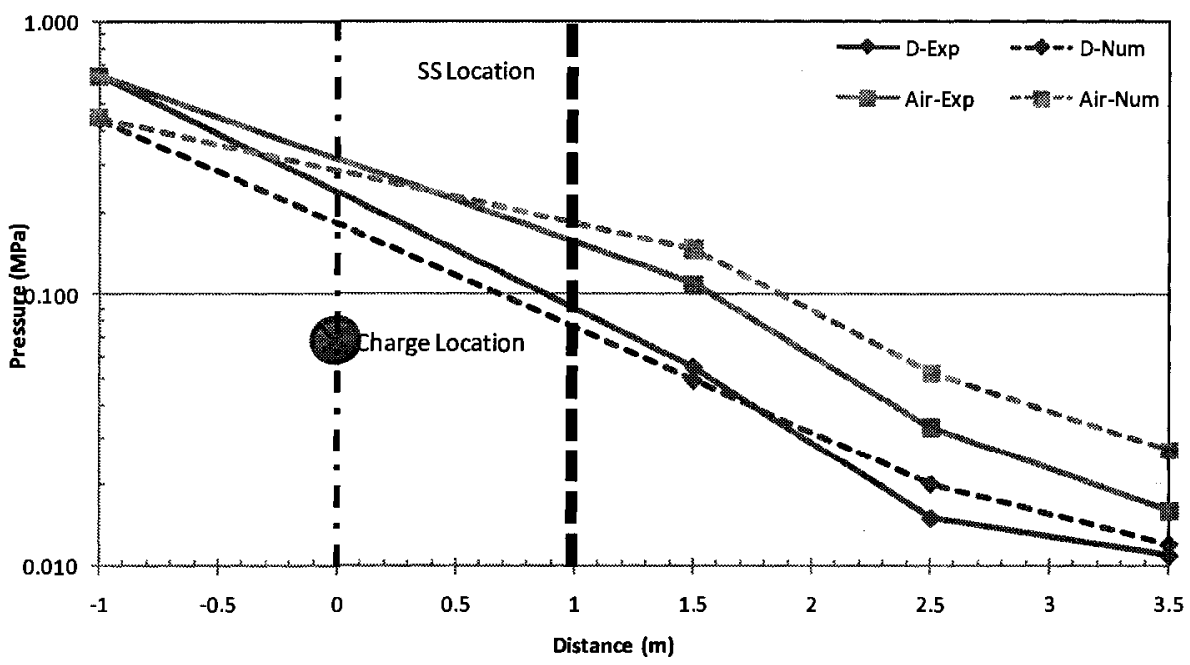

Figure 8.15: Numerical \& Experimental pressure versus gauge location-SSP-D-0.25 kg of Pentolite 


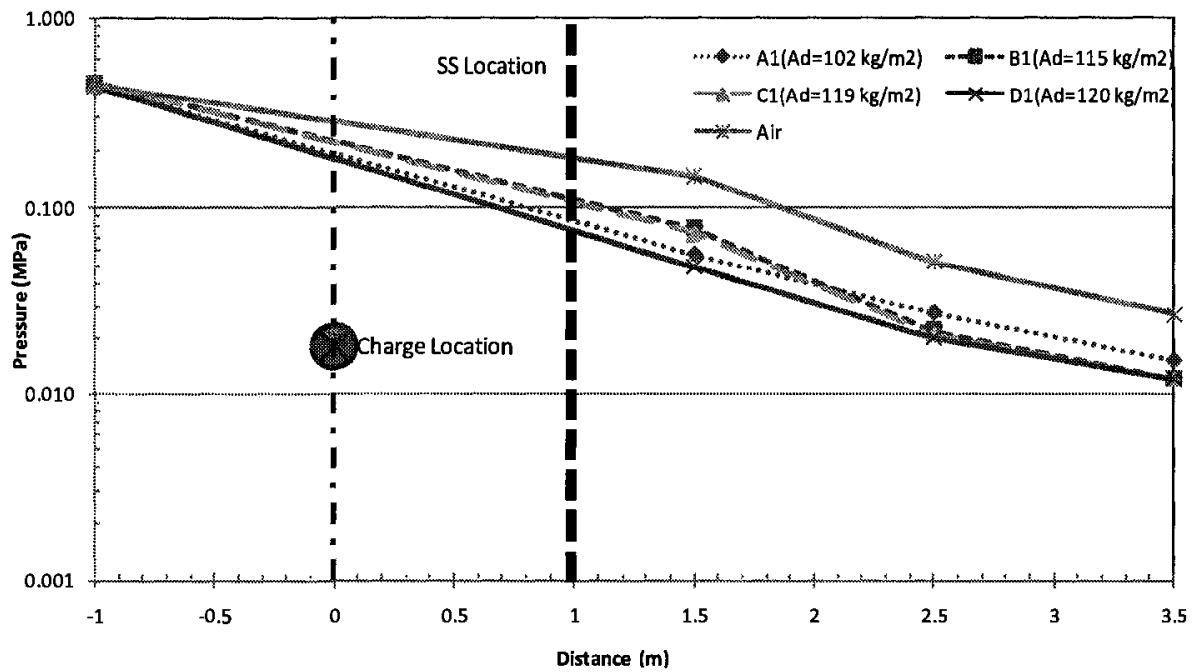

Figure 8.16: Numerical pressure versus gauge location-All SSPs-0.25 kg of Pentolite

Figure 8.17 shows the percentages of pressure attenuation relative to the results of the air scenario obtained numerically at the various gauge locations for the $0.25 \mathrm{~kg}$ of Pentolite. At gauge location, $G_{2}$, it is clear that the best performance was achieved when SSP-D was utilized followed by SSP-A, SSP-C and SSP-B, respectively. At gauge location, $\mathrm{G}_{3}$, the performance of SSP-A is lowered dramatically due to the difference in the experimental conditions of the blast chamber when SSP-A was tested as will be explained in later section. However for the furthest gauge location, $\mathrm{G}_{4}$, the various designs showed equal attenuation percentages. The Average attenuation percentages of the outside gauges only, $\mathrm{G}_{2}, \mathrm{G}_{3}$ and $\mathrm{G}_{4}$, would be of more value in SSPs comparison of numerical and experimental results. Thus, average attenuation percentages are computed and presented in Figure 8.18

Figure 8.18 shows that the pressure attenuation percentages for the simulated cases correlate well with those obtained using experimental data. The figure shows that the maximum attenuation was achieved by SSP-D with average attenuation of $62 \%$ compared 
to the measured value of $45 \%$. Similarly, the second best performance was given by SSPB with a computed average attenuation of $54 \%$ compared to the same value of $54 \%$ measured in the experiments. SSP-C and SSP-A had 55\% and 51\% attenuation rates determined by the numerical simulations compared to $42 \%$ and $37 \%$ measured in the experiments, respectively. A comparison between the calculated average attenuation percentages for numerical models and experimental tests showed that under the $0.25 \mathrm{~kg}$ charge there were no significant differences in the performance of the three heavier panels; SSP-B, SSP-C, and SSP-D which makes the selection of the lightest; SSP-B, the most effective solution.

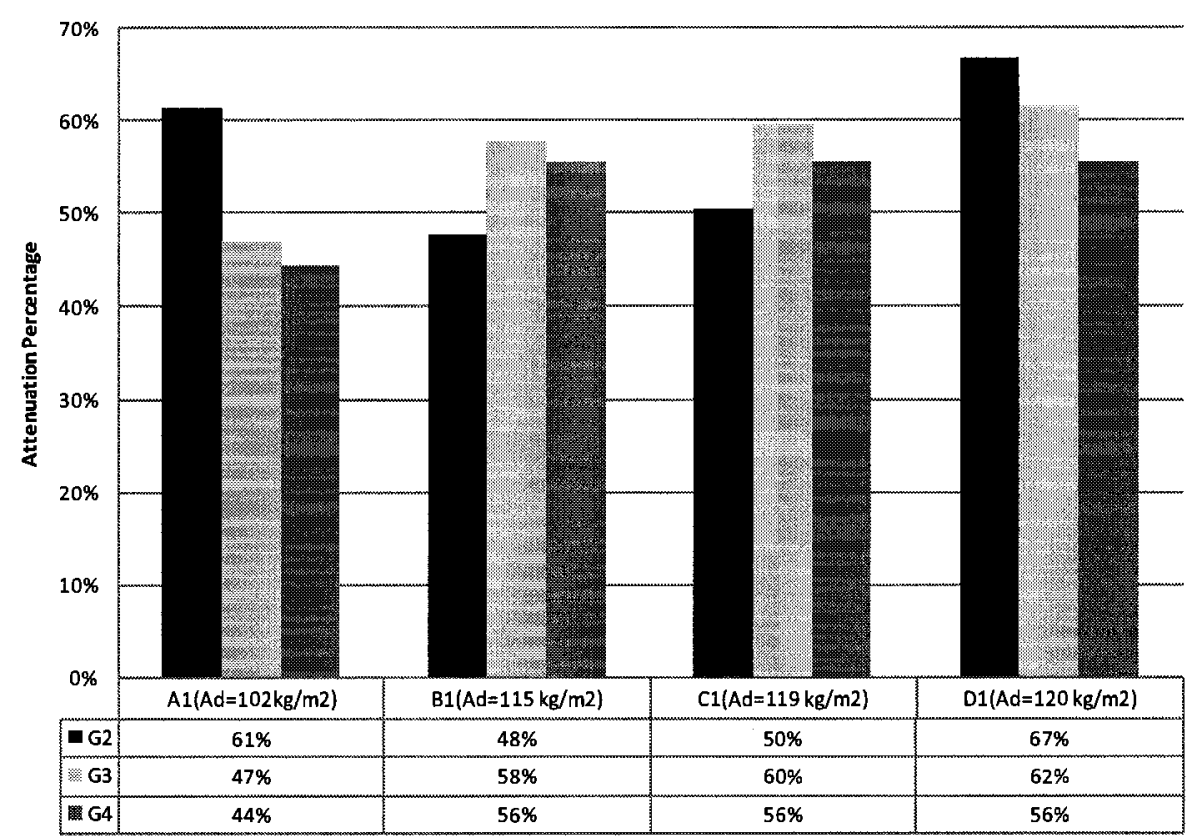

Figure 8.17: SSPs Numerical pressure attenuation percentage-0.25 kg of Pentolite 


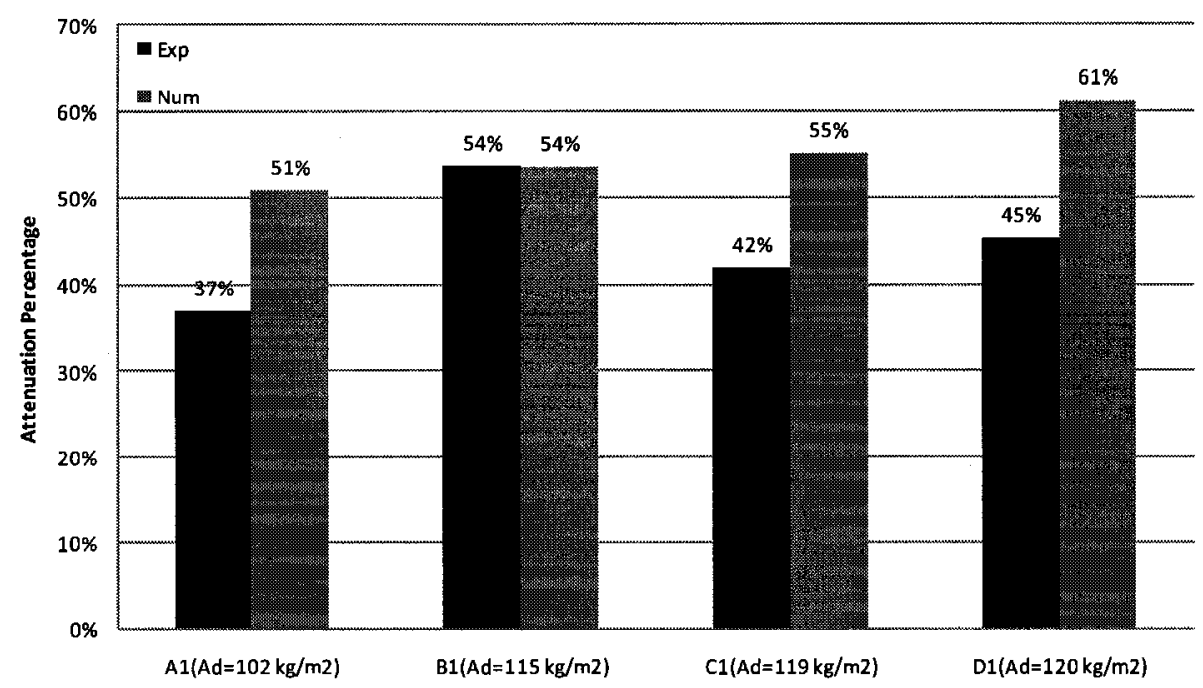

Figure 8.18: Average SSPs Numerical pressure attenuation percentage-0.25 kg of Pentolite

Figure 8.19 represents the incident impulse at various gauge locations for numerical simulations only. It is obvious that the designed SSPs significantly reduce the impulse values compared to the case of air or no obstacles. Again and as expected the SSP-A with the largest vent area ratio is having higher impulse values compared to other panels, which similar to the results of the experimental investigation. It is interesting to note that the numerical simulation shows there is no significant difference in the calculated the impulse values for the three design scenarios; SSP-B, SSP-C and SSP-D. Figure 8.20 provides the calculated values of the average percentage of impulse attenuation for each of the four design scenarios of the SSPs which showed that design scenario SSP-B was the most effective in terms of reducing the impulse value, $67 \%$, compared to $75 \%$ obtained from experimental results and at the same time has the second lightest areal density.

Table 8.1 provides the measured and computed values of the pressures for the design scenarios and the air case. The calculated error or difference between the measured and 
estimated values ranged between $9 \%$ and $100 \%$. At first glance these differences or errors may appear to be large from a general engineering view. However, research involving explosives and field measurements is very complex and involves many unknown variables that could influence the accuracy of the measurements such as speed and direction of the wind during the tests.

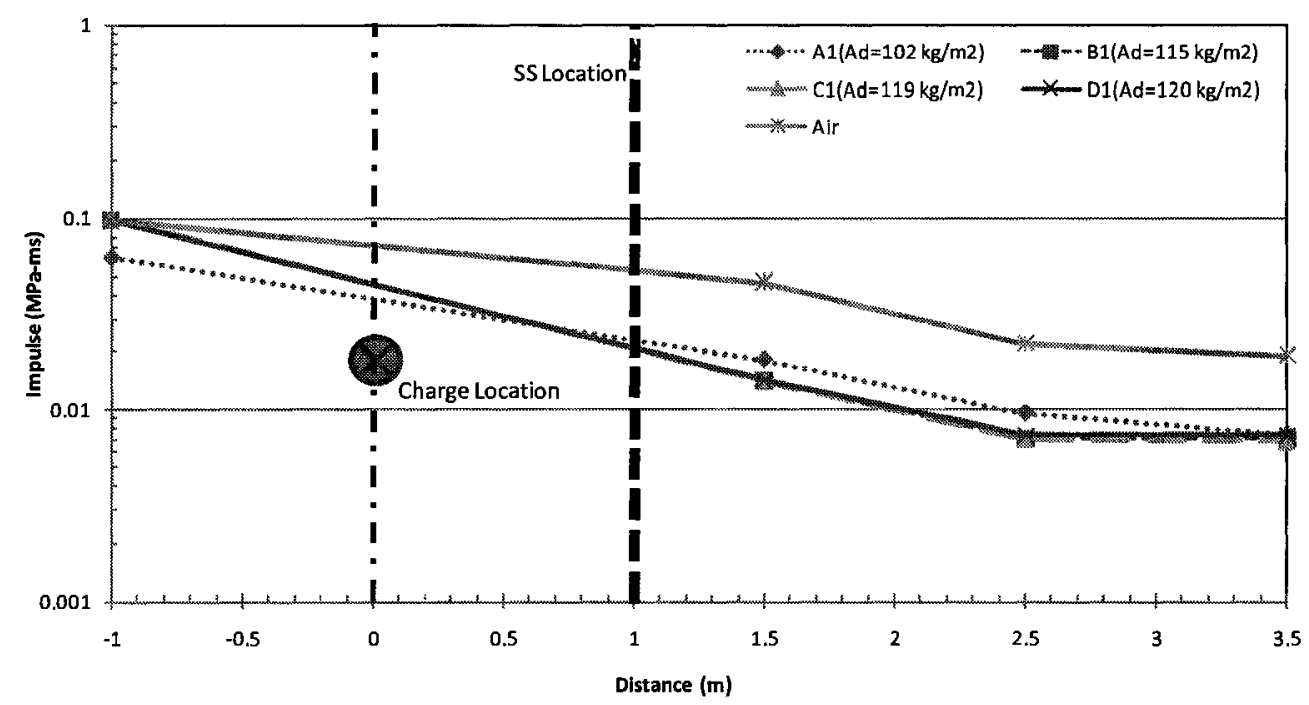

Figure 8.19: Numerical impulse versus gauge location-0.25 kg of Pentolite

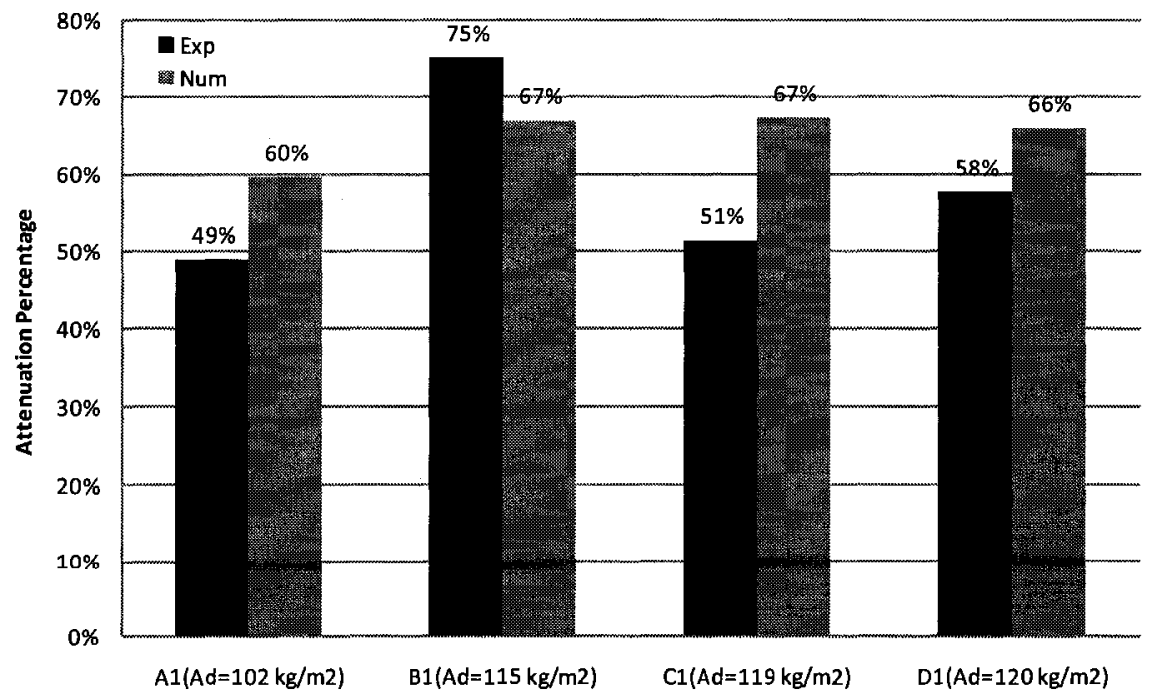

Figure 8.20: Average SSPs numerical impulse attenuation percentage $0.25 \mathrm{~kg}$ of Pentolite 
Table 8.1: Percentage of differences between numerical predictions for $0.25 \mathrm{~kg}$ of Pentolite

\begin{tabular}{ccccc}
\hline SSPs & & $\begin{array}{c}\text { Exp } \\
(\mathrm{MPa})\end{array}$ & $\begin{array}{c}\text { Num } \\
(\mathrm{MPa})\end{array}$ & $\begin{array}{c}\text { Error } \\
(\%)\end{array}$ \\
\hline \multirow{4}{*}{$\mathrm{A}$} & $\mathrm{G}_{1}$ & 0.638 & 0.439 & 31 \\
& $\mathrm{G}_{2}$ & 0.069 & 0.057 & 17 \\
& $\mathrm{G}_{3}$ & 0.019 & 0.028 & -46 \\
& $\mathrm{G}_{4}$ & 0.011 & 0.015 & -36 \\
$\mathrm{~B}$ & $\mathrm{G}_{1}$ & 0.638 & 0.451 & 29 \\
& $\mathrm{G}_{2}$ & 0.054 & 0.077 & -42 \\
& $\mathrm{G}_{3}$ & 0.011 & 0.022 & -100 \\
& $\mathrm{G}_{4}$ & 0.009 & 0.012 & -33 \\
& $\mathrm{G}_{1}$ & 0.638 & 0.450 & 29 \\
& $\mathrm{G}_{2}$ & 0.057 & 0.073 & -28 \\
& $\mathrm{G}_{3}$ & 0.018 & 0.021 & -19 \\
& $\mathrm{G}_{4}$ & 0.011 & 0.012 & -9 \\
& $\mathrm{G}_{1}$ & 0.638 & 0.440 & 31 \\
& $\mathrm{G}_{2}$ & 0.055 & 0.049 & 11 \\
& $\mathrm{G}_{3}$ & 0.015 & 0.020 & -33 \\
& $\mathrm{G}_{4}$ & 0.011 & 0.012 & -9 \\
& $\mathrm{G}_{1}$ & 0.638 & 0.448 & 30 \\
& $\mathrm{G}_{2}$ & 0.110 & 0.147 & -34 \\
& $\mathrm{G}_{3}$ & 0.033 & 0.052 & -58 \\
& $\mathrm{G}_{4}$ & 0.016 & 0.027 & -69 \\
\hline \multirow{4}{*}{$\mathrm{C}$} & & & & \\
& & & &
\end{tabular}

\subsubsection{Results of $0.50 \mathrm{~kg}$ of Pentolite}

Figures 8.21 to 8.24 show the numerical and experimental blast pressures at the various gauge locations for the air and SSP-A, SSP-B, SSP-C and SSP-D, respectively. These figures illustrate the excellent correlation between the computed and measured values of the blast pressure generated by detonation of the $0.5 \mathrm{~kg}$ charge of Pentolite. The numerical simulations were able to predict the pressure profiles very closely to those obtained experimentally at different gauge locations. The results shown in the figures suggested that the accuracy of predicting the pressure values using the numerical models increases with the increase of the detonated charge; for example the case of the $0.50 \mathrm{~kg}$ 
compared with using $0.25 \mathrm{~kg}$ of Pentolite. Figure 8.25 illustrates the performance of each of the design scenarios SSPs relative to that of the case of air model. The results showed the effectiveness of the SSPs in reducing the impact of the detonation beyond the critical distance of $1.50 \mathrm{~m}$ from the centre of the explosion. While all the design scenarios produced good and effective results, it is noted that different pressure values depended on the effective multi-area ratio of each panel. For example, the SSP-A, which has large unit vent area ratio, showed higher pressure over the panels with less unit vent area. This observation has been confirmed with the results obtained from the experimental investigation as discussed before.

Figure 8.26 shows that the pressure attenuation percentages for the simulated cases correlate well with those obtained using experimental data. The figure shows that the maximum attenuation was achieved by SSP-D with average attenuation of $62 \%$ which is agreement with the measured value of $60 \%$. Similarly, the second best performance was given by SSP-B with a computed average attenuation of $61 \%$ compared to a close value of $57 \%$ measured in the experiments. SSP-A and SSP-C had 57\% and 58\% attenuation rates determined by the numerical simulations compared to $43 \%$ and $53 \%$ measured in the experiments, respectively. A comparison between the calculated average attenuation percentages for numerical models and experimental tests showed that under the $0.50 \mathrm{~kg}$ charge there were no significant differences in the performance of the three heavier panels; SSP-B, SSP-C, and SSP-D which makes the selection of the lightest; SSP-B, the most effective solution. Similar to the results obtained in the case of the $0.25 \mathrm{~kg}$ it will appear that areal densities less than $115 \mathrm{~kg} / \mathrm{sq} \mathrm{m}$ may not perform as desired, see Figure 8.26. These attenuation values correlate well with the experimental tests results as well as 
the effective multi-layer vent area ratios estimated earlier except in the case of SSP-A. This can be explained by the difference in the experimental conditions of the blast chamber when SSP-A was tested. The boundary conditions during the SSP-A testing were different when compared with those during testing air shots as well as the other three SSP designs. The blast chamber was damaged after the completion of the SSP-A tests; therefore it was rebuilt to fix the entire back wall of the chamber. The chamber kept its internal dimensions; however additional sides were added around the chamber to strengthen it externally. Clearly, these additions and modifications resulted in changing the overall testing conditions within the chamber especially its front which in turn affected the new measurements compared with tests performed earlier. Subsequently and due to the fact that the numerical simulations were performed on the new chamber configurations, the noted differences between the measured and simulated SSP-A results can easily be explained.

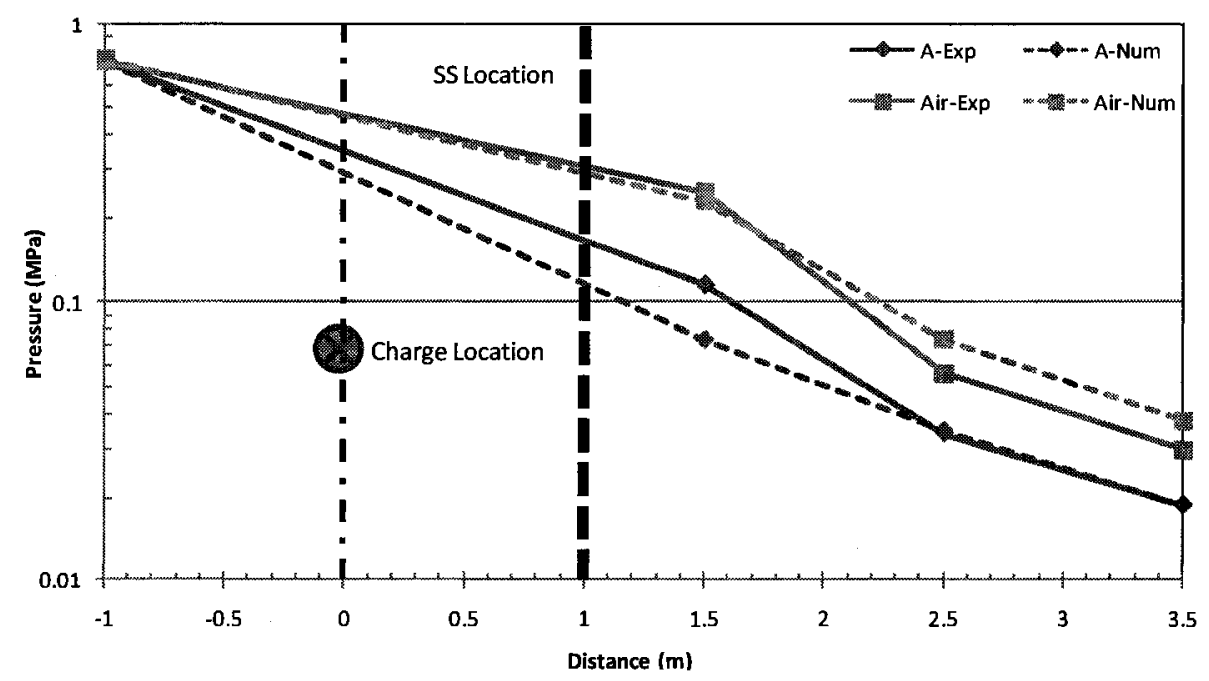

Figure 8.21: Numerical \& Experimental pressure versus gauge location-SSP-A-0.5 kg of Pentolite 


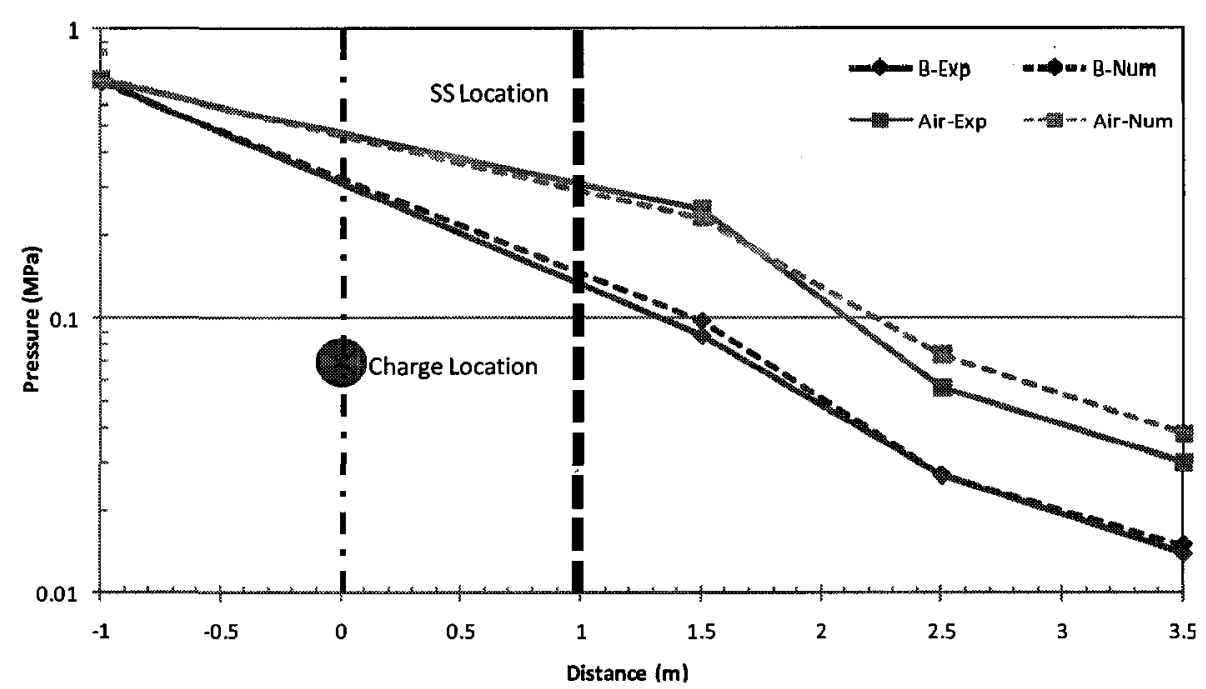

Figure 8.22: Numerical \& Experimental pressure versus gauge location-SSP-B-0.5 kg of Pentolite

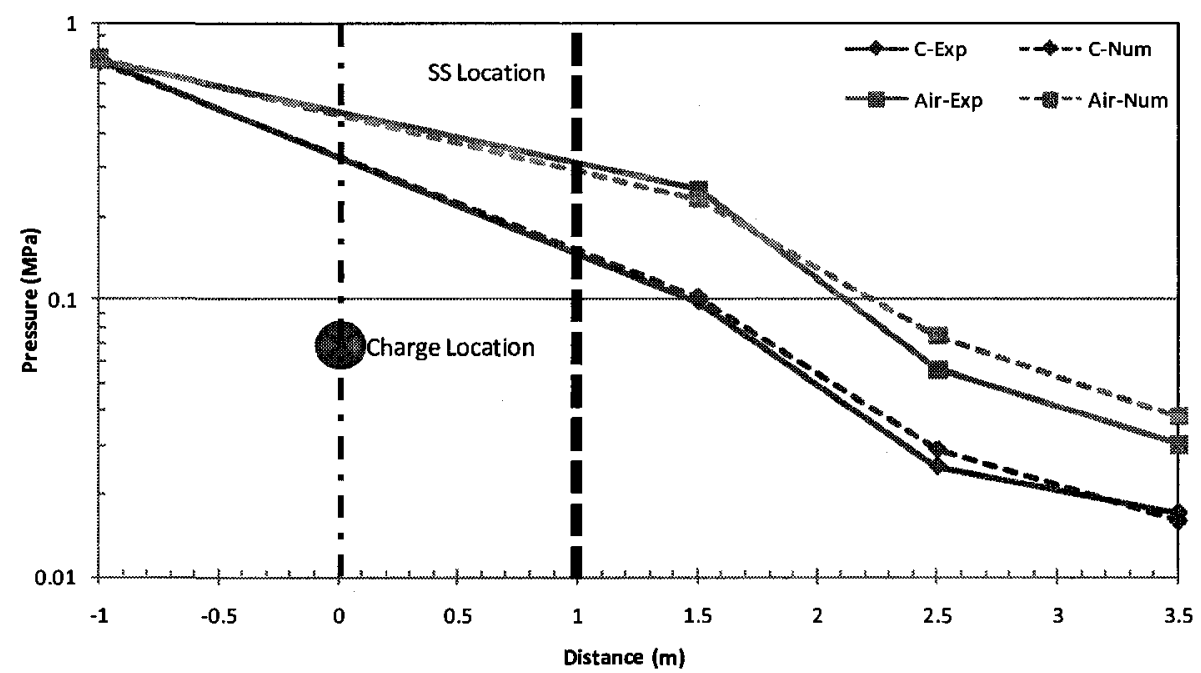

Figure 8.23: Numerical \& Experimental pressure versus gauge location-SSP-C-0.5 kg of Pentolite

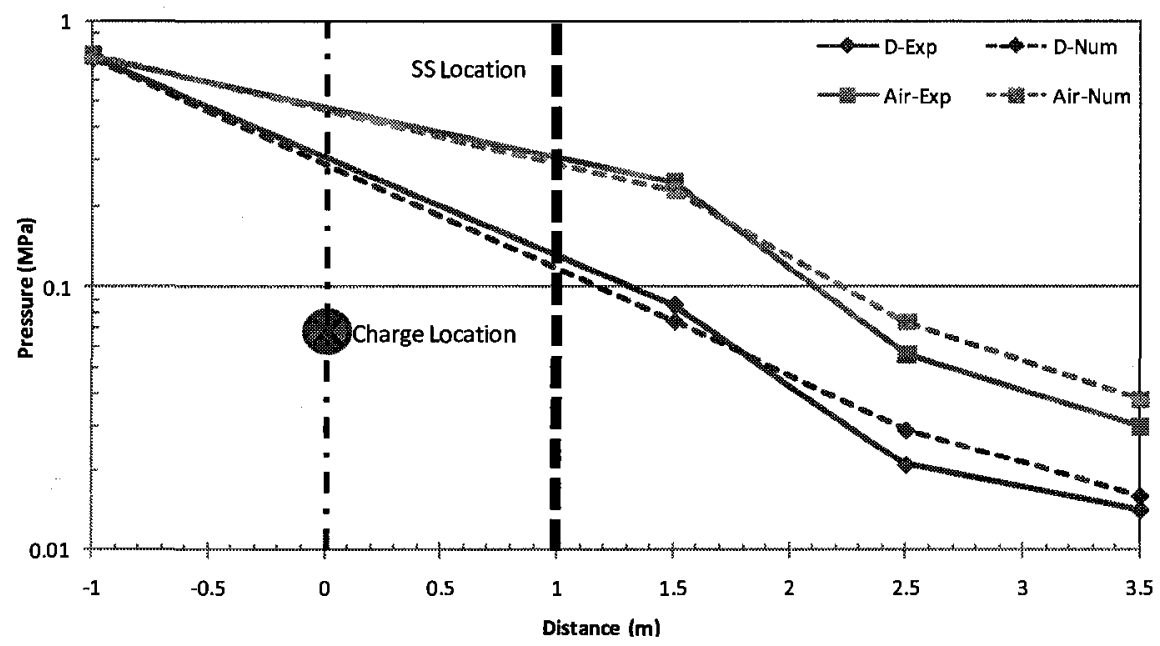

Figure 8.24: Numerical \& Experimental pressure versus gauge location-SSP-D-0.5 kg of Pentolite 


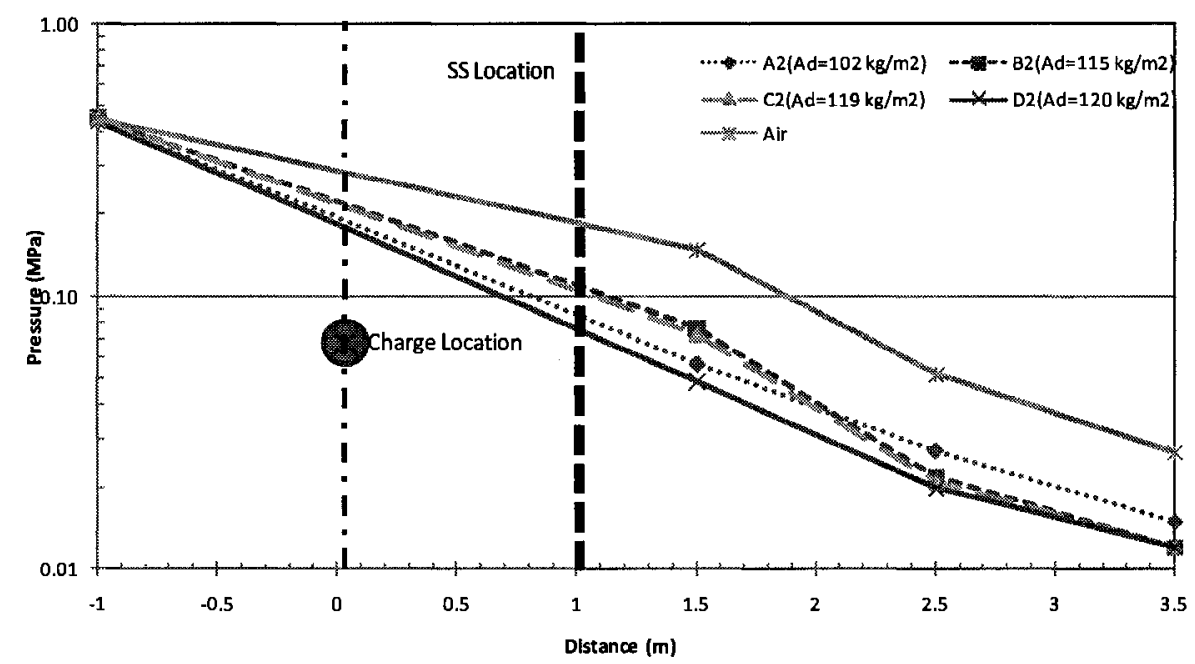

Figure 8.25: Numerical blast pressure versus gauge location- $0.5 \mathrm{~kg}$ of Pentolite

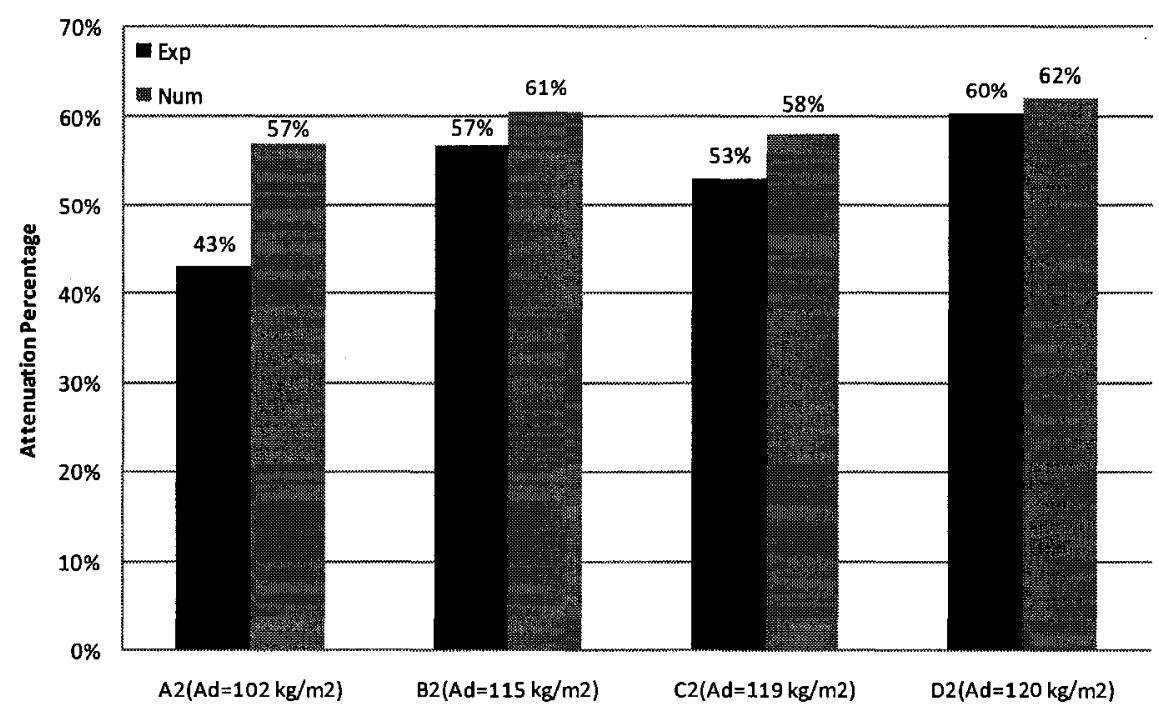

Figure 8.26: Average SSPs numerical pressure attenuation percentage- $0.5 \mathrm{~kg}$ of Pentolite

Figure 8.27 represents the incident impulse versus the various gauge locations. The results followed similar behaviour to that observed in the case of the $0.25 \mathrm{~kg}$ results. As concluded before, SSP-B and SSP-D are the best panels in comparison with the other two SSPs. In order to evaluate the performance of the four panels with respect to impulse attenuation, average attenuations were calculated and shown in Figure 8.28. The results confirmed that both SSP-B and SSP-D provided the best performance numerically and experimentally. Finally, the results and analysis presented herein support the conclusion 
that the numerical models and simulations are able to predict influence of the designed panels in reducing the effect of blast with reasonable degree of accuracy.

Table 8.2 presents the percentage of differences between numerical predictions and experimental measurements. It is interesting to note that the calculated values are much smaller in the case of the heavier charge of $0.50 \mathrm{~kg}$ when compared to those of the 0.25 $\mathrm{kg}$ which indicate better agreement for larger charges.

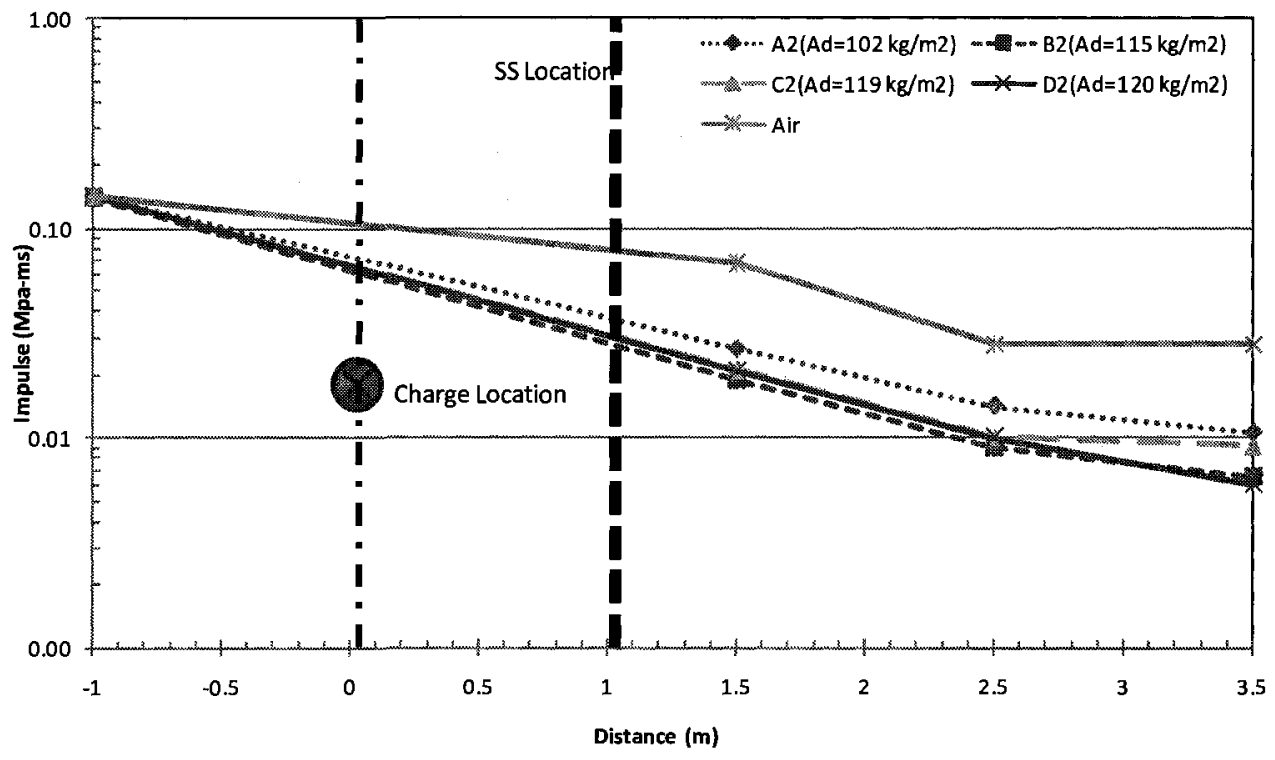

Figure 8.27: Numerical impulse versus gauge location-0.5 kg of Pentolite 


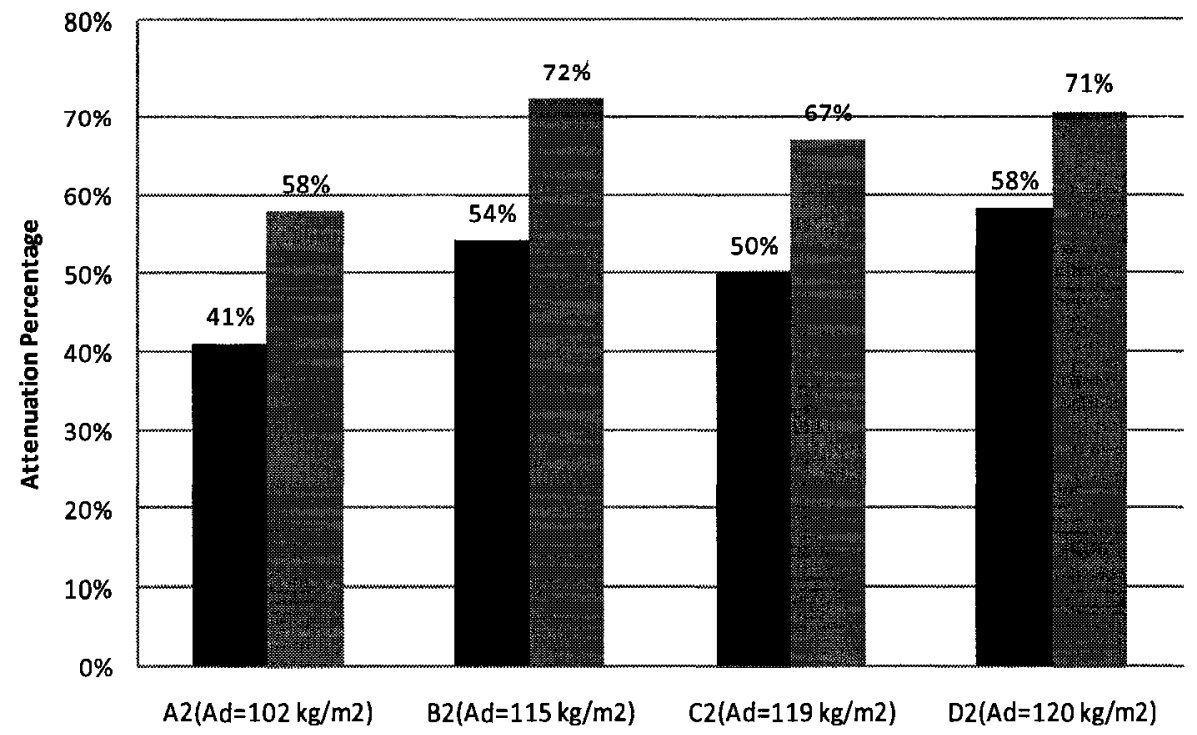

Figure 8.28: Average SSPs numerical impulse attenuation percentage $0.5 \mathrm{~kg}$ of Pentolite

Table 8.2: Percentage of differences between numerical predictions for $0.5 \mathrm{~kg}$ of Pentolite

\begin{tabular}{|c|c|c|c|c|}
\hline$\overline{\text { SSPs }}$ & & $\begin{array}{c}\text { Exp } \\
(\mathrm{MPa})\end{array}$ & $\begin{array}{c}\text { Num } \\
(\mathrm{MPa})\end{array}$ & $\begin{array}{c}\text { Error } \\
(\%)\end{array}$ \\
\hline \multirow{4}{*}{ A } & G1 & 0.733 & 0.735 & 0 \\
\hline & $\mathrm{G} 2$ & 0.116 & 0.074 & 36 \\
\hline & G3 & 0.034 & 0.035 & -2 \\
\hline & G4 & 0.019 & 0.019 & 0 \\
\hline \multirow{4}{*}{ B } & G1 & 0.733 & 0.725 & 1 \\
\hline & G2 & 0.087 & 0.098 & -13 \\
\hline & G3 & 0.027 & 0.027 & 0 \\
\hline & G4 & 0.014 & 0.015 & -6 \\
\hline \multirow{4}{*}{$\mathrm{C}$} & G1 & 0.733 & 0.725 & 1 \\
\hline & $\mathrm{G} 2$ & 0.098 & 0.103 & -5 \\
\hline & G3 & 0.025 & 0.029 & -16 \\
\hline & G4 & 0.017 & 0.016 & 6 \\
\hline \multirow{4}{*}{$\mathrm{D}$} & G1 & 0.733 & 0.725 & 1 \\
\hline & $\mathrm{G} 2$ & 0.086 & 0.075 & 13 \\
\hline & G3 & 0.021 & 0.029 & -38 \\
\hline & G4 & 0.014 & 0.016 & -13 \\
\hline \multirow{4}{*}{ Air } & G1 & 0.733 & 0.744 & -2 \\
\hline & $\mathrm{G} 2$ & 0.250 & 0.232 & 7 \\
\hline & G3 & 0.056 & 0.074 & -32 \\
\hline & G4 & 0.030 & 0.038 & -27 \\
\hline
\end{tabular}




\subsubsection{Results of $1.00 \mathrm{~kg}$ of Pentolite}

Figures 8.29 to 8.32 show the results of the numerical and experimental blast pressures at the various gauge locations for the air and the four SSPs. The results in the figures illustrate close agreement between the pressure values calculated by the numerical models and the measured one during experimental tests for the case of the $1.00 \mathrm{~kg}$ charge of Pentolite. The results confirmed the observation reported earlier that the prediction ability of numerical simulation improves with the increase of the charge mass used in the simulation. Figure 8.33 illustrates the results of the numerical simulation and experimental investigation for the case of $1.00 \mathrm{~kg}$ charge. The results of the numerical simulation suggest significant reduction in the calculated values of the pressure values when the SSPs were mobilized. Since, the air shot for $1 \mathrm{~kg}$ of Pentolite was not performed in the field due to the restriction on sound levels at the test site; the attenuation percentage in pressure was only calculated based on the numerical predictions of $1 \mathrm{~kg}$ charge. Figure 8.34 shows the calculated attenuation percentages. It is shown from the calculation of attenuation percentage that the models were able to predict the behaviour of SSPs in attenuation of applied pressure while recognizing the significance of the unit vent area ratio in determining these values. The results confirmed the previous observations which suggest that SSP-B and SSP-D would give more effective performance when used to reduce effect of blast when compared to the performance of the other two panels; SSP-A and SSP-C. 


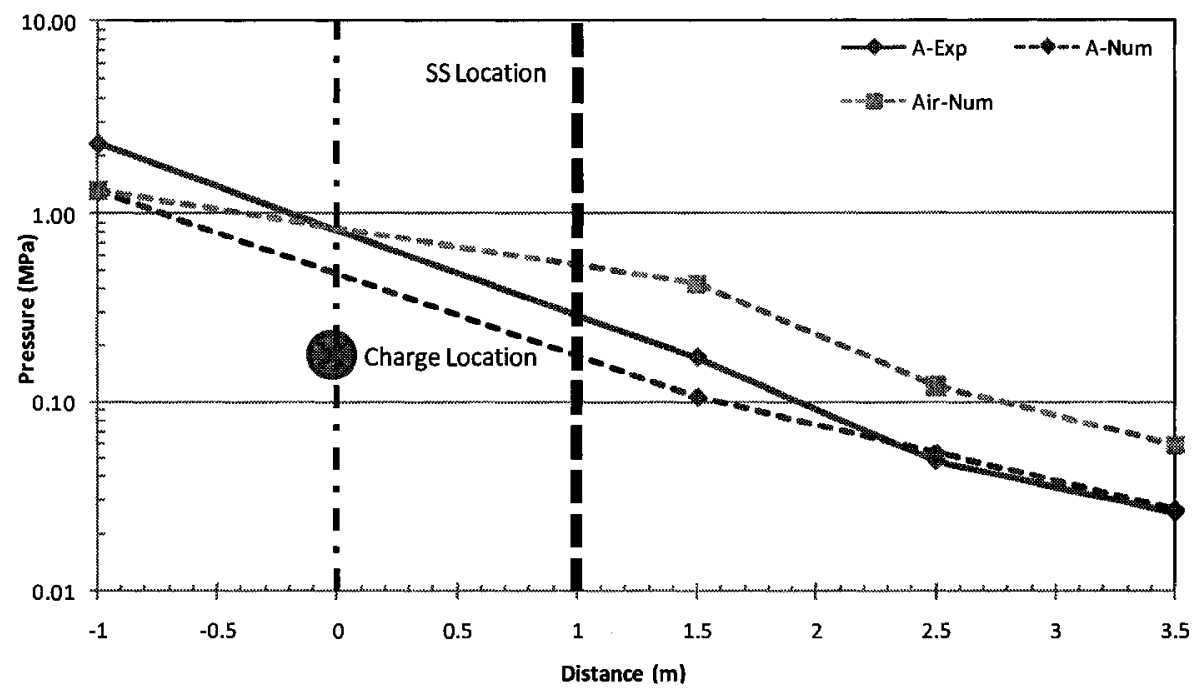

Figure 8.29: Numerical \& Experimental pressure versus gauge location-SSP-A-1 kg of Pentolite

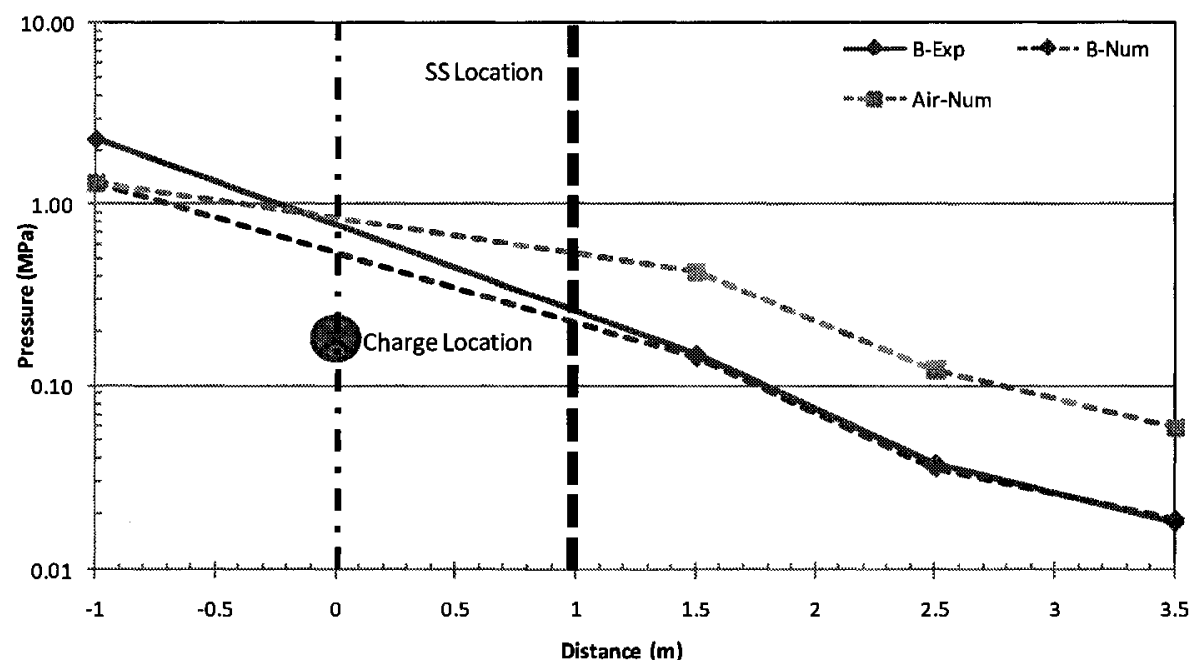

Figure 8.30: Numerical \& Experimental pressure versus gauge location-SSP-B-1 kg of Pentolite

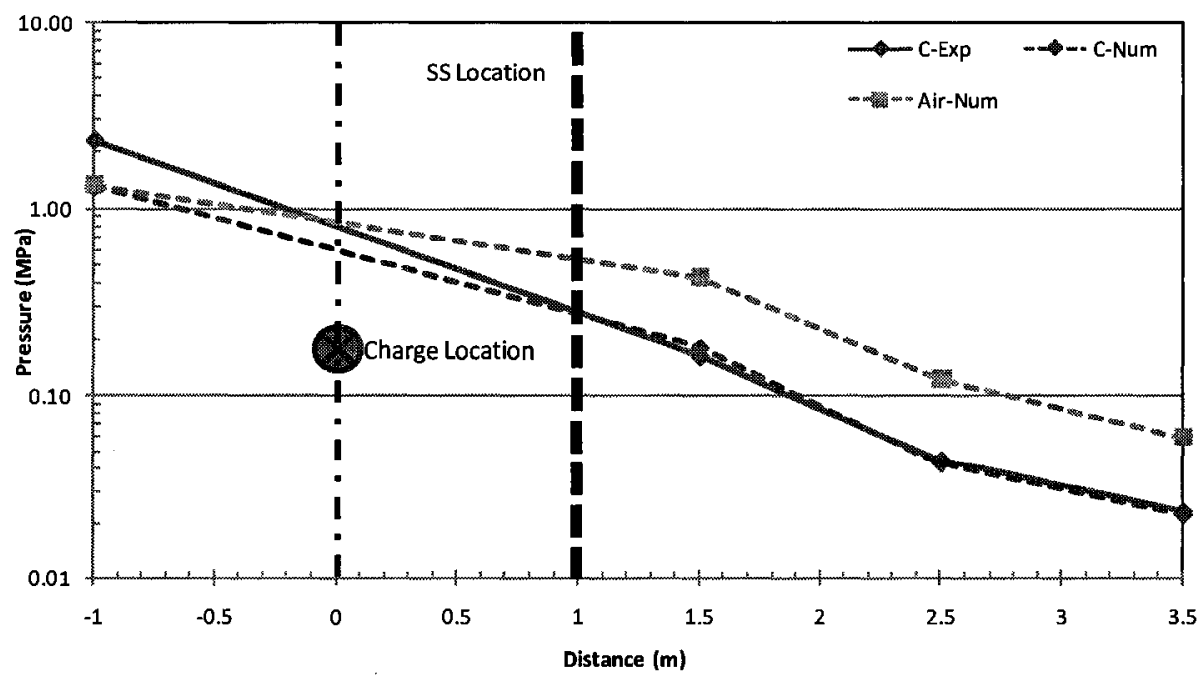

Figure 8.31: Numerical \& Experimental pressure versus gauge location-SSP-C-1 kg of Pentolite 


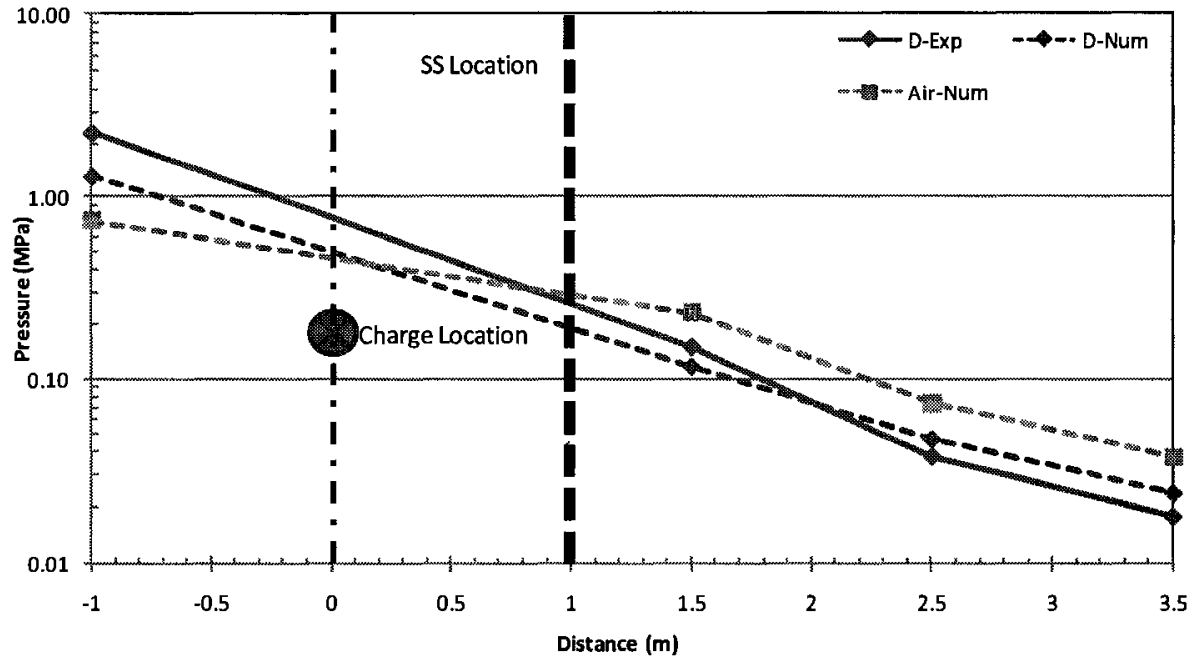

Figure 8.32: Numerical \& Experimental pressure versus gauge location-SSP-D-1 kg of Pentolite

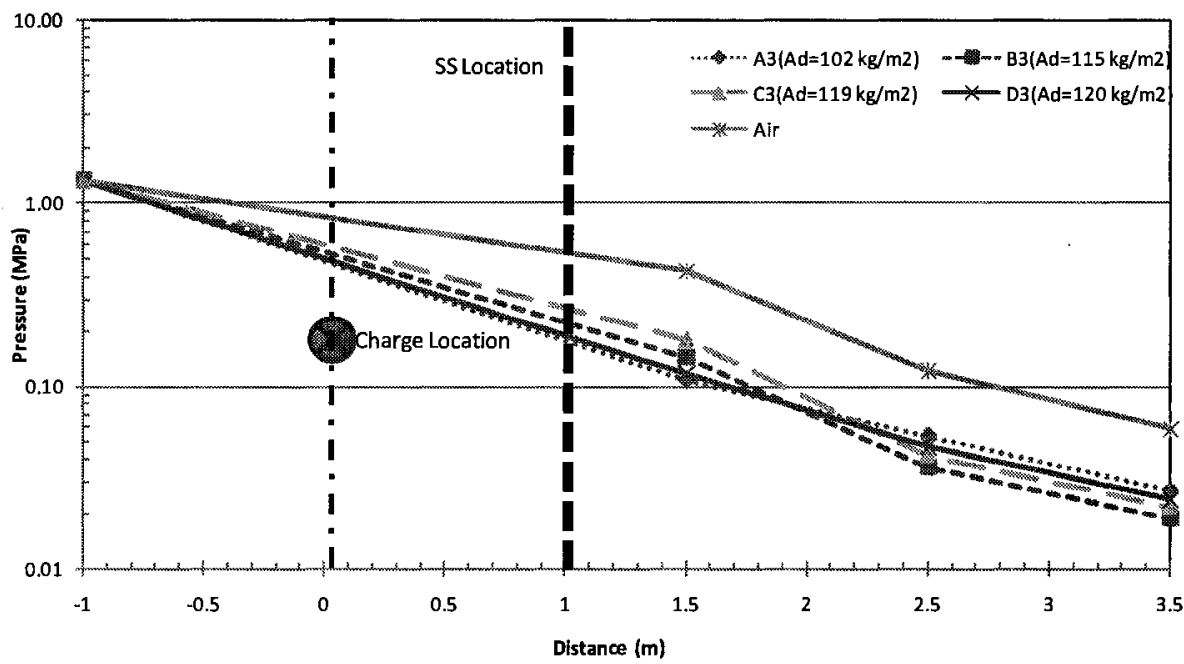

Figure 8.33: Numerical blast pressure versus gauge location-1 kg of Pentolite

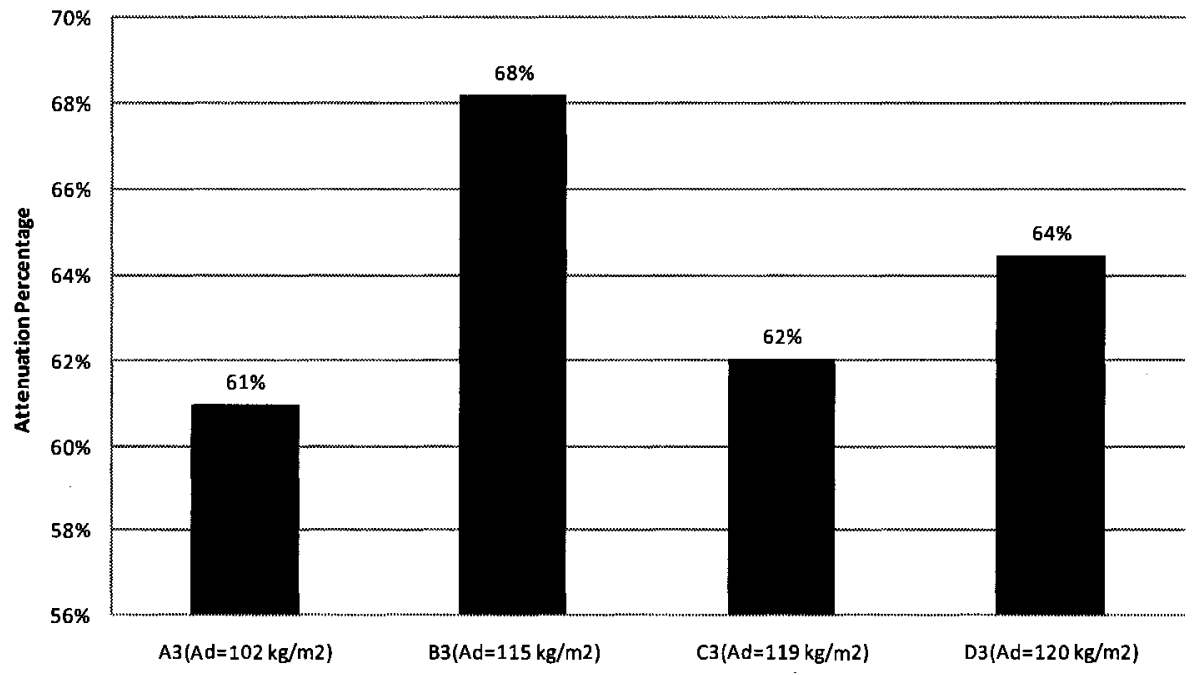

Figure 8.34: Average SSPs numerical impulse attenuation percentage $1 \mathrm{~kg}$ of Pentolite 
Figure 8.35 represents the incident impulse results of the numerical simulation at various gauge locations. The results confirmed the experimental findings that SSPs are effective in reducing the impulse values substantially compared to normal attenuation through air. Also, the results shown in the figure confirmed that PPSB was the most effective panel while PPSA was the least effective as discussed before. When the average values for each panel was calculated, the differences between the three panels SSPB, SSPC and SSPD become negligible. Figure 8.36 shows that SSP-D has reduced the average impulse value by up to $70 \%$ compared with the reference case of air only. Furthermore, the results showed that each of the SSP-B and SSP-C reduced the average impulse values by $67 \%$. On the other hand as indicated above, the least impulse attenuation of $60 \%$ is obtained by SSP-A. Table 8.3 presents the percentage of difference between the numerical predictions and the experimental measurements. With the exception of the G1 location which is inside the blast chamber, values at the other gauges showed good agreement between measured and calculated values. The noted higher differences at G1 could be explained by the damage occurred to the chamber when the $1.0 \mathrm{~kg}$ was detonated.

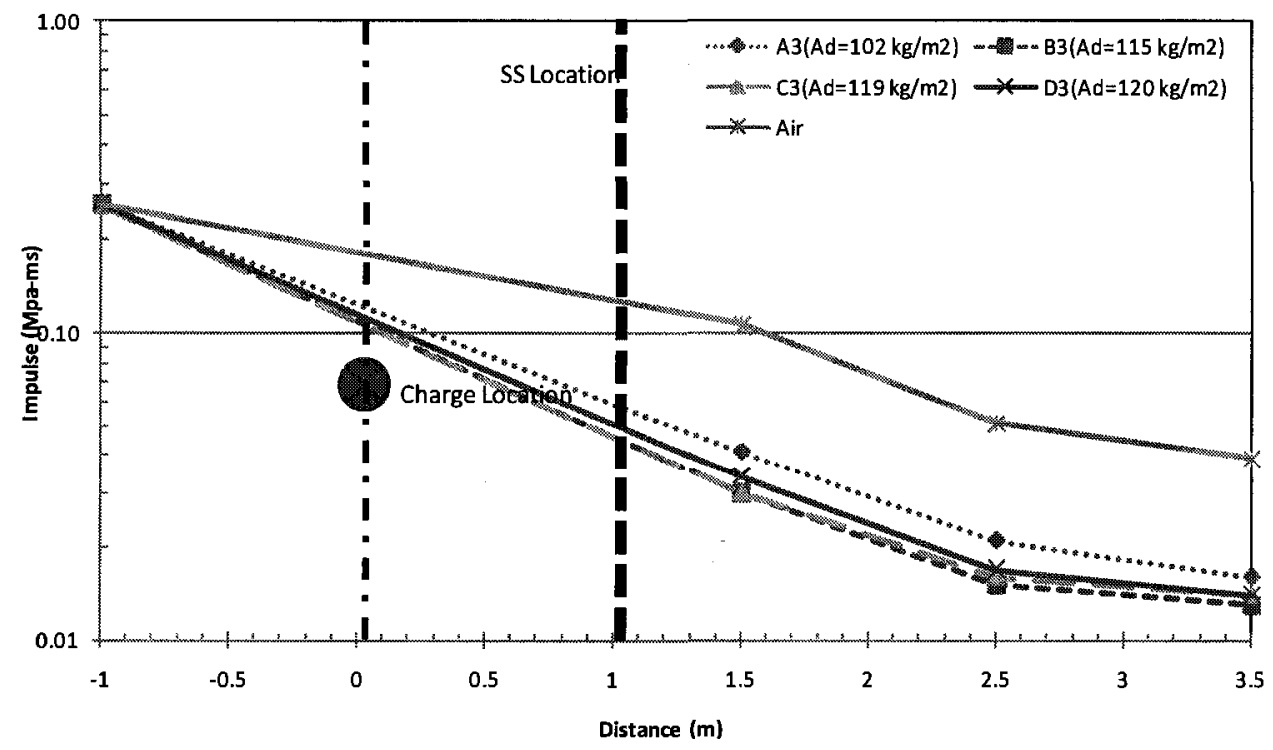

Figure 8.35: Numerical impulse versus gauge location-1 kg of Pentolite 


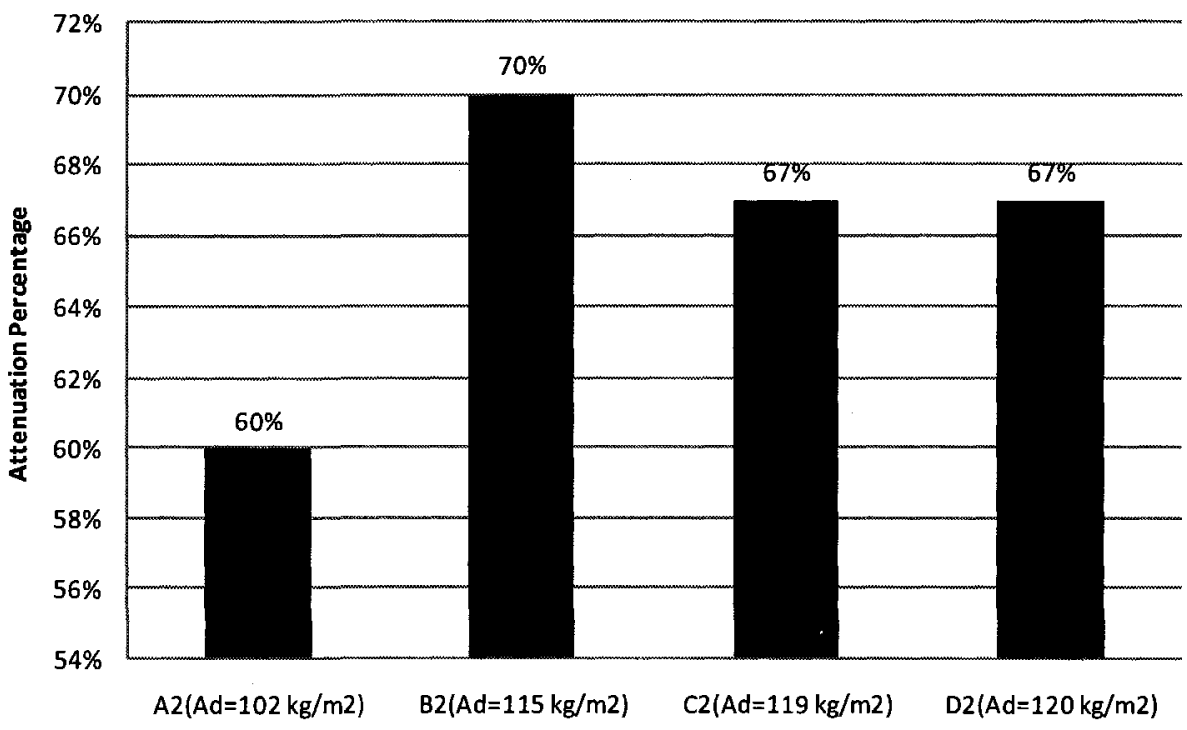

Figure 8.36: Average SSPs numerical impulse attenuation percentage $1 \mathrm{~kg}$ of Pentolite

Table 8.3: Percentage of differences between numerical predictions for $1 \mathrm{~kg}$ of Pentolite

\begin{tabular}{ccccc}
\hline SSPs & & $\begin{array}{c}\text { Exp } \\
\text { (MPa) }\end{array}$ & $\begin{array}{c}\text { Num } \\
(\mathrm{MPa})\end{array}$ & $\begin{array}{c}\text { Error } \\
(\%)\end{array}$ \\
\hline \multirow{4}{*}{ A } & G1 & 2.313 & 1.323 & 43 \\
& G2 & 0.173 & 0.107 & 38 \\
& G3 & 0.049 & 0.054 & -9 \\
& G4 & 0.026 & 0.027 & -3 \\
B & G1 & 2.313 & 1.319 & 43 \\
& G2 & 0.150 & 0.144 & 4 \\
& G3 & 0.038 & 0.036 & 5 \\
& G4 & 0.018 & 0.019 & -6 \\
& G1 & 2.313 & 1.310 & 43 \\
& G2 & 0.162 & 0.180 & -11 \\
& G3 & 0.044 & 0.042 & 5 \\
& G4 & 0.023 & 0.022 & 4 \\
& G1 & 2.313 & 1.319 & 43 \\
& G2 & 0.142 & 0.117 & 18 \\
& G3 & 0.036 & 0.047 & -31 \\
& G4 & 0.019 & 0.024 & -26 \\
& G1 & N/A & 1.319 & N/A \\
& G2 & N/A & 0.427 & N/A \\
& G3 & N/A & 0.122 & N/A \\
& G4 & N/A & 0.059 & N/A \\
\hline
\end{tabular}


The results and analysis of the 2-D simulations discussed in earlier sections showed good correlation between various experimental measurements and numerical predictions as well as the ability of FEM to estimate the blast parameters. However, these 2-D scenarios only accounted for pressure measurements without taking into consideration any structural response. Thus, 3-D modeling was utilized to investigate and verify the structural response of the tested SSPs in order to provide sufficient data and information for improving the design of the suppressive shields. The following sections present the various 3-D scenarios that were modeled using AUTODYN.

\subsection{3-D Modelling}

A total of seven scenarios were modeled to investigate the structural response of SSPs to explosive detonation. The first step involved using three models to assess and verify experimental tests using the SSP-A panel. Second step tested the same panel under different explosive masses, 10, 25 and $50 \mathrm{~kg}$ of Pentolite, respectively. In the next step six of the seven design scenarios were modeled as panels while the last design scenario a $2.00 \mathrm{~m}$ by $2.00 \mathrm{~m}$ by $2.00 \mathrm{~m}$ cubicle was subjected to internal detonation of $5.00 \mathrm{~kg}$ of Pentolite charge.

\subsubsection{Numerical Analysis and Verification of the Suppressive Shield Panels}

The following sections present and discuss the results and structural responses obtained from the numerical modeling of the suppressive shields considered in this research. Three unique designs are presented and discussed utilizing the design scenario termed SSP-A. The first design is the basic shield design where only steel panel is used. The second 
design takes advantage of a new $\mathrm{AF}$ as add-on facing the on-coming shock wave while the third design involved using a thin steel plate as a backing for the $\mathrm{AF}$ in front of the panel.

\subsubsection{Case of Basic SSP-A design}

The structural response of this panel was tested under $0.5 \mathrm{~kg}$ of Pentolite detonated in the blast chamber. Figure 8.37 shows the stress counters computed using the AUTODYN. One can readily identify the locations at which the yield stresses exceeded the material yield strength, $4 \times 10^{5} \mathrm{kPa}$, causing plastic deformation as shown in the figure. It can be seen that the main sections where stresses exceeded the defined yield strength are the mid-span of the angles, where the load is maximum, and their end points, where the fixed boundary condition was applied. These small plastic deformations did not cause major changes in the shape of the panel, same as observed in the experimental test, Figure 8.38. Due to the inability to install strain gauges in the field tests to track occurring deformations, a photometric comparison was carried out between test specimens after the experimental tests and shapes obtained from the results of the numerical model. The pictures and the simulation obtained shapes are in good agreement and indeed there were no or very little deformations occurred. 


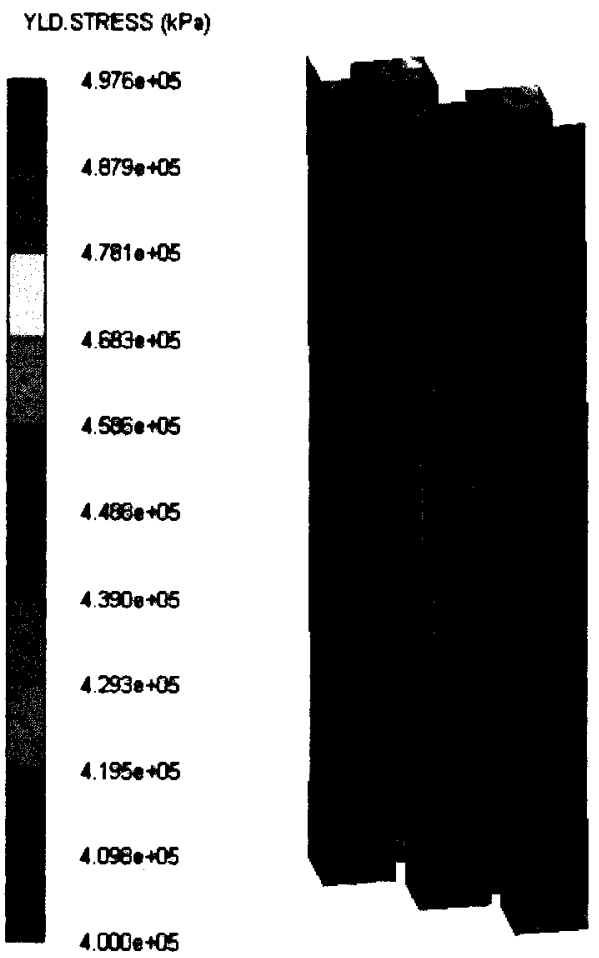

Figure 8.37: Yield stress contour for SSP-A subjected to $0.5 \mathrm{~kg}$ of Pentolite

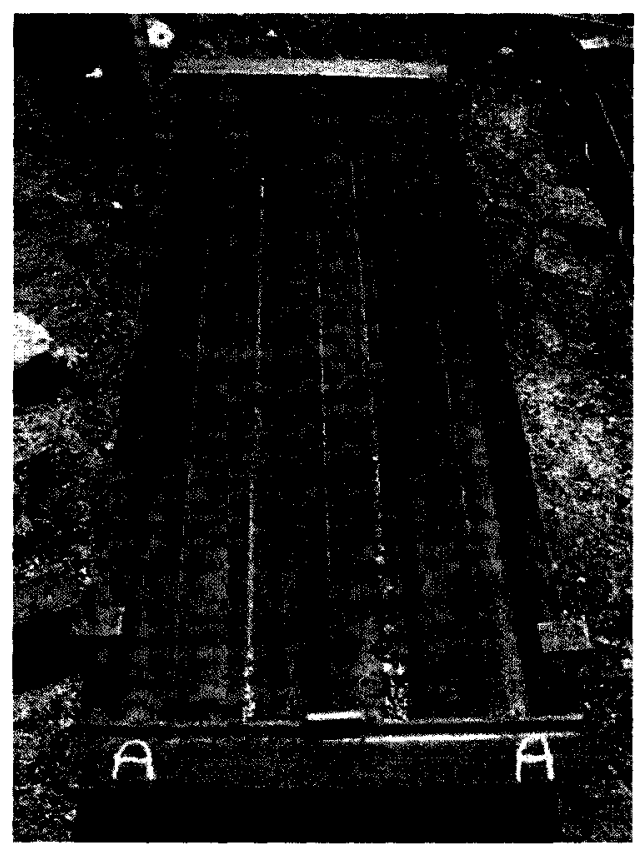

Figure 8.38: SSP-A after testing 


\subsubsection{Case of SSP-A with add-on Aluminum Foam}

This simulation was carried out to verify the ability to model AF material used as inner lining or add-on layer to the basic design of the SSP. The experimental tests while demonstrated the benefits of using the AF as an additional protective light weight layer the tests also showed that AF disintegrates under the effect of the explosive. As shown earlier in Chapter 6, Section 6.4.1, the degree of disintegration depends on the thickness of the used AF sheets, 13,29, and $43 \mathrm{~mm}$. Only the largest thickness, $43 \mathrm{~mm}$, was used in the modelling. Figures 8.39 and 8.40 show the numerical and experimental behaviour of the add-on AF sheets when subjected to $0.50 \mathrm{~kg}$ of Pentolite. It is clear that the results of the numerical simulation achieved failure similar to the one observed in the field although the simulation was stopped after $10 \mathrm{~ms}$ only.

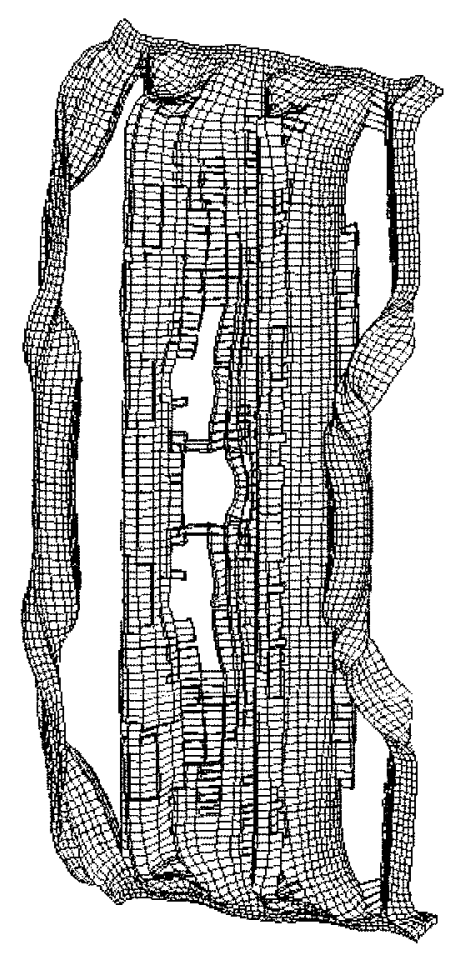

Figure 8.39: Numerical modelling of un-backed AF sheets 


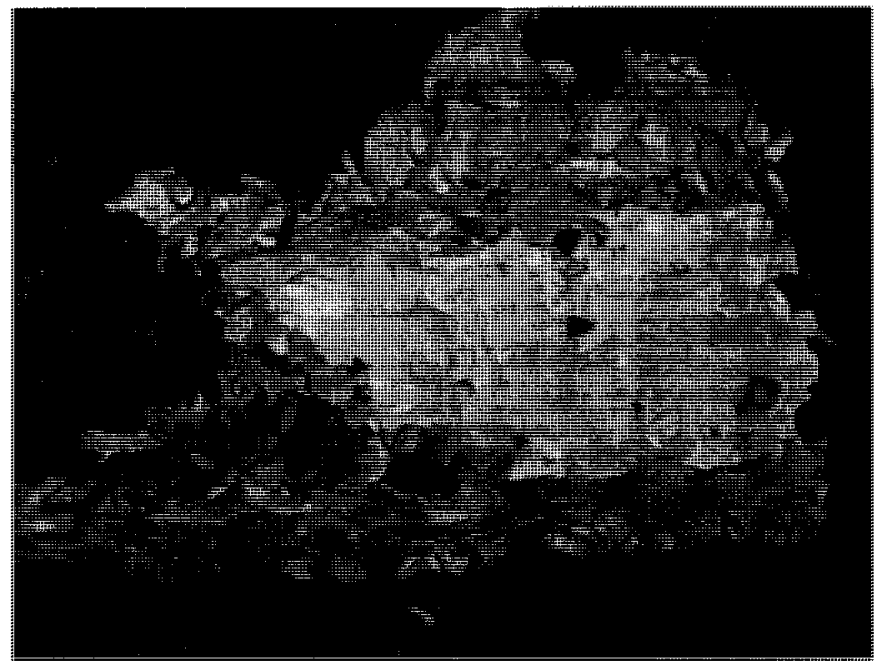

Figure 8.40: Un-backed AF sheets after testing

\subsubsection{Case of SSP-A with backed Aluminum Foam}

This case is similar to the case discussed above except that there was a steel plate inserted between the steel shield and the Aluminum Foam. Figure 8.41 shows the deformation of the plate-backed AF sheet after being pushed against the SSP for both experimental test and numerical model. The effect of the plate backing is obvious in preventing the disintegration of the AF as can be seen in the figure. It is clear that the AF sheet did not disintegrate but deformed taking the same shape of the SSP angles. However, some parts still disintegrated which is also shown in the numerical model. Figure 8.42 shows the density of the AF sheet at $5 \mathrm{~ms}$. It can be seen that, the parts which absorbed more energy or compression at that time gained more density. This is due to the collapse of the AF sheet on itself before reach final failure. 

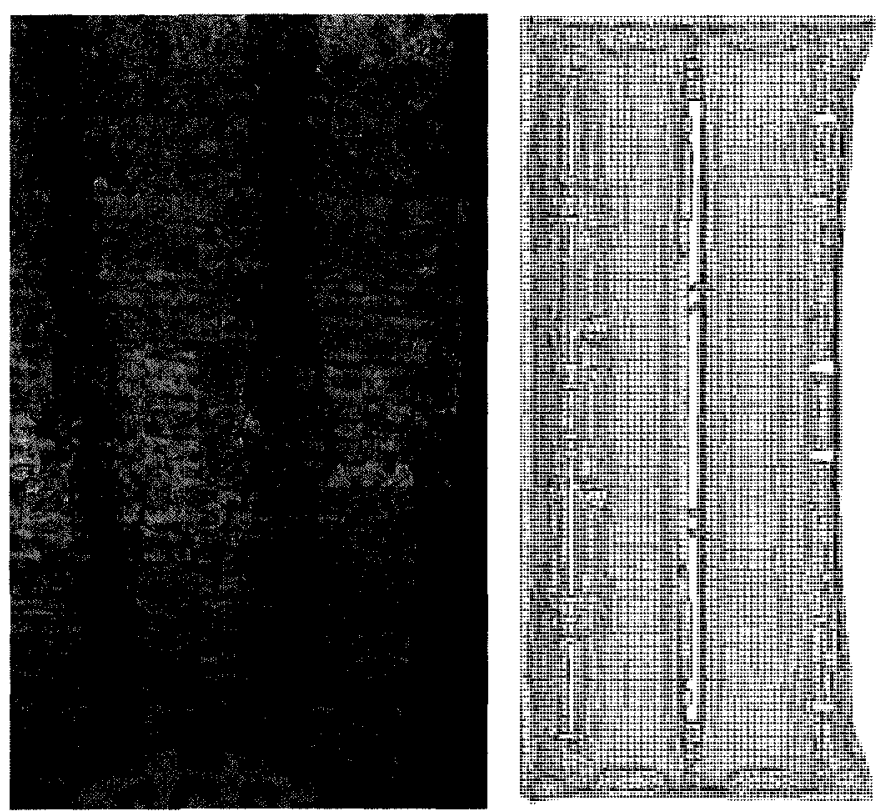

Figure 8.41: Experimental test versus numerical model- backed AF sheet
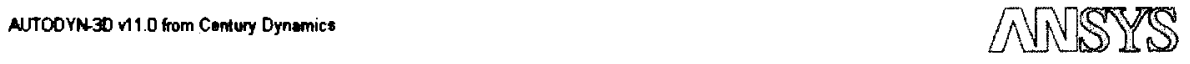

DENSITY $\left(g / \mathrm{cm}^{3}\right)$
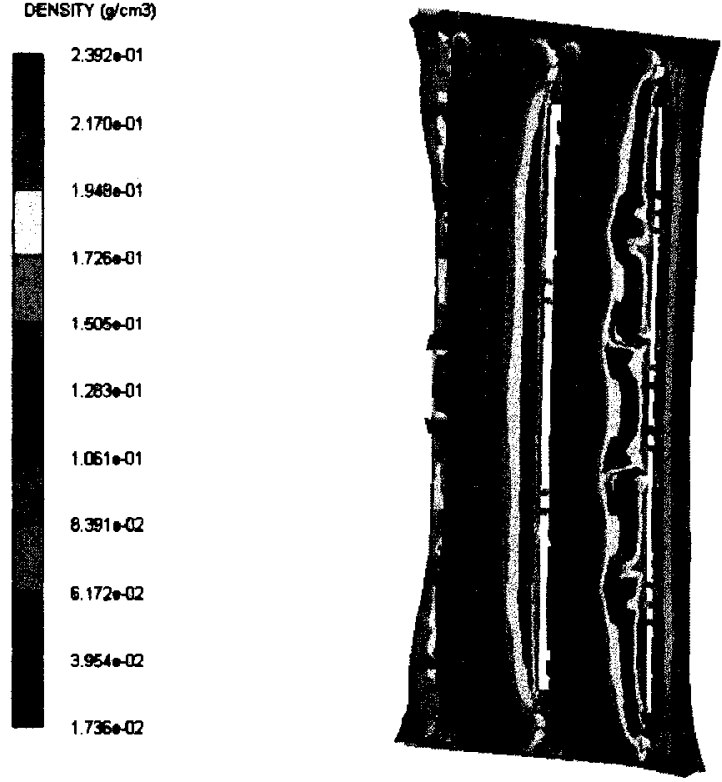

1.736000

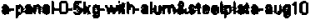

Cyclo 6000

Timo $5.031 \mathrm{E}+000 \mathrm{~ms}$

Unis $\mathbf{m m}, \mathrm{mg}$, $\mathrm{ms}$

Figure 8.42: Density of AF sheet at $5 \mathrm{~ms}$ 


\subsection{Design alternatives of the SSPS}

The experimental tests were verified through three design scenarios using SSP-A. The three scenarios included the modeling of steel panel, AF without backing and AF with backing. The results obtained from such models showed good correlation with the experimental tests results and support the proposed use of FEM to investigate other scenarios with different designs and objectives. As discussed in the experimental design of the investigation carried out in this thesis, it was not possible to perform any field tests using explosive charges heavier than $1.00 \mathrm{~kg}$. However, the results of the numerical investigation and its verification provided another reliable means to examine the proposed design alternatives of the SSPs under larger chargers. The following sections present the results of modelling SSPs and their performance under larger charge masses. Also, the numerical simulation technique has been utilized to evaluate a full container of $2.00 \mathrm{~m}$ cubicle under $5 \mathrm{~kg}$ of Pentolite.

\subsubsection{Case of SSPs subjected to higher charge masses}

Three charges, 10,25 , and $50 \mathrm{~kg}$ of Pentolite, were used to investigate the structural response of SSPs for higher blast loads. Figure 8.43 shows the stress contours computed for the case of $10.00 \mathrm{~kg}$ blast charge. The figure shows the locations at which the yield

strength, $4 \times 10^{5} \mathrm{kPa}$ was exceeded and plastic deformation had occurred at $10 \mathrm{~ms}$. It is clear that all angles exceeded the yield strengths of the material. However, the maximum yield stress, $7.8 \times 10^{5} \mathrm{kPa}$ was observed to occur at the ends of the angles in the outside row, where the fixed boundary condition was applied. As a result, the outside angles start deforming and moved away from the SSP system as shown in the figure. It is worth 
mentioning that the alignment of angles utilized in SSPs had resulted in two loading conditions. Figure 8.44 shows the two loading directions acting on the legs of different shapes of angles. It can be seen in Figure 8.44 (a) that the load is attacking the angles from the inside. The load acts on the legs, flanges, of the angle forcing them to flatten to the outside. On the other hand in Figure 8.44 (b), the load is acting on the legs of the angles from the outside. The arrow shape facing the load helped diverging the blast wave and at the same time squashed to the inside.

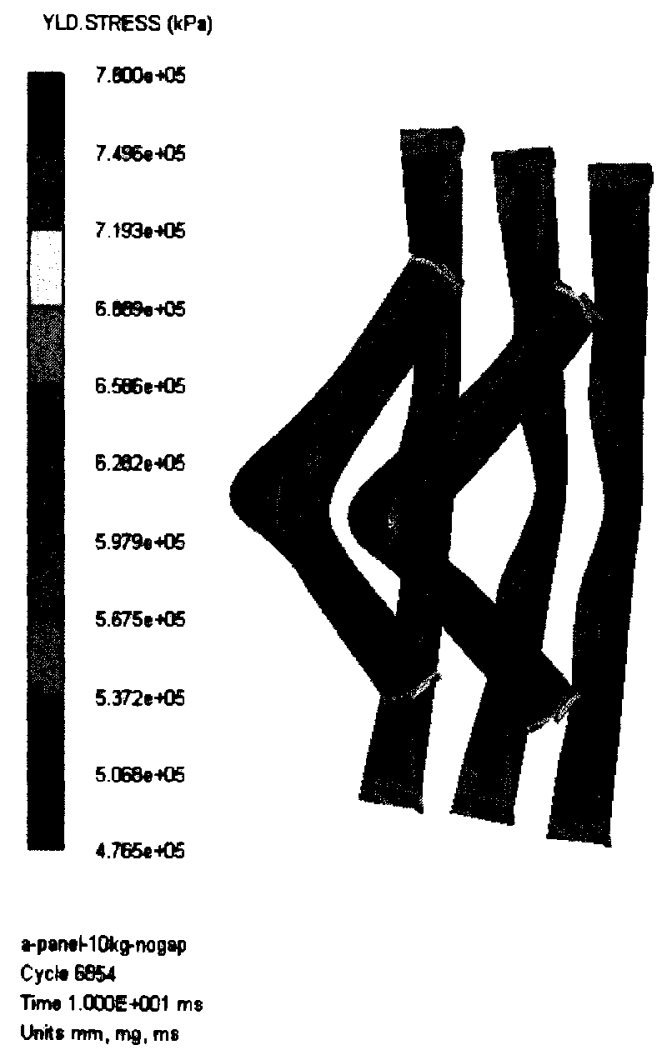

Figure 8.43: Yield stress contour for SSP-A subjected to $10 \mathrm{~kg}$ of Pentolite 


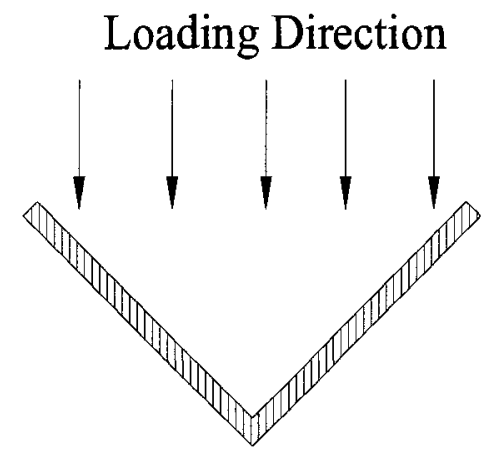

(a)
Loading Direction

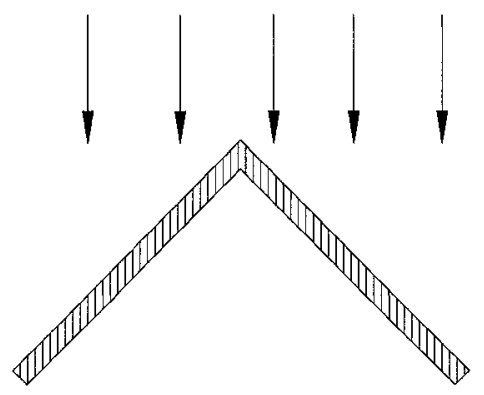

(b)

Figure 8.44: Angle shape effect on loading direction

Figure 8.45 (a) shows the yield stress generated by $25 \mathrm{~kg}$ blast load along the angle sections at $2 \mathrm{~ms}$. It is obvious that as the blast load becomes larger, less time is needed for the applied stresses to cause the angles to reach the allowed yield strength. The failure of the angles under the heavier blast charge showed similar failure to the ones observed in the 0.5 and $10 \mathrm{~kg}$ of Pentolite scenarios. However, the influence of the heavy blast was evidence at $10 \mathrm{~ms}$ as the angles deformed more severely and some of its parts started to disintegrate as shown in Figure 8.45 (b). It is also noticeable that, one of the inside angles was pulled back into the blast chamber due to negative pressure, suction, at this region. 


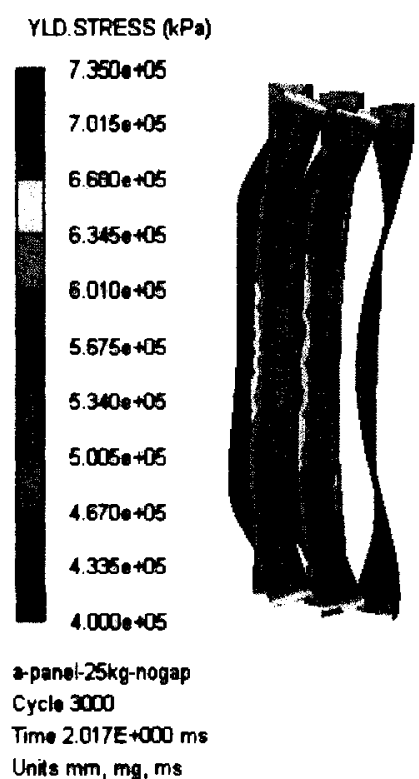

(b)

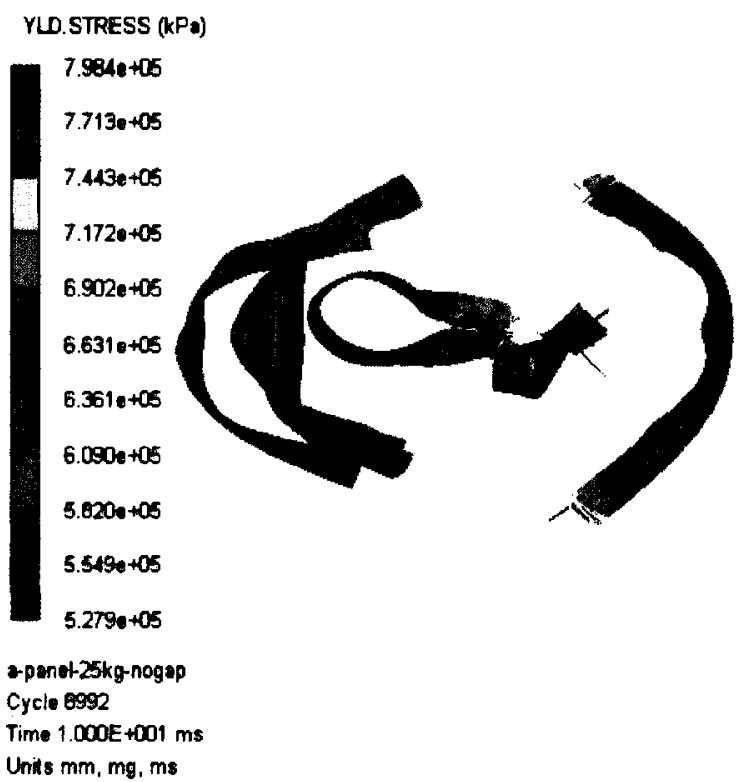

(b)

Figure 8.45: Yield stress contour for SSP-A subjected to $25 \mathrm{~kg}$ of Pentolite

Figure 8.46 (a) shows the yield stress for angles sections at $2 \mathrm{~ms}$ subjected to the explosive charge of $50 \mathrm{~kg}$. As expected at the same time, $2 \mathrm{~ms}$, the stresses acting on angles are higher than the scenario of $25 \mathrm{~kg}$ of Pentolite. Moreover, more substantial deformations and disintegrations were obtained as shown in Figure 8.46 (b).

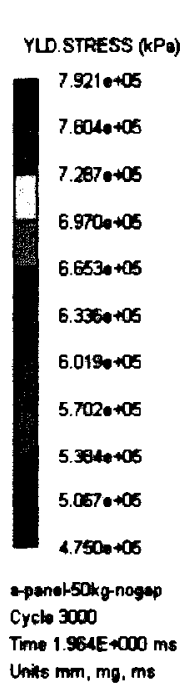

(a)

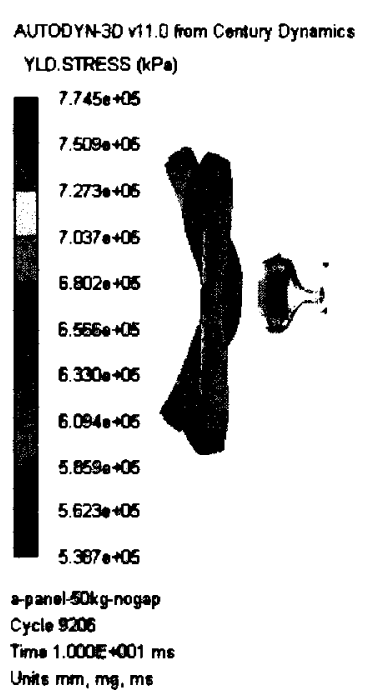

(b)

Cycle 9206

Unins $\mathrm{mm}, \mathrm{mg}, \mathrm{ms}$
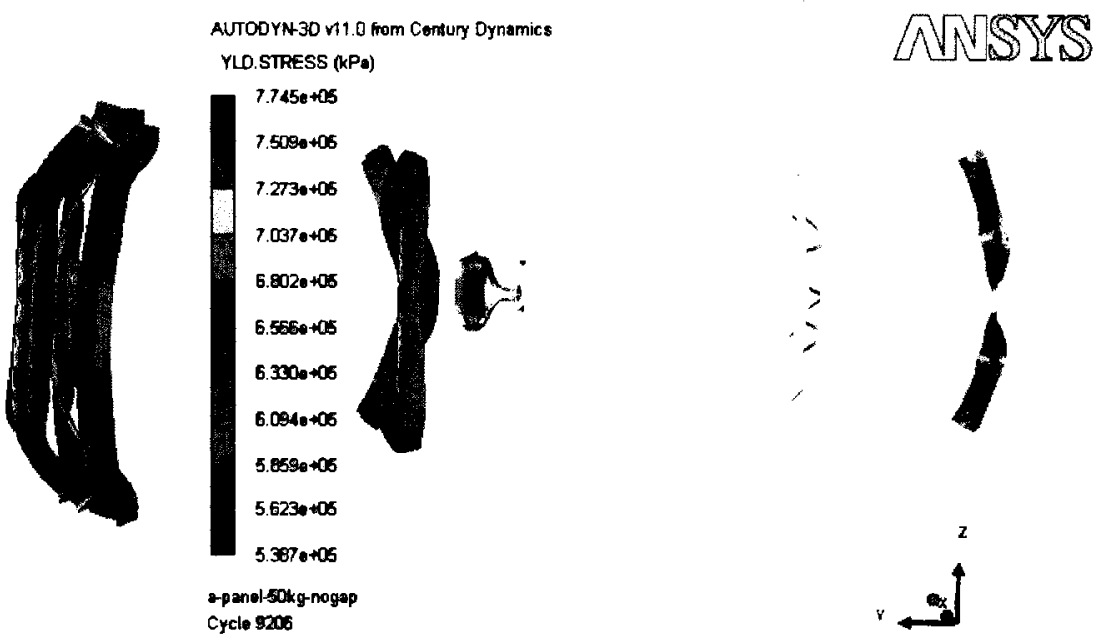

Figure 8.46: Yield stress contour for SSP-A subjected to $50 \mathrm{~kg}$ of Pentolite 


\subsubsection{Case of the Cubicle subjected to $5 \mathrm{~kg}$ of Pentolite}

A numerical model simulating a $2 \mathrm{~m}$ cubicle was built using SSP-A design to be tested using $5 \mathrm{~kg}$ of Pentolite. Figure 8.47 shows the yield stress contour of angle sections at 10 ms. It can be seen from this figure that stress values at the mid span of the angle sections exceeded the allowable yield strength, while other parts of the angles still lower than that. It is important to note that the maximum yield stress was found to be at the connections between angle sections and posts of the cubicle.

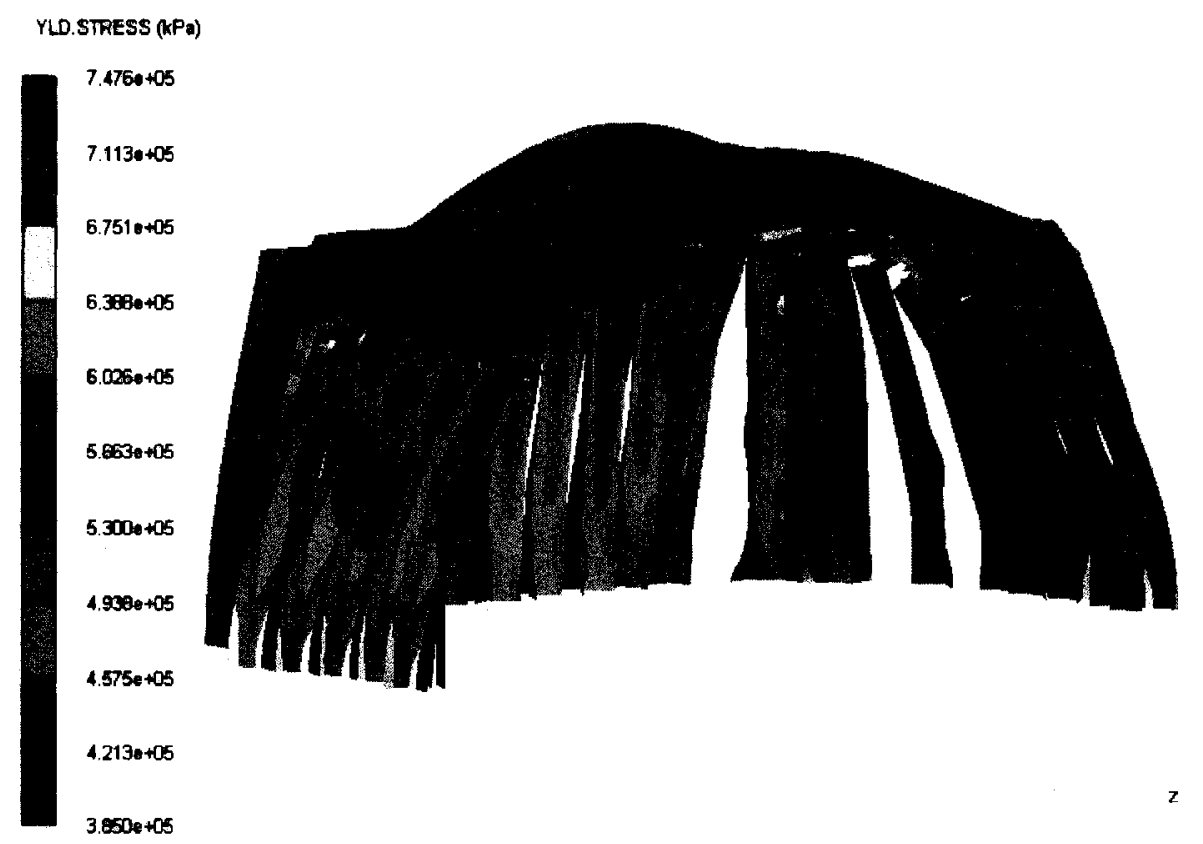

Figure 8.47: Yield stress contour for cubicle subjected to $5 \mathrm{~kg}$ of Pentolite

Figure 8.48 shows the plastic deformations of the cubicle at various time intervals. It can be seen that the posts and the middle angle sections reached the plastic strain limit first at $1 \mathrm{~ms}$ after detonation. After that, the angles start deforming as the wave being reflected on them. Although plastic deformations have been reached, but complete failure did not occur. This research support the construction of suppressive shield panels (SSPs) as a $2 \mathrm{~m}$ 
cubicle container to contain blast loading resulted from $5 \mathrm{~kg}$ of Pentolite. However it requires further investigation which is out of the scope of this thesis.

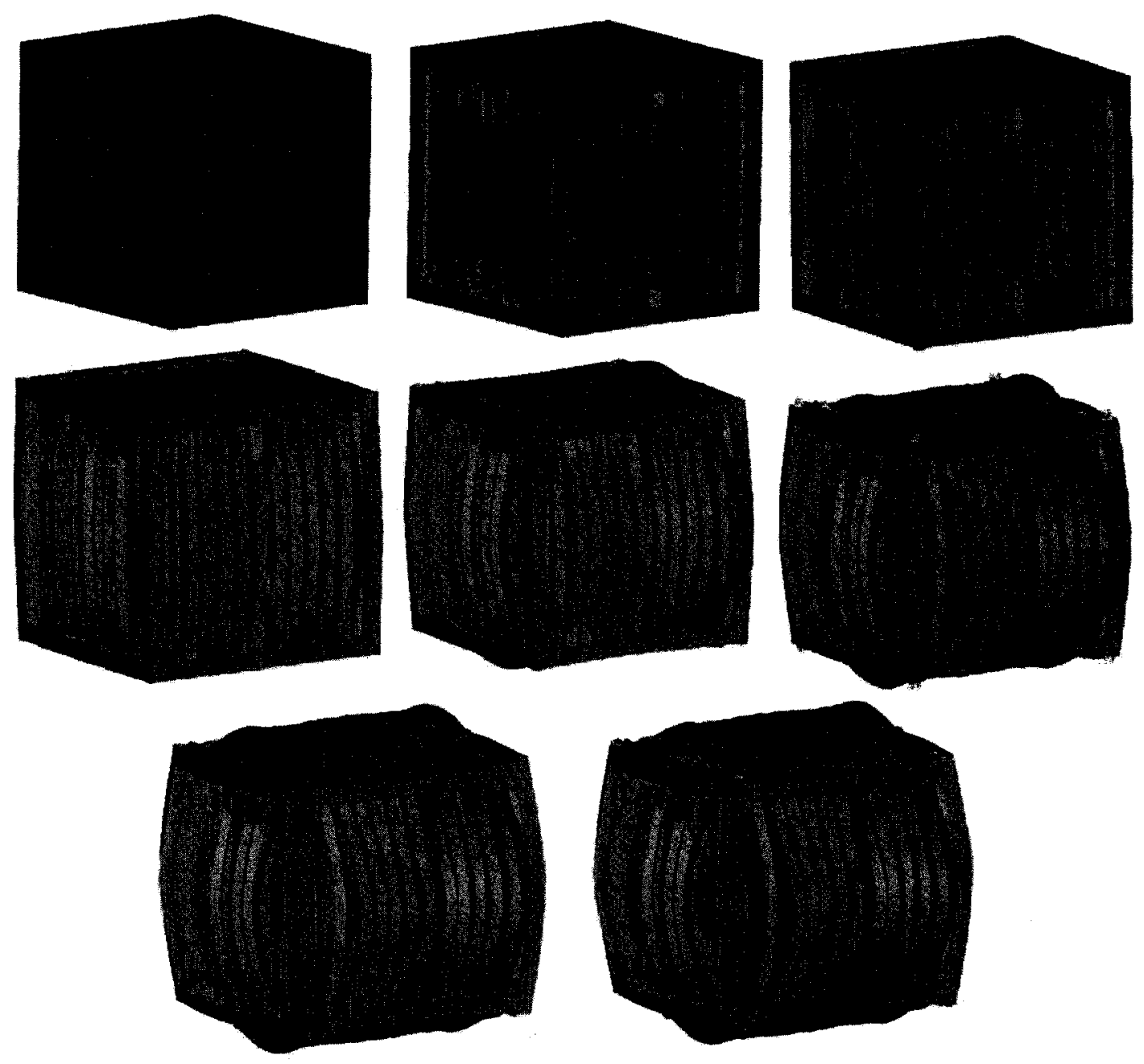

Figure 8.48: Plastic deformation of cubicle at various time intervals

\subsection{Basis for sizing and using SSPs}

The findings from this thesis indicate the capability of SSPs to be used to increase the resistance of transport containers to blast loads and to enhance the safety and security of transportation infrastructure. Although no tests were performed to determine the 
capability of SSPs to contain fragments, it may be possible to use such panels to construct a vessel to complement other tools in the arsenal of bomb-disposal equipment. Consider the fact the RCMP's Canadian Bomb Data Centre recommends a minimum safe distance for personnel of $274 \mathrm{~m}$ from a 12-kg fragment-type bomb (RCMP). Evacuating people from an area of this radius, about 24 hectares, can be time consuming and can result in injuries or casualties if the bomb were to detonate. Having a bird-cage-type device manufactured as a suppressive shield, based on the principles utilized in this thesis, that can be placed onto the explosive device could substantially reduce the safe distance and evacuation area and can allow in-situ detonation of the bomb when its movement to a safer area cannot be achieved.

Applications in transport and infrastructure protection require different guidelines. In transport applications where the mass is the main concern, the relation between vent area and areal density can be the guide to deciding the optimum design. On the other hand, in security applications where mass is secondary, the panel with least vent area ratio would typically be recommended. Depending on the required application and level of security, a vent area ratio and corresponding areal density can be selected from Figure 8.49. Once the optimum vent area ratio and the amount of explosive involved have been determined for a design situation, the transmitted pressure at $2.5 \mathrm{~m}$ from the outer face of the SSPs and $3.5 \mathrm{~m}$ from the center of the explosive charge can be obtained from Figure 8.50. These guidelines provide the first step in selecting optimal design parameters from data based on actual numerical models and supported by field test data. 


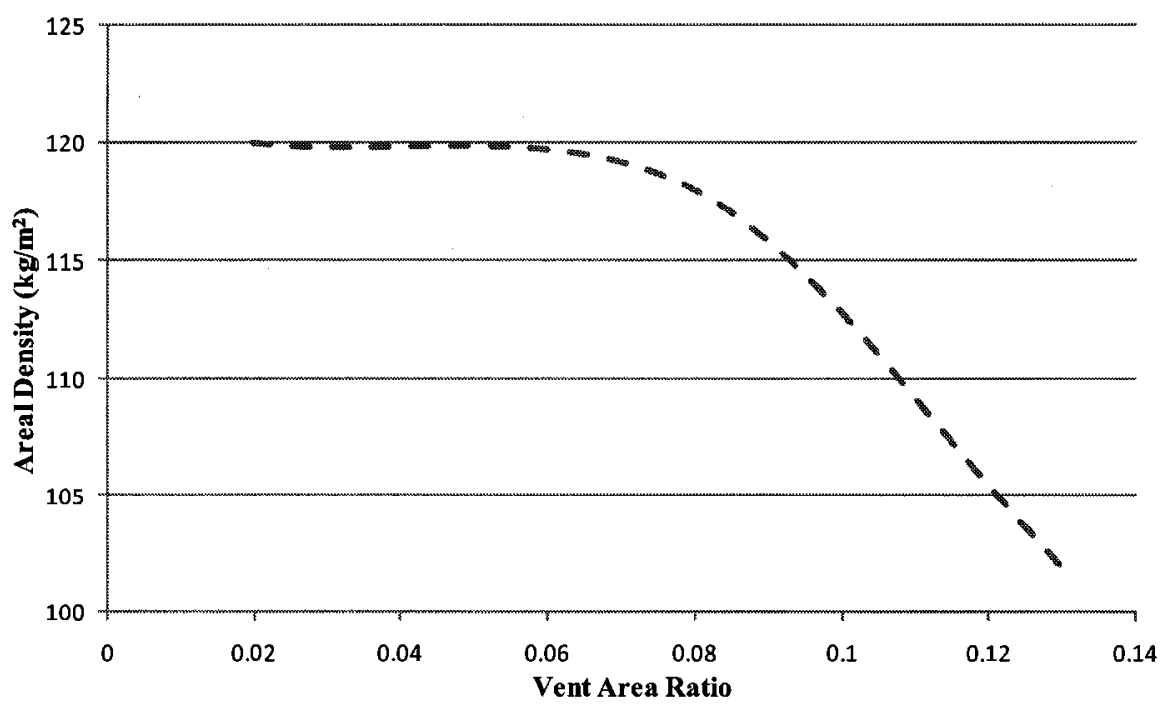

Figure 8.49: Vent Area Ratio versus Areal Density

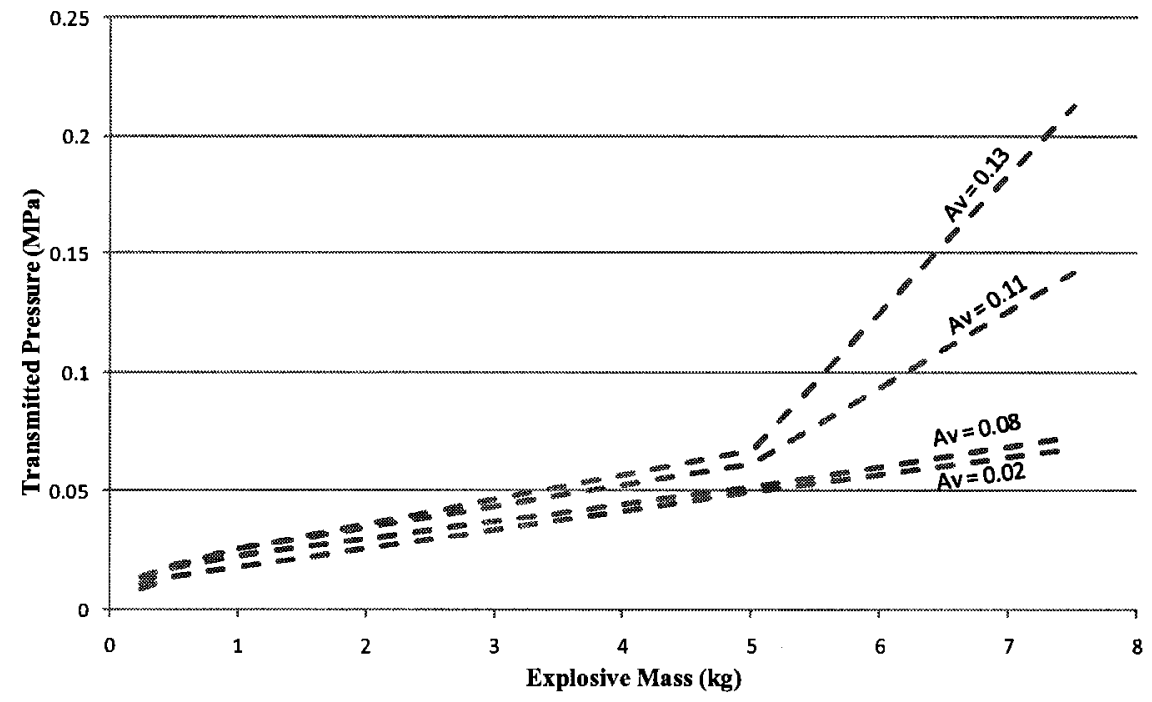

Figure 8.50: Explosive mass versus transmitted pressure

With regard to storage of Class 1.1 and 1.5 explosives, the SSPs can be used as secondary containment to the magazines to achieve the same safety requirements but with reduced distances to the surrounding targets. The Canadian Quantity Distance Principles Manual provides guidelines for the storage of explosives and the required safety distances. The following example will consider storage of $50 \mathrm{~kg}$ (TNT equivalent) in a light unbarricaded structure or an un-barricaded truck, trailer or railcar. The safety distances to 
other explosive stores are denoted by D1 and D2, to explosive process buildings (less than $4000 \mathrm{~kg}$ ), by D3, and to light traffic public routes, by D4 (Table 8.4). Table 8.4 also shows the reduced pressures when SSPs providing $60 \%$ attenuation are used to surround the explosive stores. Note that using the SSPs with $60 \%$ attenuation would almost allow the existing D4 requirement of $30 \mathrm{~m}$ (Scaled Factor $=8$, Pressure $=0.015 \mathrm{MPa})$ to be reduced to $18 \mathrm{~m}$ (Scaled Factor $=4.4$, Pressure $=0.016 \mathrm{MPa})$ so that the lower D3 distance requirements could be used instead. Similarly, the D3 requirement of $18 \mathrm{~m}$ $($ Scaled Factor $=4.4$, Pressure $=0.04 \mathrm{MPa})$ can almost be reduced to the lower D2 distance of $10 \mathrm{~m}($ Scaled Factor $=2.4$, Pressure $=0.052 \mathrm{MPa})$.

Although the drop to lower safety distances in the above example is not quite achieved, it must be remembered the SSPs in this research did not suffer any damage. This means that they can withstand higher blast loads that can easily substantiate their use to lower the present Quantity-Distance Requirements.

Table 8.4: Reduced safety distances when SSPs are used as secondary protection

\begin{tabular}{|c|c|c|c|c|}
\hline $\begin{array}{c}\text { Safety } \\
\text { Distances } \\
\text { Categories }\end{array}$ & $\begin{array}{l}\text { Scaled } \\
\text { Factor }\end{array}$ & $\begin{array}{l}\begin{array}{l}\text { ConWep } \\
\text { Incident } \\
\text { Pressure }\end{array} \\
(\mathrm{MPa}) \\
\end{array}$ & $\begin{array}{c}\text { Existing } \\
\text { Required } \\
\text { Safety } \\
\text { Distances } \\
\text { (m) } \\
\end{array}$ & $\begin{array}{c}\text { Pressures with } \\
\text { SSPs } \\
\text { Containment } \\
(60 \% \text { Attenuation }) \\
(\mathrm{MPa}) \\
\end{array}$ \\
\hline D1 & 0.8 & 1.5 & 5 & 0.6 \\
\hline D2 & 2.4 & 0.13 & 10 & 0.052 \\
\hline D3 & 4.4 & 0.04 & 18 & 0.016 \\
\hline D4 & 8 & 0.015 & 30 & 0.006 \\
\hline
\end{tabular}

Note that additional protection can be achieved with AF in conjunction with SSPs. This of course requires further studying to ensure that fragments are also considered in redefining the quantity-distance tables in consultation with the authorities. 


\subsection{Summary}

This chapter presents the numerical investigation using results obtained from the experimental study and extended to include various scenarios beyond the ones completed during the experimental investigation. The blast pressure values obtained from 2-D numerical simulations correlate well with those of the experimental results for the various SSPs subjected to range of explosive masses 0.25 to $1 \mathrm{~kg}$ of Pentolite. As for the 3-D simulations, the program showed its ability to represent field conditions and verified the structural response obtained from experimental tests under different explosive charges. 


\section{Chapter 9}

\section{Conclusions, Recommendations and Future Research Work}

\subsection{Summary of the Results}

The main objectives of this thesis were to investigate the validity of utilizing Suppressive Shield Panels (SSPs) to mitigating the blast pressure and impulse resulting from accidental or intentional explosions in transport or storage conditions, to optimize the design of SSPs to minimize the consequence of explosions, and to provide preliminary guidelines for designing SSPs for improving the resistance of transport vehicles and storage containers to explosions. These objectives have been met through a well-designed and implemented research plan that included both experimental and numerical studies.

Chapter 1 presented an introductory overview on the storage and transport of Class 1 hazardous materials, defined the objectives and the rationale and described the research plan implemented in this research. Chapter 2 included in-depth discussion of the problem by presenting accident statistics, examples of consequences resulting from accidents involving explosives, provided background on explosion phenomena and its effects, and finally, described the evolution of the suppressive shield concept. Chapter 3 provided details of the numerical approach and presented the verification of the numerical simulation using theoretical data as well as experimental data from literature. The results and discussion of a preliminary study of SSPs using numerical simulations were presented in Chapter 4. The results and observations obtained in Chapter 4 paved the way to the main objectives of this research. Chapters 5 and 6 presented the procedures, the 
results and analysis of the experimental investigation, where it was observed that various SSPs attained average pressure attenuation from $40 \%$ to $60 \%$, and average pressure impulse attenuation from $40 \%$ to $70 \%$. Furthermore when AF sheets were used, the average pressure attenuation increased to $85 \%$ while the average impulse attenuation increased to $90 \%$. These increases demonstrate the ability of AF sheets to improve the overall ability of the SSPs to absorb more energy. Finally, Chapters 7 and 8 presented the numerical simulations of the experimental data, the correlation between them and validation of the numerical simulation methods. The blast pressures and structural response of the SSPs obtained from the numerical simulations correlate well with those of the experimental results for the various SSPs subjected to detonation from a range of explosive masses. The results and findings of this research can provide the civilian users, transport companies and government authorities' new possibilities and more reliable guidelines for transportation and storage of dangerous goods. The major contributions and summary of the main conclusions and recommendations are discussed below.

\subsection{Major Contributions}

\subsubsection{Blast Effects Assessment}

A thorough literature review was carried out to identify the consequences resulting from accidents involving UN Class 1 explosives. The literature review included UN classification of dangerous goods, accident statistics and examples, blast theory and effects, and finally the evolution of suppressive shield system. The information presented in Chapter 2 supported the need for investigating advanced suppressive shield designs for 
civilian applications to help mitigate blast effects and minimize the resulting consequences.

\subsubsection{Validity of Suppressive Shield Panels}

\subsubsection{Experimental Investigation}

The SSPs evaluated in this thesis, were subjected to twenty tests from detonations of $0.25,0.50$ and $1.00 \mathrm{~kg}$ of Pentolite charges as explained earlier. Two free-air shots were carried out without SSPs panels and were used as reference data to calculate attenuation. Two test configurations were used for the remaining tests. The first series made use of only the SSPs, while the second utilized AF sheets in conjunction with SSPs.

In general, all SSPs showed good performance in mitigating the blast effects from the various explosive charge masses. The results of the experimental investigation showed that the most effective panels at attenuating blast pressure and impulse were the ones with lowest vent area ratios of 0.02 ; i.e., SSP-B and SSP-D. In addition to the vent area ratio, the areal density of the tested panels was a critical variable since it affects the transportability of these panels and their economic effectiveness. This variable was important to make comparisons between two panels, SSP-B and SSP-D, having the same vent area ratio but different areal densities. Since both panels performed equally well, the one with the lowest areal density would be chosen for economic reasons. Furthermore, the results of the experimental and numerical studies showed that panels with two angle sections per row performed better than those with only one angle section per row. This conclusion is significant since it points to the importance of the geometric shape of the 
front face of the designed SSPs. Thus, the results presented so far pointed to the fact that SSP-B provided the optimum design with reasonable weight and effective attenuation capability.

When AF was added to the SSPs the results showed improved performance without significant addition of mass. The utilization of the AF sheets enhanced the mitigation ability of the SSPs by $25 \%$ in pressure and $30 \%$ in impulse. The AF backed with a $2 \mathrm{~mm}$ steel plate increased the SSP pressure and impulse attenuation capacity by $40 \%$ and the SSP with AF by more than $30 \%$ and $20 \%$, respectively.

Clearly, the utilization of any of the three alternatives would offer various levels of blast pressure and impulse attenuation depending on the desired level of protection. The final selection would depend on the economy and importance of the assets to be protected.

\subsubsection{Numerical Investigation}

The numerical study was divided into two main parts. The first part dealt with the attenuation effect of the shock wave and was carried out by developing 2-D models. The second part involved analyzing some of the structural response to the shock loads and it was carried out by developing 3-D models.

The results of the 2-D simulations showed good correlation with the experimental data. As with the experimental results, the numerical results agreed with the significance of the vent area ratio as well as areal density of various panels in determining the optimum design alternative. A comparison between the calculated average attenuation percentages 
from the numerical and experimental tests showed that for the $0.25 \mathrm{~kg}$ charge there were no significant differences in the performance of the three heavier panels; SSP-B, SSP-C, and SSP-D which makes the selection of the lightest of the three; SSP-B, the most effective solution. The numerical results for SSP-B subjected to charge masses, 0.25 , 0.50 , and $1.00 \mathrm{~kg}$ of Pentolite, resulted in pressure attenuation similar to that obtained from the experimental tests. For example, SSP-B subjected to $0.25 \mathrm{~kg}$ of Pentolite caused a pressure attenuation of $54 \%$ which is the same as that obtained in the experimental investigation. Similar results were found for the attenuation of the blast pressure-impulse pointing to SSP-B to be the most effective panel.

The results of the 3-D simulations also correlated well with the observations from the experimental tests. The photometric comparison between the test specimens after the experimental tests and shapes obtained from the results of the numerical model are in good agreement, in fact there was practically $\mathrm{n}$ deformations in the case of subjecting SSP-A to the detonation of $0.50 \mathrm{~kg}$ of Pentolite.

When the AF sheet was modelled as the inner lining to the SSPs subjected to $0.50 \mathrm{~kg}$ of Pentolite, the results from the numerical simulations resulted in failure similar to that observed in the field tests, where the AF sheet was seen to disintegrate under the effect of the explosion. On the other hand when a steel plate was inserted between the SSP and the $\mathrm{AF}$ sheet, the AF did not disintegrate but deformed taking the shape of the SSP angles. Such deformation was observed in both the experimental test and the numerical model. 
When larger explosive charge masses were used in the numerical simulations, 10, 25, and $50 \mathrm{~kg}$ of Pentolite, the angles deformed more severely as the explosive mass was increased. When SSP-A was utilized in the numerical model simulating a 2-m cubicle subjected to $5 \mathrm{~kg}$ of Pentolite, plastic deformations resulted but complete failure did not occur.

\subsection{Conclusions}

The experimental and numerical studies presented in this thesis led to several important conclusions summarized below:

- In general, the numerical models showed great ability to estimate the blast pressure distribution on both sides of the SSPs and correlate to the experimental data. Similar conclusions can be made with regard to the free field blast pressures, with small error margins.

- The pressure profiles from the numerical models correlate well with those from the experimental tests with respect to time of arrival of the incident and reflected blast pressures.

- AUTODYN blast pressure and impulse predictions correlated with those from ConWep.

- The 2-D mesh convergence study showed that a $10-\mathrm{mm}$ mesh size was the optimum size for free field blast pressure tracking. However when an obstacle is placed in its path, finer mesh sizes are recommended.

- The 3-D mesh convergence study indicated that a 40-mm mesh size was the optimum size to be used to track pressure in air. Also, the numerical results agree 
well with those from the experimental tests with respect to structural response, when there were little or no deformations.

- In the area restriction verification, the magnitude of the transmitted wave obtained from the numerical model and that from the theoretical charts correlated very well.

- For explosive charge masses less than $0.5 \mathrm{~kg}$ of Pentolite, the SSPs showed reduction in blast pressure of up to $60 \%$ and reduction in impulse of up to $75 \%$.

- The use of angle combinations in two rows, outer and inner layers, resulted in higher attenuations than using one single row combination.

- The use of the low density AF sheets further attenuated blast pressures by up to $28 \%$.

- An additional $30 \%$ attenuation was achieved when a 2-mm thick steel plate was used as backing behind the AF sheets.

- The SSPs have the potential to attenuate blast pressures and blast pressure impulses with and without utilizing AF sheets without suffering any damage from charges up to $1.00 \mathrm{~kg}$ of Pentolite.

- The experimental tests demonstrated the minor deflections similar to the one computed using the numerical method.

- Numerical simulation results showed that a container consisting of SSP-A panels modeled as a full cubicle would be able to withstand blast loads from explosive charge up to $5 \mathrm{~kg}$ of Pentolite without serious signs of failure.

- The attenuation capacity of SSP systems can be used to reduce Quantity-Distance requirements. Sufficient data has been generated to present this application to the 
Canadian Authorities so as to consider revisions to the Quantity-Distance requirements.

\subsection{Recommendations}

The results and observations of both the field experimental tests and the numerical investigation showed that well designed and thoroughly analyzed SSPs provide promising protection and safer transport methods for goods of hazardous materials. The following areas are identified as possible topics for future research.

- Full scale testing of cubicle container is recommended to verify the numerical results and to investigate the risks associated with it.

- Specific attention should be given for the analysis and understanding of the welding of containers subjected to blast pressures. The numerical simulations carried out in this thesis indicated that failure of containers made of the designed SSPs will fail at the welded corners.

- When full protection is desired beyond the shielding walls a perforated steel plate preceding the suppressive shield lining is recommended. The design of such plate is important to distribute the pressure on the whole area of AF sheets and at the same time allowing the release of pressure.

- Lighter and advanced materials such as composite systems are recommended to reduce the areal density of suppressive shield panels such as Aluminum and Carbon fibres.

- Field testing utilizing heavy explosive charge masses is needed to examine the ultimate strength of the heavier designed SSPs and determining their actual field 
capacities. Also, more research is required to study the ability of SSPs to stop fragments for fragment-type bombs. 


\section{References}

Ambrosini, R.D., Luccioni, B.M., Danesi, R. F., Riera, J.D., Rocha, M.M., "Size of craters produced by explosive charges on or above the ground surface", Shock Waves, 12: 69-78, 2002.

Arab News, "Hundreds Die in Iran Train Horror", Thursday, 19, February, 2004, http://www.arabnews.com/?page $=4 \&$ section $=0 \&$ article $=39740 \& d=19 \& \mathrm{~m}=2 \& \mathrm{y}=2004$, (February 20, 2006 8:30pm)

Australian Government, Department of Transport and Regional Services http://www.dotars.gov.au/transreg/str_dgoodsum.htm\#ADGCode

Baker, W.E., "Explosions in Air", University of Texas press, Austin and London, 1973.

Baker, W.E., Cox, P.A., Westine, P.S., Kulesz, J.J. and Strehlow, R.A. "Explosion hazards and evaluation", Elsevier Scientific Publishing Company, New York, 1983.

BBC news, "Iran train blast kills hundreds", Wednesday, 18 February, 2004, http://news.bbc.co.uk/2/hi/in depth/photo gallery/3500379.stm, (February 20, 2006 $8: 30 \mathrm{pm})$.

BBC news, "N Korea train blast 'kills many", Thursday, 22 April, 2004, http://news.bbc.co.uk/2/hi/asia-pacific/3649655.stm, (March 05, 2006 8:00pm). 
Bjerketvedt, D., Bakke, J.R., Wingerden, K.V., "Gas Explosion Handbook”, Journal of Hazardous Materials, Volume 52, n 1, p 1-150, January 1997.

C. A. Kot, IIT Research Institute for the Office of the Chief of Engineers, "Air Blast Attenuation", Final Technical Report, Contract no. DA-49-129-ENG-549, Champaign, Illinois, United States of America, February 1971.

CBS news, "North Korea Spurns South's Aid Offer", April 26, 2004, http://www.cbsnews.com/stories/2004/04/22/world/main613176.shtml, (March 05, 2006 $8: 00 \mathrm{pm})$.

Charles P. Weeth, Weeth \& Associates, "M/V Hanjin Pennsylvania: Explosions at Sea", 7th International Symposium on Fireworks, October 6-10, Valencia, Spain.

Chemical Accident Prevention, Preparedness and Response http://europa.eu.int/comm/environment/seveso/, (April 01, 2006 8:00pm).

Davis, L.K., "Performance of Sand-filled Barricades for Protection of Containerized Ammunition in Temporary Storage", Minutes of the Twenty-Ninth DoD Explosives Safety Seminar, July 2000.

Department of the Army, U.S. Army Corps of Engineering, "Suppressive Shields Structural Design and Analysis Handbook”, Huntsville Division, November 18, 1977. 
Department of the Army, U.S. Army Corps of Engineers, "Engineering and Design Explosives Storage Magazines", Washington, D.C., August 31, 1995.

Dioxin: Seveso disaster testament to effects of dioxin http://www.getipm.com/articles/seveso-italy.htm, (March 20, 2006 10:00am).

Dixon, P. and Halsey, C., "Advanced EOD Magazine Concept", Minutes of the TwentyNinth DoD Explosives Safety Seminar, July 2000.

E.L. Quarantelli, "Disaster planning for transportation accidents involving hazardous materials", Journal of Hazardous Materials, volume 27, pp 49-60, 1991.

Formby, S.A., Wharton, R.K., "Blast characteristics and TNT equivalence values for some commercial explosives detonated at ground level", Journal of Hazardous Materials, Volume: 50, Issue: 2-3, pp. 183-198, October, 1996.

Gere, J. M. and Timshenko, S. P., "Mechanics of Materials", Third Edition Boston, Pws Pub Co, 1990.

German Marine Insurer, "Transport Information Service: Standard containers", Version 1.1.0.05, Gesamtverband der Deutschen Versicherungswirtschaft (GDV), Berlin 20022006, http://www.tis-gdv.de/tis e/containe/arten/standard/standard.htm\#abmessungen, (April 12, 2006 11:00am). 
Global Security, "Ryongchon, DPRK Train-wreck and Explosion", April 27, 2004, http://www.globalsecurity.org/military/world/dprk/ryongchon-imagery.htm, (March 06, 2006 10:00am).

Gulf News, "Two workers dead and two policemen hurt as fireworks on truck explode", April 11, 2007, http://archive.gulfnews.com/articles/07/04/11/10117512.html, (April 14, 2007 9:30pm)

Hanssen, A.G., Enstock, L. and Langseth, M., "Close-range Blast Loading of Aluminium Foam Panels", International Journal of Impact Engineering, Volume 34, Issue 3, pp. 509521, March 2007.

Keenan, W. A., Tancreto, J. E., Civil Engineering Lab (NAVY) Port Hueneme Calif, "Blast Environment from Fully and Partially Vented Explosions in Cubicles", Final Report, Hueneme, California, United States of America, November 1975.

King, Kim W., Waclawczyk, Johnny H., Jr., "Development of the SV-23 Explosive Storage Vessel", DoD Explosives Safety Seminar, August 2002.

King, P.V., Becher, A.F., Henderson, W.P., "Blast Suppressive Shielding”, United States Patent, number 4248342, February $3^{\text {rd }}$, 1981.

Li, H., and Ben-dor, G., "A parametric study of Mach reflection in steady flows", Journal Fluid Mech. (1997), volume 341, pp 101-125, 1997. 
Lind, C.A,, Cybyk, B.Z., Boris, J.P., "Attenuation of Shock Waves by Geometrically Complex Objects", PVP-Vol. 396, Emerging Technologies in Fluids, Structures, and Fluid/Structure Interactions, ASME, pp. 231-239.

Ludwig Benner, Jr., "Accident Investigations-A Case for New Perceptions And Methodologies", http://members.cox.net/lbjr99/papersa/SAE80.html\#Heading14

M. Provencher, "A Few Risk Analysis in the Transport of dangerous Good - A Canadian Experience", Transport Canada, Transport Dangerous Goods Directorate, Ottawa, Ontario, Canada

M. Provencher, "Road transport of explosives small or large quantities - which are safer?", Transport Canada, Transport Dangerous Goods Directorate, Ottawa, Ontario, Canada, May 2005

Maveyraud, C., Vila, J.P., $\quad$ Sornette, D., $\quad$ Le Floc'h, C., $\quad$ Dupiller, J. M., Salome, R., "Numerical Modeling of the Behaviour of High Pressure Vessel Under an Hypervelocity Impact", Spacecraft Propulsion, Third International Conference, p.811, Cannes, France, October, 2000.

Merrifield R and Moreton P A, "An examination of the major-accident record for explosives manufacturing and storage in the UK", Journal of Hazardous Materials, Volume: 63, Issue: 2-3, December 1, 1998. 
Merrifield R and Moreton P A, "The debris hazard from portable steel magazines", Minutes of the Twenty-Ninth DoD Explosives Safety Seminar, July 2000.

Merrifield, R., Wharton, R.K., "Measurement of the size, duration and thermal output of fireballs produced by a range of propellants", Journal of Propellants, explosives Pyrotechnics, Volume: 25, pp. 179-185, 2000.

Mills, C.A., "The Design of Concrete Structures to Resist Explosions and Weapons Effects", Proceedings of $1^{\text {st }}$ International Conference on Concrete for Hazard Protections, Edinburgh, pp.61-73, 1987.

Ministere de la Defense, Service Technique des Bâtiments Fortifications et Travaux, Etude Technique de la Section, Protection Effets des Armes, $N^{\circ}$ STBFT/DTL/BIPO/PEA

Nesterenko, V. F., "Shock (Blast) Mitigation by "Soft" Condensed Matter", MRS Symposium. Proceedings, vol. 759 pp. MM4.3.1- 4.3.12, MRS, Pittsburgh, PA, 2003.

Newmark, N.M. and Hansen, R.J., "Design of Blast-Resistant Structures" Shock and Vibration Handbook, Volume 3, Eds. Harris and Crede, McGraw-Hill, 1961.

One News, "Truck explosion takes toll", May 24, 2004, http://tvnz.co.nz/view/news_world story skin/427368? format=html, (April 14, 2007 $8: 30 \mathrm{pm})$ 
Part 6, Requirements for the construction and testing of packagings, intermediate bulk containers (IBCS), large packagings, portable tanks, multiple-element gas containers(MEGCS) and bulk containers.

Production and Consumption Branch, APELL, Transportation disasters http://www.uneptie.org/pc/apell/disasters/lists/cstransport.html\#accidents

Prugh, R. W., "Quantitative Evaluation of Fireball Hazards”, Process Safety Progress, Volume 13, No. 2, pp. 83-91, April, 1994.

R. N. Schumacher and C. N. Kingery, Air blast and Structural Response Testing of a 1/4 Scale Category I Suppressive Shield, USA Ballistic Research laboratories Interim Memorandum, Aberdeen Proving Ground, MD.

RCMP, Canada Bomb Data Centre, Ottawa, Canada.

Report of an Investigation into the Explosion during Transport of Blasting Explosives that occurred in Walden, Ontario on August 5, 1998, Natural Resources Canada, Mineral Technology Branch, Explosives Regulatory Division.

Sadot, O., Anteby, I., Harush, S., Levintant, O., Nizri, E., Ostraich, B., Schenker, A., Gal, E., Kivity, Y., Ben-Dor, G., "Experimental Investigation of Dynamic Properties of Aluminum Foams”, Journal of Structural Engineering, Vol. 131, No. 8, pp. 1226-1232, August 2005. 
Swisdak, M. M., Crull, M., "Primary Fragment Ranges for Explosives Safety", Minutes of the Twenty-Ninth DoD Explosives Safety Seminar, July 2000.

Technical Manual TM5-855-1, "Fundamentals of Protective Design for Conventional Weapons", U.S. Army, Washington, D.C., 1986.

Technical Manual TM5-1300, "Structures to Resist the Effects of Accidental Explosions", U.S. Army, Washington, D.C., 1990.

The Age, Hamish McDonald "Dynamite blamed for train blast", Dandong, North Korean border, April 24, 2006, (March 06, 2006 10:00am). http://www.theage.com.au/articles/2004/04/23/1082616328558.html?oneclick=true

The International Civil Aviation Organization Technical Instructions on the Safe Transport of Dangerous Goods by Air (ICAO TI), http://hazmat.dot.gov/icao.htm

The International Maritime Organisation (IMO), International Maritime Dangerous Goods (IMDG) Code, http://hazmat.dot.gov/imdg.htm

The TDG Excerpt, "Transport Canada's 2006 Annual Report", News Bulletin, Propane Gas Association of Canada, No. 12, 26 Sep 2007.

Transport Canada, "A Historical Perspective on the Review of the TDG Act", http://www.tc.gc.ca/tdg/consult/actreview/historical.htm 
Transport Canada, "Transportation in Canada 2003", http://www.tc.gc.ca/pol/en/Report/anre2003/add/taba419.htm, (March 02, 2006 3:00pm)

Transport Canada, "Users' Guide to UN Packaging", Revised March 1999 http://www.tc.gc.ca/tdg/info/moc/un_pkg/unguide_e.htm

Transportation Division, United Nations $13^{\text {th }}$ Edition, Manual of Tests and Criteria http://www.unece.org/trans/danger/publi/manual/manual_e.html

Transportation Division, United Nations Manual of Tests and Criteria http://www.unece.org/trans/danger/publi/manual/manual e.html

Transportation of Dangerous Goods Act, 1992, Transportation of Dangerous Goods Regulations Clear Language, Part 4

http://www.tc.gc.ca/acts-regulations/general/t/tdg/regulations/tdg001/part $4 . h$ tm

Treasury Board of Canada Secretariat, Chapter 5-2 - A Guide to Accident Investigation http://www.tbs-sct.gc.ca/pubs_pol/hrpubs/tbm_119/chap5_2-1_e.asp\#int

UN Model Regulations, The Transport of Dangerous Goods http:/hazmat.dot.gov/untdg.htm

VanWees, Rolf M.M., "Optimal Design of Explosion Containment Vessels", Minutes of the Twenty-Sixth DoD Explosives Safety Seminar, Auguist 1994. 
Weeth \& AssociatesLLC, "M/V HYUNDAI FORTUNE", http://pyropages.com/weeth/hyunfort.htm, (April, 2007, 10:00am)

Wharton, R.K., Formby, S.A., Merrifield, R., "Airblast TNT equivalence for a range of commercial blasting explosives", Journal of Hazardous Materials, Volume: 79, Issue: 12, pp. 31-39, December 1, 2000.

White, J.J., Trott, B.D., Backofen, J.E., “The Physics of Explosion Containment”, Journal of Physics in technology, pp. 94-100, May 1977. 